$$
\text { João Lucas Dozzi Dantas }
$$

Metodologia numérica para estimativa da manobrabilidade de veículos autônomos submarinos

São Paulo 

João Lucas Dozzi Dantas

\section{Metodologia numérica para estimativa da manobrabilidade de veículos autônomos submarinos}

Tese apresentada à Escola Politécnica da Universidade de São Paulo como requisito para obtenção do Título de Doutor em Ciências.

Área de Concentração:

Engenharia Mecânica

Orientador: Prof. Livre-Docente

Ettore Apolonio de Barros

São Paulo

2014 
Este exemplar foi revisado e corrigido em relação à versão original, sob responsabilidade única do autor e com a anuência de seu orientador.

São Paulo, 25 de julho de 2014.

Assinatura do autor

Assinatura do orientador

FICHA CATALOGRÁFICA

Dantas, João Lucas Dozzi

Metodologia numérica para estimativa da manobrabilidade de veículos autônomos submarinos / J.L.D. Dantas. -- versão corr. -- São Paulo, 2014.

$354 \mathrm{p}$.

Tese (Doutorado) - Escola Politécnica da Universidade de São Paulo. Departamento de Engenharia Mecatrônica e de Sistemas Mecânicos.

1.Hidrodinâmica 2.Submersíveis não tripulados 3.Sistemas autônomos I.Universidade de São Paulo. Escola Politécnica. Departamento de Engenharia Mecatrônica e de Sistemas Mecânicos II.t. 
Dedico aos que quiseram desistir, mas não desistiram... que quiserem mudar de ideia, mas não mudaram... 



\section{AGRADECIMENTOS}

Primeiramente gostaria de agradecer a Fundação de Amparo a Pesquisas do Estado de São Paulo, FAPESP, por me conceder uma bolsa de estudos que possibilitou desenvolver esta tese, realizando publicações e apresentações em congressos.

Ao Prof. Dr. Ettore Apolonio de Barros, por sua orientação neste projeto de pesquisa, e pelas diversas discussões que culminaram em seu aperfeiçoamento.

Aos companheiros de laboratório: Lucas Machado de Oliveira, Luciano Ondir Freire, Persing Junior Cardenas Vivanco, Rodrigo Telles da Silva Vale, William da Silva Caetano (ordenados em ordem alfabética), por toda a ajuda concedida nestes anos às atividades rotineiras do laboratório (demonstrando de forma explicita como certas atividades não devem ser realizadas!), e principalmente a realização dos testes de campo, que possibilitaram que os resultados desta tese fossem validados.

Ao capitão de fragata André Ricardo Mendonça Pinheiro, e aos outros membros da Marinha do Brasil, por permitirem a realização dos ensaios do AUV Pirajuba na Escola Naval de Angra dos Reis.

Ao Prof. Dr. Thiago de Castro Martins, cujas as discussões não correlacionadas a este estudo permitiram analisar certos assuntos sobre outras perspectivas.

Aos meus pais, Lucia de Fátima Silveira Dozzi e Agamenon Sérgio Lucas Dantas, pelo suporte concedido durante todos estes anos, e ao empréstimo do carro, que me permitiu estudar até mais tarde.

E pro último, mas não menos importante, a minha mais que namorada, Liliana José Barbosa, que me aguentou durante todos estes anos, e me ajudou nas mais difíceis situações. 



\section{RESUMO}

O uso de modelos de manobras representa um auxilio importante no projeto de veículos marinhos, permitindo a verificação do desempenho destes veículos, desenvolver o sistema de piloto automático, dentre outras aplicações durante a fase de projeto. Na área de veículos submarinos, seus modelos são tradicionalmente baseados em equações de movimento que incluem expressões polinomiais para representar os esforços hidrodinâmicos. Estes modelos são derivados de uma expansão em série de Taylor de forças e momentos, sendo representados em função das variáveis de movimento. Entretanto, estes modelos limitam a representatividade dos esforços hidrodinâmicos, e, especialmente para os termos de segunda ou mais altas ordens, eles requerem ensaios custosos em tanque de provas para identificar corretamente cada um dos coeficientes polinomiais. Esta dependência em ensaios de tanque de provas tem um impacto critico, ou até mesmo não realístico, durante o desenvolvimento de veículos autônomos submarinos, AUVs, de baixo ou médio custo. Utilizando métodos atuais da fluidodinâmica computacional (CFD), este trabalho propõe um roteiro alternativo para definir os modelos de manobras não lineares para uma classe de AUVs. As simulações de CFD, verificados e validados por normas rigorosas, são utilizados como base para derivar as funções não lineares que representam os esforços hidrodinâmicos, devido variações na velocidade lateral, velocidade angular e deflexão dos lemes. A abordagem numérica é complementada pelo uso de modelos analíticos e semi-empíricos oriundos da indústria de mísseis, que tiveram que ser melhorados com informações retiradas das simulações de CFD. Ajustes adicionais e derivações nos intervalos de confiança para as estimativas produzidas por métodos numéricos também são fornecidos pelo uso de modelos analíticos e semi-empíricos. Adotando o AUV Pirajuba como caso de estudo, a validação dos modelos de manobra foi realizada em duas etapas. Primeiro, são comparadas as estimativas dos esforços hidrodinâmicos com as medições em tanque de provas de um modelo cativo, e em seguida a resposta dinâmica dos modelos de manobras são comparadas com aquelas obtidas por ensaios em mar, sempre utilizando critérios de verificação e validação. Este tipo de análise indicou uma validação dos esforços hidrodinâmicose do movimento para grande parte dos ensaios, sendo que nos demais casos o AUV teve seu comportamento dinâmico bem reproduzido. Este resultado demonstra que a metodologia proposta pode ser utilizada para estimar o modelo de manobra de um AUV típico, gerando uma solução de menor custo para a fase de desenvolvimento destes veículos.

Palavras-chave: Hidrodinâmica. Submersíveis não tripulados. Sistemas autônomos 



\section{ABSTRACT}

The use of maneuvering models represents an important assistance in the project of marine vessels, allowing for the evaluation of the vehicle performance, the autopilot system development, among other tasks during the design phase. In the field of underwater vehicles, those models commonly are based on equations of motion that include polynomial expressions for representing the hydrodynamic efforts. They are derived from Taylor series expansion of forces and moments represented as functions of the motion variables. However, those models limit the representativeness of the hydrodynamic efforts, and, especially for the second order or higher terms, they require expensive trials in towing tank facilities to correctly identify each polynomic coefficient. This dependence on intensive tank tests has a critical impact, or is even unrealistic during the development of middle or low cost autonomous underwater vehicles, AUVs. Using current methods of computational fluid dynamics (CFD), this work proposes an alternative roadmap to construct nonlinear manoeuvring models, which can be applied to a class of AUVs. CFD simulations, verified and validated by rigorous standards, are used as basis to derive nonlinear functions that represent the hydrodynamic efforts due to variations in lateral velocity, angular rate and rudder deflection. The numerical approach is complemented by the use of analytical and semi-empirical models derived from missile industry, which have been improved according to the information taken from the CFD simulations. Further adjustments and derivation of confidence intervals to the estimates produced by the numerical method are also provided by the use of analytical and semi-empirical models. Adopting the Pirajuba AUV as a test bed, the manoeuvring model validation was carried out in two stages. Firstly, estimates of hydrodynamic efforts are compared with measurements obtained from experiments using a captive model in a towing tank. In the second step, the dynamic response predicted by the maneuvering model was compared with the output measured during free model trials. This type of analysis validated the hydrodynamic efforts and motion in most of the experiments, whereas for the remaining cases the AUV had its dynamic behavior well reproduced. This result demonstrates that the proposed methodology can be used to estimate the maneuvering model of a typical type AUV, generating a lower cost solution for the development phase of the vehicle.

Keywords: Hydrodynamic. Unmanned submersibles. Autonomous Systems 



\section{LISTA DE GRÁFICOS}

Figura 1 - AUV Pirajuba durante ensaios de manobrabilidade no mar . . . . . . . 42

Figura 2 - Definição dos sistemas de coordenadas fixo e móvel . . . . . . . . . 57

Figura 3 - Parâmetros nominais do hélice Kaplan série 4-70 com duto de perfil 19A, gráfico retirado de Lewis $^{[68]}$. . . . . . . . . . . . . 63

Figura 4 - Malha da região próxima ao corpo do Pirajuba . . . . . . . . . . 74

Figura 5 - Região mais externa da malha do corpo do AUV Pirajuba . . . . . . . 75

Figura 6 - Condições de contorno e os campos de velocidade, obtidos pelas simulações de Phillips, Furlong e Turnock ${ }^{[24]} \ldots$. . . . . . . . . . . . . 78

Figura 7 - Histórico da convergência iterativa da norma $L_{\infty}$ dos resíduos . . . . . 80

Figura 8 - Histórico da convergência iterativa da diferença entre valores consecutivos das forças hidrodinâmicas axiais e normais . . . . . . . . . . . 80

Figura 9 - As subdivisões da camada limite ${ }^{[94]} \ldots \ldots$. . . . . . . . . . 83

Figura 10 - Exemplo de um histórico de iteração com comportamento oscilante (figura adaptada de Stern et al. ${ }^{[114]}$ ) . . . . . . . . . . . . . . . 94

Figura 11 - Definição do erro de validação de comparação $(E)$ (figura adaptada de Stern et al. $\left.{ }^{[114]}\right) . \ldots \ldots$. . . . . . . . . . . . . . . . . 99

Figura 12 - Definição geométrica das forças longitudinais. . . . . . . . . . . . . . 109

Figura 13 - Exemplo ilustrativo de vórtices gerados pelo corpo quando este está inclinado em relação ao escoamento ${ }^{[121]} \ldots$. . . . . . . . . . . . 112

Figura 14 - Exemplo do efeito do estol de um perfil no comportamento do coeficiente de sustentação ${ }^{[141]} \ldots \ldots \ldots$. . . . . . . . . . . . . . . . . . . . . . . . . .

Figura 15 - Exemplo qualitativo da interferência que o corpo gera em um leme/asa, figura retirada de Roskam ${ }^{[126]} \ldots$. . . . . . . . . . . . . . . . 119

Figura 16 - Exemplo qualitativo da interferência que o leme/asa gera no corpo, figura retirada de Roskam ${ }^{[126]} \ldots$. . . . . . . . . . . . . . 120

Figura 17 - Derivada dos coeficiente de sustentação e momento de um duto ${ }^{[136]}$. . . 125

Figura 18 - Tanque de provas e carro dinamométrico do CNAVAL - IPT . . . . . . 137

Figura 19 - Balanças utilizadas durante os ensaios estáticos dos modelos cativos do AUV Pirajuba . . . . . . . . . . . . . . . . . . . 138

Figura 20 - Exemplo de duas series temporais obtidas pela balança durante ensaios distintos do IPT. . . . . . . . . . . . . . . . . . . . . 140

Figura 21 - Fotos submersas e da superfície dos experimentos de manobra do AUV Pirajuba, realizados no Colégio Naval de Angra dos Reis . . . . . . . . 141

Figura 22 - Etapas dos ensaios de campo de Angra dos Reis com o AUV Pirajuba . 142 
Figura 23 - Diagramação de uma manobra de giro, com uma entrada de leme de 20 graus no instante de tempo de $10 \mathrm{~s}$. . . . . . . . . . . . . 143

Figura 24 - Diagramação da manobra de Zigzag do tipo 20-20, iniciada no instante de 10 segundos . . . . . . . . . . . . . . . . . . 145

Figura 25 - Comparação dos diversos filtros para as medições da taxa de rumo nas manobras de giro de 5 graus . . . . . . . . . . . . . . . . . . . 146

Figura 26 - Resultados experimentais da taxa de rumo para a manobra de giro, considerando as quatro deflexões do ângulo de leme . . . . . . . . . . . 148

Figura 27 - Resultados experimentais da taxa de rumo para a manobra de zigzag, considerando as quatro deflexões do ângulo de leme . . . . . . . . . . . 149

Figura 28 - Comparação da taxa de rumo da resposta transiente das manobras de zigzag e giro . . . . . . . . . . . . . . . . . . . . . . 153

Figura 29 - Análise do espectro da frequência das manobras de giro de 5 graus . . 154

Figura 30 - Malha de refino médio do perfil NACA0015, utilizada na seleção do modelo de turbulência . . . . . . . . . . . . . . . . . . . . . 162

Figura 31 - Comparação experimental ${ }^{[169]}$ e numérica do coeficiente de sustentação para o perfil NACA0015 (caso 2D) . . . . . . . . . . . . . . 163

Figura 32 - Comparação experimental ${ }^{[169]}$ e numérica do coeficiente de arrasto para o perfil NACA0015 (caso 2D) . . . . . . . . . . . . . . . . . . 164

Figura 33 - Validação das estimativas numéricas da força normal e momento do caso 3D da seleção dos modelos de turbulência . . . . . . . . . . . . . . 169

Figura 34 - Validação das estimativas numéricas da força axial do caso 3D da seleção dos modelos de turbulência . . . . . . . . . . . . . . . . . . 170

Figura 35 - Validação das estimativas numéricas do centro hidrodinâmico do caso 3D da seleção dos modelos de turbulência . . . . . . . . . . . . . . . . 171

Figura 36 - Análise do efeito da ordem do equacionamento dos modelos convectivos das equações de transporte para o caso 3D de seleção . . . . . . . . . . 175

Figura 37 - Verificação de convergência de discretização para malha do corpo sozinho178

Figura 38 - Coeficientes hidrodinâmicos do corpo isolado do Pirajuba . . . . . . . . 179

Figura 39 - Linhas de fluxo do escoamento sobre o AUV Pirajuba, em uma condição de $25^{\circ}$ de ângulo de incidência . . . . . . . . . . . . . . . . . . . 180

Figura 40 - Malha de refino médio da asa original do AUV Pirajuba . . . . . . . . 181

Figura 41 - Malha de refino médio da asa alterada do AUV Pirajuba . . . . . . . . 182

Figura 42 - Coeficientes hidrodinâmicos do leme original do AUV Pirajuba . . . . . 183

Figura 43 - Coeficientes hidrodinâmicos do leme alterada do AUV Pirajuba . . . . 183

Figura 44 - Coeficientes hidrodinâmicos do leme original do AUV Pirajuba . . . . . 185

Figura 45 - Coeficientes hidrodinâmicos do leme modificado do AUV Pirajuba . . . 186

Figura 46 - Análise da convergência de malha para a força normal dos lemes . . . . 187 
Figura 47 - Linhas de fluxo do escoamento sobre o leme original do AUV Pirajuba, em uma condição de $22^{\circ}$ de ângulo de incidência . . . . . . . . . . . . . 188

Figura 48 - Coeficientes dos esforços hidrodinâmicos do duto Clark-Y ${ }^{[151]}$. . . . . . 191

Figura 49 - Malha de refino médio do duto propulsor 19A do AUV Pirajuba . . . . 191

Figura 50 - Coeficientes dos esforços hidrodinâmicos do duto propulsor do AUV Pirajuba . . . . . . . . . . . . . . . . . . . . 192

Figura 51 - Linhas de escoamento das simulações de 0 e 25 graus do duto propulsor do AUV Pirajuba . . . . . . . . . . . . . . . . . . . . . 192

Figura 52 - Linhas de fluxo do escoamento sobre o duto propulsor do AUV Pirajuba, em uma condição de $25^{\circ}$ de ângulo de incidência . . . . . . . . . . . . . 193

Figura 53 - Malha de refino médio da combinação corpo e lemes . . . . . . . . . . . 195

Figura 54 - Comparação dos coeficientes hidrodinâmicos estáticos da combinação leme-corpo do AUV Pirajuba . . . . . . . . . . . . . . 196

Figura 55 - Linhas de fluxo do escoamento sobre o corpo e o leme do AUV Pirajuba, em uma condição de $20^{\circ}$ de ângulo de incidência . . . . . . . . . . . . . 197

Figura 56 - Comparação dos coeficientes hidrodinâmicos estáticos do leme na presença do corpo do AUV Pirajuba . . . . . . . . . . . . . . . . . . 199

Figura 57 - Superfícies do coeficiente de força normal estático do leme na presença do corpo do AUV Pirajuba pelo método de CFD. . . . . . . . . . . . . 201

Figura 58 - Linhas de contorno da soma das derivadas parciais da força normal estática do leme na presença do corpo pelo método de CFD . . . . . . 201

Figura 59 - Malha de refino médio da combinação corpo mais duto . . . . . . . . . 202

Figura 60 - Comparação das linhas de escoamento sobre o duto propulsor 19A sozinho e na presença do corpo do AUV Pirajuba . . . . . . . . . . . . 203

Figura 61 - Linhas de fluxo do escoamento sobre o corpo e o duto do AUV Pirajuba, em uma condição de $20^{\circ}$ de ângulo de incidência . . . . . . . . . . . . . 204

Figura 62 - Coeficientes hidrodinâmicos da combinação duto-corpo do AUV Pirajuba205

Figura 63 - Coeficientes dos esforços hidrodinâmicos dinâmicos do corpo isolado do Pirajuba . . . . . . . . . . . . . . . . . . 209

Figura 64 - Linhas de fluxo do escoamento sobre o corpo e o leme do AUV Pirajuba, em uma condição de incidência nula e uma velocidade de rotação de $15 \%$ s210

Figura 65 - Comparação dos coeficientes hidrodinâmicos dinâmicos da combinação leme-corpo do AUV Pirajuba . . . . . . . . . . . . . . . . . . . . . 211

Figura 66 - Comparação dos coeficientes hidrodinâmicos dinâmicos do leme na presença do corpo do AUV Pirajuba . . . . . . . . . . . . . . . . . 214

Figura 67 - Superfícies do coeficiente de força normal dinâmico do leme na presença do corpo do AUV Pirajuba pelo método de CFD . . . . . . . . . . 215 
Figura 68 - Linhas de contorno da soma das derivadas parciais da força normal dinâmica do leme na presença do corpo do AUV Pirajuba pelo método de CFD . . . . . . . . . . . . . . . . . . 2 . 216

Figura 69 - Comparação das manobras de giro obtidas numericamente, com os resultados obtidos experimentalmente . . . . . . . . . . . . . . . 222

Figura 70 - Comparação das manobras de giro obtidas pelo modelo numérico corrigido, com os resultados obtidos experimentalmente . . . . . . . . . . 224

Figura 71 - Comparação das manobras de zigzag obtidas numericamente, com os resultados obtidos experimentalmente . . . . . . . . . . . . . . . 227

Figura 72 - Comparação das manobras de zigzag obtidas pelos modelos numéricos corrigidos, com os resultados obtidos experimentalmente . . . . . . . 228

Figura 73 - Perfil dos elipsoides inscritos e circunscritos no casco do AUV Pirajuba 234

Figura 74 - Coeficiente de arrasto para cilindros circulares lisos em regime subsônico 238

Figura 75 - Erros máximos e mínimos dos termos potenciais, viscosos e totais (soma), para o caso da força e do momento, normalizados pelo maior valor de cada caso . . . . . . . . . . . . . . . . . . . . . 240

Figura 76 - Comparação das linhas de escoamento sobre o corpo, para uma variação na velocidade angular com um ângulo de incidência nulo . . . . . . . . 241

Figura 77 - Comparação das linhas de escoamento sobre o corpo, para uma variação no ângulo de incidência com uma velocidade angular de $5^{\circ} / \mathrm{s}$. . . . . . 242

Figura 78 - Resultados da resposta dinâmica da manobra de giro para a análise de sensibilidade dos parâmetros mais significativos . . . . . . . . . . . . . 248

Figura 79 - Resultados da resposta dinâmica da manobra de zigzag para a análise de sensibilidade dos parâmetros mais significativos . . . . . . . . . . 257

Figura 80 - Modelo cativo do AUV Pirajuba e a primeira versão do Maya . . . . . 296

Figura 81 - Componentes do AUV Pirajuba . . . . . . . . . . . . . . . . . . . 297

Figura 82 - Representação qualitativa dos centro de coordenadas utilizadas . . . . 299

Figura 83 - Desenho em CAD do AUV Pirajuba, com a representação dos volumes de água internos ao casco mais significativos . . . . . . . . . . . 300

Figura 84 - Representação das características geométricas de um elipsoide . . . . . 306

Figura 85 - Representação das características geométricas de uma asa/leme . . . . 307

Figura 86 - Coeficiente adimensional de massa adicional de uma asa/leme fina e finita308

Figura 87 - Coeficientes de massa adicional bidimensional de uma placa plana . . . 309

Figura 88 - Coeficientes de massa adicional bidimensional de uma seção cilíndrica . 309

Figura 89 - Coeficientes de massa adicional bidimensional de uma seção cilíndrica com vigas/arrestas equidistantes . . . . . . . . . . . . . . . 310

Figura 90 - Coeficientes de massa adicional bidimensional de rotação, $m_{33}$, de uma seção cilíndrica com vigas/arrestas equidistantes . . . . . . . . . . . . . 310 
Figura 91 - Resposta da taxa de rumo para a sensibilidade dos parâmetros inerciais nas manobras de giro . . . . . . . . . . . . . . . . . . . . . . 312

Figura 92 - Resposta da taxa de rumo para a sensibilidade dos parâmetros hidrodinâmicos de massa adicional nas manobras de giro . . . . . . . . . . . 320

Figura 93 - Resposta da taxa de rumo para a sensibilidade dos parâmetros hidrodinâmicos do corpo do AUV nas manobras de giro . . . . . . . . . . . . . 321

Figura 94 - Resposta da taxa de rumo para a sensibilidade dos parâmetros hidrodinâmicos do leme do AUV nas manobras de giro . . . . . . . . . . . . . 322

Figura 95 - Resposta da taxa de rumo para a sensibilidade dos parâmetros hidrodinâmicos do AUV (leme e corpo) nas manobras de giro . . . . . . . . . 325

Figura 96 - Resposta da taxa de rumo para a sensibilidade dos parâmetros inerciais nas manobras de zigzag . . . . . . . . . . . . . . . . . . . 330

Figura 97 - Resposta da taxa de rumo para a sensibilidade dos parâmetros hidrodinâmicos de massa adicional nas manobras de zigzag . . . . . . . . . . . 332

Figura 98 - Resposta da taxa de rumo para a sensibilidade dos parâmetros hidrodinâmicos do corpo do AUV nas manobras de zigzag . . . . . . . . . . . 334

Figura 99 - Resposta da taxa de rumo para a sensibilidade dos parâmetros hidrodinâmicos do leme do AUV nas manobras de zigzag . . . . . . . . . . . . 338

Figura 100 - Resposta da taxa de rumo para a sensibilidade dos parâmetros hidrodinâmicos do AUV (leme e corpo) nas manobras de zigzag . . . . . . . . 343 



\section{LISTA DE TABELAS}

Tabela 1 - Nomenclatura dos movimentos navais, segundo SNAME ${ }^{[61]}$ e Fonseca ${ }^{[62]} 56$

Tabela 2 - Propriedades da resposta dinâmica das manobras de giro. . . . . . . . 150

Tabela 3 - Propriedades da resposta de oscilação das manobras de zigzag. . . . . . 151

Tabela 4 - Dimensões do leme original e modificado ${ }^{[120]}$ do AUV Pirajuba . . . . . 161

Tabela 5 - Propriedades das malhas do corpo do AUV Pirajuba utilizadas no procedimento de $\mathrm{V} \& \mathrm{~V} \ldots \ldots$. . . . . . . . . . . . . . . . 168

Tabela 6 - Características dos modelos numéricos testados na análise da influência da ordem dos equacionamentos convectivos . . . . . . . . . . . . . . 174

Tabela 7 - Verificação das incertezas de discretização do coeficiente de arrasto do corpo do AUV Pirajuba . . . . . . . . . . . . . . . . . . . . 178

Tabela 8 - Propriedades das malhas do leme original (perfil NACA0012) do AUV Pirajuba. . . . . . . . . . . . . . . . . . . . 184

Tabela 9 - Propriedades das malhas do leme modificado (perfil NACA0015) do AUV Pirajuba. . . . . . . . . . . . . . . . . . . . . . 184

Tabela 10 - Características geométricas do duto do AUV Pirajuba, e do duto ensaiado por Fletcher ${ }^{[151]} \ldots$. . . . . . . . . . . . . . . . . . . . . . 189

Tabela 11 - Propriedades das malhas do duto propulsor de perfil Clark-Y ${ }^{[151]}$ utilizadas no procedimento de V\&V . . . . . . . . . . . . . . . . . . . 189

Tabela 12 - Propriedades das malhas do duto propulsor do AUV Pirajuba (perfil 19A) utilizadas no procedimento de V\&V . . . . . . . . . . . . . 190

Tabela 13 - Propriedades das malhas da combinação corpo-leme (perfil NACA0012) do AUV Pirajuba, utilizadas na análise de sensibilidade de malha. . . . 194

Tabela 14 - Propriedades das malhas da combinação corpo mais duto (perfil 19A) do AUV Pirajuba utilizadas na análise de sensibilidade de malha . . 202

Tabela 15 - Comparação experimental (EXP) e numérica (ASE e CFD), com e sem a correção no centro de gravidade (COR), das propriedades da resposta dinâmica das manobras de giro . . . . . . . . . . . . . . . . . 225

Tabela 16 - Comparação experimental (EXP) e numérica (ASE e CFD), com e sem a correção no centro de gravidade (COR), das propriedades da resposta dinâmica das manobras de zigzag . . . . . . . . . . . . . . . . . . . . . 229

Tabela 17 - Valores e desvio padrões $(1 \sigma)$ da incerteza dos parâmetros do modelo de manobra utilizados na análise de sensibilidade . . . . . . . . . . 232

Tabela 18 - Comparação da estimativa da massa adicional de força lateral em função da aceleração lateral, por métodos analíticos e pelos métodos das faixas 234 
Tabela 19 - Comparação da estimativa da massa adicional do momento de guinada em função da aceleração de guinada, por métodos analíticos e pelos métodos das faixas . . . . . . . . . . . . . . . . . . . . 235

Tabela 20 - Análise de sensibilidade dos parâmetros mais significativos para as manobras de giro com as quatro deflexões do leme . . . . . . . . . . . 249

Tabela 21 - Cálculo dos coeficientes de sensibilidade e incerteza dos parâmetros mais significativos para as manobras de giro . . . . . . . . . . . 251

Tabela 22 - Comparação das incertezas paramétricas das principais características da manobra de giro, para cada conjunto de parâmetros analisados . . . 253

Tabela 23 - Cálculo dos erros e incertezas de validação dos principais características da manobra de giro segundo a norma ASME ${ }^{[33]}$, considerando os resultados obtidos pelas simulações numéricas com os modelos hidrodinâmicos obtidos por CFD e ASE. . . . . . . . . . . . . . . . . . . . 254

Tabela 24 - Análise de sensibilidade dos parâmetros mais significativos para as manobras de zigzag com as quatro deflexões do leme, considerando a variação de 1, 2 e 3 vezes o valor dos parâmetros apresentados na tabela 17

Tabela 25 - Cálculo dos coeficientes de sensibilidade e incerteza dos parâmetros mais significativos para as manobras de zigzag.

Tabela 26 - Comparação das incertezas paramétricas das principais características da manobra de zigzag, para cada conjunto de parâmetros analisados . 262

Tabela 27 - Cálculo dos erros e incertezas de validação dos principais características da manobra de zigzag segundo a norma $\mathrm{ASME}^{[33]}$, considerando os resultados obtidos pelas simulações numéricas com os modelos hidrodinâmicos obtidos por CFD e ASE. . . . . . . . . . . . 263

Tabela 28 - Parâmetros Geométricos do Corpo do AUV Pirajuba . . . . . . . . . . 296

Tabela 29 - Parâmetros geométricos das superfícies de controle do AUV Pirajuba. . 296 Tabela 30 - Parâmetros inerciais do AUV Pirajuba ${ }^{[177]} \ldots$. . . . . . . . . . . . . . 298

Tabela 31 - Análise de sensibilidade dos parâmetros inerciais da manobra de giro . 313

Tabela 32 - Análise de sensibilidade dos parâmetros de massa adicional da manobra de giro . . . . . . . . . . . . . . . . . . . 316

Tabela 33 - Análise de sensibilidade dos parâmetros do corpo da manobra de giro . 318

Tabela 34 - Análise de sensibilidade dos parâmetros do leme da manobra de giro 323

Tabela 35 - Análise de sensibilidade dos parâmetros da combinação da manobra de

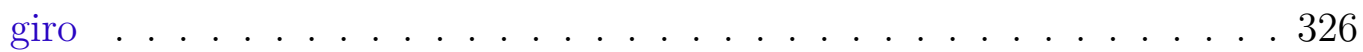

Tabela 36 - Análise de sensibilidade dos parâmetros inerciais da manobra de zigzag 331

Tabela 37 - Análise de sensibilidade dos parâmetros de massa adicional da manobra de zigzag . . . . . . . . . . . . . . . . . . . . . . . . . . . . . . . . .

Tabela 38 - Análise de sensibilidade dos parâmetros do corpo da manobra de zigzag 335 
Tabela 39 - Análise de sensibilidade dos parâmetros do leme da manobra de zigzag 339

Tabela 40 - Análise de sensibilidade dos parâmetros da combinação da manobra de zigzag . . . . . . . . . . . . . . . . . . . . 341

Tabela 41 - Cálculo dos coeficientes de sensibilidade e incerteza dos parâmetros inerciais das manobras de giro . . . . . . . . . . . . . . . . . . . 346

Tabela 42 - Cálculo dos coeficientes de sensibilidade e incerteza dos parâmetros de massa adicional das manobras de giro . . . . . . . . . . . . . . 347

Tabela 43 - Cálculo dos coeficientes de sensibilidade e incerteza dos parâmetros do corpo das manobras de giro . . . . . . . . . . . . . . . . . . . . 348

Tabela 44 - Cálculo dos coeficientes de sensibilidade e incerteza dos parâmetros do leme das manobras de giro . . . . . . . . . . . . . . . . . . . . 349

Tabela 45 - Cálculo dos coeficientes de sensibilidade e incerteza dos parâmetros da combinação das manobras de giro . . . . . . . . . . . . . . . . 350

Tabela 46 - Cálculo dos coeficientes de sensibilidade e incerteza dos parâmetros inerciais para as manobras de zigzag. . . . . . . . . . . . . . . . . . 352

Tabela 47 - Cálculo dos coeficientes de sensibilidade e incerteza dos parâmetros de massa adicional para as manobras de zigzag. . . . . . . . . . . . . . . 352

Tabela 48 - Cálculo dos coeficientes de sensibilidade e incerteza dos parâmetros do corpo para as manobras de zigzag. . . . . . . . . . . . . . . . 353

Tabela 49 - Cálculo dos coeficientes de sensibilidade e incerteza dos parâmetros da combinação para as manobras de zigzag. . . . . . . . . . . . . . . 353

Tabela 50 - Cálculo dos coeficientes de sensibilidade e incerteza dos parâmetros do leme para as manobras de zigzag. . . . . . . . . . . . . . . . . . . 354 



\section{LISTA DE ABREVIATURAS E SIGLAS}

\begin{tabular}{|c|c|}
\hline AIAA & American Institute of Aeronautics and Astronautics \\
\hline ASME & American Society of Mechanical Engineers \\
\hline AUV & Autonomous Underwater Vehicles \\
\hline AV & Autonomous Vehicles \\
\hline CAD & Computer Aided Design \\
\hline CEPEUSP & Centro de Práticas Esportivas da USP \\
\hline CFD & Computational Fuid Dynamics \\
\hline $\mathrm{CB}$ & Centro de Flutuação \\
\hline CG & Centro de Gravidade \\
\hline CGI & Grid Convergence Index \\
\hline CNAVAL & Centro de Engenharia Naval e Oceânica \\
\hline COR & Corrigido \\
\hline CTMSP & Centro Tecnológico da Marinha em São Paulo \\
\hline DNS & Direct Numerical Simulation \\
\hline DVL & Doppler Velocity Log \\
\hline ENS & Equações de Navier-Stokes \\
\hline EXP & Experimental \\
\hline FFT & Fast Fourier Transform \\
\hline FFTW & Fastest Fourier Transform in the West \\
\hline GPS & Global Positioning System \\
\hline HIL & Hardware-in-the-Loop \\
\hline $\mathrm{HR}$ & High Reynolds \\
\hline IMU & Inertial Measurement Unit \\
\hline
\end{tabular}


IPT-SP Instituto de Pesquisas Tecnológicas do estado de São Paulo

IST Instituto Superior Técnico de Lisboa

ISR Instituto de Sistemas e Robótica

ITTC International Towing Tank Conference

JONSWAP Joint North Sea Wave Project

LabHidro Laboratório de Hidrodinâmica

LES Large Edge Simulation

LLA Latitude, Longitude e Altitude (LLA)

LR Low Reynolds

LVNT Laboratório de Veículos Não Tripulados

MMS Method of Manufactured Solutions

MRF Moving Reference Frame,

NACA National Advisory Committee for Aeronautics

NOA Instituto Nacional de Oceanografia da Índia

NS Navier-Stokes

PC Personal Computers

PMM Planar Motion Mechanism

RANS Reynolds Averaged Navier Stokes

RAO Response Amplitude Operators

RE Richarson Extrapolation

RNG Renormalization Group Theory

RP Regime Permanente

RSM Reynolds Stress Model

SA Spalart-Allmaras

SBT Slender Body Theory

SIMMAN Workshop on Verification and Validation of Ship Manoeuvring Simulation Methods 
SNAME Society of Naval Architects and Marine Engineers

SST Shear-Stress Transport

SWT Slender Wing Theory

USP Universidade de São Paulo

VSA Veículos Autonômos Submarinos

V\&V Verificação e Validação 



\section{LISTA DE SÍMBOLOS}

Eixo cartesiano na direção longitudinal do corpo (avanço / surge)

Eixo cartesiano na direção lateral do corpo (deriva / sway)

Eixo cartesiano na direção vertical do corpo (afundamento / heave)

Ângulo de jogo (Roll)

Ângulo de arfagem ou caturro (Pitch)

Ângulo de rumo ou guinada (Yaw)

Grandeza vetorial genérica

Matriz de transformação de coordenadas

Velocidade angular não inercial, referente ao eixo x

Velocidade angular não inercial, referente ao eixo y

Velocidade angular não inercial, referente ao eixo z

Vetor contendo as forças externas atuantes em um corpo

Vetor contendo os momentos externos atuantes em um corpo

Massa de um corpo

Vetor das velocidade lineares não inerciais

Vetor das velocidade angulares não inerciais

Vetor das posições do CG em relação ao coordenadas fixo ao corpo

Força inercial atuante na direção do eixo i

Velocidade linear não inercial, referente ao eixo x

Velocidade linear não inercial, referente ao eixo y

Velocidade linear não inercial, referente ao eixo z

Volume de um corpo

Momento inercial atuante na direção do eixo i 
Produto de inércia de um corpo em relação aos eixos i e j

$\left[M_{i j}\right] \quad$ Matriz de massa e inércia de um corpo

$\left[A_{i j}\right] \quad$ Matriz de massa e inércia adicional de um corpo

$F_{I} \quad$ Vetor de esforços inerciais atuantes em um corpo

$F_{H} \quad$ Vetor de esforços hidrodinâmicos atuantes em um corpo

$F_{G} \quad$ Vetor de esforços devido a aceleração da gravidade atuante em um corpo

$F_{E} \quad$ Vetor de esforços devido ao empuxo atuante em um corpo

$F_{P} \quad$ Vetor de esforços hidrodinâmicos de propulsão atuantes a um corpo

$g$

$\rho$

$p_{G}$

$n$

V

$K_{T}$

$K_{T n}$

$K_{Q}$

$J$

$P$

$D_{h} \quad$ Diâmetro de um hélice

$w_{h}$

$T_{\text {req }}$

$t$

$A_{i j}$

$m_{i j}$ duto propulsor

Coeficiente de avanço

Passo de um hélice
Aceleração da gravidade local

Densidade da água que se encontra um corpo

Vetor das posições do centro de empuxo em relação ao sistemas de coordenadas fixo ao corpo

Velocidade de rotação de um hélice

Velocidade de avanço longitudinal de um veículo

Coeficientes adimensional da força de tração de um hélice

Coeficientes adimensional do ganho de força de tração de um hélice com

Coeficientes adimensional do momento resistivo gerado por um hélice

Coeficiente de esteira, gerada pelo veículo sobre o hélice

Tração requerida pelo hélice para vencer o arrasto do veículo

Fator de redução de empuxo

Massa adicional na direção i relativo ao movimento na direção j

Massa adicional bidimensional (de seção) na direção i relativo ao movimento na direção $\mathrm{j}$ 


\begin{tabular}{|c|c|}
\hline$x_{m}$ & Posição longitudinal de referência dos cálculos hidrodinâmicos \\
\hline$\alpha$ & $\begin{array}{l}\text { Ângulo incidente do escoamento no plano longitudinal, i.e., ângulo de } \\
\text { ataque }\end{array}$ \\
\hline$\beta$ & $\begin{array}{l}\text { Ângulo incidente do escoamento no plano horizontal, i.e., ângulo de } \\
\text { deriva }\end{array}$ \\
\hline$\delta_{s}$ & Deflexão das superfícies de controle horizontais \\
\hline$\delta_{r}$ & Deflexão das superfícies de controle verticais \\
\hline$X$ & Força hidrodinâmica axial (direção x), componente de $F_{H}$ \\
\hline$Y$ & Força hidrodinâmica lateral (direção y), componente de $F_{H}$ \\
\hline$Z$ & Força hidrodinâmica vertical (direção z), componente de $F_{H}$ \\
\hline$K$ & Momento hidrodinâmico de rolagem (direção x), componente de $F_{H}$ \\
\hline$M$ & Momento hidrodinâmico de arfagem (direção y), componente de $F_{H}$ \\
\hline$N$ & Momento hidrodinâmico de guinada (direção z), componente de $F_{H}$ \\
\hline$k$ & Energia cinética turbulenta \\
\hline$\epsilon$ & Taxa de dissipação turbulenta \\
\hline$\omega$ & Taxa de dissipação turbulenta especifica \\
\hline$I$ & Intensidade turbulenta \\
\hline$l$ & Comprimento característico da turbulência \\
\hline$u_{\text {med }}$ & Velocidade média do escoamento simulado \\
\hline$C_{\mu}$ & Constante empírica dos modelos de turbulência \\
\hline$L_{\infty}$ & Norma de convergência \\
\hline$t$ & Variável de tempo \\
\hline$\mu$ & Viscosidade dinâmica (molecular) \\
\hline$p$ & é a pressão estática \\
\hline$\partial$ & Operador de derivada parcial \\
\hline$\nabla$ & Operador diferencial \\
\hline$\vec{v}$ & Vetor de velocidade local \\
\hline
\end{tabular}


$\vec{F}$

$\delta_{i j}$

$\rho \overline{u_{i}{ }^{\prime} u_{j}{ }^{\prime}}$

$\mu_{t}$

$U$

$U_{\tau}$

$\tau_{w}$

$y^{+}$

$y$

$\nu$

$P h i_{i j}$

$U_{\phi}$

$\phi$

$U_{\text {num }}$

$U_{i t}$

$U_{d i s}$

$S_{U}$

$S_{L}$

$\epsilon_{n}$

$\delta_{R E}$

$\phi_{0}$

Tensor de tensão

Tensor unitário

Tensor que representa os esforços externos nas equações RANS

Delta Kronecker

Tensor de Reynolds

Viscosidade turbulenta

Velocidade nominal do escoamento

Velocidade de fricção

Tensão de cisalhamento na superfície do corpo

Representação do número de Reynolds local e normal a superfície da parede

Distância normal a parede

Viscosidade cinemática do fluido

Termo de tensão-pressão (pressure-strain)

Incerteza de uma grandeza genérica $\phi$

Valor de uma grandeza genérica obtida por uma solução numérica

Incerteza numérica total

Incerteza numérica iterativa

Incerteza numérica de discretização

Valor superior de uma convergência oscilatória, de uma grandeza numérica

Valor inferior de uma convergência oscilatória, de uma grandeza numérica

Erro de discretização de uma grandeza numérica

Erro estimado de discretização de uma grandeza numérica

Extrapolação de uma grandeza genérica e numérica para uma malha de discretização infinita 


\begin{tabular}{|c|c|}
\hline$h_{i}$ & Tamanho típico da malha \\
\hline$\alpha$ & $\begin{array}{l}\text { Constante do modelo de extrapolação de resultados numéricos de dis- } \\
\text { cretização infinita }\end{array}$ \\
\hline$p$ & $\begin{array}{l}\text { Fator de potência do modelo de extrapolação de resultados numéricos } \\
\text { de discretização infinita }\end{array}$ \\
\hline$\Delta x_{\max }$ & $\begin{array}{l}\text { Tamanho máximo de um elemento de uma malha numérica na direção } \\
\text { cartesiana } \mathrm{x}\end{array}$ \\
\hline$\Delta y_{\max }$ & $\begin{array}{l}\text { Tamanho máximo de um elemento de uma malha numérica na direção } \\
\text { cartesiana y }\end{array}$ \\
\hline$\Delta z_{\max }$ & $\begin{array}{l}\text { Tamanho máximo de um elemento de uma malha numérica na direção } \\
\text { cartesiana z }\end{array}$ \\
\hline$N$ & Número de elementos da malha de uma simulação numérica \\
\hline$\Delta V_{i}$ & Volume de um elemento da malha numérica \\
\hline$r_{i+1 / i}$ & Razão dos tamanhos específicos de malha $\left(h_{i+1} / h_{i}\right)$ \\
\hline$q(p)$ & Variável da extrapolação de Richardson \\
\hline$s$ & Constante da extrapolação de Richardson \\
\hline$\delta_{R E}^{02}$ & Erro estimado de discretização por uma extrapolação de potência 2 \\
\hline$\delta_{R E}^{12}$ & Erro estimado de discretização por uma extrapolação de potência 1 e 2 \\
\hline$\alpha_{02}$ & Constante do fator quadrático do modelo de extrapolação de potência 2 \\
\hline$\alpha_{11}$ & Constante do fator linear do modelo de extrapolação de potência 1 e 2 \\
\hline$\alpha_{12}$ & $\begin{array}{l}\text { Constante do fator quadrático do modelo de extrapolação de potência } 1 \\
\text { e } 2\end{array}$ \\
\hline$n_{g}$ & Número de malhas analisadas na estimativa do erro de discretização \\
\hline$\Delta_{M}$ & $\begin{array}{l}\text { Maior intervalo de dados analisados em uma extrapolação de discretiza- } \\
\text { ção }\end{array}$ \\
\hline$F_{s}$ & Fator de segurança da extrapolação de discretização \\
\hline$U_{s}$ & Incerteza do processo de regressão da extrapolação de discretização \\
\hline$U_{v a l}$ & Incerteza de validação \\
\hline
\end{tabular}




\begin{tabular}{|c|c|}
\hline$U_{\text {exp }}$ & Incerteza experimental \\
\hline$U_{\text {par }}$ & Incerteza paramétrica \\
\hline$E$ & Erro de validação de comparação \\
\hline$S$ & Valor de uma grandeza qualquer predita numericamente \\
\hline$D$ & Valor de uma grandeza qualquer medida experimentalmente \\
\hline$F_{h}$ & $\begin{array}{l}\text { Derivada parcial de primeira ordem do esforço } F \text { em relação a variável } \\
h\left(F_{h}=\partial F / \partial h\right)\end{array}$ \\
\hline$F_{h h}$ & $\begin{array}{l}\text { Derivada parcial de segunda ordem do esforço } F \text { em relação a variável } \\
h\left(F_{h}=\partial^{2} F / \partial h^{2}\right)\end{array}$ \\
\hline$F_{h}^{\prime}$ & Forma adimensional de $F_{h}$ \\
\hline$C_{F}$ & Forma adimensional de uma força $(F)$ pela nomenclatura da SNAME \\
\hline$C_{M}$ & Forma adimensional de um momento $(M)$ pela nomenclatura da SNAME \\
\hline$U_{\infty}$ & Velocidade relativa entre o veículo e o fluído ao longe \\
\hline$U_{\text {ref }}$ & Velocidade de referência de adimensionalização \\
\hline$S_{r e f}$ & Área de referência de adimensionalização \\
\hline$L_{r e f}$ & Comprimento de referência de adimensionalização \\
\hline$\nabla_{r e f}$ & Volume de referência de adimensionalização \\
\hline$F_{L}$ & Força de sustentação \\
\hline$F_{D}$ & Força de arrasto \\
\hline$C_{D}$ & Coeficiente de arrasto \\
\hline$C_{L}$ & Coeficiente de sustentação \\
\hline$C_{N}$ & Coeficiente de força normal \\
\hline$C_{A}$ & Coeficiente de força axial \\
\hline$S(x)$ & Área de seção transversal do corpo na posição x \\
\hline$\left(K_{2}-K_{1}\right)$ & Fator de Munk \\
\hline$r(x)$ & Raio da seção transversal do corpo na posição x \\
\hline$C_{d}$ & Coeficiente de arrasto cruzado de um cilindro infinito \\
\hline
\end{tabular}




\begin{tabular}{|c|c|}
\hline$R e_{y}$ & Número de Reynolds transversal \\
\hline$M_{c}$ & Número de Mach \\
\hline$\eta$ & Fator de correção do $C_{d_{c}}$ para um cilindro finito \\
\hline$x_{0}$ & $\begin{array}{l}\text { Coordenada longitudinal do corpo onde ocorre o descolamento da ca- } \\
\text { mada limite }\end{array}$ \\
\hline$x_{1}$ & Coordenada longitudinal do corpo que apresenta a menor derivada \\
\hline$x^{*}$ & $\begin{array}{l}\text { Coordenada longitudinal do corpo onde ocorre o descolamento da ca- } \\
\text { mada limite estimada pelo CFD }\end{array}$ \\
\hline$K$ & $\begin{array}{l}\text { Intensidade de atenuação da força normal, devido os vórtices gerados } \\
\text { na lateral do corpo }\end{array}$ \\
\hline$\alpha_{e q}(x)$ & Ângulo de ataque equivalente na seção do corpo na posição $\mathrm{x}$ \\
\hline$\alpha_{p o t}(x)$ & $\begin{array}{l}\text { Ângulo de ataque equivalente dos esforços potenciais na seção do corpo } \\
\text { na posição x }\end{array}$ \\
\hline$S_{w}$ & Área de planta de um leme (asa) \\
\hline$C_{D_{c_{w}}}$ & Coeficiente de arrasto cruzado de uma asa \\
\hline$b_{w}$ & Envergadura de uma asa \\
\hline$a_{w}$ & Razão de aspecto de uma asa \\
\hline$\Lambda$ & ângulo de enflexamento de uma asa \\
\hline$C_{l_{2 D}}$ & Coeficiente de sustentação bidimensional de um perfil \\
\hline$e$ & Fator de eficiência de Oswald de uma asa \\
\hline$C_{m_{\bar{c} / 4 w}}$ & $\begin{array}{l}\text { Coeficiente de momento de um leme (asa), calculado no centro pressão } \\
\text { teórico }\end{array}$ \\
\hline $\bar{c}$ & Corda média de uma asa (leme) \\
\hline$\alpha_{e f}$ & Ângulo de incidência efetivo no leme (asa) \\
\hline$x_{A C_{w}}$ & Centro hidrodinâmico de um leme (asa) \\
\hline$C L_{(w b)}$ & Coeficiente de sustentação da combinação leme e corpo \\
\hline$C L_{b}$ & Coeficiente de sustentação do corpo sozinho \\
\hline$C L_{w(b)}$ & Coeficiente de sustentação do leme na presença do corpo \\
\hline
\end{tabular}




$$
\begin{aligned}
& C L_{b(w)} \quad \text { Coeficiente de sustentação do corpo na presença do leme } \\
& C L_{\alpha} \quad \text { Derivada de primeira ordem do coeficiente de sustentação em função do } \\
& \text { ângulo de incidência } \\
& K_{w(b)} \quad \text { Fator de interferência do leme na presença do corpo devido o ângulo de } \\
& \text { incidência } \\
& K_{b(w)} \quad \text { Fator de interferência do corpo na presença do leme devido o ângulo de } \\
& \text { incidência } \\
& k \quad \text { Razão entre o diâmetro do corpo e a envergadura do leme }\left(k=D / b_{w}\right) \\
& \zeta \quad \text { Variável de cálculo dos fatores de interferência corpo-leme } \\
& (\Delta \alpha)_{v} \quad \text { Variação do ângulo de incidência no leme devido aos vórtices laterais } \\
& \text { gerados pelo corpo } \\
& k_{w(b)} \quad \text { Fator de interferência do leme na presença do corpo devido a deflexão } \\
& \text { dos lemes } \\
& k_{b(w)} \quad \text { Fator de interferência do corpo na presença do leme devido a deflexão } \\
& \text { dos lemes } \\
& C L_{\text {duct }} \quad \text { Coeficiente de sustentação de um duto } \\
& C M_{\text {duct }} \quad \text { Coeficiente de momento de um duto } \\
& C D_{\text {duct }} \quad \text { Coeficiente de arrasto de um duto } \\
& c_{d} u c t \quad \text { Corda do perfil de um duto } \\
& D_{d} \text { uct } \quad \text { Diâmetro de um duto } \\
& \alpha_{e f_{d}} \quad \text { Ângulo de incidência efetivo no duto } \\
& \Delta x_{C G_{d}} \quad \text { Distância do centro hidrodinâmico do duto ao centro de rotação do } \\
& \text { veículo } \\
& \eta_{\omega} \quad \text { Eficiência hidrodinâmica do escoamento incidente ao duto }\left(\eta_{\omega}=q_{d} / q_{\infty}\right) \\
& q_{d} \quad \text { Pressão dinâmica do escoamento na posição do duto } \\
& q_{\infty} \quad \text { Pressão dinâmica do escoamento longe do duto } \\
& K_{\omega} \quad \text { Coeficiente geométrico da esteira } \\
& C_{\omega s w f} \quad \text { Coeficiente prismático da área superficial de proa }
\end{aligned}
$$




\begin{tabular}{|c|c|}
\hline$C_{\omega s w a}$ & Coeficiente prismático da área superficial de popa \\
\hline$L_{f}$ & Comprimento da proa do corpo \\
\hline$L_{a}$ & Comprimento da popa do corpo \\
\hline$r_{0}$ & Raio externo do duto \\
\hline$r_{i}$ & Raio interno do duto \\
\hline$C N_{A U V}$ & Coeficiente de força normal de todo AUV \\
\hline$C N_{F B}$ & Coeficiente de força normal da combinação leme e corpo \\
\hline$C N_{B}$ & Coeficiente de força normal do corpo isolado \\
\hline$C N_{F-B}$ & $\begin{array}{l}\text { Coeficiente de força normal da combinação leme e corpo, menos a } \\
\text { contribuição do corpo isolado }\end{array}$ \\
\hline$C N_{F(B)}$ & Coeficiente de força normal do leme na presença do corpo \\
\hline$C N_{B(F)}$ & Coeficiente de força normal do corpo na presença do leme \\
\hline$K N_{F-B}$ & $\begin{array}{l}\text { Fator de correção da interferência do coeficiente de força normal da } \\
\text { combinação leme e corpo, menos a contribuição do corpo isolado }\end{array}$ \\
\hline$s p(m, n)$ & $\begin{array}{l}\text { Função de interpolação polinomial bidimensional por partes, em função } \\
\text { das coordenadas locais m e } n\end{array}$ \\
\hline$b_{i j}$ & $\begin{array}{l}\text { Coeficientes da função de interpolação polinomial bidimensional por } \\
\text { partes }\end{array}$ \\
\hline B & $\begin{array}{l}\text { Matriz que relaciona as condições de contorno de uma interpolação } \\
\text { polinomial bidimensional por partes }\end{array}$ \\
\hline$\gamma$ & Vetor que agrupa os termos $b_{i j}$ \\
\hline$h$ & Profundidade do veículo \\
\hline$\sigma$ & $\begin{array}{l}\text { Soma das variâncias das incertezas de medições e da precisão da célula } \\
\text { de carga }\end{array}$ \\
\hline$\sigma_{m}$ & Variância das incertezas de medições \\
\hline$\sigma_{r}$ & Variância de medição da célula de carga \\
\hline$N_{m}$ & Número de dados medidos \\
\hline$g(t)$ & Função do filtro Gaussiano continua definida no tempo \\
\hline
\end{tabular}




\begin{tabular}{|c|c|}
\hline$G(k)$ & Função do filtro Gaussiano discreta definida nos pontos de medição \\
\hline$X(k)$ & Função que define a transformada de FFT discreta \\
\hline$t_{i}$ & Tempo de iteração do modelo de turbulência $i$ \\
\hline$n_{i}$ & $\begin{array}{l}\text { Número de iterações necessários para a simulação do modelo de turbu- } \\
\text { lência } i \text { convergir }\end{array}$ \\
\hline$T_{i}$ & Tempo total de simulação do modelo de turbulência $i$ \\
\hline$C A_{i}$ & $\begin{array}{l}\text { Coeficiente de força axial induzida (devido a ângulo de incidência não } \\
\text { nulo) }\end{array}$ \\
\hline$C A_{0}$ & Coeficiente de força axial parasita (com ângulo de incidência nulo) \\
\hline$X_{h c}$ & Posição do centro hidrodinâmico \\
\hline$\eta_{F(B)}$ & $\begin{array}{l}\text { Função que define a soma das derivadas parciais do coeficiente de força, } \\
\text { em função do ângulo de incidência e da deflexão do leme. }\end{array}$ \\
\hline$\delta_{\text {Estol }}$ & Deflexão do leme que ocorre o estol do leme \\
\hline$\delta_{\text {Estol }_{\alpha=0}}$ & Deflexão do leme que ocorre o estol do leme, quando a incidência é nula \\
\hline$\alpha_{E s t o l_{\delta=0}}$ & $\begin{array}{l}\text { Ângulo de incidência que ocorre o estol do leme, quando a deflexão do } \\
\text { leme é nula }\end{array}$ \\
\hline$q_{\text {Estol }}$ & Velocidade de rotação que ocorre o estol do leme \\
\hline$q_{E s t o l}{ }_{\alpha=0}$ & $\begin{array}{l}\text { Velocidade de rotação que ocorre o estol do leme, quando a incidência é } \\
\text { nula }\end{array}$ \\
\hline$F_{P}$ & Componente potencial da força normal \\
\hline$M_{P}$ & Componente potencial do momento \\
\hline$C_{d_{n}}$ & Coeficiente de arrasto cruzado de um cilindro infinito \\
\hline$F_{V}$ & Componente viscosa da força normal \\
\hline$M_{V}$ & Componente viscosa do momento \\
\hline$X_{i}$ & Parâmetro qualquer do modelo numérico em análise \\
\hline$\Delta X_{i}$ & Variação de um parâmetro qualquer do modelo numérico em análise \\
\hline$u_{X_{i}}$ & Incerteza de variação do parâmetro $X_{i}$ \\
\hline$u_{\text {Inercial }}$ & Incerteza paramétrica dos parâmetros inerciais \\
\hline
\end{tabular}


$u_{\text {M.adi }} \quad$ Incerteza paramétrica dos parâmetros de massa adicional

$u_{\text {Parte }} \quad$ Incerteza paramétrica de cada parte do veículo

$u_{\text {Esforço }} \quad$ Incerteza paramétrica dos esforços hidrodinâmicos

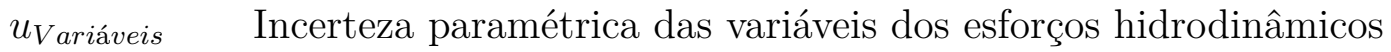

$u_{\text {Corpo }} \quad$ Incerteza paramétrica dos esforços hidrodinâmicos do corpo

$u_{\text {Leme }} \quad$ Incerteza paramétrica dos esforços hidrodinâmicos do leme 



\section{SUMÁRIO}

Introdução $\ldots \ldots \ldots \ldots \ldots \ldots \ldots \ldots$

1.1 Revisão bibliográfica . . . . . . . . . . . . . . . . . . . . 44

1.1.1 CFD aplicado à predição de esforços hidrodinâmicos em um AUV . . . 44

1.1.2 Desenvolvimento do modelo de manobra a partir dos resultados de CFD 47

1.1.3 Procedimento de validação do modelo de Manobra . . . . . . . . . . . 50

$1.2 \quad$ Objetivos desta tese . . . . . . . . . . . . . . 53

1.3 Organização do texto da tese . . . . . . . . . . . . . . 54

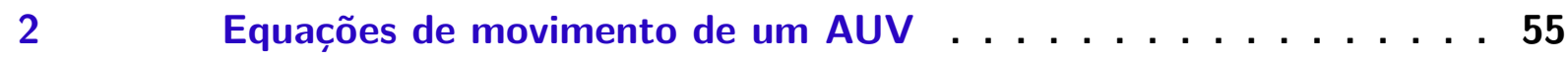

$2.1 \quad$ Equacionamento Cinemático . . . . . . . . . . . . . 56

2.2 Modelagem Dinâmica em águas calmas . . . . . . . . . . . . . 58

2.2 .1 Equações de movimento . . . . . . . . . . . . . . . . 58

2.2 .2 Esforços de gravidade e empuxo . . . . . . . . . . . . . . 61

2.2 .3 Esforços hidrodinâmicos: Propulsão . . . . . . . . . . . . . . . . 62

2.2.4 Esforços hidrodinâmicos: Massa Adicional de aceleração . . . . . . . . . 64

2.2.5 Esforços hidrodinâmicos: amortecimento e controle . . . . . . . . . . . 67

3 Metodologia para simulações de um AUV pelo método de CFD . . 69

3.1 Geração de Malha . . . . . . . . . . . . . . . . . . . 72

$3.2 \quad$ Condições de Contorno . . . . . . . . . . . . . . . . . . . 75

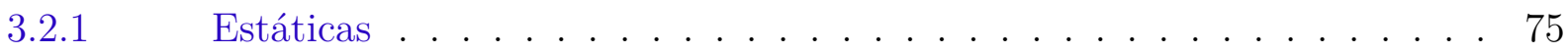

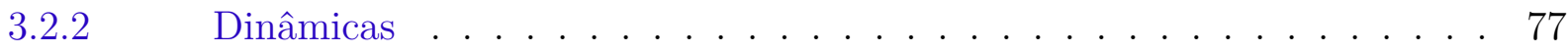

$3.3 \quad$ Critério de convergência . . . . . . . . . . . . . . . 79

$3.4 \quad$ Modelos de Turbulência . . . . . . . . . . . . . . . . . . . . . . . 79

3.4.1 Modelos de solução na parede . . . . . . . . . . . . . . . . . 82

3.4.2 Modelo de 1 equação: Spalart-Allmaras . . . . . . . . . . . . . . . . 84

3.4.3 Modelo de 2 equações $k$-e: padrão, RNG e Realizável . . . . . . . . . . 85

3.4.4 Modelo de 2 equações $k$-w: padrão e SST . . . . . . . . . . . 86

3.4.5 Modelo de 4 equações: Transição SST . . . . . . . . . . . . . . 87

3.4.6 Modelo de 7 equação: Tensores de Reynolds . . . . . . . . . . . . . . 88

$3.5 \quad$ Procedimento de verificação e validação . . . . . . . . . . . . . . . . 89

3.5.1 Procedimento de verificação . . . . . . . . . . . . . . . . . . 91

3.5.1.1 Verificação de código . . . . . . . . . . . . . . . . . . . 91

3.5.1.2 Verificação de solução . . . . . . . . . . . . . . . . . . . . . . . . . 92

3.5.2 Procedimento de validação . . . . . . . . . . . . . . . . . . 98 
$4.1 \quad$ Modelo baseado nas séries de Taylor . . . . . . . . . . . . . . . . 103

4.2 Modelo baseado nas funções analíticas e semi-empíricas . . . . . . . . . 105

4.2.1 Definição dos Coeficientes Hidrodinâmicos . . . . . . . . . . . . . . . . 107

$4.2 .2 \quad$ Corpo Isolado . . . . . . . . . . . . . . . . . . . . . . 109

4.2.2.1 Modelo Potencial . . . . . . . . . . . . . . . . . . . . 109

4.2.2.2 Modelo Potencial e Viscoso . . . . . . . . . . . . . . . . . 110

4.2.2.3 Inclusão de Fatores Semi-Empíricos . . . . . . . . . . . . . . 111

4.2.2.4 Modelo Dinâmico . . . . . . . . . . . . . . . . . . . 113

4.2.2.5 Modelo Dinâmico com Fatores Semi-Empíricos . . . . . . . . . . . . . 114

$4.2 .3 \quad$ Leme isolado . . . . . . . . . . . . . . . . . . 116

4.2.3.1 Modelo Estático . . . . . . . . . . . . . . . . . 117

4.2.3.2 Modelo Dinâmico . . . . . . . . . . . . . . . . . . . . 118

4.2.4 Interferência Corpo-Asa . . . . . . . . . . . . . . 119

4.2.4.1 Modelo Estático Linear . . . . . . . . . . . . . . . . . . . . 120

4.2.4.2 Modelo Estático Não-Linear . . . . . . . . . . . . . . . . . 121

4.2.4.3 Modelo Dinâmico . . . . . . . . . . . . . . . . . . . . . . . 122

4.2.5 Duto propulsor isolado . . . . . . . . . . . . . 123

4.2.5.1 Modelo Estático . . . . . . . . . . . . . . . . . . . . 124

4.2.5.2 Modelo Dinâmico . . . . . . . . . . . . . . . . . 125

4.2.6 Interferência Corpo-Duto . . . . . . . . . . . . . 126

4.2.6.1 Modelo Estático . . . . . . . . . . . . . . . 126

4.2.6.2 Modelo Dinâmico . . . . . . . . . . . . . . . . . . . . 128

$4.3 \quad$ Modelo baseado nas simulações de CFD . . . . . . . . . . . . . . . 128

4.3.1 Modelo de interpretação dos esforços hidrodinâmicos numéricos . . . . . 129

4.3.2 Metodologia de interpolação dos resultados discretos . . . . . . . . . 133

5 Ensaios de validação dos modelos de manobras . . . . . . . . . . 135

$5.1 \quad$ Ensaios estáticos em tanques de prova . . . . . . . . . . . 136

5.1.1 Infraestrutura e procedimento dos ensaios . . . . . . . . . . . 136

5.1.2 Equipamentos e sistemas de medições . . . . . . . . . . . . . 137

5.1.3 Tratamento das medições . . . . . . . . . . . . . . . . . . . . 139

$5.2 \quad$ Ensaios de manobra com modelo livre . . . . . . . . . . . . . . . . . 139

5.2.1 Metodologia de ensaios . . . . . . . . . . . . . 141

$5.2 .2 \quad$ Manobra de giro . . . . . . . . . . . . . . . . . 143

$5.2 .3 \quad$ Manobra de zigzag . . . . . . . . . . . . . . . . . . 144

5.2.4 Tratamento dos dados experimentais . . . . . . . . . . . . . . 144

5.2.5 Identificação do ruído do ambiente . . . . . . . . . . . . 153

6 Investigação dos esforços hidrodinâmicos do AUV Pirajuba . . . . 157

6.1 Seleção dos modelos numéricos . . . . . . . . . . . . . . . . 159

6.1.1 Caso 2D: Asa sozinha . . . . . . . . . . . . . 160 
6.1.2 Caso 3D: Corpo sozinho . . . . . . . . . . . . . 167

6.1.3 Ordem do equacionamento: Corpo sozinho . . . . . . . . . . . 174

6.2 Validação dos esforços hidrodinâmicos estáticos por ensaios em tanque de provas . . . . . . . . . . . . . . . . . . . 176

6.2.1 Corpo isolado . . . . . . . . . . . . . 177

$6.2 .2 \quad$ Leme isolado . . . . . . . . . . . . . . . . . . . 180

$6.2 .3 \quad$ Duto propulsor isolado . . . . . . . . . . . . . . . . . 189

6.2.4 Combinação corpo e leme . . . . . . . . . . . . . . . . . . 194

6.2.5 Combinação corpo e duto . . . . . . . . . . . . . . 200

6.3 Análise numérica e analítica dos coeficientes dinâmicos . . . . . . . . 206

6.3.1 Corpo sozinho . . . . . . . . . . . . . . 207

6.3.2 Combinação corpo e leme . . . . . . . . . . . . . . . 210

6.4 Validação da estimativa dos esforços dinâmicos por ensaios de modelo livre217

6.4.1 Implementação do modelo de manobra . . . . . . . . . . . . . . . . . . . 219

6.4.2 Comparação dos resultados numéricos e experimentais . . . . . . . . . . 220

6.4.2.1 Manobra de giro . . . . . . . . . . . . . . . . . 221

6.4.2.2 Manobra de zigzag . . . . . . . . . . . . . . . . 223

6.4.3 Análise da sensibilidade e validação dos modelos de manobras . . . . . . 229

6.4.3.1 Simplificação do modelo dinâmico no plano lateral . . . . . . . . . . . . 231

6.4.3.2 Sensibilidades consideradas dos parâmetros do modelo . . . . . . . . . . 231

6.4.3.3 Método de cálculo dos coeficientes de sensibilidade e incerteza paramétrica244

6.4.3.4 Metodologia de validação dos resultados do simulador . . . . . . . . . . 246

6.4.3.5 Análise de sensibilidade e validação da manobra de giro . . . . . . . . . 247

6.4.3.6 Análise de sensibilidade e validação da manobra de zigzag . . . . . . . . 256

Conclusão . . . . . . . . . . . . . . . . . . . 265

Referências ...................... . . 277

Apêndices $\quad 293$

APÊNDICE A - O Veículo Submarino Autônomo Pirajuba . . . . . 295

APÊNDICE B - Metodologia para o cálculo das propriedades inerciais molhadas do AUV Pirajuba . . . . . . . . . . 299

APÊNDICE C - Modelo simplificado das equações dinâmicas laterais de um AUV . . . . . . . . . . . . . . 303 
APÊNDICE D - Modelos para cálculo da massa adicional de um AUV esbelto do tipo torpedo . . . . . . . . . . 305

D.1 Modelo analítico de um elipsoide de revolução prolato . . . . . . . . . . 305

D.2 Modelo numérico de uma asa fina e de envergadura finita . . . . . . . . 307

D.3 Formulação dos coeficientes bi-dimensionais de corpos e lemes . . . . . . 309

APÊNDICE E - Análise de sensibilidade da manobra de giro . . . 311

E.1 Sensibilidade dos parâmetros inerciais . . . . . . . . . . . . . . 312

E.2 Sensibilidade dos parâmetros de massa adicional . . . . . . . . . . . 315

E.3 Sensibilidade dos parâmetros hidrodinâmicos do corpo . . . . . . . . . . 315

E.4 Sensibilidade dos parâmetros hidrodinâmicos do leme . . . . . . . . . 315

E.5 Sensibilidade dos parâmetros hidrodinâmicos da combinação . . . . . . 320

APÊNDICE F - Análise de sensibilidade da manobra de zigzag . . 329

F.1 Sensibilidade dos parâmetros inerciais . . . . . . . . . . . . . 330

F.2 Sensibilidade dos termos de massa adicional . . . . . . . . . . . . . . 332

F.3 Sensibilidade dos parâmetros hidrodinâmicos do corpo . . . . . . . . . . 334

F.4 Sensibilidade dos parâmetros hidrodinâmicos do leme . . . . . . . . . 337

F.5 Sensibilidade dos parâmetros hidrodinâmicos da combinação . . . . . . 337

APÊNDICE G - Cálculo dos coeficientes de sensibilidade da manobra de giro . . . . . . . . . . . . . . . 345

APÊNDICE H-Cálculo dos coeficientes de sensibilidade da manobra de zigzag . . . . . . . . . . . 351 


\section{INTRODUÇÃO}

Atualmente, tanto instituições governamentais quanto privadas tem aumentado seus investimentos para pesquisa e desenvolvimento de veículos autônomos ( $A V s$, sigla em inglês para Autonomous Vehicles) para operações em ambientes terrestres, aéreos, marinhos e espaciais. Por apresentarem uma alta capacidade de modularidade e adaptação às necessidades de empresas e instituições estes veículos estão criando uma nova gama de missões, que antes eram consideradas como impraticáveis ou inviáveis devido aos riscos e/ou custos envolvidos. Mesmo em missões típicas, estes veículos apresentam vantagens de custos e eficácia em relação aos veículo tripulados, tornando-os em uma melhor opção com o melhor custo-benefício.

No campo da robótica subaquática destacam-se os autonomous underwater vehicles, $A U V s$, também conhecidos por veículos submarinos autônomos (VSA). Estes robôs representam uma classe de veículos que foi responsável por um aumento de eficiência significativo na execução de missões subaquáticas de águas rasas e profundas nos últimos anos. Pode-se destacar o seu uso em missões de mapeamento oceanográficos de áreas costeiras $^{[1,2,3]}$ e de águas profundas ${ }^{[4]}$, inspeção de dutos ${ }^{[5,6]}$ e cabos de comunicação submarinos $^{[7]}$, monitoramento ambiental ${ }^{[8]}$ e em aplicações militares, como a detecção de minas marinhas ${ }^{[9,10]}$.

A aplicação destes veículos tem sido impulsionada por grandes desenvolvimentos da indústria eletrônica e robótica, podendo-se citar a miniaturização de sensores científicos e de navegação, possibilitando a execução de missões de alta precisão por pequenos e acessíveis veículos; a diminuição do custo e aumento do nível de processamento de computadores embarcados, permitindo o desenvolvimento de unidades de processamento que consigam trabalhar em tempo real com algoritmos e softwares complexos; e o desenvolvimento de novas tecnologias de baterias e gerenciamento de energia, possibilitando aumentar a autonomia, manutenção e segurança na operação destes veículos.

Entretanto, para que os $A U V s$ se mantenham como ferramentas de alto desempenho e produtividade, eles devem apresentar uma evolução de projeto que reflita as necessidades presentes e futuras da indústria. Para isto um desenvolvimento tecnológico/teórico a contento deve ser apresentado nas áreas de projeto: mecânico, onde novas tecnologias de materiais e estruturas são desenvolvidas para resistir à pressão de altas profundidades e aumentar a vida útil do veículo em ambientes marinhos; hidrodinâmico, melhorando as características de manobra e a eficiência hidrodinâmica do veículo e de seu propulsor; navegação, possibilitando um posicionamento e mapeamento preciso do $A U V$ em ambientes desconhecidos por longos períodos; e controle, onde as novas arquiteturas e algoritmos 


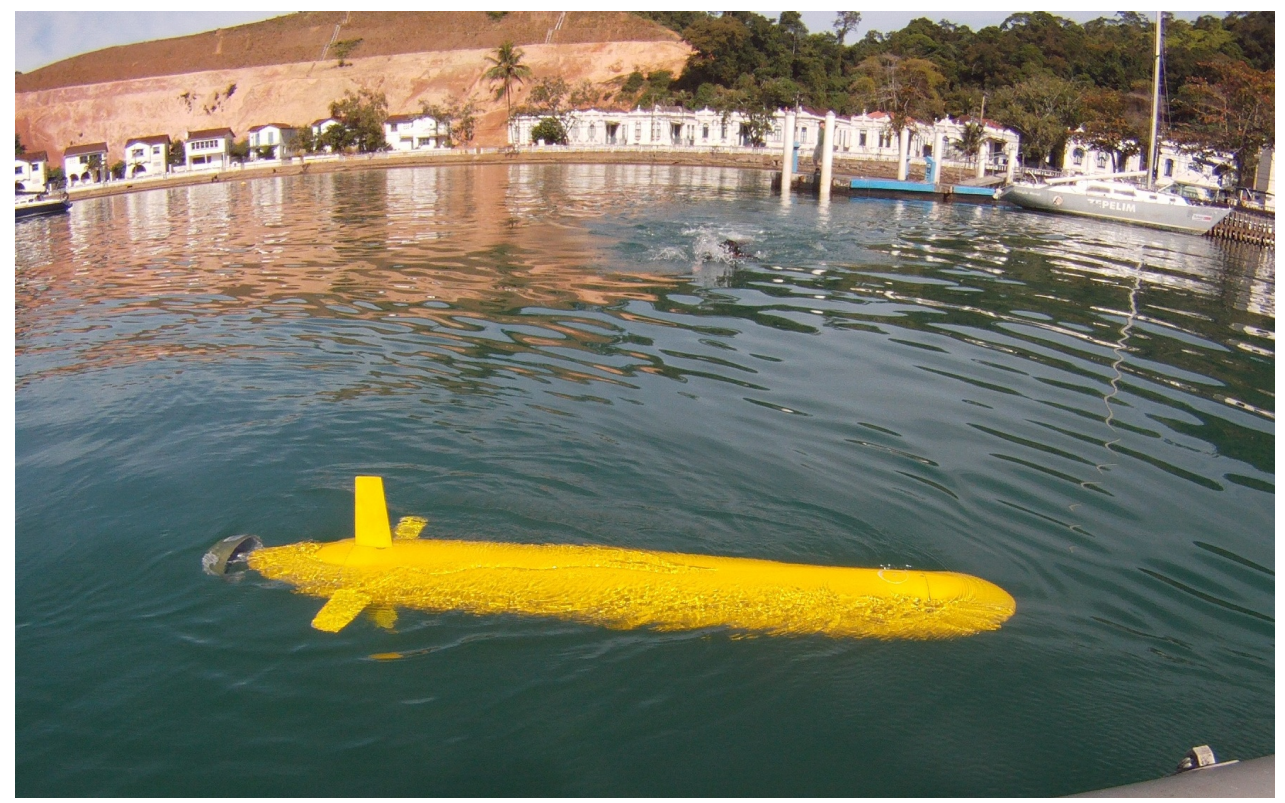

Figura 1 - AUV Pirajuba durante ensaios de manobrabilidade no mar

permitem a obtenção de sistemas de piloto automático robustos, capazes de manter a trajetória do veículo nas mais diversas condições de ambiente e adaptar-se a modificações do próprio veículo.

Motivado pelo grupo de requisitos hidrodinâmicos e a importância que esta área de projeto representa às demais áreas, este trabalho propõe uma metodologia para estimar os modelos de manobras de $A U V s$. O objeto de investigação deste trabalho será focado em $A U V s$ que apresentem a forma geométrica do casco e a configuração de suas superfícies de controle conhecidas como "casco tipo torpedo", ou seja, será considerado um veículo que tenha um casco de revolução (axissimétrica) com quatro superfícies de controle, ou lemes (hidroplanos), em disposição cruciforme ("+").

Tal forma é comumente adotada em AUVs desenvolvidos por várias instituições e empresas ao redor do mundo. Considerando esta forma de veículo, simulações e testes de mar envolveram o AUV Pirajuba, desenvolvido no Laboratório de Veículos Não Tripulados (LVNT) da Escola Politécnica da Universidade de São Paulo (USP). O AUV Pirajuba é apresentado na figura 1 durante ensaios de manobrabilidade no mar.

Os modelos desenvolvidos como aplicação desta metodologia serão voltados a estudos de manobrabilidade, e devem servir como base para o desenvolvimento de algoritmos de piloto automático e outros subsistemas. Tais aplicações são utilizadas como condição de contorno ao grau de precisão desejada e de recursos a serem comprometidos na derivação destes modelos. Corrobora ainda o esforço no desenvolvimento de modelos de manobra simples e que comprometam baixos custos, que refletem o baixo orçamento atrelados à classe de $A U V s$ investigados em comparação à outros veículos na área naval, não se justificando 
economicamente o emprego de recursos experimentais e computacionais intensivos. No entanto, a simplificação do modelo de manobra não deverá negligenciar efeitos não-lineares nas características hidrodinâmicas, como os efeitos viscosos e perda de sustentação no casco e nas superfícies de controle.

Os modelos de manobra mais complexos, tradicionalmente empregados na indústria naval, são baseados em expansões polinomiais dos esforços hidrodinâmicos em função de valores absolutos ou algébricos das variáveis de movimento do veículo (velocidades lineares e angulares ${ }^{[11,12]}$. Os valores dos coeficientes de tais polinômios seriam, então, estimados experimentalmente com ensaios realizados por modelos cativos em tanques de provas.

Como alternativa aos ensaios de modelos cativos, podem ser utilizadas formulações analíticas e semi-empíricas (ASE) para estimar estes coeficientes ${ }^{[13,14,15,16]}$. Por apresentar uma implementação mais simples, com um custo muito menor, os métodos analíticos tendem a apresentar erros muito maiores do que os métodos experimentais, principalmente em condições que os efeitos viscosos são significativos.

Com o objetivo de desenvolver uma metodologia que consiga representar os esforços hidrodinâmicos por uma função não linear de estrutura genérica e dependente das principais variáveis de manobra, neste projeto é utilizada uma metodologia que se utiliza de simulações da fluidodinâmica computacional ( $C F D$, da sigla em inglês computational fluid dynamics) de volumes finitos, para estimar os esforços hidrodinâmicos do modelo de manobras de AUVs. Utilizando esta metodologia, os esforços hidrodinâmicos terão uma melhor representatividade em comparação aos modelos tradicionais, por não ficarem necessariamente vinculados a uma estrutura matemática polinomial como a baseada na série de Taylor, possibilitando o estudo de modelos de manobras com efeitos não lineares, como aqueles relacionados ao estol dos hidroplanos e lemes.

Por serem baseadas apenas em técnicas numéricas, a metodologia desenvolvida também apresenta um menor custo em relação aos modelos de manobras baseados em ensaios experimentais, que tem que arcar com a produção de modelos cativos, aluguel dos tanques de provas, aquisição de dados e seu processamento. Do ponto de vista de projeto de $A U V s$, esta vantagem é bastante importante, pois normalmente o desenvolvimento destes veículos não apresentam um orçamento que consigam arcar com os custos destes experimentos, como é o caso de submarinos e navios.

O desenvolvimento desta metodologia foi realizado em três etapas. Primeiro, são definidos os procedimentos numéricos das simulações de $C F D$ para estimar os diferenças esforços hidrodinâmicos em função das variáveis de manobra. Em seguida é apresentado o modelo de manobra desenvolvido em função dos resultados de $C F D$. Por último, serão apresentados os procedimentos de verificação dos resultados numéricos e de validação dos modelos de manobra desenvolvidos neste trabalho. 
Nas demais seções deste capítulo são apresentados os objetivos e as principais contribuições originais desta tese, apresentando o estado da arte das pesquisas previamente realizadas nos diversos temas abordados. Uma breve apresentação sobre o AUV Pirajuba é realizada no apêndice A, ilustrando as suas principais características de projeto que são pertinentes à investigação conduzida nesta tese.

\subsection{REVISÃO BIBLIOGRÁFICA}

Para melhor apresentar o estado da arte dos temas abordados nesta tese, a revisão bibliográfica será dividida em três tópicos distintos. Serão abordadas as predições dos esforços hidrodinâmicos por simulação de $C F D$ de corpos imersos, os modelos de manobras de veículos submarinos, e os procedimentos de validação para confirmar estes modelos.

\subsubsection{CFD aplicado à predição de esforços hidrodinâmicos em um AUV}

As ferramentas de CFD de volume ou elementos finitos são largamente empregadas na indústria naval e oceânica, por representar uma classe de ferramenta que possibilita a redução dos custos de desenvolvimento na área hidrodinâmica, além de melhorar os modelos de predição dos fenômenos hidrodinâmicos. Devido à sua generalidade, este tipo de ferramenta pode ser aplicado aos mais diversos tipos de veículos e estruturas oceânicas ${ }^{[17,18]}$, permitindo a modelagem de escoamentos complexos em conjunto com a estimativa dos esforços hidrodinâmicos.

No desenvolvimento dos $A U V s$ atuais, que possuem um orçamento de projeto muito menor do que as grandes embarcações navais, o $C F D$ permite que grupos de pesquisa pequenos consigam desenvolver projetos fluidodinâmicos de grande complexidade a um custo relativamente baixo, obtendo veículos que apresentam uma melhor eficiência e desempenho.

No caso específico do modelo de manobra, esta ferramenta vem sendo mais aplicada na identificação dos esforços hidrodinâmicos estáticos de cascos/corpos sem ${ }^{[19,20,21,22,23]}$ e com apêndices ${ }^{[24,25,26,27,28,29]}$, que corresponde à condição em que o veículo está sujeito a um escoamento oblíquo de velocidade constante, i.e., o escoamento apresenta uma velocidade constante e inclinada em relação a linha central do corpo do AUV. Este tipo de abordagem resulta em uma maior exatidão na estimativa destes esforços em comparação com métodos analíticos ${ }^{[20,21,22,28]}$ ou métodos numéricos menos sofisticados.

Para a estimativa dos esforços hidrodinâmicos dinâmicos, que são gerados em função da velocidade de rotação relativa entre o fluído e o veículo, a ferramenta de $C F D$ ainda é pouco utilizada, devido aos cuidados que devem ser tomados na configuração do software de $C F D$ para impor estas condições de escoamento ${ }^{[24,30,31]}$. No entanto, mesmo quando são empregadas modelagens numéricas simplificadas, que não condizem com a real 
condição de operação, o $C F D$ tem produzido resultados animadores quando comparados aos valores experimentais ${ }^{[31]}$.

Para caracterizar os esforços hidrodinâmicos atuantes em um AUV por $C F D$, o processo de uso da ferramenta numérica deve considerar a influência de três variáveis: o ângulo do escoamento incidente relativo ao veículo, a velocidade de rotação relativa sobre o veículo, e a deflexão das superfícies de controle em relação ao seu corpo. Considerando estas variáveis as simulações de CFD produzem estimativas dos esforços hidrodinâmicos estáticos e dinâmicos. Contudo, as simulações para estimar cada tipo de esforço requerem diferentes condições de contorno.

No caso das estimativas dos esforços estáticos, as simulações foram realizadas considerando condições de contorno encontradas tipicamente na literatura ${ }^{[19,21,22]}[26,27]$, simulando ângulos de incidência altos o suficiente para considerar condições realísticas de manobra, e que implica no surgimento de efeitos não-lineares nos esforços hidrodinâmicos. Além deste tipo de simulação ter sido aplicado para todo o veículo, ele também foi considerado separadamente para o casco nu e os apêndices do AUV isolados, permitindo uma investigação numérica sobre os efeitos de interferência entre os diferentes apêndices e o casco do veículo ${ }^{[20,28,29]}$.

Para que os esforços das superfícies de controle fossem considerados de maneira conjunta com o ângulo de incidência ${ }^{[25,29]}$, as simulações também foram realizadas considerando a deflexão dos lemes. Este estudo permitiu identificar os esforços de interferência casco-leme considerando as duas variáveis na região de operação não linear, verificando, por exemplo, a modificação que a deflexão do lemes gera no nas características de seu estol, e aprimorando o modelo de manobra do AUV. Apesar de Phillips, Turnock e Furlong ${ }^{[25]}$ terem realizado um estudo similar para o caso do $A U V$ Autosub, os mesmos não apresentaram uma investigação sobre a interferência casco-leme ou considerações sobre o estol, limitando-se à consideração de ângulos de incidência restritos à faixa de valores para a qual os esforços hidrodinâmicos podem ser representados como funções lineares de tal variável.

No caso dos esforços dinâmicos, já foram apresentadas na literatura duas maneiras para se estimar estes esforços numericamente. Phillips, Furlong e Turnock ${ }^{[30]}$ realizaram simulações transientes para simular dinamicamente um $A U V$ em diversas condições de manobra, imitando os ensaios de oscilação em tanque de provas utilizados para estimar estes esforços. Mesmo conseguindo estimar estes esforços com relativa exatidão, esta solução apresenta um custo computacional muito elevado, requerendo o uso de servidores por um período de tempo maior em comparação com as simulações estáticas/não transientes.

Phillips, Furlong e Turnock ${ }^{[24]}$ e Toxopeus et al. ${ }^{[31]}$ estimaram os mesmos tipos de esforços utilizando uma abordagem quasi-estática, e consequentemente tendo uma economia significativa do tempo de simulação. Nestes trabalhos, modelos de um $A U V$ e 
de submarinos foram utilizados na simulação de manobras de giro, onde apenas a variação da velocidade de rotação é imposta. A partir desta simplificação para a representação do movimento, foram estimados os esforços dinâmicos em uma condição/simulação quasiestática, apresentando um custo computacional similar aos casos estáticos.

Por este procedimento apresentar um baixo custo, ele também será adotado nesta tese para estimativas dos esforços dinâmicos. No entanto, propõe-se uma modificação em relação aos trabalhos precedentes para que se considere conjuntamente os efeitos de incidência do escoamento (estáticos) e os efeitos de rotação (dinâmicos). Seguindo-se de tal modificação, imposta através das condições de contorno do escoamento, foram incluídas estimativas de componentes não-lineares dos esforços oriundas da interação entre os efeitos mencionados.

Este tipo de simulação também foi aplicado ao casco nu e para a combinação casco-leme. Com estas simulações foi possível estender os estudos de interferência e da condição de estol, iniciados no caso estático, para a condição dinâmica.

Além de abordar as condições de contorno, os procedimentos das simulações de CFD enunciadas nesta tese também apresentaram os detalhes de geração de malha, critérios de convergência, a seleção do modelo de turbulência, e o procedimento de verificação e validação das simulações.

Nas simulações de $C F D$ é preciso definir quais modelos utilizar para modelar a turbulência do escoamento. Contudo, a literatura não apresenta um consenso de qual modelo de turbulência consegue realizar a melhor estimativa dos esforços hidrodinâmicos par veículos submersíveis, deixando esta escolha a cargo das preferências dos pesquisadores e centros de pesquisa. Para ter uma maior confiança nas investigações de $C F D$ realizadas e servir de referência a trabalhos futuros, os trabalhos de Phillips, Turnock e Furlong ${ }^{[26]}$, Song et al. ${ }^{[27]}$ e Toxopeus et al. ${ }^{[31]}$, analisaram alguns modelos de turbulência em casos de veículos submarinos, para encontrar o modelo que apresentassem a melhor capacidade de predição dos esforços hidrodinâmicos ou características do escoamento.

No caso destes trabalho, os veículos foram analisados para números de Reynolds baseados no comprimento entre $1.1 \cdot 10^{7}$ e $1.8 \cdot 10^{7}$, indicando um número de Reynolds uma ordem de grandeza maior do que o encontrado no caso AUV Pirajuba, que é cerca de $1.7 \cdot 10^{6}$. Esta diferença no número de Reynolds pode indicar que os modelos de turbulência encontrados nestes trabalhos podem não ter o mesmo desempenho no caso do AUV Pirajuba, que apesar de estar no regime turbulento uma parte significativa do seu comprimento se encontra no regime laminar.

Devido a esta diferença no regime de escoamento, nesta tese, o procedimento para a escolha do modelo de turbulência foi refeito e melhor analisado para o caso específico do AUV Pirajuba ${ }^{[29]}$. Ao invés de realizar todas as simulações com diversos modelos, foram 
utilizados alguns casos específicos para selecionar os modelos que apresentassem a melhor estimativa dos esforços hidrodinâmicos em comparação aos resultados experimentais. Além disso, foram utilizados mais modelos do que as demais referências, os trabalhos de Phillips, Turnock e Furlong ${ }^{[26]}$, Song et al. ${ }^{[27]}$ e Toxopeus et al. ${ }^{[31]}$, incluindo modelos novos que ainda não haviam sido utilizados para este tipo de investigação.

Seguindo a tendência recente dos trabalhos que utilizam a ferramenta de $C F D^{[32]} \mathrm{em}$ suas investigações, todas as simulações deste trabalho utilizaram o critério de convergência e o procedimento de verificação e validação $(V \& V)$ estabelecidos pela norma internacional de verificação e validação de simulações de $C F D$ da $\mathrm{ASME}^{[33]}$. Estes procedimentos são utilizados para que as análises de CFD sejam corretamente verificadas, com a estimativa dos seus erros e incertezas numéricas, e validadas em função de resultados experimentais utilizando critérios estatísticos.

Apesar de serem poucos os trabalhos da área naval que apresentam este tipo de preocupação com os erros numéricos ${ }^{[23,26,31,29,34]}$, o uso da metodologia da ASME ${ }^{[33]}$, ou similares, está cada vez mais recorrente, devido a maior qualidade e confiabilidade dos resultados apresentados.

Neste trabalho serão adotadas as estratégias da norma ASME ${ }^{[33]}$, com algumas das modificações recomendadas por Eça, Vaz e Hoekstra ${ }^{[35][36]}$. Esta modificação será adotada para que as análises numéricas/estatísticas utilizem critérios de maior robustez na estimativa dos erros e incertezas relativos a sensibilidade de malha, conforme foi demostrado em Vaz, Toxopeus e Holmes ${ }^{[34]}$. Para confirmar esta robustez, foi realizado um estudo comparativo entre ambos os procedimentos para um caso específico.

\subsubsection{Desenvolvimento do modelo de manobra a partir dos resultados de CFD}

O modelo de manobra de um veículo pode ser definido como a representação matemática e/ou numérica das equações que regem o seu movimento sobre determinadas circunstâncias, como condições do ambiente ou entradas de controle. Na área de engenharia naval e oceânica, estes modelos são bastante utilizados no desenvolvimento de simuladores de diversos tipos de embarcações, testando e verificando o desempenho do veículo e dos seus subsistemas em diversas condições.

Em geral, os equacionamentos dos modelos de manobras são divididos nos equacionamentos cinemáticos, dinâmicos/inerciais e hidrodinâmicos. Destas três, apenas o equacionamento hidrodinâmico não possui uma solução matemática exata, devido a dificuldade em modelar sistemas complexos e caóticos inerentes dos escoamentos turbulentos, sendo necessário adotar modelos que consigam representar o equacionamento dos esforços hidrodinâmicos.

Os modelos de manobras tradicionais, como o modelo de Gertler e Hagen ${ }^{[11]}$ e 
seu aprimoramento proposto por Feldman ${ }^{[12]}$, consideram que os esforços hidrodinâmicos possam ser definidos por uma série de expansões polinomiais, i.e., séries de Taylor. Estas séries são escritas em função das variáveis de manobra, sendo que os seus coeficientes são determinados através de ensaios de modelos cativos em tanques de provas. Bohlmann ${ }^{[13]}$ apresentou uma alternativa aos ensaios de modelos cativos, ao incluir formulações baseadas na teoria de corpos esbeltos com algumas adaptações semi-empíricas ${ }^{[14,15,16]}$. Normalmente, os modelos que utilizam esta estrutura consideram os coeficientes de até segunda ordem, apesar que em embarcações de superfícies podem ser considerados coeficientes de até terceira ordem.

Apesar de serem mais aplicados a submarinos ${ }^{[11,12,13]}$, estes modelos também já foram aplicados no desenvolvimento de $A U V s^{[14,15,16]}$, e mesmo apresentando uma estrutura matemática simples a dinâmica destes veículos pode ser bem representada em diversas condições de operação. Entretanto, quando estes veículos experimentam fenômenos altamente não lineares, como o estol das superfícies de controle, o tipo de estrutura matemática destes modelos (baseada nas séries de Taylor) não tem a capacidade de representar estes esforços com uma alta fidelidade, principalmente quando estes fenômenos dependem de diversas variáveis.

Para que os fenômenos não lineares sejam incorporados ao modelo de manobra do $A U V$ Pirajuba, os esforços hidrodinâmicos serão modelados de forma genérica utilizando os resultados de diversas simulações de $C F D$ em condições quasi-estáticas, que considerarão todo o envelope de operação deste veículo. Além de possibilitar uma maior fidelidade na representação dos esforços hidrodinâmicos em comparação às estruturas baseadas em expansões polinomiais de segunda ordem ${ }^{[11,12,13,14,15,16]}$, o método de $C F D$ representa uma solução de menor custo em comparação aos métodos que utilizam ensaios experimentais para estimar estes esforços ${ }^{[11,12]}$.

Uma abordagem similar à proposta é encontrada no trabalho de Tang et al. ${ }^{[37]}$, em que seus autores desenvolveram o modelo de manobra de um AUV não hidrodinâmico (estrutura tipo caixa, i.e., block-type) de múltiplos propulsores, utilizando os métodos de CFD para estimar os esforços hidrodinâmicos. Apesar das simulações de CFD terem sido restritas aos casos de movimentos de baixa amplitude, sem os acoplamentos entre os escoamentos de diferentes direções e tipos, este modelo pôde ser validado por ensaios de manobras. Neste caso, a modelagem hidrodinâmica simples foi possível devido o veículo apresentar movimentos simples com escoamentos de baixa amplitude, fazendo com que o seu movimento seja praticamente regido pelos esforços inerciais e de atuação dos propulsores. Este tipo de simplificação não funcionaria para o caso do AUV Pirajuba, pois por ele apresentar uma geometria hidrodinâmica (com curvas suaves), os esforços hidrodinâmicos apresentam uma maior contribuição em seu movimento, e erros na modelagem destes esforços influenciariam mais na trajetórias simuladas. 
Toxopeus ${ }^{[23]}$ utilizou uma abordagem similar ao trabalho de Tang et al. ${ }^{[37]}$ para estimar o modelo de manobra de navios e submarinos, apesar da validação do modelo de manobra somente ter sido feita para o caso de navios. Contudo, neste caso, o CFD foi utilizado para estimar os coeficientes de primeira e segunda ordem da estrutura polinomial dos modelos de manobras clássicos ${ }^{[11,12,13]}$, resultando em um modelo de manobra que apresentava uma melhor estimativa da manobrabilidade do veículo em comparação com os modelos que utilizem estimativas analíticas.

Bettle, Gerber e Watt ${ }^{[38]}$ apresentaram uma solução alternativa para este tipo de modelagem ao resolver as equações de movimento cinemáticas e dinâmicas de um submarino em conjunto com uma simulação transiente de CFD, sem precisar de modelos intermediários para estimar os esforços hidrodinâmicos. Entretanto, para evitar a rotação da malha de elementos nos lemes devido às suas deflexões, evitando possíveis problemas na atualização da malha, os autores consideraram que os esforços devido a deflexão fossem estimados por modelos analíticos, considerando uma sobreposição aos demais esforços hidrodinâmicos do veículo. No caso de grandes veículos submarinos, esta abordagem é valida devido aos altos ângulos de estol dos lemes, encontrados em escoamentos de alto número de Reynolds. Entretanto, no caso de AUVs que operam em baixos números de Reynolds, como o Pirajuba, os lemes tendem a apresentar um baixo ângulo de estol ${ }^{[39]}$, reduzindo a efetividade deste tipo de análise.

Carrica et al. ${ }^{[40]}$ e Sakamoto, Carrica e Stern ${ }^{[41]}$ conseguiram resolver o problema da malha do leme ao utilizar malhas com sobreposição (overset grids), utilizando o software proprietário CFDShip-Iowa. Nestes trabalhos, navios e submarinos foram simulados em condições transientes, considerando tanto a deflexão dos lemes quanto a rotação dos propulsores, verificando a capacidade de manobrabilidade destes veículos em condições de operação críticas.

Mesmo com a vantagem de não considerar a simplificação dos modelos de interpretação dos esforços hidrodinâmicos, estes tipos de modelos tem a desvantagem de apresentar um custo computacional bastante elevado, precisando utilizar diversos servidores para analisar apenas um ensaio. Devido a esta desvantagem, um modelo de manobra com estas características seria inviável para o desenvolvimento de sistemas de piloto automático e outros subsistemas dos $A U V s$, devido à necessidade de realizar inúmeras simulações para verificar e validar os subsistemas.

A predição de esforços hidrodinâmicos baseada em modelos analíticos e semiempíricos (ASE) representa uma abordagem fácil e prática, evitando os custos experimentais e computacionais dos outros métodos. Por outro lado, por utilizarem modelos com diversas simplificações, as estimativas destes esforços tendem à apresentar um erro maior. Outra vantagem dos modelos ASE é que eles podem apresentar estruturas matemáticas distintas dos modelos tradicionais (séries de Taylor) ${ }^{[11,12]}$, podendo representar uma maior variedade 
de fenômenos fluidodinâmicos.

Os modelos mais atuais estão vinculados a indústria aeronáutica, especificamente à área de mísseis ${ }^{[42,43]}$. A complexidade destes modelos está atrelada a necessidade de representar os esforços aerodinâmicos para movimentos rápidos e de grande amplitudes, de forma a representar o comportamento não linear e acoplado dos esforços aerodinâmicos. Estes modelos podem ser adaptados e aplicados, totalmente ou parcialmente, na representação dos esforços hidrodinâmicos atuantes em AUVs ${ }^{[20,44]}$.

Existem abordagens para modelar os esforços hidrodinâmicos que propõem uma simbiose entre modelos ASE e métodos CFD. Nelas, os resultados obtidos para alguns valores de incidência do escoamento são interpolados e extrapolados de acordo com conceitos e expressões analíticas e semi-empíricas, que também servem à análise e interpretação da composição de esforços hidrodinâmicos estimados numericamente. Por outro lado, formulações ASE são aperfeiçoadas através de informações proporcionadas pela visualização

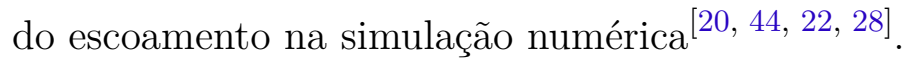

Devido ao embasamento conceitual necessário para desenvolver um modelo de manobra com base nas formulações ASE, neste trabalho, o desenvolvimento do modelo de manobra de CFD será acompanhado de um modelo de manobra ASE. Apesar de ser baseado em formulações analíticas, diversos dos seus parâmetros serão estimados em função das simulações de CFD, tornando este um modelo híbrido. Este modelo irá fornecer explicações sobre os comportamentos dos esforços hidrodinâmicos, apoiando as decisões sobre a derivação do modelo de manobra, principalmente na composição dos esforços entre diferentes partes do veículo (interferência).

\subsubsection{Procedimento de validação do modelo de Manobra}

Segundo ASME ${ }^{[33]}$, o procedimento de validação é definido como um processo que determina o grau de exatidão que um modelo matemático possui na determinação de uma grandeza especifica em relação a dados experimentais, sobre a ótica de definição do próprio modelo. Isto implica que não pode haver validação de resultados numéricos/analíticos sem uma comparação adequada aos dados experimentais.

O objetivo final do procedimento de validação é determinar se a diferença entre os resultados numéricos/analíticos e experimentais está contida no intervalo de confiança de validação, ou seja, o procedimento verifica se o erro de modelagem é englobado pelas próprias incertezas deste processo ${ }^{[33]}$. Portanto, durante a validação de um modelo é preciso verifica-lo quanto aos diversos tipos incertezas de todo o processo, e.g., numéricas, paramétricas e experimentais.

No caso de um modelo de manobra completo, o procedimento de validação é bastante complexo e difícil, requerendo a execução de diversas etapas para completa-lo 
corretamente. Devido a esta dificuldade, é difícil encontrar trabalhos na literatura que abordem a validação sobre todos os aspectos.

$\mathrm{Na}$ área de engenharia naval, a maioria dos trabalhos encontrados na literatura são referentes a embarcações de superfície, i.e., barcos e navios, sendo vinculados aos procedimentos e orientações estabelecidos pelo comitê do ITTC (International Towing Tank Conference $)^{[45]}$. Estes procedimentos foram estabelecidos por diversos trabalhos apresentados nas conferências do próprio ITTC, e por um seminário específico de Verificação e Validação dos Métodos de Validação da Manobrabilidade de Navios (Workshop on Verification and Validation of Ship Manoeuvring Simulation Methods, SIMMAN) ${ }^{[46]}$, apresentado de forma resumida em Stern et al. ${ }^{[4]}$.

Em termos gerais, o ITTC ${ }^{[45]}$ estabelece algumas diretrizes para o procedimento de validação, recomendando que ele seja dividido na validação dos esforços hidrodinâmicos por ensaios de modelo cativo, e na validação do modelo de manobra com ensaios de modelo livre. Entretanto, este procedimento não apresenta detalhes específicos de como realizar as suas etapas, deixando para o próprio pesquisador/engenheiro responsável a tarefa de definir as ferramentas e os detalhes do procedimento de validação para o seu veículo específico.

$\mathrm{Na}$ investigações dos esforços hidrodinâmicos de AUVs e submarinos, grande parte das publicações que investigam este tema ${ }^{[19,24,30,20,21,22,27]}$ apenas validam seus resultados numéricos/analíticos ao realizar comparações simples entre os seus resultados e os resultados experimentais, sem apresentar um estudo profundo das incertezas envolvidas na determinação do intervalo de confiança de validação destes resultados. Conforme a norma $\mathrm{ASME}^{[33]}$, que é recomendada pela própria ITTC ${ }^{[45]}$, este tipo de procedimento simples não garante a validação destes métodos ou de seus resultados, pois é possível que as incertezas experimentais e de modelagem sejam maiores do que próprios erros encontrados durante a comparação dos resultados.

Entretanto, em estudos mais recentes, os autores já estão utilizando procedimentos de validação complexos para embasar suas pesquisas. Phillips, Turnock e Furlong ${ }^{[26]}$ utilizaram os procedimentos da ASME ${ }^{[33]}$ para estimar as incertezas numéricas das simulações de CFD de um submarino, usando estes resultados para selecionar o modelo de turbulência que melhor estimasse os esforços hidrodinâmicos e a estrutura dos vórtices gerados pelo corpo do veículo. Vaz, Toxopeus e Holmes ${ }^{[34]}$ utilizaram a modificação deste procedimento $^{[33]}$ proposta por Eça, Vaz e Hoekstra ${ }^{[35]}$, para verificar a capacidade de predição de dois softwares de CFD nas estimativas dos esforços hidrodinâmicos devido ao ângulo de incidência do escoamento de um submarino padrão. Toxopeus ${ }^{[23]}$ utilizou este mesmo procedimento para validar os resultados numéricos dos esforços estáticos e dinâmicos de alguns tipos de navios e dos esforços estáticos de um submarino, sendo este estudo posteriormente estendido em Toxopeus et al. ${ }^{[31]}$, realizando a validação de simulações que consideram o escoamento com velocidade rotacional para a mesma geometria de submarino. 
Barros e Dantas ${ }^{[28]}$ também utilizaram os procedimentos de Eça, Vaz e Hoekstra ${ }^{[35]}$ para verificar a incerteza das simulações de CFD na estimativa dos parâmetros de seus modelos analíticos e semi-empíricos dos esforços hidrodinâmicos do casco de um AUV com o seu duto propulsor.

Em todos estes trabalhos, os procedimentos da ASME ${ }^{[33]}$ e de Eça, Vaz e Hoekstra ${ }^{[35]}$ foram utilizados para estimar as incertezas das simulações de CFD, verificando que os erros numéricos destas simulações, como o erro de discretização de malha, são aceitáveis para validar os resultados encontrados. Este tipo de verificação aumenta a qualidade dos resultados de CFD, garantindo que as simulações não estejam susceptíveis a erros significativos da modelagem numérica ${ }^{[32,33]}$.

No procedimento de validação do modelo de manobra completo, considerando toda a dinâmica, a ITTC ${ }^{[45]}$ recomenda que sejam realizadas comparações dos parâmetros característicos de manobras obtidas numericamente com aquelas medidas experimentalmente ${ }^{[23]}$. No caso de um navio, esta trajetória pode ser medida facilmente através de sistemas de GPS (Global Positioning System, ou em português, sistema de posicionamento global).

Contudo, no caso de veículos submersíveis a medição da posição é mais complicada, devido a inoperabilidade do GPS quando submerso. Apesar de existirem sistemas de posicionamento por triangularização de sinais de ultrassom, o custo de implementação deste tipo de sistema aliado as suas limitações de desempenho em águas rasas, tornaram esta alternativa pouco atrativa ou viável para o caso de AUVs.

Para manter os erros e incertezas de medição a baixos níveis, esta validação pode ser conduzida utilizando as medições das variáveis de estado do veículo, e.g., velocidades lineares e/ou angulares, que podem ser medidos por sensores internos ao veículo. Este mesmo tipo de comparação é utilizado nos algoritmos de identificação de sistemas ${ }^{[48,49]}$, pois estas variáveis tem uma relação mais direta aos esforços hidrodinâmicos, e não apresentam a "filtragem" gerada pela integração destas variáveis em posição.

Um procedimento de validação similar foi utilizado por Tang et al. ${ }^{[37]}$, ao realizar a validação do modelo de manobra do AUV TUNA-SAND através de comparação de manobras. Contudo, neste trabalho não foi utilizado nenhum tipo de validação das trajetórias, não identificando possíveis erros e incertezas oriundas do procedimento utilizado. Como resultado, a validação apresentada não indica que o modelo de manobra desenvolvido está correto, pois tanto a estimativa dos esforços hidrodinâmicos quanto a medição, ou escolha das manobras utilizadas, podem resultar em erros que se compensam, podendo indicar uma "falsa validação" para alguns tipos de manobras.

Pela recomendação do procedimento da ITTC ${ }^{[45]}$, e de maneira genérica pela norma da $\mathrm{ASME}^{[33]}$, é recomendado que todo o procedimento de validação também considere o erro e incerteza devido às incertezas nos diversos parâmetros do modelo de manobra, e.g., 
erro/incerteza paramétrico. Normalmente, esta incerteza é estimada com o uso de análises de sensibilidade, onde é verificada a influência de variação de algum parâmetro da equação de movimento nas características das manobras realizadas. Apesar da sensibilidade global

apresentar uma análise mais robusta para sistemas não lineares ${ }^{[33]}$, a sensibilidade local também permite verificar a sensibilidade do modelo de manobra do veículo ${ }^{[50]}$, conseguindo estimar as suas incertezas.

Mesmo não sendo utilizado para validar um modelo de manobra, Sen ${ }^{[50]}$ realizou uma análise bastante extensa sobre a sensibilidade dos diversos parâmetros hidrodinâmicos de um submarino. Cada parâmetro teve uma variação imposta proporcional às próprias incertezas de medição experimental, estabelecidas pela própria experiência do autor. Com este estudo, o autor verificou quais parâmetros apresentam a maior sensibilidade ao calcular a trajetória de algumas manobras, devendo tomar um maior cuidado em suas determinações.

Neste trabalho, parte dos parâmetros do modelo de manobra terão sua incerteza estimada por correspondência às incertezas de medição, no caso dos parâmetros inerciais, e às incertezas numéricas de estimação, caso dos esforços hidrodinâmicos obtidos por CFD. No entanto, nos casos que não foram realizadas o procedimento de validação de forma completa, por não haver resultados experimentais, as incertezas tiveram que ser estimadas em função de procedimentos que consideram os valores máximos e mínimos que certos parâmetros, relacionados a estes esforços, poderiam apresentar.

\subsection{OBJETIVOS DESTA TESE}

Como comentado anteriormente, o objetivo final desta tese é estabelecer uma metodologia que permita o desenvolvimento de um modelo de manobra baseado em métodos de CFD de um AUV do tipo torpedo, que tenha a capacidade de prever os movimentos do veículo mesmo em condições em que as variáveis de movimento gerem esforços hidrodinâmicos com características não lineares.

Contudo, o cumprimento deste objetivo requer o desenvolvimento de diversas atividades que podem ser definidas como objetivos secundários. Esses objetivos são definidos por:

- Desenvolver um procedimento para a realização de simulações numéricas de CFD por volumes finitos para levantar os esforços hidrodinâmicos estáticos e dinâmicos quasi-estáticos de um AUV.

- Desenvolver o modelo de manobra no plano lateral do AUV Pirajuba com base nos resultados de simulação de CFD de volumes finitos, apresentando características não lineares e acoplamento entre as variáveis. 
- Adaptar formulações ASEs para desenvolver um modelo de manobra que auxilie na análise e desenvolvimento do modelo de manobra principal (numérico) desta tese.

- Estabelecer um procedimento de validação dos modelos de manobra utilizando tanto ensaios de reboque de modelo cativo quanto ensaios de manobra de modelo auto-propelido, considerando as incertezas experimentais, paramétricas e numéricas.

O conjunto destes quatro objetivos secundários estabelecem a metodologia desenvolvida para o cumprimento do objetivo principal desta tese.

\subsection{ORGANIZAÇÃO DO TEXTO DA TESE}

Na seção 2 são apresentados os modelos dos equacionamentos dinâmicos e cinemáticos que compõe as equações de movimento de um AUV, apresentando detalhadamente a composição dos esforços externos atuantes em um AUV operando em águas calmas.

Na seção 3 são apresentadas as metodologias de simulação adotadas para realizar o levantamento dos modelos de manobras numéricos do AUV Pirajuba. Nesta seção também são apresentadas as metodologias utilizadas no procedimento de verificação e validação dos resultados numéricos.

As metodologias numéricas, com base nos resultados de CFD, e analíticas, com base nas função modificadas da indústria aeronáutica e naval, do desenvolvimento dos modelos de manobras serão apresentadas na seção 4. Nesta seção também serão apresentados os modelos de manobras tradicionais, comparando-os aos modelos desenvolvidos.

O procedimento de validação experimental dos modelos de manobras é apresentado na seção 5. São apresentados as metodologias de validação por modelos cativos, para validar os esforços hidrodinâmicos estáticos, e por modelos livres, para validar as manobras geradas pelos modelos de manobras.

Na seção 6 é apresentada a investigação e validação dos modelos de manobras desenvolvidos, realizando a comparação entre os diversos modelos e os resultados experimentais. Esta seção também apresenta diversas discussões sobre os modelos adotados, como o estol das superfícies de controle e a sensibilidade paramétrica dos modelos.

O texto é concluído com um breve resumo dos resultados obtidos pelos modelos de manobras desenvolvidos, enfatizando as contribuições originais estabelecidas e apresentando uma análise crítica das aproximações dos modelos utilizados. Ao final, é feita uma discussão sobre as dificuldades encontradas no decorrer do trabalho, apresentando sugestões de como melhorar os resultados obtidos neste trabalho. 


\section{EQUAÇÕES DE MOVIMENTO DE UM AUV}

A representação de sistemas dinâmicos reais por modelos matemáticos e numéricos é uma técnica essencial para todas as áreas de engenharia. Estes modelos possibilitam que as características dinâmicas dos sistemas sejam mais bem analisadas, permitindo uma redução nos custos de desenvolvimento destes sistemas ao diminuir o número de ensaios de ajustes e verificação.

$\mathrm{Na}$ área de robôs submarinos esta modelagem é utilizada no desenvolvimento de simuladores de dinâmica ${ }^{[51]}$, sistemas de verificação hardware-in-the-loop ${ }^{[52]}$, projetos de sistemas de controle ${ }^{[53,54,55,56]}$, avaliação da manobrabilidade ${ }^{[57,58]}$, dimensionamento estrutural, navegação ${ }^{[59]}$, entre outras aplicações essenciais para o desenvolvimento destes veículos.

Devido à importância que o estudo da modelagem matemática e numérica das equações de movimento representa no desenvolvimento do modelo de manobra, nesta seção serão apresentadas as metodologias adotadas para se calcular o comportamento dinâmico de robôs submarinos, com foco na análise da manobrabilidade destes veículos.

Na seção 2.1, é apresentado o equacionamento cinemático para representar as grandezas inerciais do veículo em função dos estados não inerciais, i.e., no referencial fixo ao próprio veículo. Na seção 2.2, serão apresentados os modelos dinâmicos utilizados para determinar as equações de movimento de um AUV navegando em águas calmas, no referencial do próprio veículo. Também serão apresentados os modelos para cálculo dos esforços inerciais, não inerciais, e hidrodinâmicos atuantes sobre um AUV que possuem influência sobre o seu movimento.

Todos os modelos apresentados nesta seção foram implementados numericamente utilizando os softwares Matlab e Simulink da empresa Mathworks, com o objetivo de simplificar a execução das simulações de manobrabilidade. Maiores detalhes desta implementação são apresentadas em Dantas e Barros ${ }^{[60][52]}$.

Em todas as seções é utilizada a nomenclatura de movimento navais sugeridas por SNAME $^{[61] 1}$. Na tabela 1 é apresentada esta nomenclatura em inglês e português ${ }^{[62]}$.

$1 \quad$ Society of Naval Architects and Marine Engineers, ou por uma tradução livre, Sociedade dos Arquitetos Navais e Engenheiros Marinhos 
Tabela 1 - Nomenclatura dos movimentos navais, segundo SNAME ${ }^{[61]}$ e Fonseca ${ }^{[62]}$

\begin{tabular}{cccc}
\hline Símbolo & $\begin{array}{c}\text { Nomenclatura } \\
\text { em inglês }\end{array}$ & $\begin{array}{c}\text { Nomenclatura } \\
\text { em português }\end{array}$ & $\begin{array}{c}\text { Eixo de } \\
\text { referência }\end{array}$ \\
\hline- & Surge & Avanço & $\mathrm{x}$ \\
- & Sway & Deriva & $\mathrm{y}$ \\
- & Heave & Afundamento & $\mathrm{z}$ \\
$\phi$ & Roll & Jogo & $\mathrm{x}$ \\
$\theta$ & Pitch & Arfagem ou Caturro & $\mathrm{y}$ \\
$\psi$ & Yaw & Rumo ou Guinada & $\mathrm{z}$ \\
\hline
\end{tabular}

\subsection{EQUACIONAMENTO CINEMÁTICO}

As equações matemáticas que descrevem o movimento de um corpo sem o modelos das forças são chamadas de equações cinemáticas. Em outras palavras, as equações cinemáticas são utilizadas para descrever as posições, velocidades e acelerações de um corpo utilizando apenas relações matemáticas e trigonométricas, em função das mesmas variáveis representadas no sistema de coordenadas do corpo.

Para missões típicas de um AUV de curto alcance, como o Pirajuba, o equacionamento cinemático é utilizado para realizar a transformação de uma grandeza vetorial, expressa em um sistema de coordenadas não inercial (fixo ao corpo do AUV) para um sistema de coordenadas inercial fixo (figura 2).

Este tipo de equacionamento é conhecido por "transformação de coordenadas", e pode ser visto genericamente na equação 2.1 , onde $\vec{p}_{n i}$ é uma grandeza vetorial não inercial linear, $\vec{p}_{i}$ é a mesma grandeza representada no sistema inercial, e [T] é a matriz de transformação de coordenadas.

$$
\vec{p}_{i}=[\mathbf{T}] \cdot \vec{p}_{n i}
$$

Por exemplo, ao substituir o vetor $\vec{p}_{n i}$ da eq. 2.1 pelo vetor de velocidade linear não inercial, é obtido o vetor de velocidade no referencial inercial. Integrando individualmente os componentes do vetor de velocidade inercial é obtido a posição inercial do veículo.

Nos casos em que os sistemas de coordenadas não estejam alinhados, é preciso descrever a orientação entres estes sistemas de coordenadas. Apesar de existirem diversas formas de determinar a orientação de um sistemas de coordenadas, como os quatérnios ou cossenos diretores, neste trabalho foram utilizados os ângulos Euler (apresentados na tabela 1), por sua interpretação física direta e simples.

A matriz de rotação em função dos ângulos de Euler é obtida pela rotação independente e consecutiva ao redor de cada eixo do sistemas de coordenadas não inercial. Por essas rotações não serem cumulativas elas devem ser realizadas sempre na mesma ordem, no caso de sistemas navais ${ }^{[61]}$ é utilizada a ordem de rotação $Z, Y$ e $X$. Esta matriz é 


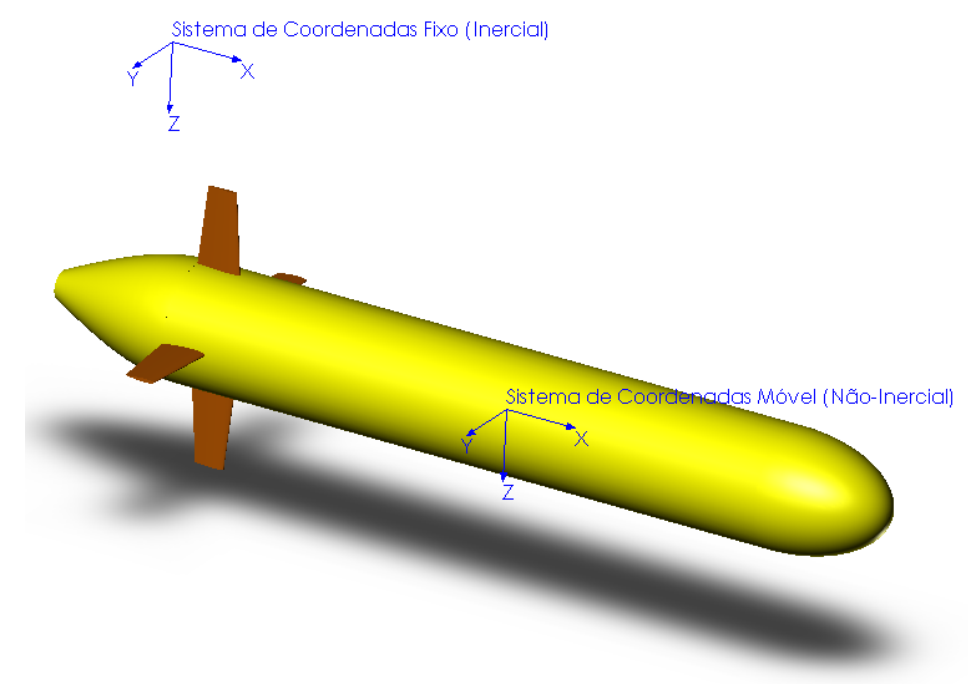

Figura 2 - Definição dos sistemas de coordenadas fixo (inercial) e móvel (não inercial)

representada por

$$
[\mathbf{T}]=\left[\begin{array}{ccc}
\cos (\theta) \cos (\psi) & \sin (\phi) \sin (\theta) \cos (\psi) & \cos (\phi) \sin (\theta) \cos (\psi) \\
& -\cos (\phi) \sin (\psi) & +\sin (\phi) \sin (\psi) \\
\sin (\phi) \sin (\theta) \sin (\psi) & \cos (\phi) \sin (\theta) \sin (\psi) \\
\cos (\theta) \sin (\psi) & +\cos (\phi) \cos (\psi) & -\sin (\phi) \cos (\psi) \\
-\sin (\Theta) & \sin (\phi) \cos (\theta) & \cos (\phi) \cos (\theta)
\end{array}\right] .
$$

No caso da transformação das velocidades angulares, o mesmo procedimento não pode ser aplicado, pois as rotações dos ângulos de Euler não são aplicadas às coordenadas ortogonais do referencial não inercial, e sim aos eixos no quais eles são definidos durante o processo de rotação. A relação entre as velocidades angulares não inerciais $(p, q, r$, respectivamente relacionados aos eixos $x, y, z)$ com a taxa temporal dos ângulos de Euler $(\dot{\phi}, \dot{\theta}, \dot{\psi})$ é obtida ao considerar rotações infinitesimais. Esta transformação é representada por

$$
\left[\begin{array}{l}
p \\
q \\
r
\end{array}\right]=\left[\begin{array}{ccc}
1 & 0 & -\sin (\theta) \\
0 & \cos (\phi) & \cos (\theta) \sin (\phi) \\
0 & -\sin (\phi) & \cos (\theta) \cos (\phi)
\end{array}\right] \cdot\left[\begin{array}{c}
\dot{\phi} \\
\dot{\theta} \\
\dot{\psi}
\end{array}\right]
$$

Estritamente falando, a matriz desta equação não pode ser considerada uma matriz de transformação, pois os eixos em que elas são aplicadas não são ortogonais. Desta forma a transformação inversa não pode ser obtida pela transposta desta matriz. A relação inversa desta transformação é representada por

$$
\left[\begin{array}{c}
\dot{\phi} \\
\dot{\theta} \\
\dot{\psi}
\end{array}\right]=\left[\begin{array}{ccc}
1 & \sin (\phi) \tan (\theta) & \cos (\phi) \tan (\theta) \\
0 & \cos (\phi) & -\sin (\phi) \\
0 & \sin (\phi) \sec (\theta) & \cos (\phi) \sec (\theta)
\end{array}\right] \cdot\left[\begin{array}{c}
p \\
q \\
r
\end{array}\right]
$$


Para o caso de AUVs que realizam navegações de grandes distâncias com sistemas inerciais de alta precisão, as velocidade e acelerações devem considerar correções para a geometria e a rotação da Terra, e a posição deve ser expressa em termos da latitude, longitude e altitude (LLA). Em Brown e Hwang ${ }^{[63]}$ pode ser encontrado o equacionamento cinemático em que estas condições são consideradas.

\subsection{MODELAGEM DINÂMICA EM ÁGUAS CALMAS}

A modelagem dinâmica de um sistema tenta representar o movimento de um ou mais corpos a partir da interação entre outro(s) corpo(s). Resumidamente, na modelagem dinâmica o movimento de um corpo é obtido pela relação de sua inércia com as forças e momentos externos atuantes sobre ele. Comparativamente, enquanto que na cinemáticas as relações de movimento são puramente matemáticas, na modelagem dinâmica os movimentos são obtidos através de relações/hipóteses baseados em conceitos e fenômenos físicos.

O método de solução e organização das equações dinâmicas foi baseada no trabalho de Ishidera et al. ${ }^{[64]}$, onde foi realizada a modelagem numérica de um ROV para verificar a sua dinâmica e testar o seu controlador. Contudo, neste trabalho a modelagem dos esforços hidrodinâmicos foi realizada com modelos mais complexos e detalhados, pois para um AUV do tipo torpedo ${ }^{[65,66]}$ os esforços hidrodinâmicos apresentam uma maior influência na manobrabilidade.

A apresentação do modelo dinâmico é feita da seguinte maneira: na seção 2.2.1 serão apresentadas as equações de movimento e esforços inerciais de um corpo rígido; na seção 2.2.2 serão apresentados os esforços devido a gravidade e empuxo; os modelos hidrodinâmicos de propulsão por hélice em regime permanente serão apresentados na seção 2.2.3; a apresentação de uma metodologia para a estimativa de uma parcela da massa adicional será realizada na seção 2.2.4; e por último, na seção 2.2.5, será apresentada a forma adotada para a representação dos esforços hidrodinâmicos de amortecimento de um AUV em movimento.

Os esforços apresentados nesta última seção compõe a principal parte do modelo de manobra desenvolvido nesta tese. Como estes modelos serão apresentados com mais detalhes na seção 4, neste capítulo eles serão apresentados de forma simples e genérica com o objetivo de demostrar a relação destes esforços com as equações de movimento.

\subsubsection{Equações de movimento}

A equação de movimento para um corpo rígido é obtida através da segunda lei de Newton, onde a resultante das forças externas agindo sobre o veículo é igual à taxa de variação do momento linear (quantidade de movimento) em relação ao tempo. O mesmo 
pode ser aplicado ao momento, onde a resultante dos momentos externos que agem no veículo é igual à taxa de variação de momento angular em relação ao tempo.

Em um sistema de coordenadas fixo e inercial são obtidas as equações 2.5 e 2.6, para os movimentos lineares e angulares, respectivamente. Nestas equações, as grandezas vetoriais de forças externas $\left(\sum \mathbf{F}\right)$, momentos externos $\left(\sum \mathbf{M}\right)$, quantidade de movimento $(m \cdot \mathbf{U})$ e momento angular $\left(\frac{d}{d t} \mathbf{h}\right)$ possuem componentes nos três eixos ortogonais fixos: $x_{i}$, $y_{i}$ e $z_{i}$.

$$
\begin{gathered}
\sum \mathbf{F}=\frac{d}{d t}(m \cdot \mathbf{U})=m \cdot \dot{\mathbf{U}} \\
\sum \mathbf{M}=\frac{d}{d t} \mathbf{h}=\dot{\mathbf{h}}
\end{gathered}
$$

É mais conveniente expressar estas equações no referencial fixo ao corpo (não inercial), para que não seja necessário corrigir a inércia e os esforços inerciais ção das variáveis inerciais. Contudo, e para resolver esta equação no referencial não inercial é preciso corrigir a velocidade linear e o momento angular das equações acima.

Para considerar os efeitos das incertezas na localização do centro de massa (ou centro de gravidade, CG) do veículo sem alterar o restante das equações de movimento, estas correções são aplicadas a um ponto arbitrário $\mathbf{p}_{\mathbf{G}}$, com componentes $x_{G}, y_{G}$ e $z_{G} \mathrm{em}$ relação ao sistema de coordenadas fixo ao corpo do veículo $\left(p_{G}=\left[x_{G}, y_{G}, z_{G}\right]\right)$.

As forças no sistema do corpo são obtidas pelo cálculo do vetor velocidade relativo ao ponto $p_{G}$, visto na equação 2.7 , considerando as velocidades de rotações do corpo $(\boldsymbol{\Omega}=[p, q, r])$ e as suas acelerações em relação ao referencial fixo $\left(\dot{\mathbf{U}}_{i}=\left[\dot{u}_{i}, \dot{v}_{i}, \dot{w}_{i}\right]\right)$.

$$
\dot{\mathbf{U}}_{G}=\dot{\mathbf{U}}_{i}+\Omega \times \mathbf{U}+\dot{\Omega} \times \mathbf{p}_{\mathbf{G}}+\Omega \times\left(\Omega \times \mathbf{p}_{\mathbf{G}}\right)
$$

Aplicando a equação 2.7 a equação das forças lineares (equação 2.5), e resolvendo os seus componentes são obtidas as equações de movimento lineares para um sistema não inercial:

$$
\begin{aligned}
& \begin{array}{r}
F_{x}=m \cdot[\dot{u}-v \cdot r+w \cdot q \\
\left.\quad-x_{G} \cdot\left(q^{2}+r^{2}\right)+y_{G} \cdot(p \cdot q-\dot{r})+z_{G} \cdot(p \cdot r+\dot{q})\right]
\end{array} \\
& \begin{array}{r}
F_{y}=m \cdot[\dot{v}-w \cdot p+u \cdot r \\
\left.\quad-y_{G} \cdot\left(r^{2}+p^{2}\right)+z_{G} \cdot(q \cdot r-\dot{p})+x_{G} \cdot(p \cdot q+\dot{r})\right]
\end{array} \\
& \begin{array}{r}
F_{z}=m \cdot[\dot{w}-u \cdot q+v \cdot p \\
\left.\quad-z_{G} \cdot\left(p^{2}+q^{2}\right)+x_{G} \cdot(p \cdot r-\dot{q})+y_{G} \cdot(q \cdot r+\dot{p})\right]
\end{array}
\end{aligned}
$$

Para as equações de momento, o momento angular em relação a um referencial fixo deve ser corrigido para considerar os efeitos gerados pelas rotações dos sistemas de 
coordenadas e a translação do CG. Com estas correções a equação 2.6 é reescrita da forma

$$
\sum \mathbf{M}=(\dot{\mathbf{h}}+\Omega \times \mathbf{h})_{i}+p_{G} \times \mathbf{f},
$$

onde o termo $\mathbf{h}$ representa o momento angular calculado em relação a um referencial fixo, definido pela integral volumétrica $(\nabla)$ apresentada na equação 2.12 , e f são as forças inerciais calculados no ponto $p_{G}$, como se ele fosse o CG.

$$
\mathbf{h}=\int_{\nabla} p_{G} \times\left(\Omega \times p_{G}\right) d m
$$

Expressando a equação 2.11 em termos de seus componentes, utilizando a definição de tensor de inércia ${ }^{[67]}$ e das forças inerciais f $\mathbf{f}$, que são obtidas pelas equações 2.8 a 2.10 ao desconsiderar as distâncias ao CG, são obtidas as seguintes equações:

$$
\begin{gathered}
M_{x}=I_{x} \cdot \dot{p}+\left(I_{z}-I_{y}\right) \cdot q \cdot r-I_{x z} \cdot(\dot{r}+p \cdot q)+I_{y z} \cdot\left(r^{2}-q^{2}\right)+I_{x y} \cdot(p \cdot r-\dot{q}) \\
+m \cdot\left[y_{G} \cdot(\dot{w}-u \cdot q+v \cdot p)-z_{G} \cdot(\dot{v}-w \cdot p+u \cdot r)\right] \\
M_{y}=I_{y} \cdot \dot{q}+\left(I_{x}-I_{z}\right) \cdot p \cdot r-I_{x y} \cdot(\dot{p}+q \cdot r)+I_{x z} \cdot\left(p^{2}-r^{2}\right)+I_{y z} \cdot(p \cdot q-\dot{r}) \\
\quad+m \cdot\left[z_{G} \cdot(\dot{u}-v \cdot r+w \cdot q)-x_{G} \cdot(\dot{w}-u \cdot q+v \cdot p)\right] \\
M_{z}=I_{z} \cdot \dot{r}+\left(I_{y}-I_{x}\right) \cdot p \cdot q-I_{y z} \cdot(\dot{q}+p \cdot r)+I_{x y} \cdot\left(q^{2}-p^{2}\right)+I_{x z} \cdot(p \cdot r-\dot{p}) \\
+m \cdot\left[x_{G} \cdot(\dot{v}-w \cdot p+u \cdot r)-y_{G} \cdot(\dot{u}-v \cdot r+w \cdot q)\right]
\end{gathered}
$$

Até este ponto foram definidas apenas as componentes inercias da equação de movimento. A consideração dos esforços externos é melhor apresentada ao considerar a forma compacta e vetorial destas equações:

$$
\left[M_{i j}+A_{i j}\right] \cdot[\dot{U}, \dot{\omega}]+F_{I}=F_{H}+F_{G}+F_{E}+F_{P}
$$

Nesta equação, os esforços inerciais foram divididos em dois termos distintos. O termo $\left[M_{i j}\right] \cdot[\dot{U}, \dot{\omega}]$, representa os esforços que são diretamente e linearmente proporcionais às acelerações lineares e angulares, enquanto o termo $F_{I}$ representa as forças inerciais geradas pelas acelerações de Coriolis e centrípetas, que surgem por combinações dos movimentos lineares e angulares.

A mesma divisão é aplicada aos esforços hidrodinâmicos chamados de massa adicional, que surgem devido à modificação da energia cinética do fluído gerada pela presença do AUV. Neste caso, o termo representado pela matriz $\left[A_{i j}\right]$ é um modelo linear dos esforços hidrodinâmicos que surgem devido as acelerações lineares e angulares, de maneira matematicamente similar ao termo $\left[M_{i j}\right]$. O restante dos termos conhecidos por massa adicional são matematicamente incluídos no vetor $F_{H}$, que modelo o restante dos esforços hidrodinâmicos gerados pelo movimento do corpo do veículo em relação ao fluido.

Está divisão e organização das equações de movimento é comumente utilizada em simuladores de dinâmica ${ }^{[51,64]}$ e em sistemas de controle ${ }^{[53,54]}$, pois permite que as 
acelerações sejam facilmente resolvidas pela multiplicação da inversa da soma das matrizes de inércia e de massa adicional pela soma dos vetores de esforços,

$$
[\dot{U}, \dot{\omega}]=\left[M_{i j}+A_{i j}\right]^{-1} \cdot\left(F_{H}+F_{G}+F_{E}+F_{P}-F_{I}\right)
$$

sendo que as velocidades são encontradas pela integração numéricas destas acelerações.

O restante dos termos da equação 2.16 são definidos por:

- $F_{G}$, é o vetor de esforços gerados pela aceleração da gravidade, apresentado na seção 2.2 .2 .

- $F_{E}$, é o vetor de esforços devido ao empuxo gerado pelo volume do veículo imerso no fluído, também apresentado na seção 2.2.2.

- $F_{P}$, é o vetor de esforços hidrodinâmicos gerados pelo sistema de propulsão com hélice, descrito sucintamente na seção 2.2.3.

- $A_{i j}$, é a matriz que modela a parcela de massa/inércia adicional que surge devida às acelerações lineares e angulares do veículo em relação ao fluido, apresentada na seção 2.2.4.

- $F_{H}$, é o vetor de esforços hidrodinâmicas de amortecimento gerados pelo movimento relativo entre o veículo e o fluído, descrito brevemente na seção 2.2.5.

\subsubsection{Esforços de gravidade e empuxo}

Os esforços de gravidade são gerados pela aceleração da gravidade aplicado à massa do veículo, enquanto os esforços de empuxo são gerados pela flutuabilidade do volume imerso do veículo. Estas duas forças são representadas juntas por ambas terem natureza gravitacional, podendo cancelar alguns de seus termos.

Em termos inerciais, estas forças atuam sempre na mesma direção, i.e., a força de gravidade $(m g)$ sempre atua na direção do campo gravitacional resultante, que de forma simples aponta para o centro da Terra, e a de empuxo $(g \rho \nabla)$ na direção contrária. Contudo, no referencial do veículo estas forças precisam ser corrigidas, pois apesar da magnitude destes esforços serem constantes, as componentes nos eixos do veículos irão variar em função de sua orientação. Ao considerar que os centros de gravidade $\left(p_{G}=\left[x_{G}, y_{G}, z_{G}\right]\right)$ e empuxo $\left(p_{B}=\left[x_{B}, y_{B}, z_{B}\right]\right)$ estão deslocados do centro de cálculo/referência, estas forças também geram momentos. 
A somatória destes dois esforços são expressos pela equação 2.18

$$
\begin{aligned}
& F_{G}+F_{E}=F_{G E}= \\
& g\left[\begin{array}{l}
- \\
(m-\rho \nabla) \sin (\theta) \\
\\
(m-\rho \nabla) \sin (\phi) \cdot \cos (\theta) \\
(m-\rho \nabla) \cos (\phi) \cdot \cos (\theta) \\
\left(m y_{G}-\rho \nabla y_{B}\right) \cos (\phi) \cos (\theta)-\left(m z_{G}-\rho \nabla z_{B}\right) \sin (\phi) \cos (\theta) \\
\left(m x_{G}-\rho \nabla x_{B}\right) \cos (\phi) \cos (\theta)-\left(m z_{G}-\rho \nabla z_{B}\right) \sin (\theta) \\
-\left(m x_{G}-\rho \nabla x_{B}\right) \sin (\phi) \cos (\theta)+\left(m y_{G}-\rho \nabla y_{B}\right) \sin (\theta)
\end{array}\right],
\end{aligned}
$$

sendo $\rho$ a densidade do fluido em que o veículo se encontra, $\nabla$ o volume imerso de todo o veículo, $m$ a massa do veículo e $g$ o módulo da aceleração da gravidade local. Para o desenvolvimento desta equação é assumido que a gravidade local seja constante, e tenha apenas uma componente vertical no sistema de coordenadas inercial $(\vec{g}=[0,0, g])$.

Normalmente, em veículos submarinos, as coordenadas lateral $(y)$ e longitudinal $(x)$ do centro de gravidade e empuxo são coincidentes, para evitar que o veículo apresente um ângulo de inclinação (caturro e/ou jogo) quando em repouso. Contudo, estes veículos são projetados para que o centro de gravidade sempre fique abaixo do centro de flutuabilidade, de forma que esta diferença gere um momento que restaure a orientação do veículo sem necessitar utilizar seus atuadores quando ele apresenta um ângulo de jogo e/ou de arfagem. Devido a este efeito na dinâmica, os esforços de gravidade e empuxo são normalmente denominados de esforços de restauração.

\subsubsection{Esforços hidrodinâmicos: Propulsão}

Em qualquer sistema de propulsão por hélice são gerados apenas os esforços hidrodinâmicos de empuxo (tração) e de torque resistivo. Considerando um modelo quasiestático, estes esforços podem ser estimados pelos parâmetros geométricos e hidrodinâmicos do conjunto hélice-duto propulsor, da rotação do hélice $(n)$ e da velocidade de avanço do veículo $(V)$.

Os parâmetros do hélice que definem as suas características hidrodinâmicas são os coeficientes adimensionais de tração do hélice, $K_{T}$, de ganho na força de tração devido ao uso de um duto propulsor, $K_{T n}$, e de momento resistivo gerado pelo hélice, $K_{Q}$. Estes coeficientes dependem das características geométricas do hélice e da sua condição de operação.

Na figura 3, são apresentadas as curvas destes coeficiente para um hélice de perfil Kaplan série 4-70, junto a um duto propulsor de perfil 19A. Estes coeficiente são representados em função do coeficiente de avanço $(J)$, que define o seu ponto de operação, 


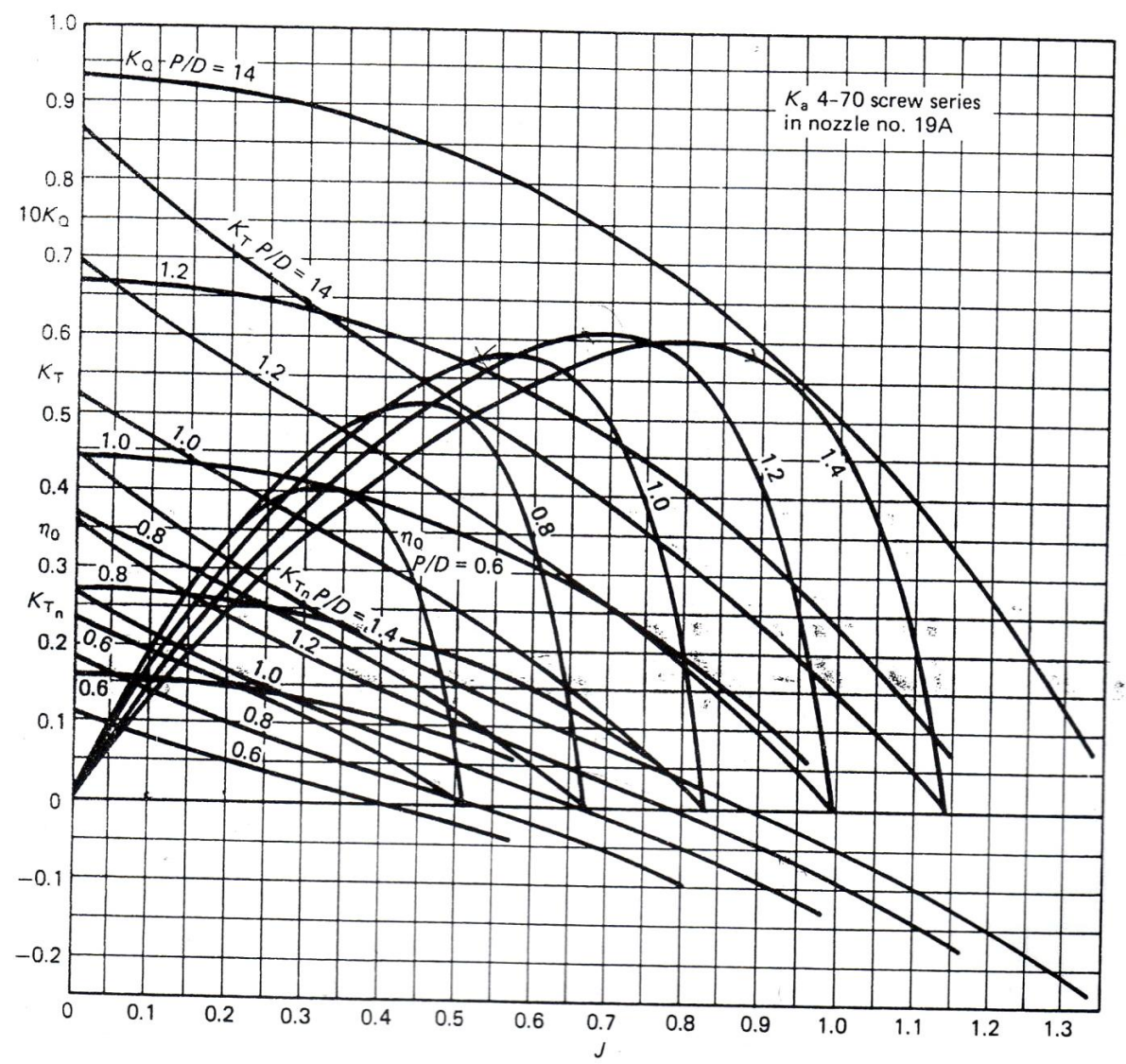

Figura 3 - Parâmetros nominais do hélice Kaplan série 4-70 com duto de perfil 19A, gráfico retirado de Lewis ${ }^{[68]}$.

e a razão do ângulo de pitch do hélice pelo seu diâmetro $(P / D)$. O conjunto hélice-duto apresentado nesta figura é o mesmo conjunto utilizado pelo AUV Pirajuba.

O ponto de operação do conjunto de propulsão, definido pelo coeficiente de avanço, é obtido quando a curva de tração requerida pelo veículo $\left(K_{T(r e q)}\right)$ cruza com a curva de tração fornecida pelo hélice $\left(K_{T}\right)$ somada a "tração" gerada pelo duto propulsor $\left(K_{T n}\right)$. A tração requerida pode ser calcula por

$$
K_{T(r e q)}=\frac{T_{r e q}}{\rho \cdot D_{h}^{2} \cdot V^{2} \cdot\left(1-w_{h}\right)^{2}} \cdot J^{2}
$$

onde $\rho$ é a densidade do fluido, $V$ é a velocidade de operação do veículo, $D_{h}$ é o diâmetro do hélice, $w_{h}$ é o coeficiente de esteira do veículo, $J$ é o coeficiente de avanço e $T_{\text {req }}$ é o empuxo requerido para igualar o arrasto do veículo $\left(F_{D}\right)$.

Considerando o fator de empuxo $t$, que corrige a tração gerada pelo propulsor pela presença do corpo do veículo, a relação entre a força de arrasto e a tração requerida pelo sistema hélice-duto é obtida por

$$
T_{r e q}=\frac{F_{D}}{1-t}
$$


Com o coeficiente de avanço definido, a velocidade de rotação do hélice é calculada pela definição deste coeficiente, que representa a razão da velocidade que chega ao hélice $V \cdot\left(1-w_{h}\right)$ sobre a multiplicação da rotação e diâmetro do hélice, como apresentado na equação 2.21 .

$$
J=\frac{V \cdot\left(1-w_{h}\right)}{n \cdot D_{h}}
$$

O coeficiente de esteira do veículo $\left(w_{h}\right)$ relaciona a velocidade do veículo com a velocidade do escoamento que chega ao hélice, ou seja, o termo $V \cdot\left(1-w_{h}\right)$ representa a verdadeira velocidade "enxergada" pelo hélice. O cálculo deste coeficiente e do fator de empuxo podem ser realizados por funções analíticas e semi-empíricas ${ }^{[69]}$ em função dos parâmetro geométricos do corpo e do hélice, ou por métodos numéricos ${ }^{[70,71,28]}$.

Com o ponto de operação definido, é utilizada novamente a figura 3 para se encontrar o coeficiente do torque resistivo $K_{Q}$.

A transformação dos coeficientes adimensionais em esforços hidrodinâmicos é realizado pelas equações 2.22 e 2.23, para o caso da força de tração e do momento resistivo, respectivamente.

$$
\begin{gathered}
T_{P}=T_{h}+T_{d}=\left(K_{T}+K_{T n}\right) \cdot \rho \cdot n^{2} \cdot D_{h}^{4} \\
Q_{P}=K_{Q} \cdot \rho \cdot n^{2} \cdot D_{h}^{5}
\end{gathered}
$$

Os esforços hidrodinâmicos apresentados nesta seção representam os modelos hidrodinâmicos de propulsão em regime permanente, ou seja, não são modelados os esforços transientes devidos a uma variação na velocidade do veículo ou na velocidade de rotação do hélice. Metodologias alternativas para modelar os efeitos transientes podem ser encontrados nos trabalhos de Whitcomb e Yoerger ${ }^{[72]}$ e Bachmayer, Whitcomb e Grosenbaugh ${ }^{[73]}$.

Apesar do modelo quasi-estático ter sido utilizado no simulador de manobrabilidade, não é esperado que esta simplificação influencie significativamente nos resultados finais, pois não é esperada que durante as manobras o veículo experimente variações significativas da força de arrasto e tração devido a dinâmica da velocidade de avanço, i.e., aceleração de avanço.

\subsubsection{Esforços hidrodinâmicos: Massa Adicional de aceleração}

Ao considerar um escoamento potencial, quando um corpo imerso é acelerado ou desacelerado a energia cinética do fluído ao seu redor é modificada, fazendo com que o corpo experimente esforços hidrodinâmicos proporcionais ao movimento experimentado.

Por serem proporcionais aos movimentos relativos entre o veículo e o fluído de maneira matematicamente similar aos esforços inerciais, estes esforços são denominados 
de massa/inércia adicional (aparente ou virtual). Conforme apresentado na equação de movimento, eq. 2.16, estes esforços podem ser representados pelos termos $A_{i j}$, onde o subíndice $i$ indica a direção do esforço e o subíndice $j$ a direção da aceleração que gera este. Estes índices variam de 1 a 6 , correspondendo aos movimentos de avanço, deriva, afundamento, jogo, arfagem e rumo, respectivamente.

Segundo Newman ${ }^{[74}$, em um escoamento puramente potencial, quando um corpo apresenta velocidades lineares e angulares relativas ao movimento do fluido, as forças $\left(F_{A M}\right)$ e os momentos $\left(M_{A M}\right)$ gerados podem ser escritos pelas seguintes equações vetoriais

$$
\begin{aligned}
F_{A M} & =-\sum_{j=1}^{6}\left(\dot{\mathrm{U}}_{j} \mathbf{A}_{j}+\mathrm{U}_{j} \boldsymbol{\Omega} \times \mathbf{A}_{j}\right) \\
M_{A M} & =-\sum_{j=1}^{6}\left(\dot{\mathrm{U}}_{j} \mathbf{A}_{j}^{*}+\mathrm{U}_{j} \boldsymbol{\Omega} \times \mathbf{A}_{j}^{*}+\mathrm{U}_{j} \mathbf{U} \times \mathbf{A}_{j}\right),
\end{aligned}
$$

onde os vetores contendo os termos de massa adicional $\mathbf{A}_{j}$ e $\mathbf{A}_{j}^{*}$ são definidos por:

$$
\begin{aligned}
\mathbf{A}_{j} & \equiv\left[\begin{array}{lll}
A_{1 j}, & A_{2 j}, & A_{3 j}
\end{array}\right]^{T} \\
\mathbf{A}_{j}^{*} & \equiv\left[\begin{array}{lll}
A_{4 j}, & A_{5 j}, & A_{6 j}
\end{array}\right]^{T}
\end{aligned}
$$

Assim como os esforços inerciais, os esforços de massa adicional podem ser divididos em duas partes. Esta divisão é feita por simplificar a apresentação destes termos na equação de movimento, e porque estes termos são estimados de formas distintas.

Nos modelos de manobra desenvolvidos neste trabalho, os termos que são escritos a esquerda da equação de movimento, eq. 2.16, que multiplicam diretamente o vetor de acelerações lineares e angulares, são denominados de massa adicional de aceleração, representando um subconjunto de todos os esforços de massa adicional. A metodologia para a determinação destes termos, junto com algumas simplificações, é apresentada no decorrer desta seção.

Os demais termos são definidos em conjunto com os esforços hidrodinâmicos, pois as metodologias utilizadas não consideram uma distinção para esta classe de esforços. Estes termos são brevemente apresentados na seção 2.2.5, tendo uma apresentação mais detalhada no capítulo 4.

Pelos esforços de massa adicional de aceleração terem componentes em todos os graus de liberdade (acelerações lineares e angulares nos três eixos), o termo de massa adicional pode ser definido por uma matriz quadrada de dimensão igual a seis. No caso de corpos imersos em um fluído ideal (sem fricção), esta matriz é simétrica $\left(A_{i j}=A_{j i}\right)^{[75]}$.

Para o caso específico de um veículo com simetria no plano lateral e vertical, caso 
do AUV Pirajuba, ainda podem ser consideradas as seguintes simplificações ${ }^{[75]}$ :

$$
\begin{gathered}
A_{12}=A_{13}=A_{14}=A_{15}=A_{16}=A_{23}=A_{24}=0 \\
A_{25}=A_{34}=A_{36}=A_{45}=A_{46}=A_{56}=0 .
\end{gathered}
$$

Em outras palavra, além dos termos da diagonal principal, apenas os termos $A_{26}$ e $A_{35}$ não são nulos.

Existem diversas formas de se realizar o cálculo destes termos da matriz de massa adicional. Os modelos mais complexos são baseados nos métodos dos painéis de altas ordens $^{[74,76,77]}$, enquanto que os modelos mais simples utilizam o método das faixas [78, 79, 80]. Também seria possível utilizar as ferramentas de CFD para realizar a estimativa destes termos, mas neste caso seriam necessários realizar simulações transientes que apresentariam um alto tempo de simulação em comparação com as demais simulações utilizadas.

Devido ao escopo da seção, apenas será realizada uma rápida introdução do método das faixas, que foi utilizado para estimar os termos de massa adicional do AUV Pirajuba. Contudo, uma apresentação mais detalhada é feita no apêndice D.

No método das faixas, é assumido que o escoamento em torno do veículo é potencial, não exercendo esforços de características viscosas. O cálculo dos coeficientes é iniciado ao discretizar-se o veículo longitudinalmente em $n$ seções infinitesimais, assumindo que o escoamento em cada seção se mantenha potencial e não interaja com as demais seções. Para cada seção são atribuídos três coeficientes de massa adicional bidimensional $\left(a_{i j}\right)$, relativos aos movimentos lineares e de rotação da seção, com a sua magnitude dependente apenas do formato da geometria e da densidade do fluído.

O cálculo dos termos da matriz de massa adicional em função das acelerações lateral e vertical ( $i=j=2,3,4)$, e da aceleração angular em torno do eixo longitudinal (rolagem) do veículo, são realizados pela integração dos coeficientes bidimensionais $\left(m_{i j}\right)$ lateral, vertical e de rotação, respectivamente, ao longo do corpo do veículo, conforme a equação

$$
A_{i j}=\int_{0}^{L} m_{i j} \mathrm{~d} x
$$

As forças geradas pela massa adicional quando o veículo experimenta uma aceleração angular $(i=2,3$ e $j=5,6)$, são obtidas pelas integrais das massas adicionais verticais e laterais multiplicadas pelas distâncias das seções $(x)$ ao centro de referência $\left(x_{m}\right)$, ou seja,

$$
A_{i j}=\int_{0}^{L} m_{i j} \cdot\left(x-x_{m}\right) \mathrm{d} x
$$

Já os momentos gerados por estas mesmas acelerações $(i, j=5,6)$ são obtidos pela integração das massas adicionais bidimensionais verticais e laterais, multiplicadas pela 
distância ao centro de referência $\left(x-x_{m}\right)$ ao quadrado, representando o momento gerado por cada seção em função de sua velocidade local devido ao movimento de rotação. Esta equação é definida por:

$$
A_{i j}=\int_{0}^{L} m_{i j} \cdot\left(x-x_{m}\right)^{2} \mathrm{~d} x
$$

No apêndice D, são apresentados as equações e gráficos dos coeficientes de massa adicional bidimensional que foram utilizados para se estimar os termos para o caso específico do AUV Pirajuba

\subsubsection{Esforços hidrodinâmicos: amortecimento e controle}

Nesta seção são apresentados, resumidamente, os esforços hidrodinâmicos que dependem da velocidade relativa entre o veículo e o fluído, e da deflexão das suas superfícies de controle em relação ao corpo. Estes esforços são gerados pelos esforços de arrasto, sustentação e massa adicional, podendo ser classificados em esforços de amortecimento e controle, devido aos efeitos hidrodinâmicos causados ao movimento do AUV.

Os esforços de amortecimentos, como o próprio nome diz, são os esforços responsáveis por impor amortecimento ao movimento do veículo, retirando energia do sistema. Estes esforços são gerados por velocidades lineares e angulares relativas entre o fluído e o veículo, desacelerando o seu movimento. Apesar do arrasto ser responsável por parte deste amortecimento, os esforços de sustentação também apresentam um papel importante no amortecimento do movimento, principalmente no caso do movimento de rotação.

Os esforços denominados de controle são classificados desta forma por serem gerados ativamente pelas deflexões das superfície de controle em relação ao casco do veículo, servindo para controlar a trajetória do veículo.

De forma geral, no caso do AUV Pirajuba, um esforço hidrodinâmico qualquer pode ser representado por

$$
F=f\left(\alpha, \beta, p, q, r, \delta_{s}, \delta_{r}\right)
$$

onde $f$ é uma função genérica relativa ao esforço $F, \alpha$ é o ângulo incidente do escoamento no plano longitudinal (ângulo de ataque), $\beta$ é o ângulo incidente do escoamento no plano horizontal (ângulo de deriva), $\delta_{s}$ é a deflexão das superfícies de controle horizontais, $\delta_{r}$ é a deflexão das superfícies de controle verticais, e os termos $p, q$ e $r$ são as velocidades angulares de rotação previamente definidas.

Ao considerar a simetria do veículo e que os movimentos realizados em um plano são pequenos o suficiente para não interferir no do outro plano, pode ser considerado que os movimentos são desacoplados, ou seja, o movimento de um plano não gera esforço em outro plano. Com esta simplificação, a equação 2.31 pode ser reduzida ao eliminar as 
variáveis que não estão contidas no mesmo plano do esforço. Para o esforço hidrodinâmico genérico do plano longitudinal esta equação pode ser reescrita por

$$
F=f\left(\alpha, q, \delta_{s}\right)
$$

enquanto que para o esforço lateral ela fica reduzida a

$$
F=f\left(\beta, r, \delta_{r}\right)
$$

Utilizando a notação adotada nas demais seções deste capítulo, junto com as equações simplificadas 2.32 e 2.33, o esforço hidrodinâmico do AUV Pirajuba pode ser modelado por

$$
F_{H}=\left[\begin{array}{c}
X\left(\alpha, \beta, p, q, r, \delta_{s}, \delta_{r}\right) \\
Y\left(\beta, r, \delta_{r}\right) \\
Z\left(\alpha, q, \delta_{s}\right) \\
K(r) \\
M\left(\alpha, q, \delta_{s}\right) \\
N\left(\beta, r, \delta_{r}\right)
\end{array}\right]
$$

Nesta equação é utilizada a notação do SNAME ${ }^{[61]}$, onde $X$ representa a força axial, $Y$ a força lateral, $Z$ a força vertical, $K$ o momento de rolagem (roll, em volta do eixo $x$ ), $M$ o momento de arfagem (pitch, em volta do eixo $y$ ), e $N$ o momento de guinada (yaw, em volta do eixo $z$ ).

A função que define a força no eixo $x$ é dependente de todas as variáveis, pois o eixo $x$ é a intersecção dos planos longitudinais e verticais. Isto indica que a força $X$ deve representar as componentes longitudinais geradas pelos dois os planos. Este fato pode ser exemplificado pelo esforço de arrasto, que é gerado tanto pelas variáveis de movimento verticais quanto laterais, devendo ser somada as duas componentes para modelar o arrasto total.

A função que define o esforço de rolagem $K$ depende apenas da velocidade angular de rolagem $(p)$ devido a simetria do veículo ${ }^{[75]}$, ou seja, nenhum dos demais movimentos considerados gera um esforço assimétrico no veículo, quando são considerados os movimentos desacoplados. Este esforço é responsável pelo amortecimento no eixo de rolagem.

Como comentado anteriormente, os métodos utilizados para definir analiticamente e numericamente estes esforços, compõe os modelos de manobras desenvolvidos nesta tese, sendo detalhadamente apresentados na seção 4 . 


\section{METODOLOGIA PARA SIMULAÇÕES DE UM AUV PELO MÉTODO DE CFD}

Na área de fluidodinâmica, o uso de métodos numéricas em projetos de engenharia de ponta gera um desenvolvimento mais eficiente e com melhores resultados, representando uma fase fundamental do desenvolvimento destes projetos tanto para a área academia quanto para a industrial. Particularmente no campo de escoamentos externos, que é o interesse deste trabalho, o uso de métodos computacionais gerou um grande avanço na modelagem de escoamentos encontrados na indústria aeronáutica ${ }^{[81,32]}$ e na naval ${ }^{[17,18]}$.

Atualmente existem diversos métodos numéricos que podem ser utilizadas na estimativa de diversas características fluidodinâmicas, contudo a escolha do melhor método depende do veículo e da análise a ser feita. Os métodos mais comuns no desenvolvimento de veículos marinhos são aqueles baseados em teorias potenciais, como o método dos painéis $^{[74,77]}$ ou o métodos das faixas ${ }^{[78,82]}$, devido à sua simplicidade e boa capacidade de predição em escoamentos cujos efeitos viscosos podem ser desprezados (como os efeitos de ondas em embarcações offshore, cálculo da massa adicional, etc.), e principalmente devido a facilidade de realizar análises no domínio da frequência ${ }^{[83,84]}$.

Entretanto, em casos em que a teoria potencial não é mais valida, como nos casos em que ocorre o descolamento da camada limite em grande parte do corpo, as características hidrodinâmicas devem ser preditas com o auxílio de ferramentas mais robustas, como os métodos de volume ou elementos finitos aplicados a dinâmica dos fluidos computacionais (CFD, Computational Fluid Dynamics). Estes métodos conseguem realizar tais predições, pois eles são desenvolvidos utilizando diversos modelos matemáticos/numéricos que modelam grande parte dos fenômenos complexos, ao custo de demandarem uma maior carga computacional. Desta forma, ao utilizar estes métodos é possível modelar os esforços hidrodinâmicos e as características hidrodinâmicas dos veículos que executam manobras de grande amplitude ${ }^{[20,22]}$, altas velocidades de rotação ${ }^{[24,31]}$ e apresentam uma forma rombuda ou complexa ${ }^{[37]}$.

No caso de veículos submarinos o uso destes softwares tem aumentado significativamente nos últimos anos, principalmente no caso dos AUVs. Isto porque os softwares de CFD tem melhorado bastante as suas interfaces com o usuário, os seus modelos matemáticos têm evoluído para apresentar um comportamento mais robusto, e ainda a evolução tecnológica dos computadores está permitindo que simulações simples sejam realizadas em computadores domésticos e as simulações mais complexas em pequenos servidores ${ }^{[32,85]}$. Além disso, novos estudos estão sendo realizados para desenvolver procedimentos e normas que possam ajudar a reduzir e estimar as incertezas e os erros numéricos destas simulações ${ }^{[35,36]}$, como 
a norma de verificação e validação $(V \& V)$ da $\mathrm{ASME}^{[33]}$.

Contudo, mesmo com a evolução destes softwares e desenvolvimentos de normas específicas, ainda existem diversos parâmetros das simulações de CFD que não podem ser determinados com uma metodologia específica, sendo necessário depender da experiência de projetistas/engenheiros para configurar corretamente o software para se obterem resultados corretos e significativos.

Utilizando argumentos semelhantes, Phillips, Turnock e Furlong ${ }^{[85]}$ acreditam que com o auxílio de softwares de CFD, o custo e o tempo necessário para o desenvolvimento de AUVs poderão ser reduzidos significativamente, ao se reduzir o número de experimentos necessários para levantar a sua dinâmica. Segundo os autores, o desenvolvimento numérico de um AUV pode ser dividido em quatro partes: o projeto do corpo e das superfícies de controle; o cálculo da potência propulsiva; análise da estabilidade estática e dinâmica; e a análise da manobrabilidade do veículo.

No caso específico de AUVs, pode-se citar os trabalhos de Tyagi e Sen ${ }^{[19]}$ e Jagadeesh, Murali e Idichandy ${ }^{[21]}$, onde os esforços hidrodinâmicos gerados por corpos axissimétricos submetidos a escoamentos oblíquos são estimados por simulações de volume-finitos e validados através de ensaios em tanque de prova.

Apesar de uma apresentação semelhante para os casos estáticos, Phillips, Furlong e Turnock ${ }^{[24]}$ estimaram as derivadas de estabilidade dinâmica do AUV inglês Autosub por simulações estáticas (não transientes), de forma a diminuir o custo computacional, e compararam estes resultados com os obtidos em ensaios de oscilação em um mecanismo de movimento planar (PMM, Planar Motion Mechanism) ${ }^{[86]}$. No trabalho de Toxopeus et al. ${ }^{[31]}$ as simulações de CFD também foram realizadas utilizando um modelo numérico similar, contudo as simulações foram realizadas com diversos softwares e modelos de turbulência para um modelo em escala de um submarino, representando uma abordagem mais completa.

Barros et al. ${ }^{[20]}$, Barros e Dantas ${ }^{[28]}$ e Jeans et al. ${ }^{[22]}$, realizaram simulações de volumes finitos de corpos de AUVs para analisar o escoamento em seu entorno, e assim conseguir estimar fatores de correção para modelos analíticos e semi-empíricos. Sendo o modelo de Barros et al. ${ }^{[20]}$ apresentado na seção 2.2.5.

Tang et al. ${ }^{[37]}$ aplicaram os métodos de CFD na predição dos coeficientes hidrodinâmicos do AUV TUNASAND, que possui uma forma complexa (estrutura do tipo "Bloco"). Contudo, neste caso a validação da predição foi realizada por uma comparação entre o movimento realizado pelo AUV em testes de campo com os obtidos em um simulador de dinâmica, o os esforços hidrodinâmicos estimados pelo CFD.

Singh, Simha e Mittal ${ }^{[87]}$ e Lauder et al. ${ }^{[88]}$ também utilizaram métodos de CFD transientes em suas investigações do desempenho de propulsão e controle de aerofólios 
oscilantes, com o objetivo de imitar as barbatanas de peixes para a nova geração de AUVs bio-mecânicos, que se assemelham a diversos tipos de animais da fauna marinha ${ }^{[89]}$.

Além da identificação dos coeficientes hidrodinâmicos, as ferramentas de CFD também estão sendo utilizadas na otimização da geometria de AUVs ${ }^{[90,89]}$, investigação do desempenho de propulsores ${ }^{[91]}$, no estudo do escoamento sobre um AUV durante o processo de docagem ${ }^{[92]}$, e nas interferências hidrodinâmicas que ocorrem quando AUVs estão operando cooperativamente ${ }^{[93]}$, i.e., navegando próximos.

Motivado por esses e outros benefícios que a utilização dos métodos de CFD por volumes finitos proporcionam à área de veículos submarinos, nesta seção serão apresentadas as metodologias desenvolvidas para estimar numericamente os esforços hidrodinâmicos do AUV Pirajuba, mas que podem ser aplicadas para outros AUVs de corpos de revolução. Os resultados desta investigação, considerando o AUV operando em sua velocidade de cruzeiro $(1 \mathrm{~m} / \mathrm{s})$ com um número de Reynolds baseado no comprimento de $1.7 \cdot 10^{6}$, serão posteriormente apresentadas na seção 6 .

Pela investigação hidrodinâmica do AUV Pirajuba ter sido principalmente utilizada para determinar a manobrabilidade deste veículo, a metodologia numérica apenas se concentrará na estimativa dos esforços hidrodinâmicos de força normal (perpendicular ao casco do veículo) e do momento gerado pela distribuição desta força, apresentando tanto caráter estático quanto dinâmico. Mesmo com o arrasto (força longitudinal) apresentando um efeito pouco significativo para a manobrabilidade, em comparação aos demais esforços, ele será investigado neste trabalho, contudo, o procedimento de análise será mais focado na força normal e no momento.

Em termos gerais, as metodologias para a realização das simulações estáticas utilizadas são bastante semelhantes às encontradas na literatura aberta ${ }^{[19,20,28,21,22,85]}$ [23, 31, 29], utilizando o mesmo tipo de condições de contorno e análises. Contudo, neste trabalho, a metodologia de seleção dos modelos de turbulência ${ }^{[26,27,31]}$ e análise da sensibilidade de malha ${ }^{[33,35,36]}$ foram melhores investigadas. Na seleção do modelo de turbulência foram investigados um número maior de modelos, considerando casos 2D e 3D, enquanto que o desempenho dos dois modelos da análise de sensibilidade de malha foram comparados em casos que o escoamento apresentavam fenômenos bastante complexos, como grandes regiões de recirculação.

Além destas características, as simulações apresentadas neste trabalho se diferenciarão por realizar um estudo bastante completo, realizando a análise separada e conjunta do casco do AUV Pirajuba e seus apêndices, identificando isoladamente os efeitos não lineares devido a interferência entre os corpos nos esforços hidrodinâmicos. Para o caso da análise do corpo com a superfície de controle, também foi analisado a deflexão das superfícies de controle em conjunto com a variação do ângulo de incidência do escoamento, representando uma análise diferenciada que foi pouco vista para o caso de AUVs ${ }^{[25]}$. 
No caso dos coeficientes dinâmicos a diferença em relação a literatura ${ }^{[24,31]}$ foi maior, pois ao invés da investigação ficar restrita a estimação dos esforços em função apenas da velocidade angular, nesta trabalho as metodologias de Phillips, Furlong e Turnock ${ }^{[24]}$ e Toxopeus et al. ${ }^{[31]}$ serão estendidas para considerar os efeitos acoplados entre o ângulo de incidência do escoamento com o movimento de rotação angular. Esta análise é realizada com o objetivo similar as análises estáticas, onde também é realizada a análise dos efeitos de interferência.

Seguindo o exemplo de outros trabalhos desta área ${ }^{[81,32,85,31]}$, as análises de ambos os estudos serão feitas com simulações estáticas (não transientes), pois apesar das simulações transientes conseguirem capturar fenômenos de alta turbulência que as simulações estáticas não conseguem, elas apresentam um custo muito maior do que as simulações estáticas, resultando em um custo-benefício menos atrativo ${ }^{[81,32]}$.

Em todas as simulações apresentadas o software de simulação utilizado foi o ANSYS FLUENT nas versões 12.1 e 13.0, e software de geração de malha (pré-processador) foi o ANSYS ICEM 12.1 e 13.0, isto devido ao grande respaldo que estes softwares tem no meio científico e também por já terem apresentado bons resultados em pesquisas anteriores $^{[20,28,29,44]}$.

Na seção 3.1 serão apresentadas as principais características consideradas na geração de malhas para os casos analisados, ou seja, a organização espacial dos volumes finitos. Na seção 3.2 serão apresentadas as condições de contornos dos modelos numéricos aplicados para as malhas geradas, diferenciando as condições estáticas e dinâmicas. Na seção 3.3 será apresentado o critério utilizado para indicar o término da simulação, i.e., que a simulação convergiu. E na seção 3.4 serão apresentados os modelos de turbulência utilizados nas simulações para contabilizar os efeitos turbulentos inerentes ao escoamento.

Por último, na seção 3.5, serão apresentadas as metodologias utilizadas para verificar e validar as simulações numéricas de CFD para escoamentos externos. Na etapa de verificação serão levantadas as incertezas numéricas dos resultados das simulações de CFD, utilizando análises como a de sensibilidade de malha. Na etapa de validação é verificado se os resultados numéricos analisados estão estatisticamente condizentes com os resultados experimentais.

\subsection{GERAÇÃO DE MALHA}

Em uma simulação numérica de volumes finitos, e até mesmo elementos finitos, o fluido ao redor do corpo é discretizado por diversos polígonos convexos, sendo normalmente polígonos de quatro (tetraedros) a seis lados (hexaedros). Em cada um destes volumes são utilizados os modelos simplificados e discretos das equações de Navier-Stokes (NS), que descrevem o movimento continuo de um fluído, para montar um sistema de equações 
matriciais que é resolvido através de algorítimos iterativos para encontrar as propriedades dinâmicas do escoamento em cada um destes volumes.

Entretanto, para que uma simulação convirja para uma solução correta, a malha de volumes deve estar distribuída de forma concisa com o escoamento local representado por ela. Por exemplo, uma malha com uma discretização grosseira, que apresenta volumes grandes onde o escoamento apresenta características pequenas, tende a apresentar a difusão numérica. Esta difusão gera uma "filtragem" dos fenômenos menores do escoamento, como turbilhões pequenos (escala viscosa), podendo causar uma solução errada ou até mesmo uma divergência de simulação.

Para as simulações do AUV Pirajuba todas as malhas foram geradas utilizando elementos hexaédricos em uma malha estruturada, pois desta forma é obtido um melhor controle do refino e da qualidade da malha quando comparado a malhas tetraédricas e/ou prismáticas. Na construção destas malhas foi utilizada a técnica de geração de malhas por blocos do software comercial ANSYS ICEM 13.0, devido as suas boas qualidades de geração e manutenção de malhas hexaédricas.

Como o modelo do AUV Pirajuba, com e sem seus apêndices, apresenta uma simetria no plano lateral e vertical, e os escoamentos dos casos de interesses também apresentam simetrias, as malhas foram geradas considerando apenas metade dos modelos, ou seja, foi adotada a condição de escoamento simétrico. Com esta abordagem o número de volumes foi reduzido pela metade, reduzindo consideravelmente o custo computacional.

Em todos os casos, a construção das malhas foi dividida em três regiões, distintas pelos tipos de escoamento que pretendem modelar e pela distância das superfícies do corpo. São elas: a região da camada limite, a região próxima aos corpos simulados e a região mais externa da malha.

A região da camada limite (detalhes da figura 4), como o próprio nome diz, é a região que compreende a camada limite do escoamento junto aos corpos simulados. Nesta região, a malha apresenta o maior grau de refinamento, possibilitando a modelagem numérica da camada limite até a sub-camada viscosa, de acordo com as hipóteses dos modelos de turbulência utilizado ${ }^{[94]}$. Esta região foi discretizada por malhas que apresentam topologias do tipo "O", i.e., a malha é gerada na direção normal da superfície do corpo.

Na região próxima ao corpo (figura 4), que é adjacente a região da camada limite, são modelados os efeitos viscosos e potenciais do escoamento perturbado pela presença do corpo. A distribuição de malha nesta região deve ser mais refinada nas regiões em que os efeitos turbulentos/viscosos sejam mais preponderantes, ou seja, em regiões de recirculação, de geração de vórtice e de esteiras. Contudo, esta região deve apresentar um crescimento potencial (com expoente entre 1.1 e 1.4) a medida que os volumes se afastam do corpo, com o objetivo de reduzir o número de elementos da malha. Em termos geométricos, a região 


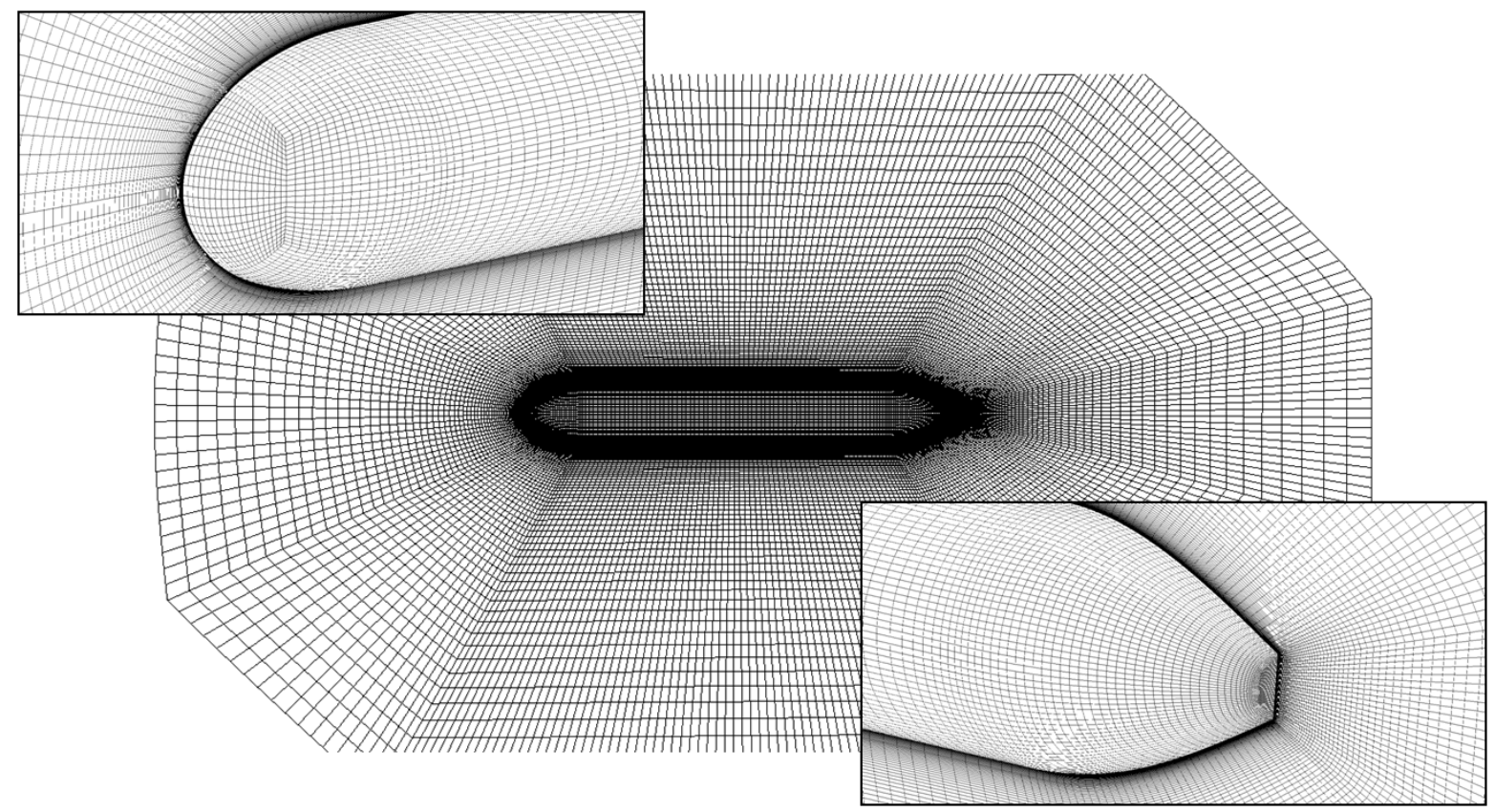

Figura 4 - Malha da região próxima ao corpo do Pirajuba, com detalhes da malha da camada limite da popa e proa. Ambas regiões utilizam uma malha com topologia do tipo "O"

próxima ao corpo possuí um formato de um elipsoide, cujas dimensões são uma escala das maiores distâncias cartesianas do corpo simulado. Na maioria dos casos, a malha desta região também é modelada utilizando a topologia do tipo "O", a única exceção é o caso do leme isolado que foi modelada por uma topologia do tipo "C", em que o crescimento dos volumes são normais a superfície do corpo e a superfície gerada pela prolongação virtual do bordo de fuga do leme.

A região mais externa da malha, vista na figura 5, tem como principal objetivo garantir que escoamento perturbado pelo corpo não chegue próximo as condições de contorno que são aplicadas aos extremos da malha, evitando assim problemas numéricos. Para que este problema seja evitado, esta região teve que ser construída a uma distância mínima do corpo. Nas simulações dos casos do Pirajuba, esta região apresenta um formato retangular, com os corpos simulados postos a uma distância de 3 a 5 vezes o seu comprimento significativo em relação às faces frontais e laterais, e de 10 a 20 vezes o mesmo comprimento em relação aos lados traseiros e superiores.

Estas distâncias foram determinadas empiricamente, ao considerar uma grande margem de segurança em relação aos tamanhos dos campos de velocidade, pressão e turbulência observados em diversas simulações deste trabalho, i.e., estas distâncias são grandes o suficiente para que uma perturbação maior do que a observada não interfira à níveis significativos nas condições de contorno impostas aos extremos da malha. Desta forma, em nenhuma simulação deste trabalho o escoamento perturbado chegou próximo aos extremos das malhas. 


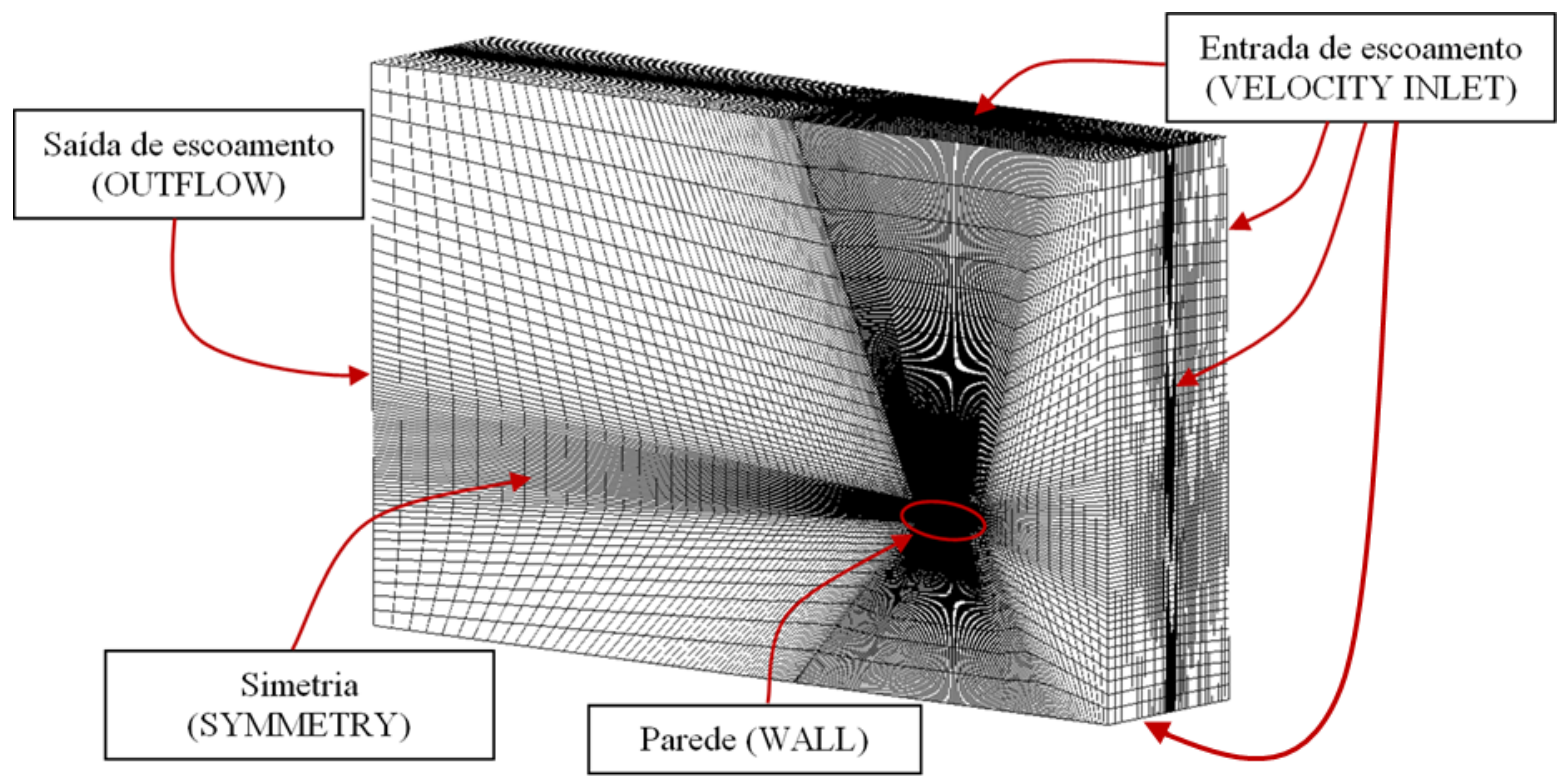

Figura 5 - Região mais externa da malha do corpo do AUV Pirajuba, indicando as condições de contornos utilizadas

Diferente das demais regiões, a malha mais externa apresenta uma topologia do tipo "H", em que o crescimento da malha é dado nas direções cartesianas. Nesta região, os elementos também apresentam um crescimento potencial, mas em um grau maior do que o encontrado na região próxima do corpo. Contudo, um refino na região de esteira ainda deve ser considerado, de forma a modelar corretamente o decaimento energético e a dissipação energética do escoamento.

\subsection{CONDIÇÕES DE CONTORNO}

Resumidamente, as condições de contorno especificam valores dinâmicos ou estáticos sobre as superfícies das regiões das malhas, para diversas variáveis de escoamento. As condições de contorno são utilizadas para que as condições reais do modelo possam ser reproduzidas pelas simulações.

Em todos os casos investigados, os tipos de condições de contorno utilizadas foram bastante semelhantes. Uma exceção pode ser encontrada nos casos dinâmicos, que apresentaram uma condição de contorno adicional em relação aos casos estáticos.

Devido a esta diferença, ambos os casos serão apresentados de forma separada nas próximas seções.

\subsubsection{Estáticas}

$\mathrm{Na}$ investigação dos esforços estáticos, são analisados os esforços que são gerados quando um corpo possui uma velocidade longitudinal constante e uma inclinação em 
relação ao escoamento (ângulo de ataque ou deriva). Para identificar os efeitos não lineares do ângulo de incidência do escoamento, as simulações são realizadas para diversos ângulos.

A modelagem numérica deste caso foi realizada considerando o corpo estático (parado) enquanto o fluído ao redor dele apresenta as condições de velocidade e inclinação, ou seja, condição inversa a condição real, no qual o veículos se move em um fluído estático. Como este caso não apresenta movimentos que gerem esforços inerciais (relativos a aceleração), este modelo numérico é equivalente aos experimentos em tanque de provas para medição dos esforços estáticos.

Para configurar este modelo matemático no software ANSYS Fluent, três condições de contorno diferentes foram aplicadas as superfícies externas da malha (figura 5), uma aplicada as superfícies dos corpos simulados (figura 4), e uma aplicado a todos os volumes.

Nas face frontal, lateral, superior e inferior do paralelepípedo da malha externa foram aplicadas a condição de entrada de escoamento (VELOCITY INLET). Nesta condição são impostas as condições de velocidades determinadas pelo ângulo de incidência do escoamento, os parâmetros de turbulência dos modelos de turbulência, como por exemplo a energia cinética turbulenta $(k)$, a taxa de dissipação turbulenta $(\epsilon)$ e a taxa de dissipação turbulenta especifica $(\omega)$, e a pressão estática de referência considerada, que não interfere nos cálculos dos modelos RANS incompressíveis ${ }^{[94]}$. Os parâmetros de turbulência são determinados seguindo a metodologia apresentada em ANSYS ${ }^{[94]}$, em que estes parâmetros são relacionados a intensidade turbulenta $(I)$ e ao comprimento característico da turbulência $(l)$, segunda as equações

$$
\begin{aligned}
k & =3 / 2\left(u_{\text {med }} I\right)^{2}, \\
\omega & =\frac{k^{1 / 2}}{C_{\mu}^{1 / 4} l} \mathrm{e} \\
\epsilon & =C_{\mu}^{3 / 4} \frac{k^{3 / 2}}{l},
\end{aligned}
$$

onde $u_{m e d}$ é a velocidade média do escoamento e $C_{\mu}$ é uma constante empírica dos modelos de turbulência.

Nas simulações deste trabalho, foi considerada uma intensidade turbulenta de $0.05 \%$ e um comprimento de turbulência igual a $7 \%$ do comprimento característico do modelo, que caracteriza o escoamento analisado como as condições tipicamente encontradas em túneis de vendo ou tanque de provas ${ }^{[94]}$.

Na face de simetria da simulação, parede lateral que "divide" o modelo ao meio, foi aplicada uma condição de simetria (SYMMETRY), onde é considerado que os gradientes das grandezas do escoamento normais a esta face são nulos.

Na face traseira foi aplicado a condição de saída de escoamento (OUTFLOW), onde é considerado que o escoamento já se encontra em regime permanente. Esta condição 
é modelada ao considerar uma difusão nula para todas as variáveis do escoamento, i.e., este modelo considera que o escoamento permanece constante após esta face.

As superfícies do corpo são modeladas como sendo paredes estacionárias sem escorregamento (WALL). Pelo tratamento numérico na condição de parede ser bastante dependente do modelo de turbulência da simulação, as apresentações destes serão feitas na seção 3.4.

Por último, o volume interno dado pelo 'sólido' que compreende todos os elementos da malha, são definidos com propriedades fluídicas (FLUID) da água doce a $20^{\circ} \mathrm{C}$, i.e., densidade igual a $998.2 \mathrm{~kg} / \mathrm{m}^{3}$ e viscosidade dinâmica igual a $1.003 \cdot 10^{-3} \mathrm{~kg} /(\mathrm{m} . \mathrm{s})$.

A designação das condições de contorno para as suas respectivas superfícies são apresentadas na figura 5 .

\subsubsection{Dinâmicas}

Neste trabalho, os esforços dinâmicos são definidos pelos esforços que surgem quando um corpo possui uma velocidade de rotação em relação ao escoamento. Como comentado anteriormente, as simulações destes esforços consideração de forma simultânea tanto a velocidade de rotação quanto o efeito da inclinação do escoamento, relativo aos esforços estáticos.

Esta condição poderia ser obtida ao considerar uma simulação transiente, com o corpo de estudo realizando movimentos de rotação ou oscilação ${ }^{[30]}$. Entretanto, por ser uma solução transiente ela apresentaria um custo computacional muito mais elevado do que uma solução estática, inviabilizando realizar todas as análises necessárias para identificar estes tipos de esforços.

Em seu trabalho, Phillips, Furlong e Turnock ${ }^{[24]}$, propuseram uma solução quasiestática para este problema, onde o AUV Autosub foi simulado estaticamente em condições que "forçam" o escoamento a ter um comportamento semelhante ao encontrado em uma manobra de curva. Neste método, o AUV de estudo foi simulado dentro de um duto curvado, com condição de entrada de velocidade em uma ponta e condições de saída na outra, e condições de parede com escorregamento nas paredes do duto (figura 6).

A desvantagem deste método está na necessidade de gerar uma nova malha para cada condição de velocidade angular, e poder gerar a blocagem do escoamento caso o duto não apresente uma abertura suficientemente grande para comportar o campo de pressões gerados pelo corpo. E no caso deste projeto, em que é estudado o acoplamento entre velocidade angular e ângulo de incidência, para cada condição de combinações das duas variáveis também deveriam ser geradas novas malhas, gerando um gasto muito alto na geração de malhas. 

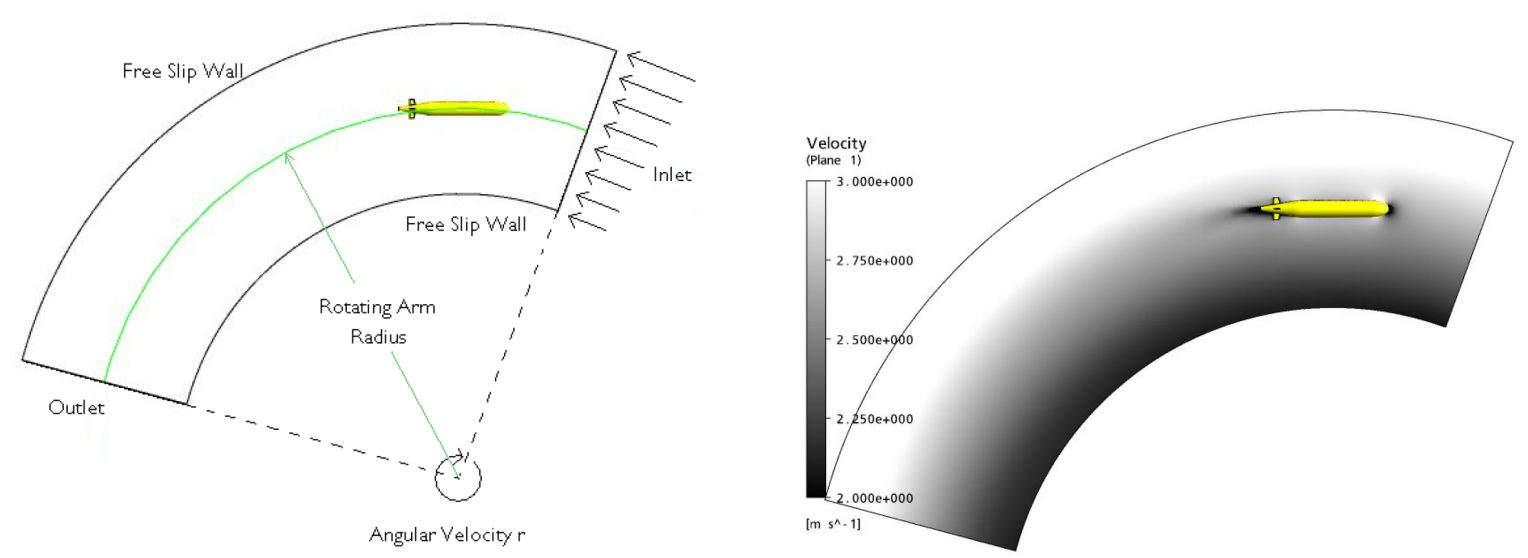

Figura 6 - Condições de contorno (a esquerda) e os campos de velocidade (a direita), obtidos pelas simulações de Phillips, Furlong e Turnock ${ }^{[24]}$ para investigação de coeficientes dinâmicos de AUVs

Para resolver este problema foi proposto uma nova metodologia, em que para realizar todas as simulações acopladas é apenas necessário utilizar uma malha. Nesta nova metodologia todas as condições de contorno enunciadas no caso estático são mantidas, sendo modificada apenas a formulação de velocidade relativa em cada volume do fluido. Nesta nova condição é considerado que o fluido possua uma velocidade de rotação relativa (conhecida no software ANSYS Fluent como Moving Reference Frame, ou MRF), com intensidade e centro de rotação escolhidos de forma que o corpo simulado aparente estar realizando uma curva com o raio escolhido. Por utilizar uma formulação de velocidade de rotação relativa, em que o fluído não se move, não é preciso corrigir os esforços gerados pela aceleração centrípeta do fluído, que seria o caso em um procedimento em que a velocidade de rotação fosse imposta ao fluído, como o visto na maioria dos casos analisados em Toxopeus et al. ${ }^{[31]}$.

Com este procedimento a condição de contorno da velocidade do escoamento modela a condição de inclinação do escoamento, enquanto que a condição de velocidade relativa do escoamento produz a condição de rotação angular de forma simultânea.

A desvantagem desta metodologia é que malha deve ser gerada de forma a apresentar uma distribuição de volumes adequados para as esteiras de todas as condições analisadas ${ }^{[31]}$, resultando em uma malha mais refinada em comparação com as malhas estáticas. Mesmo com este maior custo de simulação, por apresentar um refino mais generalizado, o custo total é inferior ao método transiente de Phillips, Furlong e Turnock ${ }^{[24]}$. 


\subsection{CRITÉRIO DE CONVERGÊNCIA}

Em uma simulação de CFD estática, o critério de convergência define quando uma simulação converge não precisando realizar mais iterações, ou seja, define indiretamente o número de iterações necessárias para considerar que tanto o escoamento modelado esta numericamente estabilizado quanto os resultados observados não apresentam mais variações significativas.

O manual do software ANSYS Fluent ${ }^{[94]}$ recomenda que sejam utilizados as normas dos resíduos das equações de transporte como critério de convergência. Entretanto, Eça, Vaz e Hoekstra ${ }^{[36]}$ não recomendam que sejam apenas utilizados critérios baseados nos resíduos, pois a convergência deles podem não indicar que os esforços hidrodinâmico convergiram para níveis insignificativos. Eça, Vaz e Hoekstra ${ }^{[36]}$ recomendam que sejam utilizados critérios baseados nos próprios esforços observados em adição aos critérios de resíduos, de forma que a convergência seja definida pela observação das variáveis de interesse da simulação em conjunto aos resíduos.

Neste trabalho, foi considerado que uma simulação convergiu quando a norma $L_{\infty}$ dos resíduos das equações de transporte estavam abaixo de $10^{-6}$, e quando as diferenças entre valores consecutivos dos esforços hidrodinâmicos (força axial, força normal e momento) apresentavam variações abaixo do sexto dígito significativo $\left(10^{-6}\right)$.

Como exemplo de análise de convergência, nas figuras 7 e 8 são apresentados os históricos de convergência dos resíduos das equações de transporte e da variação da força, respectivamente, para diversos ângulos de deriva (11 simulações, de 0 a 25 graus) do caso do corpo sozinho com o modelo de turbulência $k-\omega$ SST.

Adotando somente o critério da diferença dos esforços ${ }^{[95,36]}$, na maioria dos casos é observado que a convergência ocorreu antes das 500 iterações, mas para os casos de 0 e 3 graus de ângulo de deriva a convergência somente ocorreu depois das 1000 iterações. Esta mesma conclusão não pode ser obtida ao analisar somente os resíduos ${ }^{[94]}$, pois dependendo do ângulo de deriva os resíduos se comportam de maneiras distintas, podendo indicar uma convergência enquanto os esforços ainda não estabilizaram aos níveis considerados, como é o caso para os ângulos de 0 e 3 graus.

\subsection{MODELOS DE TURBULÊNCIA}

Para resolver as equações que descrevem o movimento dos fluídos Newtonianos, mais conhecidas por equações de "Navier-Stokes" (ENS), o software ANSYS FLUENT dispõe de diversos métodos/modelos matemáticos, cada um tendo as suas vantagens e desvantagens.

As ENS são compostas pelas equações de conservação de massa e quantidade de 


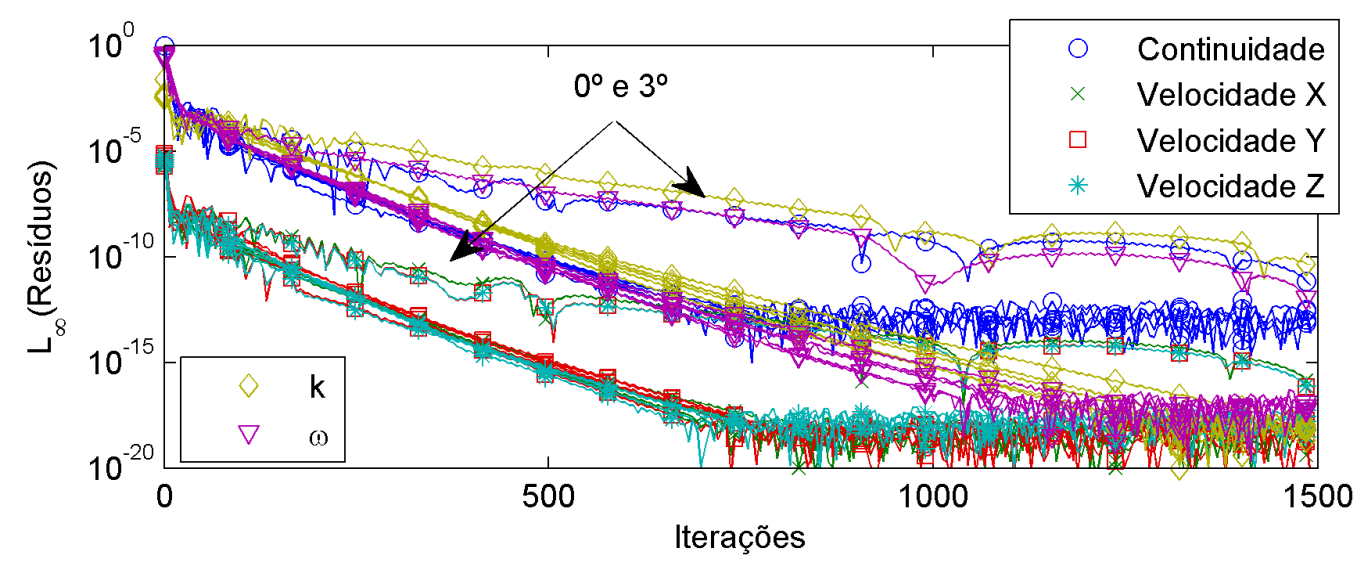

Figura 7 - Histórico da convergência iterativa da norma $L_{\infty}$ da continuidade (massa), velocidade (momento), energia cinética turbulenta $(k)$ e dissipação específica $(\omega)$, das simulações do casco nu com o modelo de turbulência $k-\omega$ SST

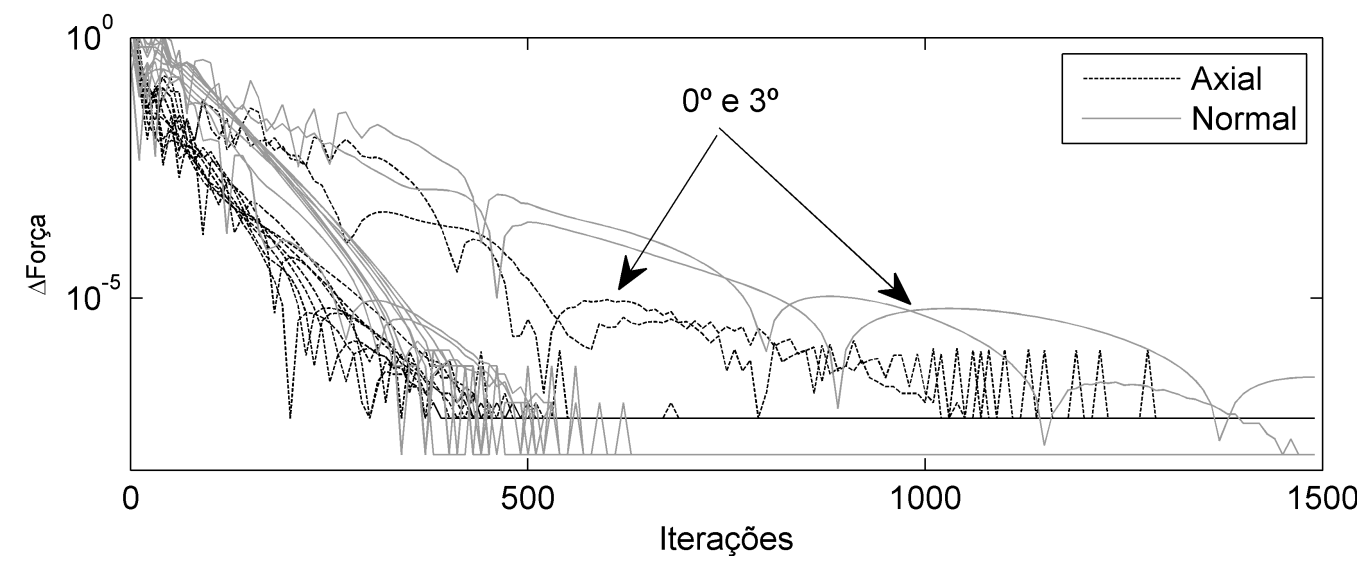

Figura 8 - Histórico da convergência iterativa da diferença entre valores consecutivos das forças hidrodinâmicas axiais e normais, das simulações do casco nu com o modelo de turbulência $k-\omega$ SST

movimento, vistas em notação vetorial em (3.4) e (3.5), respectivamente. Nestas equações, a variável escalar $\rho$ é a densidade do fluido, $t$ é o tempo, $\mu$ é a viscosidade dinâmica (molecular), $p$ é a pressão estática, $\partial$ é o operador de derivada parcial, $\nabla$ é o operador diferencial, $\vec{v}$ é o vetor velocidade, $\vec{g}$ é o vetor aceleração da gravidade, $\overline{\bar{\tau}}$ é o tensor de tensão (apresentado na equação (3.6)), $I$ é o tensor unitário e $\vec{F}$ é um tensor que representa os esforços externos.

$$
\begin{gathered}
\frac{\partial \rho}{\partial t}+\nabla \cdot(\rho \vec{v})=0 \\
\frac{\partial}{\partial t}(\rho \vec{v})+\nabla \cdot(\rho \vec{v} \vec{v})=-\nabla p+\nabla \cdot(\overline{\bar{\tau}})+\rho \vec{g}+\vec{F} \\
\overline{\bar{\tau}}=\mu\left[\left(\nabla \vec{v}+\nabla \vec{v}^{T}\right)-\frac{2}{3} \nabla \cdot \vec{v} I\right]
\end{gathered}
$$


Utilizando o método conhecido por DNS (Direct Numerical Simulation) é possível resolver as ENS discretas de forma bastante acurada sem utilizar simplificações. No entanto, para realizar este cálculo a malha de simulação deve ser refinada o suficiente para que os efeitos de difusão (micro-escalas de Kolmogorov ${ }^{[96]}$ ) sejam modelados, e isto apresenta um custo computacional excessivamente alto que impossibilita o seu uso para resolver a maioria dos problemas práticos de engenharia, sendo mais utilizado para fins de pesquisa ${ }^{[32,81,94]}$.

Ao se resolver as equações filtradas de $\mathrm{NS}^{[97]}$ é possível diminuir o custo computacional da solução de forma bastante significativa, sem apresentar grandes perdas em sua predição. Este modelo de solução é conhecido por LES (Large Edge Simulation), e com ele é possível resolver as grandes escalas e modelar as pequenas escalas dos turbilhões, que são filtradas pelo tamanho dos volumes da malha.

Entretanto, a solução de um problema pelo método LES ainda requer um poder computacional bastante alto, pois a solução do problema deve apresentar tanto uma convergência iterativa quanto temporal. Em casos onde se deseja investigar apenas a solução média (não instantânea) este custo se torna pouco atrativo quando comparado com outros métodos numéricos ${ }^{[32,81,94]}$.

Uma solução de menor custo e mais acessível para as investigações dos esforços hidrodinâmicos quasi-estáticos, é encontrada na versão média-temporal das ENS (vista na equação (3.7) e (3.8) em sua forma cartesiana, isotérmica e incompressível, sendo $\delta_{i j}$ o delta Kronecker), comumente denominadas de equações RANS (Reynolds-Averaged Navier-Stokes). Neste método a solução das ENS é decomposta em valores médios $\left(\overline{u_{i}}\right)$ e de flutuação $\left(u_{i}{ }^{\prime}\right)$, ou seja, $u_{i}=\bar{u}_{i}+u_{i}{ }^{\prime}$, e o cálculo das equações de transportes são realizadas sobre um domínio temporal suficientemente grande, representando uma média destas equações no tempo.

$$
\begin{gathered}
\frac{\partial \bar{\rho}}{\partial t}+\frac{\partial}{\partial x_{i}}\left(\bar{\rho} \bar{u}_{i}\right)=0 \\
\frac{\partial}{\partial t}\left(\bar{\rho} \bar{u}_{i}\right)+\frac{\partial}{\partial x_{j}}\left(\bar{\rho} \bar{u}_{i} \bar{u}_{j}\right)=-\frac{\partial \bar{p}}{\partial x_{i}}+\frac{\partial}{\partial x_{j}}\left(\bar{\tau}_{i j l}\right)+\frac{\partial}{\partial x_{j}}\left(-\rho \overline{u_{i}{ }^{\prime} u_{j}^{\prime}}\right) \\
\bar{\tau}_{i j l}=\mu\left(\frac{\partial \bar{u}_{i}}{\partial x_{j}}+\frac{\partial \bar{u}_{j}}{\partial x_{i}}-\frac{2}{3} \delta_{i j} \frac{\partial \bar{u}_{l}}{\partial x_{l}}\right)
\end{gathered}
$$

Apesar da simplificação, as equações RANS ainda não podem ser resolvidas, pois nestas quatro equações existem dez incógnitas que devem ser determinadas, três velocidades $\left(\bar{u}_{i}\right)$, a pressão $(\bar{p})$, e seis termos únicos do tensor de Reynolds (produto tensorial apresentado a direita da equação $\left.(3.8), \rho \overline{u_{i}{ }^{\prime} u_{j}{ }^{\prime}}\right)$. Este último termo das equações de transporte é o termo responsável pela modelagem da turbulência do escoamento. Pelo AUV Pirajuba apresentar um número de Reynolds, baseado no comprimento e na velocidade de cruzeiro $(1 \mathrm{~m} / \mathrm{s})$, igual a $1.7 \cdot 10^{6}$ grande parte do escoamento sobre seu corpo se encontra em 
regime turbulento, indicando que este termo é essencial para modelar corretamente este escoamento.

Uma forma usual de modelar o tensor de Reynolds é dado pela aplicação da hipótese de Boussinesq ${ }^{[96]}$, matematicamente apresentada na equação (3.10). Esta hipótese assume que o tensor de Reynolds é proporcional apenas aos gradientes de velocidades médios, a aproximação isotrópica escalar da viscosidade turbulenta $\left(\mu_{t}\right)$ e a energia cinética do fluido $(k)$, Apesar desta hipótese ser suficiente para modelar grande parte dos escoamentos, para alguns casos complexos ela pode pode prejudicar a modelagem numérica. Os modelos de turbulência, conjunto de equações que modelam os termos do tensor de Reynolds, que utilizam esta metodologia serão apresentados nas seções de 3.4.2 a 3.4.5.

$$
-\rho \overline{u_{i}{ }^{\prime} u_{j}{ }^{\prime}}=\mu_{t}\left(\frac{\partial \bar{u}_{i}}{\partial x_{j}}+\frac{\partial \overline{u_{j}}}{\partial x_{i}}\right)-\frac{2}{3}\left(\bar{\rho} k+\mu_{t} \frac{\partial \overline{u_{k}}}{\partial x_{k}}\right) \delta_{i j}
$$

Uma solução alternativa para este problema é resolver as equações de transporte de cada um dos termos do tensor de Reynolds. O modelo de turbulência que utiliza este método será apresentado na seção 3.4.6.

Segundo Fujii ${ }^{[32]}$ e Jameson ${ }^{[81]}$, apesar dos métodos RANS sofrerem mais simplificações do que o método LES, para soluções de problemas de engenharia o seu uso é mais recomendado devido ao custo computacional relativamente baixo de suas simulações, e que a melhor modelagem da turbulência pelo LES não aumenta significativamente a precisão das estimativas dos esforços hidrodinâmicas quasi-estáticos para a maioria dos casos. Por estes motivos, a investigação dos esforços hidrodinâmicos do AUV Pirajuba somente será realizada pelos métodos RANS.

Para apresentar melhor o problema de escolha do modelo de turbulência, na seção 3.4.1 será apresentada uma introdução sobre o problema de cálculo do escoamento próximo a parede, ou seja, serão explicados as metodologias utilizadas para a modelagem da camada limite do escoamento pelos modelos de turbulência.

\subsubsection{Modelos de solução na parede}

Para problemas de escoamentos de corpos imersos a determinação correta da camada limite é bastante importante para se obter uma modelagem acurada do problema, pois os efeitos de turbulência e os campos de velocidade são bastante afetados pelas características da camada limite.

Levando em consideração o comportamento fluido-dinâmico, a camada limite pode ser dividida em três regiões distintas: a sub-camada viscosa, a camada de amortecimento, e a região totalmente turbulenta.

A sub-camada viscosa é a região localizada mais próxima a parede. Nesta região o escoamento se comporta como sendo praticamente laminar, onde os esforços viscosos 


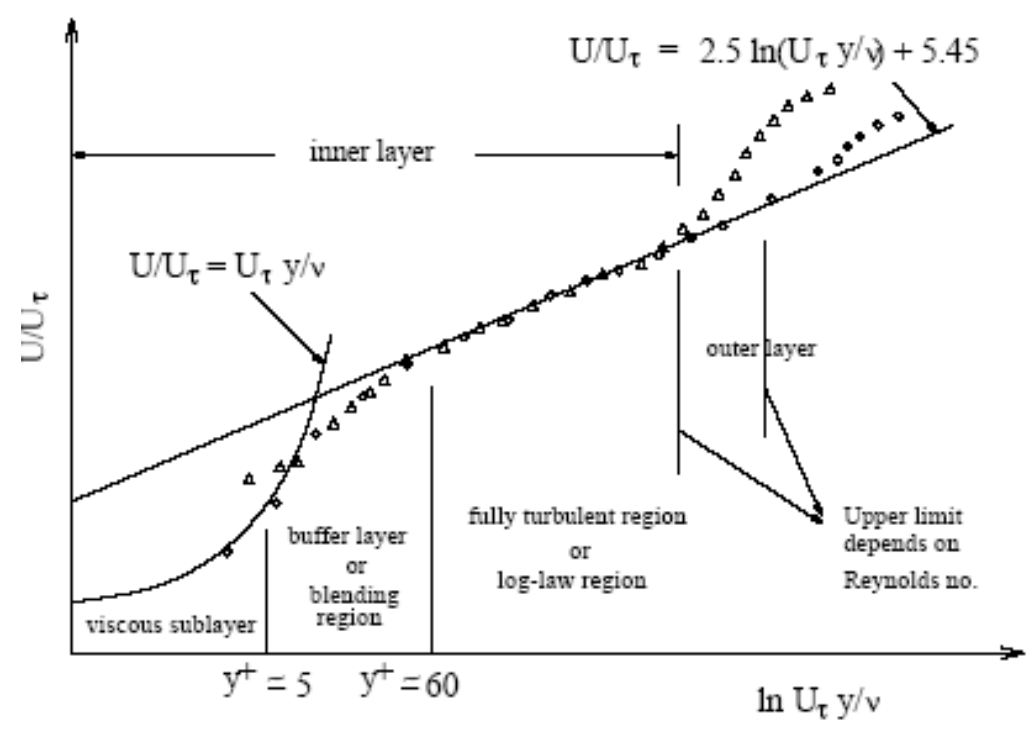

Figura 9 - As subdivisões da camada limite ${ }^{[94]}$

predominam, amortecendo as flutuações da velocidade tangencial. Na região totalmente turbulenta, também conhecida por região "log" (devido a formulação logarítmica utilizada em seu modelamento), os esforços inerciais são predominantes, contribuindo com a produção de energia cinética devido aos grandes gradientes de pressão da velocidade média. A camada de amortecimento está localizada entre estas duas regiões, podendo ser descrita como uma região que une os efeitos encontrados na região laminar com a da região turbulenta, apresentando igual importância para os esforços inerciais e viscosos.

Na figura 9 são apresentados os efeitos destas três regiões na razão da velocidade nominal do escoamento $U$, pela velocidade de fricção $U_{\tau}$, que é definida por

$$
U_{\tau}=\sqrt{\frac{\tau_{w}}{\rho}}
$$

onde $\tau_{w}$ é a tensão de cisalhamento na superfície do corpo.

O eixo de abscissa desta figura, apresentado em escala logarítmica, é definido em função do parâmetro $y^{+}$, que é uma representação do número de Reynolds local e normal a superfície da parede. Este parâmetro é definido pela equação

$$
y^{+}=\frac{y U_{\tau}}{\nu}
$$

onde $y$ é a distância normal a parede, e $\nu$ é a viscosidade cinemática do fluido.

Por não ser trivial a modelagem matemática destas regiões, o software ANSYS FLUENT possibilita o uso de duas abordagens distintas: o uso da função de parede, e o modelo próximo à parede. $\mathrm{O}$ uso destas abordagens é diferenciado pela complexidade da modelagem, e depende diretamente do valor do $y^{+}$que as superfícies apresentam. Na 
função de parede, o cálculo das regiões da camada limite é realizado a partir da região turbulenta, utilizando uma função analítica e semi-empírica para extrapolar a solução numérica até a sub-camada viscosa, tentando imitar o comportamento visto na figura 9. Já no modelo próximo à parede, os modelos de turbulência são modificados para incluir parâmetros que possibilitem o cálculo completo da camada limite, i.e. até a sub-camada viscosa.

Apesar da utilização das funções de paredes não requererem uma malha de alto refino, necessitando que o volume próximo à parede apresente um $y^{+}$com valores entre 30 e 100, o seu uso pode não considerar corretamente os efeitos viscosos da sub-camada viscosa, podendo afetar significativamente a solução para escoamentos de baixos número de Reynolds e que possuem gradientes adversos de pressão ${ }^{[94]}$. Por este motivo este modelo é recomendado para escoamentos totalmente turbulentos, i.e., que apresentem um alto número de Reynolds ${ }^{[94]}$.

Para a investigação dos esforços hidrodinâmicos do AUV Pirajuba será optado por sempre utilizar os modelos "próximo à parede". Este modelos serão utilizados por uma parte significativa do casco do Pirajuba e seus apêndices estarem submetidos a escoamentos de número de Reynolds baixos, e pelos casos simulados apresentarem grandes gradientes adversos de pressão devidos aos altos ângulos de incidência.

O software ANSYS FLUENT apresenta duas formas distintas de implementação numérica para os modelos próximos à parede, as funções de parede aprimoradas (enhanced wall functions) e os tratamentos de parede avançados (ehanced walll treatment), mas em ambos os casos o valor de $y^{+}$deve ser próximo de 1 para os modelos serem válidos. Desta forma, em todas as simulações do AUV Pirajuba, foi buscado obter um $y^{+}$próximo de 1 , considerando a média em toda a superfície do corpo.

A diferença entre os dois modelos está na definição do próprio modelo de turbulência. Caso o modelo de turbulência apresente uma definição robusta e razoável para os efeitos encontrados dentro da camada limite, com as condições de contorno na parede definidas para todas as equações de transporte, são utilizados as funções de parede aprimoradas. Caso a definição do modelo e as condições de contorno sejam feitas por aproximações empíricas ou aproximadas, é utilizado o tratamento de parede avançado, onde os modelos tem parte de sua formulação modificada para contabilizar tais efeitos.

\subsubsection{Modelo de 1 equação: Spalart-Allmaras}

O modelo proposto por Spalart e Allmaras ${ }^{[98]}$, e nomeado pelos seus criadores, é o único modelo de turbulência presente no software ANSYS FLUENT que apresenta apenas uma equação de transporte para a modelagem da turbulência.

Este modelo foi desenvolvido para resolver escoamentos de corpos imersos para a 
indústria aeroespacial em casos que o fluido envolve um corpo com a condição de contorno do tipo parede, sendo este o tipo de problema tratado neste projeto. Numericamente, este modelo resolve diretamente a equação de transporte da viscosidade turbulenta das equações RANS, adicionalmente às soluções das equações de transporte da continuidade e quantidade de movimento.

Para que este modelo seja utilizado corretamente, as regiões da camada limite precisam ser resolvidas com uma malha de alto refino $\left(y^{+} \leq 1\right)$, possibilitando o usa das funções de parede aprimoradas. Apesar de não ser aplicado a este trabalho, no software ANSYS FLUENT também foi implementada a função de parede para os casos em que a camada limite apresenta uma discretização grosseira $\left(30 \leq y^{+} \leq 100\right)^{[99]}$.

Mesmo apresentando uma solução simples, este modelo tem conseguido bons resultados para os casos de escoamentos externos aeronáuticos, mesmo quando a camada limite está sujeita a efeitos de gradientes de pressão adversos ${ }^{[32,94]}$. Além disso, o custo computacional deste método é significativamente inferior aos demais métodos que são apresentados nas próximas seções, tornando-se uma opção com bom custo-benefício.

\subsubsection{Modelo de 2 equações k-e: padrão, RNG e Realizável}

O modelo de turbulência $k-\epsilon$, desenvolvido por Launder e Spalding ${ }^{[100]}$, resolve as equações de transporte da energia cinética turbulenta $(k)$ e da taxa de dissipação $(\epsilon)$ para completar a solução das equações RANS, de forma que as escalas de comprimento e velocidade turbulenta sejam resolvidas independentemente.

A equação de transporte da energia cinética turbulenta é derivada da solução matemática exata, enquanto que a equação de transporte da taxa de dissipação é obtida por aproximações empíricas com considerações embasadas na física, mas que possui pouca semelhança ao modelo matemático exato. Outra desvantagem do modelo $k-\epsilon$ padrão é encontrada em sua derivação, que é feita considerando o escoamento totalmente turbulento, menosprezando os efeitos de viscosidade molecular isotrópica.

Apesar desta modelagem aproximada, o modelo $k-\epsilon$ padrão apresenta uma boa robustez e acurácia para diversos tipos de escoamentos turbulentos encontrados em problemas de engenharia, conseguindo modelar tanto escoamentos internos quanto externos $^{[94]}$.

Devido às suas boas características, novas versões deste modelo foram propostas desde o seu desenvolvimento. Duas destas versões estão disponíveis no software ANSYS FLUENT 13.0, o RNG (renormalization group theory) ${ }^{[101]}$ e o Realizável (Realizable) ${ }^{[102]}$.

O modelo de turbulência $k-\epsilon$ RNG é derivado das equações instantâneas de Navier-Stokes, usando técnicas estatísticas chamadas por teoria de renormalização de grupo (RNG). Matematicamente esta nova formulação adiciona novas constantes e funções 
as equações de transporte deste modelo, como uma função analítica para o cálculo do número de Prandtl e uma função diferencial para o cálculo da viscosidade efetiva.

Com estas mudanças, o modelo RNG apresenta melhores resultados do que o modelo padrão em escoamentos que apresentam uma rápida aceleração ou um movimento curvilíneo. Devido as modificações na formulação da viscosidade efetiva ${ }^{[103]}$, este modelo também consegue corrigir os efeitos de da viscosidade para escoamentos de baixo Reynolds.

Diferente do modelo padrão e RNG, o modelo $k-\epsilon$ Realizável deriva uma equação de transporte exata para a taxa de dissipação, dada em função da equação de transporte da média ao quadrado da flutuação da vorticidade. Devido à esta nova formulação, é esperado que o modelo Realizável apresente um desempenho superior em escoamentos que envolvam rotação, com camadas limites sobre fortes gradientes de pressão adversos, separação e recirculação, que são fenômenos típicos encontrados em escoamentos de AUVs submetidos a altos ângulos de incidência.

Para este modelo de turbulência, a modelagem do escoamento próximo a parede é realizada utilizando o tratamento aprimorado de parede (enhanced wall treatment) de duas camadas. A modelagem é realizada dividindo a região da camada limite em duas sub-regiões, uma inteiramente turbulenta e outra afetada pela viscosidade da sub-camada viscosa, e a união destas sub-regiões é realizada por uma função união ${ }^{[94]}$.

\subsubsection{Modelo de 2 equações $k$-w: padrão e SST}

Para a predição de fenômenos turbulentos, o modelo $k-\omega$ padrão ${ }^{[104]}$ resolve as equações de transporte da energia cinética turbulenta (a mesma dos modelos $k-\epsilon$ ) e da taxa de dissipação específica $(\omega)$, que pode ser interpretada como uma razão da taxa da dissipação e da energia cinética turbulenta $(\omega=k / \epsilon)$. Por utilizar esta formulação

Wilcox ${ }^{[104]}$ enunciou que a vantagem do seu modelo em relação aos modelos $k-\epsilon$ seria dado pelas condições de contorno na parede, que poderiam ser obtidas de maneira mais efetiva e robusta do que as encontrada nos modelos $k-\epsilon$. No entanto, este modelo mostrou-se ser muito sensível às condições de contorno de turbulência para o escoamento livre.

Este problema foi resolvido no modelo de turbulência $k-\omega$ SST (Shear-Stress Transport), apresentado por Menter ${ }^{[105]}$. Nesta variação do modelo $k-\omega$, foi proposta a utilização de uma função que unisse a equação de transporte de $\omega$ na região próxima à parede e a equação de transporte de $\epsilon$ na região de escoamento livre, i.e., longe da parede. Desta forma, conseguindo utilizar ambos os modelos nas regiões que são melhores definidos, eliminando as suas desvantagens e unificando as suas vantagens ${ }^{[106]}$.

Com o passar do tempo novas modificações dos modelos $k-\omega$ foram propostas para melhorar o seu desempenho e efetividade para um número maior de escoamentos ${ }^{[106]}$. 
Atualmente, o software ANSYS FLUENT incorpora modificações na viscosidade para os efeitos de baixo número de Reynolds, compressibilidade e fluxo de cisalhamento (shearflow).

Destas modificações a mais interessante, e analisada neste trabalho, é a de baixo número de Reynolds, devido a natureza dos escoamentos encontrados no AUV Pirajuba e em seus apêndices. Nesta correção, é utilizado um coeficiente de amortecimento,

$$
\mu_{t}=a_{\infty}^{*} \frac{a_{0}^{*}+R e_{t} / R_{k}}{1+R e_{t} / R_{k}}
$$

para o cálculo da viscosidade turbulenta (3.14), onde $R e_{t}$ é o número de Reynolds local, $\rho$ é a densidade do fluído, $k$ é a energia cinética turbulenta do fluído, $\omega$ é a taxa de dissipação específica do fluído, $\mu$ é a viscosidade molecular do fluído, e $R_{k}$ e $a_{0}^{*}$ são parâmetros empíricos constantes do modelo, com valor igual a 6.0 e 0.024 , respectivamente.

$$
\mu_{t}=a^{*} \frac{\rho k}{\mu \omega}
$$

No software ANSYS FLUENT, o tratamento da condição de contorno de parede, ou seja, o cálculo do escoamento até a sub-camada viscosa da camada limite, nos dois modelos $k-\omega$ é realizado por uma função aprimorada de parede. Esta condição é semelhante à encontrada no modelo Spalart-Allmaras, pois estes modelos foram desenvolvidos com condições de contorno que podem ser aplicadas até a parede, i.e., utilizando formulações de baixo Reynolds.

\subsubsection{Modelo de 4 equações: Transição SST}

Apesar dos modelos de turbulência apresentados nas seções anteriores terem correções para os efeitos de escoamentos com número de Reynolds baixos, todas as suas formulações são baseadas em escoamentos completamente turbulentos. Para resolver este problema, os pesquisadores Menter e Langtry da empresa ANSYS desenvolveram em 2006 o modelo de turbulência Transição SST (Transitional SST) ${ }^{[107,108]}$, que possibilita a modelagem tanto dos efeitos do escoamento laminar quanto do turbulento.

Para realizar este cálculo, este modelo utiliza equações de transporte para a intermitência e para o critério de início de transição, baseado no número de Reynolds da espessura da quantidade de movimento, em conjunto com as equações utilizadas no modelo $k-\omega$ SST, por isso o nome SST dado a este modelo.

A equação da intermitência é utilizada para indicar a intensidade de turbulência do escoamento, apresentando valor igual a 1 para escoamentos laminares e 0 para escoamento turbulentos. Este parâmetro é utilizada para melhor definir alguns termos e funções das equações do modelo $k-\omega$ SST, que são influenciados pela condição laminar ou turbulenta do escoamento. A equação de transporte do número de Reynolds da espessura 
da quantidade de movimento é utilizada somente como critério de transição do escoamento laminar para turbulento, e vice-versa, atuando diretamente na definição da equação de transporte da intermitência.

De forma simples, pode-se considerar que a equação de transporte do critério de turbulência define se o escoamento em cada volume está em condições de passar do laminar para o turbulento. Esta informação é utilizada pela equação de transporte da intermitência, para definir a razão de escoamento laminar/turbulento neste volume. Por sua vez, a intermitência é utilizada para corrigir alguns termos da equação de transporte da energia cinética turbulenta, para que possa considerar tanto correções para o escoamento laminar quanto para o turbulento.

Um dos problemas deste modelo se encontra na determinação dos parâmetros de turbulência da condição de entrada do escoamento. Devido a sua formulação transitória, a intensidade turbulenta tende a diminuir exponencialmente em função da distância percorrida pelo escoamento ${ }^{[94]}$, devido a variação da viscosidade turbulenta, de forma que a incidência de turbulência em um corpo imerso deve ser calculada em função da distância do corpo a condição de entrada.

O tratamento da condição de parede deste modelo é bastante similar ao utilizado no modelo $k-\omega \mathrm{SST}$, com a diferença que alguns termos, como a viscosidade turbulenta, são calculados em função da intermitência.

\subsubsection{Modelo de 7 equação: Tensores de Reynolds}

Diferente dos outros modelos apresentados, a primeira versão do modelo de turbulência dos tensores de Reynolds (mais conhecido por Reynolds Stress Model, ou simplesmente RSM) ${ }^{[109,110,111]}$ não utiliza a hipótese de viscosidade turbulenta isotrópica (hipótese de Boussinesq ${ }^{[96]}$. Por não utilizar esta hipótese este modelo resolve individualmente as equações de transporte dos tensores de Reynolds em conjunto com a equação de transporte da taxa de dissipação $(\epsilon)$, resultando em um modelo de sete equações para escoamentos tri-dimensionais e de cinco equações para escoamentos bi-dimensionais.

O software ANSYS FLUENT também implementa uma modificação do modelo RSM apresentada por Wilcox ${ }^{[104]}$, que ao invés de utilizar as equações de transporte da taxa de dissipação $(\epsilon)$ são utilizadas as equações de transporte da taxa de dissipação específica $(\omega)$. A ideia desta modificação é semelhante à aplicada no modelo $k-\omega$ SST, onde as equações do modelo $k-\epsilon$ são utilizadas para o escoamento livre, enquanto as equações do modelo $k-\omega$ são utilizadas no escoamento próximo a parede. A diferença é que neste modelo não é necessário utilizar uma função de união para as equações, pois elas são tratadas pelas equações de fechamento das equações de transporte dos tensores de Reynolds. 
Os coeficientes de fechamento deste modelo são bastante semelhantes as do modelo $k-\omega$, com a adição de mais dois coeficientes que fazem a ligação entre as diferentes equações de transporte. As modificações para baixo número de Reynolds deste modelo também são realizadas de maneira bastante similar ao do $k-\omega$, ou seja, com a utilização de coeficientes de amortecimento. Mas no caso deste modelo é necessário fazer esta correção no termo de tensão-pressão (pressure-strain, $P h i_{i j}$ ) das equações de transporte e em um dos termos da equação de fechamento ${ }^{[104]}$.

Por não utilizar a hipótese de Boussinesq ${ }^{[96]}$, seria esperado que o modelo RSM apresentasse um resultado bastante superior aos demais modelos em escoamentos sobre superfícies curvadas, e em situações que o escoamento apresente altas taxas de rotação e de mudança de direção de fluxo. Entretanto, a fidelidade da predição do modelo RSM fica limitada pelas suposições de fechamento das equações de transporte dos termos do tensor de Reynolds, que não representam um modelo matemático com solução exata. Desta forma, as simulações podem apresentar grandes dificuldades de convergência devido a estas aproximações ${ }^{[94]}$, sendo difícil reduzir o resíduo das equações de transporte, ou até mesmo apresentar uma convergência para uma solução errada.

Para a aplicação do RSM quando o escoamento está próximo à parede, o software ANSYS FLUENT utiliza o método de tratamento aprimorado da parede, com a formulação similar ao de seus modelos bases $(k-\epsilon$ e $k-\omega)$, com a aproximação de fluxo zero para os termos do tensor de Reynolds.

Devido o maior número de equações de transporte a serem resolvidas e a dificuldade de convergência dos resíduos destas equações, este modelo de turbulência apresenta uma relação custo-benefício muito baixa em comparação aos demais modelos, sendo seu uso aconselhável para alguns casos.

\subsection{PROCEDIMENTO DE VERIFICAÇÃO E VALIDAÇÃO}

O procedimento de verificação e validação ${ }^{[33]}(\mathrm{V} \& \mathrm{~V})$ é uma metodologia que foi desenvolvida para quantificar os erros e incertezas existentes em procedimentos numéricos, como as simulações de CFD.

Como mencionado por Roache ${ }^{[112]}$, "a verificação é um exercício puramente matemático que propõe mostrar que as 'equações são corretamente resolvidas', enquanto que a validação é uma atividade cientifica que se atêm a "resolver as equações certas". Isto significa que a verificação tenta identificar os erros e incertezas da formulação do próprio modelo, i.e., incertezas numéricos, enquanto a validação trabalha com os erros e as incertezas geradas pelas hipóteses e suposições adotadas no desenvolvimento do modelo ${ }^{[35]}$.

O desenvolvimento deste procedimento para as mais diversas áreas, foi impulsionado 
pelo uso extensivo de ferramentas numéricas aplicadas para casos cada vez mais complexos, de forma que a solução simulada poderia não apresentar semelhança com os resultados experimentais, ou em casos mais problemáticos, a coincidência de algum resultado poderia ser gerada por uma mera coincidência numérica.

Apesar de existirem discussões/trabalhos anteriores que tratavam do assunto, as primeiras metodologias, conceitos e terminologias de V\&V foram abordadas em Roache ${ }^{[112]}$, com enfoque na determinação de uma metodologia robusta e genérica (aplicada a problemas numéricos em geral), e AIAA ${ }^{[13]}$, cujo o problema de $\mathrm{V} \& \mathrm{~V}$ foi especificado para o caso de CFD em escoamentos aerodinâmicos.

Baseando-se no trabalho de ambos os autores ${ }^{[12,113]}$, e em conjunto com a $21^{\circ}$ e $22^{\circ}$ conferencia internacional de resistência em tanque de provas (mais conhecido por ITTC, ou International Towing Tank Resistance Conference), Stern et al. ${ }^{[114]}$ propuseram mudanças em suas metodologias para se melhor adequar ao problema de CFD aplicado a indústria naval, focando-se em códigos de CFD do tipo RANS validado por ensaios estáticos em tanques de provas, apesar da metodologia proposta poder ser aplicada para um maior número de casos. Um exemplo deste procedimento para uma navio de carga pode ser visto em Stern et al. ${ }^{[115]}$ (teoria e metodologia) e Wilson et al. ${ }^{[116]}$ (aplicação em um navio cargueiro).

Devido ao foco utilizado e a metodologia apresentada, o procedimento de Stern et al. ${ }^{[114]}$ ainda hoje é considerado um procedimento necessário para publicação de resultados de CFD em alguns congressos e jornais relacionadas ao $\operatorname{ITTC}^{[46,117]}$.

Mais recentemente, a ASME (American Society of Mechanical Engineers, ou Sociedade Americana dos Engenheiros Mecânicos), com o objetivo de padronizar alguns tópicos e metodologias dos procedimentos de $\mathrm{V} \& \mathrm{~V}$, lançou uma nova norma ${ }^{[33]}$ para a especificação destes procedimentos e quantificação do grau de acurácia de simulações numéricas de CFD e transporte de calor. Mas mesmo com esta norma, alguns tópicos do procedimento $\mathrm{V} \& \mathrm{~V}$ ainda não foram fechados, sendo ainda discutidos em congressos ${ }^{[35]}$.

Algum destes tópicos "não fechados" foram recentemente discutidos por Eça, Vaz e Hoekstra $^{[35]}$, onde também foi apresentada uma especificação do procedimento de V\&V da $\mathrm{ASME}^{[33]}$ aplicado a engenharia oceânica, cuja a metodologia foi baseada em experiências na área de V\&V aplicada aos métodos de soluções manufaturadas (conhecidos do Method of Manufactured Solutions, ou MMS) ${ }^{[118]}$.

Como exemplo de aplicação, Eça, Vaz e Hoekstra ${ }^{[36]}$ aplicaram esta metodologia para o estudo das incertezas das propriedades numéricas de uma simulação de CFD do tipo RANS para o estudo do escoamento sobre um degrau de face oposta. Foi verificada a influência de diversos parâmetros da metodologia $V \& \mathrm{~V}^{[33]}$ nos cálculos de incertezas, e ainda foram apresentadas maneiras de realizar as interpretações dos resultados deste 
procedimentos. Em um exemplo mais direcionado, Vaz, Toxopeus e Holmes ${ }^{[34]}$ utilizaram o procedimento $\mathrm{V} \& \mathrm{~V}^{[33,35]}$ para a investigação dos esforços hidrodinâmicos estáticos para duas configurações de um submarino de geometria padrão (DARPA SUBOFF), utilizando três modelos de turbulência. Sendo posteriormente estendido para os esforços hidrodinâmicos dinâmicos em Toxopeus et al. ${ }^{[31]}$.

Em ambos os trabalhos ${ }^{[36,34]}$, seus autores demonstraram que a determinação dos erros e incertezas das simulações numéricas geram uma análise numérica mais embasada, podendo considerar as simulações validadas sobre alguns aspectos. Este tipo de resultado demonstra uma melhoria considerável sobre a simples comparação gráfica de valores experimentais e numéricos, embora o procedimento como um todo ainda não esteja fechado.

Desta forma, a investigação numérica dos esforços hidrodinâmicos do AUV Pirajuba utilizará o procedimento de V\&V apresentado em $\mathrm{ASME}^{[33]}$ com algumas das modificações utilizadas por Eça, Vaz e Hoekstra ${ }^{[35]}$, com o objetivo de conseguir verificar e validar a metodologia de simulações de CFD proposta neste trabalho. Na seção 6.2.2 é realizada uma comparação entre os dois modelos, justificando o resultado final obtido.

Nas próximas seções, serão apresentados os procedimentos que são de interesse para este projeto na área de verificação (seção 3.5.1) e validação (seção 3.5.2), aplicados as simulações de CFD do tipo RANS estáticas (não transientes).

\subsubsection{Procedimento de verificação}

Por definição ${ }^{[112]}$, o procedimento de verificação pode ser dividido em duas atividades distintas: a verificação de código e a verificação de solução. Sendo ambas os procedimentos explicados nas próximas seções.

\subsubsection{Verificação de código}

Na verificação de código é verificado se um código, algoritmo ou software, consegue resolver corretamente um modelo numérico que possua uma solução exata, não precisando ser fiel a realidade.

No caso de escoamentos turbulentos, não é possível realizar uma verificação com este tipo procedimento ${ }^{[35,36]}$, pois o inerente comportamento caótico do escoamento não permite a obtenção de uma solução exata. Neste caso, a verificação de código somente pode ser realizada em modelos definidos com o MMS ${ }^{[118]}$, onde uma solução continua é especificada inicialmente e as incógnitas do problema são geradas por funções matemáticas (que não representam necessariamente um modelo físico/real), pois a solução exata do problema é parte de sua condição inicial. 
Apesar de alguns softwares comerciais permitirem a variação de alguns parâmetros dos modelos, a variação e manipulação de suas funções são bem mais limitadas ${ }^{[94]}$, tornando a tarefa de verificação de código por MMS uma tarefa mais voltada aos próprios desenvolvedores do software.

Desta forma, na investigação numérica deste trabalho não serão feitas verificações de código do software ANSYS Fluent, por fugir do escopo deste trabalho, sendo considerado que o software já foi verificado pelos seus desenvolvedores.

\subsubsection{Verificação de solução}

A verificação de solução trata da estimação de erros e incertezas $\left(U_{\phi}\right)$ existentes em uma solução numérica $\left(\phi_{i}\right)$, cuja solução exata $\left(\phi_{\text {exata }}\right)$ pode não ser conhecida, mas está contida dentro do intervalo de incerteza de cerca de $95 \%$. Ou seja,

$$
\phi_{i}-U_{\phi} \leq \phi_{\text {exata }} \leq \phi_{i}+U_{\phi}
$$

Contudo, para que esta estimação seja realizada, os métodos atuais ${ }^{[33,35,36]}$ requerem que a análise das soluções seja feita na denominada "região assintótica", ou seja, o erro numérico das variáveis analisadas deve apresentar um comportamento de convergência com apenas um termo dominante em uma expansão de potência em função do refino da discretização numérica.

Em termos práticos, isto significa que é esperado que as simulações sejam feitas com uma malha com alto nível de refino, que podem ser considerados impraticáveis para algumas aplicações. Para estes casos, as incertezas devem ser estimadas com fatores de segurança que refletem esta falta de conhecimento.

Para melhor analisar o erro numérico, Roache ${ }^{[112]}$ propôs que este erro seja dividido em três componentes: arredondamento, iteração e discretização.

O erro de arredondamento surge pela diferença entre a solução matemática exata e a solução obtida por operações matemáticas que utilizam um número finito de algarismos significativos, que são definidos pela precisão numérica do software/hardware onde são realizados estes cálculos. Em condições normais, este erro pode ser considerado negligenciável se a solução do problema for calculada em precisão dupla ${ }^{[35,36]}$, que seria equivalente a pelo menos 15 dígitos de precisão. Para manter este erro em um nível insignificativo, toda as simulações deste trabalho foram realizadas com o software ANSYS FLUENT operando em precisão dupla.

O erro de iteração é a diferença entre a solução numérica utilizada e a solução obtida caso fossem realizadas infinitas iterações. Idealmente, é esperado que este erro seja reduzido para o mesmo nível do erro de arredondamento, mas isso resultaria em um custo computacional impraticável. Em condições mais práticas, Eça e Hoekstra ${ }^{[95]}$ demonstraram 
que quando o erro de iteração é de duas a três ordens de grandeza menor do que o erro de discretização ele pode ser desprezado. O problema é que o erro de discretização não é conhecido a priori, impossibilitando determinar do erro de iteração.

Quando a simulação apresenta uma convergência oscilatória ao invés de uma convergência monotônica decrescente, devido a grandes instabilidades do escoamento ou uma fraca discretização da malha, é preciso tomar mais cuidado com o erro de iteração. Nestes casos, além destas incertezas serem consideradas no cálculo da incerteza total ${ }^{[114]}$, ela pode prejudicar o cálculo da incerteza de discretização ${ }^{[36]}$, como será explicado mais a frente.

Como comentado na seção 3.3, o objetivo de todas as simulações foi reduzir o erro iterativo dos esforços monitorados para ordens de grandezas próximas ao erro de arredondamento, para que seu efeito possa ser negligenciado. Em casos que esta ordem não foi alcançada, devido a complexidade do modelo numérico ou escoamento encontrado na simulação, a incerteza numérica $\left(U_{\text {num }}\right)$ pode ser calculado pela raiz quadrada da soma das incertezas de iteração $\left(U_{i t}\right)$ e discretização $\left(U_{\text {dis }}\right)$ ao quadrado,

$$
U_{\text {num }}=\sqrt{U_{i t}^{2}+U_{d i s}^{2}} \text {. }
$$

A incerteza de iteração oscilatória pode ser estimada pela equação $(3.17)^{[114]}$, onde $S_{U}$ é o valor superior e $S_{L}$ é o valor inferior de oscilação, como visto na figura 10.

$$
U_{i t}=\left|\frac{1}{2}\left(S_{U}-S_{L}\right)\right|
$$

Contudo, deve ser tomado cuidado com o uso desta equação, pois caso esta oscilação ocorra para baixos níveis de convergência dos resíduos, a solução pode estar muito longe da solução correta, representando uma falsa estimativa para a incerteza de iteração e para as soluções das grandezas observadas. Em outras palavras, a equação (3.17) somente deve ser utilizada quando a análise de convergência dos resíduos indicar que um bom nível de convergência.

Por último, o erro de discretização é definido pelo erro entre a solução obtida e a solução que seria obtida por uma malha com "refino infinito" (contínua). Apesar de ser impossível realizar uma simulação com uma "malha infinita", é bem aceito na literatura $^{[114,33,35]}$ que o resultado para esta suposta malha possa ser obtido utilizando um método de extrapolação, de preferência o método de extrapolação de Richardson (RE, de Richarson extrapolation) ${ }^{[33]}$ com o índice de convergência de malha (conhecido por CGI, sigla para grid convergence index ${ }^{[112]}$ aplicado a uma função potencial, que têm seus parâmetros definidos pelos resultados de outras simulações.

Seguindo esta metodologia, o cálculo do erro de discretização deve ser estimado pela extrapolação de uma função exponencial com parâmetros desconhecidos, que tem 


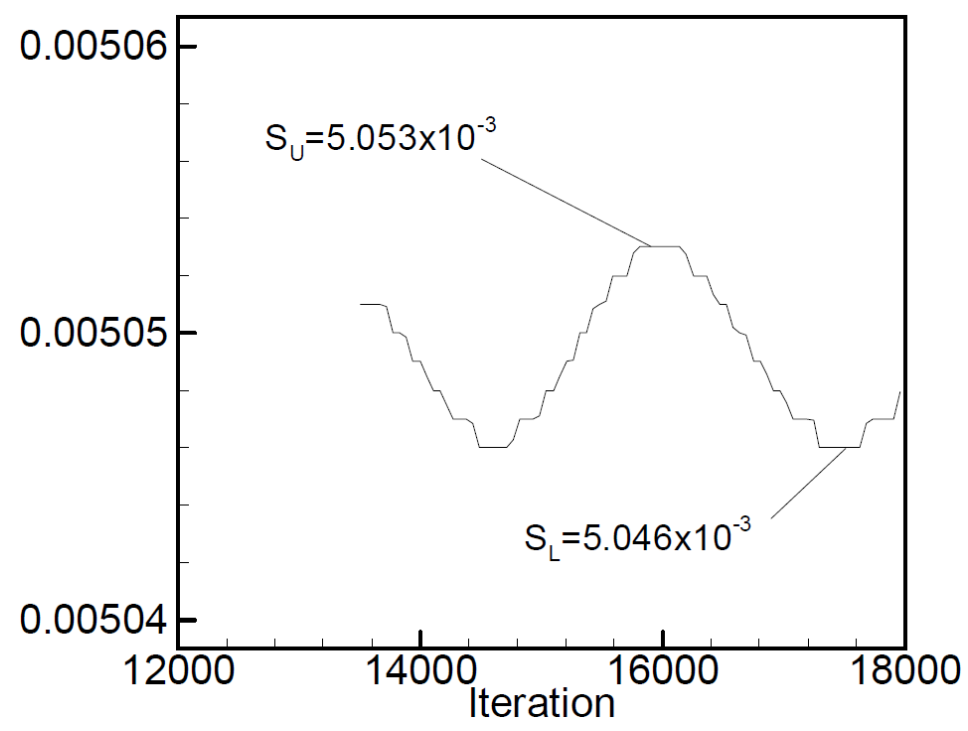

Figura 10 - Exemplo de um histórico de iteração com comportamento oscilante, detalhando os valores superiores e inferiores utilizados para o calculo de incerteza de iteração (figura adaptada de Stern et al. ${ }^{[14]}$ ).

como variável dependente algum parâmetro de discretização de malha, e como variável independente algum resultado integral de interesse da simulação, como forças (integral da pressão pela superfície). Contudo, para realizar esta extrapolação é preciso primeiro identificar os parâmetros da função exponencial, que somente podem ser estimados utilizando os resultados de diversas simulações com diferentes graus de refinamento.

Assumindo, que a análise está sendo realizada na "região assintótica", na qual os resultados estimados pelas simulações apresentam um comportamento monotônico convergente em função do parâmetro de discretização de malha, o erro de discretização $\left(\epsilon_{n}\right)$ pode ser estimado pela seguinte função:

$$
\epsilon_{n} \approx \delta_{R E}=\phi_{i}-\phi_{0}=\alpha h_{i}^{p}
$$

onde, $\phi_{i}$ é algum resultado obtido pela integração de alguma grandeza da simulação, $\phi_{0}$ é a extrapolação do mesmo resultado para uma malha de "refino infinito" (com erro de discretização nulo), $h_{i}$ é o tamanho típico da malha, $\alpha$ é uma constante e $p$ é a ordem de acurácia observada, que teoricamente seria igual a $2^{[36]}$.

O tamanho típico de malha $\left(h_{i}\right)$ é um parâmetro que deve ser definido em função das características das malhas. Para que ele seja definido corretamente, todas as malhas analisadas devem apresentar estruturas, razões de refino e distribuições similares, independentes do refino de malha utilizado. Em casos simples, cujas as malhas sejam estruturadas, a geração de malhas é um processo relativamente simples, mas em casos de geometrias complexas, como um AUV, a geração das malhas refinadas devem ser realizadas de forma bastante cuidadosa, pois pequenas desvios na determinação de $h_{i}$ podem causar grandes erros de extrapolação ${ }^{[35]}$. 
Para malhas estruturadas, a ASME ${ }^{[33]}$ recomenda que o parâmetro $h_{i}$ seja calculado por uma média geométrica (quadrática para malhas bi-dimensionais, e cúbicas para malhas tri-dimensionais) das maiores dimensões dos elementos (equação 3.19, para malhas tridimensionais cartesianas),

$$
h=\left[\left(\Delta x_{\max }\right)\left(\Delta y_{\max }\right)\left(\Delta z_{\max }\right)\right]^{1 / 3} .
$$

E para malhas não estruturadas tri-dimensionais, o parâmetro $h_{i}$ pode ser definido como a raiz cúbica da média da soma do volume dos $N$ elementos da simulação $(\Delta V)$,

$$
h=\left[\left(\sum_{i=1}^{N} \Delta V_{i}\right) / N\right]^{1 / 3} .
$$

Contudo, para simulações de escoamentos em que a modelagem da camada limite é bastante importante, como no caso de escoamentos externos, Eça, Vaz e Hoekstra ${ }^{[35]}$ recomendam que seja utilizado o valor de $h_{i}$ como sendo igual a espessura do elemento próximo a parede do corpo, devido a sua relação ao parâmetros $y^{+}$que define diversas propriedades dos parâmetros de turbulência (visto na seção 3.4.1).

Para determinar o valor de $h_{i}$ entre diferentes malhas de um mesmo estudo, a razão entre os $h_{i}$ 's consecutivos, ou fator de refino de malha $\left(r_{i+1 / i}=h_{\text {grossa }} / h_{f i n a}=h_{i+1} / h_{i}\right)$, devem ser mantidos constantes. Para casos práticos, é recomendado que este fator seja maior do que $1.3^{[33]}$, sendo um valor de 1.4 , ou $\sqrt{2}$ bem aceito e utilizado na literatura ${ }^{[35,35]}$. Apesar de ser altamente recomendável que a razão de refino seja mantida constante em todas as dimensões da malha ${ }^{[33]}$, as malhas que apresentam razões dimensionais distintas (e.g., $r_{x} \neq r_{y}$ ) também apresentam uma boa convergência, mas tendem a apresentar valores maiores para a ordem de grandezas de convergência $(p)^{[119]}$. Neste trabalho, todas as simulações foram realizadas com ordens distintas, devido ao custo computacional envolvido em considerar uma razão igual em todas as dimensões.

O cálculo do valor integral de extrapolação $\phi_{0}$ é calculado de maneira distinta na metodologia da $\mathrm{ASME}^{[33]}$ e no procedimento apresentado por Eça, Vaz e Hoekstra ${ }^{[35]}$.

A metodologia da $\mathrm{ASME}^{[33]}$ realiza este cálculo ao aplicar a $\mathrm{RE}$ com os dados de três simulações $\left(\phi_{1}, \phi_{2}\right.$ e $\phi_{3}$, sendo o índice 1 referente a malha de maior refino e o 3 para a de menor) para estimar todos os parâmetros da equação de extrapolação,

$$
\phi_{0}=\left(r_{2 / 1}^{p} \phi_{1}-\phi_{2}\right) /\left(r_{2 / 1}^{p}-1\right)
$$

Os parâmetros desta equação são calculados pela resolução iterativa das equações 3.22 a 3.24, usando como valor inicial $q=0$. Os termos $\epsilon_{3 / 2}=\phi_{3}-\phi_{2}$ e $\epsilon_{2 / 1}=\phi_{2}-\phi_{1}$ são as diferenças entre os valores integrais de simulações de refino consecutivo.

$$
p=\left[1 / \ln \left(r_{2 / 1}\right)\right]\left[\ln \left|\epsilon_{3 / 2} / \epsilon_{2 / 1}\right|+q(p)\right]
$$




$$
\begin{aligned}
& q(p)=\ln \left(\frac{r_{2 / 1}^{p}-s}{r_{3 / 2}^{p}-s}\right) \\
& s=1 \cdot \operatorname{sign}\left(\epsilon_{3 / 2} / \epsilon_{2 / 1}\right)
\end{aligned}
$$

Aplicando este método apenas em um conjunto de três malhas não é possível demonstrar que o valor de $p$ é constante, provando a convergência do estudo de verificação. Para resolver este problema o método da $\mathrm{ASME}^{[33]}$ recomenda utilizar pelo menos mais uma malha para verificar o comportamento de $p$. Contudo, em casos onde os resultados não apresentam um bom comportamento (i.e. os valores de $p$ variam muito), como quando existem problemas nas gerações das malhas refinadas (ruído de malha), um erro de iteração e/ou arredondamento maior que o esperado, um pós-processamento ruim de $\phi_{i}$, ou ainda pelas soluções não estarem na região assintótica ${ }^{[35]}$, pode ser necessário utilizar ainda mais malhas ${ }^{[33]}$, e mesmo assim a convergência monotônica poderá não ser demonstrada devido a sensibilidade inerente de uma função exponencial.

Para estes casos é recomendável utilizar métodos de regressão robusta não linear baseado no método dos mínimos quadrados, desenvolvidos por Eça e Hoekstra (ver por exemplo $[95,35,36])$. Com esta metodologia os parâmetros da equação $3.18, \phi_{0}, p$ e $\alpha$, são obtidos em função do tamanho típico de malha $\left(h_{i}\right)$ e o valor integral observado $\left(\phi_{i}\right)$ de pelo menos quatro malhas diferentes (caso se conheça a ordem da discretização este número pode ser reduzido para três ${ }^{[35]}$, utilizando um método de regressão por mínimos quadrados não linear, onde o erro quadrático entre a função obtida com os resultados observados são minimizados.

Por utilizar um método de regressão pelos mínimos quadrados, esta metodologia apresenta uma menor sensividade a um fraco comportamento da análise de sensibilidade, pois dados espúrios acabam por ser filtrados pelos mínimos quadrados. Além disso ao se aumentar o número de malhas investigadas, a solução tende a melhorar a sua predição, pois diferente do método da $\mathrm{ASME}^{[33]}$, a adição de casos contribuí com a estimação final e não para comprovar a convergência do estudo de verificação.

Para os casos em que a análise de convergência da discretização não apresenta comportamento monotônico convergente, a RE, e consequentemente a metodologia da $\mathrm{ASME}^{[33]}$, não pode ser aplicada. Para estes casos, Eça, Vaz e Hoekstra ${ }^{[36]}$ apresentou três funções alternativas para a estimação do erro de discretização, que seus usos dependem do comportamento de discretização observado e do valor de $p$ obtido.

Estas funções são reproduzidas nas equações 3.25, 3.26 e 3.28, em que a suposta ordem de acurácia é igual a teórica $(p=2)$. Nestas equações os termos $\alpha_{02}, \alpha_{11}$ e $\alpha_{12}$ são constantes determinadas pelo métodos dos mínimos quadrados juntamente com os erros $\delta_{R E}^{02}$ e $\delta_{R E}^{12}, n_{g}$ é o número de malhas analisadas e $\Delta_{M}$ é o maior intervalo de dados obtidos 
(equação 3.28).

$$
\begin{gathered}
\delta_{R E}^{02}=\phi_{i}-\phi_{0}=\alpha_{02} h_{i}^{2} \\
\delta_{R E}^{12}=\phi_{i}-\phi_{0}=\alpha_{11} h_{i}+\alpha_{12} h_{i}^{2} \\
\delta_{\Delta_{M}}=\frac{\Delta_{M}}{\left(\frac{h_{n_{g}}}{h_{1}}\right)-1} \\
\Delta_{M}=\max \left(\mid \phi_{i}-\phi_{j}\right) \mid \quad 1 \geq i, \quad j \geq n_{g}
\end{gathered}
$$

Utilizando a aproximação proposta por Roache ${ }^{[112]}$, a incerteza numérica é estimada pela multiplicação do erro de discretização por um fator de segurança, $F_{s}$, ou seja:

$$
U_{\phi}=F_{s}|\epsilon|
$$

O valor para o fator de segurança é determinado segundo as condições estabelecidas pelo modelo do CGI ${ }^{[12]}: F_{s}=1.25$ se o comportamento de $p$ estiver razoavelmente próximo de do valor teórico ou do valor unitário $(0.95 \leq p \leq 2.05)$, e $F_{s}=3$ se não for o caso.

Para determinar o modelo de estimação de erro mais apropriado, é preciso determinar a condição aparente de convergência. Segundo Eça, Vaz e Hoekstra ${ }^{[36]}$ :

- Convergência monotônica: no caso que o comportamento da análise de discretização seja bem reproduzida pela função da equação 3.18, ou seja, o coeficiente de determinação $\left(R^{2}\right.$ ou $\left.R 2\right)$ da regressão por mínimos quadrados não deve apresentar um valor muito baixo, indicando que os coeficientes encontrados não representam fielmente os dados de análise.

- Convergência oscilatória: no caso que as soluções tenham um comportamento oscilatório, com as soluções apresentando valores que se alternam em relação a média, matematicamente: $\left(\phi_{i+1}-\phi_{i}\right)\left(\phi_{i}-\phi_{i-1}\right)<0$. Neste caso, é recomendado utilizar um número de casos maior que a solução monotônica, para realmente verificar se o comportamento é oscilatório ou a oscilação é devido um ruído numérico.

- Comportamento anormal: caso o comportamento observado não seja descrito pelos casos anteriores. Neste caso também recomenda-se analisar mais casos, para tentar observar algum comportamento semelhante aos outros casos.

Por último, a incerteza de discretização é determinada de acordo com o comportamento observado ${ }^{[36]}$, já incluindo a definição do fator de segurança:

- Convergência monotônica: 
$-0.95 \leq p \leq 2.05$ :

$$
U_{d i s}=1.25 \delta_{R E}+U_{s}
$$

$-p \leq 0.95:$

$$
U_{d i s}=\min \left(1.25 \delta_{R E}+U_{s}, 3 \delta_{R E}^{12}+U_{s}^{12}\right)
$$

$-p \geq 2.05$ :

$$
U_{d i s}=\max \left(1.25 \delta_{R E}+U_{s}, 3 \delta_{R E}^{02}+U_{s}^{02}\right)
$$

- Convergência oscilatória:

$$
U_{d i s}=3 \delta_{\Delta_{M}}
$$

- Comportamento anormal:

$$
U_{d i s}=\min \left(3 \delta_{\Delta_{M}}, 3 \delta_{R E}^{12}+U_{s}^{12}\right)
$$

Em todas as definições de incertezas de discretização $\left(U_{i t}\right)$, as incertezas $U_{s}, U_{s}^{02}$ e $U_{s}^{12}$ representam as incertezas do processo de regressão pelo métodos dos mínimos quadrados, calculadas para um intervalo de confiança de predição de função simultânea igual as das demais incertezas (95\%).

\subsubsection{Procedimento de validação}

O procedimento de validação tem como principal objetivo investigar se os modelos numéricos/matemáticos conseguem estimar os resultados experimentais com uma incerteza satisfatória para o problema investigado. Este procedimento é realizado considerando tanto as incertezas numéricas $\left(U_{\text {num }}\right)$, experimentais $\left(U_{\text {exp }}\right)$ e paramétricas $\left(U_{\text {par }}\right)$. As incertezas paramétricas representam as incertezas encontradas nos resultados numéricos devido às incertezas de medição dos próprios parâmetros do modelo numérico, como por exemplo as propriedades do fluido, a geometria do modelo e as grandezas adotadas nas condições de contorno.

Um procedimento para combinar todas estas incertezas e analisar os seus significados, foi proposto pela ASME ${ }^{[33]}$. Neste procedimento é preciso realizar o cálculo da incerteza de validação $\left(U_{v a l}\right)$,

$$
U_{\text {val }}=\sqrt{U_{\text {num }}^{2}+U_{e x p}^{2}+U_{p a r}^{2}},
$$

e o erro de validação de comparação $(E)$,

$$
E=S-D
$$

sendo $S$ o valor predito numericamente (apresentado como $\phi_{i}$ na seção anterior) e $D$ o valor medido experimentalmente. Uma definição destes valores pode ser visto na figura 11. 


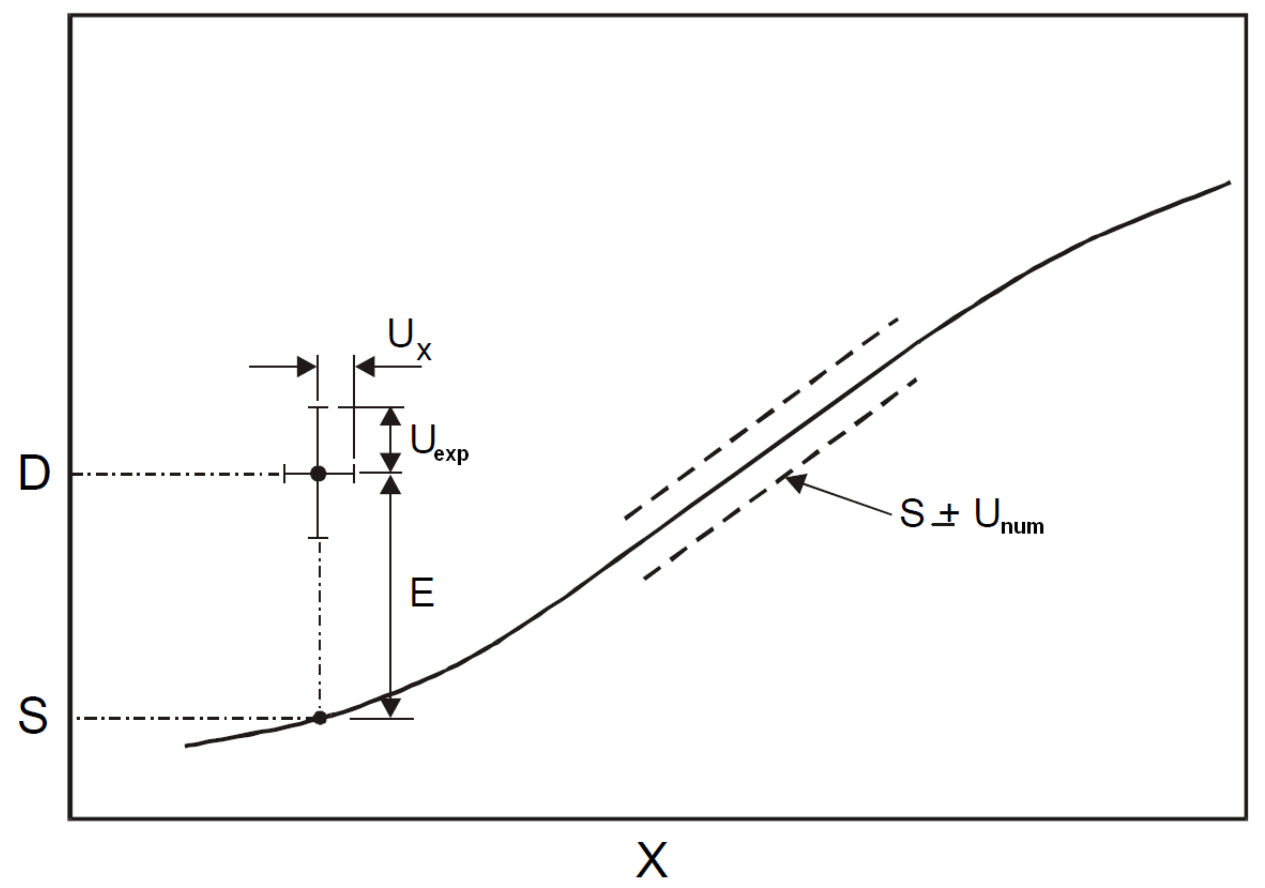

Figura 11 - Definição do erro de validação de comparação $(E)$ (figura adaptada de Stern et al. $\left.{ }^{[14]}\right)$.

O objetivo deste procedimento ${ }^{[33]}$ é determinar o intervalo que contêm o erro de modelagem com $95 \%$ de confiança, ou seja, $\left[E-U_{v a l}, E+U_{v a l}\right]$. Com as incertezas e erros obtidos, as conclusões sobre a qualidade dos modelos numéricos podem ser obtidas ao se comparar $|E| \operatorname{com} U_{\text {val }}$.

Se o erro de comparação for muito maior que a incerteza de validação $\left(|E|>>U_{v a l}\right)$, pode-se concluir que o erro de comparação é dominado pelo erro de modelagem, o que indica que o modelo numérico utilizado deve ser melhorado.

No caso da comparação ser menor que a incerteza de validação $\left(|E|<U_{v a l}\right)$, o erro de modelagem está dentro do 'nível de ruído' imposto pelas incertezas, numéricas, experimentais e paramétricas. Isto pode significar duas coisas: Se $E$ for considerado suficientemente pequeno, o modelo numérico e a solução experimental podem ser considerados validados, com a precisão dada por $U_{v a l}$; No caso contrário, a qualidade da solução numérica e/ou da metodologia experimental devem ser melhoradas, antes que conclusões sobre a adequação do modelo numérico possam ser feitas. 



\section{DESENVOLVIMENTO DO MODELO DE MANOBRA DE UM AUV}

O modelo de manobra de um veículo pode ser considerado como um ferramenta matemática e/ou numérica utilizada para representar o seu movimento, devido a entradas de controle ou perturbações do ambiente. Na área oceânica e naval, estes modelos são exaustivamente utilizados no desenvolvimento de diversos tipos de veículos e embarcações, servindo para analisar a manobrabilidade ${ }^{[52]}$, otimizar o desempenho, ajustar o sistema de piloto automático ${ }^{[53,120,54]}$, verificar o algorítimo de navegação ou guiamento, entre outras atividades.

Os primeiros modelos de manobras amplamente aplicados na indústria naval, sendo ainda bastante utilizados nos dias de hoje $\mathrm{e}^{[13,14,15,16]}$, são aqueles em que os esforços hidrodinâmicos são representados pela somatória de uma série de potências das variáveis de estado ${ }^{[11,12]}$, tendo uma estrutura bastante similar a de uma série de Taylor de diversas variáveis. Nestes modelos, consegue-se atribuir significado físico, com relativa facilidade, até os termos de segunda ordem, atribuindo-se, comumente, ajustes para se lidar com efeitos viscosos aos termos de ordem superior, que possuem menor magnitude.

A popularidade deste tipo de formulação está relacionada à simplicidade matemática de implementação do modelo de manobra, e pelos seus termos terem relação bastante direta e simples com as medições dos mesmos esforços em ensaios de tanque de provas. A desvantagem deste tipo de estrutura está na fraca representatividade dos esforços não lineares e de acoplamento entre as diferentes variáveis de estado, pois uma formulação potencial somente consegue representar estes tipos de esforços com coeficientes de alta ordem, que são em geral muito difíceis de se obter. Uma breve introdução a estes modelos para o caso específico do AUV Pirajuba é apresentada na seção 4.1.

Estes tipos de esforços podem ser melhor representados por funções analíticas e semiempíricas (ASE), que utilizam modelos matemáticos embasados na física dos fenômenos fluidodinâmicos para estimar os esforços hidrodinâmicos de alguns tipos de veículos. Este tipo de modelo surgiu na indústria aeronáutica ${ }^{[121,122,42,43]}$, particularmente na área de mísseis, devido a necessidade em modelar os esforços aerodinâmicos para ângulos de incidência e taxas de rotação.

O problema deste tipo de modelo está no procedimento de cálculo dos diversos termos destas funções, que podem apresentar uma fraca aderência aos esforços medidos experimentalmente, devido a dificuldade de modelar certos fenômenos fluidodinâmicos de alta complexidade. Nos trabalhos de Barros et al. ${ }^{[20]}$, Barros e Dantas ${ }^{[28]}$ e Jeans et al. ${ }^{[22]}$, 
esta deficiência pôde ser reduzida ao corrigir os parâmetros destes modelos e adicionar outros, através de informações e observações retiradas das predições numéricas de CFD do escoamento em torno do veículo. Este tipo de correção possibilitou melhorar a capacidade de predição dos modelos ASE ao incluir efeitos hidrodinâmicos que não eram considerados em suas formulações, principalmente nas regiões de predições não lineares, que ocorrem devido a altos ângulo de incidência e/ou taxa de rotação

Contudo, mesmo com as correções propostas, a predição dos modelos fica limitada às suas estruturas básicas, que são desenvolvidas a partir de suposições iniciais das condições do escoamento sobre o veículo, que muitas vezes não se sustentam frente à realidade durante a sua operação. Para estes casos foi desenvolvido o modelo de manobra baseado nas simulações numéricas de CFD, que utiliza os resultados de simulações quasi-estáticas para estimar os esforços hidrodinâmicos para qualquer condição do envelope de operação do AUV Pirajuba.

Por ser um modelo puramente numérico, ele não fica restrito as estruturas matemáticas dos outros dois tipos de modelos, possibilitando estimar qualquer fenômeno hidrodinâmico que possa ser representado pelas simulações de CFD. A desvantagem desta metodologia está nos custos computacionais das próprias simulações, que, mesmo não sendo transientes, necessitam de um longo período de tempo para gerar os resultados necessários para construir o modelo de manobra.

Mesmo com o alto custo das simulações numéricas, devido ao tempo de simulação e a compra/aluguel dos softwares, o modelo de manobra de CFD apresenta um custo bem menor em relação aos modelos de manobras que utilizam resultados experimentais, em que devem ser considerados os custos referentes a fabricação dos modelos, o aluguel do tanque de provas e as análises dos próprios resultados medidos ${ }^{[86,123,21,124,39,31]}$. Em termos de custos totais, o modelo puramente numérico se encontra no meio termo em relação aos modelos oriundos de ensaios e aqueles que dependem das formulações ASE, se tornando uma ótima solução quando considerado os bons resultados que as simulações de CFD vem apresentando ao longo dos anos ${ }^{[19,20,44,21,22,26,27,28,29,24,30,31]}$.

O modelo de manobra baseado nas simulações numéricas quasi-estáticas desenvolvido nesta tese será apresentado na seção 4.3. Este modelo utilizará simulações do AUV Pirajuba realizadas com as metodologias apresentadas na seção 3, onde o modelo de manobra em um plano será obtido em função da velocidade angular e do ângulo de inclinação do veículo em relação ao escoamento, e da deflexão das superfícies de controle em relação ao casco do veículo. Apesar do modelo de manobra ser apresentado neste capítulo, o resultado da estimativa dos esforços hidrodinâmicos e a sua validação em relação aos ensaios experimentais serão apresentados posteriormente na seção 6 .

Com o objetivo de melhor entender os mecanismos de geração dos esforços hidrodinâmicos do modelo baseado nas simulações de CFD, na seção 4.2 será apresentada 
uma metodologia de desenvolvimento de um modelo de manobra baseado nos métodos ASE. O desenvolvimento deste método também permitirá uma análise mais detalhada dos efeitos da interferência entre os apêndices e o casco do veículo na geração dos esforços hidrodinâmicos, além de melhor entender os efeitos conjuntos entre as diversas variáveis de estado.

No caso particular deste trabalho, o modelo de manobra ASE será desenvolvido por uma metodologia baseada na adaptação dos trabalhos de Barros et al.; Barros e $\operatorname{Dantas}^{[20,28]}$ e Barros e Dantas ${ }^{[125]}$, no qual os esforços hidrodinâmicos são preditos por funções oriundas de modelos aerodinâmicos ${ }^{[121,122,126]}$ e hidrodinâmicos ${ }^{[68]}$ já consagrados na literatura, com os seus parâmetros adaptados em função dos resultados das simulações de CFD. O uso de uma metodologia híbrida, com uma capacidade de predição melhorada em relação aos modelos tradicionais, permite que análise do modelo de manobra não apresente grandes erros causados pela fraca estimativa dos esforços hidrodinâmicos, focando a análise na interpretação dos efeitos das variáveis de estado no próprio modelo de manobra.

\subsection{MODELO BASEADO NAS SÉRIES DE TAYLOR}

Os modelos baseados na representação dos esforços hidrodinâmicos por funções de séries de Taylor podem ser definidos como modelos tradicionais, devido a sua simplicidade e boas características de predição que este tipo de metodologia apresenta na predição de manobras de embarcações navais de superfície ${ }^{[83,84]}$ e submersas $^{[13,14,15,16]}$.

Este tipo de modelo surgiu na indústria naval para realizar a predição do movimento de navios e outros tipos de embarcações de superfície, sendo posteriormente aplicados a veículos submarinos. Este tipo de estrutura foi escolhido por apresentar uma relação direta às análises dos resultados dos ensaios dinâmicos ${ }^{[86,123]}$ e estáticos ${ }^{[21,124,39]}$ de tanque de provas com modelos cativos, que também são obtidos por coeficientes de diversas ordens de uma série de Taylor.

Apesar de não ser o primeiro trabalho que apresentou/publicou este tipo de modelo de manobra, o trabalho de Gertler e Hagen ${ }^{[11]}$ padronizou as notações e as estruturas de equações para submarinos, além de apresentar o modelo completo de seis graus de liberdade para este tipo de veículo. Com o passar dos anos, este tipo de modelo sofreu diversas alterações para poder incorporar outros tipos de efeitos hidrodinâmicos, oriundos tanto de fenômenos hidrodinâmicos que foram descobertos quanto dos novos formatos de veículos desenvolvidos.

Como exemplo, pode-se citar o trabalho de Feldman ${ }^{[12]}$, que além de simplificar o modelo de Gertler e Hagen ${ }^{[11]}$, retirando termos da série dos esforços que eram pouco significativos para as análises de manobra, incluiu os efeitos dos vórtices gerados pela vela no casco do submarino e os efeitos de escala entre o modelo e o veículo real nos esforços 
hidrodinâmicos. Posteriormente, Bohlmann ${ }^{[13]}$ também propôs modificações deste modelo, ao realizar o cálculo dos coeficientes da série de esforços por métodos ASE.

Atualmente, os modelos de manobra apresentados por estes autores vem sendo aplicados na análise de manobra e definição dos sistemas de piloto automático de AUVs de diversos tipos ${ }^{[14,15,16]}$, apresentando resultados considerados satisfatórios.

Por estes modelos estarem disponíveis na literatura ${ }^{[11,12,13]}$ aberta de forma completa, para os seis graus de liberdade, nesta seção apenas serão apresentados o modelo simplificado para o caso do AUV Pirajuba. Em outras palavras, será aplicado o mesmo procedimento da seção 2.2.5, onde é considerado a simetria do veículo e que os esforços no plano horizontal e longitudinal somente dependem das variáveis contidas em seus respectivos planos.

Nestes modelos cada tipo de esforço é representado por uma série de Taylor, cujos termos são derivados em função das variáveis de estado e das deflexões das superfícies de controle. No caso de veículos submarinos, normalmente são consideradas séries com termos de até segunda ordem com derivadas mistas, já no caso de navios podem ser considerados termos de até terceira ordem.

Para simplificar a notação, a derivada primeira de um esforço $F$ por uma variável $h$ é representada pelo símbolo da força com a variável como subscrito,

$$
F_{h}=\frac{\partial F}{\partial h},
$$

enquanto que, para a derivada de segunda ordem, são utilizados dois subscritos iguais

$$
F_{h h}=\frac{\partial^{2} F}{\partial h^{2}}
$$

Também é adotado que os termos da série, chamados de coeficientes, são adimensionalizados seguindo o padrão de $\mathrm{SNAME}^{[61]}$, sendo divididos pela metade da densidade $\rho$, uma potência do comprimento do veículo $(L)$ e uma potencia do módulo da velocidade do veículo $(U)$. De forma genérica, está adimensionalização pode ser representada por

$$
F_{h}^{\prime}=\frac{F_{h}}{1 / 2 \cdot \rho \cdot L^{n} \cdot U^{m}},
$$

onde $n$ e $m$ são escolhidos de acordo com a variável relativa ao coeficiente.

Utilizando estas notações e simplificações, o modelo de Gertler e Hagen ${ }^{[11]}$ fica reduzido a (4.4) para a força longitudinal, (4.5) para a força lateral, (4.6) para o momento de rolagem, e (4.7) para o momento de guinada.

$$
\begin{aligned}
X & =\frac{\rho}{2} L^{4}\left[X_{q q}^{\prime} q^{2}+X_{r r}^{\prime} r^{2}\right]+\frac{\rho}{2} L^{3}\left[X_{v r}^{\prime} v r+X_{w q}^{\prime} w q\right] \\
& +\frac{\rho}{2} L^{2}\left[X_{u u}^{\prime} u^{2}+X_{v v}^{\prime} v^{2}+X_{w w}^{\prime} w w^{2}+X_{\delta_{r} \delta_{r}}^{\prime} u^{2} \delta_{r}^{2}+X_{\delta_{s} \delta_{s}}^{\prime} u^{2} \delta_{s}^{2}\right]
\end{aligned}
$$




$$
\begin{gathered}
Y=\frac{\rho}{2} L^{3}\left[Y_{r}^{\prime} u r+Y_{|r| \delta_{r}}^{\prime} u|r| \delta_{r}+Y_{v|r|}^{\prime} v|r|\right] \\
+\frac{\rho}{2} L^{2}\left[Y_{u}^{\prime} u^{2}+Y_{v}^{\prime} u v+Y_{v|v|}^{\prime} v|v|+Y_{\delta_{r}}^{\prime} \delta_{r} u^{2}\right] \\
K=\frac{\rho}{2} L^{5}\left[K_{p|p|}^{\prime} p|p|\right]+\frac{\rho}{2} L^{4}\left[K_{p}^{\prime} u p\right] \\
N=\frac{\rho}{2} L^{5}\left[N_{r|r|}^{\prime} r|r|\right] \\
+\frac{\rho}{2} L^{4}\left[N_{w r}^{\prime} w r+N_{r}^{\prime} u r+N_{|r| \delta_{r}}^{\prime} u|r| \delta_{r}+N_{|v| r \mid}^{\prime}|v| r\right] \\
+\frac{\rho}{2} L^{3}\left[N_{u}^{\prime} u^{2}+N_{v}^{\prime} u v+N_{v|v|}^{\prime} v|v|+N_{\delta_{r}}^{\prime} \delta_{r} u^{2}\right]
\end{gathered}
$$

Nota-se, que as equações para força vertical e momento de arfagem não foram apresentados por elas serem idênticas às equações (4.5) e (4.7), ao trocar as variáveis do plano lateral pelas variáveis do plano vertical, i.e., $v, r$ e $\delta_{r}$ por $w, q$ e $\delta_{s}$.

\subsection{MODELO BASEADO NAS FUNÇÕES ANALÍTICAS E SEMI- EMPÍRICAS}

Os métodos analíticos e semi-empíricos (ASE) são largamente utilizados na estimativa de parâmetros hidrodinâmicos de veículos navais ${ }^{[68]}$ e submarinos ${ }^{[20,44,28,57,58]}$, e dos parâmetros aerodinâmicos de aeronaves e mísseis ${ }^{[122,126]}$. Isto porque esses métodos possuem um alto grau de desenvolvimento na teoria fluidodinâmica, gerando resultados bastante satisfatórios a um custo consideravelmente baixo quando comparados aos métodos numéricos, que em muitos casos precisam de um alto poder computacional, i.e. diversas simulações por longos períodos, para obter os mesmos tipos de resultados ${ }^{[17,18,32,85]}$.

Por possuir um custo computacional bastante reduzido, os métodos ASE são muito utilizados em aplicações que devem ser realizadas inúmeras estimativas dos esforços hidrodinâmicos, de maneira rápida e simples. Por exemplo, estes métodos são aplicados na etapa de desenvolvimento conceitual ou preliminar de veículos marinhos ${ }^{[68]}$, onde é preciso verificar tanto a viabilidade do projeto quanto realizar adaptações na sua hidrodinâmica para se melhor adequar aos demais subsistemas (espiral de projeto), como estruturas ou estabilidade.

$\mathrm{Na}$ área de controle também destaca-se o uso de métodos $\mathrm{ASE}^{[127,128]}$. Neste caso, o projetista precisa conhecer tanto a planta do sistema linearizada, para desenvolver a sua arquitetura de controle, quanto o sistema não-linear para testar se seu controle funciona adequadamente, ou verificar se o próprio sistema não consegue atender os requisitos de projeto $^{[53,54]}$.

Em simulações "Hardware-in-the-Loop" (HIL), simulações que verificam o comportamento hardware e software do sistema embarcado do veículo em função de sua 
dinâmica ${ }^{[129,130]}$, é necessária uma operação em tempo real sincronizada com os sistemas embarcados. Neste caso também é recomendado o uso de métodos $\mathrm{ASE}^{[51]}$, pois em operações de tempo real é preciso calcular os esforços atuantes no veículo diversas vezes por segundo (50 à 200 vezes por segundo), e com o uso de métodos ASE isto pode ser obtido facilmente em computadores pessoais (PC).

Os métodos ASE também são utilizados em problemas de otimização da geometria de um AUV para diversas condições de operação ${ }^{[131]}$. Neste caso, os métodos ASE aumentam a "eficiência computacional" da otimização, pois a cada passo da otimização é necessário calcular os esforços hidrodinâmicos de veículos com geometrias modificadas.

Apesar das vantagens no uso dos métodos ASE, é necessário verificar se a natureza física dos fenômenos envolvidos e as hipóteses adotadas no seu desenvolvimento são compatíveis com as características geométricas do veículo, e.g., corpos esbeltos, e as condições do escoamento geradas pelos movimentos realizados e pelas condições do ambiente. Como por exemplo, os coeficientes hidrodinâmicos de submarinos e AUVs são modificados quando os mesmos estão próximos da superfície, devido ao efeito da superfície livre ${ }^{[83]}$.

Considerando as capacidades dos métodos ASE, nesta seção serão apresentados os modelos ASE para o cálculo dos esforços hidrodinâmicos dinâmicos e estáticos, em que são considerados os efeitos devido a velocidade angular, o ângulo de incidência (ataque e deriva) e a deflexão das superfícies de controle (lemes). Nestes modelos sempre será considerado que o veículo apresenta uma velocidade constante em relação ao fluido.

Os modelos apresentados considerarão de forma isolada e conjunta os efeitos do corpo, das superfícies de controle, e do duto propulsor do AUV, conseguindo analisar os efeitos de interferência entre as diferentes partes.

Para o corpo, a metodologia de análise será baseada no modelo apresentado por Lesieutre, Love e Dillenius ${ }^{[42][43]}$, onde os autores adaptaram os modelos desenvolvidos por Munk $^{[132]}$ e Jorgensen ${ }^{[121]}$ para calcular a distribuição de pressão em corpos esbeltos de seções cilíndricas e elípticas, em função do ângulo de incidência e da velocidade angular.

Contudo, seguindo o exemplo de Barros et al. ${ }^{[20]}$, neste trabalho serão adotadas modificações e inclusões de parâmetros ASE nas equações de cálculo dos esforços hidrodinâmicos em função do ângulo de inclinação e da velocidade de rotação, para melhorar a sua capacidade de predição. No trabalho de Barros et al. ${ }^{[20]}$, foi proposto uma modificação do método de cálculo de esforços hidrodinâmicos de um corpo de revolução de Jorgensen ${ }^{[121]}$, com a inclusão de fatores de descolamento da camada limite ${ }^{[122]}$ e da perda da eficiência do escoamento potencial ${ }^{[133]}$, devido aos vórtices gerados pelo corpo em condições de alto ângulo de incidência ${ }^{[134]}$.

Similar ao corpo, os modelos ASEs para as superfícies de controle (lemes) na presença do casco também serão determinados em função dos efeitos do ângulo de inci- 
dência e do movimento de rotação do fluido em relação ao veículo. Mas neste caso será utilizada a metodologia de ângulo de ataque equivalente ${ }^{[135]}$, onde o ângulo de incidência "enxergado/visto" por um leme será modelado pela composição destes movimentos e da sua própria deflexão (rotação da asa em relação ao corpo do veículo).

A inclusão dos esforços hidrodinâmicos relacionados ao duto propulsor, duto que fica ao redor do hélice, foi realizada ao utilizar o modelo de folio anular apresentada por Morgan e Caster ${ }^{[136]}$. Neste trabalho, este modelo será estendido ao considerar a metodologia de ângulo de ataque equivalente, para considerar os efeitos do ângulo de incidência e da rotação do fluido. A interferência entre o duto propulsor e o corpo será calculada ao considerar a redução da pressão dinâmica no duto devido à esteira gerada pelo corpo do AUV, conforme o modelo proposto por Barros e Dantas ${ }^{[28]}$.

Resumidamente, na seção 4.2.1 será dada uma introdução à representação dos esforços hidrodinâmicos por coeficientes, utilizada na maioria dos modelos ASE, e ao sistema de coordenadas destes esforços; Nas seções 4.2.2 e 4.2.3 serão apresentados os modelos hidrodinâmicos isolados do corpo e das superfícies de controle (leme), respectivamente, enquanto que na seção 4.2.4 é apresentado o modelo de interferência entre ambos os corpos; Na seção 4.2.5, é apresentado o modelo do duto propulsor isolado; e por último, na seção 4.2.6, é apresentado o modelo de interferência entre o corpo e o duto.

\subsubsection{Definição dos Coeficientes Hidrodinâmicos}

Os coeficientes hidrodinâmicos são definidos de maneira a expressar os esforços (forças e momentos) hidrodinâmicos de forma adimensional, de maneira semelhante ao apresentado na seção 4.1. Esta forma é normalmente utilizada para que seja possível realizar comparações quantitativas e qualitativas dos esforços entre diferentes tipos e tamanhos de veículos.

Tanto na indústria naval ${ }^{[61]}$ quanto na indústria aeronáutica ${ }^{[122]}$, os coeficientes de forças e momentos 'genéricos' são definidos segundo as equações

$$
\begin{aligned}
C_{F} & =\frac{F}{1 / 2 \cdot \rho \cdot U_{r e f}^{2} \cdot S_{\text {ref }}} \mathrm{e} \\
C_{M} & =\frac{M}{1 / 2 \cdot \rho \cdot U_{r e f}^{2} \cdot S_{r e f} \cdot L_{r e f}}
\end{aligned}
$$

respectivamente. Onde $F$ e $M$ são forças e momentos dimensionais genéricos, respectivamente, $\rho$ é a densidade do fluido, $U_{\text {ref }}$ é a velocidade de referência (normalmente é dada pelo módulo da velocidade relativa do veículo), $S_{\text {ref }}$ é a área de referência do esforço, e $L_{r e f}$ é o comprimento de referência do esforço.

Neste projeto, será utilizada a mesma nomenclatura adotada pela Sociedade de 
Arquitetos e Engenheiros Navais (SNAME) ${ }^{1[61]}$, pois esta é a mais utilizada pela indústria naval. Nesta norma a área de referência é igual ao comprimento do veículo ao quadrado $\left(S_{r e f}=L^{2}\right)$, enquanto que o volume é igual ao cubo deste comprimento $\left(\nabla_{r e f}=L^{3}\right)$. A nomenclatura dos demais parâmetros também serão baseados no padrão adotado pela SNAME, isto quando existir uma definição.

No caso naval, os coeficientes hidrodinâmicos são expressos no sistema de coordenadas fixo ao corpo, onde $C_{X}, C_{Y}$ e $C_{Z}$ representam os coeficientes das forças nos eixos $x, y$ e $z$, respectivamente. No caso dos momentos são utilizados $C_{K}, C_{M}$ e $C_{N}$, para os coeficientes de momentos de rolagem (roll), arfagem (pitch) e guinada (yaw).

Contudo, como os esforços hidrodinâmicos nos planos horizontal e longitudinal são iguais, devido a simetria do veículo, para o desenvolvimento do modelo ASE será adotada o termo $C_{N}$ e $C_{A}$ para representar o coeficiente de força normal à linha central do corpo, podendo representar tanto $C_{Y}$ quanto $C_{Z}$, e o coeficiente de força axial, que é alinhado a linha central do corpo, i.e., alinha com o eixo $x$.

Diversos dos modelos ASEs apresentados nesta seção foram desenvolvidos pela indústria aeronáutica, que apresenta um sistemas de coordenadas diferente da indústria naval. No caso aeronáutico, as forças são comumente representadas no sistema de coordenadas fixo ao corpo mas com a orientação do fluido, sendo a força perpendicular ao escoamento é chamada de sustentação $\left(F_{L}\right.$, "L" de $L$ ift $)$ e a força paralela de arrasto $\left(F_{D}\right.$, "D" de Drag). O ângulo relativo entre a velocidade do fluído e o veículo é chamado de ângulo de ataque $(\alpha)$, no caso longitudinal, e de deriva $(\beta)$ no caso horizontal, sendo calculados pelas equações (4.10) e (4.11), respectivamente.

$$
\begin{aligned}
& \alpha=\operatorname{atan}(w / u) \\
& \beta=\operatorname{asin}(v / U)
\end{aligned}
$$

A diferença entre as forças normais, axiais, de arrasto e sustentação podem ser vistas na figura 12. E nas equações de (4.12) a (4.15), são apresentadas a relação dos esforços/coeficientes nestes dois sistemas de coordenadas.

$$
\begin{aligned}
& C_{D}=C_{N} \cdot \sin (\alpha)+C_{A} \cdot \cos (\alpha) \\
& C_{L}=-C_{A} \cdot \sin (\alpha)+C_{N} \cdot \cos (\alpha) \\
& C_{A}=-C_{L} \cdot \sin (\alpha)+C_{D} \cdot \cos (\alpha) \\
& C_{N}=C_{D} \cdot \sin (\alpha)+C_{L} \cdot \cos (\alpha)
\end{aligned}
$$

\footnotetext{
$1 \quad$ Society of Naval Architects and Marine Engineers
} 


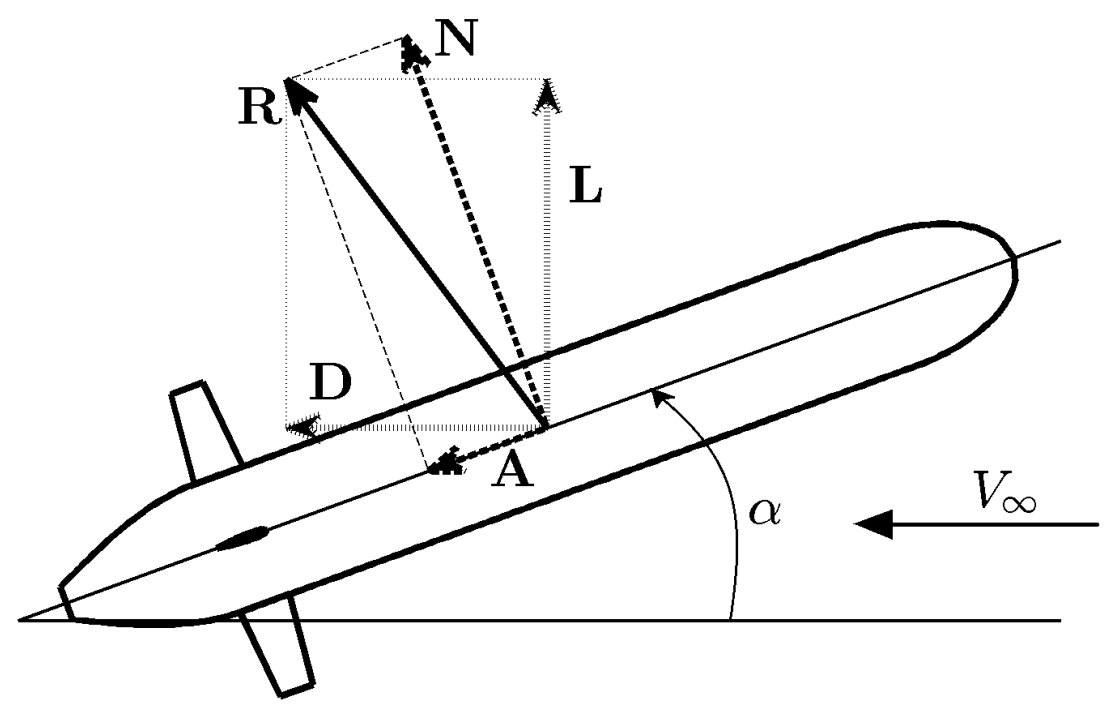

Figura 12 - Definição geométrica das forças longitudinais.

\subsubsection{Corpo Isolado}

Nesta seção, será apresentada a metodologia utilizada para calcular a distribuição de pressão, e consequentemente força normal e momento resultantes, em corpos esbeltos de seções cilíndricas, quando estes possuem um ângulo de inclinação e movimento rotacional em relação ao escoamento, de forma semelhante ao apresentado por Lesieutre, Love e Dillenius; Lesieutre, Love e Dillenius ${ }^{[42,43]}$.

Como já dito, a diferença estará na consideração de fatores semi-empíricos ${ }^{[20]}$, como a inclusão de fatores de descolamento da camada limite ${ }^{[122]}$ e perda da eficiência do escoamento potencial ${ }^{[133]}$ devido aos vórtices gerados pelo corpo em alto ângulo de incidência ${ }^{[134]}$.

Nas próximas sub-seções serão apresentados os principais modelos desenvolvidos para o cálculo dos coeficientes estáticos, considerando efeitos potenciais, viscosos e correções semi-empíricas. Em seguida será apresentado o modelo dinâmico de Lesieutre, Love e Dillenius; Lesieutre, Love e Dillenius ${ }^{[42,43]}$. E por último, a modificação deste modelo para incorporar os demais parâmetro semi-empíricos apresentados, sendo este modelo a proposta final desta seção.

\subsubsection{Modelo Potencial}

Um dos primeiros modelos de cálculo de distribuição de forças em corpos esbeltos é o modelo apresentado por Munk ${ }^{[132]}$. Neste modelo o cálculo da distribuição de pressão em corpos esbeltos é feito pela teoria potencial aplicada em infinitas seções transversais ao corpo do veículo, considerando apenas o efeito de escoamento bidimensional. Como 
resultado, têm-se a equação (4.16), onde $S$ é a área de seção transversal e $x$ é a coordenada longitudinal do corpo.

$$
\frac{\mathrm{d} C_{N}}{\mathrm{~d} x}=\frac{\sin (2 \alpha)}{S_{r e f}} \frac{\mathrm{d} S}{\mathrm{~d} x}
$$

Nota-se que devido a este modelo somente considerar os esforços potenciais, ele prediz que a força normal em um corpo esbelto pontudo é nula, pois a integral de $d S / d x$ este tipo de corpo é zero. Mesmo apresentando esta simplicidade, este modelo foi bastante utilizado como base para o desenvolvimento de diversos modelos de predição de esforços aerodinâmicos e hidrodinâmicos.

Para corrigir os efeitos de escoamento tridimensionais, o autor considerou a inclusão do fator empírico $\left(K_{2}-K_{1}\right)$, atualmente chamado de fator de Munk, onde o termo $K_{1}$ o coeficiente de massa adicional longitudinal e $K_{2}$ o transversal. Este fator corrige o cálculo dos esforços para o caso de corpos com uma baixa razão de comprimento pelo diâmetro $(L / D)$. No entanto Munk desconsiderou este fator no seu modelo final por considerar que como a sua teoria somente deveria ser aplicada em corpos esbeltos (valores altos $L / D$ ) este coeficiente sempre seria próximo de 1, e assim seu efeito pode ser considerado desprezível.

A equação de distribuição do coeficiente de força normal com a inclusão do fator de Munk é dada pela equação

$$
\frac{\mathrm{d} C_{N}}{\mathrm{~d} x}=\left(K_{2}-K_{1}\right) \frac{\sin (2 \alpha)}{S_{r e f}} \frac{\mathrm{d} S(x)}{\mathrm{d} x}
$$

\subsubsection{Modelo Potencial e Viscoso}

No trabalho de Allen e Perkins ${ }^{[137]}$, foi derivada uma solução para a distribuição de pressão em corpos esbeltos de revolução para altos ângulos de ataques (0 à 90), contabilizando tanto os efeitos potencias quanto os viscosos.

A parcela potencial resultante é igual a parcela obtida em Munk ${ }^{[132]}$, com a adição do termo $\cos (\alpha / 2)$. Este termo serve para corrigir a direção da força normal potencial, que deve estar direcionada entre o eixo normal (perpendicular) do veículo e do escoamento, este termo foi descoberto por Ward ${ }^{[138]}$. Já a parcela viscosa deste esforço foi obtido pela inclusão do termo de arrasto cruzado $C_{d_{c}}$ (corretamente direcionado), que contabiliza o arrasto bidimensional das seções circulares, ou seja, este coeficiente de arrasto cruzado é igual ao arrasto de um cilindro infinito quando o escoamento está perpendicular $\left(C_{d_{c}}=C_{d_{\alpha=90^{\circ}}}\right)$. Este coeficiente é obtido em função do número de Reynolds transversal $\left(\operatorname{Re}_{y}=\left(U_{\infty} D\right) / \nu\right)$ e do número de Mach $\left(M_{c}\right)$ do escoamento.

Com a inclusão destes dois termos, Allen e Perkins mostraram que a distribuição 
da força normal em função do comprimento do corpo pode ser estimada pela equação

$$
\frac{\mathrm{d} C_{N}}{\mathrm{~d} x}=\frac{\sin (2 \alpha) \cos (\alpha / 2)}{S_{r e f}} \frac{\mathrm{d} S(x)}{\mathrm{d} x}+\frac{2 \cdot C_{d_{c}} \cdot \sin ^{2}(\alpha)}{S_{r e f}} r(x) .
$$

Uma pequena modificação do modelo de Allen e Perkins foi proposto por Jorgensen ${ }^{[121]}$, onde o termo de arrasto cruzado deve ser corrigido (pelo fator $\eta$ ) para contabilizar o arrasto de um cilindro finito ao invés de um infinito, de maneira similar ao fator de Munk para a parcela potencial, que também é dado em função da razão de esbelteza do corpo. O modelo proposto por Jorgensen é dado por

$$
\frac{\mathrm{d} C_{N}}{\mathrm{~d} x}=\frac{\sin (2 \alpha) \cos (\alpha / 2)}{S_{\text {ref }}} \frac{\mathrm{d} S(x)}{\mathrm{d} x}+\frac{2 \cdot \eta \cdot C_{d_{c}} \cdot \sin ^{2}(\alpha)}{S_{r e f}} r(x) .
$$

Vale observar que no trabalho de Jorgensen ${ }^{[121]}$, foram realizadas derivações semelhantes ao do trabalho de Allen e Perkins ${ }^{[137]}$, mas considerando seções diferentes das circulares, como elípticas e quadradas, e a influência destas diferentes formas de seções nos coeficientes de interferência entre asa e corpo (explicado na seção 4.2.4). Contudo, como os AUVs analisados neste trabalho possuem seções circulares, não será dada uma explicação sobre estas correções.

\subsubsection{Inclusão de Fatores Semi-Empíricos}

O modelo apresentado por Fink ${ }^{[122]}$, na sua época de publicação, reuniu os principais trabalhos na área de predição das características aerodinâmicas de mísseis e aeronaves. Ainda hoje, muitos de seus modelos originais são utilizados na indústria aeroespacial e marinha ${ }^{[4]}$, sendo que os outros modelos foram atualizados para incluir novas correções. Apesar deste trabalho apresentar mais de uma forma de calcular os esforços em corpos esbeltos, apenas o modelo cujas hipóteses estão mais adequadas para o uso em veículos submarinos será apresentado, este modelo é descrito no trabalho de Hopkins ${ }^{[139]}$.

A diferença deste modelo com o modelo de Jorgensen ${ }^{[121]}$ está na integração da força ao longo do casco. Neste caso, é considerado que a integração do termo potencial deve ocorrer até o ponto onde ocorre o descolamento da camada limite $\left(x_{0}\right)$, enquanto que o termo viscoso deve ser integrado no restante do comprimento do veículo $\left(x_{0} \rightarrow L\right)$. Desta forma, para ângulos de ataque baixos $(\sin (\alpha)=\alpha$ e $\cos (\alpha)=1)$, o coeficiente de sustentação, e consequentemente o de força normal, é dado pela equação (4.20) enquanto que o momento é dado por (4.21), onde $x_{m}$ é o ponto de referência de integração.

$$
\begin{aligned}
\left.C_{L}(\alpha) \cong C_{N}\right|_{\alpha<10^{\circ}} & =\frac{2 \cdot \alpha \cdot\left(K_{2}-K_{1}\right)}{S_{r e f}} \int_{0}^{x_{0}} \frac{\mathrm{d} S(x)}{\mathrm{d} x} \cdot \mathrm{d} x \\
& +\frac{2 \cdot \alpha^{2}}{S_{r e f}} \int_{x_{0}}^{L} \eta \cdot r(x) \cdot C_{d_{c}} \cdot \mathrm{d} x
\end{aligned}
$$




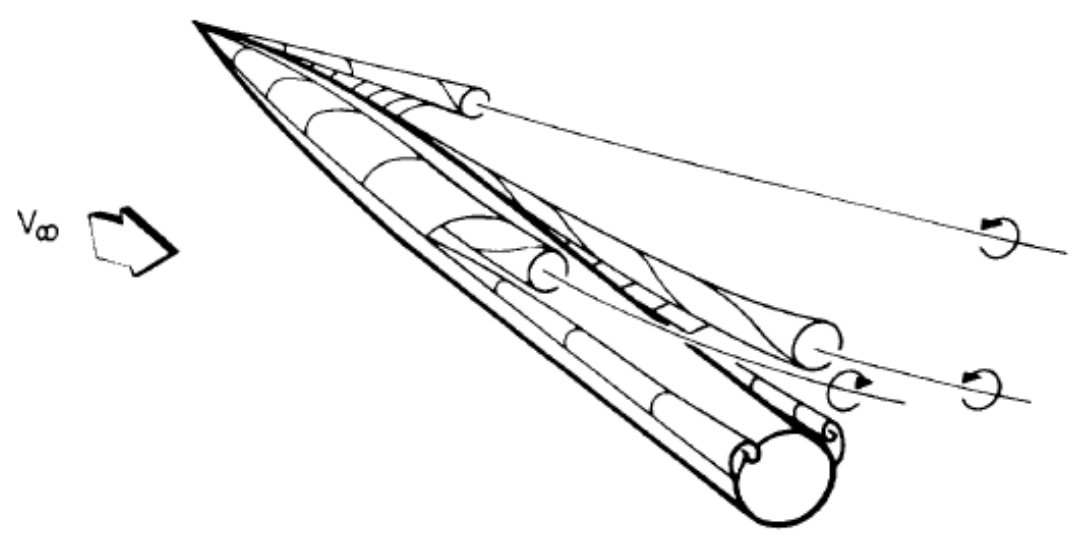

Figura 13 - Exemplo ilustrativo de vórtices gerados pelo corpo quando este está inclinado em relação ao escoamento, figura retirada de Jorgensen ${ }^{[121]}$.

$$
\begin{aligned}
\left.C_{M}\right|_{\alpha<10^{\circ}} & =\frac{2 \cdot \alpha \cdot\left(K_{2}-K_{1}\right)}{S_{r e f} \cdot L_{r e f}} \int_{0}^{x_{0}} \frac{\mathrm{d} S(x)}{\mathrm{d} x}\left(x_{m}-x\right) \cdot \mathrm{d} x \\
& +\frac{2 \cdot \eta \cdot C_{D_{c}} \cdot \alpha^{2}}{S_{\text {ref }} \cdot L_{\text {ref }}} \int_{x_{0}}^{L} r(x) \cdot\left(x_{m}-x\right) \cdot \mathrm{d} x
\end{aligned}
$$

Segundo Hopkins ${ }^{[139]}$, a equação que define o valor de $x_{0}$, em função do ponto de derivada mais negativa do perfil da cauda do veículo $x_{1}$, é dada por:

$$
x_{0}=0.378 \cdot L+0.527 \cdot x_{1}
$$

Contudo, no trabalho de Barros et al. ${ }^{[20]}$ é argumentado que dos 15 corpos de revoluções utilizados no levantamento experimental do ponto $x_{0}$ por Hopkins ${ }^{[139]}$, apenas um se assemelhava geometricamente ao corpo do AUV Pirajuba, e neste caso a estimativa obtida pela equação (4.22) não foi muito boa. Portanto, foi recomendado que fossem utilizados métodos numéricos (CFD) para encontrar o "verdadeiro" ponto de descolamento $x^{*}$. Além desta correção, também foi recomendado que a integração da parcela viscosa do escoamento fosse realizada em todo o corpo, seguindo o modelo de Jorgensen ${ }^{[121]}$, para melhor se adequar às estimativas do momento.

Outra modificação apresentada em Barros et al. ${ }^{[20]}$ é a utilização de um fator de atenuação da parcela potencial da força e do momento. Como apresentado em ESDU ${ }^{[133]}$, este fator contabiliza o efeito da diminuição da pressão ou perda da eficiência do escoamento na parte superior do casco, devido à geração de vórtices no escoamento cruzado ${ }^{[134]}$ quando o veículo possuí ângulo de incidência suficientemente alto. Um exemplo ilustrativo deste fenômeno é apresentado na figura 13, onde os vórtices gerados pelo corpo perturbam o escoamento sobre o corpo, modificando o seu campo de pressão. 
Com estas correções, o coeficiente de força normal pode ser estimado por

$$
\begin{array}{r}
C_{N}=\frac{\left(K_{2}-K_{1}\right) \cdot \sin (2 \alpha) \cdot \cos (\alpha / 2) \cdot\left(1-(\sin \alpha)^{K}\right)}{S_{r e f}} \int_{0}^{x^{*}} \frac{\mathrm{d} S(x)}{\mathrm{d} x} \cdot \mathrm{d} x \\
+\frac{2 \cdot \eta \cdot C_{d_{c}} \cdot \sin ^{2}(\alpha)}{S_{\text {ref }}} \int_{0}^{L} r(x) \cdot \mathrm{d} x
\end{array}
$$

e o coeficiente de momento por

$$
\begin{gathered}
C_{M}=\frac{\left(K_{2}-K_{1}\right) \cdot \sin (2 \alpha) \cdot \cos (\alpha / 2) \cdot\left(1-(\sin \alpha)^{K}\right)}{S_{r e f} \cdot L_{r e f}} \int_{0}^{x^{*}} \frac{\mathrm{d} S(x)}{\mathrm{d} x}\left(x_{m}-x\right) \cdot \mathrm{d} x \\
+\frac{2 \cdot \eta \cdot C_{d_{c}} \cdot \alpha^{2}}{S_{\text {ref }} \cdot L_{r e f}} \int_{0}^{L} r(x) \cdot\left(x_{m}-x\right) \cdot \mathrm{d} x .
\end{gathered}
$$

Sendo $K$ o parâmetro representa a intensidade de atenuação, que é obtido empiricamente para que a aderência desta formulação se adeque aos resultados experimentais.

\subsubsection{Modelo Dinâmico}

Nesta seção é apresentado o modelo dinâmico de Lesieutre, Love e Dillenius ${ }^{[42]}$, baseado nos modelos de Munk ${ }^{[132]}$ e Jorgensen ${ }^{[121]}$. Este modelo foi utilizado para estimar o campo de pressão em mísseis (corpos axis-simétricos com aletas), quando o escoamento possui uma velocidade angular e uma inclinação em relação ao veículo.

Este modelo, assim como outros descritos neste trabalho, foram implementados em um software proprietário, o M3HAX. No entanto, este software passou por diversas mudanças ${ }^{[140,43]}$ que possibilitaram o cálculo do campo de pressão de mísseis em diversas configurações, como múltiplas superfícies de controle (com até 8 superfícies de vante, de ré e no centro do corpo) e corpos com seções distintas, além de considerar os efeitos aerodinâmicos para altos ângulos de ataque, velocidade angular, deflexões individuais das superfícies de controle e do movimento de rolagem. Este novo software foi intitulado MISL3.

Resumidamente, o modelo proposto em Lesieutre, Love e Dillenius ${ }^{[42]}$ assume que em cada seção do corpo existe um ângulo de ataque equivalente que é dado pelo produto vetorial dos vetores de rotação $(p, q$ e $r)$ pela distância do centro de referência $\left(x_{m}, y_{m}\right.$ e $z_{m}$ ) normalizado pelo módulo da velocidade do veículo, somado ao ângulo de ataque nominal. Contudo, como no caso deste trabalho somente se pretende estudar o movimento em um plano, apenas é considerado o movimento de rotação de caturo $(q)$, e que o centro de cálculo é dado no eixo do $\operatorname{AUV}\left(y_{m}=z_{m}=0\right)$. Desta forma o ângulo de ataque equivalente é dado por

$$
\alpha_{e q}(x)=\alpha+q \cdot \frac{\left(x-x_{m}\right)}{U_{\infty}}
$$


Da mesma forma que os outros modelos apresentados, este modelo divide a solução em parcelas potenciais e viscosas. Ambas são obtidas pela derivação parcial do ângulo de ataque na equação de distribuição do coeficiente de força normal no comprimento do veículo de Jorgensen ${ }^{[121]}$, para o ângulo de ataque e a velocidade de rotação. A equação para parcela potencial é dada por

$$
\begin{aligned}
\frac{\mathrm{d} C_{N}}{\mathrm{~d} x}= & \frac{C_{N_{\alpha}}\left(K_{2}-K_{1}\right)}{2}\left[2 \frac{\pi r(x)}{S_{r e f}} \frac{\mathrm{d} r(x)}{\mathrm{d} x} \sin \left(2 \alpha_{e q}(x)\right) \cos \left(\frac{\alpha_{e q}(x)}{2}\right)+\right. \\
& \left.\frac{S(x)}{S_{r e f}} \frac{\mathrm{d} \alpha_{e q}(x)}{\mathrm{d} x}\left(2 \cos \left(\frac{\alpha_{e q}(x)}{2}\right) \cos \left(2 \alpha_{e q}(x)\right)-\frac{1}{2} \sin \left(2 \alpha_{e q}(x)\right) \sin \left(\frac{\alpha_{e q}(x)}{2}\right)\right)\right]
\end{aligned}
$$

enquanto que a da parcela viscosa é dada por

$$
\frac{\mathrm{d} C_{N}}{\mathrm{~d} x}=\frac{2 \cdot \eta \cdot C_{d_{c}} \cdot r(x)}{S_{r e f}} \sin ^{2}\left(\alpha_{e q}(x)\right) .
$$

O termo $C_{N_{\alpha}}$ a derivada do coeficiente de força normal para ângulos de ataque próximos de zero, que pela teoria dos corpos esbeltos (SBT, Slender Body Theory) é igual a 2. Pela razão $C_{N_{\alpha}} / 2$ ser igual a 1, ela não é apresentada pelos demais modelos. O termo $d \alpha_{e q} / d x$ é a derivada da equação do ângulo equivalente (4.25) pela coordenada longitudinal de integração, ou seja

$$
\frac{\mathrm{d} \alpha_{e q}(x)}{\mathrm{d} x}=q \cdot \frac{x}{U_{\infty}}
$$

Neste modelo, o coeficiente de força normal é calculado pela integral da soma das equações (4.26) e (4.27) em todo o corpo, enquanto que o momento é calculado pela integral desta soma multiplicada pela distância longitudinal ao centro de referência $\left(x-x_{m}\right)$.

\subsubsection{Modelo Dinâmico com Fatores Semi-Empíricos}

A inclusão dos fatores semi-empíricos no modelo de Lesieutre, Love e Dillenius ${ }^{[42]}$, relativos aos efeitos tridimensionais, descolamento da camada limite e da atenuação da parcela potencial do escoamento, será realizada de maneira similar a metodologia de Barros et al. ${ }^{[20]}$.

O fator de correção dos efeitos tridimensionais do termo potencial $\left(K_{2}-K_{1}\right)$ é considerado no termo potencial da equação de Lesieutre, Love e Dillenius ${ }^{[42]}$ sem restrições, pois ele não depende de fatores que a velocidade de rotação interferiria, apenas da razão de esbelteza do corpo. Nota-se que o mesmo fator de correção para o termo viscoso $(\eta)$ já é considerado no modelo original, apresentado na equação (4.27).

A consideração do termo de descolamento da camada limite é um pouco mais complicado de se analisar, pois trabalhos que estudam este efeito em função da velocidade angular são bastante escassos na literatura aberta. Assim, neste trabalho, este efeito 
foi considerado como modificações na equação do ângulo de ataque equivalente para as diferentes distribuições de força normal (4.26 e 4.27). Esta modificação pode ser realizada de quatro maneiras:

1. O ângulo de ataque equivalente é estimado de acordo com a equação (4.25), e é o mesmo para o termo potencial e viscoso, igual ao modelo de Lesieutre, Love e Dillenius $^{[42]}$.

2. De forma semelhante ao de Hopkins ${ }^{[139]}$, o ângulo de ataque equivalente ao termo potencial pode ser considerado até o ponto de descolamento da camada limite, enquanto que o termo viscoso é considerado deste ponto até o final do corpo.

3. Para o termo viscoso, é considerado como o ângulo de ataque local a equação (4.25) para todo o corpo, enquanto para o termo potencial, é considerado esta formula até o ponto de descolamento, semelhante ao modelo de Barros et al. ${ }^{[20]}$.

4. O termo rotacional $(q)$ e o termo estático $(\alpha)$ da equação (4.25) são considerados independentemente para algum dos casos enunciados.

Através de alguns testes empíricos com resultados obtidos pelo CFD, foi verificado que a melhor solução é uma mistura do item 3 com o 4. Nesta solução a integração do termo viscoso é realizada para o corpo inteiro, sendo considerado o termo estático e rotacional da equação (4.25). Na parcela potencial é considerado o termo rotacional da equação (4.25) em toda a extensão do corpo, enquanto que o termo estático somente é considerado até o ponto de descolamento da camada limite.

Matematicamente, os ângulos de ataque equivalente para a parcela potencial e viscosa são diferentes, enquanto a parcela viscosa é igual a equação (4.25), a potencial é definida pela equação (4.29).

$$
\alpha_{p o t}(x)=\left\{\begin{aligned}
\alpha+q \cdot \frac{\left(x-x_{m}\right)}{U_{\infty}} & \rightarrow x \leq x^{*} \\
q \cdot \frac{\left(x-x_{m}\right)}{U_{\infty}} & \rightarrow x>x^{*}
\end{aligned}\right.
$$

A contribuição do fator de atenuação da parcela potencial do escoamento ${ }^{[133]}$ também foi analisada empiricamente, mas apresentou um resultado diferente do encontrado para o termo de descolamento. Foi verificado que este termo não tem influência do termo de rotação da equação (4.25), sendo apenas necessário considerar o ângulo de ataque nominal. 


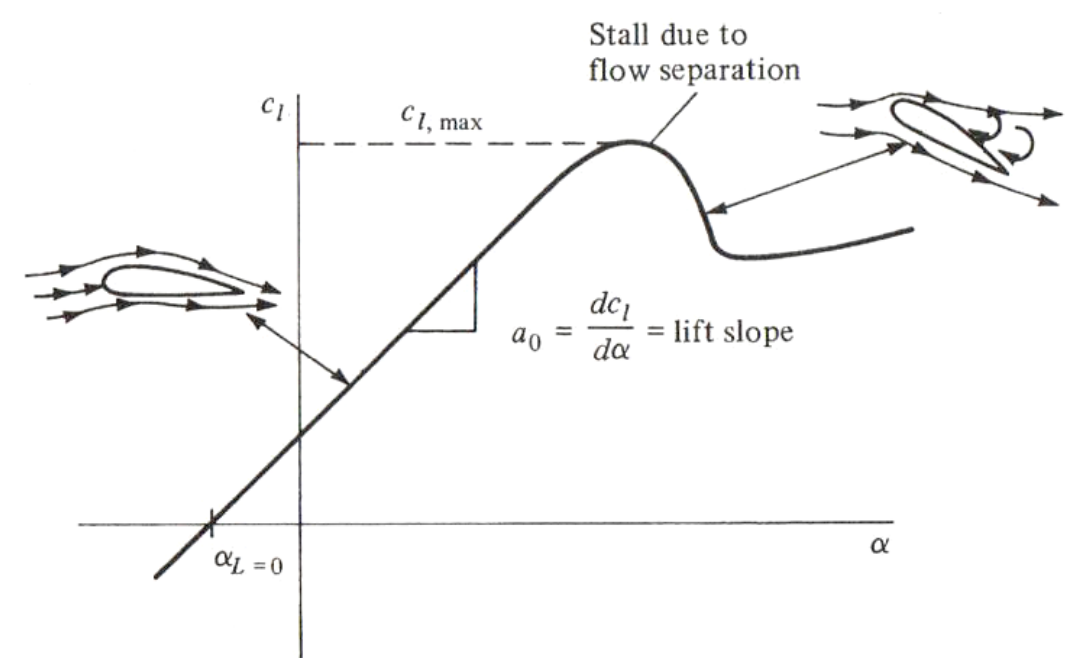

Figura 14 - Exemplo do efeito do estol de um perfil no comportamento do coeficiente de sustentação, figura retirada de Anderson ${ }^{[141]}$.

Considerando todos estes fatores, a equação de distribuição do coeficiente de força normal ao longo de um corpo axis-simétrico é calculado pela equação

$$
\begin{array}{r}
\frac{\mathrm{d} C_{N}}{\mathrm{~d} x}=\frac{C_{N_{\alpha}}}{2}\left(K_{2}-K_{1}\right)\left[2 \frac{\pi r(x)}{S_{r e f}} \frac{\mathrm{d} r(x)}{\mathrm{d} x} \sin \left(2 \alpha_{p o t}(x)\right) \cos \left(\frac{\alpha_{p o t}(x)}{2}\right)+\right. \\
\frac{S(x)}{S_{r e f}} \frac{\mathrm{d} \alpha_{p o t}(x)}{\mathrm{d} x}\left(-\frac{1}{2} \sin \left(2 \alpha_{p o t}(x)\right) \sin \left(\frac{\left.\alpha_{p o t}(x)\right)}{2}\right)+\right. \\
\left.\left.2 \cos \left(\frac{\left.\alpha_{p o t}(x)\right)}{2}\right) \cos \left(2 \alpha_{p o t}(x)\right)\right)\right] \cdot\left(1-(\sin \alpha)^{K}\right)
\end{array}
$$

e o termo viscoso é dado pela equação (4.27).

\subsubsection{Leme isolado}

Nesta seção, são apresentados os modelos hidrodinâmicos dos esforços estáticos e dinâmicos das superfícies de controle, ou lemes, de um AUV sem considerar a presença do corpo.

Os modelos apresentados consideram que o escoamento sobre o leme permanece potencial com o descolamento ocorrendo em seu bordo de fuga independente do ângulo de incidência, i.e, não é modelado o descolamento da camada limite sobre o dorso do leme, que pode resultar no fenômeno de estol. Na figura 14 é apresentado um exemplo do efeito deste fenômeno sobre o coeficiente de sustentação. Para baixos ângulos de incidência baixos, quando o escoamento está aderente a sua superfície, o coeficiente de sustentação do perfil varia linearmente com o ângulo de incidência. No entanto, após a separação/descolamento do escoamento a sustentação apresenta um comportamento não-linear, reduzindo a força com o aumento do ângulo de incidência. 
Como a ocorrência do estol depende de diversos fatores relativos as condições e propriedades do escoamento, existem poucos trabalhos na literatura que apresentam modelos adequados para realizar a predição do estol. Dos trabalhos que se dispõem à apresentar tais modelos, nenhum apresentou um resultado satisfatório para o leme do AUV Pirajuba, pois as condições que estes modelos foram desenvolvidos se diferem muito das condições experimentadas por este veículo.

Por exemplo, Anderson ${ }^{[141]}$ sugere utilizar o modelo de linha de sustentação, em que o leme é modelado por diversas seções bi-dimensionais de seu perfil, e que o ângulo de incidência em cada seção é calculado pela somatória do ângulo de incidência induzido pelo vórtice de ponta e pelo ângulo de incidência do perfil. Neste caso, o estol pode ser encontrado quando o ângulo de ataque de alguma seção atinge o ângulo de estol do perfil.

Contudo, este modelo é apenas indicado para lemes em que o perfil varie pouco na direção da envergadura, i.e., lemes com alta razão de aspecto. Pelos lemes de AUVs normalmente apresentarem baixa razão de aspecto, este modelo não seria adequado. Por este mesmo motivo e considerando também a diferença do número de Reynolds, os modelos apresentados por Fink ${ }^{[122]}$ não apresentaram resultados adequados para o modelo do estol do leme do AUV Pirajuba, e portanto nenhum destes modelos serão considerados nesta seção.

\subsubsection{Modelo Estático}

Os esforços de um leme em função apenas do ângulo de incidência podem ser estimados pelo modelo aerodinâmico de Whicker e Fehlner ${ }^{[142]}$, que também é utilizado em modelos de manobras de embarcações navais ${ }^{[68]}$. Neste modelo a sustentação é calculada pela equação (4.31), onde o primeiro termo representa os esforços potenciais e o segundo os viscosos, considerando os efeitos de arrasto cruzado de maneira similar ao modelo do corpo sozinho.

$$
C_{L_{w}}(\alpha)=\left[\left(\frac{\partial C_{L}}{\partial \alpha}\right)_{\alpha=0} \alpha+\frac{C_{D_{c_{w}}}}{a} \alpha^{2}\right] \frac{S_{w}}{S_{r e f}}
$$

Na equação (4.31), $\alpha$ é o ângulo de ataque do leme em radianos, $C_{D_{c_{w}}}$ o coeficiente de arrasto cruzado (diferente do coeficiente do corpo), $a$ é a razão de aspecto geométrica do leme, definida pela razão da envergadura $\left(b_{w}\right)$ ao quadrado pelo área de planta da asa $\left(S_{w}\right)$, i.e. $a=b_{w}^{2} / S_{w}$, e o termo potencial $\partial C_{L} / \partial \alpha$, é a derivada do coeficiente de sustentação tri-dimensional do leme em função do ângulo de incidência. O termo $\partial C_{L} / \partial \alpha$ é definido por

$$
\left(\frac{\partial C_{L}}{\partial \alpha}\right)_{\alpha=0}=\frac{C_{l_{2 D}}}{\left[\left(\cos (\Lambda) \sqrt{\frac{a^{2}}{\cos ^{4}(\Lambda)}+4}\right)+\frac{C_{l_{2 D}}}{\pi}\right]}
$$


onde $\Lambda$ é o ângulo de enflechamento (sweep angle) do leme, e o termo $C_{l_{2 D}}$ é o coeficiente de sustentação bi-dimensional do leme, obtido empiricamente ou através de técnicas numéricas.

Neste mesmo modelo ${ }^{[142]}$, o coeficiente de arrasto é calculado por

$$
C_{D_{w}}=C_{d_{0}}+\frac{C_{L_{w}}^{2}(\alpha)}{\pi a e}
$$

onde $C_{d_{0}}$ é o coeficiente de arrasto mínimo do perfil (quando a sustentação é nula), e $e$ é o fator de eficiência de Oswald, adotado igual a 0.9 em Whicker e Fehlner ${ }^{[142]}$.

Por último, o coeficiente de momento, calculado no centro pressão teórico do leme (localizado a $25 \%$ da corda média, $\bar{c}$ ), é estimado por

$$
C_{m_{\bar{c} / 4 w}}(\alpha)=\left[\left[0.25-\left(\frac{\partial C_{m}}{\partial C_{L}}\right)_{C_{L}=0}\right]\left(\frac{\partial C_{L}}{\partial \alpha}\right)_{\alpha=0} \alpha-\frac{1}{2} \frac{C_{D_{c}}}{a} \alpha^{2}\right] \frac{S_{w} \bar{c}}{S_{r e f} L_{r e f}},
$$

onde o termo $\left(\partial C_{m} / \partial C_{L}\right)_{C_{L}=0}$ é obtido pela equação de Hembold's ${ }^{[143]}$, reescrita na equação abaixo:

$$
\left(\frac{\partial C_{m}}{\partial C_{L}}\right)_{C_{L}=0}=\frac{1}{2}-\frac{\frac{2 \pi}{C_{l_{2 D}}} \sqrt{a^{2}+4}+2}{4(a+2)}
$$

\subsubsection{Modelo Dinâmico}

Os coeficientes dinâmico de rotação do leme são obtidos de uma forma relativamente mais simples do que o caso do corpo. Isto ocorre porque na maioria dos AUVs, e principalmente no tipo de AUV analisado neste projeto, o leme é dimensionalmente menor que o corpo e a influência de rotação no seu próprio eixo pode ser desprezível frente ao efeito do ângulo efetivo no leme ${ }^{[144]}$, gerado pela distância do centro de rotação que o leme se encontra, de maneira similar ao ângulo equivalente nas seções do corpo.

Matematicamente, o ângulo de incidência efetivo do leme pode ser calculado pela equação

$$
\alpha_{e f_{w}}=\alpha+q \cdot \frac{\left(x_{A C_{w}}-x_{m}\right)}{U_{\infty}}
$$

onde $x_{A C_{w}}$ é o centro hidrodinâmico, que em um modelo mais simples pode ser considerado coincidente com o centro de pressão teórico (1/4 da corda média, $\bar{c}$ ).

Utilizando a definição do ângulo efetivo no leme os coeficientes de sustentação e momento podem ser estimados ao substituir o termo $\alpha$ pelo termo $\alpha_{e f_{w}}$ nas equações (4.31) e (4.33), respectivamente.

Para o caso do coeficiente de momento, além de realizar esta substituição é preciso considerar a distância ao centro de referência em que a força normal é aplicada. A força 


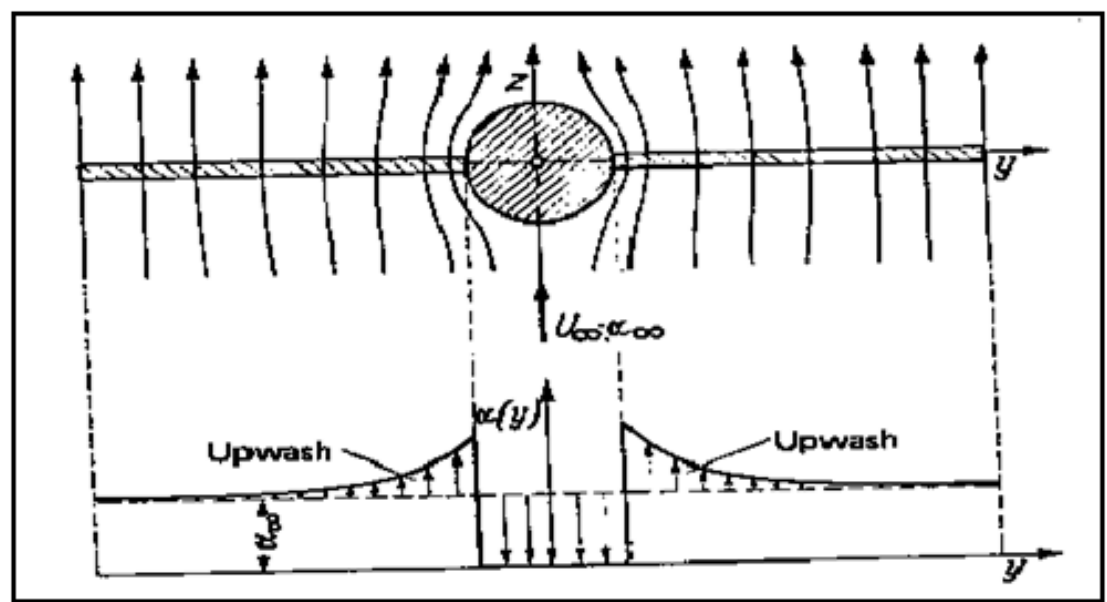

Figura 15 - Exemplo qualitativo da interferência que o corpo gera em um leme/asa, figura retirada de Roskam ${ }^{[126]}$.

normal pode ser calculada pela composição dos termos de sustentação e arrasto, apresentada na equação (4.15). Nota-se que a definição do ângulo de ataque efetivo somente deve ser aplicada aos esforços, enquanto que os termos trigonométricos devem ser resolvidos em função do ângulo de incidência nominal $(\alpha)$. Utilizando a definição de $C_{N}$, o coeficiente de momento pode ser calculado por

$$
C_{M_{w}}\left(\alpha, \alpha_{e f_{w}}\right)=C_{m_{\bar{c} / 4 w}}(\alpha)-\left(x_{A C_{w}}-x_{m}\right) C_{N}\left(\alpha, \alpha_{e f_{w}}\right)
$$

Caso o centro de referência esteja próximo do entro de pressão teórico do leme, caso das asas de aeronaves, o ângulo de ataque efetivo será praticamente igual ao ângulo de incidência nominal, desprezando o efeito da velocidade rotacional neste modelo. Nestes casos pode ser necessário utilizar a metodologia encontrada em ESDU ${ }^{[144]}$, para calcular os efeitos de rotação na distribuição de pressão do próprio leme/asa.

\subsubsection{Interferência Corpo-Asa}

Os fenômenos de interferência do corpo com a superfície de controle ocorrem devido a, basicamente, dois fenômenos.

O primeiro está relacionado à aceleração do escoamento que o corpo gera sobre o leme, como apresentado na figura 15 . O fluido que circula ao seu redor sofre um aumento de velocidade com o aumento do ângulo de incidência (upwash), devido a geometria da seção transversal do corpo, gerando um aumento na velocidade do escoamento incidente ao leme, e consequentemente provocando um aumento na sustentação.

O segundo fenômeno diz respeito a interferência que o leme cria no escoamento próximo ao corpo do veículo, representado na figura 16. Esse fenômeno está relacionado ao aumento da componente de velocidade vertical do escoamento para cima (upwash) nas regiões à frente do leme, e a um aumento da componente da velocidade vertical 


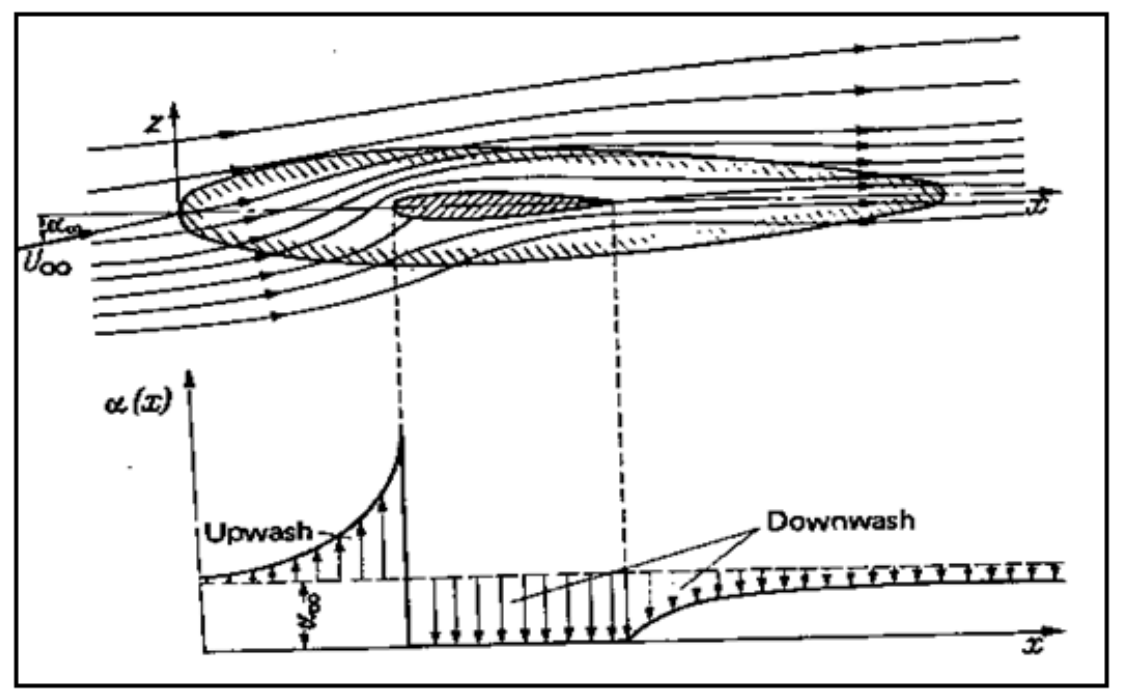

Figura 16 - Exemplo qualitativo da interferência que o leme/asa gera no corpo, figura retirada de Roskam ${ }^{[126]}$.

do escoamento para baixo (downwash) para as regiões atrás do leme. Este escoamento induzido modifica a distribuição de pressão no casco próximo ao leme, e em consequência modifica os coeficientes de força e momento.

O método apresentado nesta seção modelo as interferências através de coeficientes, simbolizados pela letra $K$ (diferentes para o caso do corpo sozinho), que corrigem a força de sustentação/normal gerada pelo leme e pelo casco do veículo devido as suas geometrias.

A apresentação dos modelos será realizada de maneira semelhante aos modelos do corpo e do leme, onde primeiramente serão explicados os modelos estáticos, lineares ${ }^{[134,122]}$ e não-lineares ${ }^{[145,146,135]}$, e em seguida a modificação destes modelos para contabilizar o efeito da velocidade angular.

\subsubsection{Modelo Estático Linear}

Conforme o trabalho de Pitts, Nielsen e Kaattari ${ }^{[134]}$, e mais genericamente no trabalho de Fink ${ }^{[122]}$, o coeficiente de sustentação da combinação leme e corpo $\left(C_{\left.L_{(} w b\right)}\right)$ é calculado pela soma dos coeficientes do corpo sozinho $\left(C_{L_{b}}\right)$, do leme na presença do corpo $\left(C_{L_{w}(b)}\right)$ e do corpo na presença do leme $\left(C_{L_{b}(w)}\right)$. Esta soma é apresentada na equação (4.38), considerando que todos os coeficientes estão representados na mesma área de referência $\left(S_{r e f}\right)$.

$$
C_{L_{(w b)}}(\alpha)=C_{L_{(b)}}(\alpha)+C_{L_{w(b)}}(\alpha)+C_{L_{b(w)}}(\alpha)
$$

Por ser um modelo linear, esta relação é mais comumente expressa utilizando as derivadas dos coeficientes de sustentação em função do ângulo de ataque, conforme a 
equação

$$
\left(\frac{\partial C_{L_{(w b)}}}{\partial \alpha}\right)_{\alpha=0}=C_{L_{\alpha_{(w b)}}}=C_{L_{\alpha_{(b)}}}+C_{L_{\alpha_{w}(b)}}+C_{L_{\alpha_{b(w)}}} .
$$

Para simplificar a equação, as derivadas foram simplificadas ao considerar o subíndice $\alpha$.

Segundo Pitts, Nielsen e Kaattari ${ }^{[134] 2}$, os dois coeficientes de interferência são considerados em função do coeficiente do leme. Utilizando os fatores de interferência, a equação (4.39) pode ser reescrita por

$$
C_{L_{\alpha_{(w b)}}}=C_{L_{\alpha_{(b)}}}+\left(K_{w(b)}+K_{b(w)}\right) C_{L_{\alpha_{(w)}}}
$$

onde o fator $K_{w(b)}$ contabiliza a interferência do corpo no leme, e o fator $K_{b(w)}$ representa o efeito gerado pelo leme no corpo.

Segundo Pitts, Nielsen e Kaattari ${ }^{[134]}$, existem diversos métodos lineares para calcular estes fatores, como a teoria de corpos e asas esbeltas (SBT e SWT, respectivamente $)^{3}$ ou a teoria das faixas (strip theory). Como os métodos SBT ainda são bastante utilizados $^{[20,44]}$, as equações destes coeficientes serão apresentadas a seguir. Os demais modelos podem ser encontrados no trabalho de Pitts, Nielsen e Kaattari ${ }^{[134]}$, ou de Hemsch e Nielsen; Hemsch e Nielsen ${ }^{[145,146]}$.

Portanto, na teoria SBT o fator $K_{w(b)}$ é calculado pela equação (4.41), e o fator $K_{b(w)}$ é dado pela equação (4.42).

$$
\begin{gathered}
K_{w(b)}=\frac{2}{\pi} \frac{\left(1+k^{4}\right) \zeta_{1}-k^{2} \zeta_{2}}{(1-k)^{2}} \\
K_{b(w)}=(1-k)^{2}-K_{w(b)}
\end{gathered}
$$

Ambas equações são expressas em função das variáveis $k$ e $\zeta$. A variável $k$ representa a razão entre o diâmetro do corpo em que o leme se encontra $\left(D_{b}\right)$ e a envergadura máxima do leme $\left(b_{w}\right)$, i.e., $s=D_{b} / b_{w}$, enquanto que as variáveis zetas são expressas por

$$
\begin{array}{r}
\zeta_{1}=\left[\frac{1}{2} \tan ^{-1}\left(1 / 2\left(k^{-1}-k\right)\right)+\frac{\pi}{4}\right] \\
\zeta_{2}=\left[\left(k^{-1}-k\right)+2 \tan ^{-1}(k)\right]
\end{array}
$$

\subsubsection{Modelo Estático Não-Linear}

2 na verdade não foi Pitts que desenvolveu este método, mas em seu trabalho existe uma ótima compilação de estudos de diversos métodos desenvolvidos na época

3 SBT, sigla em inglês para Slender Body Theory, ou Teoria de Corpos Esbeltos. SWT, sigla em inglês para Slender Wing Theory, ou Teoria das Asas Esbeltas 
Para o caso não-linear é utilizado o método de ângulo de ataque equivalente, apresentado em Hemsch e Nielsen; Hemsch e Nielsen ${ }^{[145,146]}$. Nestes modelos os fatores de interferência, apresentados pelas equações (4.41) e (4.42), modificam o ângulo de incidência efetivo do leme. Matematicamente, este efeito é representado por uma modificação de $\alpha$ "enxergado" pelo leme, o ângulo de incidência equivalente $\alpha_{e q}$. Este novo ângulo é utilizado nas funções não-lineares de sustentação do leme, como a da equação (4.31) ou através de funções obtidas empiricamente, para possibilitar a previsão do efeito do estol do leme ${ }^{[135]}$.

Com este modelo, além de ser possível prever os efeitos não-lineares de interferência entre o corpo e os lemes, é possível prever os efeitos da rolagem do veículo, dos vórtices gerados pelo corpo $^{[145]}$, e da deflexão de cada superfície de controle ${ }^{[146]}$.

No modelo de Hemsch e Nielsen ${ }^{[145]}$ o ângulo de ataque equivalente é calculado pela equação

$$
\alpha_{e q_{w}}(\alpha)=\arctan \left[K_{w(b)} \tan (\alpha)+\tan (\Delta \alpha)_{v}\right]
$$

onde $K_{w(b)}$ o coeficiente de interferência já mencionado, e $(\Delta \alpha)_{v}$ é a variação do ângulo de ataque no leme devido aos vórtices laterais gerados pelo corpo ${ }^{[134]}$.

O coeficiente de sustentação da combinação corpo e leme são calculados em função da equação

$$
C_{L_{(w b)}}(\alpha)=C_{L_{(b)}}(\alpha)+\left(1+\frac{K_{b(w)}}{K_{w(b)}}\right) C_{L_{(w)}}\left(\alpha_{e q_{w}}(\alpha)\right)
$$

Nota-se que versão linear desta equação é igual a equação (4.40).

Apresentada por Pitts, Nielsen e Kaattari ${ }^{[134]}$, esta formulação é obtida ao aplicar a hipótese de que a razão entre os fatores de interferência para o ângulo de ataque $\left(K_{w(b)}\right.$ e $\left.K_{b(w)}\right)$ são iguais a razão aos fatores de interferência da deflexão dos lemes $\left(k_{w(b)}\right.$ e $\left.k_{b(w)}\right)$, i.e.,

$$
\frac{K_{b(w)}}{K_{w(b)}}=\frac{k_{b(w)}}{k_{w(b)}} .
$$

Para melhorar a capacidade de predição deste modelo para ângulos de ataque maiores, diversos modelos semi-empíricos foram propostos para os coeficientes de interferência das equações (4.45) e (4.46). Destacam-se os modelos de Moore, McInville e Hymer ${ }^{[147]}$ e Burns e Bruns ${ }^{[135]}$, que apresentam formulações não lineares em função do ângulo de ataque nominal e de diversos parâmetros geométricos do leme e do corpo.

\subsubsection{Modelo Dinâmico}

A proposta para modelo dinâmico da combinação do corpo e do leme é semelhante ao apresentado para o leme sozinho, ou seja, somente é modificado o ângulo de incidência efetivo/equivalente sobre o leme (4.45) para incorporar o ângulo induzido pelo movimento 
rotacional (4.36), enquanto o efeito do movimento rotacional no corpo é mantido, visto pelas equações (4.30) e (4.27).

Desta forma, o ângulo de incidência equivalente no leme é calculado em função da velocidade angular e do ângulo de incidência nominal do veículo, sendo descrito pela equação

$$
\begin{aligned}
\alpha_{e q_{w}}(\alpha, q)= & \arctan \left[\tan (\Delta \alpha)_{v}+\right. \\
& \left.K_{w(b)}\left(\alpha+q \cdot \frac{\left(x_{A C_{w}}-x_{m}\right)}{U_{\infty}}\right) \cdot \tan \left(\alpha+q \cdot \frac{\left(x_{A C_{w}}-x_{m}\right)}{U_{\infty}}\right)\right] .
\end{aligned}
$$

Com a definição do novo ângulo de incidência equivalente, a função do coeficiente de sustentação da combinação corpo e leme é calculado por

$$
C_{L_{(w b)}}(\alpha, q)=C_{L_{(b)}}(\alpha, q)+\left(1+\frac{K_{b(w)}\left(\alpha_{e q_{w}}(\alpha, q)\right)}{K_{w(b)}\left(\alpha_{e q_{w}}(\alpha, q)\right)}\right) C_{L_{(w)}}\left(\alpha_{e q_{w}}(\alpha, q)\right)
$$

Apesar dos métodos de interferência terem sido apresentados apenas para o coeficiente de sustentação, de acordo com o modelo de Hemsch e Nielsen ${ }^{[145]}$ pode ser estendido para a força normal e o momento. Isto é possível, pois as forças apenas apresentam diferença no sistema de coordenada, que está rotacionado em $\alpha$, enquanto que o momento é calculado pela própria força normal. Desta forma, as equações para os coeficientes de força normal e momento, são definidas pelas equações (4.50) e (4.51), respectivamente.

$$
\begin{gathered}
C_{N_{(w b)}}(\alpha, q)=C_{N_{(b)}}(\alpha, q)+\left(1+\frac{K_{b(w)}\left(\alpha_{e q_{w}}(\alpha, q)\right)}{K_{w(b)}\left(\alpha_{e q_{w}}(\alpha, q)\right)}\right) C_{N_{(w)}}\left(\alpha_{e q_{w}}(\alpha, q), \alpha\right) \\
C_{M_{(w b)}(\alpha, q)}=C_{M_{(b)}}(\alpha, q)+\left(1+\frac{K_{b(w)}\left(\alpha_{e q_{w}}(\alpha, q)\right)}{K_{w(b)}\left(\alpha_{e q_{w}}(\alpha, q)\right)}\right) C_{M_{(w)}}\left(\alpha_{e q_{w}}(\alpha, q), \alpha\right)
\end{gathered}
$$

O mesmo procedimento não é inteiramente valido para as forças de arrasto e axial, pois nestes esforços existem os termos relativos ao arrasto parasita (que não depende da sustentação), que não estão de acordo com as hipóteses por estes métodos. Entretanto, no caso do arrasto induzido (que depende da sustentação)esta metodologia pode ser aplicada de maneira bastante similar.

\subsubsection{Duto propulsor isolado}

O duto propulsor, ou simplesmente duto, é um apêndice utilizado nos sistemas de propulsão de veículos marinhos, sendo comumente desenvolvido e utilizado para proteger o hélice e melhorar o seu desempenho durante a fase de aceleração do veículo, mesmo que o arrasto gerado pelo duto possa superar o seu ganho em empuxo quando o veículo atinge a sua velocidade de cruzeiro ${ }^{[58,28]}$.

Contudo, o duto também influencia na manobrabilidade destes veículos, principalmente no caso dos $\mathrm{AUVS}^{[58,28,148]}$, gerando esforços de restauração e amortecimento 
significativos de maneiras similares aos lemes. Devido à esta capacidade na geração de esforços aliada com uma eficiência hidrodinâmica melhor do que os lemes ${ }^{[149]}$, os dutos estão sendo testados para substituir os lemes de AUVs planadores ( gliders $^{[149]}{ }^{\text {, sendo }}$ chamados de asas anulares ${ }^{[148,150]}$ nestes casos.

O modelo hidrodinâmico do duto é obtido sem considerar o seu estol, pois da mesma forma que os lemes, não existem trabalhos que abordem este tipo de modelo para as condições de operação de AUVs. Ou seja, os modelos apresentados nesta seção apenas apresentarão a componente potencial dos esforços gerados pelo duto, que são responsáveis pela parte mais significativa dos esforços antes da ocorrência do estol ${ }^{[136]}$.

\subsubsection{Modelo Estático}

A modelagem estática dos coeficientes hidrodinâmicos do duto é realizada utilizando a metodologia ASE de Morgan e Caster ${ }^{[136]}$. Nesta metodologia, os coeficientes de força de sustentação $\left(C_{L_{\text {Duct }}}\right)$ e momento $\left(C_{M_{\text {Duct }}}\right)$ são calculados apenas por suas derivadas, ou seja, é assumido que estes esforços variem linearmente com o ângulo de incidência do escoamento sobre o duto $(\alpha)$, conforme as equações as equações abaixo:

$$
\begin{aligned}
C_{L_{D u c t}} & =\frac{\delta C_{L}}{\delta \alpha} \alpha \\
C_{M_{D u c t}} & =\frac{\delta C_{M}}{\delta \alpha} \alpha
\end{aligned}
$$

Estas derivadas foram estimadas por uma relação empírica estabelecida no trabalho de Morgan e Caster ${ }^{[136]}$, utilizando dados próprios e de Fletcher ${ }^{[151]}$ para compreender uma amostra de dutos com diversas razões de aspectos e perfis. Os gráficos para as derivadas do coeficientes de sustentação e momento são apresentados na figura 17. O coeficiente de sustentação está referenciado na área definida pela multiplicação da corda pelo diâmetro do duto $\left(c_{d} \cdot D_{d}\right)$, e o momento por esta mesma área multiplicada pela corda do duto $\left(c_{d}^{2} \cdot D_{d}\right)$.

Os coeficientes de força normal e axial são calculados utilizando as equações (4.15) e (4.14), respectivamente, juntamente com uma estimativa para o coeficiente de arrasto do duto. Pelas referências utilizadas não apresentarem um método para estimar este coeficiente, pode ser adotado que os dutos de razão de aspecto semelhantes apresentem coeficientes de arrasto semelhantes ${ }^{[28]}$. Para o caso do AUV Pirajuba, o coeficiente de arrasto para a área de referência $S_{r e f}$, utilizando os dados de Morgan e Caster ${ }^{[136]}$, pode ser estimado por

$$
C_{D_{\text {Duct }}}=0.48 \frac{C_{d} R_{d}}{S_{r e f}} .
$$




\subsubsection{Modelo Dinâmico}

Tratando o duto como um leme/asa, o seu modelo dinâmico simplificado é muito similar ao modelo do leme isolado. Portanto, ao considerar que o duto está localizado distante do centro de rotação do veículo, pode-se assumir que o efeito do ângulo de incidência efetivo ${ }^{[122]}$, ângulo de incidência local no duto gerado pela rotação e inclinação do veículo, é responsável por gerar a maior parte dos esforços hidrodinâmicos, tornando o efeito de rotação do próprio eixo desprezível.

Considerando uma composição linear entre os esforços dinâmicos e estáticos, para definir a relação entro o ângulo efetivo do duto e os esforços, o coeficiente de sustentação pode ser calculado por

$$
C_{L_{D u c t}}=\frac{\delta C_{L}}{\delta \alpha} \alpha_{e f_{d}}=\frac{\delta C_{L}}{\delta \alpha}\left(\alpha+q \cdot \frac{\left(x_{C G_{d}}-x_{m}\right)}{U_{\infty}}\right),
$$

e o momento total gerado por um duto distante $\Delta x_{C G_{d}}$ do centro de rotação, i.e. $\Delta x_{C G_{d}}=$ $\left(x_{C G_{d}}-x_{m}\right)$ pode ser definido por

$$
\begin{aligned}
C_{M_{D u c t}} & =\left(\frac{\delta C_{M}}{\delta \alpha}+\frac{\Delta x_{C G_{d}}}{D_{d}} \frac{\delta C_{L}}{\delta \alpha}\right) \alpha_{e f_{d}} \\
& =\left(\frac{\delta C_{M}}{\delta \alpha}+\frac{\Delta x_{C G_{d}}}{D_{d}} \frac{\delta C_{L}}{\delta \alpha}\right) \alpha+\left(\Delta x_{C G_{d}} \frac{\delta C_{M}}{\delta \alpha}+\frac{\Delta x_{C G_{d}}^{2}}{D_{d}} \frac{\delta C_{L}}{\delta \alpha}\right) \frac{q}{U_{\infty}} .
\end{aligned}
$$

Nas equações (4.55) e (4.56), o primeiro termo do lado direito da equação representa o efeito estático relativo ao ângulo de ataque do duto/veículo, e o segundo termo o efeito dinâmico relativo a rotação do duto/veículo. Nota-se que pela equação (4.56), a parcela do momento total gerada pela sustentação é maior do que o momento, pois normalmente o diâmetro do duto é muito menor que a distância do duto ao centro de rotação $\left(\Delta x_{C G_{d}}>>D_{d}\right)$.
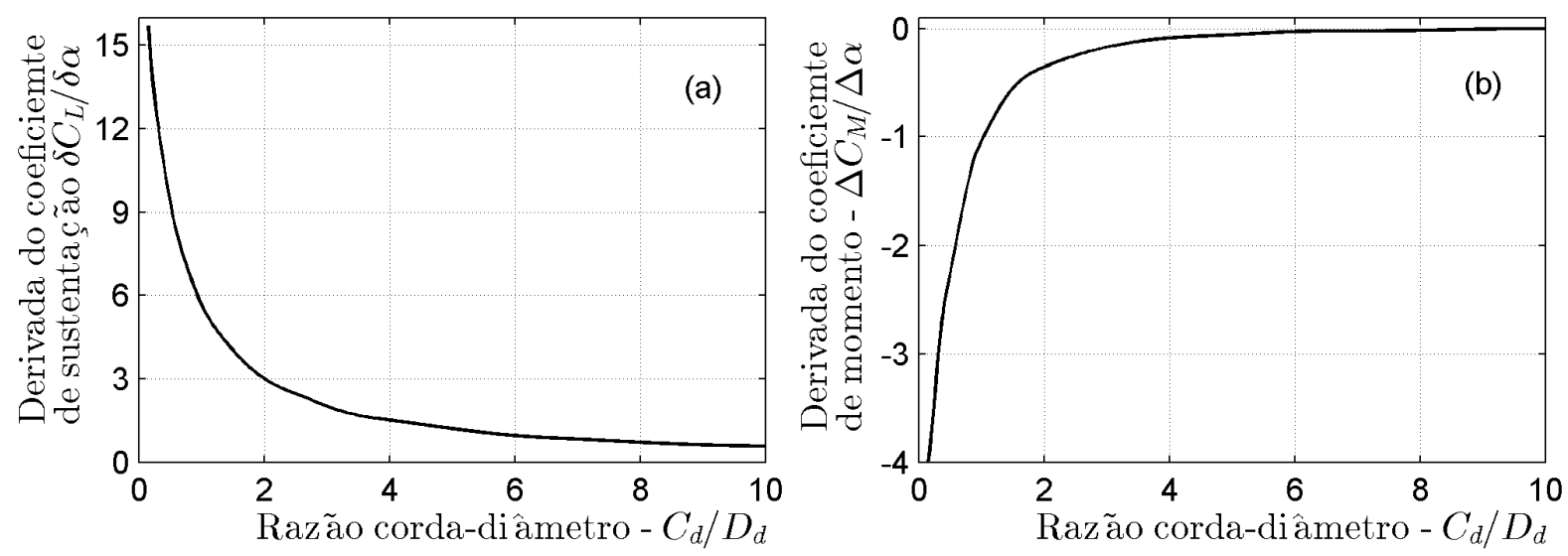

Figura 17 - Derivada dos coeficiente de sustentação (a) e momento (b) de um duto (asa anular), figuras modificadas de Morgan e Caster ${ }^{[136]}$. 


\subsubsection{Interferência Corpo-Duto}

No caso de AUVs, a interferência entre o duto e o corpo ocorre devido a alteração do campo de velocidades do escoamento gerado pela presença do corpo, ou seja, o fenômeno de interferência é regido pela esteira que o corpo gera sobre o escoamento incidente sobre o duto ${ }^{[28]}$.

Esta interferência pode ser calculada utilizando o modelo asa-anular-corpo de McCormick $^{[150]}$ (Ring-Wing-Body Model), onde assume-se o modelo geométrico de um corpo esbelto que apresente um diâmetro na região do duto menor que o próprio duto. Contudo, neste caso é assumido que a interferência é gerada apenas pela incidência do escoamento cruzado do corpo no duto, desprezando o efeito da esteira gerada pela redução do diâmetro da cauda do veículo, que em geral é mais significativo nos casos dos AUVs.

Apesar deste modelo já ter sido aplicado em AUVs ${ }^{[148]}$ similares ao AUV de estudo, ele é mais recomendável para casos que a geometria do corpo esteja mais próxima do modelo simplificado de McCormick ${ }^{[150]}$, como no caso da modificação do AUV planador SLOCUM $^{[149]}$, que apresenta uma asa anular na parte central do veículo com um diâmetro muito maior que o diâmetro do corpo.

Para o caso do AUV Pirajuba, em que o duto está localizado logo atrás da cauda, é mais adequado utilizar a metodologia de Barros e Dantas ${ }^{[28]}$, onde a redução de velocidade da esteira é tratada como uma perda de eficiência hidrodinâmica, reduzindo os esforços gerados pelo duto. Este modelo será apresentado nas próximas seções.

Diferente do caso do leme, a presença do duto não modifica os esforços do corpo, pois como o duto gera esforços de menores magnitudes e está localizado atrás do corpo do veículo, as variações no escoamento gerados pela sua presença (upwash e downwash) não afetam significativamente o escoamento sobre o corpo ${ }^{[28]}$, podendo desprezar este efeito. Portanto, nas próximas seções somente será avaliado a interferência gerada pelo corpo no duto.

\subsubsection{Modelo Estático}

Como previamente comentado, o modelo de interferência do corpo no duto considera que a esteira do veículo gera uma perda de pressão dinâmica no escoamento incidente do duto, gerando uma perda de eficiência hidrodinâmica nos esforços gerados ${ }^{[28]}$. Esta perda de eficiência pode ser relacionada ao coeficiente de esteira, $\omega$, pela equação

$$
\eta_{\omega}=\frac{q_{d}}{q_{\infty}}=\frac{V_{d}^{2}}{V_{\infty}^{2}}=\frac{V_{\infty}^{2}(1-\omega)^{2}}{V_{\infty}^{2}}=(1-\omega)^{2},
$$

onde $q$ é a pressão dinâmica $\left(1 / 2 \rho V^{2}\right)$ e $V$ é a velocidade do escoamento, e os sub-índices 
indicam que estas grandezas escalares são locais ao duto, $d$, e relativas escoamento ao longe, $\infty$.

A eficiência de esteira do duto é integrada às equações dos coeficientes de sustentação e momento ao realizar a simples multiplicação pelos coeficientes do duto isolado, representados pelas equações (4.58) e (4.59), respectivamente. Este tipo de solução é baseada em metodologias de interferências utilizados pela indústria aeronáutica ${ }^{[122,141,126]}$, como a interferência geradas pelas asas de aviões em suas superfícies de controle.

$$
\begin{aligned}
C_{L_{\text {Duct }}} & =\eta_{\omega} \frac{\delta C_{L}}{\delta \alpha} \alpha \\
C_{M_{\text {Duct }}} & =\eta_{\omega} \frac{\delta C_{M}}{\delta \alpha} \alpha
\end{aligned}
$$

O coeficiente de esteira pode ser calculado pela metodologia ASE desenvolvida para submarinos de Jackson ${ }^{[69]}$, em que este coeficiente é calculado por uma relação entre as áreas superficiais da popa e proa do AUV. Esta relação é representada pela expressão

$$
\begin{aligned}
(1-\omega) & =0.3674+\frac{0.01382}{\sqrt{L_{b} / D_{b}-K_{\omega}}} \\
& +0.008406 \frac{D_{d}}{D_{b}}+1.6732 \frac{D_{d}}{D_{b} \sqrt{L_{b} / D_{b}-K_{\omega}}}
\end{aligned}
$$

onde, $L_{b}$ é o comprimento do corpo, $D_{b}$ é o diâmetro máximo do corpo, $D_{d}$ é o diâmetro interno do duto (diâmetro do hélice), e $K_{\omega}$ é o coeficiente geométrico da esteira, definido por

$$
K_{\omega}=6-2.4 C_{w s f}-3.6 C_{w s a}
$$

em que $C_{w s f}$ é o coeficiente prismático de área superficial da proa (forebody), e $C_{w s a}$ é o coeficiente prismático de área superficial da popa (afterbody). Estes coeficientes são definidos pelas equações (4.62) e (4.63), respectivamente, sendo $S$ a área superficial e $L$ o comprimento da proa e da popa, relativo aos subíndices a e $f$.

$$
\begin{aligned}
C_{w s f} & =\frac{S_{f}}{\pi D_{b} L_{f}} \\
C_{w s a} & =\frac{S_{a}}{\pi D_{b} L_{a}}
\end{aligned}
$$

Apesar do cálculo do coeficiente de esteira pelo método de Jackson ${ }^{[69]}$ representar um ganho significativo em comparação ao caso que a esteira não é considerada ${ }^{[28]}$, este coeficiente pode ser melhor estimado com auxílio de simulações de $\mathrm{CFD}^{[28]}$.

Barros e Dantas ${ }^{[28]}$ demonstraram que a estimativa numérica do coeficiente de esteira pode ser feita com simulações de CFD bidimensionais do corpo sozinho do AUV, e mesmo sendo realizadas com ângulo de incidência nulo esta estimativa é valida para 
grandes ângulos. A esteira pode ser calculada ao aplicar numericamente a (4.64) no centro hidrodinâmico nominal do duto, tomado a $25 \%$ da corda em relação ao bordo de ataque, considerando $r_{i}$ como o raio do bosso do hélice, $r_{o}$ o raio externo do duto, e $V(r)$ o módulo da velocidade do escoamento no raio $r$.

$$
V=V_{\infty}(1-\omega)=\frac{\int_{r_{i}}^{r_{o}} V(r) \cdot r \mathrm{~d} r}{\int_{r_{i}}^{r_{o}} r \mathrm{~d} r}=\frac{\int_{r_{i}}^{r_{o}} V(r) \cdot r \mathrm{~d} r}{1 / 2\left(r_{o}^{2}-r_{i}^{2}\right)}
$$

Maiores detalhes sobre o desenvolvimento analítico e numérico deste segundo método, contendo as suposições e resultados que reforçam esta metodologia, podem ser encontrados no trabalho de Barros e Dantas ${ }^{[28]}$.

\subsubsection{Modelo Dinâmico}

Pelo modelo estático da interferência corpo-duto apresentar uma estrutura bastante similar ao modelo do duto isolado, mantendo a sua linearidade, pode ser considerado que o modelo dinâmico possua as mesmas características do que o modelo dinâmico do duto isolado. Em outras palavras, o modelo dinâmico da interferência corpo-duto pode ser obtido ao considerar a substituição do ângulo de incidência estático $(\alpha)$ pelo ângulo de incidência efetivo ${ }^{[122]}\left(\alpha_{e f_{d}}\right)$ nas equações dos coeficientes de sustentação (4.58) e momento (4.59).

Ao considerar o mesmo modelo dinâmico do duto isolado podem ser adotadas as mesmas conclusões, ou seja, que o momento gerado pelo duto devido o braço da força normal é mais significativo do que o momento gerado no duto, principalmente ao considerar o termo dinâmico.

\subsection{MODELO BASEADO NAS SIMULAÇÕES DE CFD}

Em comparação aos demais modelos apresentado nesta tese, o modelo de manobra que utiliza os resultados das simulações de CFD é o modelo que apresenta a abordagem mais moderna e atual. O uso dos modelos baseados em simulações de CFD tem aumentado nos últimos anos ${ }^{[37,38,41,40]}$, devido a popularidade deste tipo de ferramenta na área industrial e acadêmica.

Este aumento na popularidade foi gerado principalmente pelo aumento da capacidade/poder computacional disponível aos engenheiros e pesquisadores, permitindo que diversos casos fossem simulados em um período de tempo muito menor do que quando estas ferramentas de CFD começaram a ser aplicadas em problemas de engenharia naval ${ }^{[32,85]}$. A melhoria da interface com os usuários dos softwares de CFD também contribuíram com esta popularização, possibilitando que os parâmetros de simulação e as condições de contorno fossem melhor adaptadas as características do modelo de manobra ${ }^{[94]}$. 
Em geral, os modelos de manobra de CFD podem ser divididos em duas classes, diferenciadas pela forma de incorporação das simulações de CFD no próprio modelo de manobra.

No primeiro modelo, os equacionamentos cinemático e dinâmico apresentados na seção 2, sem considerar os esforços hidrodinâmicos, são integradas ao software de CFD, sendo resolvidas em conjunto com as simulações transientes de $\mathrm{CFD}^{[38,41,40]}$. Usando este modelo não é preciso utilizar modelos/condições simplificadas, e.g., quasi-estáticas, para estimar os esforços hidrodinâmicos, reduzindo o erro e a incerteza numérica do modelo de manobra. A desvantagem deste modelo está no custo computacional envolvido na realização destas simulações, pois, por serem transientes, elas requerem muito mais tempo de processamento do que as simulações quasi-estáticas, resultando que a simulação de apenas uma manobra teria um custo de simulação equivalente a de diversas simulações quasi-estáticas.

No segundo modelo, diversas simulações estáticas/quasi-estáticas de CFD são realizadas para estimar os esforços hidrodinâmicos em todas as condições de operação do $\mathrm{AUV}^{[37]}$. Estes resultados são utilizados para fornecer uma estimativa dos esforços hidrodinâmicos do AUV, em função das variáveis de estado, durante a solução das equações do modelo de manobra, apresentadas na seção 2. A vantagem deste modelo é que, depois de realizada todas as simulações para se identificar os esforços hidrodinâmicos, o modelo de manobra é concluído, podendo realizar qualquer simulação de manobra de maneira rápida e prática a um custo computacional bastante baixo. Contudo, pelos esforços hidrodinâmicos serem obtidos em condições quasi-estáticas e em condições discretas, é preciso utilizar simplificações para considerar estes esforços no modelo de manobra.

Como o objetivo desta tese é gerar um modelo de manobra confiável, aplicando o procedimento de verificação e validação, que possa ser utilizado de maneira rápida para realizar diversas simulações de manobra, nesta tese somente foi considerado o modelo de manobra de CFD que utiliza o mapeamento dos esforços hidrodinâmicos em condições quasiestáticas. A metodologia para a interpretação dos resultados das simulações realizadas são apresentadas nas seção 4.3.1, enquanto que a metodologia de interpolação dos resultados discretos são apresentados na seção 4.3.2.

\subsubsection{Modelo de interpretação dos esforços hidrodinâmicos numéricos}

Os esforços hidrodinâmicos de amortecimento e sustentação do corpo e das superfícies de controle foram numericamente implementados como funções dependentes de três variáveis: os ângulos da velocidade do veículo em relação ao fluído (ataque, $\alpha$, ou deriva, $\beta$ ), as velocidades de rotação, e a deflexão das superfícies de controle. Da mesma forma que os demais modelos, somente são apresentados os esforços atuantes em um plano, devido à geometria do veículo e às características das manobras permitirem aproximar a dinâmica 
de movimento pela combinação desacoplada dos movimentos em dois planos.

Como comentado anteriormente, neste modelo, os esforços hidrodinâmicos foram estimados pelas simulações de CFD estáticas e dinâmicas da combinação corpo e leme, cuja metodologia foi apresentada na seção 3 e os resultados serão apresentados nas seções 6.2 e 6.3, respectivamente. Entretanto, nestas simulações foram consideradas separadamente as variações combinadas do ângulo de deriva com a deflexão dos lemes (esforços estáticos) e do ângulo de deriva com a velocidade angular (esforços dinâmicos), devido ao alto custo computacional que envolveria em realizar as simulações que mapeassem os esforços considerando a variação simultânea das três variáveis.

Desta forma, duas funções distintas dos esforços hidrodinâmicos foram estimadas numericamente, negligenciando os efeitos de acoplamento simultâneo das três variáveis, e os efeitos de interferência da velocidade angular com a deflexão do leme.

Para incluir estes esforços no modelo dinâmico do simulador foram realizadas algumas simplificações. Primeiramente, é considerado que os esforços de todo AUV $\left(C N_{A U V}\right)$ são obtidos pela combinação corpo e leme $\left(C N_{F B}\right)$, conforme a equação

$$
C N_{A U V}=C N_{F B}(\beta, r, \delta)
$$

onde $\beta$ é o ângulo de deriva, $r$ é a velocidade angular de guinada (yaw) e $\delta$ é a deflexão do leme vertical. O termo $C N_{F B}$ pode ser dividido na contribuição do esforço do corpo $\left(C N_{B}\right)$ e do esforço gerado pela presença do leme $\left(C N_{F-B}\right)$, conforme a equação

$$
C N_{A U V}=C N_{B}(\beta, r)+C N_{F-B}(\beta, r, \delta)
$$

O esforço $C N_{F-B}$ compreende os esforços gerados pelo leme na presença do corpo $\left(C N_{F(B)}\right)$ e os esforços gerados no corpo pela presença do leme $\left(C N_{B(F)}\right)$. Esta divisão é utilizada nos modelos ASE que são apresentados na seção 4.2.4, conforme a equação

$$
C N_{A U V}=C N_{B}(\beta, r)+C N_{B(F)}(\beta, r, \delta)+C N_{F(B)}(\beta, r, \delta)
$$

Apesar destas equações serem apresentadas para o coeficiente de força normal $(N)$, elas podem ser consideradas como uma ilustração do procedimento, sendo validas também para o momento e força axial.

A função dos esforços do corpo $\left(C N_{B}\right)$ pode ser obtida diretamente pelos resultados das simulações numéricas do corpo, apresentada na seção 6.3.1, pois as simulações foram realizadas considerando a variação simultânea do ângulo de incidência $(\beta)$ e da velocidade angular $(r)$. Para o caso dos demais esforços, eles podem ser unidos no esforço da combinação menos a parcela do corpo $\left(C N_{F-B}=C N_{B(F)}+C N_{F(B)}\right)$, onde uma possível solução seria decompor o esforços resultante em três funções que consideram apenas uma variável de 
entrada, conforme a equação

$$
\begin{aligned}
C N_{F-B}(\beta, r, \delta) & \left.\cong C N_{F-B}(\beta, r=0, \delta=0)\right|_{\text {Estático }} \\
& +\left.C N_{F-B}(\beta=0, r, \delta=0)\right|_{\text {Dinâmico }} \\
& +\left.C N_{F-B}(\beta=0, r=0, \delta)\right|_{\text {Controle }} \\
& =\left.C N_{F-B}(\beta)\right|_{E}+\left.C N_{F-B}(r)\right|_{D}+\left.C N_{F-B}(\delta)\right|_{C}
\end{aligned}
$$

O problema deste método simples é que os efeitos de interferência/acoplamento entre as variáveis não são considerados, ocasionando na modelagem incorreta de diversos efeitos que dependem de mais de uma variável, como por exemplo, o efeito do estol dos lemes apresentado na seção 6.2.4. Para que estes efeitos sejam considerados é preciso que existam funções que modelem a interferência entre as diferentes variáveis. Uma possível representação matemática desta função seria

$$
\begin{aligned}
C N_{F-B}(\beta, r, \delta) & =\left.C N_{F-B}(\beta)\right|_{E}+\left.C N_{F-B}(r)\right|_{D} \\
& +\left.C N_{F-B}(\delta)\right|_{C}+K N_{F-B}(\beta, r, \delta)
\end{aligned}
$$

onde o coeficiente $K N_{F-B}$ representaria somente o fator de interferência entre os diferentes componentes dos esforços, incluindo o efeito do estol. Nesta equação, os três primeiros termos do lado direito podem ser obtidos com os resultados das simulações de CFD realizadas, mas não é possível obter o fator $K N_{F-B}$ em função das três variáveis, já que, como explicado anteriormente, as simulações necessárias para identificar este fator não puderam ser realizadas, devido ao alto custo computacional envolvido no processo.

Para encontrar o valor do fator $K N_{F-B}$, admite-se que o efeito simultâneo das três variáveis é capturado pela superposição linear de três funções de interferência das variáveis de movimento tomadas 2 a 2, ou seja, desprezando apenas os efeitos simultâneos das três variáveis. Considerando esta simplificação, a nova função é representada por

$$
\begin{aligned}
\left.C N_{F-B}(\beta, r, \delta) \cong C N_{F-B}(\beta)\right|_{E}+\left.C N_{F-B}(r)\right|_{D}+\left.C N_{F-B}(\delta)\right|_{C} \\
+\left.K N_{F-B}(\beta, r)\right|_{E+D}+\left.K N_{F-B}(\beta, \delta)\right|_{E+C}+\left.K N_{F-B}(r, \delta)\right|_{D+C}
\end{aligned}
$$

onde foi adotada a notação que os subíndices indicam o tipo de esforço que está relacionado a interferência. Ou seja, os índices $E, D$ e $C$ representam os coeficientes de interferência de origem estática, dinâmica e de controle, respectivamente.

Esta simplificação está de acordo com os modelos hidrodinâmicos adotados na indústria naval ${ }^{[11,12,13,14]}$, em que os termos de alta ordem que dependem simultaneamente destas três variáveis, que seria equivalente ao termo $K N_{F-B}$ da equação (4.69), são considerados insignificantes por apresentarem esforços muito menores do que os obtidos pelos demais termos. Em outras palavras, é considerado que os efeitos de acoplamento 
simultâneo das três variáveis é responsável por gerar esforços de baixas amplitudes em comparação com os termos tomados 2 a 2.

Os coeficientes de interferência $E+D$ e $E+C$ podem ser obtidos das simulações dinâmicas (seção 6.3.2) e estáticas (seção 6.2.4), respectivamente, apresentadas nesta tese. Admitindo-se que o fator de interferência $D+C$ representa uma parcela pouco significativa dos esforços hidrodinâmicos, ou seja, que o acoplamento hidrodinâmico entre o movimento de rotação e a deflexão de controle produz esforços de baixas amplitudes em comparação com os demais esforços, a equação (4.70) pode ser simplificada para a equação (4.71).

$$
\begin{aligned}
C N_{F-B}(\beta, r, \delta) & \left.\cong C N_{F-B}(\beta)\right|_{E}+\left.C N_{F-B}(r)\right|_{D}+\left.C N_{F-B}(\delta)\right|_{C} \\
& +\left.K N_{F-B}(\beta, r)\right|_{E+D}+\left.K N_{F-B}(\beta, \delta)\right|_{E+C}
\end{aligned}
$$

Os termos dos esforços da equação (4.71) podem ser obtidos utilizando os resultados das simulações de CFD realizadas neste trabalho, mas os fatores de interferência não podem ser obtidos diretamente, sendo necessário reorganizar esta equação. Primeiramente, as funções dos esforços hidrodinâmicos obtidas pelos dados de CFD, dependentes de duas variáveis de entrada, são reescritas utilizando os coeficientes de interferência e os coeficientes que dependem apenas de uma variável de entrada. As equações para as simulações dinâmicas $(E+D)$ e de controle $(E+C)$ são apresentadas na equação (4.72).

$$
\begin{aligned}
& \left.C N_{F-B}(\beta, r)\right|_{E+D}=\left.C N_{F-B}(\beta)\right|_{E}+\left.C N_{F-B}(r)\right|_{D}+\left.K N_{F-B}(\beta, r)\right|_{E+D} \\
& \left.C N_{F-B}(\beta, \delta)\right|_{E+C}=\left.C N_{F-B}(\beta)\right|_{E}+\left.C N_{F-B}(\delta)\right|_{C}+\left.K N_{F-B}(\beta, \delta)\right|_{E+C}
\end{aligned}
$$

Em seguida, são descontados os termos estáticos dos esforços $\left(C N_{F-B}(\beta)\right)$, como segue:

$$
\begin{aligned}
& \left.C N_{F-B}(\beta, r)\right|_{E+D}-\left.C N_{F-B}(\beta)\right|_{E}=\left.C N_{F-B}(r)\right|_{D}+\left.K N_{F-B}(\beta, r)\right|_{E+D} \\
& \left.C N_{F-B}(\beta, \delta)\right|_{E+C}-\left.C N_{F-B}(\beta)\right|_{E}=\left.C N_{F-B}(\delta)\right|_{C}+\left.K N_{F-B}(\beta, \delta)\right|_{E+C}
\end{aligned}
$$

Substituindo as equações (4.73) na equação (4.71) é obtida a equação (4.74).

$$
\begin{aligned}
\left.C N_{F-B}(\beta, r, \delta) \cong C N_{F-B}(\beta)\right|_{E} & +\left.C N_{F-B}(\beta, r)\right|_{E+D}-\left.C N_{F-B}(\beta)\right|_{E} \\
& +\left.C N_{F-B}(\beta, \delta)\right|_{E+C}-\left.C N_{F-B}(\beta)\right|_{E} \\
=\left.C N_{F-B}(\beta, r)\right|_{E+D} & +\left.C N_{F-B}(\beta, \delta)\right|_{E+C}-\left.C N_{F-B}(\beta)\right|_{E}
\end{aligned}
$$

A equação (4.74) representa uma relação mais direta com os dados de CFD do que a equação (4.71). No entanto, como os dados das simulações de CFD fornecem diretamente as funções dos esforços de combinação $\left(C N_{F B}\right)$ e do corpo sozinho $\left(C N_{B}\right)$, é preciso aplicar a relação apresentada na equação (4.66) para relacionar estes coeficientes 
às funções dos esforços gerados pela presença do leme no corpo $\left(C N_{F-B}\right)$. Considerando esta transformação, a equação (4.74) é reescrita na equação (4.75).

$$
\begin{aligned}
C N_{F-B}(\beta, r, \delta) & \cong\left[C N_{F B}(\beta, r)-C N_{B}(\beta, r)\right]_{E+D} \\
& +\left[C N_{F B}(\beta, \delta)-C N_{B}(\beta)\right]_{E+C} \\
& -\left[C N_{F B}(\beta)-C N_{B}(\beta)\right]_{E}
\end{aligned}
$$

A equação (4.75) pode ser simplificada ao cancelar os termos estáticos de sinais opostos dos esforços do corpo sozinho $\left(C N_{B}(\beta)\right)$. Também é considerado que os esforços estáticos $(E)$ da combinação sejam iguais aos esforços estático-dinâmicos $(E+D)$ quando a velocidade de rotação é nula $(r=0)$, e aos esforços estáticos com controle $(E+C)$ quando a deflexão é nula $(\delta=0)$, conforme a equação (4.76).

$$
\begin{aligned}
C N_{F-B}(\beta, r, \delta) & \cong\left[C N_{F B}(\beta, r)-C N_{B}(\beta, r)\right]_{E+D} \\
& +\left[C N_{F B}(\beta, \delta)-C N_{B}(\beta)\right]_{E+C}+\left[C N_{F B}(\beta,)-C N_{B}(\beta)\right]_{E}
\end{aligned}
$$

A equação (4.76) pode ser simplificada ao cancelar os termos estáticos de sinais opostos dos esforços do corpo sozinho $\left(C N_{B}(\beta)\right)$. Também é considerado que os esforços estáticos $(E)$ da combinação sejam iguais aos esforços estático-dinâmicos $(E+D)$ quando a velocidade de rotação é nula $(r=0)$, e aos esforços estáticos com controle $(E+C)$ quando a deflexão é nula $(\delta=0)$, conforme a equação (13).

$$
\left.C N_{F B}(\beta)\right|_{E}=\left.C N_{F B}(\beta, r=0)\right|_{E}=\left.C N_{F B}(\beta, \delta=0)\right|_{E}
$$

Utilizando estas simplificações, a função que relaciona os esforços gerados pela presença do leme ao corpo considerando as três variáveis de entrada, é reescrita por:

$$
\begin{aligned}
C N_{F-B}(\beta, r, \delta) & \cong\left[C N_{F B}(\beta, r)-C N_{B}(\beta, r)\right]_{E+D} \\
& +\left[C N_{F B}(\beta, \delta)-C N_{B}(\beta, \delta=0)\right]_{E+C}
\end{aligned}
$$

Por último, a equação (4.78) é aplicada a equação (4.66) obtendo-se a função que representa os esforços hidrodinâmicos de todo o veículo utilizando os resultados obtidos pelas simulações de CFD. Esta equação é apresentada pela equação

$$
\begin{aligned}
C N_{A U V} & =C N_{F-B}(\beta, r, \delta)+C N_{B}(\beta, r) \\
& \cong\left[C N_{F B}(\beta, r)-C N_{B}(\beta, r)\right]_{E+D} \\
& +\left[C N_{F B}(\beta, \delta)-C N_{F B}(\beta, \delta=0)\right]_{E+C}+C N_{B}(\beta, r)
\end{aligned}
$$

\subsubsection{Metodologia de interpolação dos resultados discretos}

A implementação destas equações no modelo de manobra é realizada por uma interpolação de uma função de terceiro grau definida por partes (spline cúbica) ${ }^{4}$ de uma

$4 \quad$ Conhecido pelo termo em inglês piecewise, que significa que a cada dupla de pontos consecutivos é realizada uma interpolação de uma função definida por estes ou mais pontos. 
ou duas variáveis ${ }^{[152]}$, em função dos pontos discretos dos esforços hidrodinâmicos obtidos pelas simulações CFD.

A função de interpolação é definida localmente a cada conjunto de pontos consecutivos, dois para o caso de uma variável e quatro ("dois a dois") para o caso de duas variáveis. Para o caso de uma função genérica de duas variáveis $u$ e $v$, esta função de interpolação é definida por

$$
s p(m, n)=\sum_{i=0}^{3} \sum_{j=0}^{3} b_{i j} m^{i} n^{j}
$$

que representa a equação de uma superfície de terceiro grau, onde os termos $b_{i j}$ representam os coeficientes desta superfície. No caso deste modelo de manobra, estes coeficientes foram obtidos utilizando condições de contorno de continuidade na função (a superfície que passa por todos os pontos é continua) e na primeira derivada destas superfícies (as superfícies adjacentes apresentam as mesmas derivadas em suas extremidades).

Estes coeficiente são obtidos simultaneamente para todas as superfícies, ao resolver a equação matricial ${ }^{[152]}$

$$
\mathbf{B} \gamma=x
$$

onde o vetor $\gamma$ agrupa os 16 coeficientes $b_{i j}$ (eq. 4.80), o vetor $x$ representa os pontos discretos dos esforços hidrodinâmicos numéricos, e a matriz $\mathbf{B}$ relaciona as condições de contorno.

Por ter sido adotada uma alta resolução nas três variáveis de estado na definição dos casos de simulação, o processo de interpolação deverá propiciar erros de pequenas magnitudes.

No caso do modelo ASE o acoplamento entre as três variáveis já é intrínseco do próprio modelo apresentado, não precisando realizar estas aproximações. No entanto, no modelo ASE são consideradas aproximações relativas ao próprio equacionamento, como o uso da curva não linear do leme isolado obtido pelo método de CFD e o uso de fatores analíticos e semi-empíricos para considerar a interferência/combinação.

Apesar de ambas as metodologias apresentarem aproximações, acredita-se que estes modelos proporcionam uma melhor estimativa dos esforços hidrodinâmicos atuantes no AUV do que os modelos clássicos da indústria naval, que são calculados por termos de primeira e segunda ordem (somente para os termos de arrasto cruzado) de uma expansão em série de Taylor dos esforços hidrodinâmicos ${ }^{[12,14]}$, conforme apresentado na seção 4.1 . Nestes modelos, os efeitos não lineares são aproximados, quando considerados, e os efeitos de estol da asa não são considerados diretamente. 


\section{ENSAIOS DE VALIDAÇÃO DOS MODE- LOS DE MANOBRAS}

Tradicionalmente, para que as estimativas dos esforços hidrodinâmicos tenham algum embasamento científico, elas devem ser validadas por resultados experimentais. Esta prática é adotada na maioria dos casos da engenharia, pois as metodologias experimentais são baseadas em medições diretas ou indiretas destes esforços, o que elimina os erros numéricos e os erros relativos a modelagem, oriundos das simplificações dos modelos.

No caso da indústria naval, as metodologias experimentais estão relacionadas a ensaios em tanques de prova com modelo cativo ${ }^{[86,123,21,124,39,31,153]}$, podendo também ser utilizados ensaios de túnel de vento ${ }^{[68,154]}$, e ensaios de manobras com um modelo livre auto-propelido $[155,156,37,157,158,48,49]$.

Nos ensaios em tanques de provas, um modelo do veículo, em escala real ou reduzida, é rebocado por um carro dinamométrico a uma velocidade constante, enquanto uma balança realiza a medição dos esforços hidrodinâmicos. Quando o modelo permanece em uma orientação fixa durante um reboque estes ensaios medem os esforços estáticos ${ }^{[21,124,39]}$, e quando são impostas oscilações harmônicas por um mecanismo de movimento planar (PMM, Planar Motion Mechanism) são medidos os esforços dinâmicos ${ }^{[86,123]}$.

No caso do AUV Pirajuba foi possível utilizar o tanque de provas do Instituto de Pesquisas Tecnológicas (IPT) do estado de São Paulo para realizar a medição dos esforços hidrodinâmicos estáticos pelo modelo cativo do veículo ${ }^{[39]}$. Apesar de existir um PMM disponível no tanque de provas do IPT, foi verificado que a estrutura do PMM não comportava os esforços gerados pelo modelo cativo do AUV em sua velocidade de cruzeiro, induzindo grandes vibrações que inseriam ruídos harmônicos na medição. O procedimento adotado nos ensaios estáticos no tanque de provas do IPT são apresentados na seção 5.1.

As medições dos esforços dinâmicos também podem ser obtidas por ensaios em um tanque de provas circular ${ }^{[31]}$, onde o veículo é rotacionado para imitar o movimento de curva/giro do veículo. Contudo, como são poucas instituições que realizam estes ensaios, além de serem específicas da indústria naval de grandes embarcações, estes ensaios não foram considerados.

Por não ter sido possível medir diretamente os esforços dinâmicos do AUV Pirajuba, estes esforços tiveram que ser validados por ensaios de manobra. Nestes ensaios o veículo executa diversos tipos de manobras, como a manobra de raio de giro e zigzag, e a relação entre as deflexões dos lemes e a medição dos sensores é utilizada para validar o modelo dinâmico do veículo. 
Como estes experimentos foram realizados em ambiente aberto, diversas considerações sobre os tipos de manobras e os tratamentos dos dados tiveram que ser analisados. $\mathrm{O}$ procedimento para a realização destes ensaios é apresentado na seção 5.2.

\subsection{ENSAIOS ESTÁTICOS EM TANQUES DE PROVA}

O procedimento experimental adotado nos ensaios hidrodinâmicos estáticos dos modelos cativos do AUV Pirajuba e seus apêndices ${ }^{[39]}$ foi dividida em três seções. Primeiramente será apresentado a infraestrutura e os procedimentos dos ensaios realizados, em seguida será comentado sobre os sistemas de medições utilizados, e por último o tratamento dos dados dos sinais.

Os experimentos de tanque de provas que envolvem o modelo cativo do AUV Pirajuba e seus apêndices fizeram parte de dois projetos da Fapesp propostos pelo Prof. Dr. Ettore Apolonio de Barros (orientador deste trabalho), o projeto "Desenvolvimento de veículos autônomos submarinos de baixo custo. parte 2: implementação e estudo de manobrabilidade" (2007/56646-5) e o projeto "Investigação numérica de esforços hidrodinâmicos sobre veículos autônomos submarinos" (2009/10205-3).

\subsubsection{Infraestrutura e procedimento dos ensaios}

Os testes de modelo cativo foram realizados no tanque de provas do laboratório de hidrodinâmica do centro de engenharia naval e oceânica (CNAVAL) do Instituto de Pesquisas Tecnológicas do estado de São Paulo (IPT-SP), apresentado na figura 18. Este tanque de provas possuí $280 \mathrm{~m}$ de comprimento, $6.6 \mathrm{~m}$ de largura e $4.0 \mathrm{~m}$ de profundidade, utiliza um carro de reboque sobre trilhos que apresenta velocidade máximas de $3.5 \mathrm{~m} / \mathrm{s}$, e um mecanismo de movimento planar (PMM - Planar Motion Mechanism), que, para os testes do Pirajuba, somente foi utilizado para orientar estaticamente os modelos cativos no plano horizontal.

Os modelos cativos foram construídos dentro do laboratório de prototipagem do CNAVAL-IPT. Os componentes pequenos, como hélices e asas, foram construídos utilizando uma máquina de prototipagem rápida de inserção de material polimérico (impressora 3D), e os cascos e estruturas maiores foram laminados em fibra de vidro, tendo a sua construção auxiliada por um braço de usinagem robótica de alta precisão.

Durante os testes estáticos, os modelos em tamanho real do AUV Pirajuba foram rebocados a uma velocidade $(V)$ de $1.0 \mathrm{~m} / \mathrm{s}$ e a uma profundidade $(h)$ de $0.9 \mathrm{~m}$, medida a partir da linha de centro do casco dos modelos. Esta profundidade foi adotada por ser maior do que três vezes o diâmetro dos modelos $\left(h>3 D_{b}\right)$, reduzindo os efeitos de sucção de Venturi ${ }^{[159]}$ para níveis insignificantes. O número de Froude baseado no comprimento do corpo $(V / \sqrt{g L})$ é de 0.24 e o baseado na profundidade $(V / \sqrt{g h})$ de 0.36 , indicando 


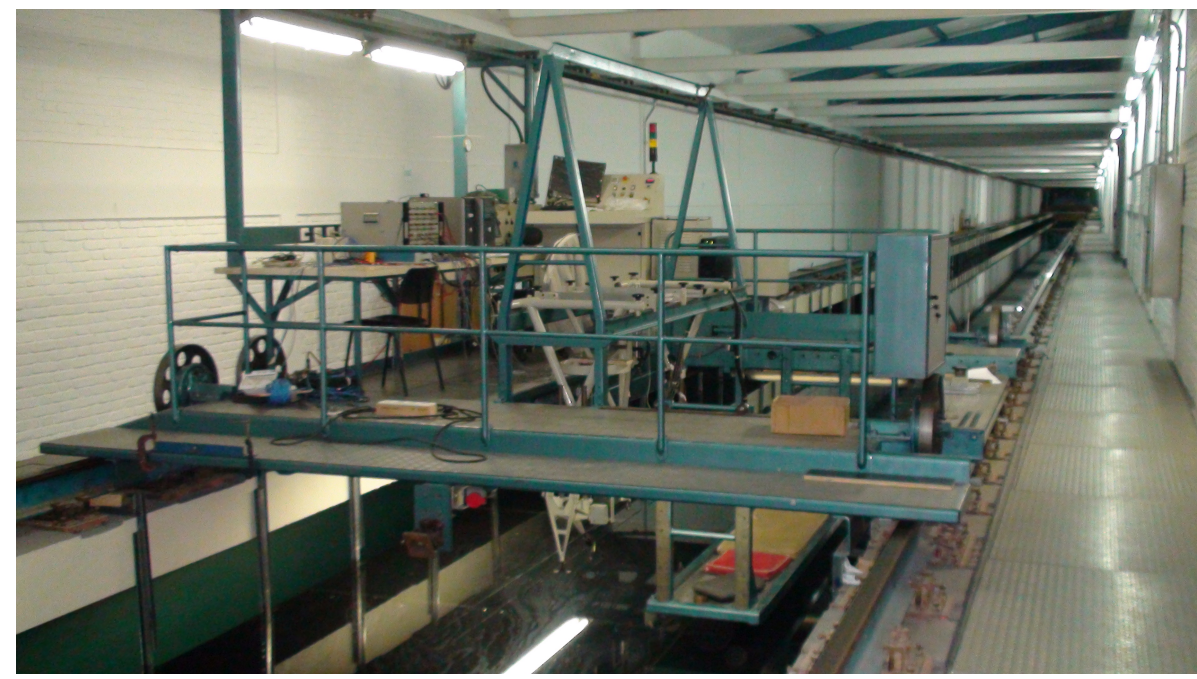

Figura 18 - Tanque de provas e carro dinamométrico do centro de engenharia naval e oceânica (CNAVAL) do Instituto de Pesquisas Tecnológicas do estado de São Paulo (IPT-SP)

um escoamento subcrítico que gera ondas de baixa energia potencial, que implica em uma menor pertubação na medição dos esforços hidrodinâmicos. Independentemente destes números, mesmo nas manobras de grandes ângulos de deriva $\left(\beta=25^{\circ}\right)$, em que o modelo é rotacionado no eixo normal a superfície da água, não foram observadas oscilações na superfície da água devido a presença dos modelos, somente devido às estruturas das balanças de medição dos esforços hidrodinâmicos.

A velocidade de reboque representa a velocidade de navegação padrão do AUV Pirajuba $(1.0 \mathrm{~m} / \mathrm{s})$. Nesta velocidade o número de Reynolds baseado no comprimento é de $1.7 \cdot 10^{6}$, resultando em um escoamento turbulento. Entretanto, este número de Reynolds indica que o corpo do AUV apresenta uma transição entre o escoamento laminar e turbulento em uma parcela significativa do corpo, cerca de um terço do comprimento.

Em todos os ensaios os modelos foram fixados a uma plataforma rotativa, que impõe um ângulo de deriva constante durante os ensaios. Cada modelo foi testado para inclinações de bombordo e estibordo para verificar a existência de eventuais desalinhamentos do próprio modelo em relação a balança, ou do modelo em relação aos seus apêndices.

\subsubsection{Equipamentos e sistemas de medições}

Os primeiros testes com os modelos do corpo isolado e do corpo com apêndices (leme e duto) do AUV Pirajuba foram realizados com uma balança de estrutura típica empregada à ensaios de embarcações navais, apresentada na imagem esquerda da figura 19. Neste arranjo, os modelos foram rebocados por uma estrutura vertical fixada próxima ao centro do veículo, $0.804 \mathrm{~m}$ medido a partir da ponta do nariz, e a unidade de medição foi instalada em uma plataforma rotatório no carro de reboque. A balança utilizada neste 

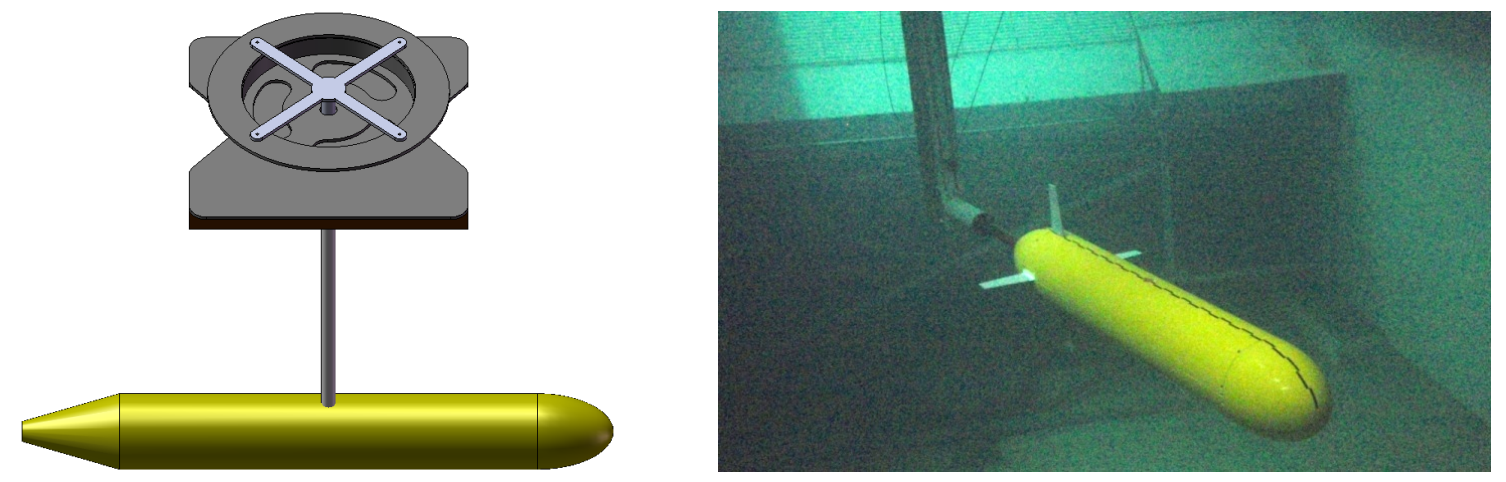

Figura 19 - Balança com estrutura vertical (figura a esquerda) e horizontal (figura a direita), desenvolvida e construída no departamento CNAVAL do IPT, conectada ao modelo cativo do AUV Pirajuba para as medições dos esforços hidrodinâmicos durante os ensaios estáticos

sistema é composta por seis células de cargas isoladas, reduzindo a influência dos diferentes esforços na medição (cross-talk). A medição da força normal e momento foram validadas por testes de um corpo ogival $\mathrm{NACA}^{[121]}$, verificando o efeito negligenciável da estrutura no escoamento sobre o corpo ${ }^{[39]}$.

Este arranjo apresentou problemas na medição dos esforços axiais, pois a medição foi afetada pelo arrasto da estrutura vertical. Este efeito foi reduzido ao utilizar uma capa protetora esbelta sobre a estrutura da balança, que não estava ligada a balança, de forma similar a Azarsina e Williams ${ }^{[124]}$. Contudo, esta capa criou uma grande interferência no escoamento, prejudicando a medição esforços hidrodinâmicos para grandes ângulos de deriva, devido aos vórtices de grande intensidades gerados por esta estrutura.

Com o objetivo de eliminar os problemas de medição, uma outra serie de testes no tanque de provas foi conduzida utilizando uma estrutura em formato de "L" fixada à popa do veículo, conhecida na indústria aeronáutica como sting, apresentada a direita da figura 19, com o sistema de medição instalado dentro do corpo do modelo. Com esta solução, foi possível reduzir a interferência hidrodinâmica gerada pela esteira da estrutura no escoamento sobre o corpo e o seu leme, além de isolar a medição da força axial da estrutura, medindo apenas a força axial do modelo.

Este tipo de arranjo é comumente utilizado em túneis de vento pela indústria aeronáutica $^{[121]}$, sendo chamados de sting. Mas arranjos similares também foram utilizados na investigação hidrodinâmica de AUVs e submarinos, como por exemplo, no trabalho de Jagadeesh, Murali e Idichandy ${ }^{[21]}$.

Nos ensaios dos lemes sozinhos, foi utilizada uma balança com apenas uma célula de carga para medir a força normal gerada. Um placa grande $(1.5 \mathrm{~m}$ de comprimento e 1.0 m de largura) foi instalada perpendicular a envergadura e a uma distância de $1 \mathrm{~mm}$ da base da raiz dos lemes, para isolar o escoamento nos lemes da esteira gerada pela estrutura 
da célula de carga, mantendo a razão de aspecto dos lemes.

\subsubsection{Tratamento das medições}

Cada um dos sistemas de balanças utilizados foi calibrado em bancada antes de serem instalados no carro de reboque. Além disso, cada uma das balanças foi validada ao ensaiar um modelo com resultados já validados. A balança de estrutura vertical foi validada com o corpo ogival $\mathrm{NACA}^{[121]}$, e a balança sting foi validada pela repetição dos casos ensaiados na balança vertical.

O valor medido de cada esforço hidrodinâmico, para um ângulo de deriva, foi calculado pela média da resposta temporal calibrada da respectiva célula de carga em uma corrida. Os efeitos transientes de aceleração e desaceleração do carro de reboque são removidos deste cálculo ao selecionar empiricamente o período de regime estacionário.

A incerteza de medição experimental foi estimada utilizando o mesmo procedimento, mas, ao invés de calcular a média, é realizado o cálculo do desvio padrão considerando os $N_{m}$ dados de medição $\left(\sigma_{m}\right)$ somado ao desvio padrão da célula de carga $\left(\sigma_{r}\right)$, como pode ser visto pela equação 5.1. Desta forma a incerteza considera os ruídos de medição e as flutuações periódicas dos esforços hidrodinâmicos.

$$
\begin{aligned}
\sigma^{2} & =\frac{1}{N_{m}\left(N_{m}-1\right)} \sum_{i=1}^{N_{m}}\left(x_{i}-\bar{x}\right)^{2}+\sigma_{r}^{2} \\
\sigma^{2} & =\sigma_{m}^{2}+\sigma_{r}^{2}
\end{aligned}
$$

Em casos que foram realizadas medições repetidas, i.e., corridas com o mesmo ângulo de deriva, o resultado utilizado foi o da média de ambos os resultados, e a incerteza foi calculada pela propagação de incertezas dos resultados individuais. Um exemplo deste procedimento para duas corridas com o mesmo ângulo de deriva, é apresentado na figura 20.

Em todos os ensaios de tanque de provas, foi aplicado esta metodologia para encontrar o valor do esforço e o seu desvio padrão. No entanto, em alguns casos, a série temporal dos dados não foi fornecida, sendo utilizado apenas o desvio padrão de medição $\left(\sigma_{r}\right)$.

\subsection{ENSAIOS DE MANOBRA COM MODELO LIVRE}

Os primeiros testes de campo do AUV Pirajuba foram realizados para testar as funcionalidades do sistema embarcado do veículo ${ }^{[48]}$, sendo, posteriormente, utilizados para

a identificação dos parâmetros hidrodinâmicos do veículo através de ensaios de manobras ${ }^{[49]}$. Estes testes serão utilizados para validar os modelos hidrodinâmicos ASE, apresentados 


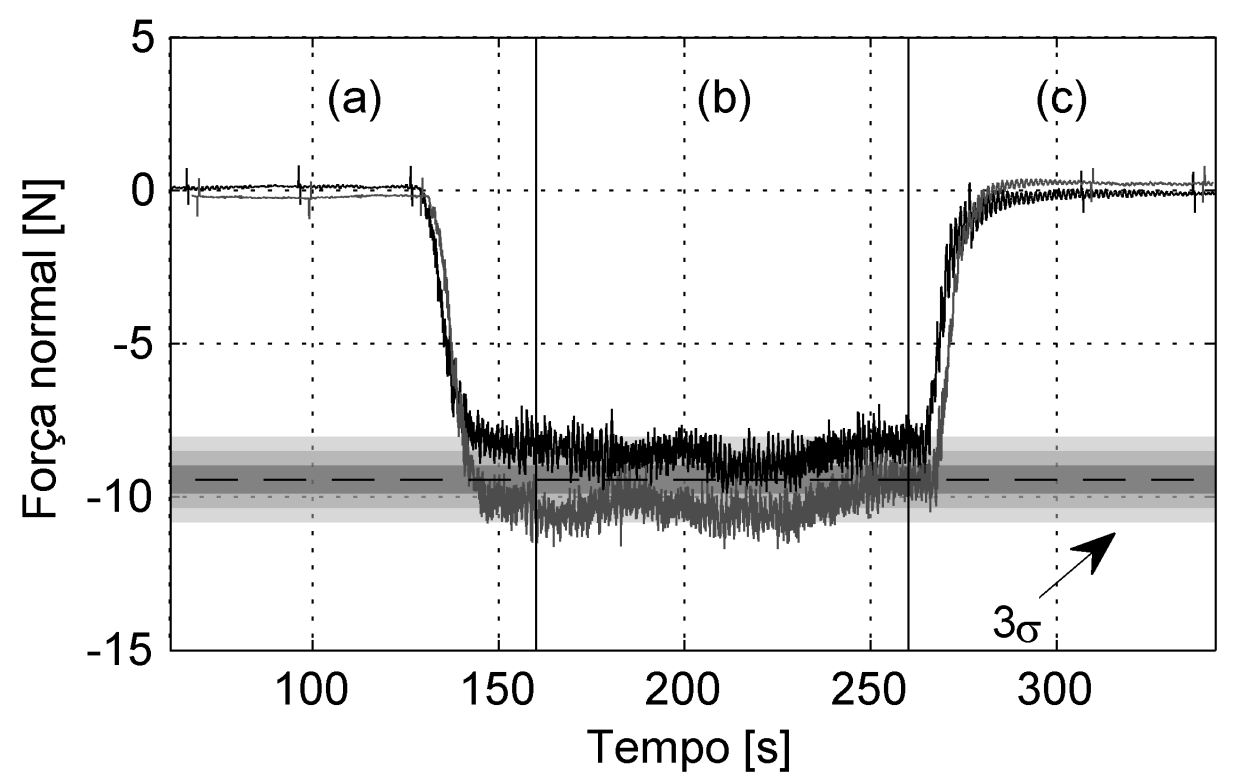

Figura 20 - Exemplo de duas series temporais (linhas pretas e cinzas escuro) da força normal do corpo com os hidroplanos a uma inclinação de $15^{\circ}$, obtidas pela balança durante ensaios distintos do IPT. A região (a) indica a fase de aceleração; a região (b) mostra o intervalo considerado; e a região (c) a fase de desaceleração. As regiões cinza indicam o intervalo de confiança de $68.3 \%$ $(1 \sigma), 95.7 \%(2 \sigma)$ e $99.7 \%(3 \sigma)$ da média de ambas medições.

na seção 2.2, e numéricos (CFD), apresentados na seção 3, através de comparações dos resultados de manobra simulados com os obtidos experimentalmente, de maneira similar ao apresentado em Tang et al. ${ }^{[37]}$.

Os testes de manobra do AUV Pirajuba foram conduzidos tanto em ambientes controlados, como a piscina do CEPEUSP (Centro de Práticas Esportivas da USP), quanto em ambientes marinhos. Apesar do ambiente marinho apresentar maiores perturbações externas, como ondas e correntezas, ele não possui as limitações de alcance impostas pela piscina, que reduzem a duração ou impossibilitam a execução completa das manobras. Por este motivo, somente serão analisadas as manobras executadas em ambiente marinho.

As manobras em mar foram realizadas no colégio Naval de Angra dos Reis, visto na figura 21, com o apoio do Laboratório de Hidrodinâmica (LabHidro) do Centro Tecnológico da Marinha em São Paulo (CTMSP). Este ambiente foi escolhido devido à pouca incidência de correnteza, baixa amplitude das ondas, por apresentar uma profundidade suficiente para os testes, e permitir que as manobras de identificação fossem realizadas por um longo período de tempo. Os ensaios em mar foram realizados em dois períodos distintos, em junho de 2012 e janeiro de 2013.

Neste experimento foram realizados diversos tipos de manobra de identificação no plano lateral e vertical. Entretanto, para este projeto de pesquisa, apenas foram utilizadas as manobras no plano lateral, por simplificar o modelo dinâmico e permitir uma melhor 

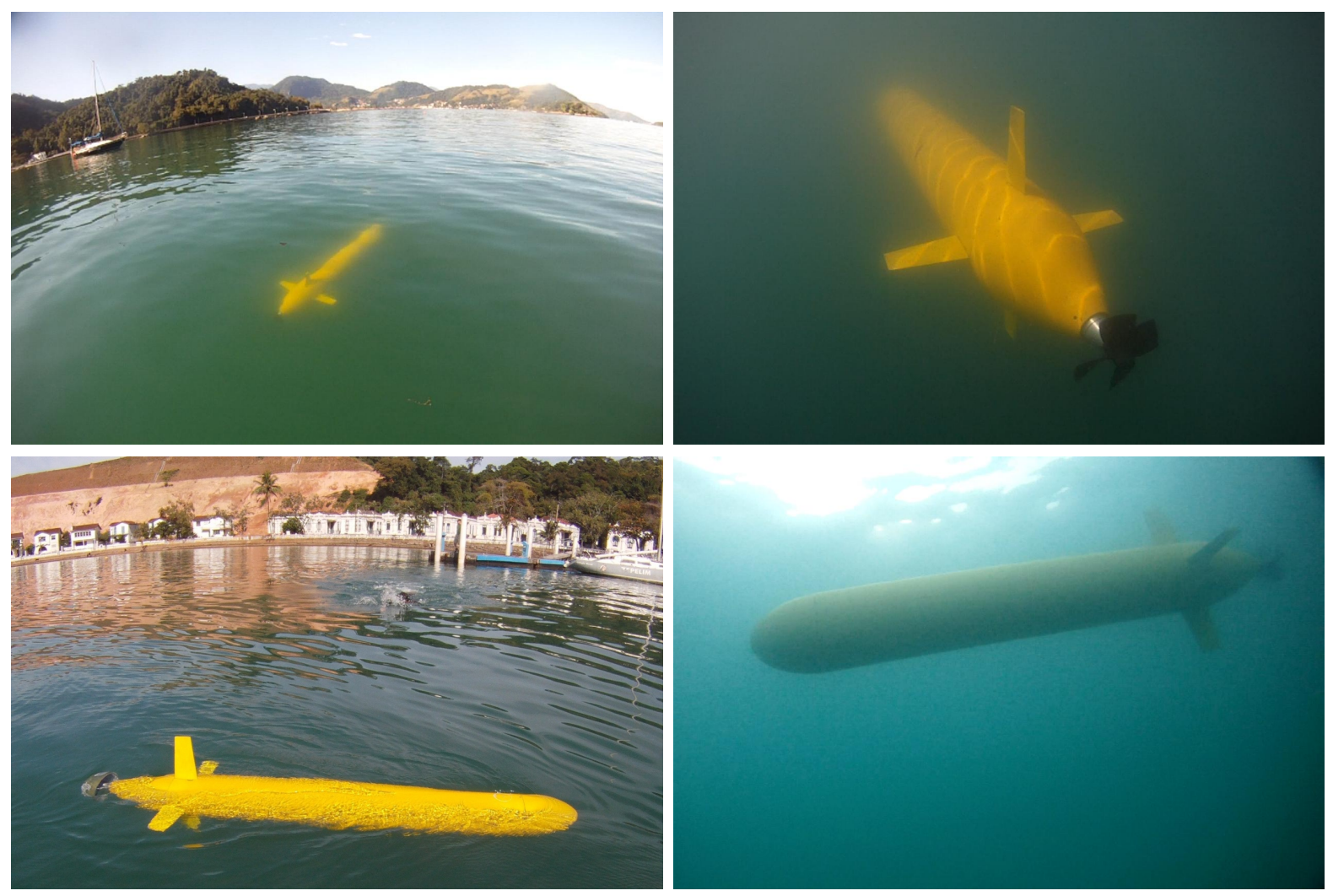

Figura 21 - Fotos submersas e de superfície dos experimentos de manobra do AUV Pirajuba, realizados no Colégio Naval de Angra dos Reis.

comparação dos esforços hidrodinâmicos. No plano vertical foram utilizadas as manobras de raio de giro e de zigzag, sendo que a primeira é comumente utilizada para se determinar os efeitos estacionários, enquanto a segunda é mais propícia para determinar os efeitos transientes ${ }^{[84]}$. Ambas as manobras podem ser utilizadas para identificar ou verificar os parâmetros da planta do AUV, elas são detalhadas nas seções 5.2.2 e 5.2.3, respectivamente, enquanto que na seção 5.2.1 é apresentada a metodologia de execução geral destes ensaios.

\subsubsection{Metodologia de ensaios}

Todos os ensaios de campo foram realizados seguindo a metodologia desenvolvida no Laboratório de Veículos não Tripulados (LVNT), laboratório que foi desenvolvido este trabalho, onde foi procurado melhorar a qualidade dos dados adquiridos pelo AUV Pirajuba e facilitar a execução dos ensaios. Nesta metodologia o AUV sempre executa as manobras no plano lateral, utilizando o controle de profundidade para garantir que o movimento permaneça neste plano, tendo uma interferência mínima entre os movimentos longitudinais e horizontais.

Esta metodologia é composta pelas seguintes etapas:

1. Inicio do experimento: através da intervenção de um operador, o AUV sai do 


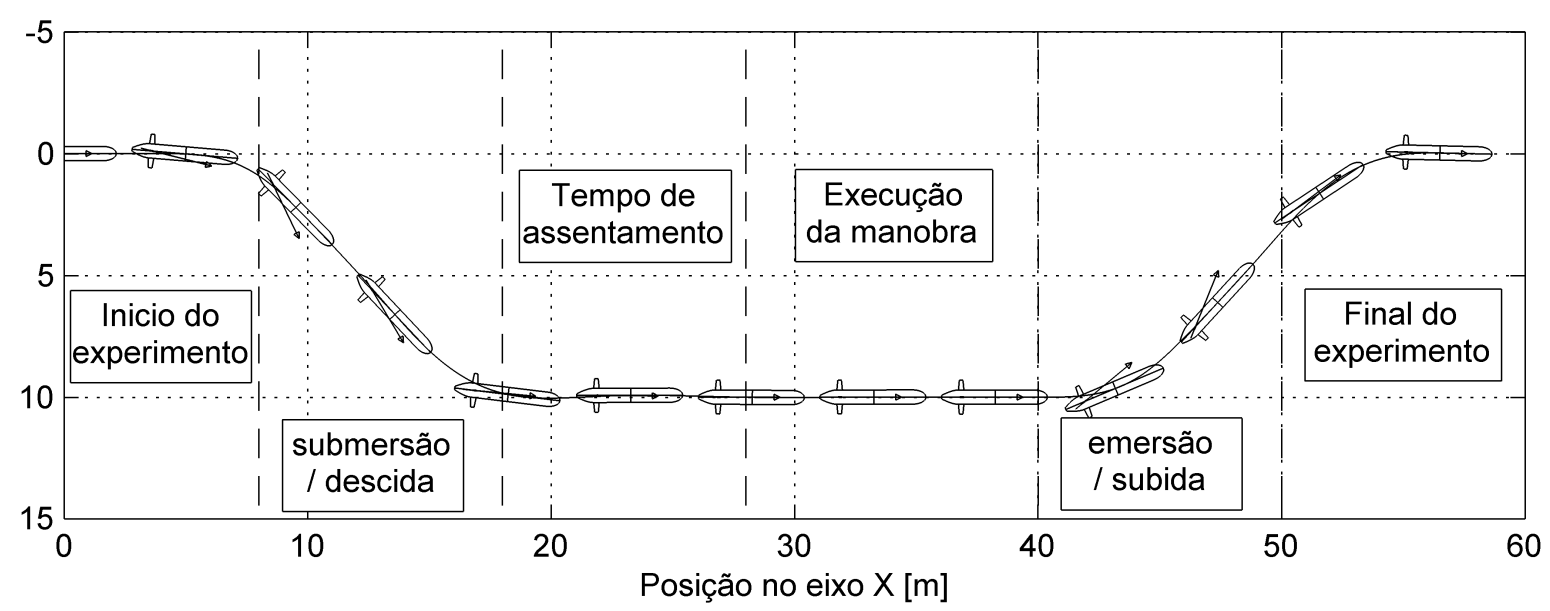

Figura 22 - Etapas dos ensaios de campo de Angra dos Reis com o AUV Pirajuba.

modo de espera e inicia a sua aceleração.

2. Submersão: Nesta etapa o AUV submerge até a sua cota de ensaio, para reduzir a influência das perturbações da superfície da água.

3. Tempo de assentamento: Após atingir a cota de manobra o AUV navega em linha reta para que os efeitos transientes da mudança de cota sejam reduzidos.

4. Execução da manobra: Ao término do tempo de assentamento, o AUV inicia a manobra pré-definida, executando-a por um tempo pré-determinado ou até que ela seja finalizada.

5. Emersão: Ao término da manobra o AUV volta a navegar em linha reta e ao mesmo tempo sobe à superfície.

6. Final do experimento: Ao chegar na superfície o AUV desliga os seus motores e espera a intervenção do operador.

Estas etapas são ilustradas na figura 22 de forma qualitativa, ou seja, o tamanho entre as etapas não é o mesmo que o encontrado nos experimentos.

Para manter o número de Reynolds do experimento constante e igual aos experimentos em tanque de prova, todos os ensaios foram realizados na velocidade de cruzeiro, $1 \mathrm{~m} / \mathrm{s}$. A velocidade do veículo foi ajustada por um controle em malha aberta, que foi regulado empiricamente por ensaios em linha reta com a medição do tempo e do espaço percorrido realizada por sensores externos.

Seria possível utilizar o DVL para medir a velocidade longitudinal do veículo, para realimentar um sistema de controle de velocidade. Entretanto, a inclusão deste sensor modificaria a forma do casco, devidos aos transdutores que tem que ficar externos ao casco, afetando o escoamento em torno do veículo e consequentemente os esforços hidrodinâmicos. 


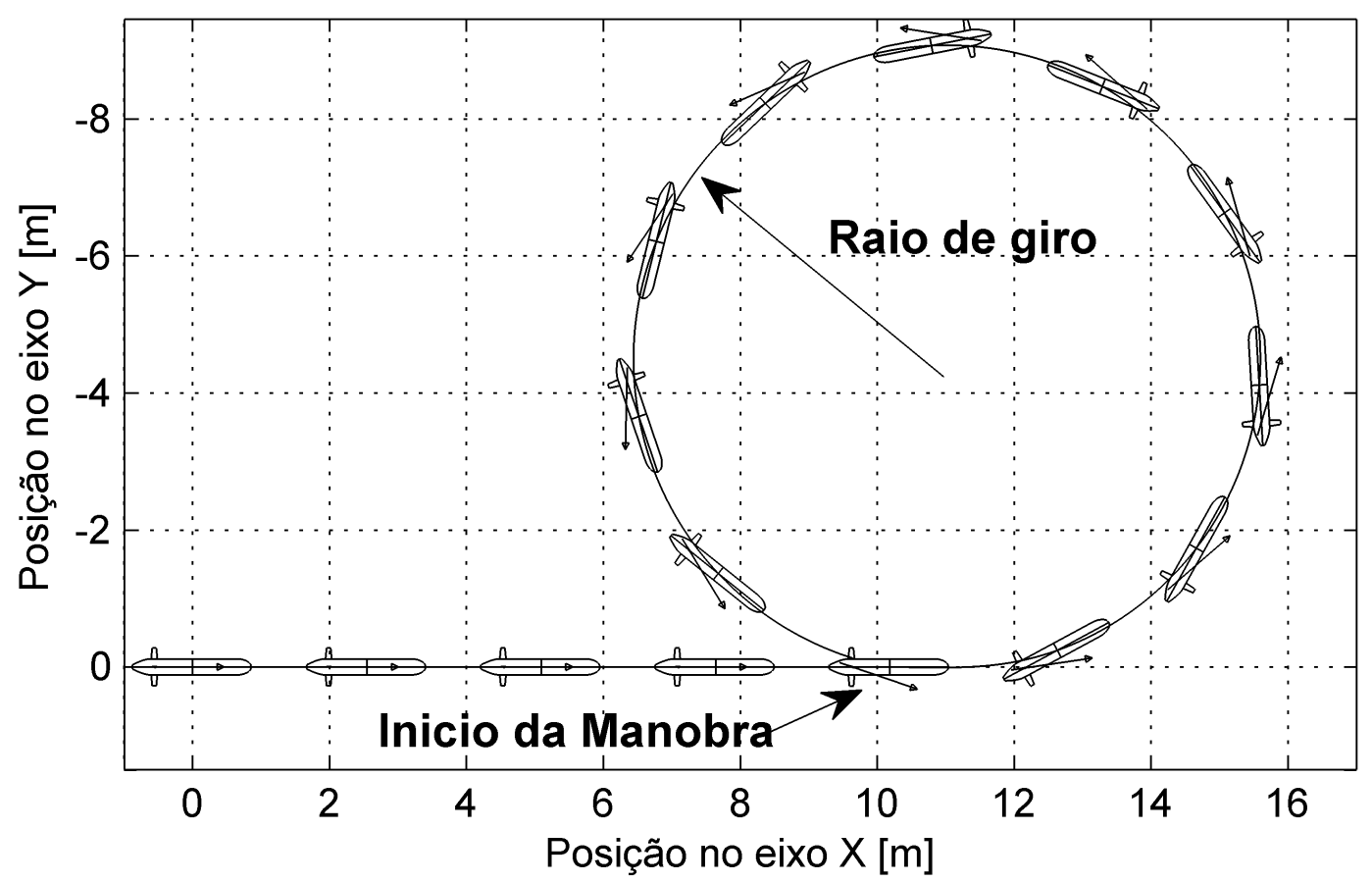

Figura 23 - Diagramação de uma manobra de giro, com uma entrada de leme de 20 graus no instante de tempo de $10 \mathrm{~s}$.

Maiores detalhes sobre a metodologia de ensaio são apresentados em Dantas et al. ${ }^{[48]}$ e Dantas et al. ${ }^{[49]}$.

\subsubsection{Manobra de giro}

A manobra de raio de giro (ou turning circle, em inglês) é uma das manobras mais antigas e clássicas utilizadas na área naval. Esta manobra é executada pela simples deflexão do leme em uma direção, fazendo o veículo executar uma manobra circular. Esta manobra é finalizada quando o veículo realiza mais de uma volta, possibilitando o cálculo do raio de manobra sem considerar o efeito transiente inicial. Uma diagramação desta manobra para um AUV é apresentado na figura 22.

$\mathrm{Na}$ área naval esta manobra é principalmente utilizada para obter-se o raio de giro de embarcações, mas ela também é utilizada para obter-se outros parâmetros, como o avanço máximo (distância em que o veículo vira 90 graus) e o diâmetro tático (distância transversal necessária para o veículo virar 180 graus). Uma descrição mais detalhada das propriedades desta manobra pode ser encontrada em Gertler e Hagen ${ }^{[160]}$.

Neste trabalho, esta manobra será utilizada como validação dos modelos no simulador a uma entrada degrau, realizando comparações da resposta em regime transiente e permanente. Ao invés de realizar a comparação das respostas pelo ângulo de rumo, que é mais usual na área naval, a comparação será realizada pela taxa de rumo, por essa variável representar uma relação mais direta com os esforços dinâmicos, além de não considerar o 
efeito de filtragem induzido pela integração da taxa de rumo.

Devido à não linearidade dos esforços hidrodinâmicos do AUV Pirajuba, as manobras de giro foram repetidas para quatro amplitudes de deflexão da superfície de controle: 5, 10, 15, e 20 graus. Cada um destes ensaios foi repetido pelo menos quatro vezes, para possibilitar uma melhor estimativa do desvio padrão deste experimento e possibilitar a correta filtragem das perturbações externas e dos ruídos do sistema. Estas manobras também foram executadas para bombordo e boreste, verificando possíveis assimetrias no veículo ou incidência de correnteza.

\subsubsection{Manobra de zigzag}

Nas manobras de zigzag o AUV executa uma trajetória harmônica, com frequência e amplitude do movimento determinadas pelo valor da deflexão de seu leme e do ângulo de acionamento de rumo. O experimento de manobra de zigzag foi proposto inicialmente por Kempf ${ }^{[161]}$, sendo posteriormente padronizado pelo ITTC (International Towing Tank Conference) em 1963, onde a manobra de Zigzag $X^{\circ}-Y^{\circ}$ indica uma deflexão de leme de $X^{\circ}$ para um ângulo de acionamento de rumo de $Y^{\circ}$.

A manobra de zigzag se inicia com o veículo acionando o leme para um lado com um certo valor $X$, a partir de um movimento em linha reta. A deflexão do leme é mantida constante até que o ângulo de rumo atinja um valor de acionamento $Y$, ao atingir este valor a deflexão do leme é invertida $(-X)$ e mantida constante até que o ângulo de rumo chegue ao valor oposto de acionamento $(-Y)$. A manobra é repetida até que seja realizado

um número suficiente de períodos. Para identificação determinística de barcos ${ }^{[162]}$ são recomendados pelo menos dois ciclos e meio ${ }^{[84]}$.

Na parte superior da figura 24 é apresentada a trajetória resultante do AUV ao executar a manobra de zigzag, enquanto que na parte inferior é apresentada a relação entre deflexão do leme e o ângulo de rumo.

Nos testes do AUV Pirajuba os valores de deflexão do leme e o valor de acionamento foram considerados iguais. Da mesma forma que no caso do raio de giro, foram consideradas quatro diferentes deflexões de leme tendo pelo menos quatro repetições, resultando em um mínimo de 16 experimentos de zigzag.

\subsubsection{Tratamento dos dados experimentais}

Em todas as manobras foi observado um grande ruído no sinal da taxa de rumo, sendo mais significativo para as manobras com menores deflexões das superfícies de controle. Acredita-se que este ruído seja gerado pelas perturbações no ambiente marinho e pelo próprio sensor inercial, representando ruídos de baixa e alta frequência, respectivamente. 

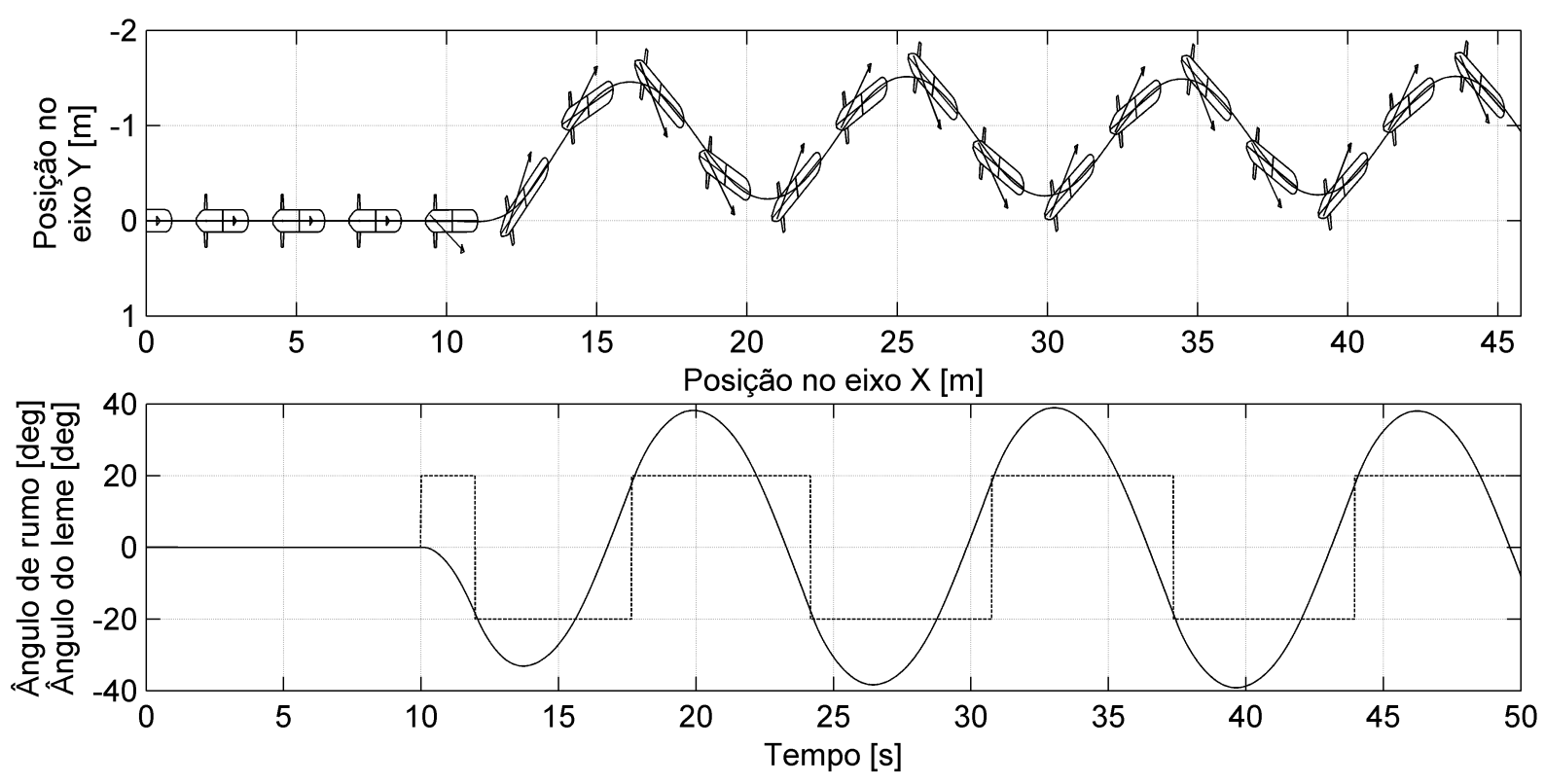

Figura 24 - Diagramação da manobra de Zigzag do tipo 20-20, iniciada no instante de 10 segundos. Na parte superior é apresentada a trajetória do AUV, e na parte inferior os sinais de controle do leme (linha tracejada cinza) junto com os sinais de rumo (linha continua preta).

Para diminuir o efeito do ruído foi proposto realizar o cálculo do valor médio e do desvio padrão dos sinais de taxa de rumo considerando todas as manobras. Para isso foi assumido que os ensaios de uma mesma deflexão possuem características similares, preservando as condições do ambiente e da geometria do veículo, o que é esperado quando as manobras são realizadas em sequência.

A média e o desvio padrão são calculados considerando que as manobras de uma mesma deflexão são sincronizadas no momento em que o leme é acionado pela primeira vez, ou seja, os dados adquiridos são transladados no tempo para que o instante de atuação do leme fique igual em todos os experimentos de mesma deflexão, como pode ser visto nas figura 25. Contudo, ao realizar este cálculo, foi verificado que as barras de erro apresentavam muitos picos e vales consecutivos, visto no primeiro gráfico (superior) da figura 25, apresentando um comportamento semelhante ao encontrado em interferências construtiva e destrutiva de ondas, que, neste caso, eram geradas por uma frequência preponderante nos ruídos dos sinais.

Para corrigir este problema foi proposto aplicar filtros discretos ao sinais de taxa de rumo. Foram testados três tipos de filtros, um filtro de janela retangular (ou filtro caixa), um filtro Butterworth ${ }^{[163] 1}$ e um filtro Gaussiano ${ }^{[164]}$. Os resultados da aplicação destes filtros são apresentados no segundo, terceiro e quarto gráfico da figura 25, respectivamente.

O filtro janela retangular, que substitui o valor em um instante de tempo pela

$1 \quad$ Filtro linear, normalmente passa-baixa, projetado para ter uma resposta em frequência plana na região de interesse (banda passante) e um baixo ganho para as outras frequências. 

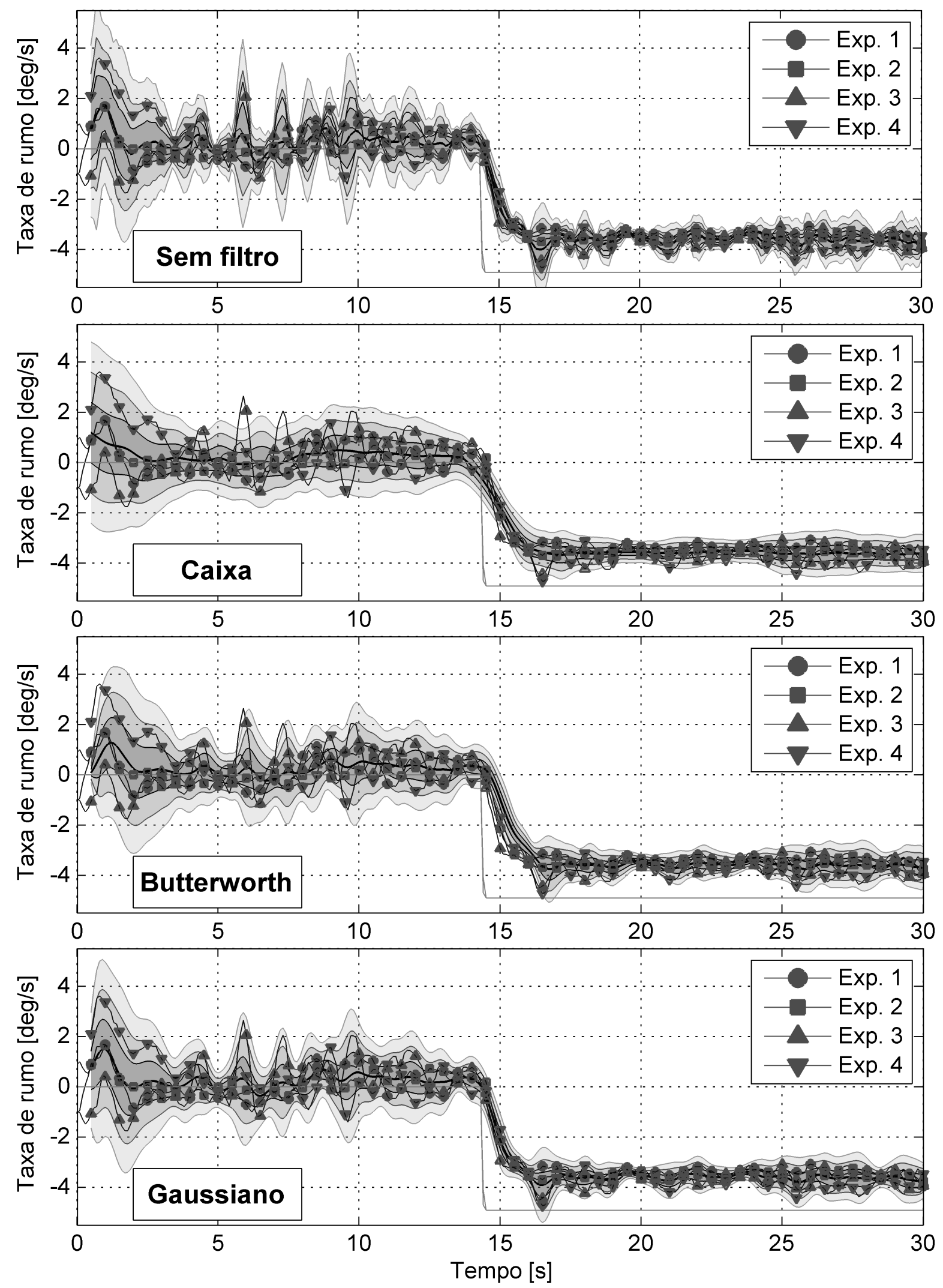

Figura 25 - Comparação dos diversos filtros para as medições da taxa de rumo nas manobras de giro de 5 graus 
média simétrica dos dados adjacentes, gerou uma grande "dispersão" temporal do intervalo de confiança dos sinais, reduzindo excessivamente a dispersão dos dados e do desvio padrão instantâneo. O filtro Butherworth foi ajustado para um filtro de segunda ordem com uma frequência de corte de dois dados consecutivos $(T=0.2 \mathrm{~s})$, reduzindo consideravelmente a dispersão dos dados, mas aumentando o atraso em relação aos dados originais e aos demais filtros. O filtro Gaussiano (equação 5.2) apresentou o melhor resultado, reduzindo os picos dos sinais e mantendo as características originais dos sinais sem gerar um atraso significativo no sinal médio filtrado.

$$
g(t)=\frac{1}{\sqrt{2 \pi} \cdot \sigma} e^{-\frac{t^{2}}{2 \sigma^{2}}}
$$

A aplicação deste filtro é feita pela convolução dos sinais (equação 5.3, sendo $f(t)$ a função que define o sinal no tempo) com a função Gaussiana. Entretanto, como os sinais adquiridos são discretos $(f d(t))$ é necessário aplicar a convolução discreta (equação 5.4) utilizando uma função Gaussiana discretizada em um espaço de tempo finito $(n)$, definido pela frequência de aquisição dos sensores. Neste caso, a convolução discreta age como uma média ponderada pela função Gaussiana. Nota-se ainda que, na verdade, o filtro de janela regular também é uma convolução de uma função constante em um espaço finito com os sinais dos sensores.

$$
\begin{aligned}
& G(t)=(g * f)(t)=\int_{-\infty}^{+\infty} g(\tau) \cdot f(t-\tau) \mathrm{d} \tau \\
& G(k)=\left(g_{d} * f_{d}\right)(k)=\sum_{j=-n}^{+n} g_{d}(k) \cdot f_{d}(k-j)
\end{aligned}
$$

$\mathrm{Na}$ análise deste experimento foi aplicado um desvio padrão da função Gaussiana igual a dois períodos de amostragem (ou dois sinais, i.e., $\sigma=2$ ), para ter a mesma frequência de corte do filtro Buterworth, com uma janela temporal de 10 dados consecutivos (cinco vezes o desvio padrão).

Os sinais da taxa de rumo medidos pelos sensores inerciais são apresentados conjuntamente com a linha média e as regiões definidas por 1, 2 e 3 vezes o valor do desvio padrão, representando um intervalo de confiança com $68.3 \%, 95.4 \%$ e 99.7\%, respectivamente, de probabilidade do valor real estar presente. Os resultados para as quatro deflexões das manobras de giro e zigzag são apresentadas na figura 26 e 27, respectivamente.

Os resultados da análise da resposta de giro podem ser vistos na tabela 2, enquanto que os resultados das manobras de zigzag são apresentados na tabela 3. Os resultados são apresentados para cada experimento e para a média destes experimentos (linha intitulada de M.), sempre acompanhado do desvio padrão de $68.3 \%( \pm 1 \sigma)$ quando cabível.

Algumas propriedades das manobras de baixas deflexões apresentaram uma variação e um desvio padrão maior em comparação com os resultados de maiores deflexões. Isto 

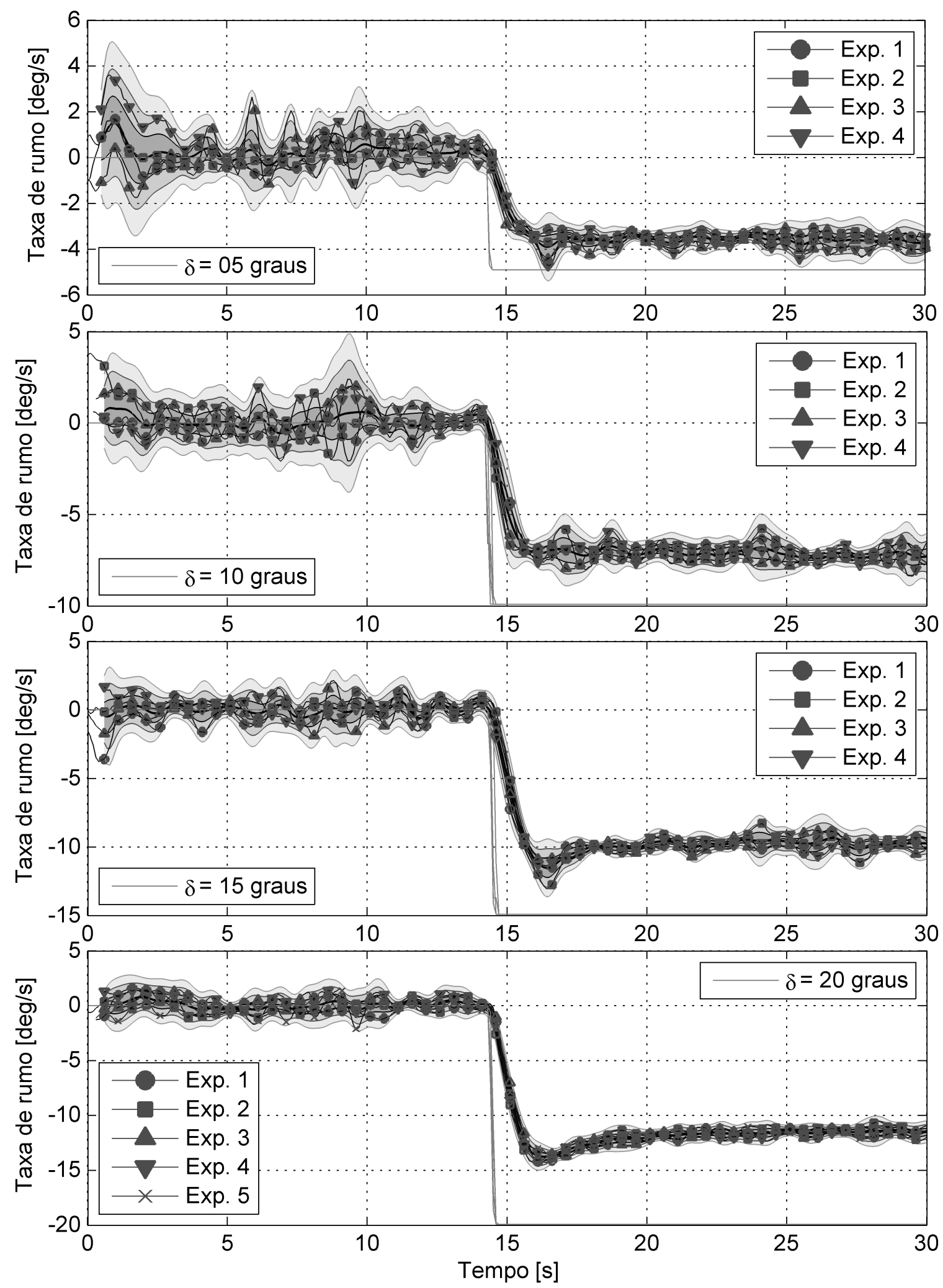

Figura 26 - Resultados experimentais da taxa de rumo para a manobra de giro, considerando as quatro deflexões do ângulo de leme. As regiões em cinza indicam a probabilidade de $68.3 \%(1 \sigma), 95.4 \%(2 \sigma)$ e $99.7 \%(3 \sigma)$ do valor real estar nesta região, considerando o método de filtro Gaussiano 

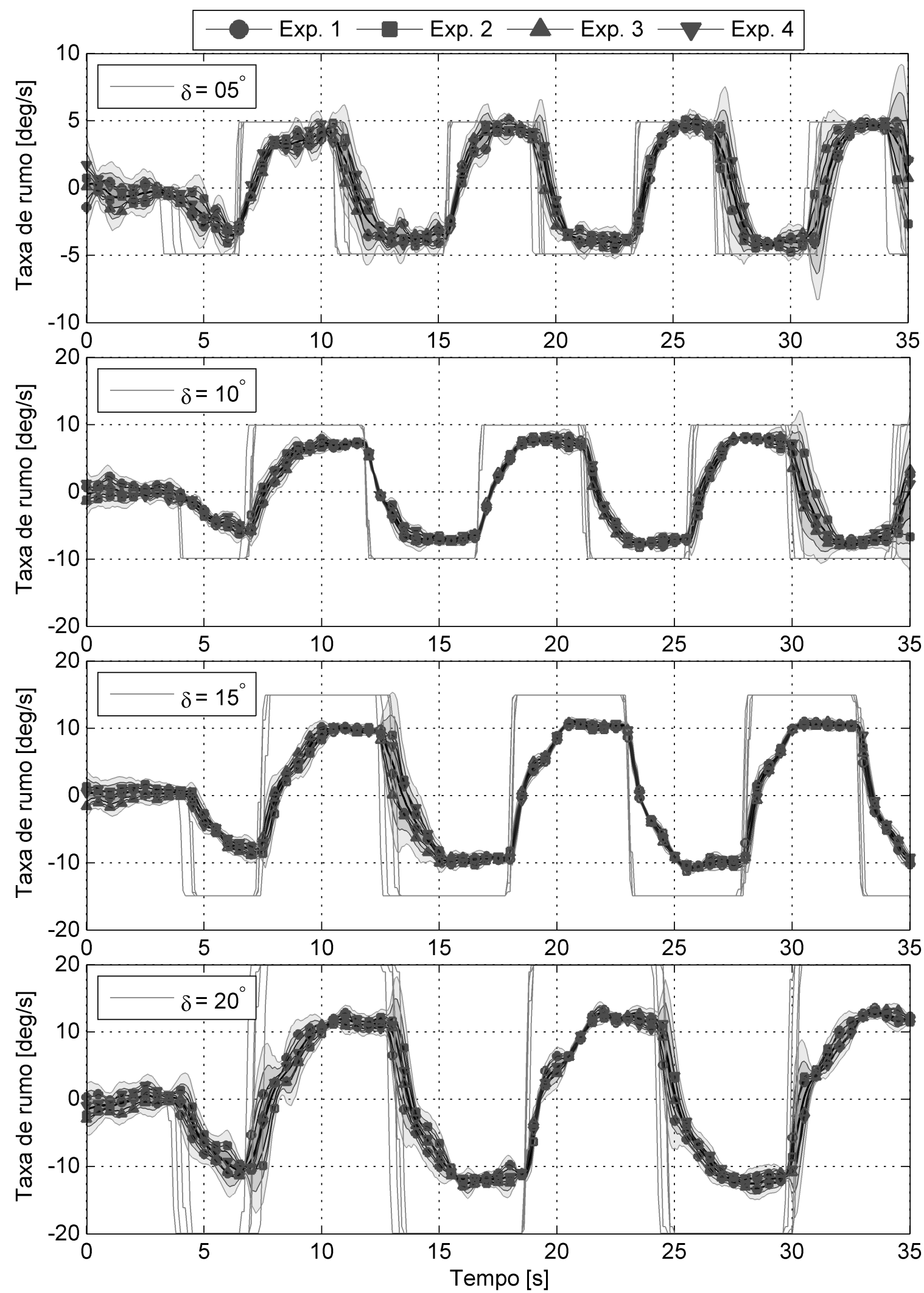

Figura 27 - Resultados experimentais da taxa de rumo para a manobra de zigzag, considerando as quatro deflexões do ângulo de leme. As regiões em cinza indicam a probabilidade de $68.3 \%(1 \sigma), 95.4 \%(2 \sigma)$ e $99.7 \%(3 \sigma)$ do valor real estar nesta região, considerando o método de filtro Gaussiano 


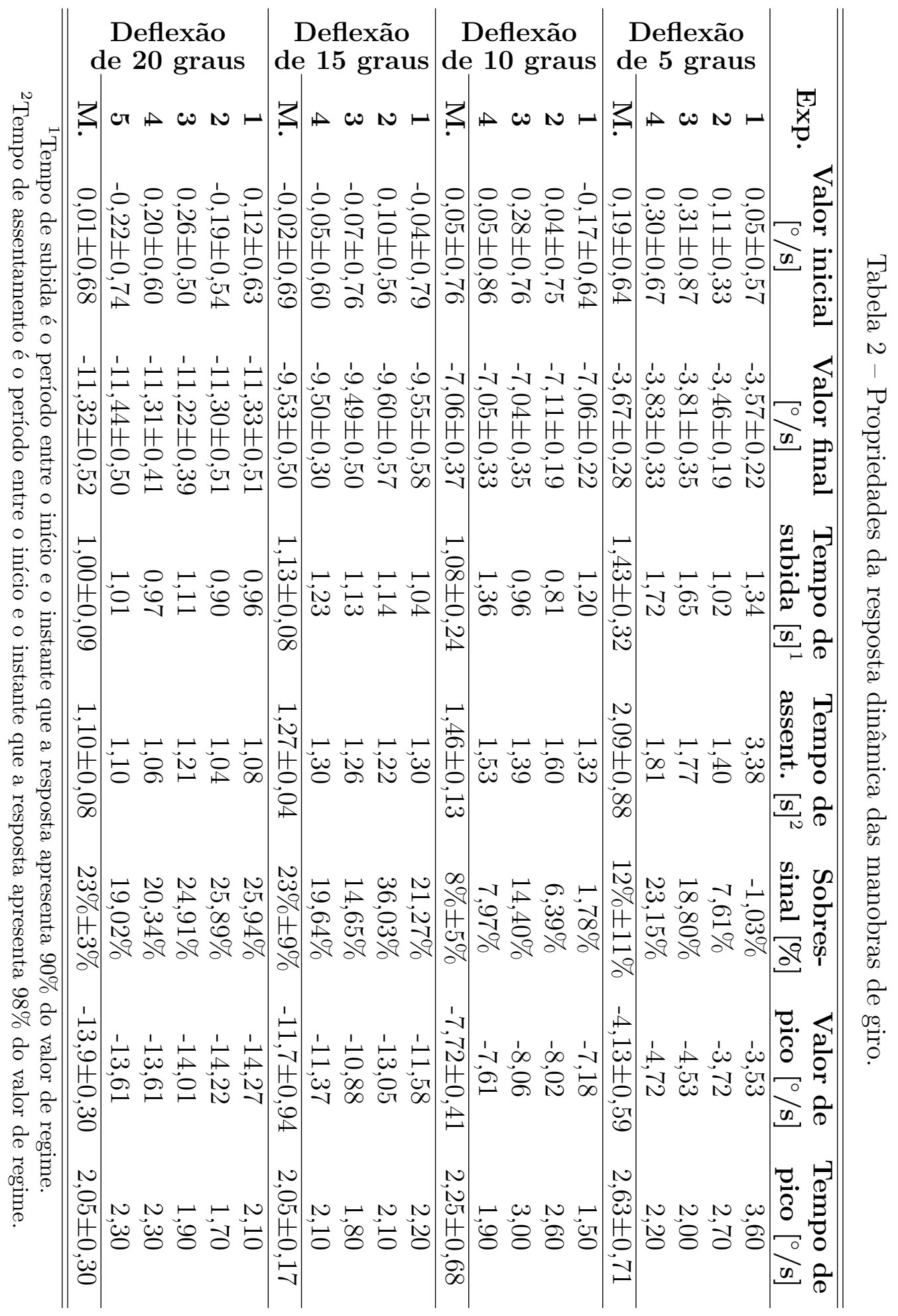




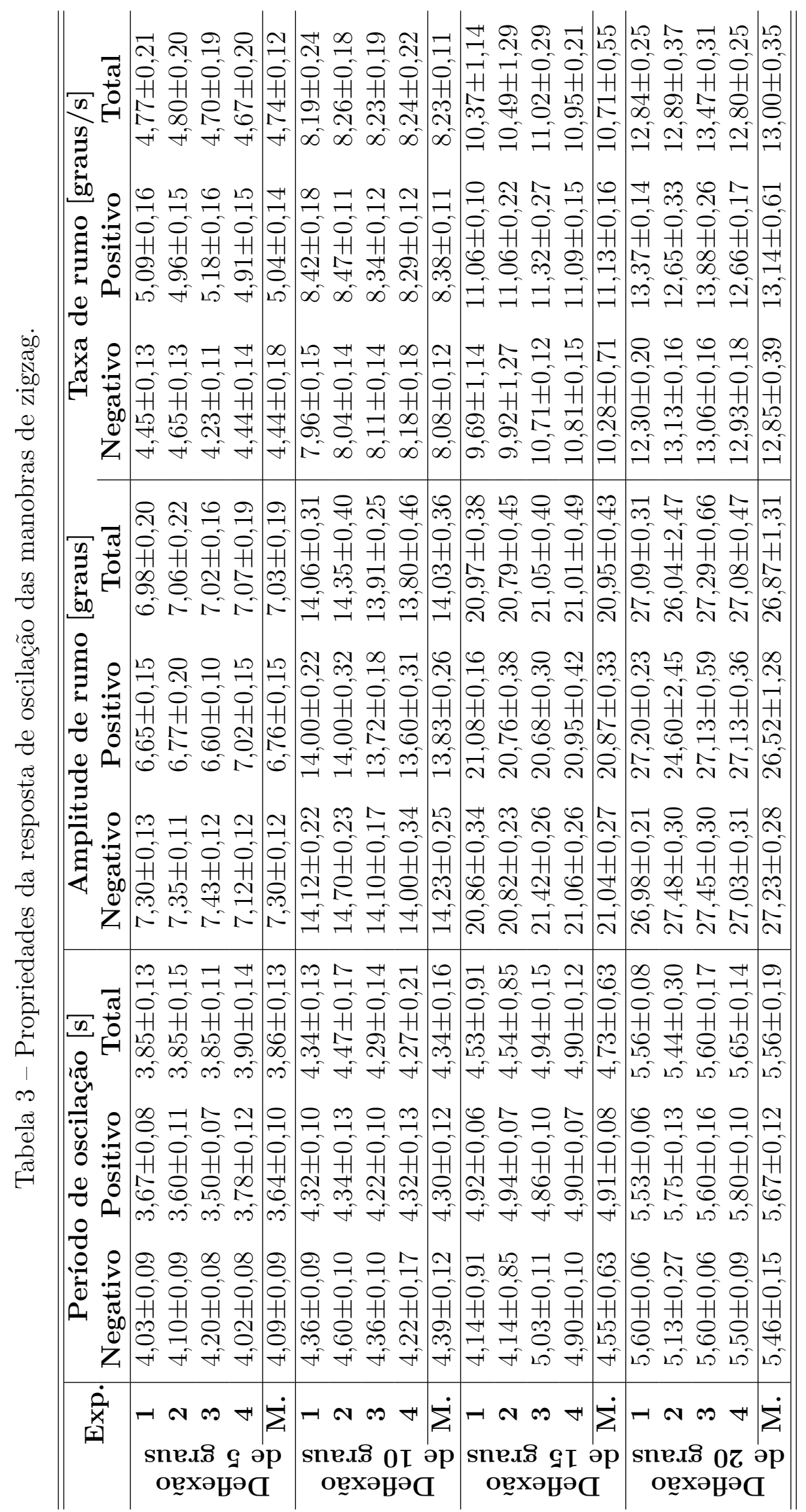


ocorreu devido a redução relativa da intensidade do ruído, que gera uma menor perturbação a medida que a amplitude do movimento aumenta.

Analisando as respostas dinâmicas da manobra de giro é observado que a amplitude de movimento não apresenta uma relação linear com o valor de deflexão do leme. Esta característica é melhor observada nas propriedades do valor final (valor em regime permanente) e do valor de pico, ou sobressinal, apresentados na tabela 2, que aumentam não linearmente com a deflexão. Além do valor final não seguir uma relação constante com o valor de deflexão, o valor de sobressinal aumentou com a deflexão do leme, indicando que o modelo dinâmico do experimento não é linear para grandes deflexões.

Uma parte deste efeito pode ter sido causado pelo estol do leme, que não apresentaria uma relação linear entre o esforço gerado e a deflexão. Este efeito também não dependeria apenas da deflexão, pois apesar que em uma manobra de giro a deflexão do leme permanece constante, o ângulo local do leme aumenta pelo aumento do ângulo de deriva $(\beta)$ e da velocidade de rotação $(r)$. No momento que este ângulo passa do ângulo de estol a força do leme apresenta uma redução, e apesar de aumentar posteriormente a uma menor razão, o leme gera um esforço bem menor do que geraria se não ocorresse o estol, representando um comportamento não linear.

Os efeitos não lineares também são observados ao analisar os resultados da manobra de zigzag (figura 27). Contudo, os efeitos não lineares entre as duas manobras tem características diferentes, resultando em diferentes curvas temporais da taxa de rumo, mesmo em condições que as curvas deveriam apresentar as mesmas características.

Estas diferenças ocorrem pela dinâmica das próprias manobras. Enquanto que na manobra de giro o movimento parte do movimento linear até o regime permanente, na manobra de zigzag o movimento semelhante se iniciam uma amplitude e vai até a amplitude oposta.

A comparação da resposta transiente de ambas manobras é apresentada na figura 28, sincronizadas para a condição que ambas manobras deveriam ter um comportamento semelhante, onde é observado que a manobra de giro apresenta uma resposta mais rápida e com um maior sobressinal do que a manobra de zigzag para as maiores deflexões. Além do ângulo de estol, este efeito pode ser relacionado ao esforço hidrodinâmico não linear relativo ao ângulo de deriva do veículo, pois a deflexão e a taxa de rumo são iguais na intersecção das manobras.

Na tabela 3 foram apresentadas as análises de oscilação da manobra de zigzag considerando separadamente os dados dos períodos de amplitude negativas e positivas, para melhor analisar as possíveis assimetrias na execução da manobra. Acredita-se que esta pequena diferença observada possa estar relacionada a um pequeno erro de alinhamento das superfícies de controle, uma assimetria do casco, ou ao ângulo de rolagem do veículo. 

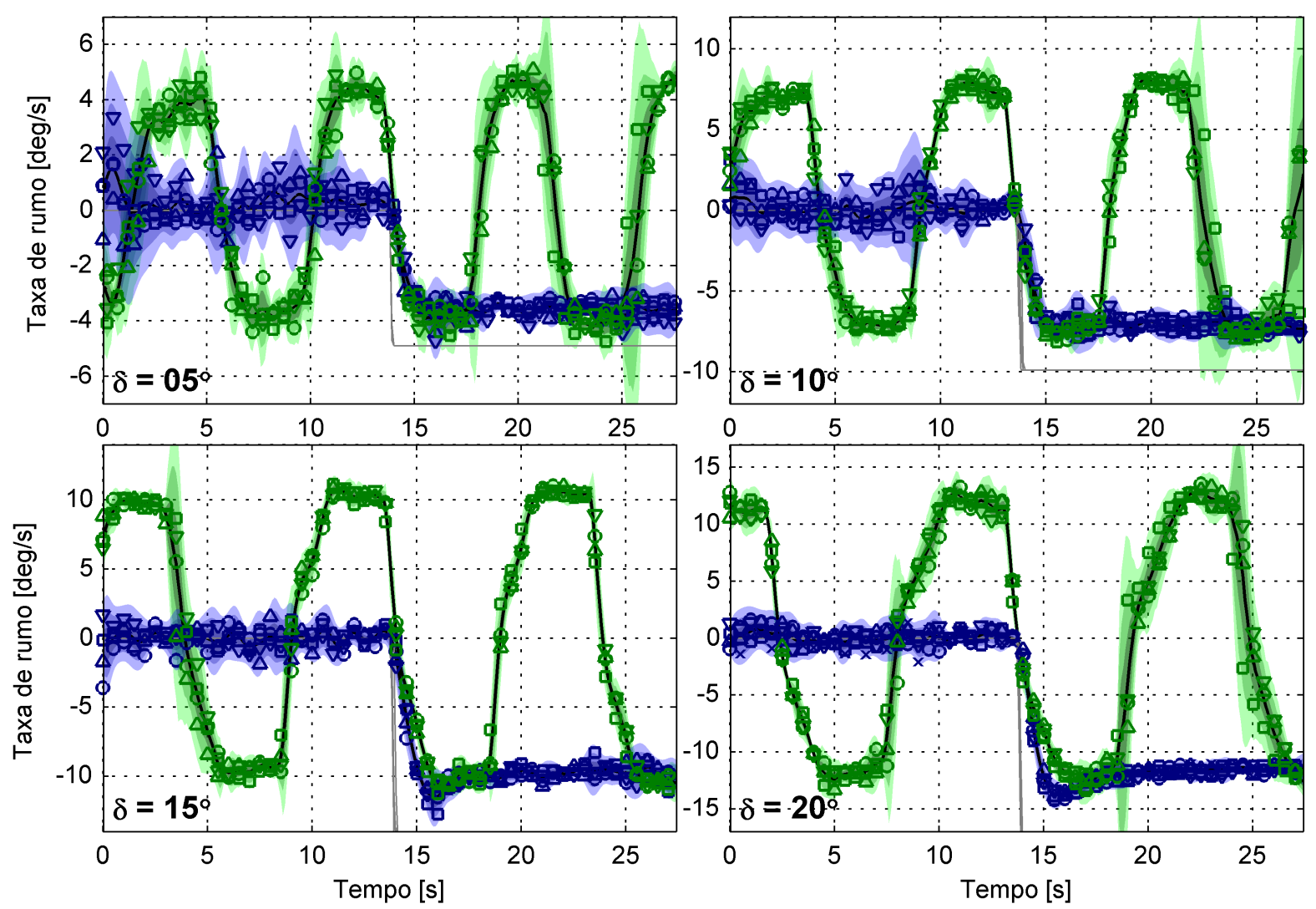

Figura 28 - Comparação da taxa de rumo da resposta transiente das manobras de zigzag e giro

Contudo, por esta assimetria ser pequena em comparação com a amplitude do movimento, não é esperado que o processo de validação seja significativamente afetado por esta assimetria do movimento.

\subsubsection{Identificação do ruído do ambiente}

Analisando os gráficos da taxa de rumo obtidos nas manobras de giro (figura 27) e zigzag (figura 26), foi observado que os ruídos apresentavam componentes em baixas frequências. Esta característica indica que a maior energia do ruído estaria relacionada a perturbações do ambiente, como a incidência de ondas e correntezas, e não a medição do sensor inercial.

Para identificar as componentes em frequência do ruído foi aplicada a transformada discreta de Fourier ${ }^{[165]}$, transformando o sinal definido no domínio do tempo para o domínio da frequência. Esta transformada foi realizada utilizando o software Matlab com a biblioteca FFTW ${ }^{[166]}$, que implementa a transformada rápida de Fourier (Fast Fourier Transform, ou FFT) utilizando o algoritmo de Cooley e Tukey ${ }^{[167]}$. Esta transformada é 

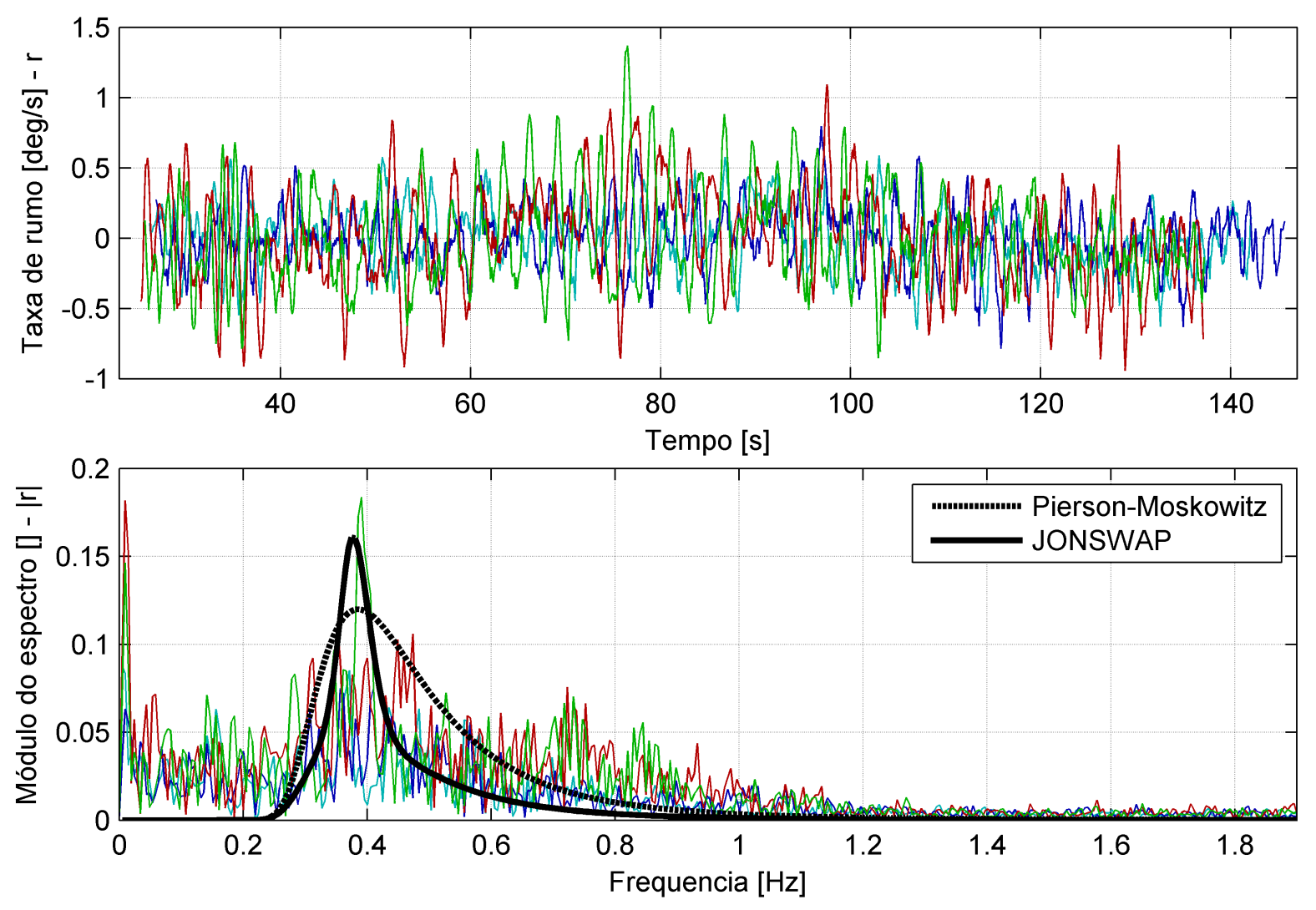

Figura 29 - Análise do espectro da frequência das manobras de giro de 5 graus. No gráfico acima são apresentados as medidas da taxa de rumo, e, no de baixo, o módulo da energia do espectro obtido pela transformada de Fourier

reescrita na equação abaixo,

$$
X(k)=\sum_{j=1}^{N} x(j T) \cdot e^{-i 2 \pi \frac{(k-1)}{N}(j-1)},
$$

onde $x$ é o vetor discreto no tempo, amostrado em períodos de $T$ e com $N$ elementos; $X$ é o vetor $x$ no domínio da frequência; e os índices $j$ e $k$, são utilizados para percorrer os vetores definidos no tempo $(x)$ e na frequência $(X)$, respectivamente.

O resultado da transformada de Fourier é apresentado na figura 29, onde o gráfico superior apresenta os dados no domínio do tempo, enquanto que no inferior é apresentado o módulo do sinal no domínio da frequência.

Pelo gráfico do sinal no domínio da frequência é observado que a energia do ruído estaria concentrada na região de 0 a $1 \mathrm{~Hz}$, com picos mais significativos nas frequências próximas de 0.4 e $0.01 \mathrm{~Hz}$. A concentração da energia nesta região indica que o ruído está relacionado a resposta dinâmica do AUV à perturbação do ambiente, pois o ruído apresenta uma baixa frequência que se assemelha a frequência natural do veículo e aquela esperada pelo próprio ambiente.

Para ressaltar este fato, foram apresentadas junto ao gráfico do espectro da frequên- 
cia as curvas dos espectros de ondas calculados pelos modelos modificados de Pierson e Moskowitz e JONSWAP (Joint North Sea Wave Project), definidos na $15^{a}$ (1978) e $17^{a}$ (1984) ITTC (International Towing Tank Conference) ${ }^{[84]}$, respectivamente. Ambas as curvas foram apresentadas com o período modal de $0.4 \mathrm{~Hz}$ e intensidade definida empiricamente.

Não é estritamente correto realizar esta comparação de maneira direta, pois os espectros de onda são relacionados à elevação da onda e os dados experimentais à taxa de rumo, sendo necessário calcular o espectro de resposta da taxa de rumo em função do espectro incidente através das funções $\mathrm{RAO}^{[83] 2}$. Entretanto, apesar da dinâmica do AUV amortecer o espectro de onda esta comparação pode ser utilizada de forma qualitativa, indicando que existe uma relação evidente que o espectro do sinal da taxa de rumo tenha sido influenciado por perturbações geradas por ondas marinhas.

Apesar das ondas explicarem o pico de energia do ruído a $0.4 \mathrm{~Hz}$ ela não explica o pico de baixa frequência $(0.01 \mathrm{~Hz})$. Acredita-se que este pico de baixa frequência esteja relacionado a correnteza local, pois apesar da correnteza em um curto período ser constante, indicando uma perturbação em frequência nula, quando o veículo está em uma manobra de giro esta perturbação oscila em função da frequência de giro do veículo. Contudo, ela não deve afetar significativamente as análises de comparação conduzidas, pois sendo uma perturbação de baixa frequência ela não afeta a resposta transiente, por ter uma dinâmica de período de cerca de 1 segundo, e nem a resposta em regime permanente, que é calculada por uma média de uma período grande (cerca de 100 segundos).

$\overline{2 \text { Response Amplitude Operators (RAO) }}$, são funções de resposta em frequência lineares que relacionam as perturbações espectrais aos estados dinâmicos do veículo. Normalmente estas funções são obtidas pela aplicação de métodos numéricos potenciais aos desenhos em CAD (Computer Aided Design, ou em português, Desenho Assistido por Computador) dos veículos. 



\section{INVESTIGAÇÃO DOS ESFORÇOS HI- DRODINÂMICOS DO AUV PIRAJUBA}

Na indústria naval, a estimativa dos esforços hidrodinâmicos representa a maior parte das incertezas do modelo de manobra de veículos submarinos e de superfície. As equações cinemáticas e os esforços inerciais não apresentam este problema, pois as suas soluções analíticas já são conhecidas na literatura ${ }^{[83,67,84]}$, sendo apresentadas na seção 2.1 e 2.2, respectivamente, e a suas incertezas estão relacionadas às incertezas de medição da massa e inércia do veículo, que podem ser encontradas por ensaios de pesagem e balanço ${ }^{[168]}$.

No caso dos esforços hidrodinâmicos, além das incertezas estarem relacionadas a inexistência de uma solução matemática do escoamento, elas são largamente influenciadas pelas condições do ambiente, impedindo que os resultados experimentais gerem uma predição isenta de incertezas. Em comparação com os demais métodos de estimativa, os métodos experimentais com modelo cativo em tanques de provas ${ }^{[86,123,21,124,39]}$ e por modelos livres em ensaios de manobras ${ }^{[155,156,37,157,158]}$ geram resultados com a melhor confiança, sendo utilizados para validar os resultados obtidos por outros métodos ${ }^{[19,24,20,25,21,22,27,31]}$.

Contudo, em geral, a realização de experimentos de campo ou em ambientes estruturados, como tanque de provas, demandam um grande investimento monetário e de recursos humanos, que estão relacionados a fabricação de modelos em escala (inteira ou reduzida) com uma boa precisão, compra ou aluguel de equipamentos de medição, calibragem e da própria execução dos ensaios. Mas mesmo com toda esta infraestrutura certos fenômenos fluidodinâmicos não conseguem ser modelados de forma idêntica ao real, sendo necessário realizar simplificações ou aproximações durantes os experimentos.

Uma solução de custo muito menor é encontrado na utilização de modelos analíticos e semi-empíricos (ASE) ${ }^{[20,44,22]}$, como por exemplo os modelos apresentados na seção 2.2.5, onde uma estimativa dos esforços pode ser obtida rapidamente por um computador simples, ou até mesmo com contas simples. Contudo, as soluções obtidas por estes métodos não apresentam uma boa acurácia, por serem baseados em diversas hipóteses e simplificações da modelagem.

Os métodos de CFD, por volumes finitos ou elementos finitos, representam um "meio termo" entre os métodos experimentais e os métodos ASE ${ }^{[85]}$, em relação à capacidade de predição dos esforços hidrodinâmicos. O uso do CFD possibilita a obtenção de bons resultados em condições típicas de operação de AUVs, e pequenas divergências quando o escoamento apresenta fenômenos de grande complexidade, como grandes gradientes 
de pressão, inversão abrupta do escoamento, entre outros. Mas, mesmo utilizando equipamentos de computação modernos, as simulações de CFD ainda consomem um tempo substancial, que aumenta consideravelmente ao se utilizar as metodologias de verificação e validação $(\mathrm{V} \& \mathrm{~V})^{[33]}$, apresentadas na seção 3.5.

Considerando as metodologias analíticas (ASE) e numéricas (CFD) para a estimativa dos esforços hidrodinâmicos de um AUV, apresentadas ao longo desta tese, neste capítulo será realizada a comparação entre os resultados obtidos por estes métodos para o caso do AUV Pirajuba, considerando os seus apêndices separados/isolados e combinados. A validação destes modelos será realizada utilizando as medições dos experimentos em tanques de prova e por ensaios de manobra de modelo livre ${ }^{[39]}$.

Esta investigação será realizada de maneira semelhante aos demais projetos de pesquisa do $\operatorname{LVNT}^{[20,44,39,28]}$. Contudo, serão realizadas análises para os diversos casos de estudos, aplicando a análise de V\&V para as simulações de CFD, e uma análise mais criteriosa das medições experimentais, onde serão consideradas as estatísticas das medições.

Apesar da metodologia das simulações de CFD por volumes finitos terem sido apresentadas na seção 3.4, não foi definido qual modelo de turbulência apresenta o melhor resultado, pois cada modelo apresenta as suas vantagens e desvantagens para cada tipo de escoamento, não existindo na literatura um consenso sobre o melhor modelo de turbulência deve ser utilizado em simulações de CFD de AUVs que possuem a geometria e as condições de operação do Pirajuba ${ }^{[26,27]}$. Para que todas as simulações não sejam realizadas com todos os modelos de turbulência, implicando em um custo computacional proibitivo, apenas um modelo de turbulência será selecionado para ser aplicado nas simulações. Esta seleção será baseada na realização de diversas simulações de casos simples, utilizando sempre o método de $\mathrm{V} \& \mathrm{~V}$, que representem os tipos de escoamentos encontrados nos estudos realizados, sendo que o modelo de turbulência que apresentar o melhor resultado será aplicado no restante da investigação.

Esta metodologia é similar à utilizada por Phillips, Turnock e Furlong ${ }^{[26]}$, que foi aplicada para a predição das estruturas dos vórtices de modelos de submarinos, e por Song et al. ${ }^{[27]}$, que foi aplicada para a estimação de arrasto de um AUV de casco triplo. Sendo que em ambos os estudos foram realizados com cinco modelos de turbulência. Entretanto, neste trabalho serão analisados o desempenho de onze modelos de turbulência, que representam todos os modelos de turbulência do equacionamento RANS presente no software ANSYS Fluent.

Com base na literatura alguns dos modelos selecionados poderiam ser descartados, devido ao seu pouco uso de aplicação nesta área de aplicação. Contudo, ao realizar o ensaio com a maioria dos modelos é possível verificar a capacidade de predição de cada modelo, para cada fenômeno fluidodinâmico analisado. A metodologia e os resultados obtidos na seleção dos modelos de turbulência serão apresentados na seção 6.1. 
Nesta seção também será realizada uma análise da ordem do equacionamento dos modelos convectivos das equações de transporte RANS, verificando se o aumento da complexidade do equacionamento numérico, e consequentemente do custo computacional, contribuí para um ganho na precisão da estimativa dos esforços hidrodinâmicos.

Com as características dos modelos numéricos de CFD definidas na seção 6.1, a seção 6.2 realizará a investigação dos esforços hidrodinâmicos estáticos e de controle, devido a diferença na velocidade relativa do veículo com o escoamento (ângulo de incidência) e a deflexão das superfícies de controle em relação o corpo do veículo, respectivamente. Nesta etapa os resultados obtidos pelos modelos ASE e CFD serão comparados entre si, sendo utilizado os resultados experimentais obtidos em tanques de provas para a validação. A apresentação destes resultados seguira a mesma metodologia utilizada na seção 2.2.5, onde primeiro serão comparados os esforços gerados pelo corpo do veículo e seus apêndices de maneira isolada, e em seguida serão analisados os esforços das combinações.

Por último será realizada a investigação dos esforços hidrodinâmicos dinâmicos, que surgem quando o veículo executa um movimento de rotação, i.e., quando o AUV apresenta uma velocidade angular. Nesta investigação também será considerada a composição do movimento de rotação com o movimento de inclinação, abrangendo a análise numérica para considerar a interferência entre o ângulo de incidência e a velocidade angular, de maneira semelhante aos métodos ASE apresentados na seção 2.2.5.

Os esforços dinâmicos serão validados por ensaios de manobras com um modelo livre auto-propelido, por não terem sido realizados experimentos desta natureza em tanques de prova. Como as manobras apenas foram realizadas com a configuração corpo e leme, a validação somente será dada nesta condição. Contudo, também será feita a comparação dos coeficientes do corpo sozinho entre os métodos ASE e CFD. Estas análises serão realizadas na seção 6.4 .

\subsection{SELEÇÃO DOS MODELOS NUMÉRICOS}

A seleção dos modelos de turbulência e da ordem do equacionamento dos modelos convectivos foi realizada em três etapas. Na primeira etapa, os onze modelos de turbulência (seis modelos com cinco variações do equacionamento), disponibilizados pelo software ANSYS Fluent $13.0^{[94]}$, foram utilizados para simular um caso bidimensional simples, por este apresentar um tempo de simulação baixo em comparação com casos tridimensionais de mesmo nível de refino.

$\mathrm{Na}$ segunda etapa, os modelos que apresentaram as estimativas dos esforços hidrodinâmicos mais próximos das medições experimentais foram utilizados em um caso de simulação tridimensional, verificando qual modelo apresenta a melhor aderência aos resultados experimentais considerando fenômenos tridimensionais. Por último, o modelo 
de turbulência selecionado foi simulado para outras duas diferentes ordens do equacionamento dos modelos convectivos, verificando qual modelo apresenta a melhor relação custo-benefício para a estimação dos esforços hidrodinâmicos do AUV Pirajuba. O modelo resultante foi empregado nas demais simulações do AUV Pirajuba

No trabalho de Phillips, Turnock e Furlong ${ }^{[26]}$ foi utilizada uma metodologia semelhante na investigação dos esforços hidrodinâmicos e da estrutura dos vórtices gerados na lateral de um corpo submarino genérico (DOR), testando cinco modelos de turbulência (considerando as variações dos modelos), selecionados pela experiência prévia dos autores. Em Song et al. ${ }^{[27]}$ também foram utilizados cinco modelos de turbulência (considerando as variações dos modelos) na simulação para um modelo de AUV composto por três corpos interconectados, para quatro diferentes velocidades.

Contudo, como no caso do AUV Pirajuba o número de Reynolds de análise é consideravelmente menor $\left(1.8 \cdot 10^{6}\right)$ que o dos outros veículos investigados $\left(11 \cdot 10^{6}\right.$ no caso do submarino DOR ${ }^{[26]}$, e 6.8 a $18 \cdot 10^{6}$ no caso do modelo de $\mathrm{AUV}^{[27]}$ ), acredita-se que os modelos de turbulência possam apresentar comportamentos de aderência diferentes, exigindo uma investigação mais ampla do modelo de turbulência.

Além disso, em ambos os trabalhos ${ }^{[27,26]}$ não foram investigados os modelos de turbulência mais novos, devido a não disponibilidade no software de análise ou por não serem modelos comuns para a área hidrodinâmica, e estas novas formulações (principalmente as de transição) podem representar um ganho significativo na estimação dos esforços hidrodinâmicos.

Desta forma, na seção 6.1.1 serão apresentados os resultados de seleção para o caso bidimensional, na seção 6.1.2 a seleção para o caso tridimensional, e na seção 6.1 .3 a seleção da ordem do equacionamento dos modelos convectivos.

\subsubsection{Caso 2D: Asa sozinha}

A seleção do modelo do caso bidimensional seguiu os seguintes requisitos:

1. O escoamento deste modelo deverá poder ser representado bidimensionalmente, para reduzir o custo computacional.

2. O número de Reynolds obtido neste modelo deve estar próximo dos valores encontrados no AUV Pirajuba ou em suas partes, verificando a capacidade de estimação dos modelos de turbulência para baixos números de Reynolds.

3. Os fenômenos fluido-dinâmicos encontrados no escoamento devem ser semelhantes aos encontrados no AUV Pirajuba, para verificar se modelos de turbulência conseguem reproduzir tais efeitos. 
Tabela 4 - Dimensões do leme original e modificado ${ }^{[120]}$ do AUV Pirajuba

\begin{tabular}{lrr}
\hline \hline Parâmetro & Leme original & Leme modificado \\
\hline Altura & $160 \mathrm{~mm}$ & $132 \mathrm{~mm}$ \\
Corda na raiz & $90 \mathrm{~mm}$ & $155 \mathrm{~mm}$ \\
Corda média & $76 \mathrm{~mm}$ & $132 \mathrm{~mm}$ \\
Corda na ponta & $60 \mathrm{~mm}$ & $101 \mathrm{~mm}$ \\
Área & $0.012 \mathrm{~m}^{2}$ & $0.017 \mathrm{~m}^{2}$ \\
Razão de aspecto & 2.13 & 1.03 \\
Enflexamento & Simétrico & Retangular* \\
Perfil & NACA0012 & NACA0015 \\
\hline \hline
\end{tabular}

*Bordo de fuga apresenta um ângulo reto.

Por estes requisitos, o perfil do leme do Pirajuba (NACA0012) deveria ser selecionado como caso de estudo. Contudo, não foram encontrados na literatura resultados experimentais que possuíssem o mesmo número de Reynolds do leme do Pirajuba $\left(R e=7.6 \cdot 10^{4}\right)$, baseado na corda média.

A solução foi utilizar a geometria de leme apresentada em Dantas, Cruz e Barros ${ }^{[120]}$, que possui um perfil diferente e um razão de aspecto menor. Este leme foi desenvolvido para aumentar o ângulo de estol e manter a razão de sustentação pelo ângulo de incidência para os ângulos baixos (região de resposta linear), em comparação com o leme original. As características geométricas dos dois lemes são comparados na tabela 4.

Para este novo perfil (NACA0015) foram utilizados os dados experimentais de Jacobs e Sherman ${ }^{[169]}$ para o número de Reynolds de $16 \cdot 10^{4}$, que está bastante próximo do número de Reynolds do novo leme $\left(13 \cdot 10^{4}\right)$. Devido a má qualidade da versão digital encontrada do trabalho de Jacobs e Sherman ${ }^{[169]}$, somente foi possível obter os dados de força de arrasto e de sustentação, pois, devido a resolução da digitalização, não foi possível interpretar os dados de momento.

Para obter estes dados, Jacobs e Sherman ${ }^{[169]}$ utilizaram tanto experimentos de características bidimensionais em túnel de vento, quanto experimentos de asas tridimensionais e de testes de campos com aviões. Como a transformação destes dados "tridimensionais" em "bidimensionais" foi feita utilizando ferramentas de correções analíticas e semi-empíricas, esta correção pode apresentar limitações para a predição dos esforços na região de estol e pós-estol, gerando uma maior incerteza para estes dados. Em nenhum momento o trabalho de Jacobs e Sherman ${ }^{[169]}$ apresentou uma estimativa para as incertezas de medições experimentais, não sendo possível representa-las durante as comparações dos resultados.

Neste estudo, também foi feita uma investigação prévia da qualidade do refino de malha e da ordem dos equacionamentos dos modelos convectivos, utilizando metodologias mais simples. 


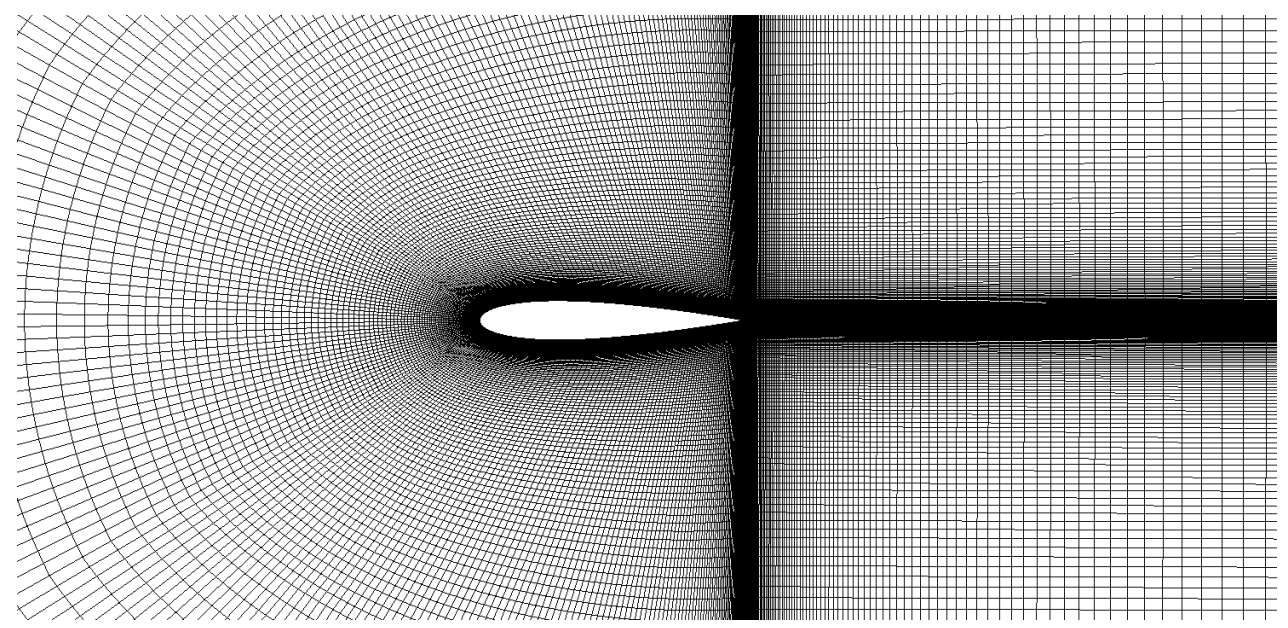

Figura 30 - Malha de refino médio do perfil NACA0015, utilizada na seleção bidimensional do modelo de turbulência

O estudo do refino de malha foi realizado de maneira similar a metodologia da $\mathrm{ASME}^{[33]}$, utilizando apenas três gradações de refino de malhas. A malha de menor refino (caso 1) possui cerca de 60 mil elementos com um $y^{+}$médio próximo de 1 , na malha de médio refino (caso 2) foram utilizados cerca de 200 mil elementos obtendo um $y^{+}$médio próximo de 0.5 , e na malha de maior refino (caso 3) foram utilizados cerca de 1 milhão de elementos com um $y^{+}$médio inferior a 0.1. Nota-se que em todas as malhas o $y^{+}$é menor ou igual ao limite superior imposto pelas funções/tratamentos avançados de parede.

Por economia de espaço apenas a malha do caso de refino médio é apresentado na figura 30 .

A investigação da ordem dos modelos foi realizada utilizando o equacionamento de segunda ordem para os modelos convectivos das equações de transporte do momento (massa) e dos parâmetros de turbulência, e de primeira ordem para a pressão. Estas simulações foram realizadas utilizando a malha com o maior refino, por apresentar o menor error de discretização.

Os resultados para o coeficiente de sustentação são apresentados na figura 31, enquanto que as polares de arrasto são apresentadas na figura 32. Em ambos os casos os esforços são adimensionalizados na pressão dinâmica de referência (499.1 Pa) e na corda média do perfil, supondo que a área é igual corda média multiplicada por uma envergadura unitária.

Em termos de estabilização numérica da solução, todos os casos apresentaram dificuldade de convergência para a região de estol e pós-estol, sendo necessário diminuir os fatores de sobre-relaxação para reduzir os resíduos das equações de transporte. Esta convergência foi ainda mais prejudicada ao utilizar os modelos convectivos de segunda ordem para as equações de pressão, momento e turbulência. 

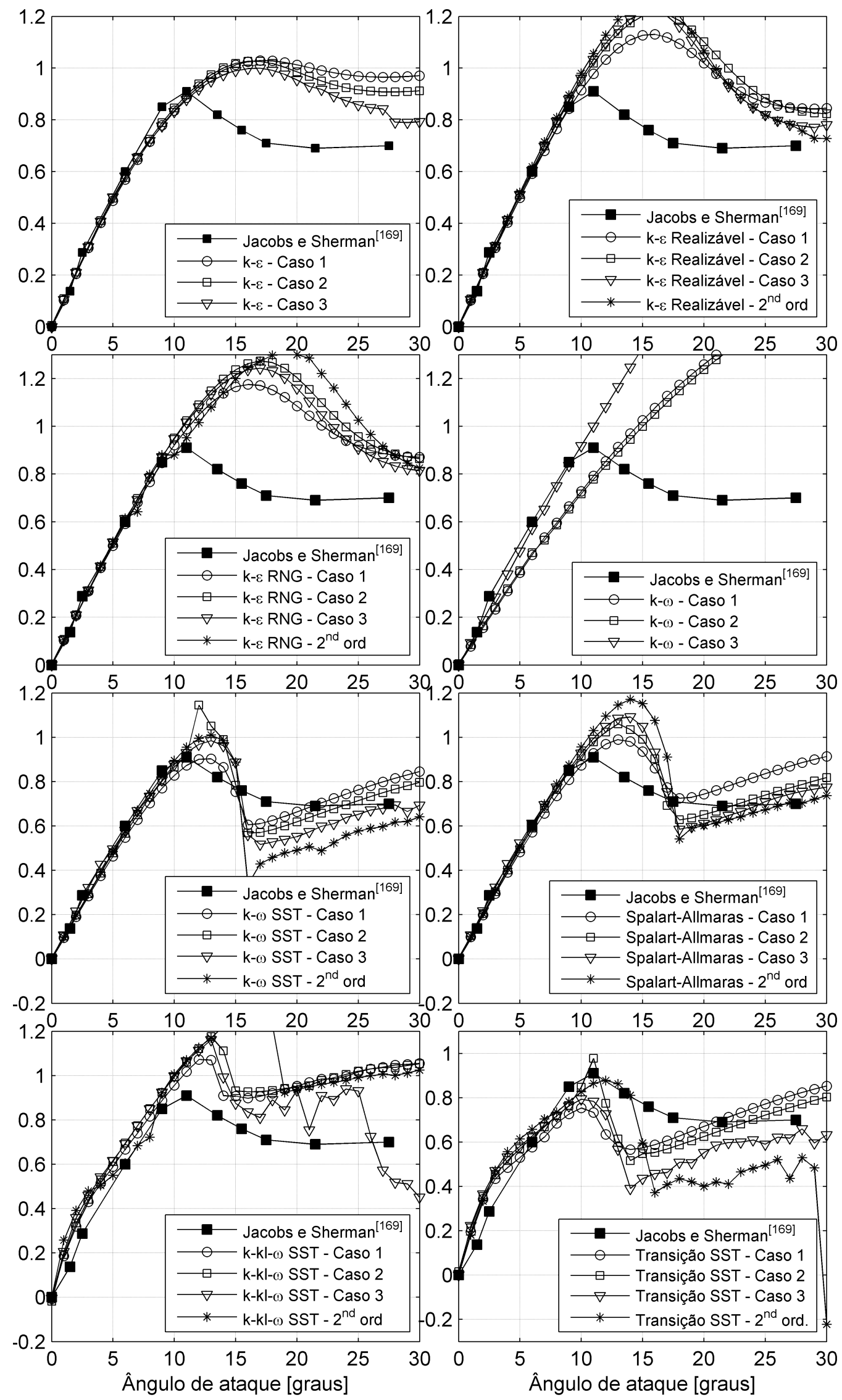

Figura 31 - Comparação experimental ${ }^{[169]}$ e numérica do coeficiente de sustentação para o perfil NACA0015 (caso 2D). 

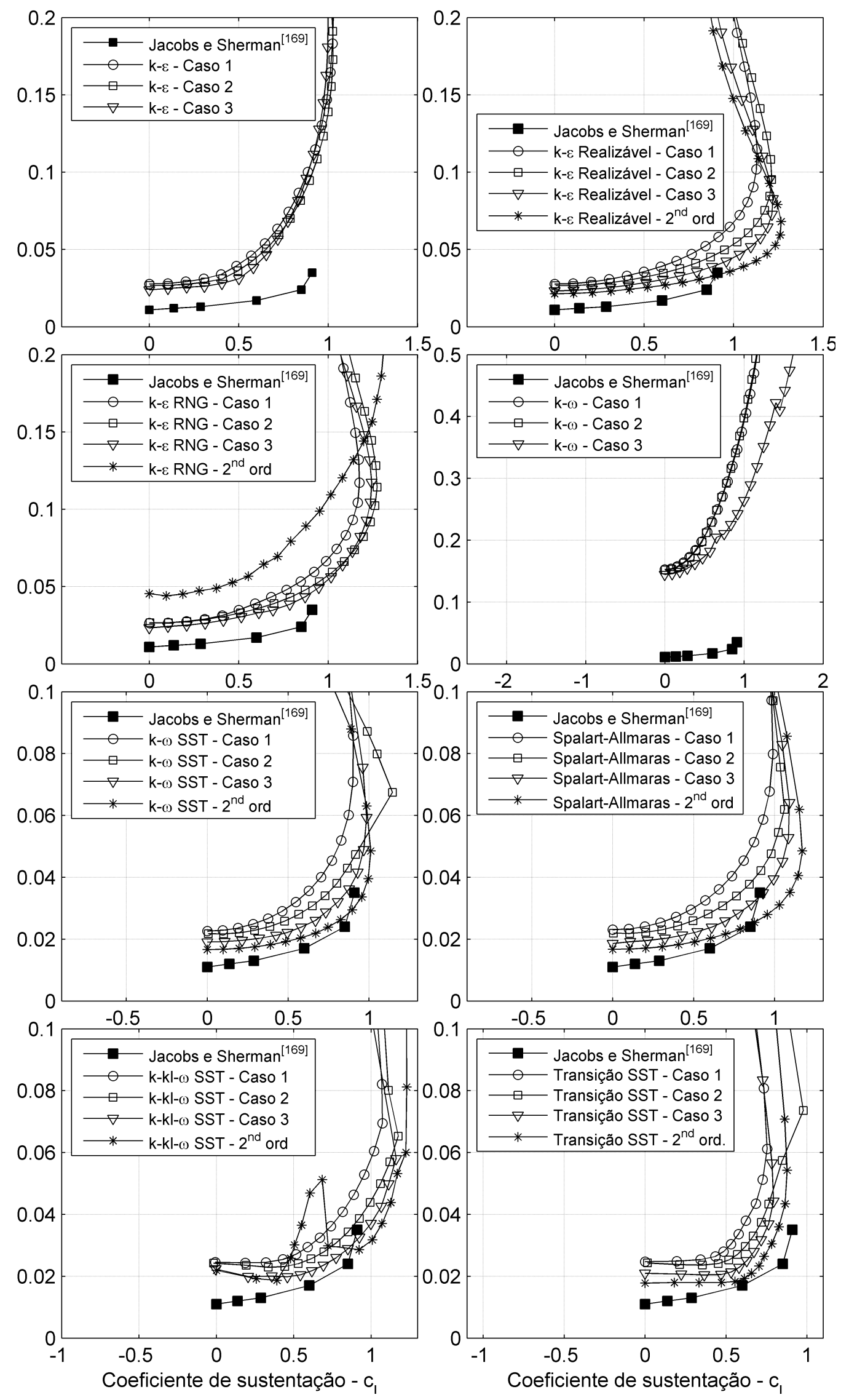

Figura 32 - Comparação experimental ${ }^{[169]}$ e numérica do coeficiente de arrasto para o perfil NACA0015 (caso 2D). 
Nos casos dos modelos de transição ( $k$ - $k l-\omega$ e Transição SST), a convergência também apresentou dificuldades na região linear (pré-estol). Na região de pós-estol, ambos os modelos apresentaram uma convergência oscilante, sendo nestes gráficos apresentados os valores médios.

Observando os resultados do coeficiente de sustentação (figura 31), é verificado que o modelos de turbulência que não apresentam transição (totalmente turbulentos), apresentaram uma boa aderência para a região de resposta linear (baixo ângulo de incidência), sendo que o modelo $k$ - $\omega$ padrão somente apresentou este resultado com a malha de maior refino. Já os modelos de transição (transição SST e $k-k l-\omega$ ) superestimaram a sustentação nesta região, por apresentar um descolamento, seguido de um recolamento, da camada limite na região de maior espessura do perfil ( $25 \%$ da corda).

Para a região do estol os modelos $k-\omega$ SST e Transição SST apresentaram os melhores resultados, superestimando e subestimando, respectivamente, o ângulo de estol em poucos graus. Utilizando a formulação de segunda ordem, o modelo de transição melhorou a sua previsão, enquanto que o modelo $k-\omega$ SST se manteve constante. Em nenhum dos casos o modelo numérico conseguiu apresentar um bom comportamento da região de pós-estol, apresentando um comportamento crescente, enquanto que o dado experimental apresentava uma estabilização.

Este comportamento se deve a dificuldade, ou até mesmo impossibilidade, de conseguir modelar o fenômeno de estol, que apresenta uma alta turbulência tridimensional e instabilidades temporais, com modelos de turbulência bidimensionais estáticos. Contudo, estas simulações ainda podem ser utilizadas para identificar o inicio do estol, quando o escoamento começa a apresentar grandes instabilidades.

O caso do modelo Spalart-Allmaras (SA) foi bastante semelhante ao do modelo $k-\omega \mathrm{SST}$, mas a previsão do ângulo de estol foi maior, e com o uso do modelo de segunda ordem esta diferença aumentou. Nenhum dos modelos $k-\epsilon$ conseguiu prever corretamente o ângulo de estol, sendo que o modelo padrão obteve o melhor resultado. O modelo $k-k l-\omega$ apresentou um resultado fraco em todas as regiões, devido às oscilações durante o processo iterativo e por não conseguir modelar corretamente as parcelas laminares e turbulentas do escoamento. O modelo $k-\omega$ padrão apresentou o pior resultado, pois não identificou o estol do perfil.

O problema de modelagem do estol com a formulação RANS é um problema conhecido na indústria aeronáutica ${ }^{[81,32,170]}$. Hall, Woodson e Chambers ${ }^{[170]}$ mostraram que mesmo para asas tridimensionais a formulação RANS apresenta divergência na predição do estol, e somente com uma formulação modificada do modelo de CFD LES (comentado na seção 3.4) é possível modelar o comportamento do estol. Contudo, Hall, Woodson e Chambers ${ }^{[170]}$ e Fujii ${ }^{[32]}$ afirmam que as simulações com o modelo LES possuem um custo de uma ordem de grandeza maior do que as simulações RANS, não apresentando 
um bom custo-benefício para a solução de problemas de engenharia. E como comentado previamente, este alto custo inviabilizaria a simulação de todos os casos neste projeto.

Para o caso do arrasto somente foram comparados os resultados na região de pré-estol, pois no trabalho de Jacobs e Sherman ${ }^{[169]}$ só foram fornecidos dados até o ângulo de $11^{\circ}$. Seguindo o exemplo desta referência, os resultados do coeficiente de arrasto foram expressos em função do coeficiente de sustentação, seguindo o padrão aeronáutico ${ }^{[126,141]}$.

Analisando a figura 32, nenhum modelo conseguiu reproduzir de maneira satisfatória os dados experimentais, sempre apresentando um valor superestimado para ângulo de ataque nulo. Isto ocorre, porque todos os modelos de turbulência totalmente turbulentos superestimam o arrasto de fricção por considerarem somente o regime turbulento, enquanto os modelos de turbulência de transição não conseguiram captar corretamente a transição. Entretanto, todos os modelos, com exceção do $k-\omega$, apresentaram valores razoavelmente próximos do experimental, tendo um comportamento em função da sustentação bastante similar.

Analisando os resultados de arrasto e sustentação, foram eliminados do processo de seleção os modelos $k-\omega$ e $k-k l-\omega$. O modelo $k-\omega$ por não representar os efeitos estol e de arrasto de maneira acurada, e o modelo $k$ - $k l-\omega$ por não apresentar boas aderências em seus resultados, além de apresentar uma alta instabilidade e tempo de convergência.

Os três modelos $k-\epsilon$ foram mantidos por apresentarem resultados semelhantes, justificando uma comparação mais acurada no modelo tridimensional.

O modelo Transição SST não apresentou uma boa modelagem da derivada da curva de sustentação para baixos ângulos de ataque, indicando que o seu modelo não conseguiu representar bem o escoamento. No entanto, por ter apresentado um bom resultado para a estimativa do ângulo de estol e do arrasto a baixos ângulos de ataque, este modelo será testado para o caso tridimensional.

Apesar de uma investigação do tempo de simulação para cada modelo ser interessante e útil em novas investigações, como discutido por Phillips, Turnock e Furlong ${ }^{[26]}$ e Phillips, Furlong e Turnock ${ }^{[30]}$, neste caso não foi possível realizar este tipo de estudo devido ao uso de diferentes servidores e computadores para realizar as simulações.

Contudo, foi possível confirmar de maneira qualitativa, que o tempo $(t)$ entre cada iteração foi proporcional ao número de equações resolvidas pelo modelo de turbulência. Ou seja:

$$
\begin{aligned}
t_{S A} \ll t_{k-\epsilon} & \approx t_{k-\epsilon \text { Realizavel }} \approx t_{k-\epsilon} R N G \\
& \approx t_{k-\omega} \approx t_{k-\omega S S T} \ll t_{k-k l-\omega} \ll t_{\text {Trans } S S T}
\end{aligned}
$$

Também de maneira qualitativa, foi verificado uma relação entre os modelos de turbulência e o número de iterações necessários para a solução estabilizar $(n)$, representada 
pela relação

$$
\begin{aligned}
n_{k-\omega} \ll n_{k-\epsilon} & \approx n_{k-\epsilon \text { Realizavel }} \approx n_{k-\epsilon \text { RNG }} \\
& <n_{S A} \ll n_{k-\omega} S S T \approx n_{\text {Trans } S S T} \ll n_{k-k l-\omega}
\end{aligned}
$$

Utilizando estas duas relações (6.1 e 6.2), foi possível estimar o tempo total de simulação $(T)$, indicando de maneira qualitativa o custo computacional relativo de cada modelo de turbulência. Esta relação é mostrada na equação 6.3.

$$
\begin{aligned}
T_{k-\omega} \ll T_{S A} & \approx T_{k-\epsilon} \approx T_{k-\epsilon \text { Realizavel }} \\
& \approx T_{k-\epsilon} R N G \ll T_{k-\omega S S T} \ll T_{\text {Trans } S S T} \ll T_{k-k l-\omega}
\end{aligned}
$$

De maneira aproximada, considerando o poder de computação de um computador pessoal $^{1}$, o tempo total de simulação para todos os ângulos de incidência com o modelo Spalart-Allmaras $\left(T_{S A}\right)$ foi cerca de um dia, com o modelo $k-\omega \operatorname{SST}\left(T_{k-\omega} S_{S T}\right)$ foi de dois a três dias, enquanto que os modelos de transição chegaram a quase uma semana.

Considerando este custo computacional e os resultados encontrados, o modelo Spalart-Allmaras apresentou o melhor custo-benefício. Contudo, pelo modelo $k-\omega$ SST ter apresentado a melhor aderência aos resultados experimentais e um custo de simulação adequado para o poder computacional disponível, pode-se considerar que este modelo teve o melhor resultado.

\subsubsection{Caso 3D: Corpo sozinho}

Mantendo os requisitos estabelecidos no caso bidimensional, foi escolhido o caso estático do corpo sozinho do AUV Pirajuba para selecionar o modelo de turbulência para os casos 3D, finalizando esta seleção. Este caso foi escolhido por apresentar uma malha relativamente simples, pelo escoamento ser relativamente comportado, e apresentar resultados experimentais exaustivamente analisados ${ }^{[39]}$, com uma análise estatística do experimento como foi descrito na seção 5.1.

Pelas condições experimentais terem sido controladas e medidas durante o ensaio, foi possível desprezar os erros paramétricos das simulações. A velocidade de ensaio/simulação foi de $1 \mathrm{~m} / \mathrm{s}$ e a densidade da água foi obtida por uma curva de calibração com a temperatura, resultando em um número de Reynolds $1.7 \times 10^{6}$.

Neste estudo o erro de discretização de malha foi estimado pelo método de Eça, Vaz e Hoekstra ${ }^{[35]}$, por apresentar uma melhor robustez na estimação deste tipo de erro ${ }^{[36]}$. Cada modelo de turbulência foi simulado em cinco malhas, que apresentaram uma elevação progressiva do nível de refino em função da espessura do volume adjacente à superfície 
Tabela 5 - Propriedades das malhas do corpo do AUV Pirajuba utilizadas no procedimento de V\&V

\begin{tabular}{lcccc}
\hline \hline & $\begin{array}{c}\mathbf{n}^{\circ} \text { de } \\
\text { volumes }\end{array}$ & $\begin{array}{c}\text { Espessura do } \\
\text { volume adjacente }\end{array}$ & $\begin{array}{c}y^{+} \\
\text {obtido* }\end{array}$ & $\begin{array}{c}\text { Índice de } \\
\text { malha }\left(h_{i} / h_{1}\right)\end{array}$ \\
\hline Caso 1 & 2008108 & $0.050 \mathrm{~mm}$ & 0.87 & 1 \\
Caso 2 & 1807332 & $0.071 \mathrm{~mm}$ & 1.25 & $\sqrt{2}$ \\
Caso 3 & 1650662 & $0.100 \mathrm{~mm}$ & 1.75 & 2 \\
Caso 4 & 1468441 & $0.141 \mathrm{~mm}$ & 2.50 & $2 \sqrt{2}$ \\
Caso 5 & 1385595 & $0.200 \mathrm{~mm}$ & 3.50 & 4 \\
\hline \hline
\end{tabular}

do corpo $\left(h_{i}\right)$. As características destas malhas são apresentadas na tabela 5 , sendo classificadas em função do índice de malha, que define a razão de $h_{i}$ da malha de análise pelo mesmo índice da malha de maior refino $h_{1}$. Segundo as recomendações de Eça, Vaz e Hoekstra ${ }^{[35]}$, a taxa de crescimento do índice de malha $\left(h_{i} / h_{1}\right)$ foi mantido em $\sqrt{2}$.

Os resultados para o coeficiente de força normal e momento são apresentados na figura 33, sendo calculados em um ponto localizado no eixo do corpo a uma distância de $0.804 \mathrm{~m}$ da ponta da proa. Enquanto que os resultados para o coeficiente de força axial e centro hidrodinâmico podem ser vistos nas figuras 34 e 35, respectivamente.

Devido ao elevado número de modelos de turbulência, os resultados foram divididos em dois gráficos distintos. Todos os dados experimentais e numéricos foram apresentados com o intervalo de confiança de $95.4 \%$, equivalente a dois desvios padrões $(2 \sigma)$. Entretanto, somente as barras de erros dos coeficientes de força axial e centro hidrodinâmico, apresentam uma magnitude suficiente para serem identificados nos gráficos.

Os esforços hidrodinâmicos foram adimensionalisados segundo as normas da SNAME ${ }^{[61]}$, onde a adimensionalização é feita dividindo o valor do esforço por $1 / 2 \rho V_{\infty}^{2}$ e pelo comprimento do corpo ao quadrado $\left(L_{B}^{2}\right)$ para as forças, e pelo comprimento ao cubo $\left(L_{B}^{3}\right)$ para o momento.

Nos gráficos dos coeficientes de força normal (os dois gráficos superiores da figura $33)$, observa-se que até $10^{\circ}$ de incidência todos os modelos apresentam uma boa aderência com os resultados experimentais. Acima deste valor o modelo Transição SST diverge significativamente, enquanto que os modelos Spalart-Allmaras, $k-\epsilon$ realizável e RNG apresentaram pouca diferença. Os modelos $k-\omega$ SST (normal e LR) e RSM $k-\omega$ apresentaram resultados muito próximos aos experimentais.

No momento (os dois gráficos inferiores da figura 33) foi observado um comportamento similar. Contudo, para valores acima de $10^{\circ}$ de incidência, apenas os modelos baseados na formulação $k-\omega$ apresentaram uma boa aderência, enquanto o modelo Transição SST subestimou e os demais modelos sobrestimaram o valor experimental.

Para o coeficiente de força axial (os dois gráficos superiores da figura 34), apenas o 

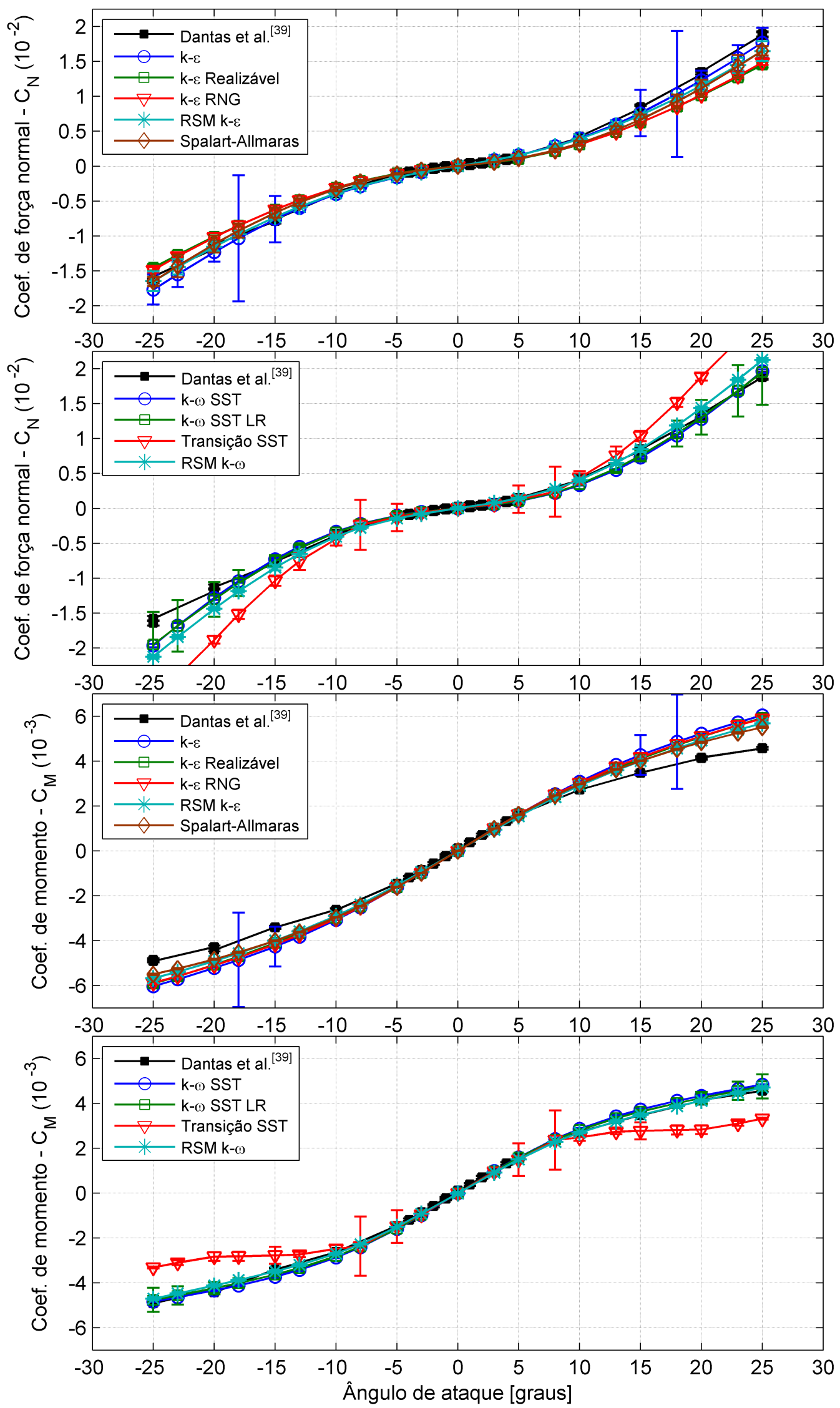

Figura 33 - Validação das estimativas numéricas dos coeficientes de força normal e momento do corpo do AUV Pirajuba, para a seleção dos modelos de turbulência 

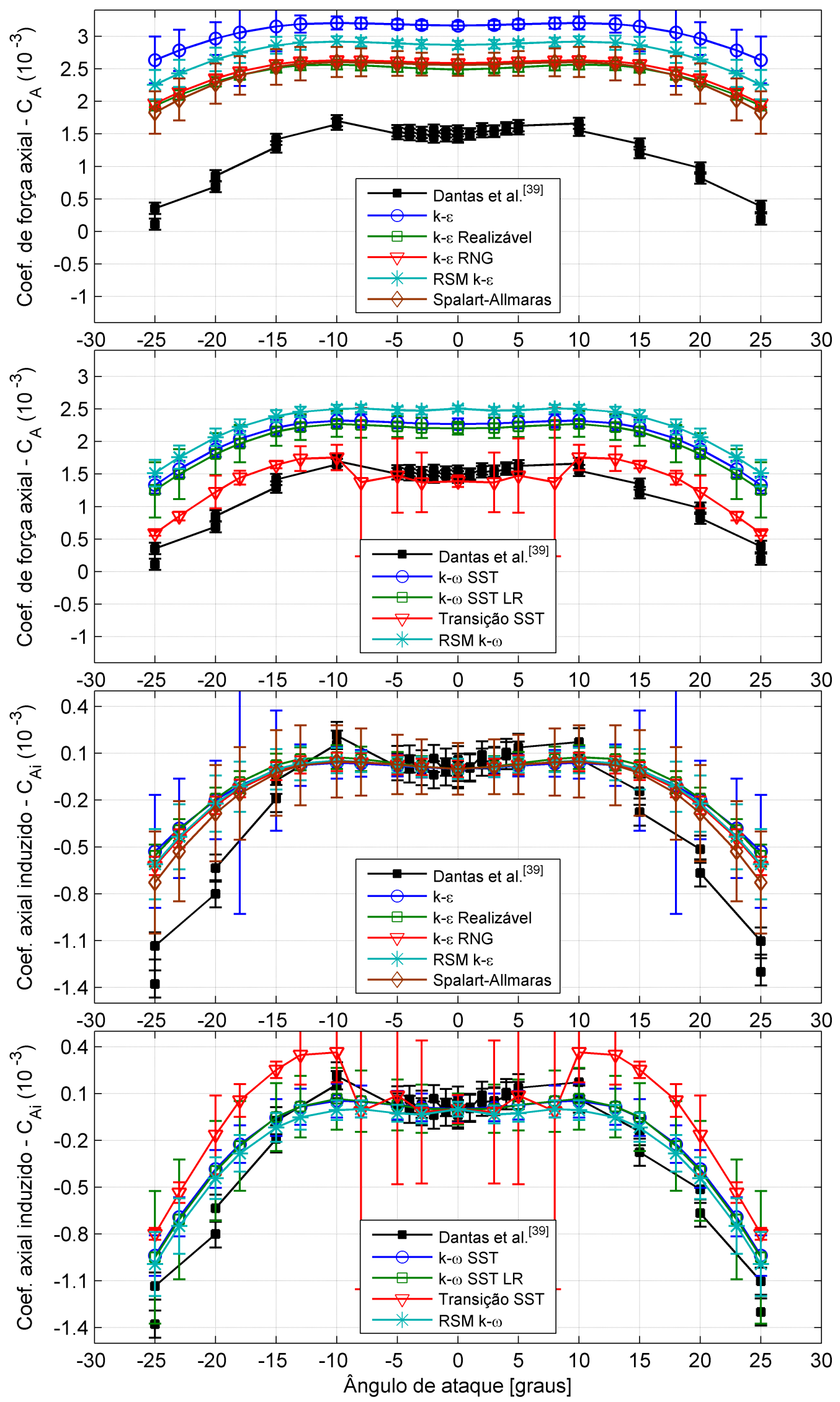

Figura 34 - Validação das estimativas numéricas dos coeficientes de força axial total e induzido do corpo AUV Pirajuba, para a seleção dos modelos de turbulência 

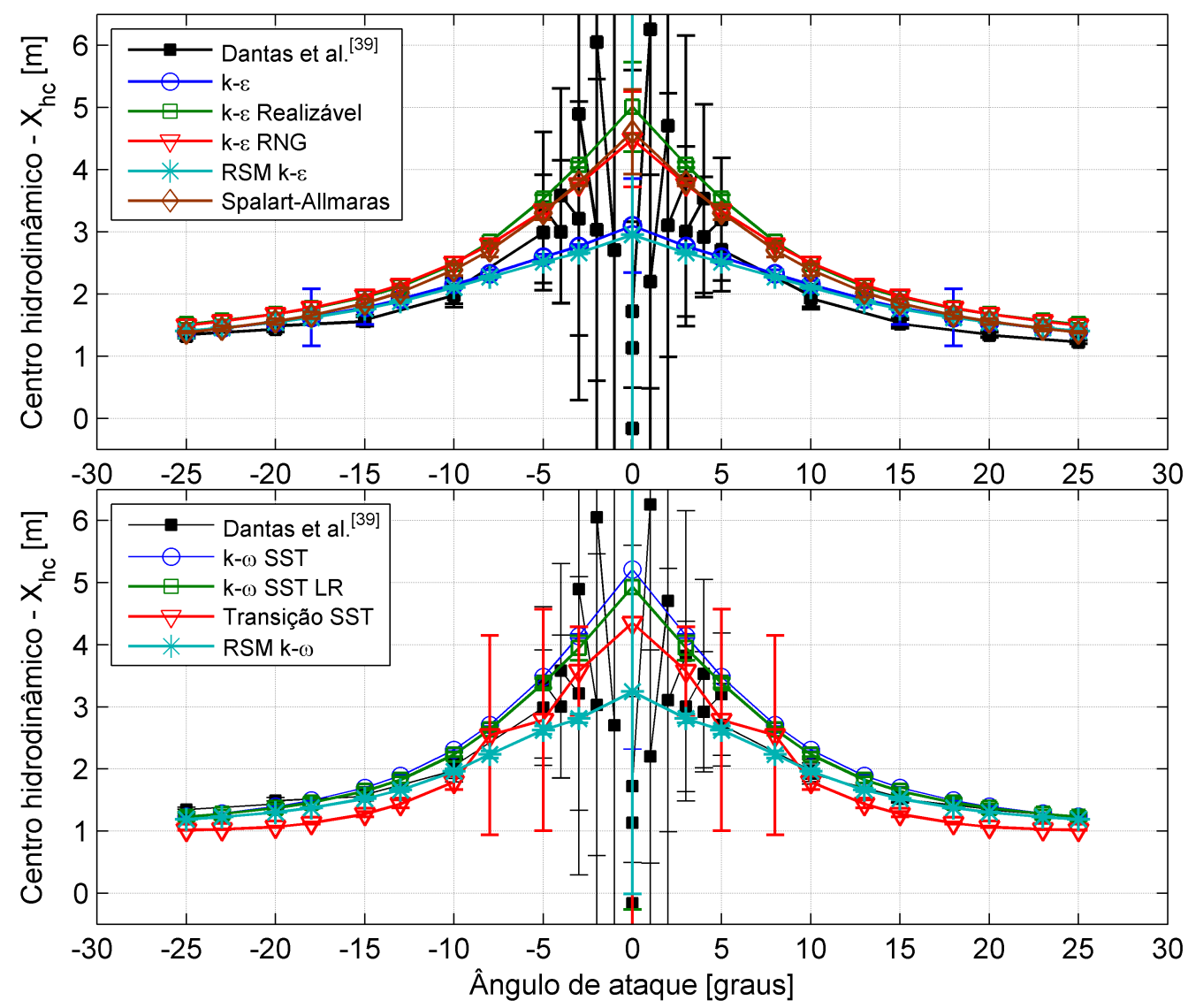

Figura 35 - Validação das estimativas numéricas do centro hidrodinâmico do corpo do AUV Pirajuba, para a seleção dos modelos de turbulência.

modelo Transição SST apresentou um resultado próximo dos resultados experimentais, sendo seguidos dos modelos $k-\omega$ SST.

Ao analisar somente a parcela de força axial induzida $\left(C_{A_{i}}(\alpha)\right)$, que corresponde ao arrasto total $\left(C_{A}(\alpha)\right)$ menos a parcela de arrasto parasita $\left(C_{A_{0}}\right.$, forma mais fricção), como visto na equação (6.4), a aderência entre os modelos de turbulência melhorou significativamente. Isto indica que a maioria dos modelos de turbulência apresenta deficiência em modelar o arrasto parasita, devido a sobrestimação do arrasto de fricção, mas consegue estimar bem o arrasto induzido, gerado pelos esforços potenciais de sustentação. Estes resultados podem ser vistos nos gráficos de arrasto induzido (os dois gráficos inferiores da figura 34).

$$
C_{A}(\alpha)=C_{A_{0}}+C_{A_{i}}(\alpha)=C_{A}(\alpha=0)+\left(C_{A}(\alpha)-C_{A}(\alpha=0)\right)
$$

No caso da força axial total, pelos modelos apresentarem um grande erro em relação as medições não foi possível validar estes modelos, somente sendo possível validar a parcela induzida desta força. Contudo, pelo arrasto parasita influenciar pouco a manobrabilidade dos AUVs, e pelo objetivo deste trabalho ser focado em manobrabilidade, a reprodução deste coeficiente não é muito importante para este trabalho, podendo dizer que estes 
modelos foram "validados" para este caso.

O centro hidrodinâmico foi calculado pela relação do coeficiente de momento $\left(C_{M}\right)$, de força normal $\left(C_{N}\right)$, e pelo centro de referência/medição $\left(X_{m}\right)$, conforme a equação 6.5 , previamente apresentada na seção 2.2.5. E a sua variância $U_{X_{h_{c}}}^{2}$ foi calculada pela propagação das incertezas do coeficiente de força normal $\left(U_{C_{N}}\right)$ e momento $\left(U_{C_{M}}\right)$, apresentada na equação 6.6.

$$
\begin{gathered}
X_{h_{c}}=X_{m}+\frac{C_{M} \cdot L_{B}}{C_{N}} \\
\left(\frac{U_{X_{h_{c}}}}{X_{h_{c}}-X_{m}}\right)^{2}=\left(\frac{U_{C_{N}}}{C_{N}}\right)^{2}+\left(\frac{U_{C_{M}}}{C_{M}}\right)^{2}
\end{gathered}
$$

Analisando apenas os dados experimentais do centro hidrodinâmico do corpo do AUV Pirajuba (figura 35), é observado que as incertezas para baixos ângulos de ataque são muito grandes, impossibilitando a validação para esta região. Isto ocorre devido aos denominadores da equação (6.6) tenderem a zero a medida que o ângulo de ataque diminui, e a incerteza permanece praticamente constante.

Devido a esta singularidade a comparação numérica e experimental somente é possível para ângulos mais altos. Para esta região, com exceção do modelo Transição SST, a maioria dos modelos apresentaram uma diferença pequena em relação aos dados experimentais. O modelo RSM apresentou o melhor resultado, seguido dos modelos $k-\omega$ SST, Spalart-Allmaras e $k-\epsilon$ padrão, os demais modelos $k-\epsilon$ apresentaram um erro um pouco maior.

Observando todos os resultados, podem ser feitas algumas observações.

No caso dos modelos $k-\epsilon$, diferente do esperado ${ }^{[27]}$, o modelo padrão apresentou um resultado melhor para o coeficiente de força normal e momento do que as suas versões "atualizadas", mas sobrestimou a força axial em comparação a estes modelos.

Este comportamento pode ser explicado ao considerar que o modelo padrão conseguiu estimar de maneira semelhante a componente potencial dos esforços, mas sobrestimou a parcela viscosa. Desta forma, a força de arrasto, que é bastante influenciada pela parcela viscosa, foi bastante sobrestimada, enquanto que a força normal teve um aumento devido a esta sobrestimação, ficando mais próximo do valor experimental em comparação aos demais modelos. Este comportamento é reforçada ao verificar que a estimativa do momento pelos três modelos são bastante similares, pois o momento é pouco influenciados pelos esforços viscosos.

Em comparação com o caso bidimensional, o modelo Transição SST apresentou uma melhoria em termos de aderência com os dados experimentais, apresentando uma boa aderência para ângulos de incidência menores que $10^{\circ}$. Outro resultado positivo deste modelo foi a previsão da força axial (ou força de arrasto) para esta região, apresentando 
um valor bastante próximo do experimental, devido a sua capacidade de contabilizar a parcela laminar e turbulenta do escoamento do veículo. Com estes resultados, pode-se considerar que o modelo Transição SST consegue prever bem os esforços hidrodinâmicos para escoamentos bem comportados, tendo uma baixa aderência para à estimativa de esforços em casos que precisem modelar fenômenos complexos que surgem em altos ângulos de incidência.

O modelo Spalart-Allmaras apresentou um resultado similar aos resultados das outros referências ${ }^{[27,26]}$, tendo um erro um pouco maior que os modelos $k-\omega$ SST e RSM, e melhor que os modelos $k-\epsilon$. A vantagem deste modelo está em seu custo computacional relativamente menor, que em alguns casos pode ser mais interessante.

De acordo com os resultados de Song et al. ${ }^{[27]}$ e Phillips, Turnock e Furlong ${ }^{[26]}$, os modelos RSM deveriam apresentar um resultado melhor do que o modelo $k-\omega$ SST. No entanto, neste trabalho foi observado que o modelo RSM $k-\omega$ apresentou um resultado bastante próximo as dos modelos $k-\omega \mathrm{SST}$, e o modelo RSM $k-\epsilon$ um resultado pior.

Devido ao custo computacional dos modelos RSM serem maiores do que os do modelos $k-\omega$ SST, o restante das simulações deste trabalho serão realizadas com os modelos $k-\omega$ SST. Pelos dois modelos $k-\omega$ SST não apresentarem diferenças significativas, o restante das simulações foi realizada com a versão LR (Low Reynolds), por esta versão ser igual a versão padrão para números de Reynolds maiores, e apresentar resultados teoricamente melhores para número de Reynolds mais baixos ${ }^{[94]}$.

O modelo de Transição SST foi o único modelo que conseguiu estimar o arrasto total do AUV Pirajuba com um erro menor do que a incerteza de validação. Contudo, esta estimativa apresentou grandes incertezas devido a oscilações na análise de convergência interativa e de discretização, não garantindo uma predição estatística deste esforço. Devido a estas grande incerteza, o uso deste modelo deve ser feito com cuidado, pois em casos de escoamentos mais complexos este modelo pode apresentar uma predição errada.

Da mesma forma que no caso 2D, não foi possível realizar uma estimativa preciso do custo computacional, pois as simulações foram realizadas de forma não organizada em diferentes hardwares, um workstation ${ }^{2}$ e um cluster com dois diferentes tipos de nós ${ }^{3}$. Entretanto, por estes hardwares serem relativamente semelhantes, apresentando cerca de $10 \%$ de diferença no tempo das simulações, é possível fazer uma estimativa média, e grosseira, do tempo de simulação de cada simulação.

2 Workstation: Xeon Quad-Core X5450 de $3.0 \mathrm{GHz}$

3 Cluster nó 1: Intel Xeon Quad-Core 5550 de $2.66 \mathrm{GHz}, 16$ DDR3 $1333 \mathrm{MHz}$

Cluster nó 2: 2 x Intel Xeon Quad-Core 5570 de 2.93 GHz, 48 GB DDR3 $1333 \mathrm{MHz}$ 


\subsubsection{Ordem do equacionamento: Corpo sozinho}

Nesta última etapa foram realizadas as simulações para verificar a influência da ordem do equacionamento dos modelos convectivos das forças internas e dos parâmetros de turbulência, nos esforços hidrodinâmicos do corpo do AUV Pirajuba. Foi utilizado o mesmo caso geométrico da seleção do modelo de turbulência utilizando o modelo de turbulência $k-\omega$ LR.

Foram testados três diferentes ordens para estes equacionamentos. No primeiro caso, que foi utilizado nas simulações da seção anterior, foi utilizado o equacionamento dos modelos convectivos de primeira ordem ( Upwind ${ }^{[94]}$ ), com o equacionamento padrão do acoplamento pressão-velocidade. No segundo caso (Upwind ${ }^{[94]}$ ), foram utilizados os modelos de segunda ordem para os modelos convectivos, e o modelo linear para o acoplamento pressão-velocidade. No último caso, foram utilizados os modelos de terceira ordem $\left(M U S C L^{[94]}\right.$ ) para os modelos convectivos, e o modelo de segunda ordem para o acoplamento pressão-velocidade. Na tabela 6 é apresentado um resumo das características dos modelos testados.

Na figura 36 é apresentado os resultados destes diferentes modelos para os coeficientes dos esforços hidrodinâmicos e do centro hidrodinâmico do corpo do AUV Pirajuba.

O coeficiente de força axial apresentou a maior diferença entre o modelo de primeira ordem e os modelos de alta ordem ( $2^{a}$ e $3^{a}$ ordem). Neste caso os modelos de alta ordem apresentaram uma boa estimação do arrasto parasita. Entretanto, ambos os modelos apresentaram incertezas numéricas bastante elevadas, indicando que ainda é necessário melhorar o refinamento das malhas para que estes resultados possam ser estatisticamente validados com uma boa acurácia.

No caso do coeficiente de força normal, os modelos de alta ordem apresentaram um resultado próximo ao modelo de primeira ordem, apresentando apenas uma pequena diferença nos maiores ângulos. Acredita-se que esta diferença seja devido a melhor estimativa do arrasto do corpo, que apresenta uma parcela na composição da força normal (ver eq. 4.15).

Esta hipótese é reforçada ao verificar que o momento do corpo se manteve pra-

Tabela 6 - Características dos modelos numéricos testados na análise da influência da ordem dos equacionamentos convectivos

\begin{tabular}{lcccrr}
\hline Nome / & Ordem dos & Esquema dos & Modelo do & \multicolumn{2}{c}{ No de iterações } \\
Legenda & modelos & modelos $^{[\mathbf{9 4}]}$ & eq. pre-vel & Mín. & Máx. \\
\hline $1^{a}$ Ordem & Primeira ordem & Upwind & Padrão & 1000 & 2500 \\
$2^{a}$ Ordem & Segunda ordem & Upwind & Linear & 7500 & 14000 \\
$3^{a}$ Ordem & Terceira ordem & MUSCL & Segunda ordem & 13000 & 50000 \\
\hline
\end{tabular}



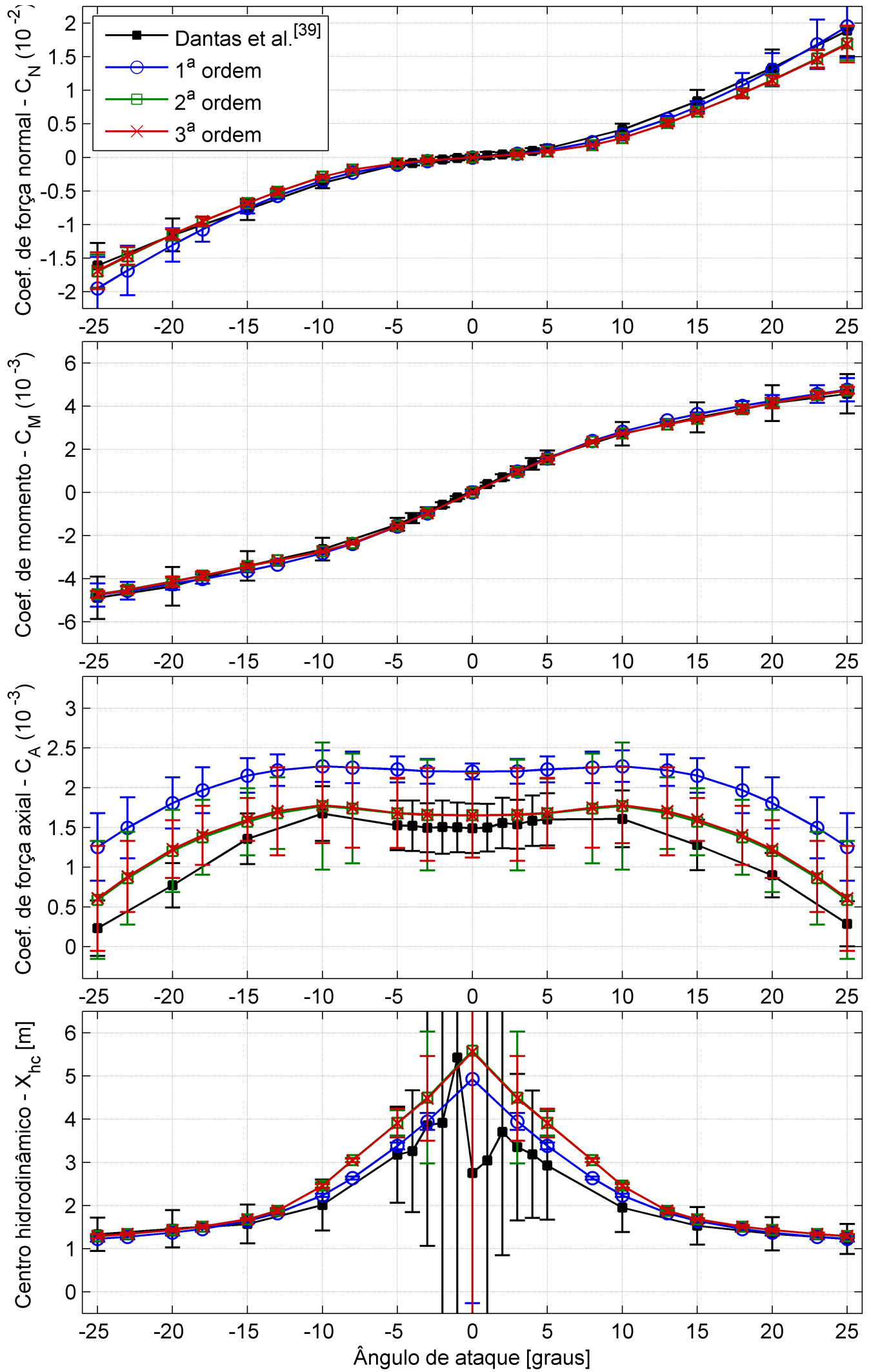

Figura 36 - Análise do efeito da ordem do equacionamento dos modelos convectivos das forças internas e dos parâmetros de turbulência para o modelo $k-\omega$ de baixo Reynolds, comparando com os resultados experimentais ${ }^{[39]}$ do corpo sozinho do AUV Pirajuba. 
ticamente constante com o aumento da ordem dos modelos. Indicando que a mudança do equacionamento não alterou o campo de pressões sobre o corpo, melhorando apenas a estimativa da componente de fricção, que apenas modifica a força do corpo e não o momento.

Em todos os casos, os modelos de $2^{a}$ e $3^{a}$ ordem apresentaram resultados muito próximos, com a diferença que o modelo de $2^{a}$ ordem apresentou uma incerteza maior do que o modelo de $3^{a}$ ordem. Esta diferença já era esperada, pois segundo ANSYS ${ }^{[94]}$ o modelo de $3^{a}$ ordem apenas consegue uma melhor precisão em casos de escoamentos altamente rotativos, que não é este caso.

O custo computacional também representa uma importante característica que deve ser analisada na seleção da ordem dos modelos. Informações qualitativas sobre os custos computacionais dos diferentes métodos são apresentado na tabela 6 , indicando o menor e o maior número de iterações necessárias para a convergência dos casos. Por esta tabela verifica-se que o modelo de $2^{a}$ ordem necessita de cerca de sete vezes mais iterações do que o modelo de $1^{a}$ ordem, e o de $3^{a}$ ordem de duas a três vezes mais iterações do que o de $2^{a}$ ordem.

Devido ao alto custo e as grandes incertezas apresentadas pelos modelos de altas ordens, as investigações realizadas no restante deste trabalho serão realizadas com os modelos de primeira ordem para os equacionamentos dos modelos convectivos. Este tipo de equacionamento foi escolhido por apresentar uma melhor relação custo-benefício para à estimativa do modelo de manobra do AUV Pirajuba, que é muito mais influenciado pelos esforços de força normal e momento, que são estimados com a mesma precisão do que os modelos de alta ordem, do que o arrasto de parasita, que tem baixa influência na manobrabilidade.

\subsection{VALIDAÇÃO DOS ESFORÇOS HIDRODINÂMICOS ESTÁTI- COS POR ENSAIOS EM TANQUE DE PROVAS}

Nesta seção são comparadas as estimativas analíticas (ASE, apresentada na seção 2.2.5) e numéricas (CFD, apresentadas na seção 3) dos esforços hidrodinâmicos estáticos do AUV Pirajuba, i.e., os esforços gerados quando o escoamento apresenta um ângulo de incidência constante em relação ao veículo. Ambas metodologias são validadas por ensaios de modelos cativos em tanques de provas, cujo o procedimento foi apresentado na seção 5.1 .

De acordo com o procedimento estabelecido nesta tese, primeiro são realizadas as comparações com o corpo e os apêndices isolados do AUV Pirajuba, e em seguida são realizadas as comparações considerando a presença do leme e do duto no corpo do AUV. 
Ao utilizar este procedimento a interferência entre as diferentes partes do veículo pode ser melhor analisada e identificada.

No caso da interferência entre os lemes e o corpo também é realizado o estudo da deflexão da superfície de controle, ou seja, a inclinação do leme em relação ao corpo. Ao considerar este tipo de estudo foi possível analisar os efeitos conjuntos do ângulo de incidência e da deflexão dos lemes na geração de sustentação e no estol do leme.

Grande parte dos resultados apresentados nesta seção foram validados por ensaios em tanque de provas, realizados durante este trabalho, conforme apresentado na seção 5.1. Para os casos que não possuem dados de validação, os modelos analíticos e numéricos foram parcialmente validados por um caso geometricamente e hidrodinamicamente similar que apresenta resultados experimentais na literatura. Esta metodologia foi aplicada ao caso do duto isolado e da deflexão do leme do AUV Pirajuba.

\subsubsection{Corpo isolado}

Os experimentos e simulações do corpo do AUV Pirajuba foram realizados na velocidade nominal de operação do veículo $(1 \mathrm{~m} / \mathrm{s})$, resultando em um número de Reynolds de $1.7 \times 10^{6}$. As simulações de CFD foram realizadas de 0 a 25 graus de ângulo de ataque/deriva, com uma discretização de 5 graus com pontos intermediários, resultando em 11 casos distintos.

Em todos os casos foi aplicado a metodologia de verificação e validação (V\&V) robusta de Eça, Vaz e Hoekstra ${ }^{[35]}$, utilizando as cinco malhas previamente apresentadas na tabela 5. Na figura 4 da seção 3.1 foi apresentado a malha de refino médio utilizado neste estudo.

Todas as simulações apresentaram uma convergência estável, utilizando como critério de convergência o resíduo das equações de transporte e uma variação dos esforços hidrodinâmicos menor do que $1^{-10}$ (maior precisão do mostrador do software ANSYS FLUENT) em 200 iterações. Utilizando este critério, o erro de iteração pode ser considerado como desprezível, e a incerteza numérica depende apenas do erro de discretização $\left(U_{d i s}\right)$, pois o erro de truncamento é desprezível pelas simulações utilizarem precisão dupla $\left(10^{-32}\right)$.

A convergência de discretização de malha foi verificada para todos os esforços de todos os casos. Contudo, na figura 37, ela somente é apresentada para a força de arrasto do ângulo de incidência nulo, para não ocupar muito espaço no texto.

Em todos os casos foi observado um comportamento similar ao arrasto, onde o parâmetro exponencial $p$ apresentou um valor maior que 2.05 e uma maior incerteza do modelo quadrático ${ }^{[35]}$, sendo necessário utilizar o valor exponencial igual ao teórico $(p *=2)$ e aumentar o fator de segurança da regressão para 3. 


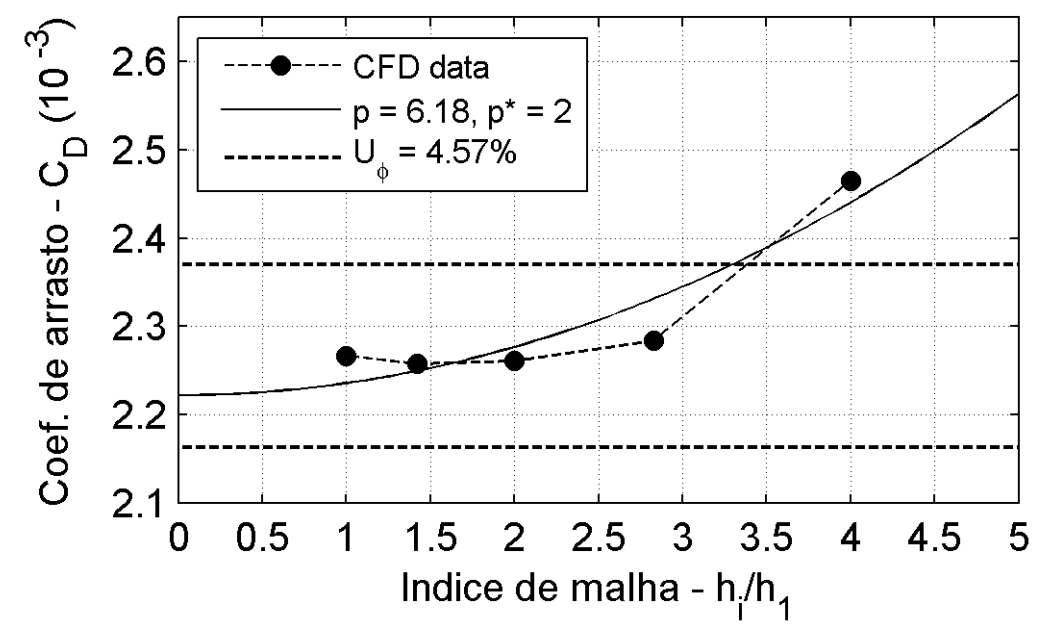

Figura 37 - Verificação de convergência de discretização para malha do corpo sozinho, para um ângulo de incidência de zero graus

Além de verificar o arrasto total, também foi verificada a convergência das parcelas de fricção e pressão, pois a convergência de uma parcela majoritária pode esconder a divergência da outra parcela ${ }^{[171]}$. Esta verificação é apresentada na tabela 7 para o caso do arrasto a zero graus, verificando que ambas parcelas apresentam convergência.

Na figura 38 é apresentada a comparação dos métodos analíticos ${ }^{[20]}$, numéricos e experimentais $^{[39]}$, para os coeficientes de força normal $\left(C_{N}\right)$, momento $\left(C_{M}\right)$, força axial $\left(C_{A}\right)$ e centro hidrodinâmico $\left(X_{h c}\right)$. Os dados experimentais médios foram representados por quadrados pretos com barras de erros e linha de tendencia, enquanto os dados originais com a repetição foram representados pelo símbolo " $x$ ". Os resultados numéricos são os mesmo apresentados na seleção do modelo de turbulência (seção 6.1.2) para o modelo $k$ - $\omega$ SST, pois este apresentou o melhor resultado com o melhor custo-benefício.

Os modelos numéricos e ASE apresentaram uma boa aderência para a força normal e o momento, refletindo em uma boa aderência para a estimativa do centro hidrodinâmico na região de baixas incertezas $(|\alpha|>10)$. Acredita-se que a divergência observada na força normal para o ângulo de $-25^{\circ}$ seja um dado experimental espúrio, devido a assimetria do gráfico em relação ao dado de $25^{\circ}$. Também foi verificado que o modelo ASE apresentou uma tendência de divergência no caso do momento para os ângulos mais altos, indicando uma possível limitação do modelo para ângulos mais altos do os analisados.

Tabela 7 - Verificação das incertezas de discretização das parcelas de fricção e pressão do coeficiente de arrasto do corpo do AUV Pirajuba

\begin{tabular}{lcccccc}
\hline \hline Arrasto & $\Phi_{0}$ & $\Phi_{1}$ & $U_{\Phi}[\%]$ & $U_{\Phi_{T}}[\%]$ & $p$ & F.S. \\
\hline Total & 0.002222 & 0.002267 & 4.57 & 4.57 & 6.18 & 3 \\
Pressão & 0.001385 & 0.001429 & 7.49 & 4.72 & 9.14 & 3 \\
Fricção & 0.000824 & 0.000837 & 3.29 & 1.21 & 1.46 & 3 \\
\hline \hline
\end{tabular}



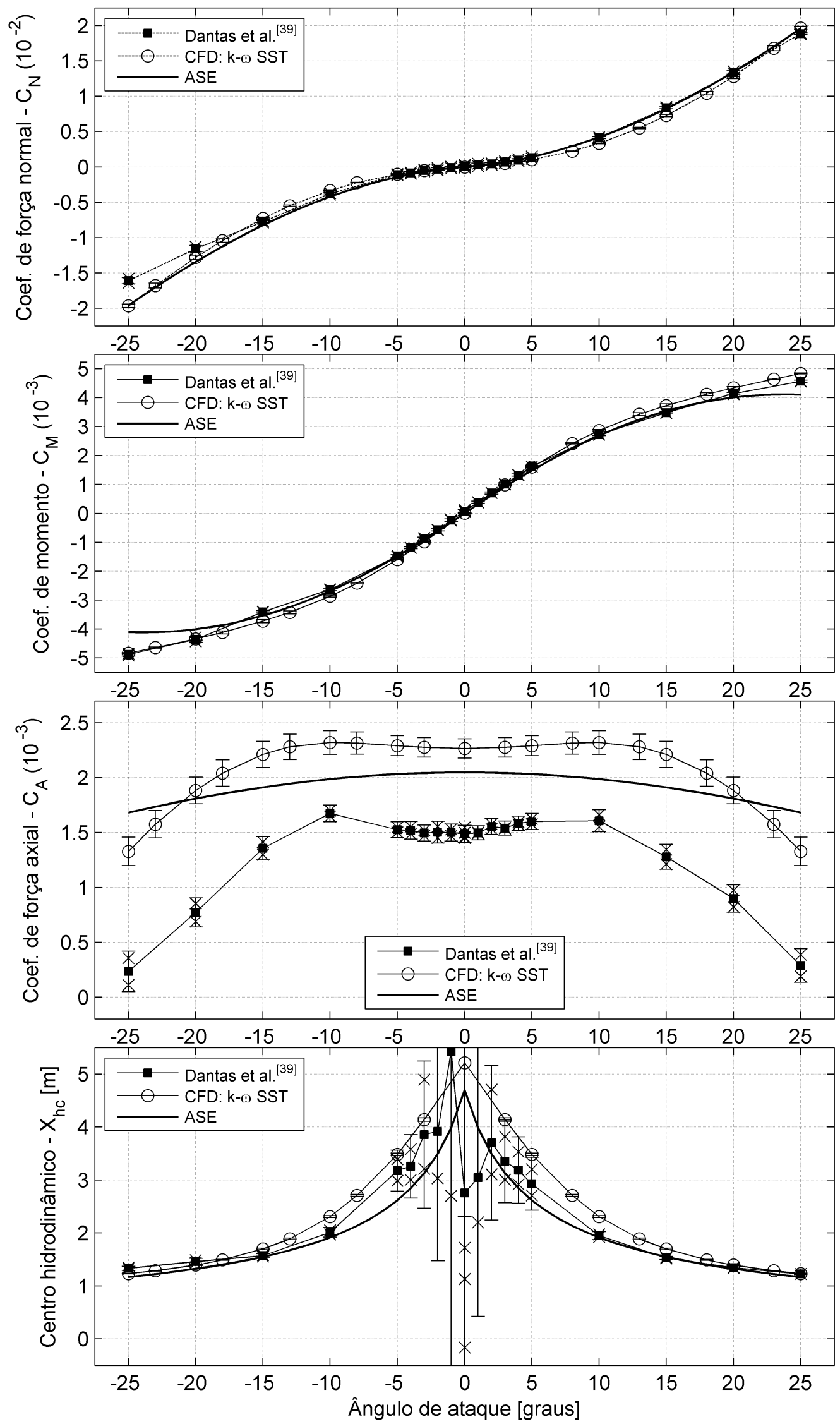

Figura 38 - Coeficientes de força normal, momento, força axial e centro hidrodinâmico do corpo isolado do AUV Pirajuba. 


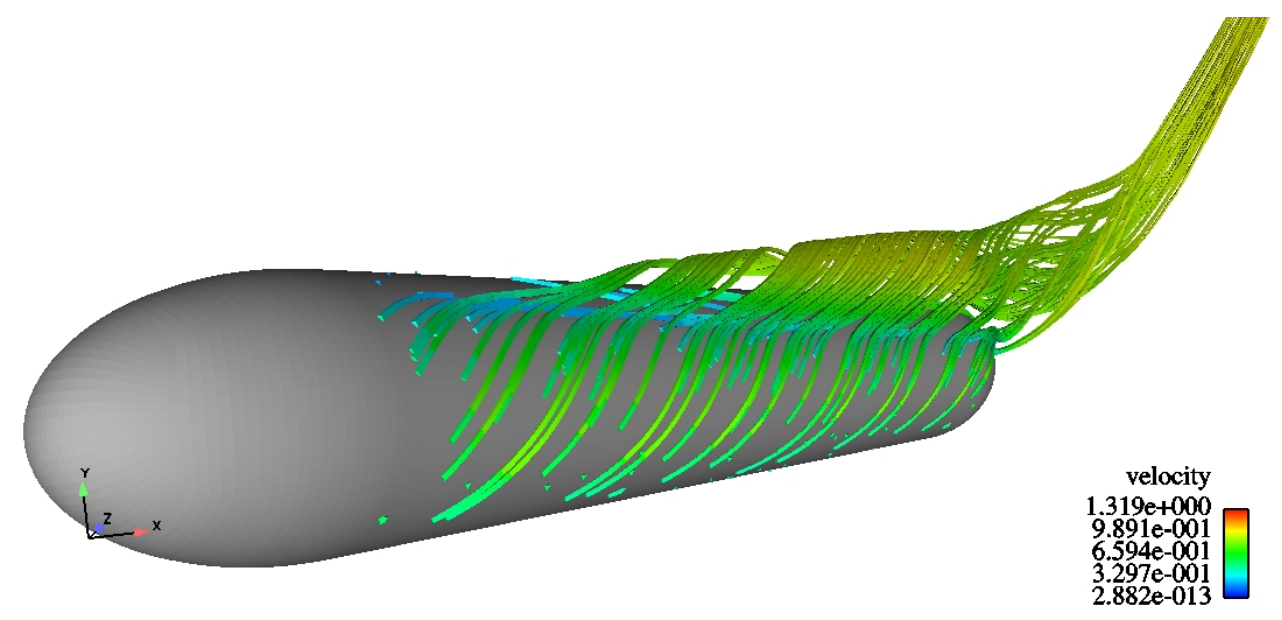

Figura 39 - Linhas de fluxo do escoamento sobre o AUV Pirajuba, em uma condição de $25^{\circ}$ de ângulo de incidência

No caso da força axial, o modelo ASE apresentou um erro de $30 \%$ para a estimativa do arrasto parasita com uma estimativa ruim para a tendência da curva. Apesar desta estimativa do arrasto parasita ser melhor do que a apresentada pelo modelo numérico, com equacionamento convectivo de primeira ordem para as equações de transporte. Como apresentado na seção 6.1.3, caso fossem utilizados os modelos de segunda ordem para este equacionamento, a aderência do modelo numérico aos dados experimentais seria muito melhor, conseguindo validar os resultados.

Na figura 39, são apresentadas as linhas de fluxo do escoamento sobre o AUV Pirajuba a uma condição de 25 graus de ângulo de incidência. Por esta figura, é observado que as simulações de CFD conseguiram reproduzir os vórtices do escoamentos gerados na lateral do corpo, que são esperadas por observações experimentais ${ }^{[121]}$, como comentado na seção 4.2.2 e apresentado na figura 13. Esta reprodução numérica das características do escoamento indicam que as simulações de CFD conseguiram reproduzir a topologia do escoamento esperada para este caso de estudo, aumentando a confiança nas simulações de CFD.

\subsubsection{Leme isolado}

No caso do leme isolado foram realizados experimentos e simulações com o leme original e modificado do AUV Pirajuba, apresentados na tabela 4 da seção 6.1.1. Em ambos os casos foram utilizadas uma velocidade de $1 \mathrm{~m} / \mathrm{s}$, resultando em um número de Reynolds de $7.6 \cdot 10^{4}$ e $13.2 \cdot 10^{4}$ para o leme original e modificado, respectivamente.

Como previamente apresentado, nos ensaios de tanque de prova ${ }^{[39]}$ dos lemes sozinhos foi somente medida a força normal, por ser o esforço mais importante gerado pelo leme. A força de arrasto não foi considerada por representar apenas uma pequena parcela do arrasto total de um AUV, cerca de $10 \%$ segundo Stevenson, Furlong e Dormer ${ }^{[172]}$ ). 


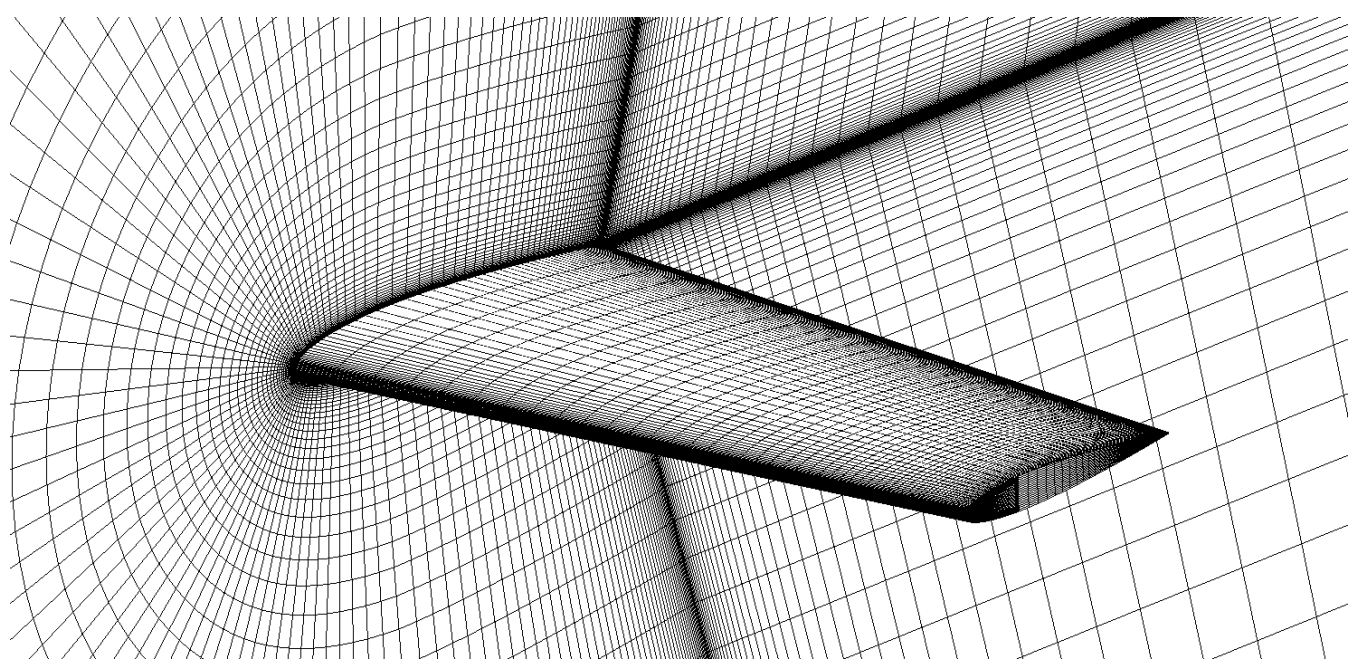

Figura 40 - Malha de refino médio da asa original (de perfil NACA0012) do AUV Pirajuba

O momento também não foi medido, pois o momento local gerado por uma superfície de controle de popa tende a ser muito menor do que o momento gerado pela multiplicação do braço e da força normal.

Antes de realizar as simulações numéricas com as malhas definitivas e aplicando a metodologia de $\mathrm{V} \& \mathrm{~V}$, foi realizado um estudo da influência da distância entre a base do leme e a placa de separação $(g a p)$. Este estudo foi realizado antes do V\&V, pois a malha com esta lacuna representa uma complexidade maior do que a malha sem, e caso os modelos não apresentem diferença nos resultados é possível economizar um tempo de simulação significativo.

Na figura 40 é apresentada a malha do leme original (NACA0012) sem considerar a lacuna, e na figura 41 é apresentada a malha do leme modificado (NACA0015) considerando a lacuna. Ambas as malhas apresentam um refino médio.

A comparação entre os coeficientes dos esforços hidrodinâmicos experimentais ${ }^{[39]}$, analíticos (baseado no modelo de Whicker e Fehlner ${ }^{[142]}$ ) e numéricos, para a condição com e sem lacuna ( $g a p)$, é apresentada na figura 42 para o leme original, e na figura 43 para o leme modificado do AUV Pirajuba. Em ambos os casos as simulações também foram realizadas com o modelo de turbulência Spalart-Allmaras (SA).

Em todos os casos, o efeito da lacuna entre o leme e o plano de simetria modificou muito pouco a curva dos coeficientes hidrodinâmicos, não alterando a região de resposta linear e nem a de estol. Devido a este resultado a aplicação da metodologia de V\&V será feita apenas para as malhas que não consideram a lacuna, simplificando o processo.

Diferente do reportado no estudo bidimensional (seção 6.1.1), o modelo $k-\omega$ SST e Spalart-Allmaras obtiveram um erro pequeno para a predição do ângulo de estol, principalmente para as malhas de menor refino. Sendo que o modelo $k-\omega$ SST apresentou 
um erro pequeno para o caso dos lemes original e modificado, enquanto o modelo SpalartAllmaras superestimou este ângulo em 2 e 5 graus para o leme original e o modificado, respectivamente. Este resultado demonstra que o erro de modelagem pode ser menor em simulações tridimensionais do que em bidimensionais, devido aos diferentes fenômenos fluidodinâmicos envolvidos, contudo é necessário realizar um estudo mais profundo para validar esta conclusão.

A análise dos coeficientes hidrodinâmico dos lemes foi realizada utilizando a mesma metodologia que foi aplicada ao caso do corpo sozinho, ou seja, foi utilizado o modelo de turbulência $k-\omega$ SST com uma interpolação de primeira ordem para os equacionamentos convectivos das equações de transporte.

As propriedades das cinco malhas, utilizadas para realizar a análise de $\mathrm{V} \& \mathrm{~V}$, do leme original e modificado são apresentados nas tabelas 8 e 9, respectivamente. Nestas malhas o refino se deu na direção normal a superfície do leme, e na direção de sua envergadura.

As malhas dos lemes apresentaram um refino relativamente maior (maior número de volumes) que o caso do corpo sozinho, aplicando o refino em duas direções ao invés de apenas uma. Isto foi feito devido a necessidade de garantir que todas as simulações estivessem na "região assintótica", possibilitando que o modelo numérico consiga uma estimativa mais precisa dos fenômenos fluidodinâmicos complexos, que ocorrem em grande intensidade na condição de estol dos lemes.

A comparação entre as predições experimentais ${ }^{[39]}$, analíticas (ASE) e numéricas (CFD) são apresentadas na figura 44 para o leme original e na figura 45 para o leme

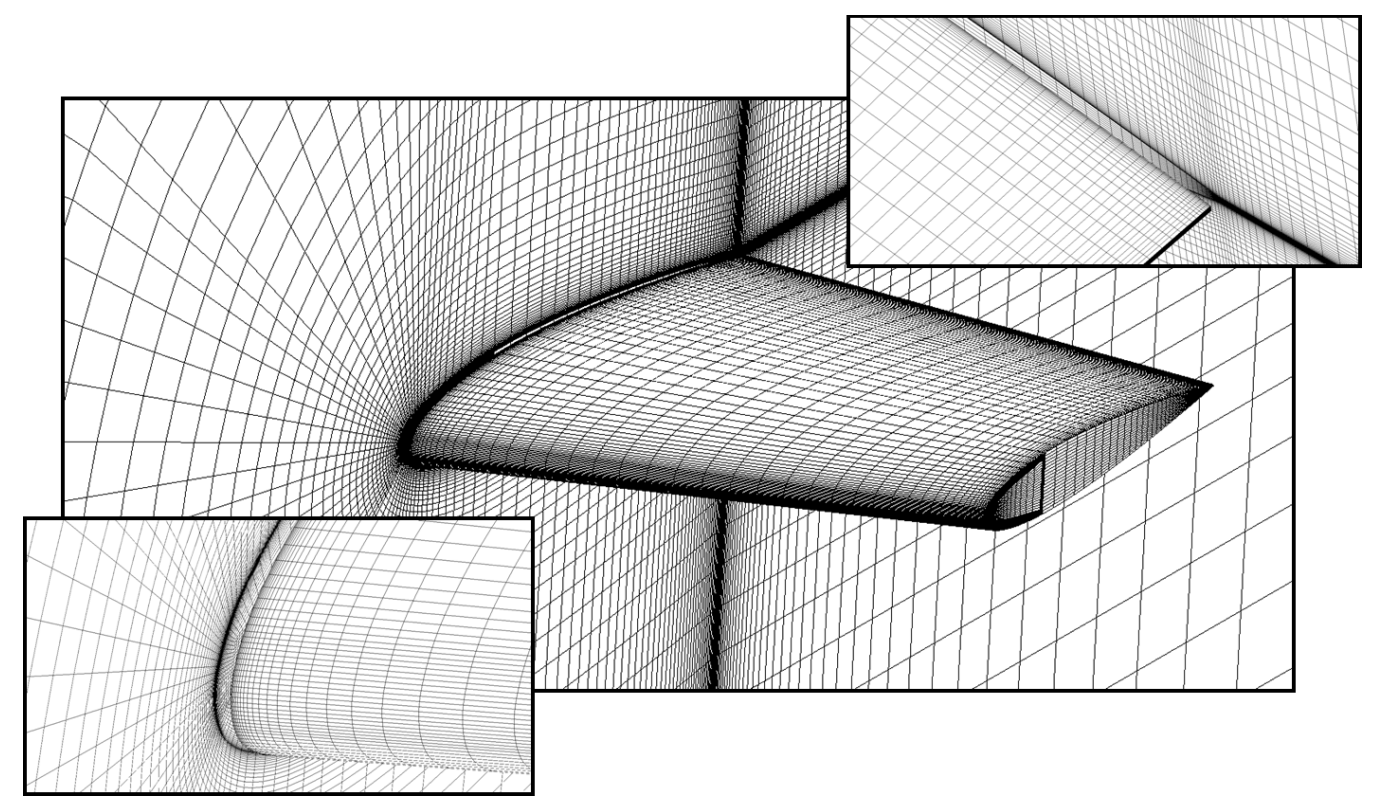

Figura 41 - Malha de refino médio da asa alterada (de perfil NACA0015) do AUV Pirajuba, modelando uma lacuna entre a raiz da asa e face de simetria 


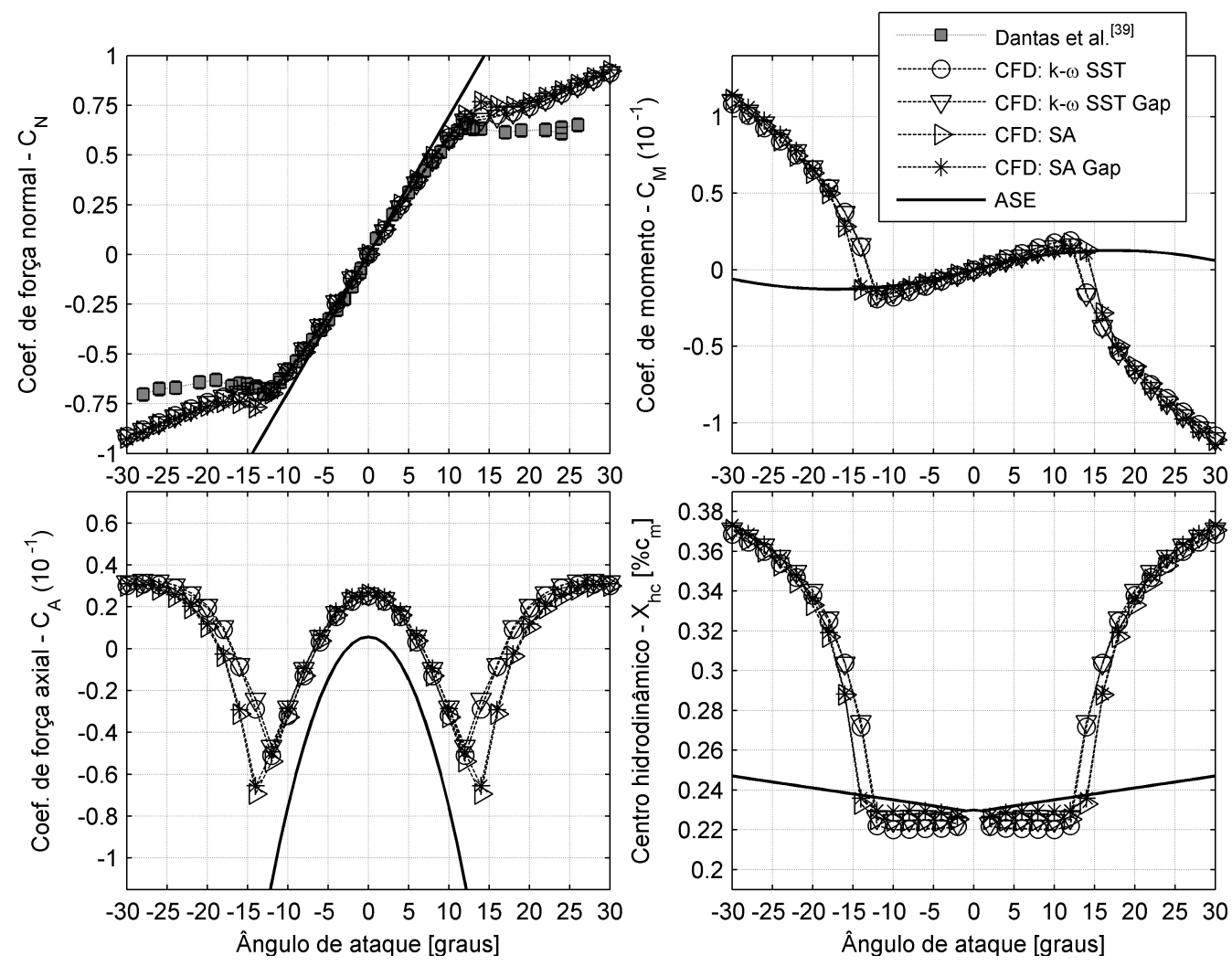

Figura 42 - Coeficientes de força normal, momento de pitch, força axial e centro hidrodinâmico do leme original (NACA0012) do AUV Pirajuba.
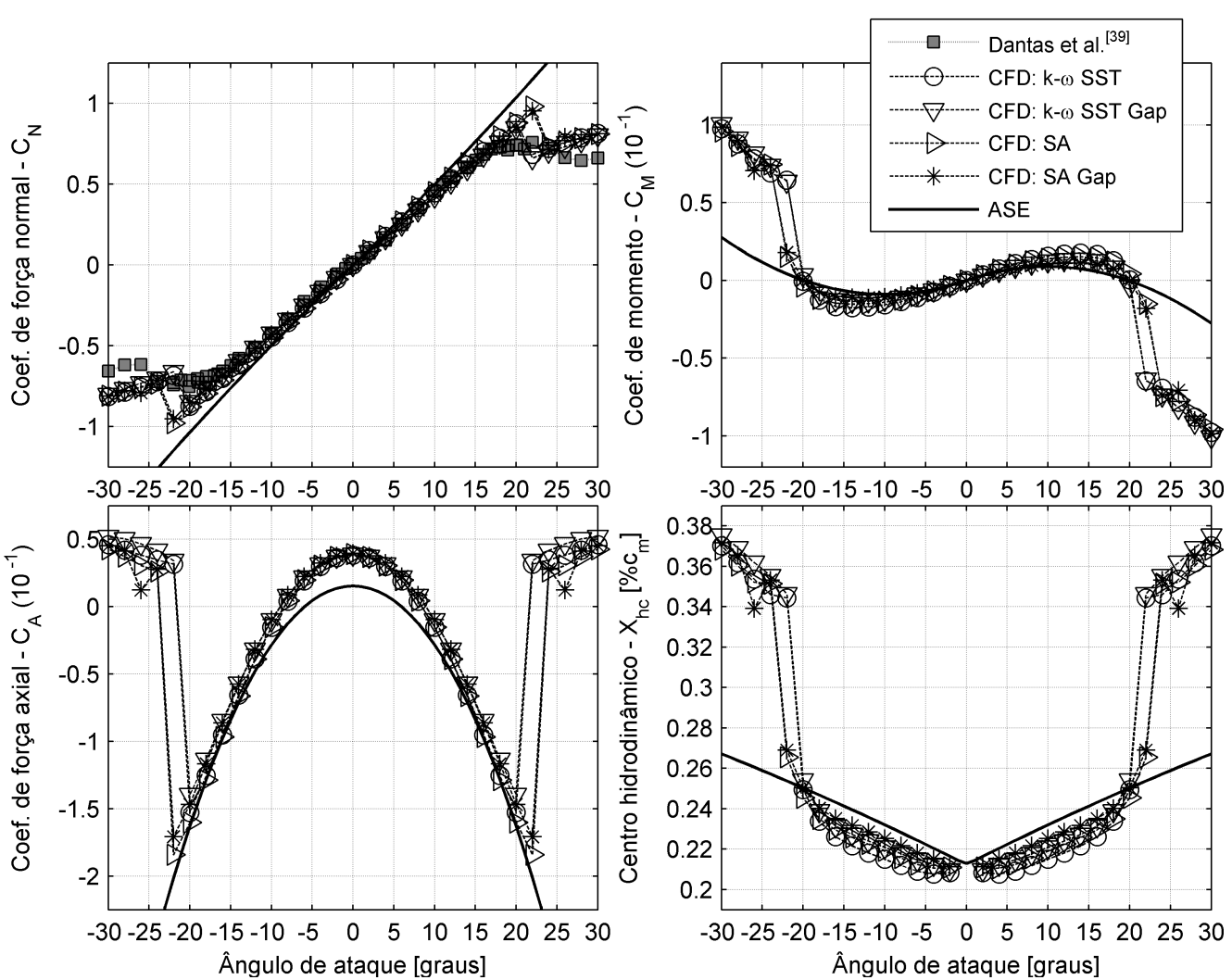

Figura 43 - Coeficientes de força normal, momento de pitch, força axial e centro hidrodinâmico do leme modificado (NACA0015) do AUV Pirajuba. 
Tabela 8 - Propriedades das malhas do leme original (perfil NACA0012) do AUV Pirajuba.

\begin{tabular}{lcccc}
\hline \hline & $\begin{array}{c}\mathbf{n}^{\circ} \text { de } \\
\text { volumes }\end{array}$ & $\begin{array}{c}\text { Espessura do } \\
\text { volume adjacente }\end{array}$ & $\begin{array}{c}y^{+} \\
\text {obtido* }\end{array}$ & $\begin{array}{c}\text { Índice de } \\
\text { malha }\left(h_{i} / h_{1}\right)\end{array}$ \\
\hline Caso 1 & 7993299 & $0.013 \mathrm{~mm}$ & 0.35 & 1 \\
Caso 2 & 5800897 & $0.019 \mathrm{~mm}$ & 0.50 & $\sqrt{2}$ \\
Caso 3 & 2757494 & $0.027 \mathrm{~mm}$ & 0.75 & 2 \\
Caso 4 & 1703576 & $0.038 \mathrm{~mm}$ & 1.10 & $2 \sqrt{2}$ \\
Caso 5 & 1119095 & $0.053 \mathrm{~mm}$ & 1.55 & 4 \\
\hline \hline
\end{tabular}

modificado. As forças foram normalizadas pela multiplicação da pressão dinâmica e da área de planta (planform) do leme, o momento foi adicionalmente normalizado pela corda média do leme sendo calculado no seu centro hidrodinâmico ( $25 \%$ da corda média), e o centro hidrodinâmico foi apresentado em porcentagem da corda média do leme.

Em todos os casos, as incertezas numéricas são calculadas pela análise de sensibilidade de malha utilizando a metodologia não linear ${ }^{[36]}$ e a tradicional ${ }^{[33]}$, para um intervalo de confiança de $95 \%(2 \sigma)$. As linhas pretas representam o método não linear ${ }^{[36]}$ aplicado a todas as malhas. $\mathrm{E}$ as linhas azuis, vermelhas e verdes representam o método tradicional $^{[33]}$ aplicados ao primeiro, segundo e terceiro casos de malhas, respectivamente, e as linhas roxas e amarelas representam as predições do quarto e do quinto caso de CFD. Da mesma forma que as simulações do corpo, as incertezas de truncamento e de iteração são negligenciáveis quando comparadas com as incertezas de discretização.

Para o coeficiente de força normal e momento, os resultados de CFD tiveram uma boa aderência com os experimentais. O estol e a região de comportamento linear foram satisfatoriamente preditas para ambos os lemes. Entretanto, na região de pós-estol, os dados do CFD mostram uma tendência de aumento maior do que os dados experimentais, indicando uma possível divergência maior para ângulos maiores.

No caso do modelo ASE, estes esforços apresentaram uma boa aderência na região de resposta linear, e uma divergência para a região do estol. Este comportamento já era esperado, pois o modelo ASE não consegue prever os efeitos de estol do leme.

Tabela 9 - Propriedades das malhas do leme modificado (perfil NACA0015) do AUV Pirajuba.

\begin{tabular}{lcccc}
\hline \hline & $\begin{array}{c}\mathbf{n}^{\circ} \text { de } \\
\text { volumes }\end{array}$ & $\begin{array}{c}\text { Espessura do } \\
\text { volume adjacente }\end{array}$ & $\begin{array}{c}y^{+} \\
\text {obtido* }\end{array}$ & $\begin{array}{c}\text { Índice de } \\
\text { malha }\left(h_{i} / h_{1}\right)\end{array}$ \\
\hline Caso 1 & 7473923 & $0.015 \mathrm{~mm}$ & 0.30 & 1 \\
Caso 2 & 4275493 & $0.021 \mathrm{~mm}$ & 0.45 & $\sqrt{2}$ \\
Caso 3 & 2532893 & $0.029 \mathrm{~mm}$ & 0.60 & 2 \\
Caso 4 & 1543365 & $0.041 \mathrm{~mm}$ & 1.05 & $2 \sqrt{2}$ \\
Caso 5 & 996319 & $0.058 \mathrm{~mm}$ & 1.45 & 4 \\
\hline \hline
\end{tabular}



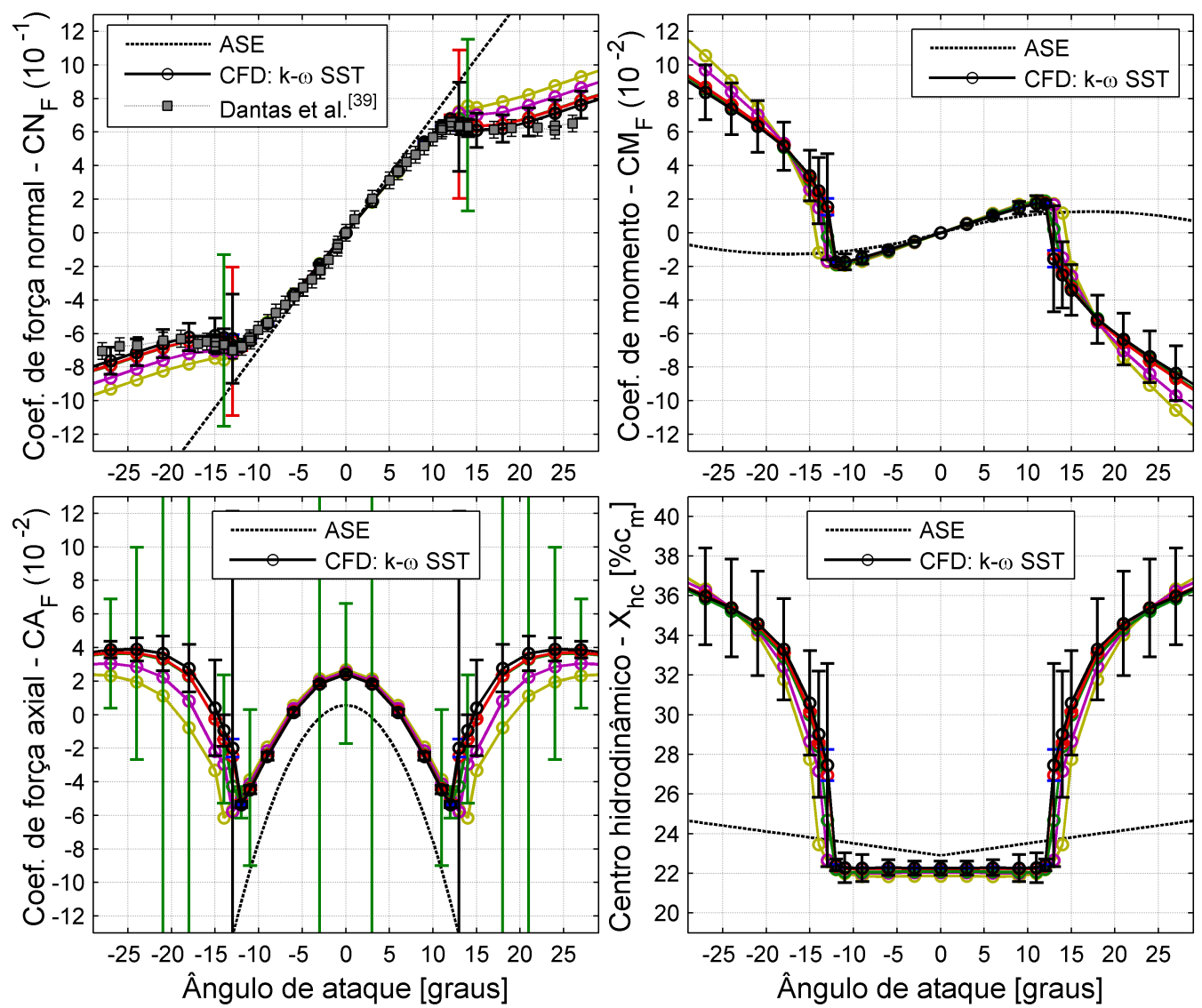

Figura 44 - Coeficientes de força normal, momento, força axial e centro hidrodinâmico do leme original (NACA0012) do AUV Pirajuba, considerando a análise não linear e tradicional no cálculo da sensibilidade de malha.

A força axial apresentou um resultado bastante semelhante ao caso do corpo sozinho em ambos os casos, i.e., a diferença entre a predição dos modelos ASE e CFD se deu apenas no termo referente ao arrasto para a incidência de zero graus. Como não existe dado experimental para estes casos, não é possível saber qual modelo apresentou o melhor resultado, mas é esperado que pelo menos o modelo CFD apresente um erro na predição deste arrasto.

Os cinco casos de malhas de ambos os lemes apresentaram uma incerteza numérica pequena para a região de pre-estol (linear), indicando uma boa convergência de malha com erros numéricos pequenos. Entretanto, com o aumento do ângulo de incidência para a região de pós-estol, os resultados apresentaram variações maiores, com alguns casos não indicando uma convergência assintótica adequada ${ }^{[33]}$, aumentando a incerteza numérica. Isto mostra que existe uma modificação no comportamento da convergência de discretização para escoamentos com grandes gradientes de pressão adversos com separação da camada limite, aumentando a dependência de malha dos cálculos específicos de CFD. Em outras palavras, a suposição de convergência assintótica na análise de dependência de malha não é necessariamente sustentada para os casos de escoamento mais complexos (região de 

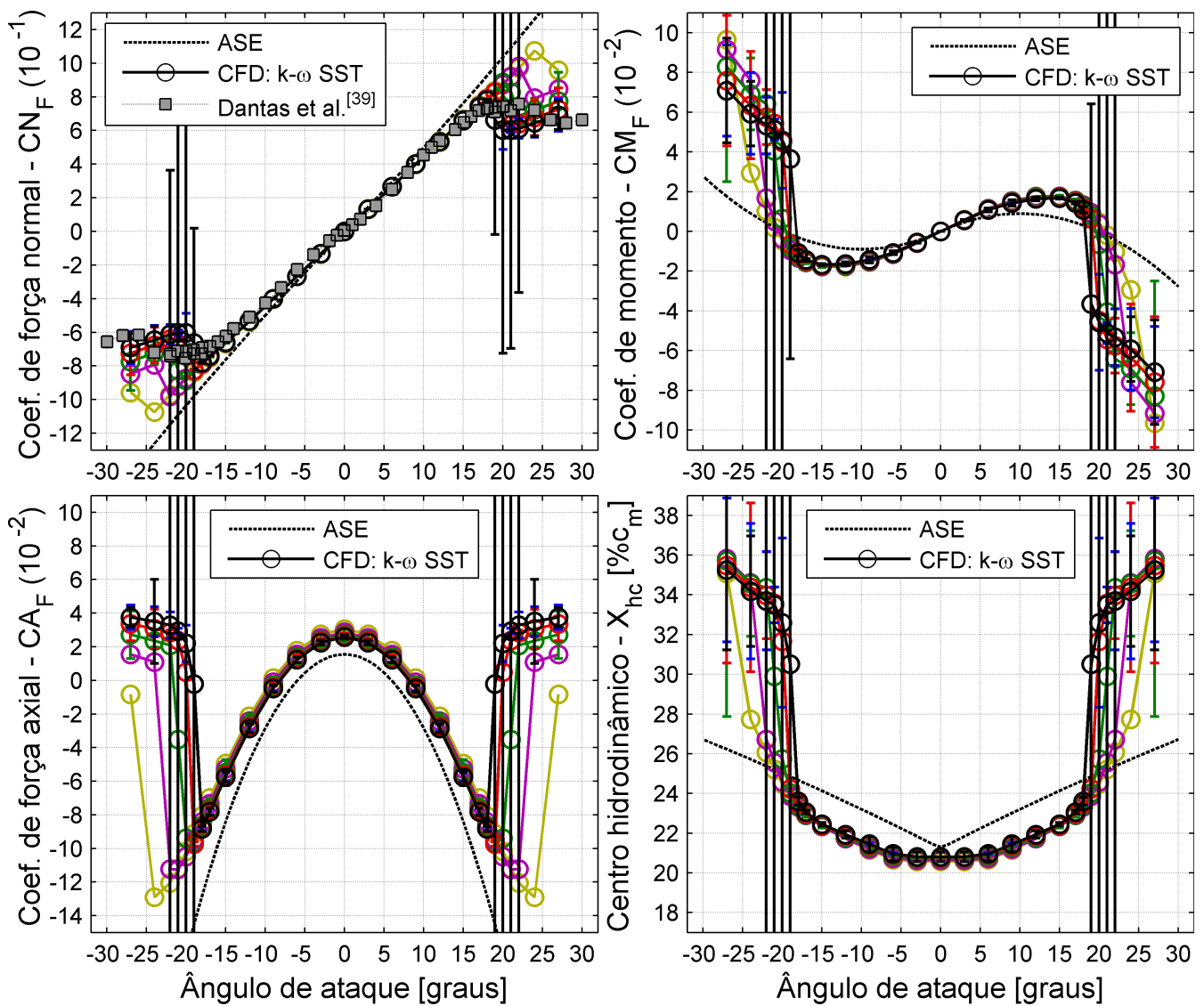

Figura 45 - Coeficientes de força normal, momento, força axial e centro hidrodinâmico do leme modificado (NACA0015) do AUV Pirajuba, considerando a análise não linear e tradicional no cálculo da sensibilidade de malha.

pós-estol), quando as mesmas malhas apresentam uma boa convergência em escoamentos simples (região de pre-estol).

Este comportamento é melhor observado na figura 46, em que a análise de convergência de malha é apresentada para alguns ângulos de incidência usando a metodologia não-linear ${ }^{[36]}$ e a da ASME ${ }^{[33]}$. Uma boa convergência exponencial das malhas foi observada para ambos os lemes a 6 e 12 graus de incidência, e somente para o leme modificado a 15 graus, com apenas poucos pontos discrepantes devido a pequenos problemas na malha. Nos outros ângulos, os dois primeiros casos de malha apresentaram tendencias de curvaturas diferentes das observadas nos últimos três.

A figura 46 também enfatiza as vantagens de robustez obtidas pelo uso da metodologia não-linear de Eça, Vaz e Hoekstra ${ }^{[36]}$, ao ser comparada com a metodologia tradicional da ASME ${ }^{[33]}$. Na região de pre-estol, pequenas variações nos resultados numéricos de algum caso de malha resultaram em um comportamento de regressão divergente com o método da ASME ${ }^{[33]}$, enquanto o método não-linear prediz um comportamento convergente com um aumento da incerteza. Este problema é amplificado nos casos de pós-estol, com a metodologia tradicional ${ }^{[33]}$ apresentando um comportamento divergente, 

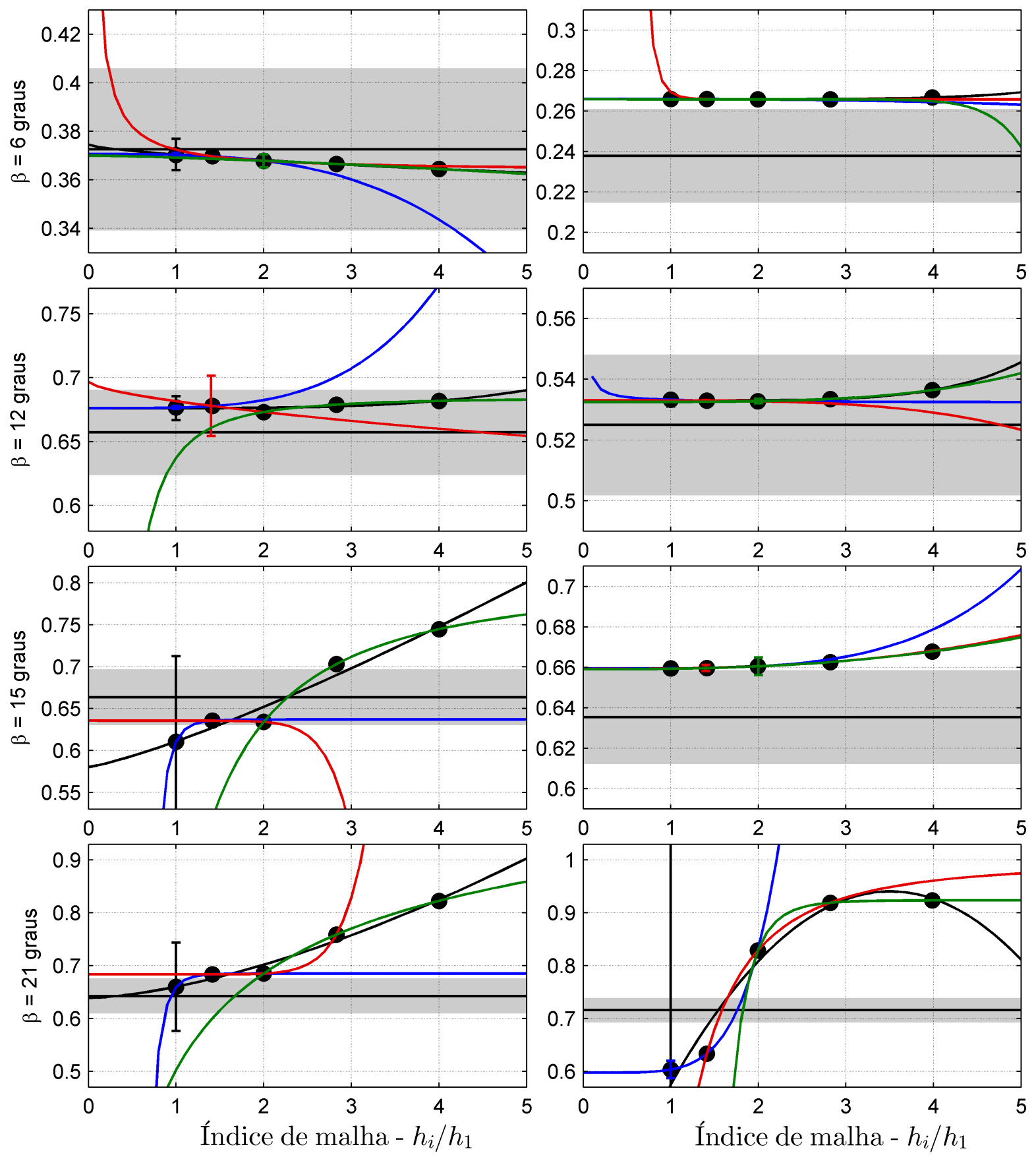

Figura 46 - Análise da convergência de malha para a força normal dos lemes. A região cinza indica o intervalo de confiança de $95.4 \%(2 \sigma)$ dos dados experimentais ${ }^{[39]}$. A linha preta representa a regressão não linear ${ }^{[36]}$ aplicada a todos os resultados. As linhas azul, vermelha e verde representam a metodologia da ASME ${ }^{[33]}$ aplicado aos casos de malha 1-3, 2-4 e 3-5, respectivamente. 


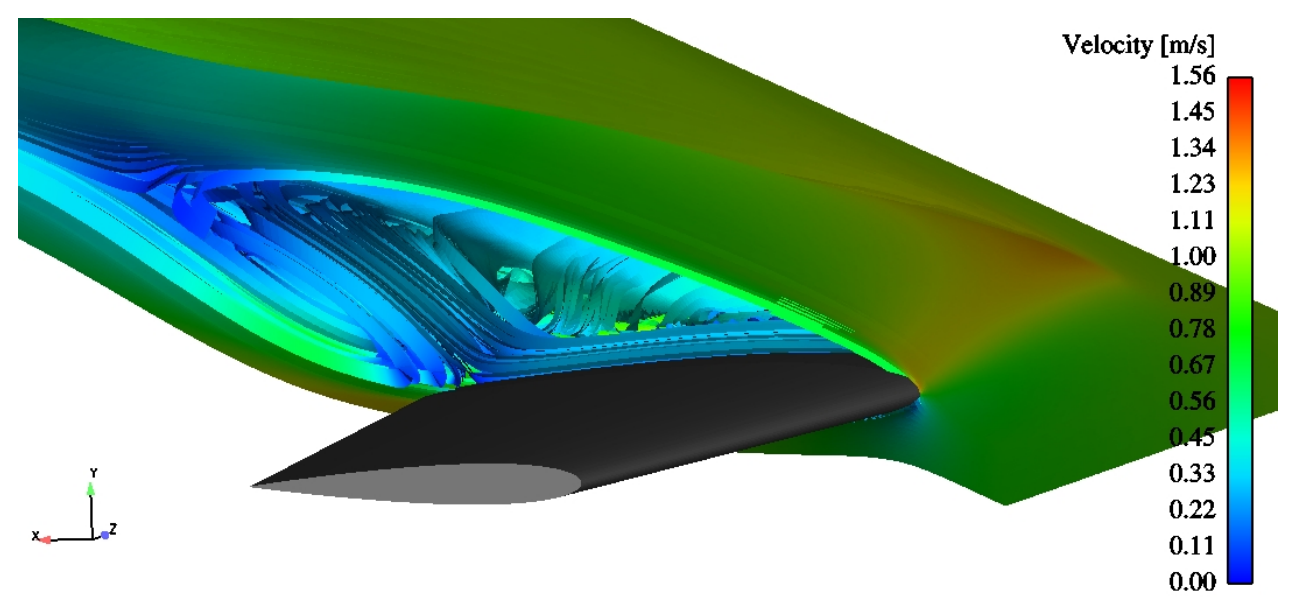

Figura 47 - Linhas de fluxo do escoamento sobre o leme original do AUV Pirajuba, em uma condição de $22^{\circ}$ de ângulo de incidência, demonstrando a complexidade do escoamento na condição de pós estol

apesar que em alguns casos foi predito uma convergência exagerada (com baixa incerteza). Tal comportamento pode ser melhor observado para as primeiros casos de regressão (casos de malha 1, 2 e 3) do maior ângulo de ataque.

Com a modificação na geometria do leme o ângulo de estol aumentou em cerca de $50 \%$ em relação ao leme original, i.e., de 12 a 18 graus, mantendo a mesma razão de força normal pelo ângulo de ataque na região de pre-estol. Com este resultado a região de resposta linear das superfícies de controle foi aumentada, aumentando a capacidade de manobra do AUV. Entretanto, este novo leme aumentou em cerca de $42 \%$ o arrasto dos lemes a incidência zero, representando um aumento de cerca de $6 \%$ no arrasto total do veículo, considerando o arrasto obtido numericamente pelo modelo $k-\omega$ SST.

$\mathrm{Na}$ figura 47, é apresentado as linhas de escoamento sobre o leme original do AUV Pirajuba, em uma condição de 22 graus de ângulo de incidência. Nesta figura, é ilustrado a complexidade do escoamento na condição de pós-estol, mesmo sendo gerada por uma simulação quasi-estática. Na realidade, os vórtices gerados em uma condição de estol apresentam uma complexidade ainda maior, com uma maior caoticidade do escoamento, dificultando bastante a modelagem deste tipo de escoamento por modelos RANS, sendo necessários utilizar modelos mais avançados com condições transientes. Contudo, os resultados apresentados nesta seção indicam que o modelo de CFD quasiestático conseguiu reproduzir a ordem de gradeza dos esforços hidrodinâmicos, reproduzindo parcialmente a topologia média do escoamento, na condição de pós estol. Na condição de pré-estol, esta topologia foi melhor identificada, pelo escoamento apresentar características mais comportada. 
Tabela 10 - Características geométricas do duto do AUV Pirajuba, e do duto ensaiado por Fletcher ${ }^{[151]}$.

\begin{tabular}{lrr}
\hline \hline Parâmetro & AUV Pirajuba & Fletcher $^{[\mathbf{1 5 1}]}$ \\
\hline Corda $\left(c_{d}\right)$ & $75.0 \mathrm{~mm}$ & $331.9 \mathrm{~mm}$ \\
Diâmetro $\left(D_{d}\right)$ & $150.0 \mathrm{~mm}$ & $497.8 \mathrm{~mm}$ \\
$c_{d} / D_{d}$ & 2 & 1.5 \\
$\mathrm{~N}^{\circ}$ de Reynolds & $7.5 \times 10^{4}$ & $99.5 \times 10^{4}$ \\
Perfil & $19 \mathrm{~A}$ & Clark-Y \\
\hline \hline
\end{tabular}

\subsubsection{Duto propulsor isolado}

Por motivos de cronograma não foi possível realizar testes em tanque de prova com o duto propulsor do AUV Pirajuba. Portanto, a validação numérica teve que ser realizada indiretamente por simulações de um modelo com características hidrodinâmicas similares ao duto do AUV Pirajuba, que apresentasse resultados experimentais abertos. Pelos resultados na área naval serem escasso, foram utilizados o estudo aerodinâmico de fólios anulares (utilizados em turbinas de aviões) de Fletcher ${ }^{[151]}$.

Foi selecionado um fólio que apresentasse uma razão de diâmetro $\left(D_{d}\right)$ por corda $\left(c_{d}\right)$ mais próximo ao do duto do AUV Pirajuba. Também procurou-se utilizar um modelo que apresentasse um número de Reynolds próximo, mas apenas foi encontrado um modelo com uma ordem de grandeza superior. Uma comparação entre as características geométricas destes dois fólios é apresentada na tabela 10.

Com o modelo de validação definido, foram realizadas as simulações com os mesmos modelos numéricos dos outros casos, utilizando o procedimento de cálculo de incertezas não-linear de Eça, Vaz e Hoekstra ${ }^{[36]}$. As propriedades das malhas do duto de Fletcher ${ }^{[151]}$ são apresentadas na tabela 11.

$\mathrm{Na}$ maioria dos casos as simulações apresentaram um comportamento iterativo convergente. Contudo, na região de ângulo de ataque entre 16 e 20 graus as simulações apresentaram uma convergência oscilatória de baixa amplitude, contribuindo para o aumento da incerteza numérica. Mesmo com este comportamento todos os casos apresentaram uma

Tabela 11 - Propriedades das malhas do duto propulsor de perfil Clark- ${ }^{[151]}$ utilizadas no procedimento de $\mathrm{V} \& \mathrm{~V}$

\begin{tabular}{lcccc}
\hline \hline & $\begin{array}{c}\mathbf{n}^{\circ} \text { de } \\
\text { volumes }\end{array}$ & $\begin{array}{c}\text { Espessura do } \\
\text { volume adjacente }\end{array}$ & $\begin{array}{c}y^{+} \\
\text {obtido* }\end{array}$ & $\begin{array}{c}\text { Índice de } \\
\text { malha }\left(h_{i} / h_{1}\right)\end{array}$ \\
\hline Caso 1 & 1470544 & $0.020 \mathrm{~mm}$ & 0.45 & 1.00 \\
Caso 2 & 1308414 & $0.035 \mathrm{~mm}$ & 0.78 & 1.75 \\
Caso 3 & 1145768 & $0.050 \mathrm{~mm}$ & 1.10 & 2.50 \\
Caso 4 & 1016808 & $0.065 \mathrm{~mm}$ & 1.42 & 3.25 \\
Caso 5 & 920234 & $0.080 \mathrm{~mm}$ & 1.77 & 4.00 \\
\hline \hline \multicolumn{5}{c}{ *Valor médio }
\end{tabular}


Tabela 12 - Propriedades das malhas do duto propulsor do AUV Pirajuba (perfil 19A) utilizadas no procedimento de $\mathrm{V} \& \mathrm{~V}$

\begin{tabular}{lcccc}
\hline \hline & $\begin{array}{c}\mathbf{n}^{\circ} \text { de } \\
\text { volumes }\end{array}$ & $\begin{array}{c}\text { Espessura do } \\
\text { volume adjacente }\end{array}$ & $\begin{array}{c}y^{+} \\
\text {obtido* }\end{array}$ & $\begin{array}{c}\text { Índice de } \\
\text { malha }\left(h_{i} / h_{1}\right)\end{array}$ \\
\hline Caso 1 & 1459968 & $0.015 \mathrm{~mm}$ & 0.63 & 1.00 \\
Caso 2 & 1436640 & $0.020 \mathrm{~mm}$ & 0.85 & 1.33 \\
Caso 3 & 1404960 & $0.025 \mathrm{~mm}$ & 1.07 & 1.67 \\
Caso 4 & 1383840 & $0.030 \mathrm{~mm}$ & 1.23 & 2.00 \\
Caso 5 & 1297440 & $0.050 \mathrm{~mm}$ & 2.00 & 3.33 \\
\hline \hline \multicolumn{5}{c}{ *Valor médio }
\end{tabular}

convergência de discretização potencial de diversos tipos e amplitudes.

Os resultados dos coeficientes hidrodinâmicos do duto Clark- $Y^{[151]}$ são apresentados na figura 48. Nesta figura é realizada uma comparação dos resultados estimados numericamente por CFD e os obtidos pelo modelo de Morgan e Caster ${ }^{[136]}$ com os resultados experimentais de Fletcher ${ }^{[151]}$. A força normal está normalizada pela pressão dinâmica e pela área de projeção do duto $\left(D_{d} \cdot c_{d}\right)$, e o momento é normalizado adicionalmente pela corda do duto (i.e., $D_{d} \cdot c_{d}^{2}$ ).

Tanto o modelo ASE ${ }^{[136]}$ quanto o modelo de CFD conseguiram estimar corretamente os esforços de momento e força normal na região de pre-estol (resposta linear). O modelo de CFD não conseguiu capturar corretamente o efeito de descolamento da camada limite, predizendo um ângulo de estol menor do que o observado experimentalmente, i.e., o modelo de CFD estimou um ângulo de estol de 14 graus enquanto o experimental foi de 20 graus. É provável que possa ser reduzido o erro na predição do estol ao considerar uma malha com o mesmo graus de refino da malha do leme, que apenas conseguiu prever bem o ângulo do estol para as malhas de alto refino.

O modelo ASE não estimou o ângulo de estol por não considerar este fenômeno em suas formulações, como explicado na seção 4.2.5. O resultado positivo do modelo ASE já era esperado, pois este modelo foi desenvolvido com os dados obtidos por Fletcher ${ }^{[151]}$.

Com estes resultados foi possível considerar que a metodologia utilizada para a definição do modelo numérico e analítico conseguem prever corretamente os coeficientes de força normal e momento, para a região de pre-estol, de um duto propulsor de condições semelhantes ao do AUV Pirajuba. Aplicando a mesma metodologia na geração de malha e análise de simulação, foram realizadas novas simulações para o duto do AUV Pirajuba (perfil 19A). As propriedades das malhas resultantes são apresentadas na tabela 12, e uma representação da malha de refino média é apresentada na figura 49.

Diferente do duto Clark-Y, as simulações do duto 19A apresentaram uma convergência com um comportamento bastante estável, sem precisar realizar modificações nos parâmetros de sobre-relaxação. Esta melhor estabilidade numérica pode indicar que as 

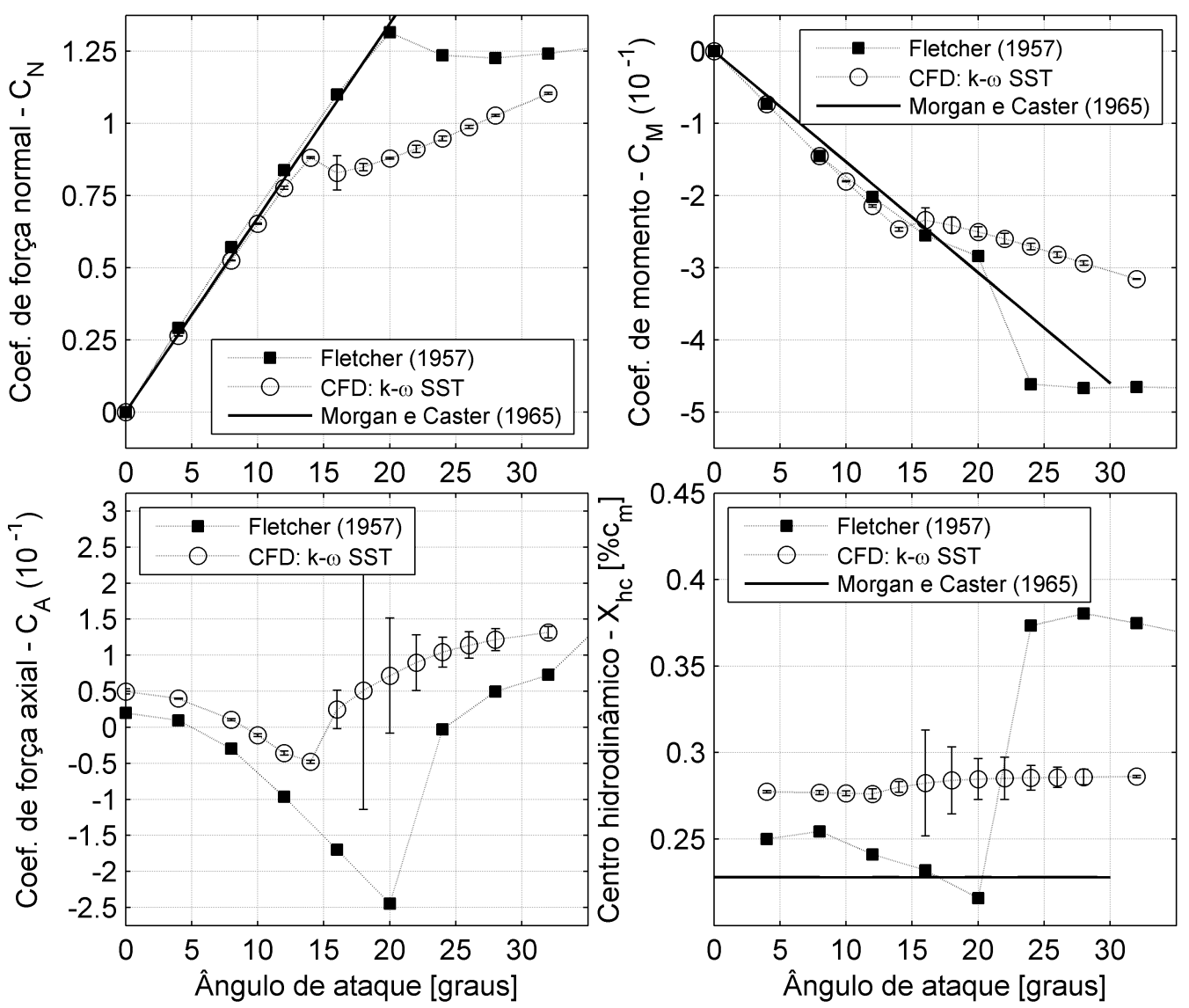

Figura 48 - Coeficientes de força normal, momento de pitch, força axial e centro hidrodinâmico do duto ensaiado por Fletcher ${ }^{[151]}$ (Clark-Y)

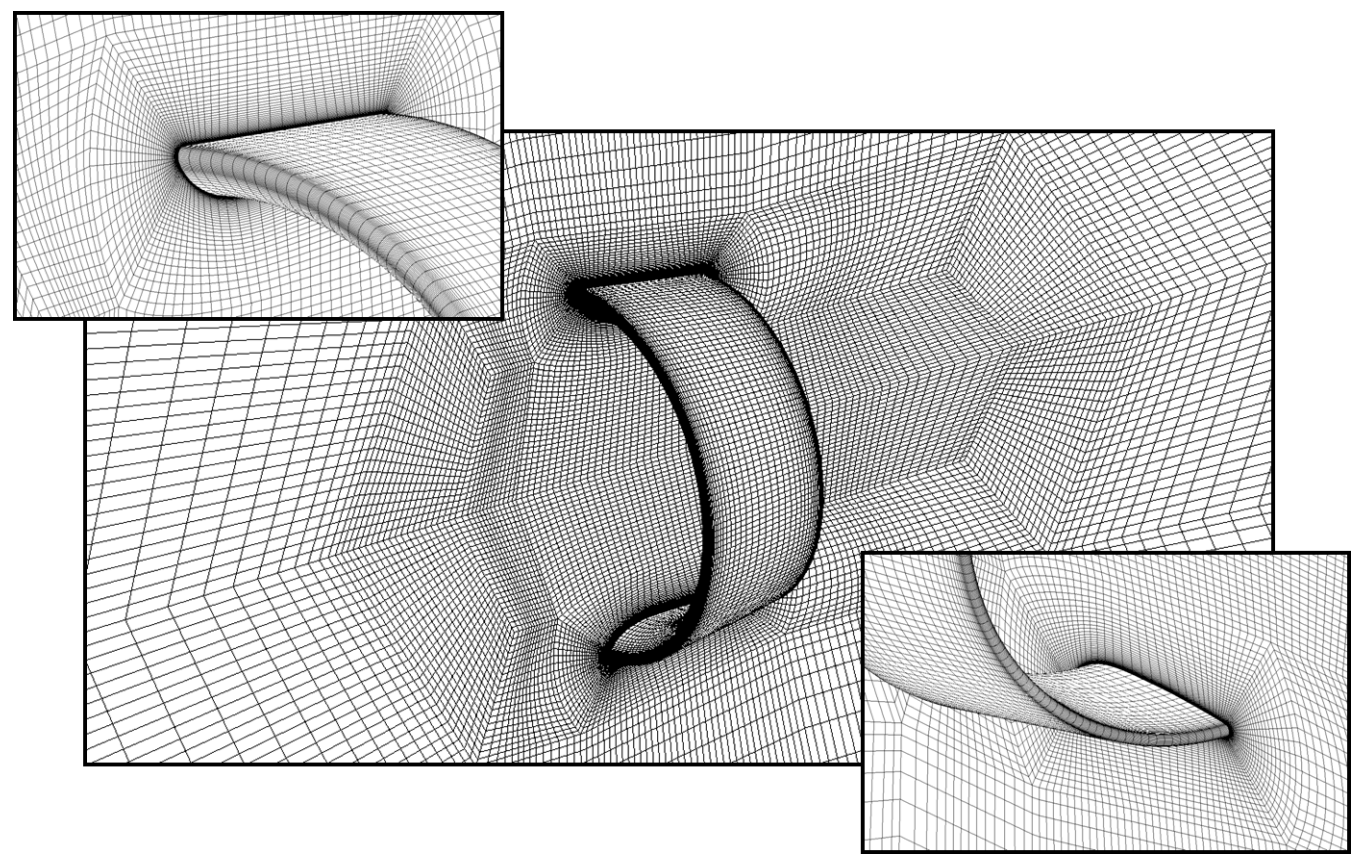

Figura 49 - Malha de refino médio do duto propulsor do 19A AUV Pirajuba, com detalhas na malha interna e externa 

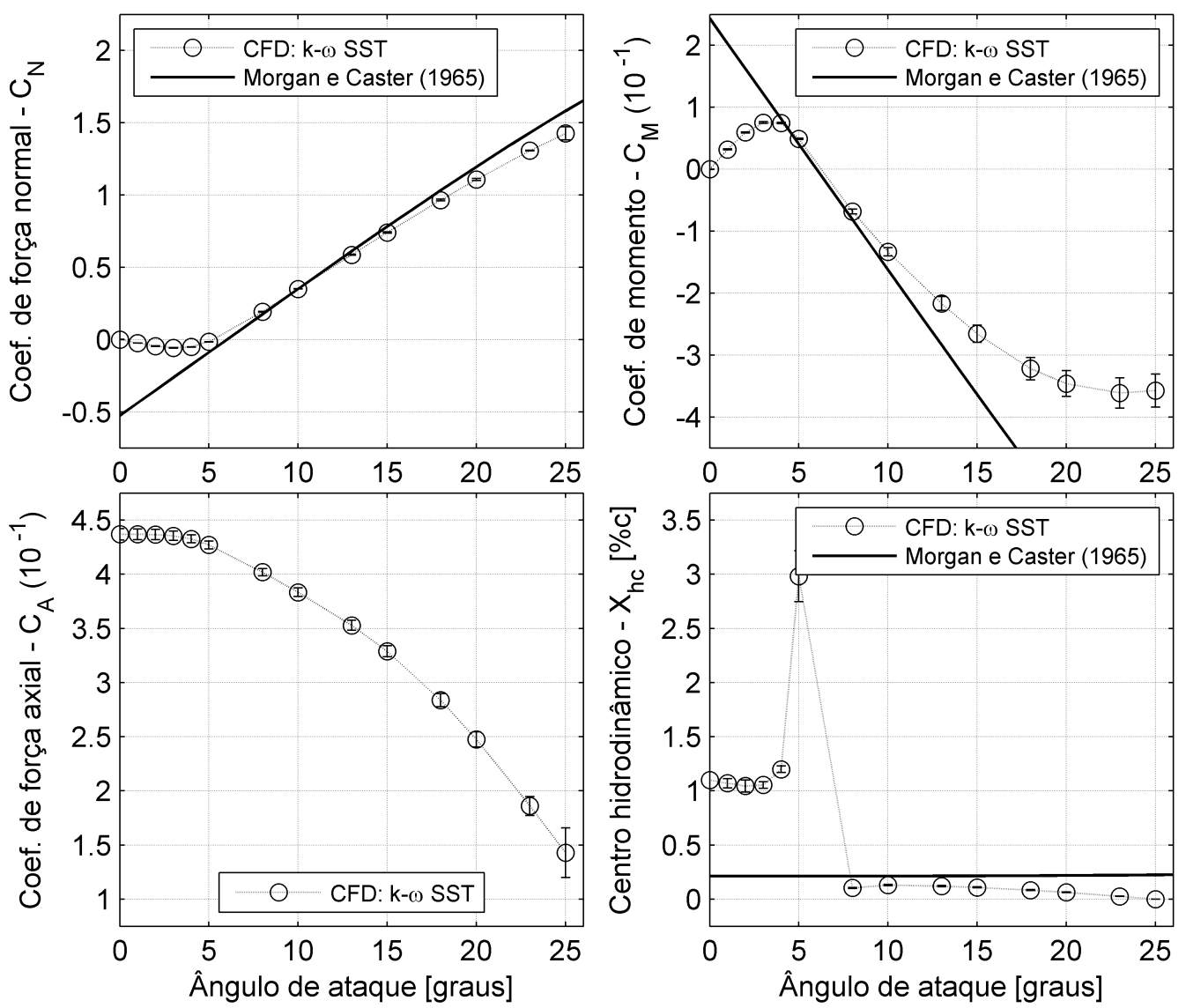

Figura 50 - Coeficientes de força normal, momento, força axial e centro hidrodinâmico do duto propulsor do Pirajuba (perfil 19A)
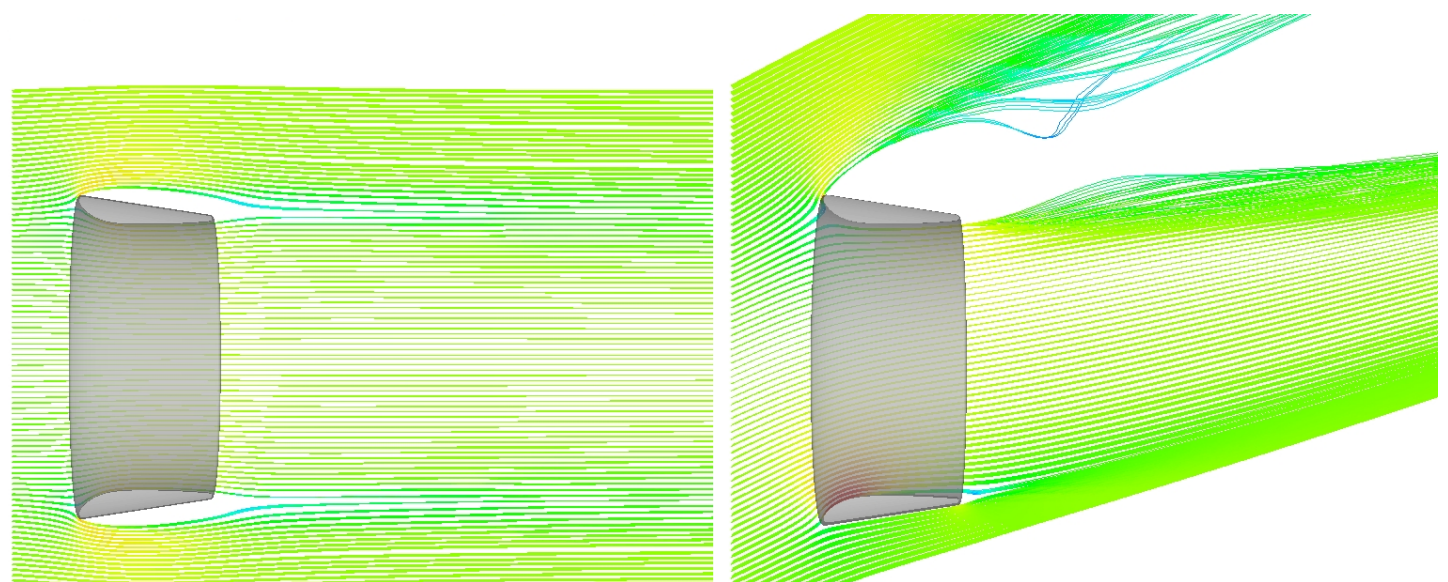

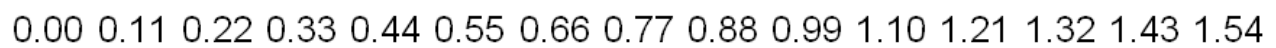

Velocity $[\mathrm{m} / \mathrm{s}]$

Figura 51 - Linhas de escoamento, coloridas pelo módulo da velocidade, da simulação de 0 (à direita) e 25 graus (à esquerda) do duto propulsor do AUV Pirajuba (de perfil 19A) 


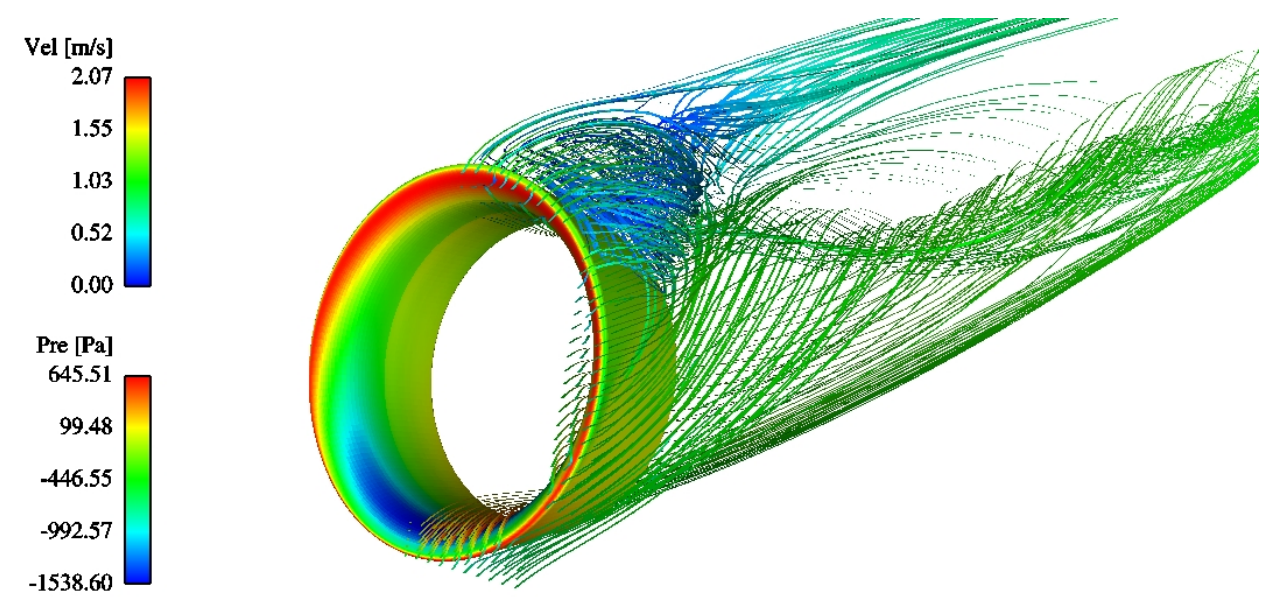

Figura 52 - Linhas de fluxo do escoamento sobre o duto propulsor do AUV Pirajuba, em uma condição de $25^{\circ}$ de ângulo de incidência, demonstrando a complexidade do escoamento na condição de pós estol

soluções obtidas foram melhor modeladas neste caso, podendo apresentar erros menores.

A comparação entre os coeficientes hidrodinâmicos estimados numericamente e analiticamente é apresentada na figura 50. Pelo modelo ASE apresentar resultados confiáveis na região de resposta linear, validado para o caso do duto com perfil Clark-Y, ele pode ser utilizado como referencia para a "validação" do modelo numérico nesta região.

As simulações de CFD indicaram que o duto 19A apresenta uma banda morta para ângulos de incidência menores do que cinco graus, sendo este efeito mais pronunciado no caso da força normal. Com o aumento do ângulo de incidência, os coeficientes do duto entram na região de resposta linear, onde o modelo numérico consegue estimar os esforços de maneira bastante semelhante ao comportamento obtido analiticamente.

Este fenômeno pode ser explicado ao analisar as linhas de fluxo das simulações numéricas para um ângulo de incidência nulo e para um ângulo de 25 graus, apresentadas na figura 51. Para ângulos de incidência baixos, o escoamento na região externa do duto apresenta uma grande região de recirculação, devido ao descolamento da camada limite próximo ao seu bordo de ataque, impedindo a geração de sustentação. A medida que o ângulo aumenta o escoamento se alinha com o perfil da parte inferior do duto, deixando o escoamento com um comportamento mais próximo ao potencial, possibilitando uma geração de sustentação linear com o ângulo de incidência. Na parte superior do duto, a região de recirculação aumenta, contribuindo somente com um aumento de arrasto. Este efeito é melhor observado na figura 52, pelas linhas de escoamento tri-dimensionais sobre o duto em condição de 25 graus de ângulo de incidência, enfatizando o escoamento em condição de estol sobre a parte superior do duto.

No caso do momento, este acréscimo de arrasto devido ao estol na parte superior acaba por diminuir o momento linear gerado pela força normal da parte inferior, reduzindo 
Tabela 13 - Propriedades das malhas da combinação corpo-leme (perfil NACA0012) do AUV Pirajuba, utilizadas na análise de sensibilidade de malha.

\begin{tabular}{lcccc}
\hline \hline & $\begin{array}{c}\mathbf{n}^{\circ} \text { de } \\
\text { volumes }\end{array}$ & $\begin{array}{c}\text { Espessura do } \\
\text { volume adjacente }\end{array}$ & $\begin{array}{c}y^{+} \\
\text {obtido* }\end{array}$ & $\begin{array}{c}\text { Índice de } \\
\text { malha }\left(h_{i} / h_{1}\right)\end{array}$ \\
\hline Caso 1 & 8536415 & $0.010 \mathrm{~mm}$ & 0.30 & 1 \\
Caso 2 & 6364269 & $0.014 \mathrm{~mm}$ & 0.45 & $\sqrt{2}$ \\
Caso 3 & 4866191 & $0.020 \mathrm{~mm}$ & 0.60 & 2 \\
Caso 4 & 3810903 & $0.028 \mathrm{~mm}$ & 1.05 & $2 \sqrt{2}$ \\
Caso 5 & 3127407 & $0.040 \mathrm{~mm}$ & 1.45 & 4 \\
\hline \hline
\end{tabular}

quadraticamente, em função do ângulo de ataque, o momento total gerado pelo duto.

Esta teoria é suportada pelo fato que nas regiões de comportamento linear, o modelo ASE linear de Morgan e Caster ${ }^{[136]}$ ao ser defasado em cerca de cinco graus apresenta uma aderência muito boa, aumentando a confiabilidade das simulações de CFD.

Morgan e Caster ${ }^{[136]}$ apresentam uma discussão semelhante em seu trabalho, sendo esperado que dutos que apresentassem uma grande recirculação a baixo ângulo de ataque deveriam apresentar um comportamento na geração da força de sustentação diferente. Contudo, apesar de um dos dutos ensaiados apresentarem este efeito, ele conseguiu gerar um aumento linear de sustentação que foi predita pelo modelo ASE.

\subsubsection{Combinação corpo e leme}

O estudo da combinação leme-corpo corresponde ao modelo mais simples do AUV Pirajuba, onde é considerado o corpo com as superfícies de controle (lemes de perfil NACA0012) em configuração cruciforme ("+")4 , sem a presença do duto. Neste estudo foi considerada a variação do ângulo de incidência do veículo e do ângulo de deflexão das superfícies de controle.

Os ensaios em tanque de provas foram realizados utilizando as balanças de estrutura vertical e com o formato "L". Contudo, somente foram utilizados os resultados da balança com estrutura em formato "L", pois a balança de estrutura vertical atrapalhou o escoamento no leme superior do veículo, interferindo na medição. Em ambos os ensaios não foi possível impor a deflexão dos lemes, pelo modelo cativo ser um modelo rígido, obtendo apenas os esforços devido a inclinação do veículo.

$\mathrm{Na}$ análise pelo método de CFD foram utilizados os mesmos modelos numéricos das outras investigações, o modelo $k-\omega$ SST. As malhas foram geradas utilizando uma estrutura semelhante às malhas individuais de cada parte, com um refino relativo determinado pela metodologia não-linear ${ }^{[36]}$ de estimativa da incerteza numérica. As propriedades das

4 Quatro lemes distribuídos a cima, abaixo, a direita, e a esquerda da circunferência do corpo, formando uma cruz quando vistos pela frente do veículo. 


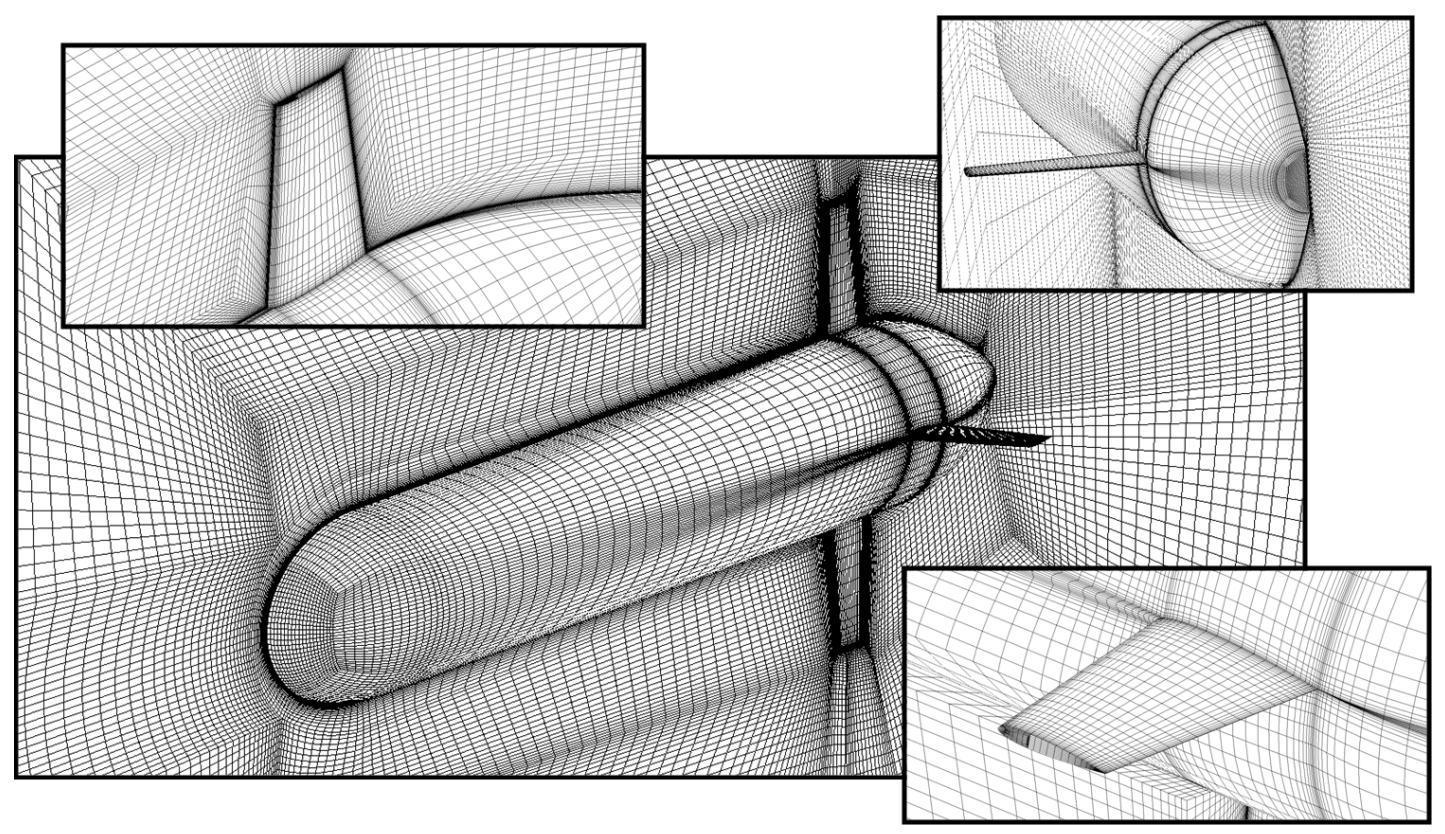

Figura 53 - Malha de refino médio da combinação corpo e lemes, com detalhes na malha dos lemes e da popa.

malhas utilizadas neste estudo são apresentadas na tabela 13, com a malha de refino médio apresentada na figura 53.

Na figura 54 é realizada a comparação das medições experimentais dos coeficientes de força normal e momento com as estimativas dos métodos numéricos e analíticos.

Neste estudo, foram utilizados duas metodologias para o cálculo da interferência dos modelos analíticos, a linear e a não-linear. A metodologia linear de Pitts, Nielsen e Kaattari $^{[134]}$ considera que os coeficiente de interferência leme-corpo $\left(K_{W(B)}\right.$ e $\left.K_{B(W)}\right)$ são linearmente combinados com a força de sustentação gerada pelos lemes, enquanto que no modelo não-linear de Hemsch e Nielsen ${ }^{[145]}$ os coeficientes de interferência modificam o ângulo de incidência local no leme (ângulo de ataque equivalente), que acaba por modificar a curva de sustentação gerada pelo leme. Ambos os modelos foram previamente apresentados na seção 4.2.4. Em ambos os modelos ASE, a parcela dos esforços do corpo foram calculados pelo modelo ASE de Barros et al. ${ }^{[20]}$, validado na seção 6.2.1, e a função da curva de sustentação foi obtida pelos resultados de CFD, validados na seção 6.2.2, para que o modelo de estol fosse considerado.

A correção da curva do estol também é utilizada neste caso, pois mesmo com a incidência dos vórtices laterais gerados pela presença do corpo, ainda ocorre o estol do leme. Este fenômeno pode ser qualitativamente observado ao analisar as linhas de escoamento sobre o corpo e o leme, apresentado na figura 55 para o caso de ângulo incidência de 20 graus. Esta figura também indica que o modelo ASE do corpo não deve ter seus parâmetros semi-empíricos modificados pela presença do leme, pois o escoamento neste caso mantêm as mesmas características e topologias do caso do corpo isolado, permitindo o uso destes 

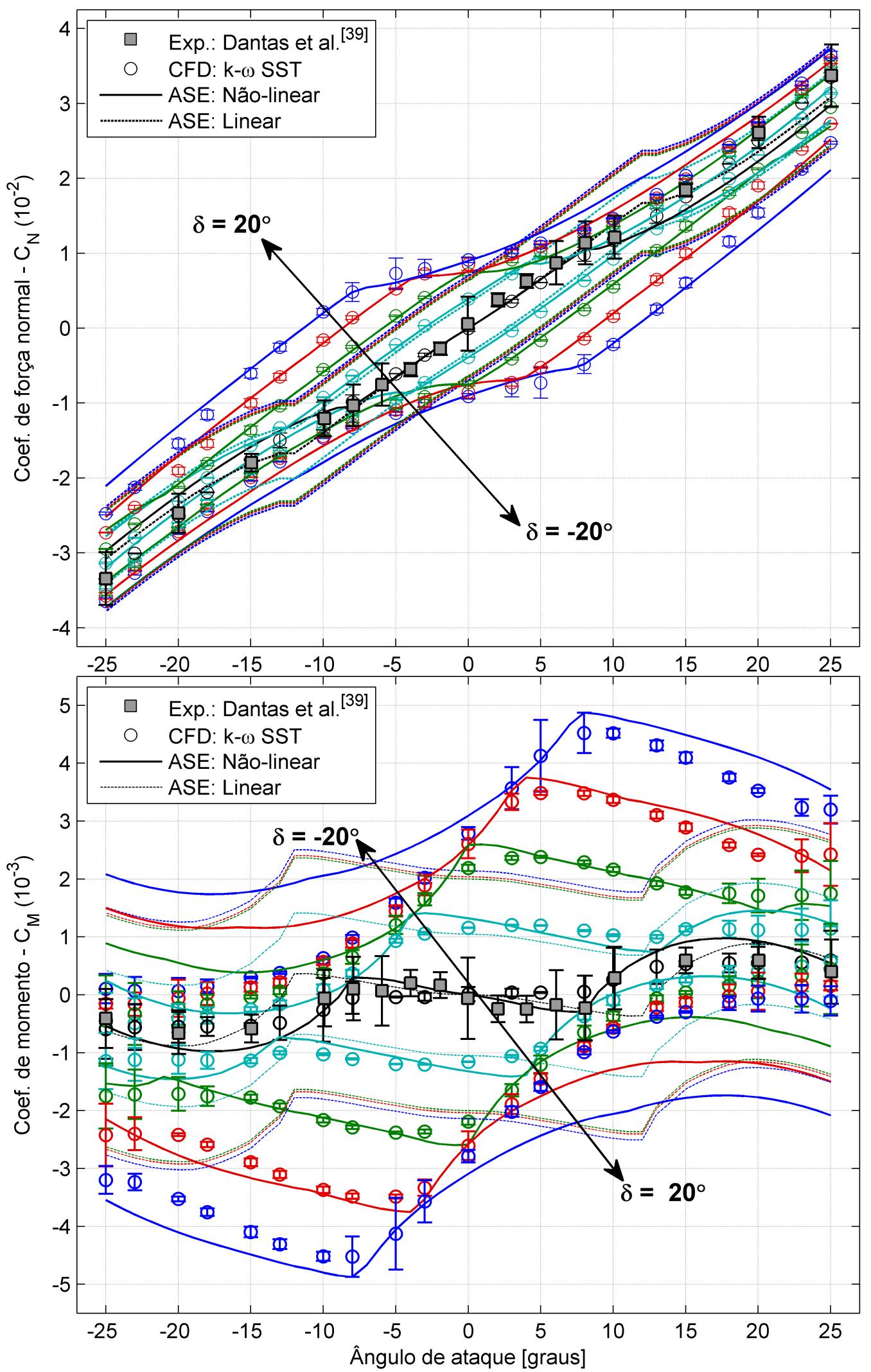

Figura 54 - Comparação dos coeficientes de força normal e momento da combinação do leme original (NACA0012) e corpo do AUV Pirajuba para variações do ângulo de incidência $(\alpha)$ e da deflexão das superfícies de controle $(\delta)$. São apresentadas as medições experimentais com as estimativas numéricas e analíticas (modelo linear $^{[134]}$ e não-linear). 


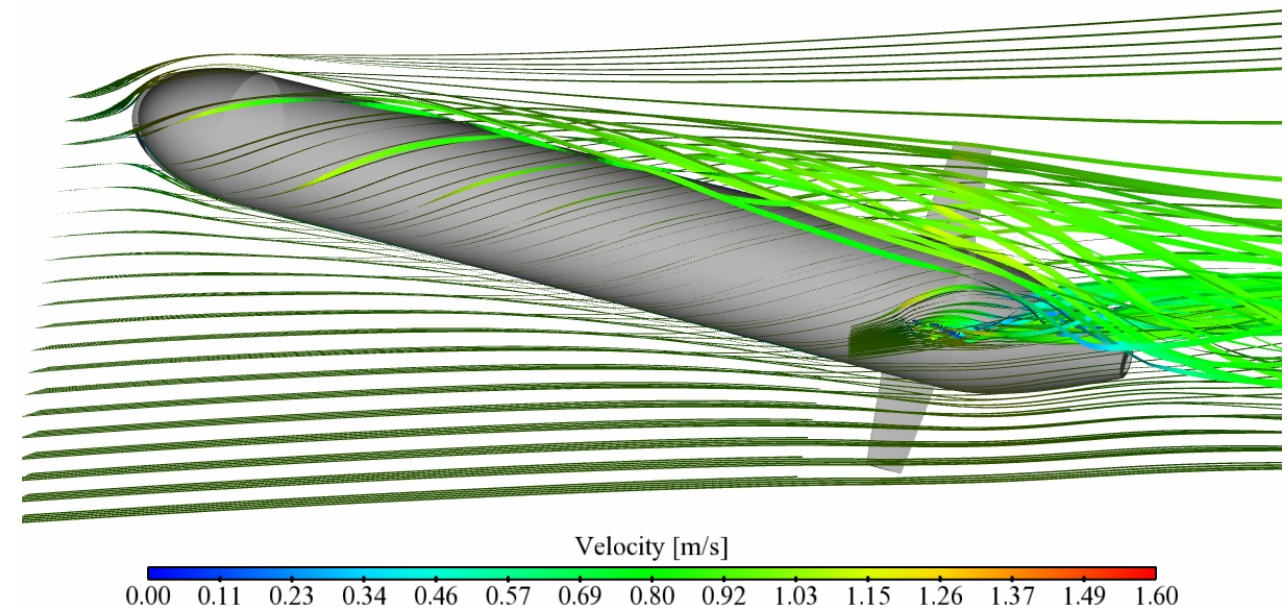

Figura 55 - Linhas de fluxo do escoamento sobre o corpo e o leme do AUV Pirajuba, em uma condição de $20^{\circ}$ de ângulo de incidência, com detalhe nos vórtices gerados pelo corpo e pelo leme

modelos sem modificações.

Considerando o caso de deflexão nula, linha preta, para baixos valores de ângulo de incidência, todos os modelos apresentaram uma boa aderência para o esforço de força normal, enquanto no caso do momento, todos os métodos apresentaram um pequeno erro nesta região. Como o valor do momento nesta região é muito baixo, acredita-se que este erro esteja relacionado a um erro de medição da posição da balança, pois caso seja considerado que a balança estava localizada apenas $3 \mathrm{~cm}$ (menos de $2 \%$ em relação ao comprimento do veículo) distante de sua posição nominal, o resultado experimental coincidiria com os resultados obtidos pelos demais modelos.

Na região de pós-estol (aproximadamente para $\alpha>14^{\circ}$ ), quando ocorrem as "quebras" das curvas dos esforços, o modelo numérico continua apresentando uma boa aderência, enquanto que os modelos ASE divergem. Acredita-se que esta divergência esteja relacionada a modificação do esfeito do estol na curva de força normal do leme devido a presença do corpo.

No caso das deflexões não nulas, foi considerado que as estimativas obtidas pelo modelo de CFD possuem um erro baixo, pelos resultados de deflexão nula terem sido validados pelas medições experimentais. Foram consideradas as simulações numéricas de -20 a +20 graus de deflexão em incrementos de cinco graus, e variação do ângulo de incidência de -25 até mais 25 graus.

Considerando a deflexão, o modelo não-linear apresentou uma aderência melhor do que o modelo linear, apesar de ter apresentado diversos erros devido a modelagem do estol. No caso do modelo linear, o ângulo de estol sempre ocorreu no mesmo ângulo, enquanto que no modelo numérico o ângulo de estol é modificado com a deflexão dos lemes. Com o uso do modelo não-linear esta relação ângulo de incidência e deflexão foi melhor estimada, 
mas o modelo ainda apresentou erros na região de pós-estol.

O problema de modelagem dos coeficientes do leme nos modelos ASE são melhor analisados na figura 56, onde são apresentados os coeficientes de força normal e momento do leme na presença do corpo. Nesta figura não são apresentados os resultados experimentais, pois os esforços no leme não foram isoladamente medidos.

Analisando apenas as curvas de deflexão nula, linhas e símbolos pretos, o modelo de CFD apresenta um ângulo de estol menor do que o estimado pelas simulações do leme sozinho, i.e., $8^{\circ}$ ao invés de $12^{\circ}$, além de apresentar uma curva de pós-estol que apenas reduz a sua declividade, enquanto que no caso do leme sozinho a curva de sustentação primeiro reduzia para somente depois crescer com uma menor declividade. O modelo ASE não-linear conseguiu estimar corretamente esta alteração no ângulo de estol por modificar o ângulo equivalente no leme, enquanto o modelo linear manteve o mesmo ângulo de estol do leme sozinho, mas ambos os modelos não conseguiram estimar a região de pós-estol, apresentando um erro nesta região.

Ao analisar as curvas com deflexão da figura 56 também é verificado as vantagens do modelo não-linear sobre o linear. Enquanto que o efeito da deflexão no modelo linear é representado por um "deslocamento" da curva de sustentação na vertical, no modelo não-linear este "deslocamento" é obtido na horizontal, de forma semelhante ao observado no modelo de CFD. Com este efeito a ocorrência do estol é bem modelada para o conjugado ângulo de ataque-deflexão.

A ocorrência do estol nos dados de CFD pode ser quantitativamente analisada ao calcular a soma das derivadas parciais do coeficiente de força normal relativo ao ângulo de incidência $(\alpha)$ e a deflexão dos lemes $(\delta)$, apresentada pela equação 6.7. Pelos dados de CFD apresentarem uma baixa discretização para esta operação, a função definida pela equação 6.7 foi aplicada a superfície gerada por uma interpolação bidimensional do tipo spline $^{5}$ aos dados brutos do CFD.

$$
\eta_{F(B)}(\alpha, \delta)=\frac{\partial C N_{F(B)}(\alpha, \delta)}{\partial \alpha}+\frac{\partial C N_{F(B)}(\alpha, \delta)}{\partial \delta}
$$

À esquerda da figura 57 são apresentados os dados brutos de CFD em conjunto com a superfície tridimensional gerada pela interpolação spline, e à direita desta figura o resultado da aplicação da equação 6.7 a esta superfície.

A condição do estol do leme pode ser melhor interpretada ao observar as linhas de contorno da superfície resultante da aplicação da equação 6.7 (gráfico a direita da figura 57), apresentada a esquerda da figura 58. A ocorrência do estol pode ser identificada por estar entre a região que apresenta uma resposta praticamente linear ao ângulo de ataque

5 Função polinomial cubica suave que é definida em partes, ou seja, é uma função definida a cada conjunto de pontos utilizando como condição de contorno a continuidade e a segunda derivada da $\operatorname{curva}^{[152]}$. 

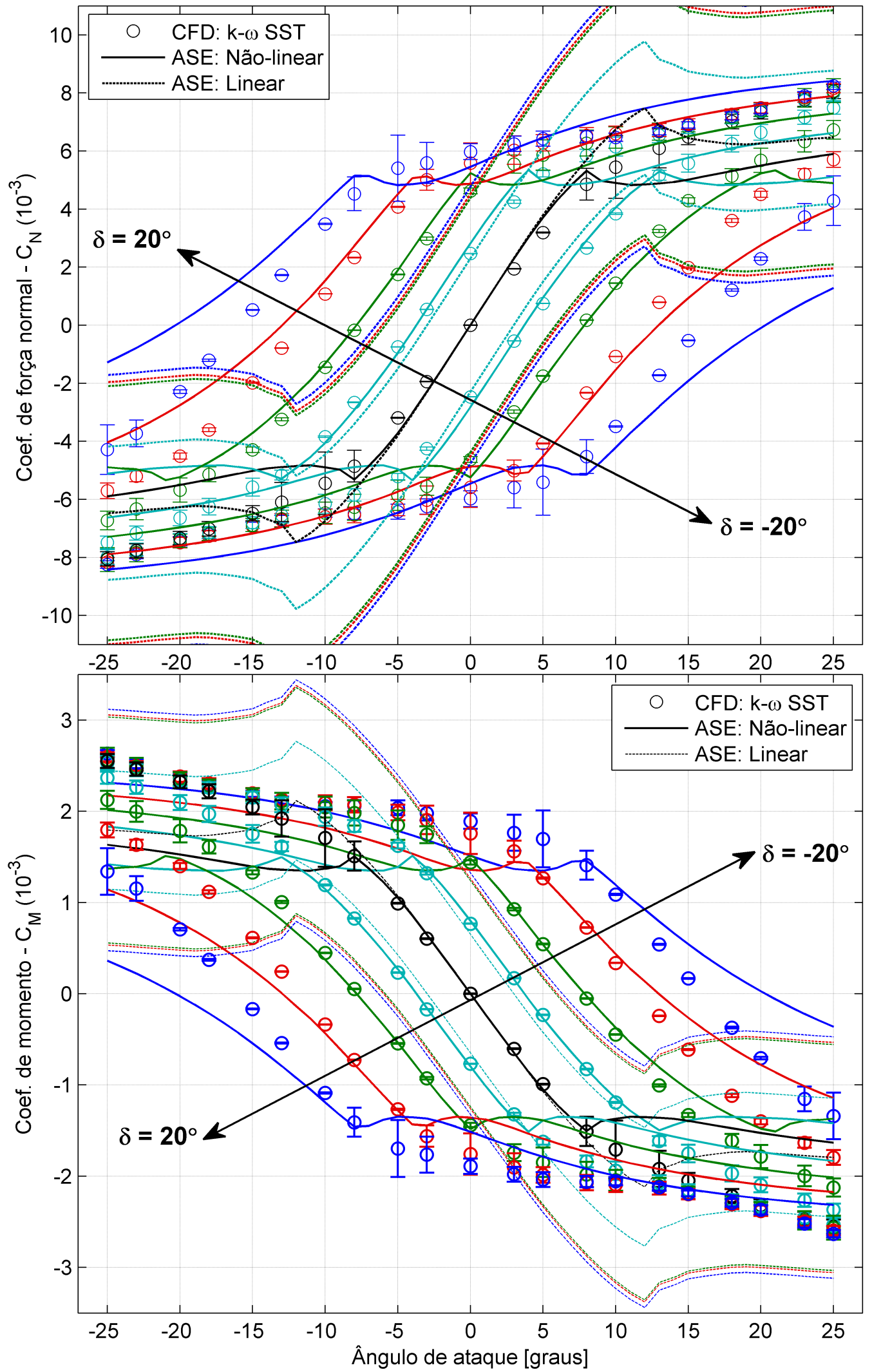

Figura 56 - Comparação dos coeficientes de força normal e momento do leme original (NACA0012) na presença do corpo do AUV Pirajuba para variações do ângulo de ataque $(\alpha)$ e da deflexão das superfícies de controle $(\delta)$. São apresentadas as medições experimentais com as estimativas numéricas e analíticas (modelo linear ${ }^{[134]}$ e não-linear). 
$(\alpha)$ e a deflexão do leme $(\delta)$, representada pelos contornos vermelhos, e a região que possui uma resposta não-linear de menor intensidade, representada pelos tons de azul.

Com esta definição, é verificado que o estol ocorre seguindo uma relação linear entre $\alpha$ e $\delta$, representada na figura 58 pela linha preta sobre a região amarela (intensidade média entre a vermelha e azul), podendo ser determinado por apenas duas condições. Por exemplo, obtendo o ângulo de ataque de estol para deflexão nula $\left(\alpha_{E s t o l_{\delta=0}}\right)$ e a deflexão de estol para o veículo alinhado $\left(\delta_{E s t o l_{\alpha=0}}\right)$, a função linear que relaciona a condição de estol pode ser determinada pela equação 6.8.

$$
\delta_{E s t o l}= \pm \delta_{E s_{o l}=0}-\frac{\delta_{E s t o l_{\alpha=0}}}{\alpha_{E s t o l_{\delta=0}}} \alpha
$$

Para o caso do AUV Pirajuba, esta função é definida pela equação 6.9, sendo que a região definida entre estas duas linhas é a região de resposta linear dos lemes.

$$
\delta_{E s t o l}= \pm 11.5-1.25 \alpha
$$

À direita da figura 58 foi realizada a comparação da estimativa da condição de estol obtida numericamente, equação 6.9, e analiticamente, relação inversa da equação 4.45 apresentada na seção 4.2.4. Em ambos os modelos foi considerado um desvio padrão de $\pm 1^{\circ}$, sendo representados por regiões ao invés de linhas. No modelo numérico este desvio padrão representa a espessura da região amarela do gráfico à esquerda da figura 58, enquanto que no modelo ASE este desvio representa a resolução do ângulo de ataque das simulações do leme sozinho, que foi utilizada para determinar a condição do estol.

As duas regiões representam uma aderência muito boa, somente apresentando um divergência para a condição de altos valores de ângulo de incidência e de deflexão com o sinal invertido, i.e., $\alpha>15^{\circ}$ e $\delta<-10^{\circ}$, ou $\alpha<-15^{\circ}$ e $\delta>10^{\circ}$. Este resultado indica que o modelo de ângulo de ataque equivalente ${ }^{[145,146]}$ consegue fornecer uma boa estimativa para a condição de estol do leme, para as condições de baixas deflexões e ângulos de ataque, resultando em uma melhor estimativa do esforço do leme em relação ao modelo linear ${ }^{[134]}$, como visto na figura 56.

Contudo, o modelo analítico não-linear ainda não apresenta uma boa estimativa para os esforços na região de pós-estol, por não apresentar uma correção para o comportamento da curva de sustentação do leme isolado, que são obtidos por CFD. Para a região de pós-estol, o modelo de CFD da combinação ainda representa uma ferramenta de melhor acurácia, apesar do modelo ASE poder ser utilizado para uma estimativa preliminar, estando bem próximo do resultado numérico.

\subsubsection{Combinação corpo e duto}

No estudo da combinação corpo-duto é investigada a influência gerada pelo duto propulsor nos coeficientes dos esforços hidrodinâmicos do AUV Pirajuba, indicando a 

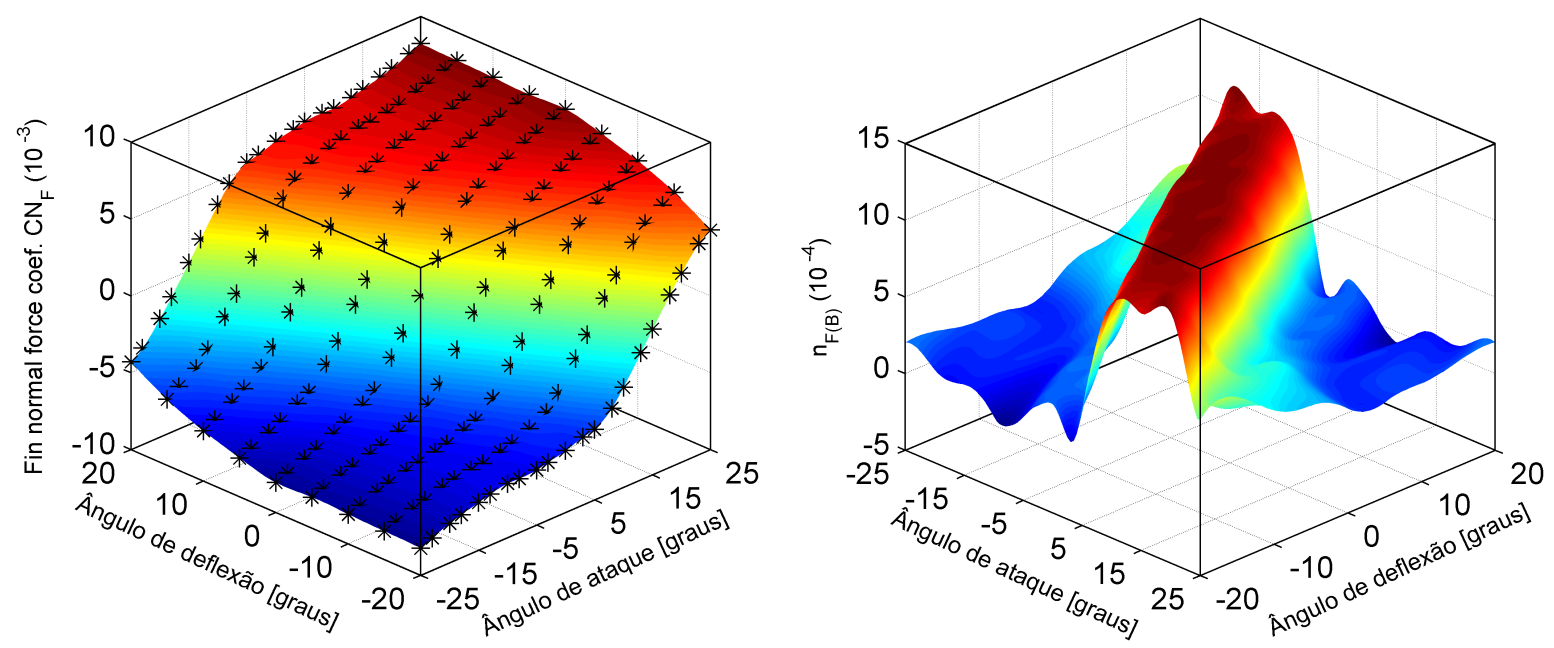

Figura 57 - A esquerda a superfície gerada por uma interpolação 'spline' de duas dimensões às estimativas discretas do coeficiente de força normal estático do leme na presença do corpo pelo método de CFD, e à direita a aplicação da equação 6.7 a esta superfície.
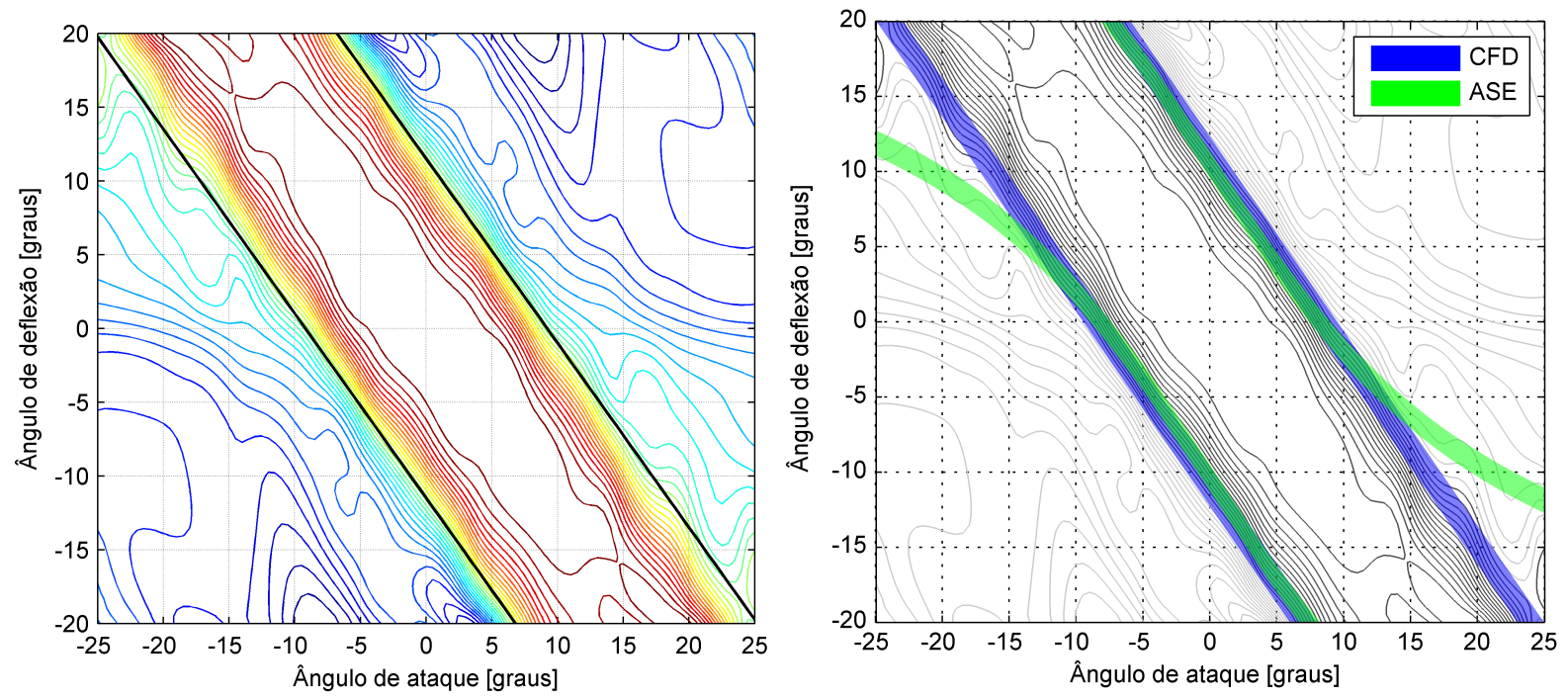

Figura 58 - Linhas de contorno resultantes da aplicação da equação 6.7 aos dados de força normal estática do leme na presença do corpo pelo método de CFD. à esquerda é apresentada a estimativa numérica do ângulo de estol (linha presta), e à direita são comparadas as estimativas dos ângulo de estol numéricos e analíticos considerando um desvio padrão de um grau. 


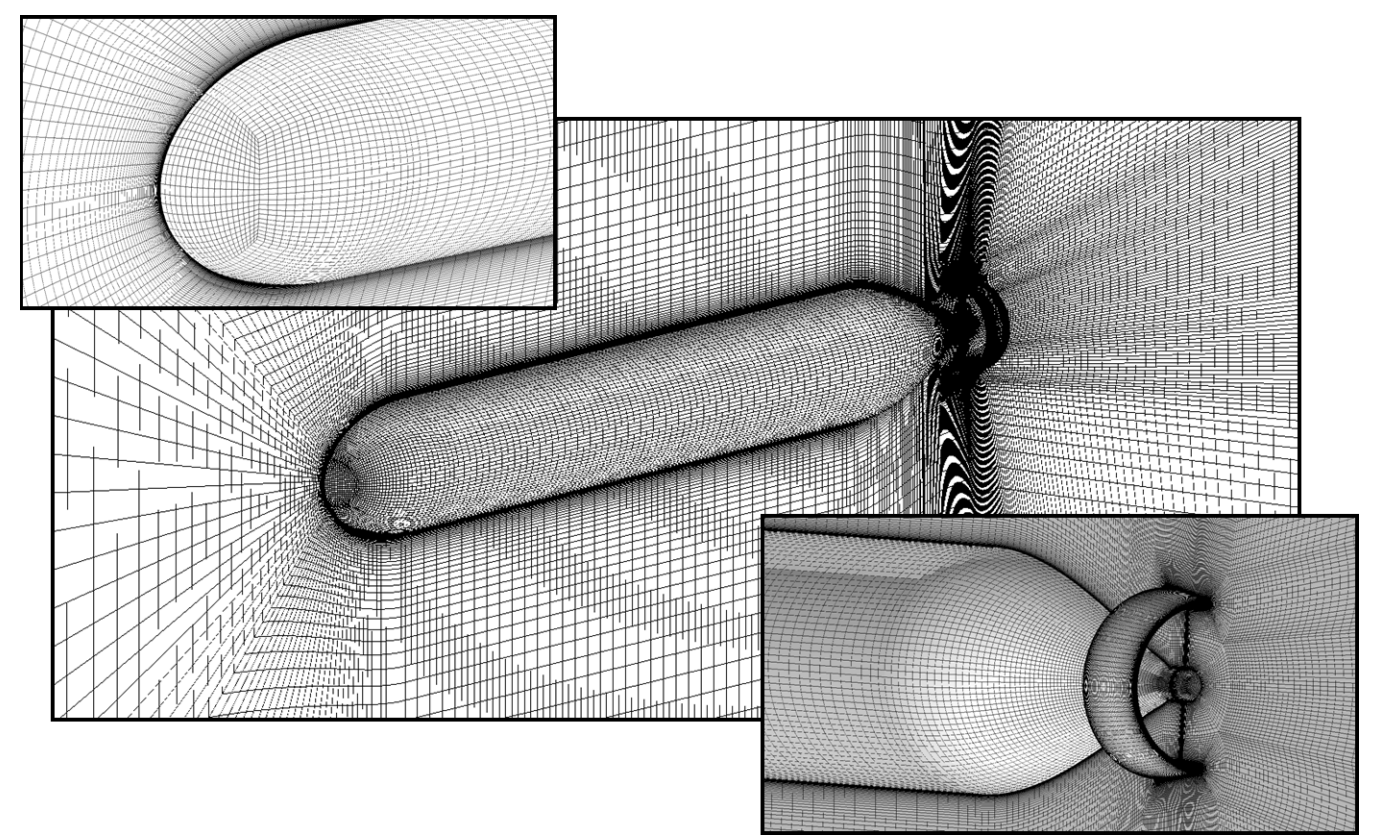

Figura 59 - Malha de refino médio da combinação corpo mais duto, com detalhes na popa e na proa

influência do duto na manobrabilidade do veículo. Este estudo é realizado pela comparação dos esforços de força normal e momento do veículo com e sem o duto propulsor.

A análise do modelo numérico foi realizada com as mesmas características dos modelos previamente apresentados, utilizando a metodologia não-linear ${ }^{[36]}$ para determinar a incerteza numérica. As malhas foram geradas utilizando uma estrutura bastante semelhantes as malhas das partes individuais, utilizando uma topologia do tipo "O" em cada superfície. As propriedades gerais das cinco malhas utilizadas no procedimento V\&V são apresentadas na tabela 14, com a malha de refino médio apresentada na figura 59.

As simulações de todos os casos apresentaram uma boa convergência iterativa, com poucos casos precisando reduzir os fatores de sobre-relaxação para obter uma baixa incerteza de convergência. A maioria dos casos apresentou um comportamento monotonicamente decrescente na análise sensibilidade de malha, com poucos casos apresentando um

Tabela 14 - Propriedades das malhas da combinação corpo mais duto (perfil 19A) do AUV Pirajuba utilizadas na análise de sensibilidade de malha

\begin{tabular}{lcccc}
\hline \hline & $\begin{array}{c}\mathbf{n}^{\circ} \text { de } \\
\text { volumes }\end{array}$ & $\begin{array}{c}\text { Espessura do } \\
\text { volume adjacente }\end{array}$ & $\begin{array}{c}y^{+} \\
\text {obtido* }\end{array}$ & $\begin{array}{c}\text { Índice de } \\
\text { malha }\left(h_{i} / h_{1}\right)\end{array}$ \\
\hline Caso 1 & 2306423 & $0.040 \mathrm{~mm}$ & 0.68 & 1 \\
Caso 2 & 2220223 & $0.056 \mathrm{~mm}$ & 0.95 & $\sqrt{2}$ \\
Caso 3 & 2111227 & $0.080 \mathrm{~mm}$ & 1.34 & 2 \\
Caso 4 & 2015283 & $0.113 \mathrm{~mm}$ & 1.98 & $2 \sqrt{2}$ \\
Caso 5 & 1929083 & $0.160 \mathrm{~mm}$ & 2.80 & 4 \\
\hline \hline \multicolumn{5}{c}{ *Valor médio }
\end{tabular}




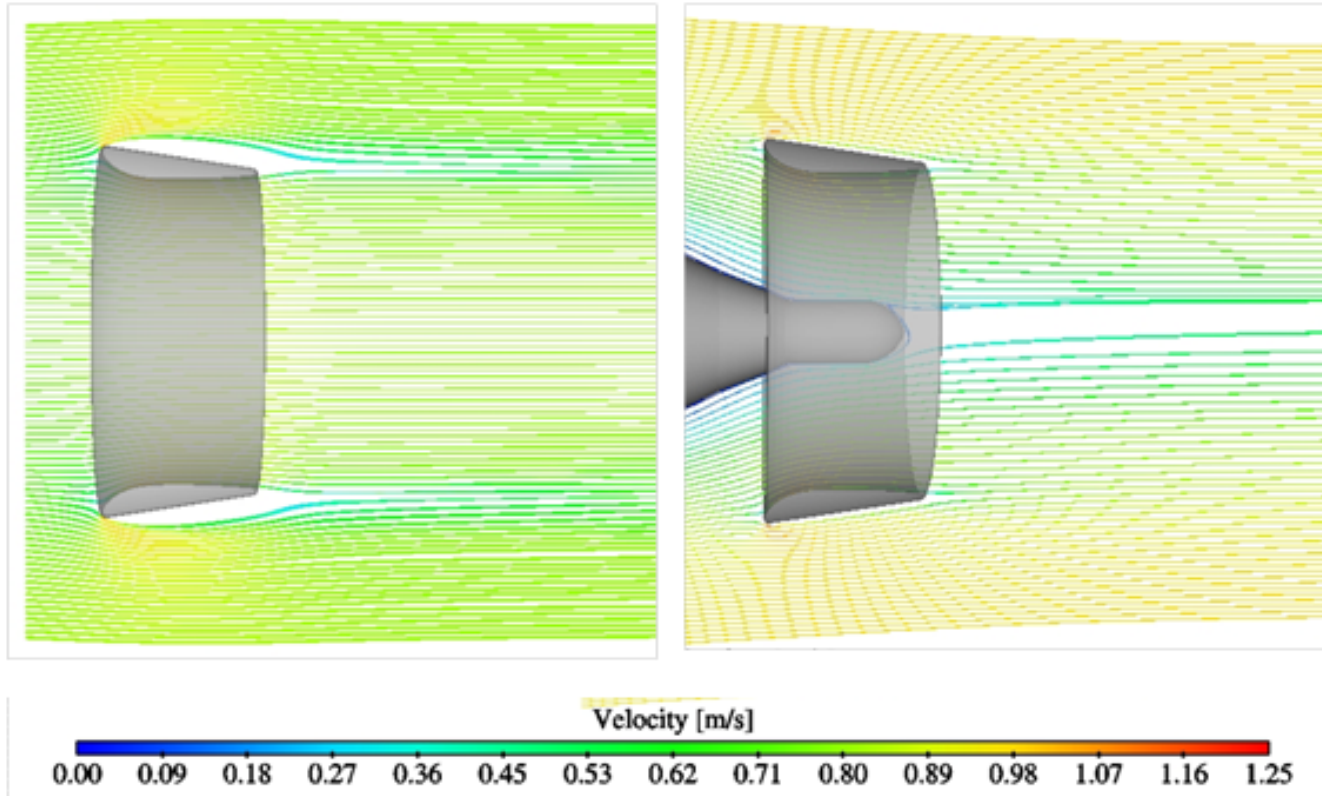

Figura 60 - Comparação das linhas de escoamento sobre o duto propulsor 19A sozinho (à esquerda) e na presença do corpo do AUV Pirajuba (à direita) para o ângulo de ataque nulo. As linhas são coloridas pelo módulo da velocidade.

comportamento que foi enquadrado como oscilatório ${ }^{[35]}$. Mesmo nesses casos a incerteza de discretização foi relativamente baixa.

Os ensaios experimentais deste modelo foram realizados com a balança de estrutura vertical utilizada no caso do corpo sozinho, sem a carenagem. Por não existir apêndices atrás da estrutura da balança, não é esperado uma pertubação significativa no escoamento ${ }^{[39]}$.

Com os resultados do duto sozinho, foi verificado que o modelo $\mathrm{ASE}^{[136]}$ não conseguia estimar a sustentação gerada pelo duto, devido ao descolamento da camada limite para baixos ângulos de incidência, que gerava uma "banda morta" na resposta dos esforços para baixos ângulos. Entretanto, ao analisar os resultados de CFD para ângulo de incidência nulo, apresentado na figura 60, foi observado que a presença do corpo modificou o escoamento de forma que ele apresentasse um ângulo de incidência em cada seção do duto, com uma inclinação semelhante ao do perfil externo, não gerando o descolamento da camada limite e permitindo a geração dos esforços de sustentação. Esta característica do escoamento incidente indica que a suposição de geração linear do esforços de sustentação no duto 19A, em função do ângulo de incidência do veículo, pode ser obtida para o caso corpo-duto, mesmo não sendo para o caso do duto sozinho.

Com o aumento do ângulo de incidência, o escoamento sobre a parte inferior do duto permanece bem comportado, sem deslocamento da camada limite, de forma bastante semelhante ao caso do duto sozinho, i.e., sem a influência do corpo. No entanto, como esperado pela teoria dos modelos ASEs, a parte superior do duto sofre bastante influência 


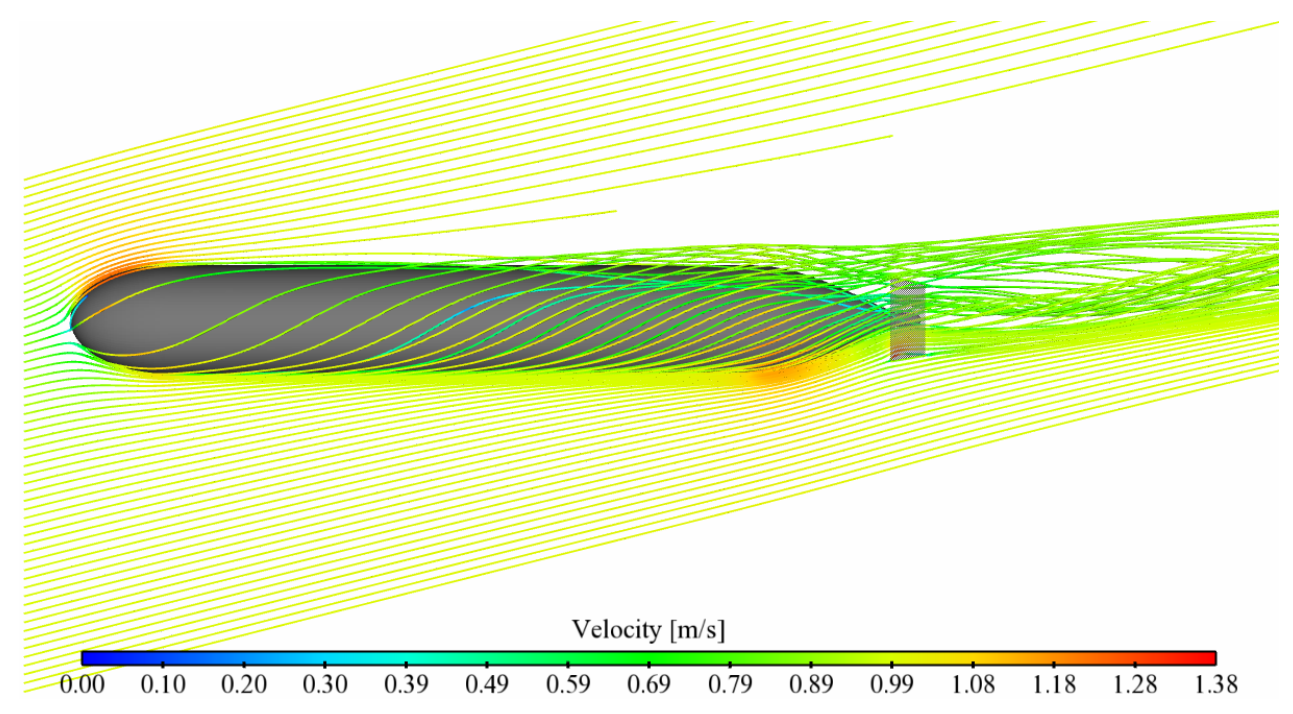

Figura 61 - Linhas de fluxo do escoamento sobre o corpo e o duto do AUV Pirajuba, em uma condição de $20^{\circ}$ de ângulo de incidência, com detalhe da incidência dos vórtices gerados pelo corpo no duto

da esteira e dos vórtices gerada pelo corpo, atrapalhando a geração dos esforços. Este efeito é ilustrado pela figura 61, onde foi apresentado as linhas de escoamento sobre o corpo e o duto em uma condição de 20 graus de ângulo de incidência.

As comparações dos modelos analíticos serão realizadas com as duas metodologias de cálculo da esteira do veículo, apresentadas na seção 4.2.6. O modelo analítico de Jackson ${ }^{[69]}$ estimou um coeficiente de esteira $(\omega)$ de 0.22 , enquanto que o modelo numérico, utilizando o campo de velocidades de uma simulação bidimensional estimou um coeficiente de esteira de 0.36. A estimativa numérica da esteira ${ }^{[28]}$ apresentou uma incerteza de aproximadamente 0.05 , calculada pela metodologia de análise de incerteza não linear ${ }^{[36]}$, representada por uma região cinza em volta dos coeficientes estimados.

A comparação dos coeficientes hidrodinâmicos da combinação corpo-duto foram apresentadas na figura 62, utilizando os métodos numéricos, analíticos e experimentais. Para melhor contrastar o efeito do duto propulsor e do coeficiente de esteira, foram apresentados os coeficientes hidrodinâmicos do corpo sozinho $(\omega=1)$ e da combinação corpo-duto sem considerar os efeitos de esteira $(\omega=0)$.

Na figura 62, os valores experimentais foram deslocados em um grau em relação aos valores medidos, por não apresentarem uma simetria e esforços não nulos para um ângulo nulo. Indicando que o veículo não foi bem alinhado no começo dos experimentos.

Para os ângulos de ataque de 19 e 24 graus os valores experimentais também apresentam uma grande assimetria, apresentando valores significativamente maiores em comparação aos seus pares negativos. Portanto, os pontos 19 e 24 positivos não foram considerados no restante da análise, somente os pares negativos. 

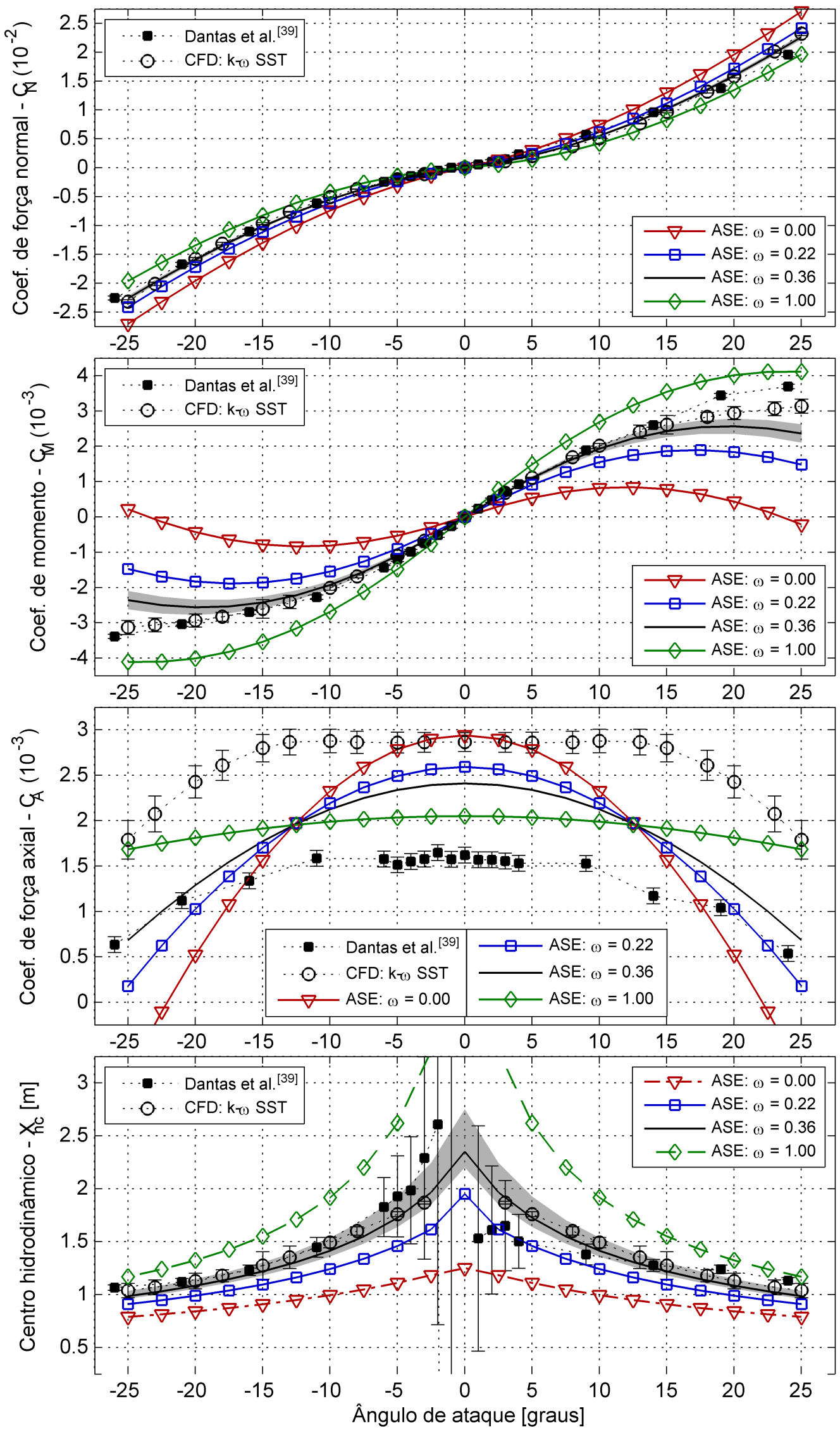

Figura 62 - Coeficientes de força normal, momento de pitch, força axial e centro hidrodinâmico da combinação duto e corpo do AUV Pirajuba. 
Na força normal e no momento a estimativa pelo CFD apresentou uma aderência muito boa aos resultados experimentais, conseguindo validar os resultados numéricos para ângulos de até 25 graus. Por consequência, o centro hidrodinâmico também apresentou uma ótima estimativa. No caso da força axial, o resultado numérico apresentou o mesmo comportamento dos outros casos, conseguindo estimar corretamente o arrasto induzido, mas falhando na estimativa do arrasto para ângulo de incidência nulo (arrasto parasita).

Em todos os casos dos modelos ASE, as curvas dos esforços do corpo sozinho $(\omega=1)$ e do corpo com o duto sem esteira $(\omega=0)$, representam os valores máximos e mínimos teóricos de previsão dos esforços de combinação pelo modelo ASE. Este resultado demonstra que a presença do duto pode influenciar muito nos esforços hidrodinâmicos, e consequentemente na manobrabilidade de um AUV, melhorando a sua estabilidade estática. Este tipo de análise também pode ser utilizado para determinar as condições de incertezas para controladores robustos ${ }^{[54]}$, em casos que não se tenha as características da esteira do veículo.

Ao utilizar o modelo de Jackson ${ }^{[69]}$ para estimar o valor da esteira média, uma melhoria significativa na predição da força normal e momento são observados, diminuindo o erro em relação as predições dos casos de $\omega=1$ e $\omega=0$. Utilizando a estimativa numérica da esteira ${ }^{[28]}$, o resultado ficou muito mais próximo do experimental, apresentando apenas um pequeno erro para o caso do momento em 20 e 25 graus de incidência, que ocorre devido à divergência do modelo ASE do corpo.

Portanto, pode-se concluir que o modelo de Jackson ${ }^{[69]}$ representa uma melhoria para a estimativa dos esforços hidrodinâmicos, e consequentemente da manobrabilidade de AUVs. Mas, caso seja necessário uma estimativa mais confiável dos esforços hidrodinâmicos de força normal e momento, é possível utilizar uma simples simulação bidimensional para estimar o coeficiente de esteira, e melhor adaptar o modelo ASE, não sendo necessário realizar simulações tridimensionais complexas para se obter uma boa estimativa dos esforços hidrodinâmicos.

\subsection{ANÁLISE NUMÉRICA E ANALÍTICA DOS COEFICIENTES DINÂMICOS}

Nesta seção são analisados os coeficientes hidrodinâmicos dinâmicos do AUV Pirajuba que dependem da velocidade de rotação e do ângulo de inclinação do veículo em relação ao escoamento. Serão analisados os resultados do corpo sozinho e da combinação corpo leme obtidos pelas simulações CFD, utilizando as metodologias apresentadas na seção 3. Em todas as análises serão comparados os resultados numéricos com os resultados obtidos pelos modelos analíticos (apresentados na seção 2.2.5), verificando se os modelos numéricos estão seguindo os embasamentos levantados nos modelos analíticos, e vice-versa. 
O caso da combinação corpo e leme foi estudado por este representar o modelo hidrodinâmico completo do AUV Pirajuba durante as manobras de validação realizadas. Já o caso do corpo sozinho complementou o estudo da combinação, possibilitando a identificação do comportamento não linear dos esforços do corpo, do leme e da interferência entre os dois, de forma separada.

Os demais apêndices e combinações, que foram estudados nos esforços estáticos, apresentados na seção 6.2, não foram estudados em função do movimento de rotação. Estes estudos não foram realizados devido a impossibilidade da validação destes resultados.

Nesta investigação sempre serão analisados dois modelos analíticos, aqueles obtidos na literatura e as suas versões modificadas. No caso do corpo sozinho será comparado o modelo ASE apresentado por Lesieutre, Love e Dillenius ${ }^{[42]}$ com o modelo desenvolvido neste trabalho. No caso da combinação, serão comparados os modelos analíticos lineares (baseado no trabalho de Pitts, Nielsen e Kaattari ${ }^{[134]}$ ) e não-lineares (baseado no trabalho de Hemsch e Nielsen ${ }^{[145]}$ ) para a inclusão dos fatores de interferência. No caso da combinação também será estudado o esforço do leme na presença do corpo, verificando o efeito da interferência e do movimento de rotação no ângulo de estol do leme.

\subsubsection{Corpo sozinho}

As simulações do corpo sozinho do AUV Pirajuba foram realizadas com a metodologia modificada de Phillips, Furlong e Turnock ${ }^{[24]}$, apresentada na seção 3.2.2. A velocidade de referência para as simulações de CFD foi de $1 \mathrm{~m} / \mathrm{s}$, a mesma dos ensaios de manobra. $\mathrm{O}$ ponto de rotação do veículo $\left(x_{r}\right)$ para os modelos ASE e numéricos foi considerado como sendo o mesmo do centro de gravidade $\left(x_{C G}\right)$, ou seja, está localizado a $0.856 \mathrm{~m}$ da ponta do nariz. O momento foi calculado neste mesmo ponto.

As simulações de CFD foram realizadas variando-se o ângulo de incidência $(\alpha)$ de $-25^{\circ}$ a $+25^{\circ}$ em incrementos de $5^{\circ}$, e a velocidade angular $(q)$ de $0 \%$ até $20 \% \mathrm{~s}$ em incrementos de $5^{\circ} \mathrm{s}$, resultando em 55 casos de simulação.

Não foi necessário realizar as simulações para as velocidades angulares negativas, pois os coeficientes dinâmicos de corpos axissimétricos possuem valores de módulo iguais com sinais opostos (valores espelhados), quando as duas variáveis tem os sinais invertidos simultaneamente, como exemplificado nas equações abaixo.

$$
\begin{aligned}
& C_{N}(+\alpha,+q)=-C_{N}(-\alpha,-q) \\
& C_{N}(+\alpha,-q)=-C_{N}(-\alpha,+q)
\end{aligned}
$$

Apesar de uma velocidade angular de $20 \%$ representar uma curva bastante fechada para um AUV do tipo do Pirajuba realizar, este valor foi empregado para fosse possível estudar o comportamento dos esforços hidrodinâmicos em condições críticas. 
Na figura 63 são comparados os coeficientes de força normal e momento obtidos pelos métodos de CFD com os resultados gerados com modelo ASE de Lesieutre, Love e Dillenius ${ }^{[42]}$, e com o modelo ASE apresentado na seção 4.2.2, baseado no trabalho de Barros et al. ${ }^{[20]}$. Os gráficos nesta figura foram apresentados com cada curva representando um ângulo de incidência, e a velocidade angular no eixo da abscissa.

Analisando o gráfico do coeficiente de força normal, gráfico superior da figura 63, é observado que este esforço apresenta uma maior sensibilidade à $\alpha$ do que para $q$, apresentando apenas variações significativas à $q$ para grandes valores de $\alpha$. Entretanto, no caso do coeficiente de momento, gráfico inferior da figura 63, variações de ambas às variáveis geram variações significativas do momento, demonstrando que a velocidade angular é tão importante quanto o ângulo de incidência na geração de momento pelo corpo.

Do ponto de vista numérico, todas as simulações apresentaram um comportamento iterativo convergente, apresentando maiores oscilações de convergência para os caso de alta velocidade angular. A incerteza numérica de discretização foi significativamente maior para os casos que consideraram alguma velocidade angular, devido as diferentes condições de contorno empregadas no modelo numérico.

No caso do coeficiente de força normal, ambos os modelos ASE possuem uma boa aderência com os resultados numéricos para baixos valores de $\alpha$ e $q$. Contudo, para altos valores de ambas variáveis, o modelo ASE introduzido neste trabalho apresentou uma melhor aderência aos resultados numéricos do que o modelo de Lesieutre, Love e Dillenius ${ }^{[42]}$. A única região que apresentou uma aderência fraca de ambos os casos, foi para a combinação de altos valores de $\alpha$ e q, que tenham o mesmo sinal, devido às grandes circulações do escoamento gerados por estas condições. De maneira geral, ambos os métodos apresentaram bons resultados.

Para o caso do coeficiente de momento, o modelo desenvolvido apresentou melhores resultados em relação ao modelo de míssil ${ }^{[42]}$, que sobrestimou a estimativa do momento em relação a $\alpha$. A baixa aderência do modelo desenvolvido para altos valores de $\alpha$ (25 graus) é devido ao próprio modelo de Barros et al. ${ }^{[20]}$ (modelo ASE em que o modelo desenvolvido foi baseado), que apresenta uma pequena falta de aderência para esta região como visto na figura 38 da seção 6.2.1.

As diferenças entre os modelos analíticos ocorreram devido ao modelo original ${ }^{[42]}$ superestimar a contribuição da força normal local (de seção) em função de $\alpha$. O modelo ASE apresentado neste trabalho corrigiu este efeito ao reduzir os efeitos potenciais gerados ao longo do corpo, devido ao descolamento da camada limite e aos vórtices laterais gerados em condições de altos ângulos de ataque.

Apesar do modelo ASE modificado melhorar significativamente a estimativa dos 

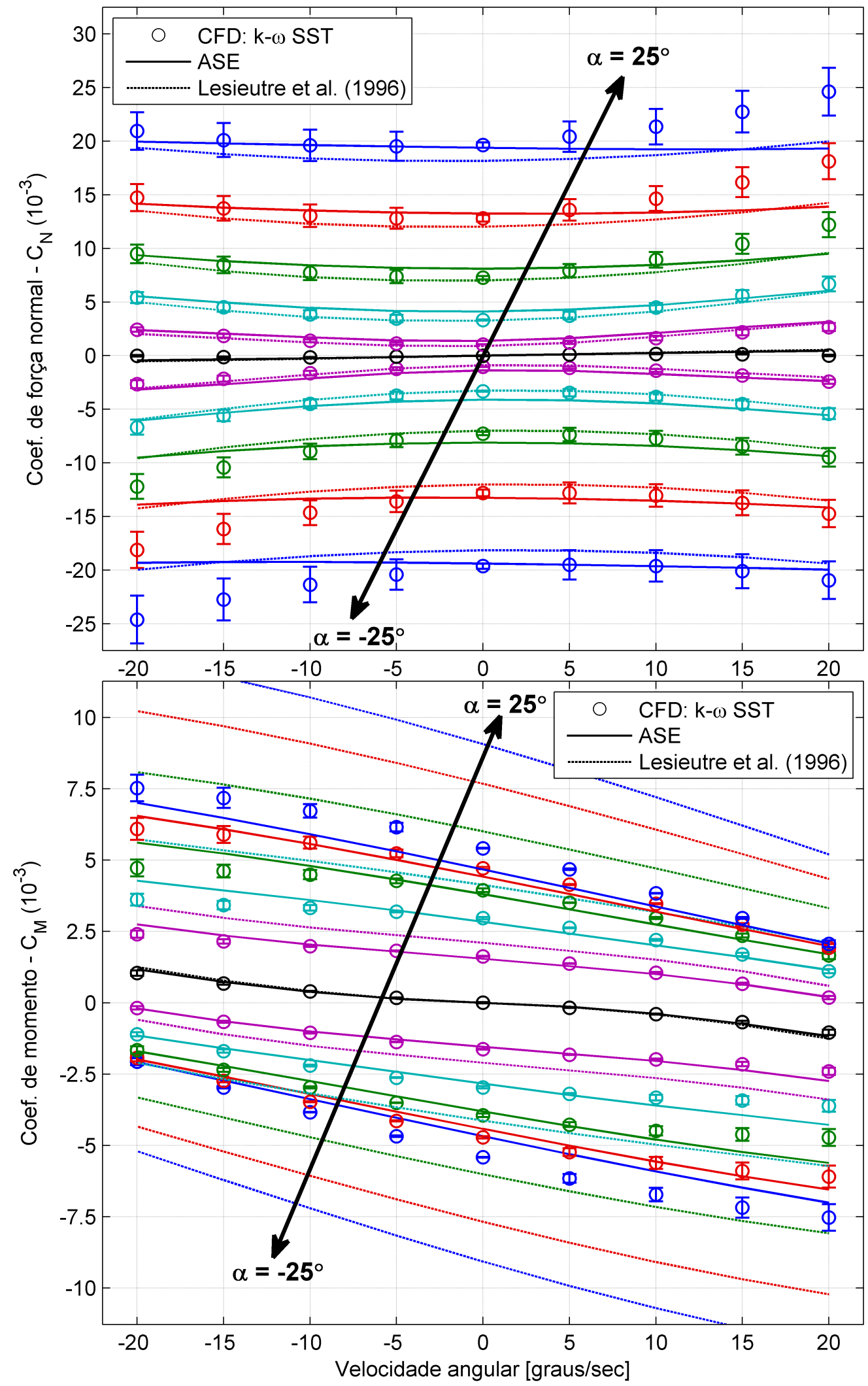

Figura 63 - Comparação entre os coeficientes hidrodinâmicos dinâmicos do corpo isolado do AUV Pirajuba, para os métodos numéricos (o), o método ASE desenvolvido $(-)$ e o apresentado por Lesieutre, Love e Dillenius ${ }^{[42]}(\cdots)$. 


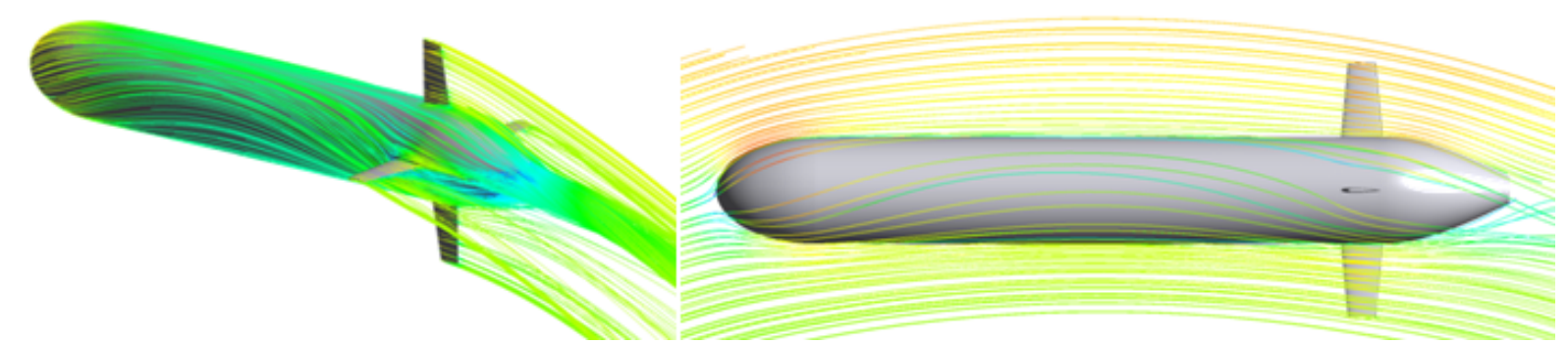

Figura 64 - Linhas de fluxo do escoamento sobre o corpo e o leme do AUV Pirajuba, em uma condição de incidência nula e uma velocidade de rotação de $15 \%$

esforços de momento e da força normal em relação ao modelo aerodinâmico de míssil ${ }^{[42]}$, acredita-se que o modelo ASE proposto possa ser melhorado ao incluir os efeitos de acoplamento entre $\alpha$ e $q$, que ocorrem para altos valores destas variáveis. Acredita-se que está correção deva ocorrer principalmente pela inserção de parâmetros ASE no termo viscoso, por ele ser um componente predominante no caso da força normal, tendo um peso relativamente menor para o caso do momento.

\subsubsection{Combinação corpo e leme}

As simulações do corpo com as superfícies de controle do AUV Pirajuba foram realizadas com as mesmas condições/metodologias das simulações dinâmicas do corpo sozinho. As simulações também foram realizadas para os mesmos casos (55 casos únicos sem considerar a análise de V\&V), possibilitando uma comparação direta entre os resultados do corpo sozinho e da combinação corpo e lemes.

Na figura 64, é apresentado as linhas de escoamento sobre o corpo do AUV Pirajuba em uma condição de incidência nula e uma velocidade de rotação de $15 \%$ s. Esta figura é apresentada para ilustrar o efeito do escoamento com velocidade rotacional sobre o veículo, indicando que para os casos de maiores velocidades as linhas de fluxo são modificadas significatiamente.

Na figura 65 são apresentados os coeficientes de força normal e momento obtidos pelo método de CFD. Neste gráfico cada curva representa uma velocidade angular apresentada em função de $\alpha$, mas para deixar os gráficos mais legíveis, somente foram apresentados as curvas para as velocidades angulares de $0, \pm 10, \pm 20 \%$ s.

Neste caso, todos os resultados numéricos apresentaram convergência iterativa, com maiores oscilações, e consequentemente maior número de iterações, nos casos próximos da região de estol do leme ou para valores grandes de $\alpha$ e q. Entretanto, com o custo de muitas iterações, todas simulações atingiram o critério de convergência previamente estabelecido, resultando em uma incerteza iterativa insignificante. Na análise da incerteza de discretização, a maioria dos casos apresentou uma convergência monotônica decrescente com valores razoáveis do expoente de convergência $(p)$, e poucos casos apresentaram os 

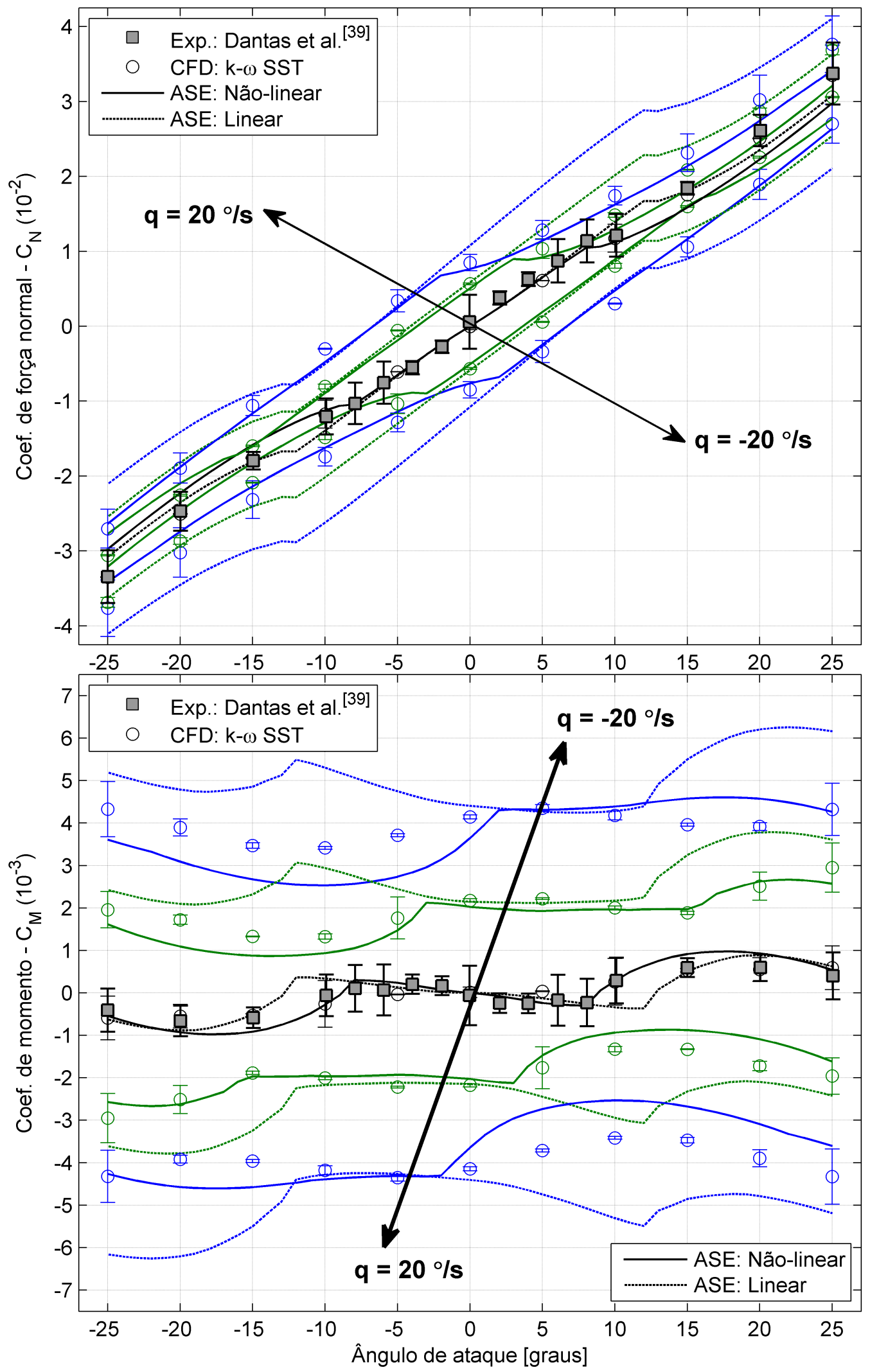

Figura 65 - Comparação dos coeficientes de força normal e momento da combinação do leme original (NACA0012) e corpo do AUV Pirajuba para variações do ângulo de incidência $(\alpha)$ e da velocidade angular $(q)$. São apresentadas as medições experimentais com as estimativas numéricas e analíticas (modelo linear ${ }^{[134]}$ e não-linear) 
outros tipos de convergência apresentadas na seção 3.5 (linear e quadrática), que possuem uma incerteza maior.

Junto com os resultados numéricos foram apresentados as estimativas obtidas por dois modelos ASE. O primeiro modelo, baseado no modelo apresentado por Pitts, Nielsen e Kaattari $^{[134]}$ (visto na seção 4.2.4), a interferência entre o corpo e o leme $\left(K_{b(f)}\right.$ e $\left.K_{f(b)}\right)$ modifica linearmente a curva de força normal do leme. A inclusão do efeito de estol neste modelo foi realizada pelo uso da curva de força normal do leme isolado $\left(C_{N_{(F)}}\right)$ obtido pelo CFD. Para o caso do coeficiente de força normal, este modelo é representado pela equação

$$
\begin{aligned}
C_{N_{(F B)}}(\alpha, q)=C_{N_{(B)}}(\alpha, q) & +\left(K_{F(B)}+K_{B(F)}\right) C_{N_{(F)}}(\alpha) \\
& +\left(K_{F(B)}+K_{B(F)}\right) C_{N_{(F)}}\left(\alpha_{q}\right) .
\end{aligned}
$$

No segundo modelo ASE, foi utilizada uma abordagem não linear para a inclusão dos efeitos de interferência. Este modelo foi apresentado ao final da seção 4.2.4, onde foi modificada a teoria de ângulo de ataque equivalente ${ }^{[145]}$ pela inclusão do ângulo de incidência gerado pela velocidade angular. Para o caso do coeficiente de força normal este modelo é representado pela equação

$$
C_{N_{(F B)}}(\alpha, q, \delta)=C_{N_{(B)}}(\alpha, q)+\left(1+\frac{K_{b(w)}\left(\alpha_{e q_{F}}\right)}{K_{w(b)}\left(\alpha_{e q_{F}}\right)}\right) \cdot C_{N_{(F)}}\left(\alpha_{e q_{F}}\right)
$$

onde a função $\alpha_{e q_{F}}$, apresentado na equação (4.48), representa o ângulo de incidência local no leme, obtido em função do ângulo de incidência do veículo $(\alpha)$, da velocidade angular $(q)$ e da deflexão da superfície de controle $(\delta)$.

Na legenda destes gráficos o primeiro modelo foi denominado "ASE: Linear", e o segundo "ASE: Não-Linear".

Ambos os modelos consideraram que a parcela de esforços do corpo $\left(C_{N_{(B)}}(\alpha, q)\right)$ foi calculada utilizando o modelo ASE desenvolvido nesta tese (ver equação 4.30), pois este modelo obteve os melhores resultados em comparação aos resultados de CFD apresentados na seção 6.3.1.

Diferente do caso do corpo sozinho, o gráfico de força normal mostra que este esforço apresenta variações significativas para variações de ambas variáveis $(\alpha$ e $q$ ). Esta maior sensibilidade à $q$ é devido a distância que o leme se encontra do centro de rotação do veículo, que gera um ângulo de incidência local no leme, devido ao movimento de rotação, equiparável aos ângulos de incidência estáticos.

No caso do momento, a combinação corpo-leme apresenta uma sensibilidade muito maior à $q$ do que ao $\alpha$. Isto ocorre, pois com o ângulo de ataque nulo o centro de medição e rotação $(0.856 \mathrm{~m})$ é bastante próximo do centro hidrodinâmico da combinação, resultando em baixos valores de momento. Quando um movimento de rotação é imposto, tanto o 
corpo quanto o leme apresentam esforços de amortecimento (contrário ao movimento), que são superiores aos momentos gerados mesmo com a ocorrência do estol.

Ao comparar os resultados analíticos (ASE) com os numéricos (CFD) é verificado que o modelo ASE não linear tem uma melhor aderência em ambos esforços. No caso da força normal, o modelo não linear se iguala aos resultados de CFD na maioria das combinações de $\alpha$ e $q$. Nas demais combinações, obtidas para maiores valores de $\alpha$ e $q$, são observadas pequenas diferenças entre o CFD e o modelo ASE não linear, mas elas se encontram dentro da barra de incerteza numérica, obtida pela análise do erro de discretização do V\&V.

O mesmo comportamento entre as diferentes estimativas é observado no caso do momento. Entretanto, neste esforço, os casos que apresentam uma aderência mais fraca são visíveis, devido a maior sensibilidade deste esforço.

Assim como no caso estático, o modelo ASE linear apresentou uma baixa aderência aos resultados numéricos em ambos os esforços, tendo apenas bons resultados para combinações de $\alpha$ e $q$ que implicam em um baixo ângulo local no leme, i.e., o ângulo gerado por uma das variáveis cancela a da outra. A baixa aderência está relacionada a falha do modelo linear de não prever a influência da velocidade angular no ângulo de estol do leme, e nos fatores de interferência.

Uma melhor análise destes problemas de aderência pode ser feita analisando os esforços do leme na presença do corpo, apresentados para o coeficiente de força normal e momento na figura 66. Nesta figura não são apresentados os resultados experimentais, pois os esforços no leme não foram isoladamente medidos durante os ensaios de reboque do corpo com as superfícies de controle.

Observando estes gráficos, as análises levantadas são as mesmas do caso estático. A presença do corpo modifica significativamente o comportamento da curva de força normal na região de pós estol gerada pelo leme em função do ângulo de incidência, gerando um erro significativo nos modelos ASE adotados, pois nestes modelos não são feitas correções na curva de força normal gerada pelo leme isolado na região de pós estol devido a presença do corpo ou da velocidade angular. Mesmo com esta diferença o modelo ASE não linear conseguiu estimar o ângulo de estol para valores pequeno e médios de $q$, em comparação aos resultados do CFD.

Em comparação com os resultados estáticos, as curvas dos resultados numéricos com a presença do movimento de rotação apresentam uma declividade menor na região de pós estol, indicando uma diferença no fenômeno do estol ao considerar as diferentes variáveis. Esta diferença também prejudica os resultados dos modelos ASE, onde é considerada uma declividade igual ao do leme sozinho, que está mais próxima do caso estático com a deflexão. 

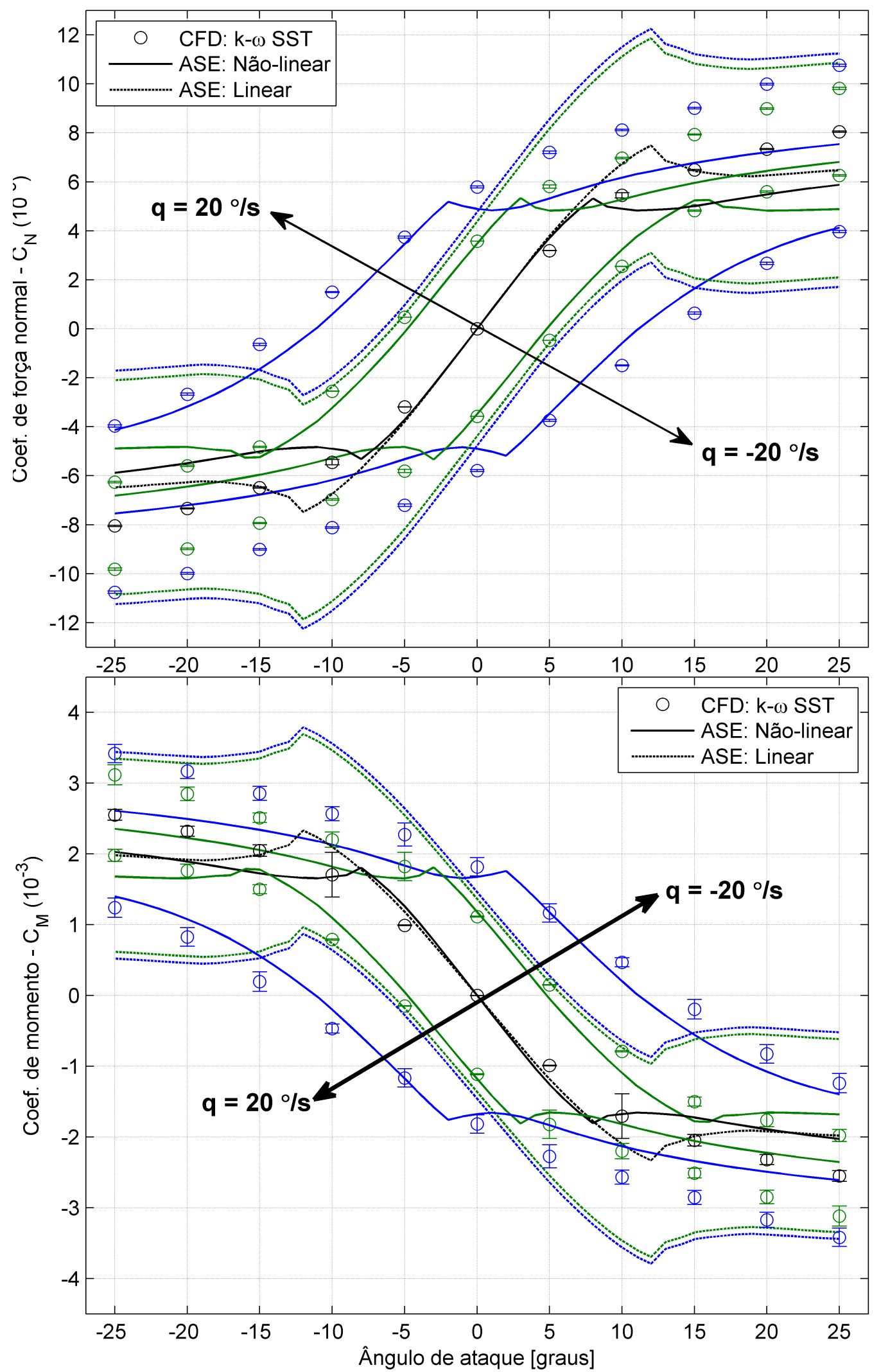

Figura 66 - Comparação dos coeficientes de força normal e momento do leme original (NACA0012) na presença do corpo do AUV Pirajuba para variações do ângulo de incidência $(\alpha)$ e velocidade angular $(q)$. Somente são apresentadas as estimativas numéricas e analíticas (modelo linear ${ }^{[134]}$ e não-linear) 

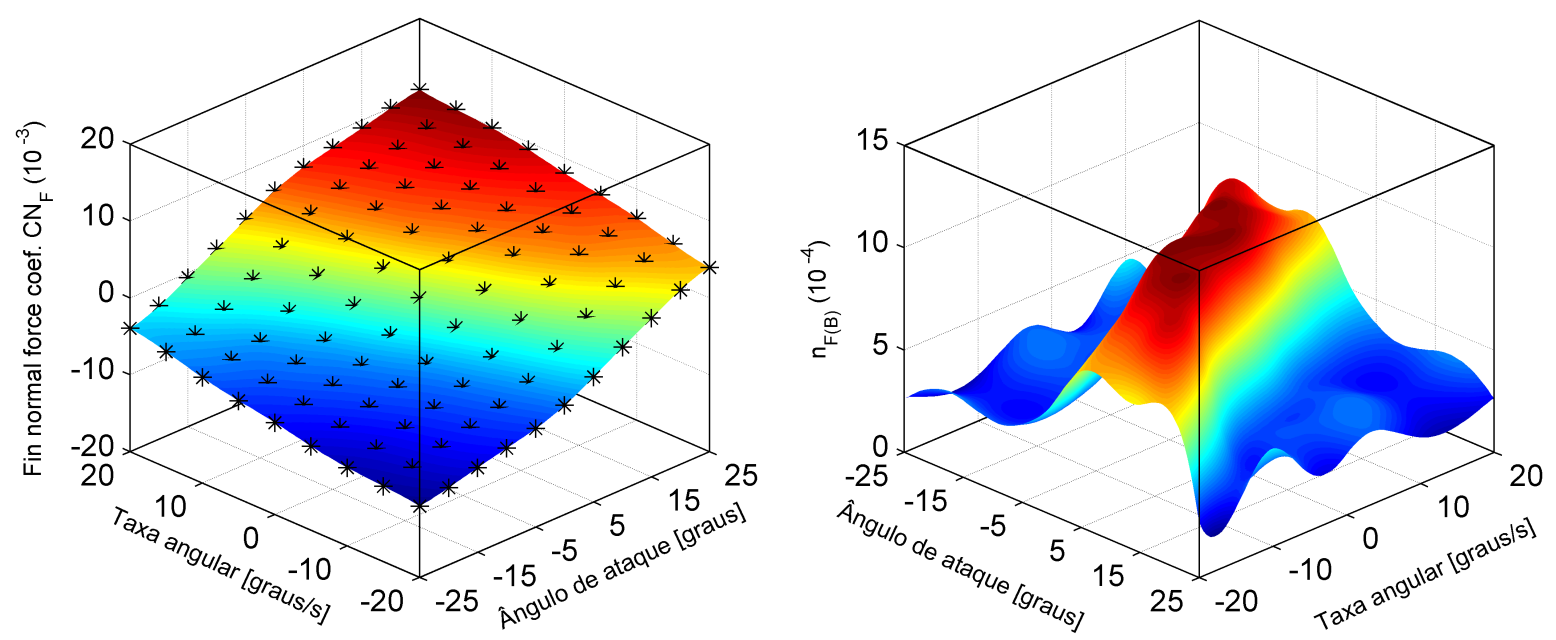

Figura 67 - À esquerda a superfície gerada por uma interpolação "spline" de duas dimensões às estimativas discretas do coeficiente de força normal estático do leme na presença do corpo pelo método de CFD, e à direita a aplicação da equação (6.7) a esta superfície

Da mesma forma que no caso estático, o fenômeno do estol pode ser melhor observado ao analisar a declividade das curvas de força normal. Esta análise é feita pela modificação da equação (6.7) para este caso, onde é realizada a soma das derivadas parciais do coeficiente de força normal relativos ao ângulo de incidência $(\alpha)$ e à velocidade angular (q). Esta operação matemática é apresentada na equação

$$
\eta_{F(B)}(\alpha, q)=\frac{\partial C N_{F(B)}(\alpha, q)}{\partial \alpha}+\frac{\partial C N_{F(B)}(\alpha, q)}{\partial q} .
$$

Pelos dados de CFD apresentarem uma baixa discretização para esta operação, a função definida pela equação 6.13 foi aplicada a superfície gerada por uma interpolação bidimensional do tipo spline aos dados brutos do CFD, aumentando virtualmente a resolução da discretização dos dados e melhorando os gráficos obtidos por estes dados.

À esquerda da figura 67 são apresentados os dados brutos de CFD em conjunto com a superfície tridimensional gerada pela interpolação spline, e a direita desta figura é apresentada a superfície resultante da aplicação da equação 6.13 à esta superfície.

Analisando a superfície resultante da soma das derivadas da força normal (6.13) é observado que a região em vermelho representa a região de resposta linear do leme, ou seja, é a região definida por $\alpha$ e $q$ em que o leme apresenta um comportamento linear de ambas variáveis.

O comportamento desta região pode ser melhor analisado pelo gráfico com as curvas de níveis desta região, apresentado no gráfico à esquerda da figura 68. Com esta figura é verificado que a condição de estol do leme, definida pelas curvas amarelas, possuí 
uma relação aproximadamente linear entre $\alpha$ e $q$. Da mesma forma do caso estático, a equação da reta que define esta região pode ser definida por duas condições de estol. Por exemplo, pode ser utilizado o ângulo de incidência de estol para velocidade de rotação nula $\left(\alpha_{E s t o l_{q=0}}\right)$, e a velocidade de rotação de estol para ângulo de incidência nulo $\left(q_{E s t o l_{\alpha=0}}\right)$. Com estes parâmetros a equação que define a velocidade de rotação limite para a ocorrência de estol pode ser definida em função de $\alpha$ é definida por

$$
q_{E s t o l}= \pm q_{E s t o l_{\alpha=0}}-\frac{q_{E s t o l_{\alpha=0}}}{\alpha_{E s t o l_{q=0}}} \alpha
$$

Para o caso do AUV Pirajuba, esta função é definida pela equação (6.15), sendo que a região definida entre estas duas linhas pode ser denominada de região de resposta linear dos lemes.

$$
q_{E s t o l}= \pm 15.0-1.76 \alpha
$$

Para comparar este resultado numérico com o obtido pelo modelo ASE, apresentado na seção 4.2.4, encima do gráfico com a estimativa numérica foi apresentado a solução inversa da função de ângulo ataque equivalente do leme (4.45), considerando o ângulo de estol obtido pelas simulações de CFD do leme isolado, corrigido pelos parâmetros ASE de interferência. Este gráfico é apresentado a direita da figura 68, onde foi considerado um desvio padrão de $\pm 1^{\circ}$ para ambas estimativas. No modelo numérico este valor representa a distância média entre os extremos da cor amarela (região de estol), e no modelo ASE este valor representa a resolução do ângulo de ataque nas simulações do leme sozinho.
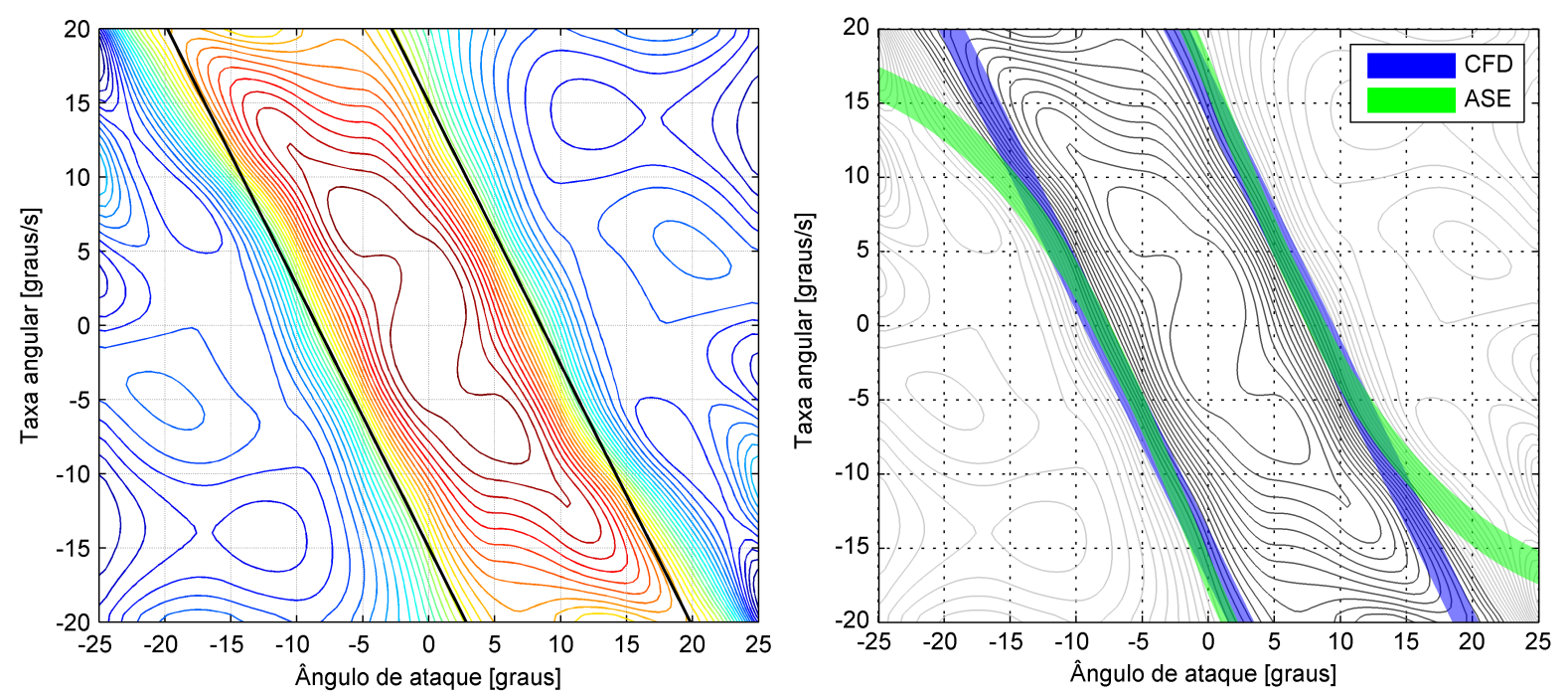

Figura 68 - Linhas de contorno resultantes da aplicação da equação 6.7 aos dados de força normal dinâmico do leme na presença do corpo pelo método de CFD. À esquerda é apresentada a estimativa numérica do ângulo de estol (linha presta), e à direita são comparadas as estimativas dos ângulo de estol numéricos e analíticos considerando um desvio padrão de um grau 
O resultado desta comparação foi bastante semelhante ao resultado estático, onde ambas estimativas apresentaram uma boa aderência para a grande parte dos valores analisados. A divergência entre as duas estimativas foi observada para valores altos do ângulo de incidência e da velocidade angular com o sinal invertido, i.e., $\alpha>15^{\circ} \mathrm{e}$ $q<-10^{\circ}$ s, ou $\alpha<-15^{\circ}$ e $q>10^{\circ} / s$.

Apesar desta divergência com a estimativa linear do modelo numérico, se for comparado a estimativa do modelo ASE com as curvas de nível do modelo ASE, é verificado que o modelo ASE apresenta o mesmo comportamento não linear da região amarela, indicando uma semelhança na tendencia entre os dois modelos.

Estes resultados indicam que o modelo de ângulo de ataque equivalente consegue fornecer uma boa estimativa da condição do estol do leme, ou da região de comportamento linear do leme. Contudo, em termos dos esforços gerados pelo leme, os modelos ASE não apresentam um resultado tão bom. Isso ocorre devido ao modelo ASE utilizar a curva de esforços do leme isolado obtido pelo CFD, e como foi observado pelas simulações de CFD (figura 66), com a presença do corpo a região de pós-estol desta curva é bastante modificada.

Para a região de pós-estol do caso dinâmico, o modelo de CFD da combinação também representa uma ferramenta de melhor precisão em comparação ao modelo ASE. Apesar deste resultado, o modelo ASE poder ser utilizado satisfatoriamente para uma estimativa destes esforços, estando bastante próximos dos resultados numéricos.

\subsection{VALIDAÇÃO DA ESTIMATIVA DOS ESFORÇOS DINÂMI- COS POR ENSAIOS DE MODELO LIVRE}

Nesta seção será apresentada a validação dos esforços hidrodinâmicos de rotação (dinâmicos) da combinação corpo e leme do AUV Pirajuba, apresentados na forma de coeficiente na seção 6.3.

Tradicionalmente na indústria naval a validação para este tipo de coeficiente é realizada por ensaios de oscilação em tanque de provas, utilizando um mecanismo de movimento planar (PMM, Planar Motion Mechanism). Neste tipo de ensaio, o PMM faz o veículo oscilar enquanto rebocado com uma frequência e amplitude que correspondem a uma velocidade de rotação, enquanto uma balança realiza a leitura dos esforços hidrodinâmicos ${ }^{[86,123]}$. Contudo, como comentado na seção 5 , apesar do IPT possuir este tipo de equipamento em suas instalações, a sua estrutura não comportava os esforços hidrodinâmicos gerados pelo modelo cativo do AUV Pirajuba, impossibilitando o seu uso.

Como solução a validação dos esforços hidrodinâmicos dinâmicos empregada neste trabalho utilizará um procedimento similar ao encontrado no trabalho de Tang et al. ${ }^{[37]}$, 
onde são utilizados os resultados experimentais de manobras com um modelo livre autopropelido para validar os resultados de uma simulação numérica, que utiliza como parâmetros hidrodinâmicos os resultados obtidos por simulações de CFD.

Em comparação ao trabalho de Tang et al. ${ }^{[37]}$, este trabalho utiliza um modelo numérico mais complexo, que considera os acoplamentos não lineares entre os modelos estáticos, dinâmicos e de controle, referentes aos esforços devido ao ângulo de incidência do escoamento, velocidade de rotação e deflexão das superfícies de controle (lemes), respectivamente. Pelo AUV Pirajuba poder ser considerado um veículo bastante afilado, os esforços hidrodinâmicos gerados pelo seu corpo são mais significativos do que os encontrados no caso de Tang et al. ${ }^{[37]}$, onde o veículo possuí um formato rombudo, i.e., tipo "bloco", e navega em baixa velocidade.

O procedimento empregado também se assemelha aos métodos baseados na identificação de sistemas ${ }^{[48,173,174]}$, em que o modelo dinâmico do veículo é obtido por análises determinísticas e/ou estocásticas, que relacionam os sinais de medição do movimento (saída) às deflexões dos lemes (entradas). Por não precisar ter um conhecimento prévio da dinâmica ou dos parâmetros dos modelos estes métodos são conhecidos por caixas pretas (blackbox), ou caixas cinzas (graybox) quando se utiliza algum conhecimento sobre a dinâmica do veículo para determinar os seus parâmetros.

Os métodos mais simples de identificação surgiram na indústria naval, sendo posteriormente aplicados a veículos submersíveis e a AUVs, utilizando considerações adicionais. Nestes métodos os modelos de navios são simplificados em um sistema de primeira ordem ${ }^{[162,175]}$, cujos parâmetros são estimados pela resposta de rumo do veículo em uma manobra de zigzag. Em sistemas mais complexos é preciso utilizar métodos

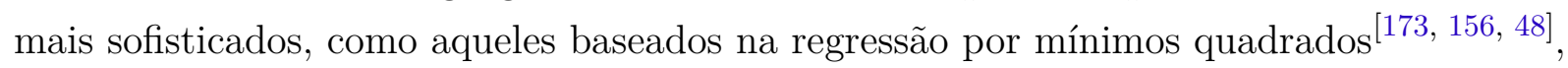
máxima verossimilhança ${ }^{[157,174]}$, filtros de Kalman estendidos ${ }^{[176]}$ e uncented $^{[158]}$, entre outros.

De maneira geral estes métodos conseguem estimar bem a dinâmica de veículos submarinos $^{[29,48,157,174,176]}$, possibilitando uma estimativa dos esforços hidrodinâmicos. Contudo, normalmente estes métodos identificam apenas o modelo hidrodinâmico simplificado dos veículos, não conseguindo estimar as funções hidrodinâmicas para altas amplitudes de movimento, o efeito do estol ou os acoplamentos entre as diferentes variáveis de movimento.

Pelo objetivo deste trabalho ser a elaboração e validação do modelo de manobra de um AUV na região de operação linear e não linear, este trabalho não utilizará o método de identificação de sistemas, ficando restrito a identificação por comparação de trajetórias de manobras ${ }^{[37]}$, que representa um método mais direto para a validação dos coeficientes hidrodinâmicos obtidos tanto numericamente (CFD) quanto analiticamente. 
Esta metodologia também permite realizar análises de sensibilidade dos parâmetros hidrodinâmicos e inerciais que regem o movimento do AUV. Este tipo de análise permite verificar a influência individual de cada parâmetro nas características das manobras de identificação, além de verificar se a estimação errada de algum parâmetro pode gerar uma compensação de erros em outros parâmetros.

Os detalhes da implementação numérica dos modelos de manobras ASE e CFD apresentados nas seções 2 e 4, são apresentados na seção 6.4.1. Na seção seguinte (6.4.2), são apresentadas as analises das respostas das manobras de giro e zigzag de ambos os métodos, comparando os resultados com os obtidos experimentalmente. Por último, na seção 6.4.3, são apresentadas as análises de sensibilidade dos modelos de manobras desenvolvidos nesta tese para o cálculo da incerteza paramétrica, a metodologia desenvolvida para validação destes modelos utilizando a estimação da incerteza paramétrica, e a própria validação destes modelos.

\subsubsection{Implementação do modelo de manobra}

A validação dos modelos de manobras, analíticos e numéricos, apresentados nesta tese, foram realizados com o auxílio do simulador de dinâmica de AUVs de Dantas e Barros $^{[60]}$, que foi desenvolvido pelo autor deste projeto. Neste simulador, os modelos cinemáticos e dinâmicos, apresentados na seção 2, foram implementados utilizando os softwares Matlab e Simulink da empresa Mathworks.

As equações de movimento foram integradas utilizando o método de Runge-Kutta de quarta ordem, com um passo de integração fixo de 0.01 segundos. O método e a frequência de integração foram selecionados empiricamente por diversas simulações, ao verificar-se o limite em que a variação destes parâmetros não afetasse os resultados de uma simulação de manobra. Mesmo selecionando estes parâmetros, foi observado que utilizando o método de Runge-Kutta de terceira ordem com 0.02 segundos de passo de integração, já apresentaria resultados satisfatórios para as manobras analisadas nesta tese.

Os esforços hidrodinâmicos dos modelos de manobra ASE e CFD foram implementados utilizando os modelos apresentados nas seções 2 e 4, respectivamente.

Pelo modelo de CFD ter sido implementado considerando as simulações discretas de CFD, foi preciso utilizar um método para interpolação destes esforços, apresentado na seção 4.3.2. No caso do modelo ASE o acoplamento entre as três variáveis e a continuidade dos esforços já são intrínsecos do próprio modelo apresentado, não precisando depender de funções de aproximação. No entanto, no modelo ASE são consideradas aproximações relativas ao próprio equacionamento, como o uso da curva não linear do leme isolado obtido por simulações de CFD, e o uso de fatores analíticos e semi-empíricos para considerar a interferência/combinação. 
Neste simulador foram consideradas as propriedades inerciais do AUV Pirajuba apresentadas no apêndice A, que foram obtidas através de testes de balanço em Caetano ${ }^{[177]}$. Contudo, pelo AUV Pirajuba não ser um veículo totalmente estanque, pois somente os vasos de pressão impedem a entrada de água deixando que ela circule livremente nos compartimentos entre as estruturas (veículos deste tipo são conhecidos pelo termo free fluid), é necessário considerar a inércia adicional deste volume de água na dinâmica do veículo.

Por não existir um método de medição direto desta inércia, foi utilizada uma metodologia baseado na medição da inércia seca (inércia no ar, sem considerar a inércia da água) do veículo e da estimativa numérica destes volumes de água por meio do desenho em CAD do AUV. A estimativa numérica da inércia molhada aumentou a incerteza das propriedades inerciais do veículo, devido às suposições utilizadas e às próprias incertezas da medição da inércia seca, que apesar de serem relativamente pequenas são significativas para definir a dinâmica do veículo. Esta metodologia é apresentada no apêndice B desta tese.

\subsubsection{Comparação dos resultados numéricos e experimentais}

Com o objetivo de validar os modelos de simulações apresentados na última seção, nesta seção serão realizadas as comparações das respostas de taxa de rumo obtidas por estes modelos numéricos em manobras de giro e zigzag, com as medições realizadas durante os testes de campo de Angra dos Reis com o AUV Pirajuba.

Todas as simulações foram conduzidas sem considerar as perturbações do ambiente ou dos sensores. Foi utilizada a densidade da água que representa a média da densidade da água dos oceanos na superfície, $1024 \mathrm{~kg} / \mathrm{m}^{3}$. Em todas as simulações foi considerado que o veículo estava perfeitamente ajustado à condição de cruzeiro de $1 \mathrm{~m} / \mathrm{s}$, sem apresentar movimentos verticais ou laterais devido à flutuação ou desalinhamento das superfícies de controle. No entanto, foi considerado que o veículo apresentasse o mesmo ângulo de rolagem observada durante os ensaios (entre 0.5 e 1.5 graus), devido ao momento resistivo do motor e o centro de gravidade.

A velocidade de rotação do hélice foi ajustada para garantir uma tração igual a resistência hidrodinâmica do veículo andando em linha reta a $1 \mathrm{~m} / \mathrm{s}$. Contudo, não foi imposta nenhuma restrição que impedisse a variação desta velocidade devido ao aumento do arrasto, que ocorre durante a realização das manobras ${ }^{[84]}$.

As comparações para a manobra de giro são apresentadas na seção 6.4.2.1 e para a manobra de zigzag na seção 6.4.2.2. 


\subsubsection{Manobra de giro}

Na figura 69, são comparados os resultados obtidos pelos modelos numéricos com aqueles medidos durante a manobra de giro, em função da taxa de rumo, separando cada um dos gráficos para uma deflexão das superfícies de controle ensaiadas $(\delta=5,10,15$ e 20 graus). Nesta figura, a linha preta continua representa o resultado de simulação com o modelo hidrodinâmico obtido pelo CFD, enquanto a linha tracejada representa o modelo obtido pelas equações ASE. Os pontos representam as medições experimentais em diferentes testes, e as regiões em cinza representam o desvio padrão, indicando a probabilidade de $68.3 \%(1 \sigma), 95.4 \%(2 \sigma)$ e $99.7 \%(3 \sigma)$ do valor real estar nesta região, considerando o método de filtro Gaussiano previamente apresentado na seção 5.2.4.

Em todos os casos de deflexão, foi observado que as respostas de ambos os modelos numéricos apresentaram uma aderência muito boa aos resultados experimentais nos instantes iniciais das manobras, quando o veículo inicia à aceleração do movimento devido à deflexão dos lemes. Este resultado indica que os modelos CFD e ASE, que estimaram esforços bastante próximos entre si (ver seção 6.2 e 6.3), apresentaram uma boa predição para os esforços gerados pela deflexão dos lemes. Entretanto, à medida que a manobra se desenvolve, o ângulo de incidência e a velocidade angular aumentam, e as diferenças entre os dois modelos fazem com que resultados divirjam.

No caso de 5 graus de deflexão, o modelo CFD apresentou uma excelente aderência ao resultado experimental, enquanto o modelo ASE apresentou uma divergência de cerca de $30 \%$ para o valor da velocidade angular em regime permanente. Nas demais deflexões a situação se inverteu, com o modelo ASE apresentando um resultado mais próximo do que o modelo CFD, principalmente no caso de deflexão de 10 graus.

As diferenças entre estes resultados podem ser explicadas pelas diferenças na capacidade de estimar os esforços hidrodinâmicos estáticos e dinâmicos entre os modelos (ver seções 6.2 e 6.3, respectivamente), que apresentam algumas divergências em função da combinação do ângulo de incidência, velocidade angular ou deflexão dos lemes. Também deve ser considerado que os dois modelos divergem entre si na forma em que são considerados o acoplamento entre as variáveis de movimento, pois enquanto o modelo de CFD considera que o acoplamento entre a velocidade angular e a deflexão do leme é desprezível, o modelo ASE considera este efeito em suas equações.

As diferenças nas predições dos modelos numéricos em relação aos resultados experimentais, também podem ser explicadas por erros de predição dos coeficientes hidrodinâmicos. No entanto, também acredita-se que estes erros possam ter ocorrido devido a uma diferença nos parâmetros inerciais nominais do AUV Pirajuba, que como já foi comentado, apresentam incertezas de medições significativas para algumas das propriedades inerciais do veículo. 

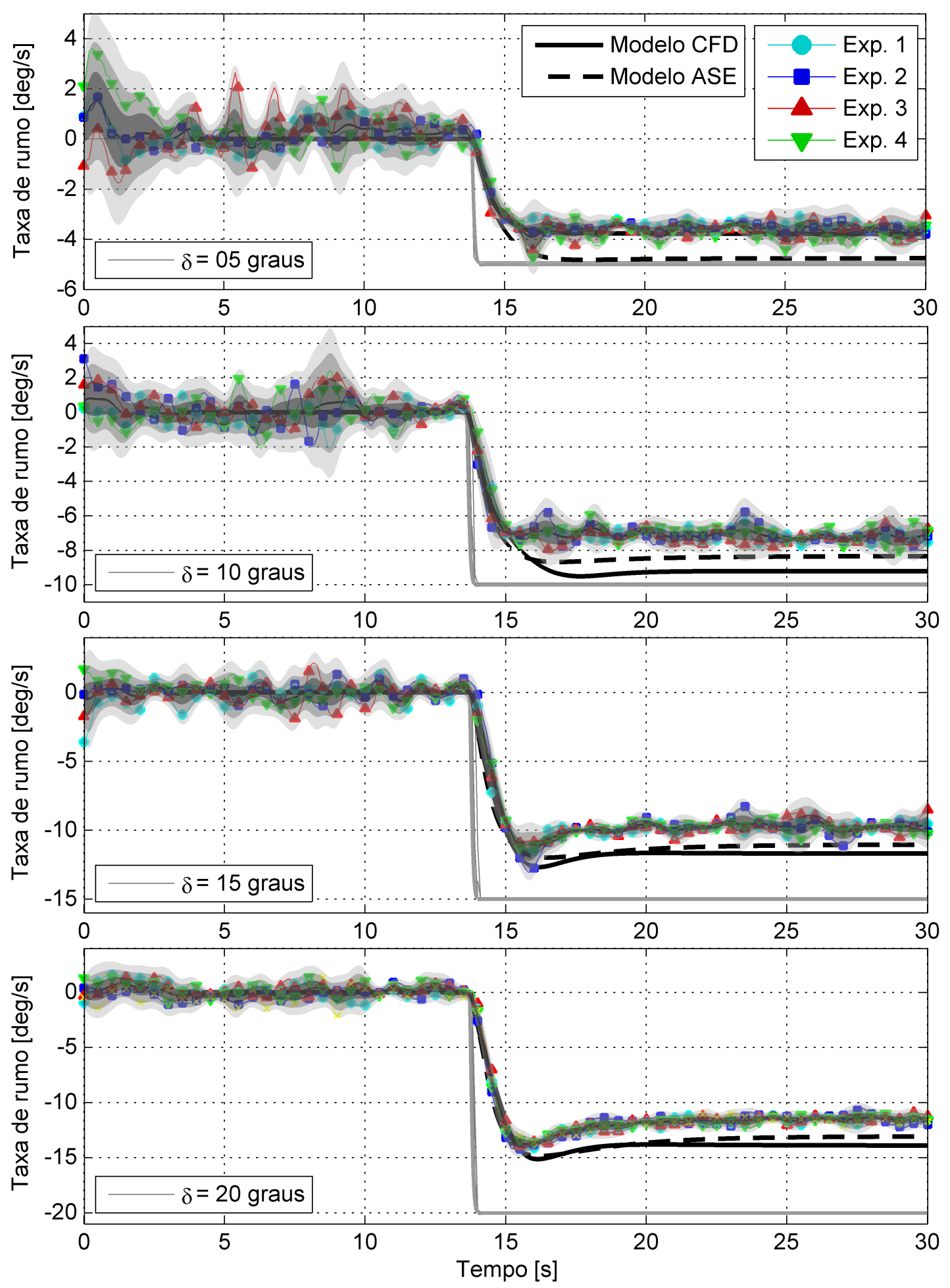

Figura 69 - Comparação das respostas de taxa de rumo das manobras de giro obtidas numericamente, utilizando os modelos hidrodinâmicos ASE e CFD, com os resultados obtidos pelo modelo livre 
Partindo desta suposição, foi realizada uma análise empírica da relação da variação do centro de gravidade do veículo com a resposta da manobra de giro. Foi observado que com uma variação de apenas $40 \mathrm{~mm}$ (cerca de $2 \%$ do comprimento do veículo), que está dentro das incertezas do processo de estimação, as respostas de ambos os modelos ficaram muito mais próximas dos resultados experimentais.

Os resultados com os modelos numéricos modificados são apresentados na figura 70 . Nesta figura é observado que os resultados com os modelos modificados apresentam uma aderência muito boa aos resultados experimentais, estando sempre dentro do intervalo de confiança de pelo menos $99.7 \%(3 \sigma)$. Os resultados que apresentam a aderência mais fraca são iguais aos que apresentaram os maiores erros com os modelos originais, ou seja, para o modelo CFD é o caso de 10 graus de deflexão, e para o modelo ASE o caso de 5 graus.

Uma comparação quantitativa das características da resposta dinâmica da taxa de rumo, interpretando-a como uma resposta a degrau, com todos os modelos numéricos e com a média dos dados experimentais é apresentada na tabela 15. Os dados experimentais foram retirados da tabela 2, apresentada na seção 5.2.4, onde algumas medições podem apresentar uma incerteza maior do que a apresentada por não considerar algumas características dos ruídos dos sinais.

Com os resultados da tabela 15, sem considerar a correção, é confirmado que o modelo ASE ficou mais próximo dos resultados experimentais do que o modelo CFD, na maioria dos critérios utilizados. A exceção foi no caso da deflexão do leme de 5 graus, em que o modelo CFD apresentou uma melhor aderência.

Também pode ser verificado, que com a correção no centro de gravidade os modelos numéricos se aproximaram mais dos resultados experimentais, com exceção de poucos casos/critérios, diminuindo os erros dos modelos numéricos. Este fato indica uma maior probabilidade dos modelos utilizados apresentem um erro maior na estimativa do centro de gravidade, quando o veículo está submerso (molhado), do que os demais parâmetros. Apesar que esta análise não indica que os demais parâmetros também apresentem erros.

A verificação da incerteza de cada parâmetro na resposta do veículo será realizada por uma análise de sensibilidade paramétrica, apresentada posteriormente na seção 6.4.3.

\subsubsection{Manobra de zigzag}

Seguindo a mesma metodologia de apresentação utilizada na manobra de giro, as comparações das taxas de rumo numéricas e experimentais, para os quatro casos de deflexão da manobra de zigzag ( $\delta=5,10,15$ e 20 graus), são apresentadas na figura 71. Por falta de espaço as legendas não foram colocadas nesta figura, mas as cores e os símbolos utilizados são os mesmos apresentados nas figuras 69 e 70.

Para facilitar a comparação entre os diferentes modelos, nesta figura, as simulações 

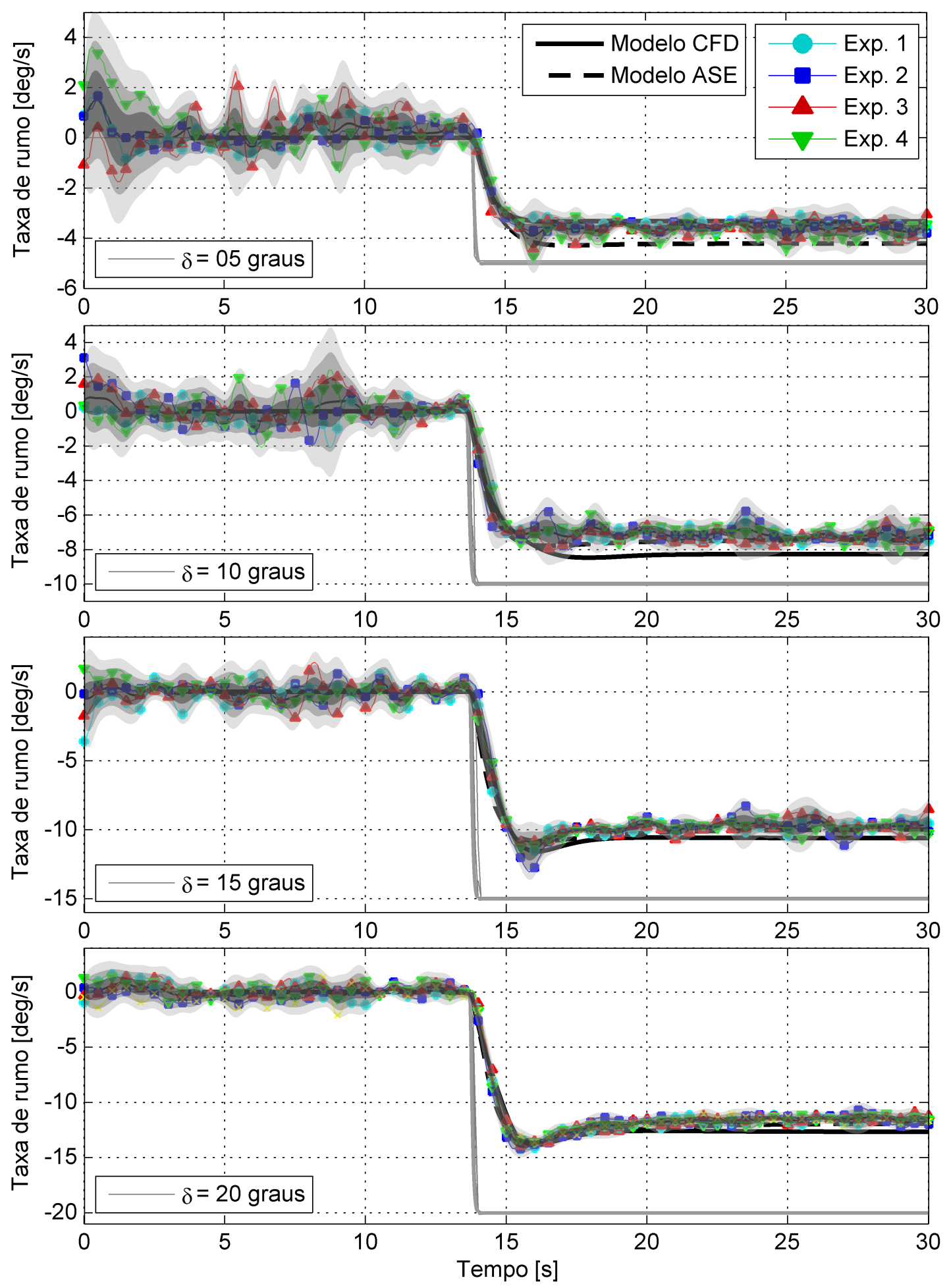

Figura 70 - Comparação das respostas de taxa de rumo das manobras de giro obtidas pelos modelos numéricos corrigidos, utilizando os modelos hidrodinâmicos ASE e CFD, com os resultados obtidos pelo modelo livre 


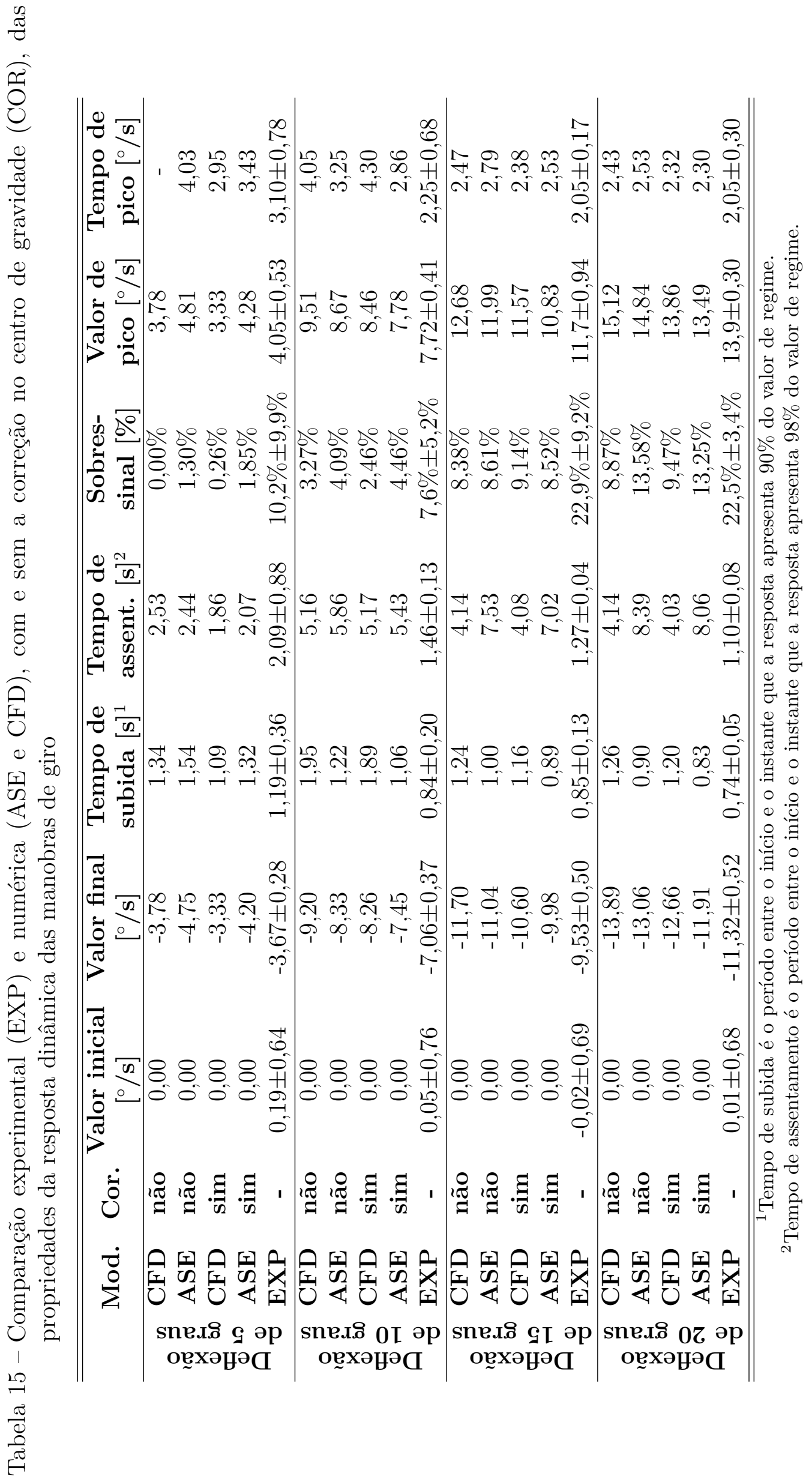


e os dados das manobras de 5 e 10 graus de deflexão foram sincronizadas no início do terceiro ciclo positivo de oscilação (sexta deflexão do leme), e para as deflexões de 15 e 20 graus no inicio do segundo ciclo positivo (quarta deflexão do leme).

Pela figura 71, é observado que ambos os modelos apresentaram uma boa aderência a pelo menos um ciclo em todos os casos analisados, apesar de apresentarem uma divergência aos ciclos mais distantes do ciclo de sincronização. Contudo, esta divergência, em menor escala, também é observada entre as repetições dos resultados experimentais.

Os resultados dos modelos numéricos para as deflexões de 15 e 20 graus foram bastante semelhantes, ficando bastante próximos dos resultados experimentais em termos de período, máxima amplitude e aceleração. A única diferença foi que o modelo ASE apresentou um menor erro no período de oscilação para o caso de 20 graus. Estes resultados indicam que as diferenças na região não linear dos coeficientes hidrodinâmicos, devido à diferença da modelagem do estol, são compensadas entre os dois modelos, ou são pequenas em relação aos esforços inerciais.

Nos casos de menor deflexão, os resultados foram opostos aos observados na manobra de giro. Na manobra de 5 graus de deflexão, o modelo ASE apresentou uma aderência muito boa enquanto o modelo CFD apresentou um valor máximo abaixo do experimental. Já no caso de 10 graus, apesar de ambos os modelos apresentarem valores máximos parecidos, o modelo ASE apresentou uma maior divergência em relação a curva do modelo CFD.

Neste caso, a explicação da divergência entre os modelos pode ser a mesma da manobra de giro. Ou seja, estas diferenças podem ocorrer devido às pequenas diferenças nas estimativas dos esforços hidrodinâmicos, ou devido ao efeito do acoplamento não linear entre a velocidade angular e a deflexão do leme, que não são consideradas no modelo CFD.

Utilizando a mesma metodologia empregada na análise das manobras de giro, foram realizadas simulações com os modelos numéricos com uma variação de $40 \mathrm{~mm}$ no centro de gravidade do veículo. Os gráficos comparativos da resposta da taxa de rumo podem ser vistos na figura 72 (utilizando as mesmas legendas das figuras 69 e 70), enquanto que na tabela 16 é apresentada uma comparação mais direta do período de oscilação, e dos valores máximos observados da taxa de rumo e do ângulo de rumo.

Tanto pela figura 72 quanto pela tabela 16, não foram observados variações significativas entre os modelos nominais e corrigidos no período de oscilação, somente nos valores máximos observados. Isto indica que as diferenças entre os modelos e os resultados experimentais podem não ser somente devido a variação do centro de massa, podendo ocorrer devido a incerteza dos demais parâmetros.

$\mathrm{Na}$ análise do valor máximo do ângulo de rumo e de sua taxa, o modelo corrigido apresentou um valor mais próximo dos resultados experimentais do que o modelo nominal. 

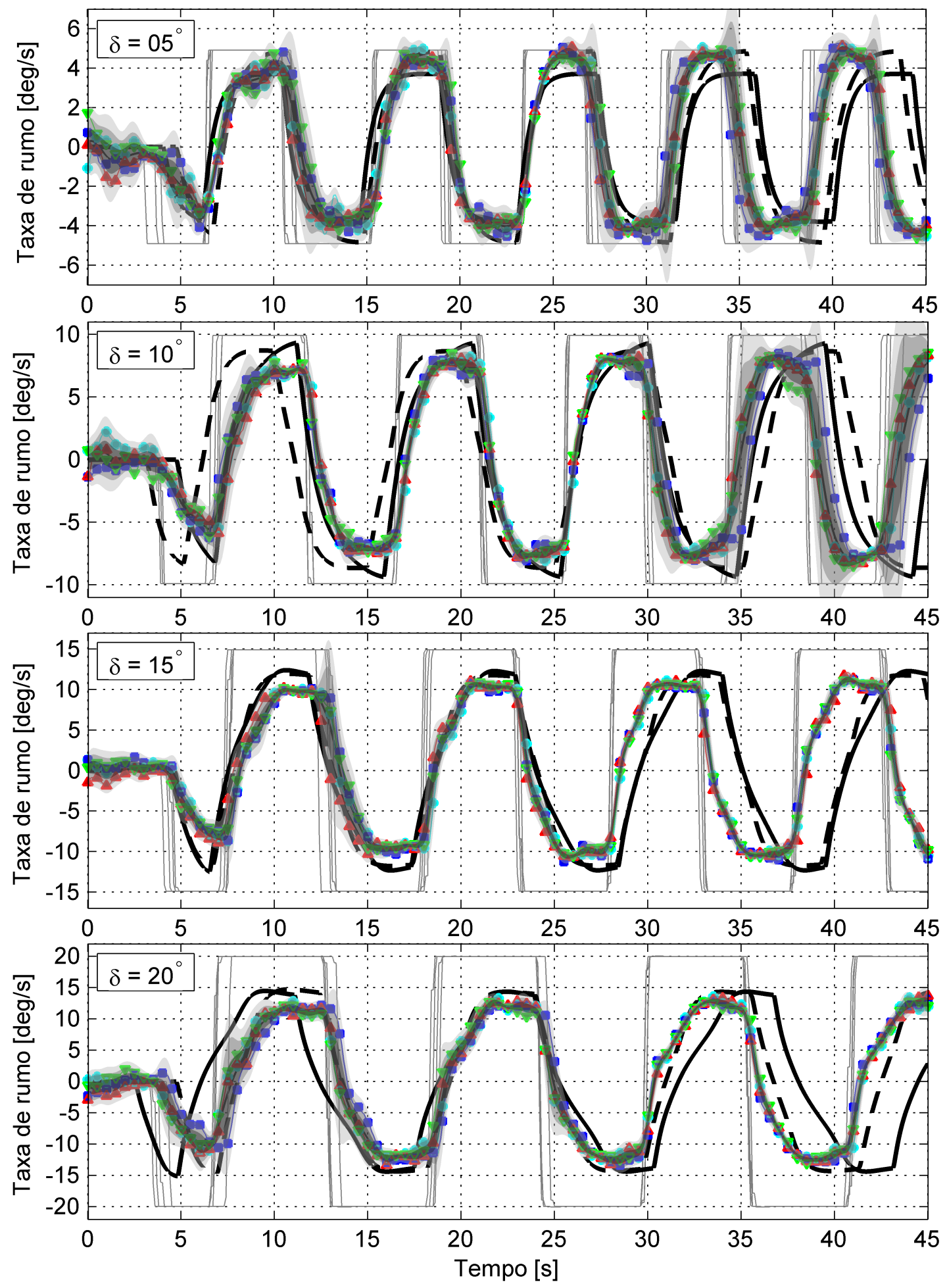

Figura 71 - Comparação das respostas de taxa de rumo das manobras de zigzag obtidas numericamente, utilizando os modelos hidrodinâmicos ASE e CFD, com os resultados obtidos pelo modelo livre. As legendas são as mesmas utilizadas nas figuras 69 e 70 

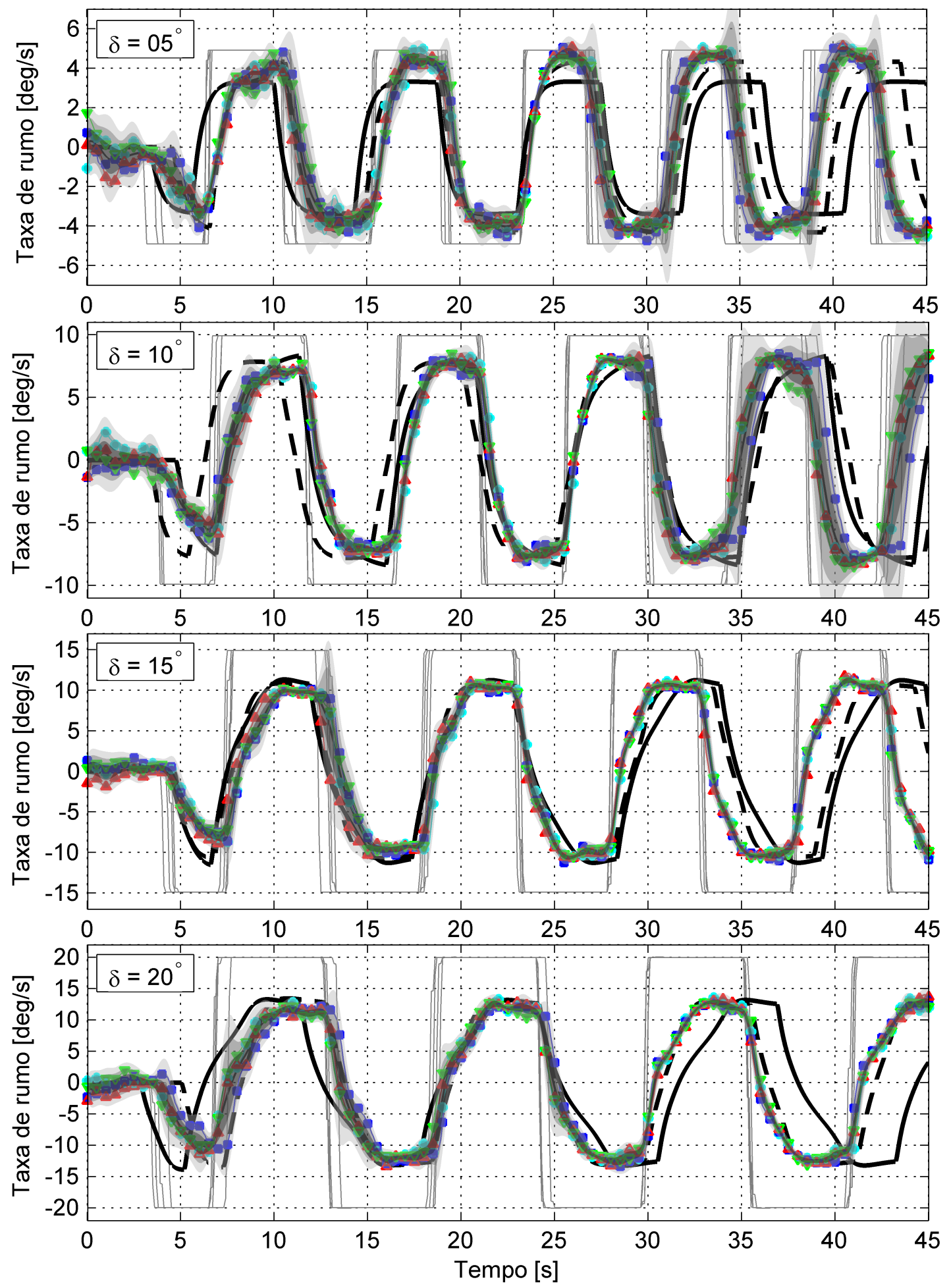

Figura 72 - Comparação das respostas de taxa de rumo das manobras de zigzag obtidas pelos modelos numéricos corrigidos, utilizando os modelos hidrodinâmicos ASE e CFD, com os resultados obtidos pelo modelo livre. As legendas são as mesmas utilizadas nas figuras 69 e 70 
Tabela 16 - Comparação experimental (EXP) e numérica (ASE e CFD), com e sem a correção no centro de gravidade (COR), das propriedades da resposta dinâmica das manobras de zigzag

\begin{tabular}{|c|c|c|c|c|c|}
\hline & Mod. & Cor. & $\begin{array}{l}\text { Período de } \\
\text { oscilação }[\mathrm{s}]\end{array}$ & $\begin{array}{c}\text { Taxa de rumo }{ }^{1} \\
\text { [graus/s] }\end{array}$ & $\begin{array}{l}\text { Amplitude de } \\
\text { rumo }^{1} \text { [graus] }\end{array}$ \\
\hline \multirow{5}{*}{ 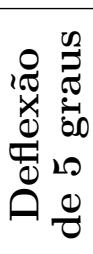 } & CFD & não & 8,46 & 3,75 & 6,43 \\
\hline & ASE & não & 8,23 & 4,84 & 7,34 \\
\hline & CFD & $\operatorname{sim}$ & 8,75 & 3,36 & 6,18 \\
\hline & ASE & $\operatorname{sim}$ & 8,24 & 4,32 & 6,89 \\
\hline & EXP & - & $7,73 \pm 0,14$ & $4,74 \pm 0,12$ & $7,03 \pm 0,11$ \\
\hline \multirow{5}{*}{ 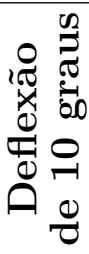 } & CFD & não & 9,44 & 9,30 & 14,96 \\
\hline & ASE & não & 10,09 & 8,63 & 16,14 \\
\hline & CFD & $\operatorname{sim}$ & 9,40 & 8,31 & 13,93 \\
\hline & ASE & $\operatorname{sim}$ & 9,88 & 7,78 & 14,80 \\
\hline & EXP & - & $8,69 \pm 0,24$ & $8,23 \pm 0,11$ & $14,03 \pm 0,30$ \\
\hline \multirow{5}{*}{ 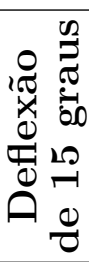 } & CFD & não & 11,09 & 12,29 & 22,57 \\
\hline & ASE & não & 10,95 & 11,74 & 23,38 \\
\hline & CFD & $\operatorname{sim}$ & 10,97 & 11,25 & 21,06 \\
\hline & ASE & $\operatorname{sim}$ & 10,76 & 10,66 & 21,68 \\
\hline & EXP & - & $9,46 \pm 0,77$ & $10,71 \pm 0,55$ & $20,95 \pm 0,24$ \\
\hline \multirow{5}{*}{ 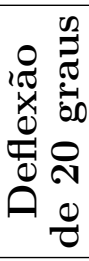 } & CFD & não & 12,83 & 14,34 & 29,48 \\
\hline & ASE & não & 11,56 & 14,29 & 30,12 \\
\hline & CFD & $\operatorname{sim}$ & 12,74 & 13,18 & 27,65 \\
\hline & ASE & $\operatorname{sim}$ & 11,36 & 13,09 & 28,02 \\
\hline & EXP & - & $11,13 \pm 0,26$ & $13,00 \pm 0,35$ & $26,87 \pm 0,87$ \\
\hline
\end{tabular}

Este resultado reforça a suposição iniciada na análise da manobra de giro, que o modelo nominal pode apresentar um erro significativo, mas dentro de sua incerteza, na determinação do centro de gravidade do veículo.

Da mesma forma da análise da manobra de giro, este resultado indica que é necessário realizar uma análise de sensibilidade paramétrica, com o objetivo de obter a incerteza numérica dos resultados obtidos, e realizar uma validação dos resultados obtidos pelos modelos de manobras.

\subsubsection{Análise da sensibilidade e validação dos modelos de manobras}

Como comentado anteriormente, a análise paramétrica da sensibilidade foi realizada principalmente para determinar as incertezas numéricas, e posteriormente, a incerteza de validação das respostas dinâmicas dos modelos de manobras, em relação aos parâmetros das equações de movimento (apresentados na seção 2 e na seção 6.4.2). A incerteza de validação é utilizada para determinar o intervalo de confiança que deve compreender as características de manobra obtidas pelos ensaios, de forma a validar as respostas geradas pelos modelos de manobra. 
A análise apresentada nesta seção é realizada em caráter local ${ }^{[33]}$, i.e., considerando as variações de sensibilidade dos parâmetros apenas na condição nominal. Este tipo de análise permite o estudo individual do efeito de variação de cada parâmetro analisado, sobre as características de manobrabilidade do veículo sem considerar os efeitos de acoplamento, possibilitando analisar o efeito individual que cada parâmetro apresenta na dinâmica do veículo.

Uma alternativa a este método seria a utilização de um método de amostragem global (Monte Carlo), onde são realizadas combinações aleatórias entre as variações dos parâmetros nominais ${ }^{[33]}$. Contudo, os métodos globais possuem um custo computacional exponencialmente proporcional ao número de parâmetros, tornando a sua aplicação impraticável aos casos com muitos parâmetros, como o caso investigado neste trabalho.

Mesmo apresentando uma abordagem mais simples do que a análise global, a análise local consegue representar bem as incertezas numéricas de diversos sistemas complexos ${ }^{[33]}$, principalmente quando as incertezas dos parâmetros dos modelos apresentam uma variação próxima aos valores dos parâmetros. No caso de análises de manobrabilidade, Sen ${ }^{[50]}$ conseguiu investigar a sensibilidade de um modelo de manobra de submarino, mesmo considerando altas incertezas. Isto indica que apesar do modelo de um AUV apresentar características não-lineares, elas conseguem ser estatisticamente bem analisadas pelos métodos locais, tornando a análise global ineficiente para este caso.

Contudo, mesmo uma análise local pode apresentar um custo relativamente alto se não for realizada uma verificação preliminar dos parâmetros que devem ser simulados, pois existem parâmetros que não influenciam significativamente na resposta dinâmica e parâmetros que possuem efeitos dinâmicos iguais a outros parâmetros. O procedimento para seleção destes parâmetros é apresentado na seção 6.4.3.1, onde são utilizados os modelos reduzidos/simplificados de análise das manobras de zigzag e giro para selecionar os parâmetros de análise.

Alguns dos parâmetros descartados foram mantidos na análise de sensibilidade, para que pudesse ser confirmada a sua baixa influência. Na seção 6.4.3.2 são apresentados os parâmetros que foram considerados na análise de sensibilidade, indicando as incertezas utilizadas com o seu procedimento de estimação.

A análise de sensibilidade paramétrica foi aplicada de três formas. Primeiro, são comparados os gráficos da resposta de taxa de rumo entre o modelo nominal e os modelos com variação paramétrica. Em seguida, através de tabelas, são apresentadas informações quantitativas das características destas respostas, como valor de regime permanente ou período de oscilação, encontrando a relação da variação que cada parâmetro gera nas características das manobras. Por último, são calculados os coeficientes de sensibilidade, que representam a relação normalizada entre a variação de cada parâmetro do modelo de manobra com a variação das características das manobras, sendo utilizados para calcular 
a incerteza numérica local dos modelos de simulação. O procedimento para o cálculo dos coeficientes de sensibilidade e da incerteza numérica são apresentadas na seção 6.4.3.3.

Após o cálculo da incerteza numérica é realizada a validação formal, segundo a norma da ASME ${ }^{[33]}$, das características das manobras obtidos pelos modelos numéricos, que utiliza esta incerteza junto à incerteza experimental, levantada na seção 5.2, para calcular a incerteza de validação. O processo de validação é apresentado na seção 6.4.3.4. Este processo permitiu validar algumas das características das manobras de giro e zigzag obtidas com as simulações numéricas, que utilizaram modelos hidrodinâmicos baseados nas metodologias de CFD e ASE.

Por último, nas seções 6.4.3.5 e 6.4.3.6, serão apresentados as três etapas da análise paramétrica de sensibilidade e a validação para as manobras de giro e zigzag, respectivamente. Devido ao limite de espaço, apenas os resultados mais significativos serão apresentados nesta seção. Entretanto, todos os resultados serão apresentados integralmente nos apêndices E e F, G e H.

\subsubsection{Simplificação do modelo dinâmico no plano lateral}

Na simplificação do modelo dinâmico lateral, as equações de movimento não lineares (apresentadas na seção 2.2.1) são reduzidas ao considerar que o movimento do veículo ocorre apenas no plano lateral, com o veículo ajustado para a condição de equilíbrio em cruzeiro.

Uma redução maior pode ser obtida ao considerar um caso particular da manobra de giro, em que o veículo se encontra em regime permanente. Neste caso, as equações de movimento podem ser linearizadas na condição de movimento curvilíneo uniforme, obtendo uma relação direta entre a deflexão do leme e a velocidade angular desenvolvida, em função dos esforços hidrodinâmicos e inerciais linearizados nesta condição.

Por este ser um procedimento bastante comum em livro textos das áreas navais ${ }^{[83,84]}$ $[78,68]$ e aeronáuticas ${ }^{[122,126,79]}$, este procedimento não será apresentado no texto principal desta tese. Contudo, no apêndice C este procedimento é apresentado de maneira sucinta.

\subsubsection{Sensibilidades consideradas dos parâmetros do modelo}

Utilizando as equações simplificados do modelo lateral, foram levantados 24 parâmetros que influenciam as manobras no plano lateral, sendo 4 relativos aos esforços inerciais e 20 aos esforços hidrodinâmicos. Para simplificar a apresentação, os esforços hidrodinâmicos foram adicionalmente divididos nos termos de massa adicional, esforços gerados pelo corpo, leme e a combinação de ambos.

Cada parâmetro teve o seu valor modificado por critérios numéricos, analíticos ou experimentais, relativos às suas incertezas. Para melhor estudar a incerteza de cada 
Tabela 17 - Valores e desvio padrões $(1 \sigma)$ da incerteza dos parâmetros do modelo de manobra utilizados na análise de sensibilidade

\begin{tabular}{|c|c|c|c|c|c|}
\hline & & Dorômotron & Valor & Sensib & lidade \\
\hline & & Parametros & nominal & Absoluto & Relativo \\
\hline & & Massa & $68.3 \mathrm{~kg}$ & $3.4 \mathrm{~kg}$ & $5 \%$ \\
\hline & ల) & $X_{C G}$ & $0 \mathrm{~mm}$ & $40 \mathrm{~mm}$ & $5 \%^{2}$ \\
\hline & 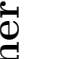 & Inercia & $15.8 \mathrm{~kg} \cdot \mathrm{m}^{2}$ & $2.4 \mathrm{~kg} \cdot \mathrm{m}^{2}$ & $15 \%$ \\
\hline & & Velocidade & $1.0 \mathrm{~m} / \mathrm{s}$ & $0.05 \mathrm{~m} / \mathrm{s}$ & $5 \%$ \\
\hline & $\Rightarrow$ & $\mathrm{A}(1,1)$ & $1.64 \mathrm{~kg}$ & $0.49 \mathrm{~kg}$ & $30 \%$ \\
\hline & : & $\mathrm{A}(2,2)$ & $78.7 \mathrm{~kg}$ & $15.7 \mathrm{~kg}$ & $20 \%$ \\
\hline & $\psi_{1}$ & $\mathrm{~A}(6,6)$ & $18.1 \mathrm{~kg} \cdot \mathrm{m}^{2}$ & $3.6 \mathrm{~kg} \cdot \mathrm{m}^{2}$ & $20 \%$ \\
\hline & $\sum$ & $\mathrm{A}(2,6), \mathrm{A}(6,2)$ & $-6.8 \mathrm{~kg} \cdot \mathrm{m}$ & $-1.4 \mathrm{~kg} . \mathrm{m}$ & $20 \%$ \\
\hline & & Vel. lateral $(v)$ & - & - & $10 \%$ \\
\hline & $\circ$ & Vel. angular $(r)$ & - & - & $10 \%$ \\
\hline & ?ํㅜ & Força em Y $\left(F_{y}\right)$ & - & - & $10 \%$ \\
\hline. & 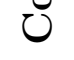 & Momento em Z $(N)$ & - & - & $10 \%$ \\
\hline $\bar{\Xi}$ & & Força em X $\left(F_{x}\right)$ & - & - & $10 \%$ \\
\hline <త్రి & & Vel. lateral $(v)$ & - & - & $10 \%$ \\
\hline تี & & Vel. angular $(r)$ & - & - & $10 \%$ \\
\hline : & $\stackrel{\varrho}{g}$ & Def. do leme $(\delta)$ & - & - & $10 \%$ \\
\hline 江 & $\stackrel{\overrightarrow{0}}{\oplus}$ & Força em Y $\left(F_{y}\right)$ & - & - & $10 \%$ \\
\hline & & Momento em Z $(N)$ & - & - & $10 \%$ \\
\hline & & Força em $\mathrm{X}\left(F_{x}\right)$ & - & - & $10 \%$ \\
\hline & జ. & Vel. lateral $(v)$ & - & - & $10 \%$ \\
\hline & ש్ & Vel. angular $(r)$ & - & - & $10 \%$ \\
\hline & 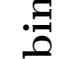 & Força em Y $\left(F_{y}\right)$ & - & - & $10 \%$ \\
\hline & $\bar{\Xi}$ & Momento em Z $(N)$ & - & - & $10 \%$ \\
\hline & ن & Força em X $\left(F_{x}\right)$ & - & - & $10 \%$ \\
\hline
\end{tabular}

parâmetro, a análise de sensibilidade foi realizada ao se considerar uma variação de duas a três vezes a incerteza padrão percentual, além de considerar a variação positiva e negativa. Por exemplo, um parâmetro que apresentasse uma incerteza padrão de 10\%, seria analisado para $-30 \%,-20 \%,-10 \%, 10 \%, 20 \%$ e $30 \%$.

A variação padrão para cada parâmetro é apresentada na tabela 17 de forma dimensional e percentual, enquanto que as justificativas da escolha destas variações são apresentadas nas sub-seções a seguir.

No caso dos esforços hidrodinâmicos foram considerados dois casos de sensibilidade para melhor analisar os seus comportamentos não lineares. No primeiro caso é realizada a análise de sensibilidade das variáveis de entrada da função que estima os esforços hidrodinâmicos, ou seja, o ganho de sensibilidade é aplicado ao ângulo de incidência, a taxa do ângulo de rumo e a deflexão do leme. No segundo caso, o ganho de sensibilidade é aplicado à estimativa das funções dos esforços hidrodinâmicos, ou seja, na força normal, 
no momento de guinada (yaw) e na força axial.

No primeiro caso, o ganho no modelo ASE afeta diretamente os fatores de interferência ( $K_{W B}, K_{B W}, k_{W B}$ e $k_{B W}$, apresentados na seção 4.2.4), enquanto no modelo CFD seria equivalente a uma multiplicação direta nas variáveis de entrada de cada função dos esforços hidrodinâmicos. No segundo caso, os ganhos de sensibilidade são multiplicados diretamente aos esforços hidrodinâmicos, i.e., força em Y, momento (N) e força em X.

Nota-se que a variação de sensibilidade das variáveis $v, r$ e $\delta$ (primeiro caso) geram incertezas redundantes à aquelas obtidas pelas variações dos parâmetros dos esforços hidrodinâmicos (segundo caso), de maneira semelhante às analises realizadas com as partes isoladas (corpo e leme) com os da combinação. Esta estrutura foi considerada para que a análise de sensibilidade verificasse o comportamento individual de cada um dos parâmetros analisados. Devido a estas considerações, o cálculo da incerteza numérica deve considerar a intersecção de cada grupo de parâmetros, como será apresentado nas próximas seções.

\section{Parâmetros inerciais}

Na estimativa das incertezas dos parâmetros inerciais de massa, centro de massa e inércia, foram consideradas as incertezas do processo de medição da inércia do veículo não submerso (inércia seca), e as incertezas da estimativa da massa/volume de água considerados quando o veículo está submerso (inércia molhada), conforme apresentado no apêndice B.

A maior parte da incerteza está relacionada a estimativa da inércia gerada pelo volume de água interno ao casco com a ferramenta de CAD, devido a dificuldade de modelar todas as peças e cavidades do AUV que modificam este volume de água. Entretanto, as incertezas de medição também foram responsáveis por uma parcela significativa da incerteza do caso da posição do centro de massa, devido ao próprio procedimento de medição e a correlação ao modelo em CAD.

Estas incertezas também consideraram a variação da densidade da água do mar, que não foi medida durante os experimentos. Devido a sazonalidade do ambiente marinho na bacia de Angra dos Reis não é possível obter uma estimativa precisa da densidade, sendo considerado que ela deve estar entre 1000 e $1035 \mathrm{~kg} / \mathrm{m}^{3}$, i.e., uma variação de $3.5 \%$.

A incerteza na velocidade do AUV está relacionada ao método utilizado para ajustar a velocidade do propulsor, conforme apresentado na seção 5.2.1 ${ }^{[49]}$.

\section{Parâmetros hidrodinâmicos de massa adicional}

Apesar dos métodos das faixas ser um método bastante difundido para o cálculo da massa adicional de corpos submersos, não existem procedimentos estabelecidos para 


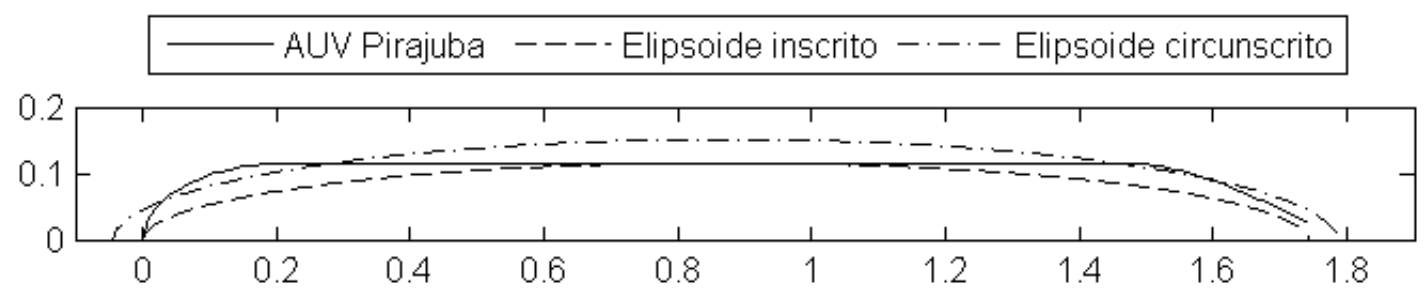

Figura 73 - Perfil dos elipsoides inscritos e circunscritos no casco do AUV Pirajuba

estimar a sua incerteza. No caso do AUV Pirajuba, esta incerteza foi estimada ao comparar a estimativa obtida pelos métodos das faixas com resultados analíticos de corpos similares ao casco e ao leme do AUV.

Para o casco foi utilizado um elipsoide/esferoide de revolução, cuja solução analítica pode ser encontrada em Imlay ${ }^{[75]}$ ou Korotkin ${ }^{[178]}$, sendo reproduzida no apêndice D. Em submarinos $^{[12,13]}$ e AUVs ${ }^{[14]}$ com geometria suficientemente semelhante, a massa adicional pode ser estimada como sendo igual a de um elipsoide inscrito no casco. Contudo, como um elipsoide inscrito não consegue representar o casco do AUV Pirajuba, nesta análise foi considerado tanto o elipsoide inscrito quanto o circunscrito, conforme é apresentado na figura 73 .

No caso do leme foi utilizado o modelo teórico de um fólio fino de envergadura finita de Belocerkovvsky ${ }^{[179]}$, apresentado em mais detalhes no apêndice desta tese, que assume que a espessura do leme seja muito menor do que sua corda ou envergadura. Neste caso foi utilizada a mesma geometria do leme do AUV, pois os modelos analíticos contemplam esta geometria.

A comparação entre ambos os métodos para o leme, o casco e a soma de ambos, é apresentado na tabela 18 para a massa adicional de força lateral em função da aceleração lateral, e na tabela 19 para a massa adicional de momento de guinada em função da aceleração de guinada.

Nestas tabelas foi possível verificar que o método das faixas superestimou todas os termos de massa adicional, principalmente no caso do momento. No caso do leme, este erro se deve a sua baixa razão de aspecto (esbelteza), que não permite que o escoamento se

Tabela 18 - Comparação da estimativa da massa adicional de força lateral em função da aceleração lateral, i.e., $Y_{\dot{v}}$, por métodos analíticos ${ }^{[75,178,179]}$ e pelos métodos das faixas

\begin{tabular}{rccccc}
\hline & \multicolumn{2}{c}{ Inscrito } & \multicolumn{2}{c}{ Circunscrito } \\
& Leme & Corpo & Comb. & Corpo & Comb. \\
\hline Analítico & $2,22 \mathrm{~kg}$ & $46,90 \mathrm{~kg}$ & $49,12 \mathrm{~kg}$ & $70,25 \mathrm{~kg}$ & $72,47 \mathrm{~kg}$ \\
Faixas & $5,63 \mathrm{~kg}$ & $49,96 \mathrm{~kg}$ & $55,59 \mathrm{~kg}$ & $76,58 \mathrm{~kg}$ & $82,21 \mathrm{~kg}$ \\
Erro & $154 \%$ & $6,53 \%$ & $13,17 \%$ & $9,00 \%$ & $13,43 \%$ \\
\hline
\end{tabular}


Tabela 19 - Comparação da estimativa da massa adicional do momento de guinada em função da aceleração de guinada, i.e., $N_{\dot{r}}$, por métodos analíticos ${ }^{[75,178,179]} \mathrm{e}$ pelos métodos das faixas

\begin{tabular}{rccccc}
\hline & & \multicolumn{2}{c}{ Inscrito } & \multicolumn{2}{c}{ Circunscrito } \\
& Leme & Corpo & Comb. & Corpo & Comb. \\
\hline Analítico & $1,21 \mathrm{~kg} \cdot \mathrm{m}^{2}$ & $6,35 \mathrm{~kg} \cdot \mathrm{m}^{2}$ & $7,56 \mathrm{~kg} \cdot \mathrm{m}^{2}$ & $9,12 \mathrm{~kg} \cdot \mathrm{m}^{2}$ & $10,33 \mathrm{~kg} \cdot \mathrm{m}^{2}$ \\
Faixas & $3,08 \mathrm{~kg} \cdot \mathrm{m}^{2}$ & $7,58 \mathrm{~kg} \cdot \mathrm{m}^{2}$ & $10,66 \mathrm{~kg} \cdot \mathrm{m}^{2}$ & $11,63 \mathrm{~kg} \cdot \mathrm{m}^{2}$ & $14,70 \mathrm{~kg} \cdot \mathrm{m}^{2}$ \\
Erro & $154 \%$ & $19,4 \%$ & $41,0 \%$ & $27,5 \%$ & $42,3 \%$ \\
\hline
\end{tabular}

comporte de forma bidimensional em cada seção/faixa, hipótese fundamental do método das faixas. No caso casco, representado pelos elipsoides, a sua razão de esbelteza não foi grande o suficiente para que o efeito da variação da cota do perfil não gerasse erros significativos nos termos de massa adicional, mesmo sendo pelo menos uma ordem de grandeza menor que a incerteza do leme.

Este resultado permite estimar que a soma do casco e do leme poderia apresentar um erro máximo de $42.3 \%$ para a estimativa da massa adicional de momento e $13.4 \%$ para a força. Entretanto, a soma simples dos termos do casco e do leme não representam a massa adicional do AUV, pois é preciso considerar a interferência gerada pela presença dos dois corpos (ver apêndice D).

Por não existir um método para estimar esta incerteza, será aplicado um fator de segurança sobre a incerteza da soma dos termos do casco e do leme. Além da interferência, este fator de segurança irá considerar um eventual aumento da incerteza do casco do AUV Pirajuba, que apresenta um perfil de maior derivada em relação aos elipsoides, e uma possível variação da densidade da água, que é diretamente proporcional aos termos de massa adicional.

Desta forma será considerado que a maior variação possível dos termo de massa adicional será de $60 \%$, sendo $40 \%$ do corpo e do leme, pior caso da tabela 19, e $20 \%$ referente a aplicação do fator de segurança. Em termos estatísticos, pode-se considerar que a maior variação possível seria equivalente a três desvios padrões $(3 \sigma)$, resultando em uma variação padrão $(1 \sigma)$ igual a $20 \%$.

Nesta simplificação foi adotado que a incerteza de todos os termos de massa adicional fossem iguais ao do momento adicional de guinada em função da velocidade de rumo $\left(N_{\dot{r}}\right)$. Isto representa uma estimativa bastante conservadora para os demais termos, que apresentaram incertezas muito menores (vide tabela 19). Apesar destas incertezas estarem superestimadas elas não vão influenciar na análise de sensibilidade, pois estes termos tem uma baixa influência na dinâmica do AUV. 


\section{Parâmetros hidrodinâmicos dos esforços estáticos}

As incertezas dos esforços hidrodinâmicos estáticos do AUV Pirajuba podem ser estimadas pela comparação dos resultados numéricos e experimentais da combinação corpo-leme, apresentados previamente na figura 54 da seção 6.2.4.

Considerando o caso de deflexão nula, os maiores erros ocorrem na região de ângulo de incidência em que o leme está estolado, i.e., região de pós-estol. Nesta região, tanto para a força lateral quanto para o momento, o modelo de CFD apresenta variações máximas de $10 \%$ em relação aos dados experimentais, podendo assumir uma incerteza de mesma magnitude para esta condição.

Como os casos com e sem deflexão do leme foram calculados com o mesmo método (CFD), apresentando a mesma condição de escoamento com os mesmos fenômenos hidrodinâmicos e o mesmo tipo de malha, pode se considerar que este valor de incerteza possa ser extrapolado para o caso em que é considerada a deflexão.

Em outras palavras, como o modelo de CFD conseguiu prever com um erro de $10 \%$ os esforços de um caso com certos fenômenos hidrodinâmicos, é esperado que o mesmo modelo de CFD consiga prever com a mesma precisão os mesmos fenômenos hidrodinâmicos em um caso que teve parte de sua geometria levemente rotacionada, mas mantendo o mesmo tipo de escoamento e fenômenos hidrodinâmicos.

Portanto, para este tipo de esforço será considerado um desvio padrão unitário de $10 \%(1 \sigma)$, que representa erros que são muito prováveis de ocorrer no ensaio de validação. Como consequência os valores de incertezas máximas estariam em uma região de três desvios padrões $(3 \sigma)$, que equivaleria a erros de baixa probabilidade de ocorrência das estimativas de CFD em comparação ao caso real dos ensaios de validação.

\section{Parâmetros hidrodinâmicos dos esforços dinâmicos}

Diferente do caso do esforço hidrodinâmico estático, o esforço dinâmico não possui um resultado experimental específico para auxiliar na estimativa de sua incerteza. Entretanto, é possível utilizar os resultados de CFD dos esforços estáticos em conjunto com o modelo ASE dinâmico para auxiliar neste processo. Este calculo pode ser simplificado ao se analisar as incertezas do leme e do corpo individualmente.

No caso do corpo, não é recomendável utilizar a similaridade com as simulações estáticas devido à diferente condição que o escoamento incide sobre o corpo. Entretanto, o modelo ASE pode ser utilizado para auxiliar neste processo, pois a sua estrutura matemática conseguiu reproduzir os esforços hidrodinâmicos de uma maneira similar ao CFD, vide seção 6.3. Desta forma, nos esforços dinâmicos do corpo as incertezas serão calculadas de acordo com os modelos ASE. 
No modelo ASE, apresentado na seção 4.2.2, os esforços são matematicamente divididos em termos potencias e viscosos, sendo que cada uma destas equações tem parâmetros que apresentam incertezas para se determinar.

No caso do modelo ASE, apresentado na seção 4.2.2, um dos parâmetros que não apresentam um método estimação definido é o ponto de referência para a integração dos esforços potenciais, $x^{*}$. Segundo Barros et al. ${ }^{[20]}$, este ponto representa a cota no eixo longitudinal do casco em que o escoamento adiante não apresenta mais características potenciais, estando vinculado ao descolamento da camada limite e o predomínio dos efeitos viscosos como a alta vorticidade. Apesar de Fink ${ }^{[122]}$ apresentar uma relação empírica para o cálculo deste ponto, eq. (4.22), Barros et al. ${ }^{[20]}$ mostrou que esta relação não apresenta um estimativa realista para o caso de geometrias como a do AUV Pirajuba. Com o CFD, foi possível estimar com melhor exatidão a posição de tal sítio, e verificar que esta posição não sofre influência do ângulo de incidência.

Contudo, não existem trabalhos na literatura que abordam a relação do ponto $x^{*}$ com a velocidade angular. Isto indica que este parâmetro apresenta uma grande incerteza, que pode ser traduzida a uma incerteza nas integrais dos esforços hidrodinâmicos. Esta influência foi analisada pela variação da posição do ponto de integração para os limites teóricos máximos e mínimos, que equivalem, respectivamente, a integração total do corpo e ao ponto calculado pela formula de Hopkins ${ }^{[139]}$, equação 4.22 , que estima um valor muito menor do que estimado pelo $\mathrm{CFD}^{[20]}$.

Considerando esta incerteza, as integrais dos termos potencias da força e do momento são reduzidas às equações

$$
\begin{aligned}
F_{P} & =\int_{0}^{x^{*}}\left(\pi r(x)^{2} \frac{\mathrm{d} \alpha}{\mathrm{d} x}(-1 / 2 \sin (2 \alpha(x)) \sin (\alpha(x) / 2)+2 \cos (\alpha(x) / 2) \cos (2 \alpha(x)))\right. \\
+ & \left.2 \pi r(x) \frac{\mathrm{d} r}{\mathrm{~d} x} \sin (2 \alpha(x)) \cos (\alpha(x) / 2)\right) \cdot \mathrm{d} x \mathrm{e} \\
M_{P}= & \int_{0}^{x^{*}}\left(\pi r(x)^{2} \frac{\mathrm{d} \alpha}{\mathrm{d} x}(-1 / 2 \sin (2 \alpha(x)) \sin (\alpha(x) / 2)+2 \cos (\alpha(x) / 2) \cos (2 \alpha(x)))\right. \\
+ & \left.2 \pi r(x) \frac{\mathrm{d} r}{\mathrm{~d} x} \sin (2 \alpha(x)) \cos (\alpha(x) / 2)\right) \cdot\left(x_{m}-x\right) \cdot \mathrm{d} x
\end{aligned}
$$

respectivamente, $x_{m}$ é ponto de referência para o momento, $r(x)$ é o raio do corpo na posição $x, \alpha(x)$ é o ângulo de ataque local definido por

$$
\alpha(x)=\alpha_{\infty}-q\left(x_{m}-x\right)
$$

$\alpha_{\infty}$ é o ângulo de incidência estático, $q$ a velocidade angular, e $\mathrm{d} \alpha / \mathrm{d} x$ é a derivada do ângulo de incidência local, que é igual a $q$.

No caso do equacionamento viscoso, em que a integral é realizada em todo o corpo, a incerteza fica restrita ao coeficiente de arrasto cruzado de um cilindro infinito, $C_{d_{n}}$. 


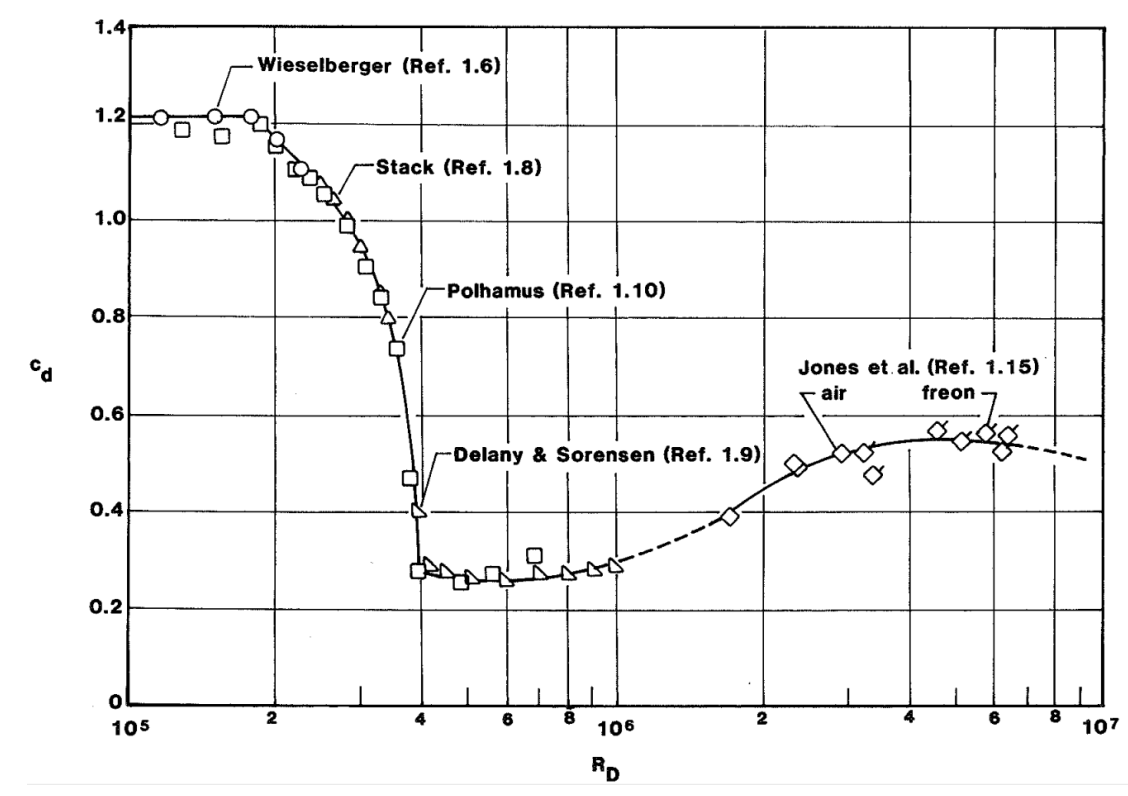

Figura 74 - Coeficiente de arrasto para cilindros circulares lisos em regime subsônico (FONTE: ${ }^{[180]}$ )

Em um escoamento subsônico, o valor de $C_{d_{n}}$ é definido apenas em função do numero de Reynolds do escoamento paralelo à seção circular do corpo (perpendicular ao eixo do corpo ${ }^{[180,121]}$, conforme apresentado na figura 74 . Considerando apenas a influência do ângulo de incidência, o número de Reynolds em cada seção do corpo indica que o escoamento é laminar $\left(R e \leq 2 \cdot 10^{5}\right)$, resultando em um valor de $C_{d_{n}}$ constante. Contudo, ao considerar a incidência do escoamento junto a um alto movimento de rotação, podem ser geradas altas velocidade nas extremidades do corpo que reduzem o valor deste coeficiente.

Para o cálculo da incerteza da parcela viscosa, serão considerados casos extremos em que o nariz ou a cauda do corpo são submetidos à altas velocidades, devido ao movimento angular, gerando a transição do escoamento local de laminar para o turbulento $\left(R e \geq 2 \cdot 10^{5}\right)$. Este procedimento resulta em um $C_{d_{n}}$ local médio igual a 1.0 onde ocorre a transição, enquanto no restante do corpo seria igual a 1.2. Com este modelo de incerteza, as integrais dos termos viscosos da força e do momento são definidas, respectivamente, por

$$
\begin{aligned}
F_{V} & =\int_{0}^{L} C_{d_{n}}(x) \cdot r(x) \sin (\alpha x)^{2} \cdot \mathrm{d} x \mathrm{e} \\
M_{V} & =\int_{0}^{L} C_{d_{n}}(x) \cdot r(x) \sin (\alpha x)^{2} \cdot\left(x_{m}-x\right) \cdot \mathrm{d} x .
\end{aligned}
$$

Utilizando estas equações o erro percentual deveria ter sido calculado em relação aos parâmetros nominais do modelo ASE do Pirajuba. Entretanto, para certas combinações de ângulo de incidência e velocidade de rotação, as integrais de força e/ou momento do modelo nominal apresentam valores próximos de zero, resultando em um alto erro percentual que não representa os erros de outras condições. Para melhor representar a magnitude destas incertezas estes erros foram normalizados em relação ao maior valor das integrais, evitando 
a singularidade.

Os gráficos dos erros máximos e mínimos, para os termos potencias, viscosos e totais, da força e do momento são apresentados na figura 75 .

Estes gráficos mostram que os erros dos termos viscosos são muito inferiores aos erros dos termos potenciais, indicando que o ponto em que o escoamento deixa de ser potencial, $x^{*}$ gera uma maior incerteza do que o coeficiente de arrasto cruzado, $C_{d_{n}}$. Considerando a soma de ambos os termos (esforços totais), a força e o momento apresentaram uma incerteza máxima de $20 \%$ e $25 \%$, respectivamente.

Apesar das incertezas encontradas pela normalização representarem bem as incertezas das integrais que apresentam altos valores, não é garantido que estas incertezas representem os possíveis erros das demais regiões. Como alternativa, é possível utilizar os resultados das simulações em condições estáticas para verificar a incerteza destes casos, pois os casos de CFD estáticos foram resolvidos com o mesmo modelo numérico e uma malha bastante similar, apresentando uma baixa incerteza quando comparado aos resultados experimentais.

Esta suposição pode ser aplicada, pois estas regiões são representadas por baixos valores de ângulo de incidência e de velocidade de rotação, resultando em escoamentos "comportados", i.e., que não apresentam grandes descolamentos ou vorticidades ${ }^{6}$, que se assemelham aos escoamentos encontrados nas simulações estáticas de baixos ângulos de incidência.

Para corroborar com o argumento que os escoamentos nas condições estáticas e dinâmicas são similares, nas figuras 76 e 77 são realizadas as comparações das linhas de escoamentos em diversas condições. Por utilizar apenas as linhas de escoamento, este tipo de análise não é propício para verificar as características turbulentas da parcela viscosa do escoamento, servindo apenas para verificar a parcela potencial. Entretanto, como apresentado na figura 75, a parcela viscosa apresenta uma incerteza muito menor do que a parcela potencial, não devendo prejudicar a análise.

Na figura 76 é apresentado o escoamento sobre o corpo para diferentes velocidades angulares com o ângulo de incidência nulo. Esta figura demonstra que com o aumento da velocidade angular os escoamentos sobre o nariz e o corpo paralelo permanecem bastante similares aos casos estáticos, apresentando as mesmas características fluidodinâmicas. Já na cauda, a região de inversão do fluxo do escoamento (representada pela região em azul), que corresponde ao descolamento da camada limite, não apresenta modificações significativas. Estas observações indicam que as características potenciais do escoamento em condições dinâmicas são similares aos casos estáticos, tendo um incerteza similar.

Na figura 77 esta análise é estendida ao comparar os efeitos combinados do ângulo de

$\overline{6}$ Comumente denominado na literatura internacional de attached flow. 

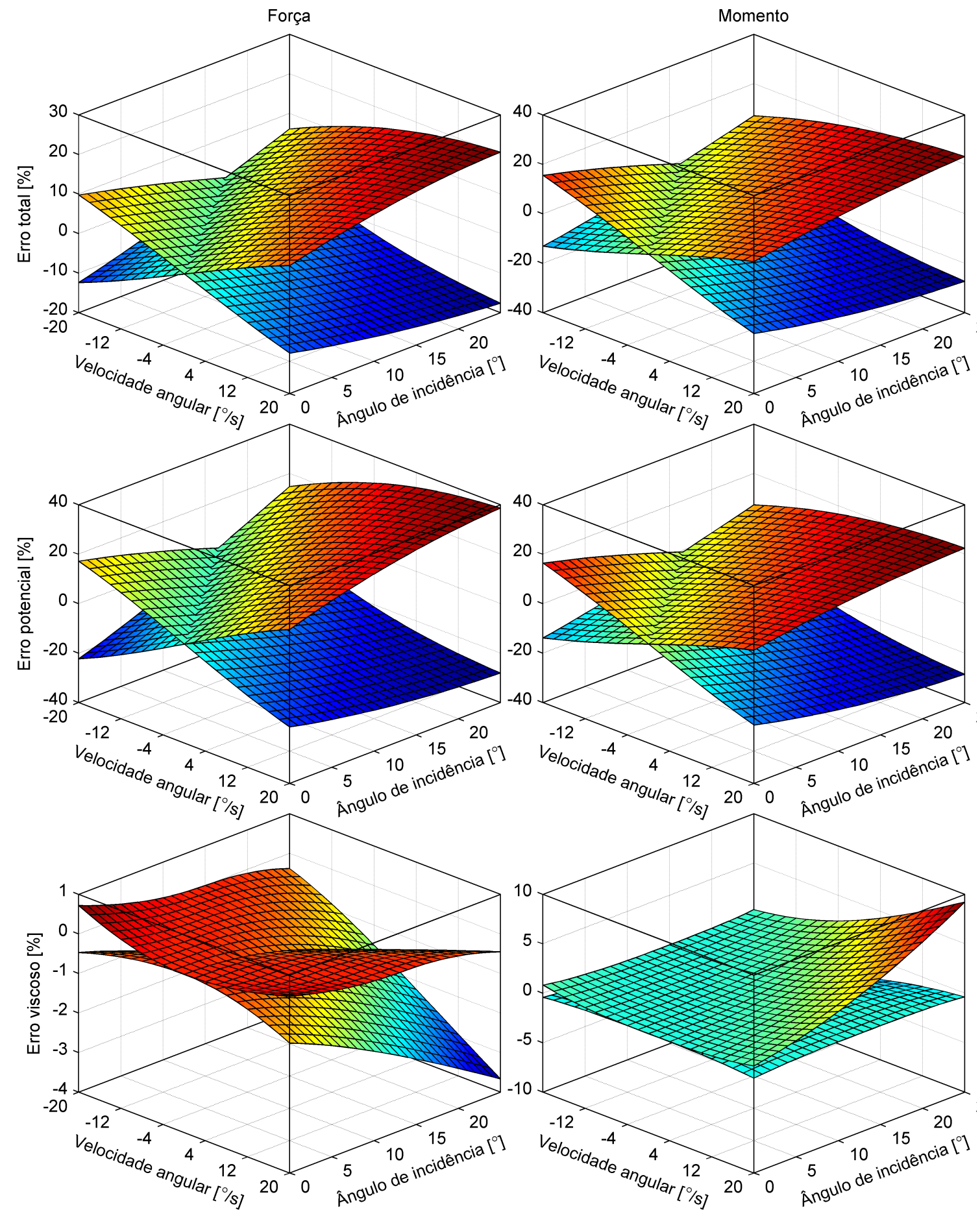

Figura 75 - Erros máximos e mínimos dos termos potenciais, viscosos e totais (soma), para o caso da força e do momento, normalizados pelo maior valor de cada caso 


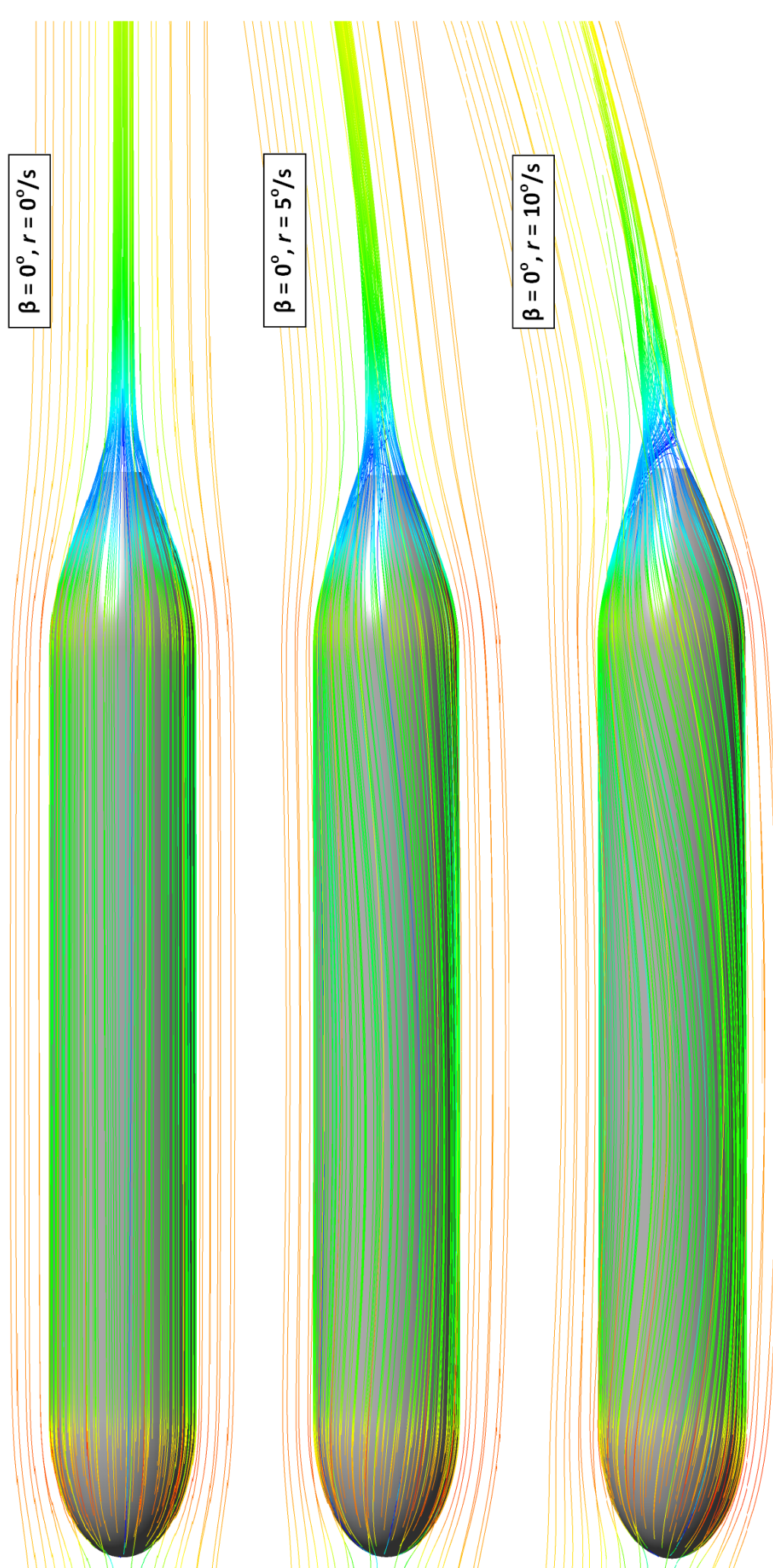

$\stackrel{0}{\circ}$

II

$\infty$

$\stackrel{\circ}{3}$

曔

응

$\stackrel{\circ}{\sigma_{0}}$

«ีี

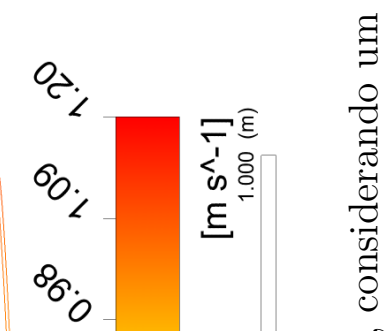

r. 管 空

$\vartheta$

$\Delta_{0}$

s.

0

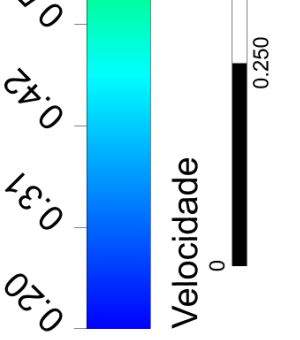

0
0
0
0
0
0
0
0
0
0
0
0
0
0

$\frac{1}{0}$

울

屯ำ

ن

ช

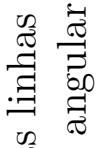

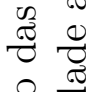

, శ.

कृ

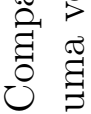

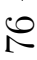

$\underset{3}{.00}$ 


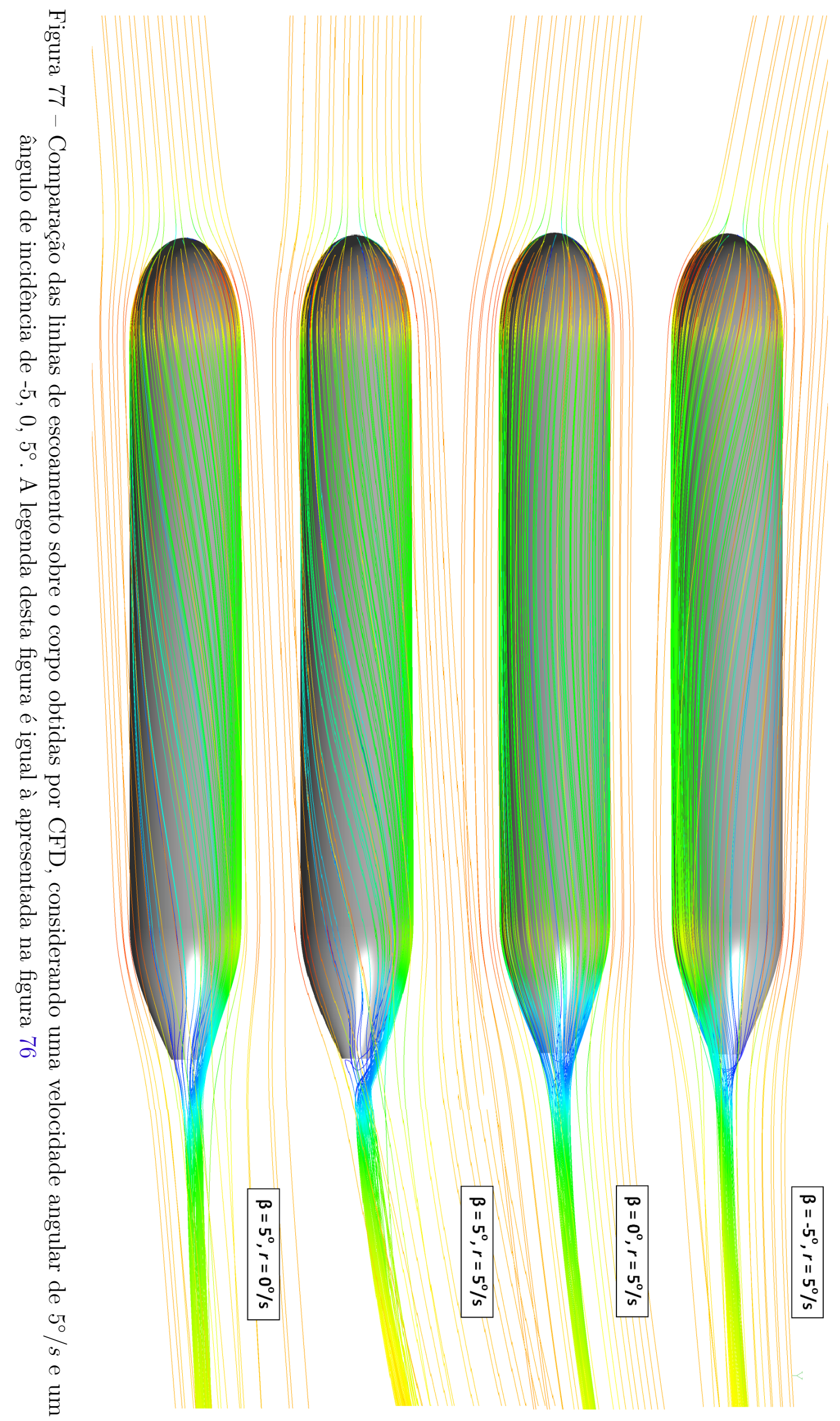


incidência e velocidade de rotação. Pelos escoamentos terem apresentados comportamentos similares, as conclusões obtidas por esta figura são as mesmas das obtidas no caso anterior, visto na figura 76.

Considerando ambos resultados, pode-se afirmar que os escoamentos estáticos e dinâmicos são bastante similares para os casos em que o escoamento sobre grande parte do corpo se mantem predominantemente potencial, sem apresentar grandes descolamentos ou vorticidades na lateral do corpo paralelo, e a região de descolamento da cauda não apresente modificações significativas. Desta forma, para estas combinações de incidência e velocidade de rotação, a incerteza para os esforços hidrodinâmicos do corpo podem ser consideradas iguais aos casos estáticos.

De forma a normalizar as incertezas das diferentes combinações de ângulo de incidência e velocidade de rotação e simplificar a análise de sensibilidade, será adotada uma abordagem conservadora em que a incerteza utilizada será igual à encontrada no pior caso desta análise. Desta forma, para os esforços hidrodinâmicos dinâmicos, será adotada

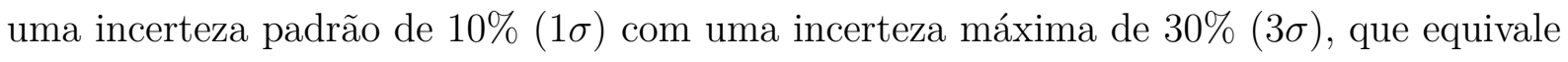
às incertezas dos esforços hidrodinâmicos obtidos pelo CFD para o caso estático.

Esta incerteza padrão está de acordo com a incerteza assumida na análise de sensibilidade dos esforços hidrodinâmicos de navios do trabalho de Toxopeus ${ }^{[23]}$, demonstrando que mesmo ao considerar estas simplificações o valor obtido não esta longe do aplicado na literatura.

No caso do leme, pode ser adotado que as incertezas das simulações de CFD dinâmicas são similares as incertezas encontradas nas simulações estáticas. Esta suposição é valida, pois como o leme se encontra a uma distância significativa do centro de rotação do veículo, e os esforços hidrodinâmicos gerados pelo ângulo de incidência local (ângulo efetivo 'enxergado' pelo leme) são mais significativos do que os esforços gerados pela rotação em seu próprio eixo ${ }^{[144]}$, tornando o efeito de rotação em seu próprio eixo desprezível.

Assim, pode ser considerado que os escoamentos sobre o leme reproduzidos pelas simulações de CFD dinâmicas apresentam os mesmos fenômenos hidrodinâmicos observados nas simulações estáticas, como o estol e geração de vórtices. Esta similaridade implica em uma incerteza equivalente entre os dois tipos de simulações, e portanto, para o caso do leme sozinho será adotada uma incerteza padrão de $10 \%(1 \sigma)$ e uma incerteza máximo de $30 \%(3 \sigma)$, que equivale ao modelamento do estol.

O caso da combinação corpo e leme pode ser analisado ao separar a contribuição do corpo sozinho e do leme em conjunto com a interferência, de maneira similar aos modelos de manobra CFD e ASE. Pelas incertezas do corpo e do leme isolados já terem sido estimadas, somente é necessário estimar a incerteza da interferência, i.e., a incerteza gerada pela presença do leme e do corpo, em função da velocidade angular. 
Diferentemente dos casos isolados, a incerteza da interferência dinâmica não pode ser diretamente estimada por métodos ASE ou pela similaridade das simulações de CFD estáticas. Contudo, pela a análise dos modelos não lineares estáticos dos coeficientes de interferência de Moore, McInville e Hymer ${ }^{[147]}$ e Burns e Bruns ${ }^{[135]}$, é observado que com o aumento do ângulo de incidência os coeficientes de interferência diminuem. Este comportamento indica que com o aumento do ângulo local gerado pela velocidade de rotação os coeficientes de interferência são reduzidos. Ou seja, ao considerar a suposição que o efeito da velocidade de rotação apenas afeta o ângulo de incidência local do leme, pode ser considerado que o efeito da velocidade de rotação é apenas a diminuição dos coeficientes de interferência.

Adotando este comportamento para os coeficientes de interferência, pode ser considerado que o pior caso de incerteza ocorreria para os valores mais altos dos coeficientes de interferência, i.e., para baixos ângulos de incidência local na região do leme. Para estes casos, por definição do ângulo de incidência local, o escoamento na região do leme é bastante semelhante aos encontrados nos casos estáticos de baixos ângulos de incidência, resultando em uma incerteza similar a estes casos.

Portanto, sendo conservador, o pior caso pode ser extrapolado para todas as combinações de incidência e velocidade de rotação, resultando em uma incerteza padrão de $10 \%(1 \sigma)$ para o caso dinâmico da combinação corpo e leme, sendo similar aos demais casos dinâmicos.

\subsubsection{Método de cálculo dos coeficientes de sensibilidade e incerteza paramétrica}

Os coeficientes de sensibilidade $\left(\partial S / \partial X_{i}\right)$ relacionam a variação de algum parâmetro observado $(S)$, como a característica de uma manobra, em relação a variação de um dos parâmetros do modelo numérico em análise $\left(X_{i}\right)^{[33]}$. Além de servir para realizar a estimativa da incerteza paramétrica, os coeficientes de sensibilidade podem ser utilizados para investigar quais parâmetros do modelo apresentam uma maior sensibilidade para alguma característica de manobra. Este tipo de informação pode ser utilizado para indicar quais parâmetros devem ser obtidos com maior precisão, para que seja reduzida a incerteza numérica da análise das características de manobra.

Como os parâmetros de um modelo podem apresentar diferentes magnitudes, é mais interessante utilizar o coeficiente de sensibilidade escalado ${ }^{[33]}, \bar{X}_{i} \partial S / \partial X_{i}$, onde $\bar{X}_{i}$ é o valor nominal do parâmetro de análise. A vantagem de utilizar este coeficiente ao invés do original, é que a unidade dos coeficientes de sensibilidade de uma mesma característica de manobra em análise fica padronizada, permitindo a comparação direta entre os coeficientes.

Existem diversas formas de realizar o cálculo do coeficiente de sensibilidade. Para modelos complexos e não lineares, como é o caso das equações de movimento de AUV utilizadas, é mais conveniente realizar este cálculo por diferenças finitass ${ }^{[33]}$. Para reduzir as 
incertezas numéricas, o coeficiente de sensibilidade foi calculado pela fórmula das diferenças centrais,

$$
\begin{array}{r}
\frac{\partial S}{\partial X_{i}}=\frac{S\left(X_{1}, \cdots, X_{i}+\Delta X_{i}, \cdots, X_{n}\right)-S\left(X_{1}, \cdots, X_{i}-\Delta X_{i}, \cdots, X_{n}\right)}{2 \Delta X_{i}} \\
+O\left(\Delta X_{i}^{2}\right)
\end{array}
$$

que possui um erro numérico $(O)$ da ordem da variação ao quadrado do parâmetro utilizado $\left(\Delta X_{i}^{2}\right)$.

Utilizando esta definição, a incerteza paramétrica $\left(u_{\text {par }}\right)$ de um parâmetro $S$ obtido pela simulação de movimento do AUV, pode ser obtida pela média geométrica do produto dos coeficientes de sensibilidade pela incerteza paramétrica de todos os $n$ parâmetros do modelo. Na equação 6.22 é apresentada a fórmula para o cálculo da incerteza paramétrica utilizando o coeficiente de sensibilidade, e o coeficiente de sensibilidade escalado.

$$
u_{\text {par }}^{2}=\sum_{i=1}^{n}\left(\frac{\partial S}{\partial X_{i}} u_{X_{i}}\right)^{2}=\sum_{i=1}^{n}\left(\bar{X}_{i} \frac{\partial S}{\partial X_{i}} \frac{u_{X_{i}}}{\bar{X}_{i}}\right)^{2}
$$

No estudo do movimento do AUV, os coeficientes de sensibilidade escalados serão calculados para os diversos parâmetros apresentados na tabela 17, considerando as quatro deflexões de leme em ambos os tipos de manobra. As incertezas paramétricas serão calculadas para os conjuntos de incerteza isolados, e para todos os parâmetros, verificando a contribuição da incerteza paramétrica de cada conjunto de parâmetros na incerteza total.

As incertezas do conjunto inercial $\left(u_{\text {Inercial }}\right)$ e de massa adicional $\left(u_{\text {M adi }}\right)$ podem ser calculadas pela simples aplicação da equação 6.22 a todos os seus respectivos parâmetros. Para os demais esforços hidrodinâmicos se o cálculo de incerteza fosse realizado da mesma forma haveria uma sobreposição de incertezas, pois para cada parte do AUV foram consideradas dois modelos de incertezas distintos, um para o ganho nas variáveis e outro para o ganho nos esforços. Desta forma a incerteza de cada parte do veículo $\left(u_{\text {parte }}\right)$, onde parte pode ser interpretada como corpo, leme e combinação (corpo com os lemes), possui dois possíveis valores

$$
u_{\text {parte }}^{2}=\left\{\begin{array}{l}
u_{\text {Esforço }}^{2} \\
u_{\text {Variáveis }}^{2}
\end{array}\right.
$$

onde $u_{\text {Esforço }}$ é a incerteza devido ao ganho aplicado aos esforços (forças e momento), e $u_{\text {Variáveis }}$ é a incerteza devido ao ganho aplicado as variáveis de entrada (velocidade lateral, velocidade angular e deflexão do leme).

Mesmo com esta consideração, também é necessário selecionar como deve ser feita a consideração entre as diferentes partes do veículo, ou seja, se a incerteza deve ser considerada pela soma quadrática das incertezas do corpo $\left(u_{\text {Corpo }}\right)$ e do leme $\left(u_{\text {Leme }}\right)$ 
ou pela soma das incertezas da combinação $\left(u_{C o m b}\right)$. Assim, a incerteza dos esforços hidrodinâmicos também é definida por dois possíveis parâmetros,

$$
u_{\text {Hidro }}^{2}=\left\{\begin{array}{l}
u_{\text {Corpo }}^{2}+u_{\text {Leme }}^{2} \\
u_{\text {Comb }}^{2}
\end{array}\right.
$$

sendo que cada uma das incertezas das partes podem obter os dois valores possíveis apresentados na equação 6.23 .

Tendo definido a forma de cálculo das três incertezas, a incerteza paramétrica total $\left(u_{\text {par }}{ }_{\text {Total }}\right)$ pode ser calculada por

$$
u_{\text {par } T \text { total }}^{2}=u_{\text {Inercial }}^{2}+u_{M a d i}^{2}+u_{\text {Hidro }}^{2}
$$

que possui seis possíveis valores distintos. Esta equação pode ser representada utilizando uma notação binomial, onde cada possível valor de uma variável é representada por diferentes linhas em um binômio. Com esta notação a equação 6.25 é reescrita por:

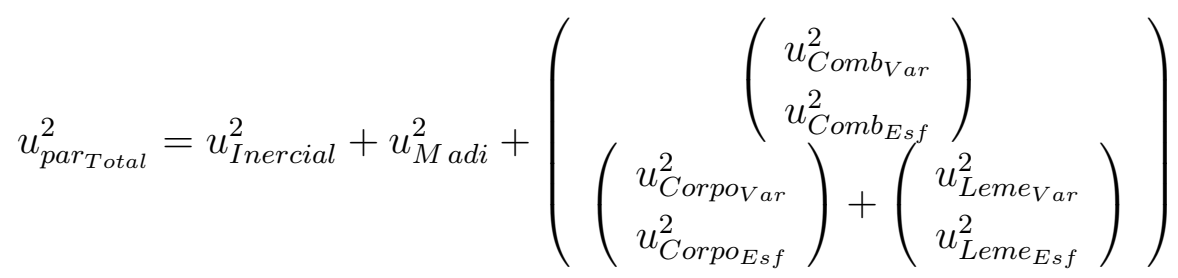

Ao invés de apresentar os seis valores possíveis da incerteza paramétrica total, em todos os casos serão apresentados os valores mínimos e máximos possíveis.

\subsubsection{Metodologia de validação dos resultados do simulador}

Como comentado anteriormente, a validação do simulador e dos modelos hidrodinâmicos ASE e CFD serão realizadas pela validação das características de manobra obtidas por estes modelos em função dos resultados experimentais. O procedimento desta validação é baseada na norma ASME ${ }^{[33]}$, apresentada na seção 3.5.2, onde considera-se que uma característica da manobra simulada $(S)$ está validada quando o erro em relação à mesma característica de manobra obtida experimentalmente $(E)$ é menor do que a incerteza de validação $\left(U_{\text {Val }}\right)$, i.e.,

$$
|E|=|S-D|<U_{V a l}
$$

Sendo que está validação é adequada apenas para um intervalo de confiança definido por esta incerteza, i.e., $\left[E-U_{V a l}, E+U_{V a l}\right]$.

A incerteza de validação é obtida pela combinação da incerteza experimental $\left(U_{E x p}\right)$, numérica $\left(U_{N u m}\right)$ e paramétrica $\left(U_{P a r}\right)$. Matematicamente, está incerteza é calculada pela raiz quadrada da soma dos quadrados de cada incerteza, i.e.,

$$
U_{\text {Val }}^{2}=U_{E x p}^{2}+U_{N u m}^{2}+U_{P a r}^{2} .
$$


Diferente do caso da validação dos esforços hidrodinâmicos do CFD, neste caso, o erro numérico é insignificativo, por apresentar uma ordem de grandeza inferior aos demais erros. Desta forma, a incerteza de validação é calculada apenas pelas incertezas experimentais e paramétricas. No caso do simulador, este erro depende dos erros numéricos da discretização do tempo da simulação, da função de integração de Runge-Kutta, e da interpolação das tabelas de esforços hidrodinâmicos (somente no modelo de CFD). O erro de truncamento não foi considerado, pois os cálculos das simulações foram realizadas utilizando números de ponto flutuante com precisão dupla.

Para verificar a ordem de grandeza do erro numérico, foram realizadas diversas simulações variando-se os parâmetros de simulação considerados. Nas simulações finais, os parâmetros foram selecionados de forma à apresentar uma diferença menor que de $10^{-6}$ nas características de manobra, ao dobrar as discretizações ou aumentar ordem das equações de integração. Este critério estabeleceu que a discretização do período de integração fosse equivalente à $100 \mathrm{~Hz}$ (0.01 s), utilizando uma função de Runge-Kutta de quarta ordem e considerando que as tabelas de interpolação fossem discretizadas por pelo menos 200 pontos.

\subsubsection{Análise de sensibilidade e validação da manobra de giro}

A análise de sensibilidade foi realizada considerando as quatro deflexões de leme utilizadas no experimento (5, 10, 15 e 20 graus), com as variações base dos parâmetros apresentados na tabela 17. Para melhor evidenciar os efeitos não lineares nas variações destes parâmetros, a análise é realizada considerando um ganho de sensibilidade múltiplo de 1, 2 e 3 dos valores base, sempre considerando os ganhos positivos e negativos. Desta forma, ao final da análise, cada parâmetro foi variado seis vezes.

Devido ao elevado número de parâmetros selecionados para esta análise, nesta seção, somente serão apresentados os gráficos de respostas e as tabelas de características dos seis parâmetros que apresentaram as maiores variações no tempo de subida e no valor de regime permanente, em relação à resposta dinâmica do modelo numérico nominal.

Os parâmetros de inércia que mais influenciaram as respostas das manobras de giro, foram a posição do centro de gravidade (CG) e a velocidade de cruzeiro. Nos casos dos parâmetros relativos aos esforços hidrodinâmicos, foram os ganhos nas variáveis de movimento do ângulo de deriva (relativa à velocidade de deriva, $v$ ) do leme e do corpo, da deflexão do leme $(\delta)$, e da combinação da velocidade angular de rumo $(r)$. Os gráficos da resposta dinâmica da análise de sensibilidade destes seis parâmetros são apresentados na figura 78, enquanto que na tabela 20 são apresentadas as variações no tempo de subida e do valor da taxa de rumo no regime permanente em relação ao modelo nominal.

O ganho na variável da velocidade angular da combinação contempla os ganhos nas variáveis das partes separadas, que também apresentaram uma variação significativa 

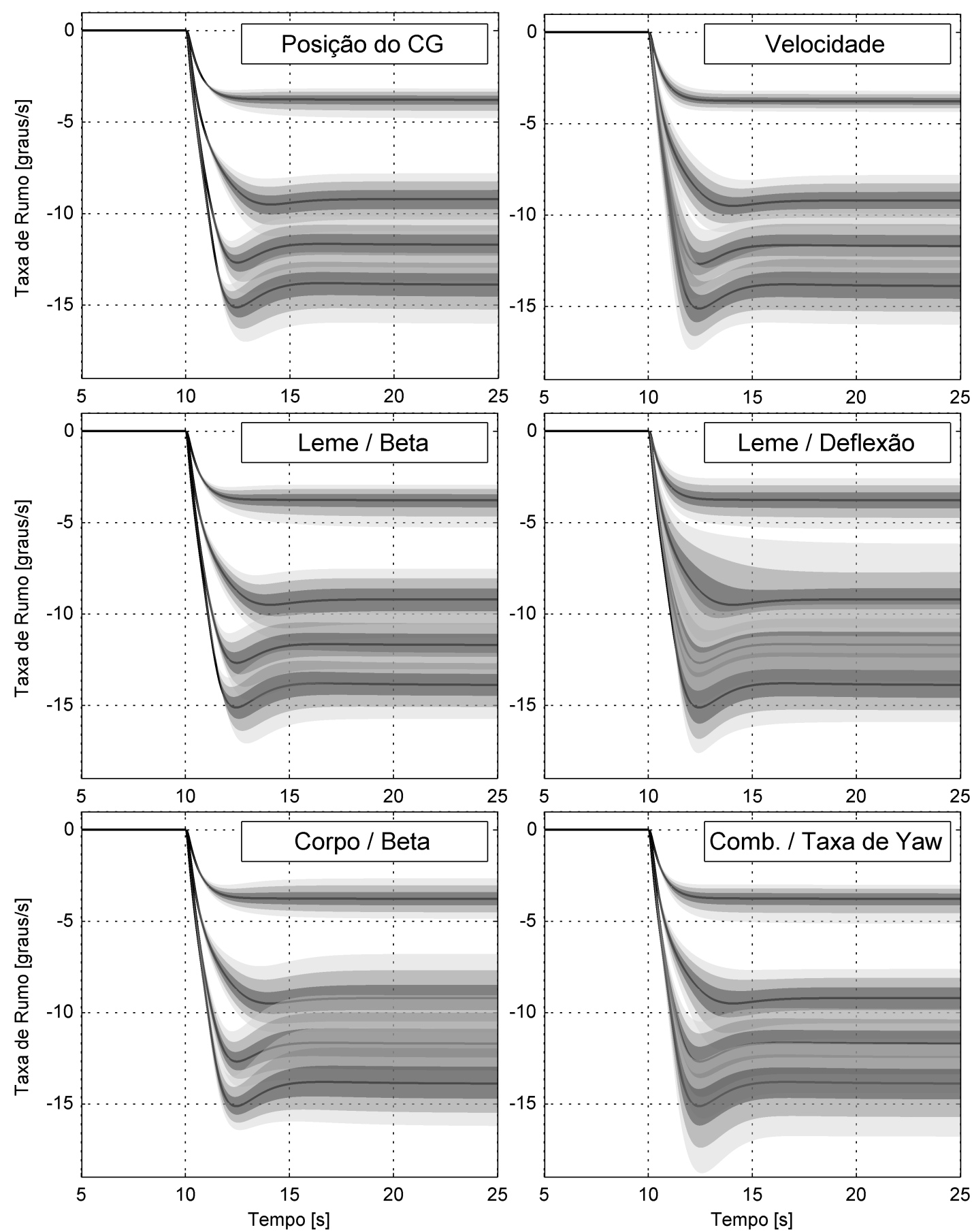

Figura 78 - Resultados da resposta dinâmica da manobra de giro para a análise de sensibilidade dos parâmetros mais significativos, utilizando os modelos do simulador com os parâmetros do CFD para deflexões do leme de 5, 10, 15 e 20 graus. Os ganhos de sensibilidade utilizados são apresentados na tabela 17 multiplicados por 1, 2 e 3, que são apresentados pelas regiões cinza ao redor dos sinais do modelo nominal (linha preta) 
Tabela 20 - Análise de sensibilidade dos parâmetros mais significativos para as manobras de giro com as quatro deflexões do leme, considerando a variação de 1, 2 e 3 vezes o valor dos parâmetros apresentados na tabela 17

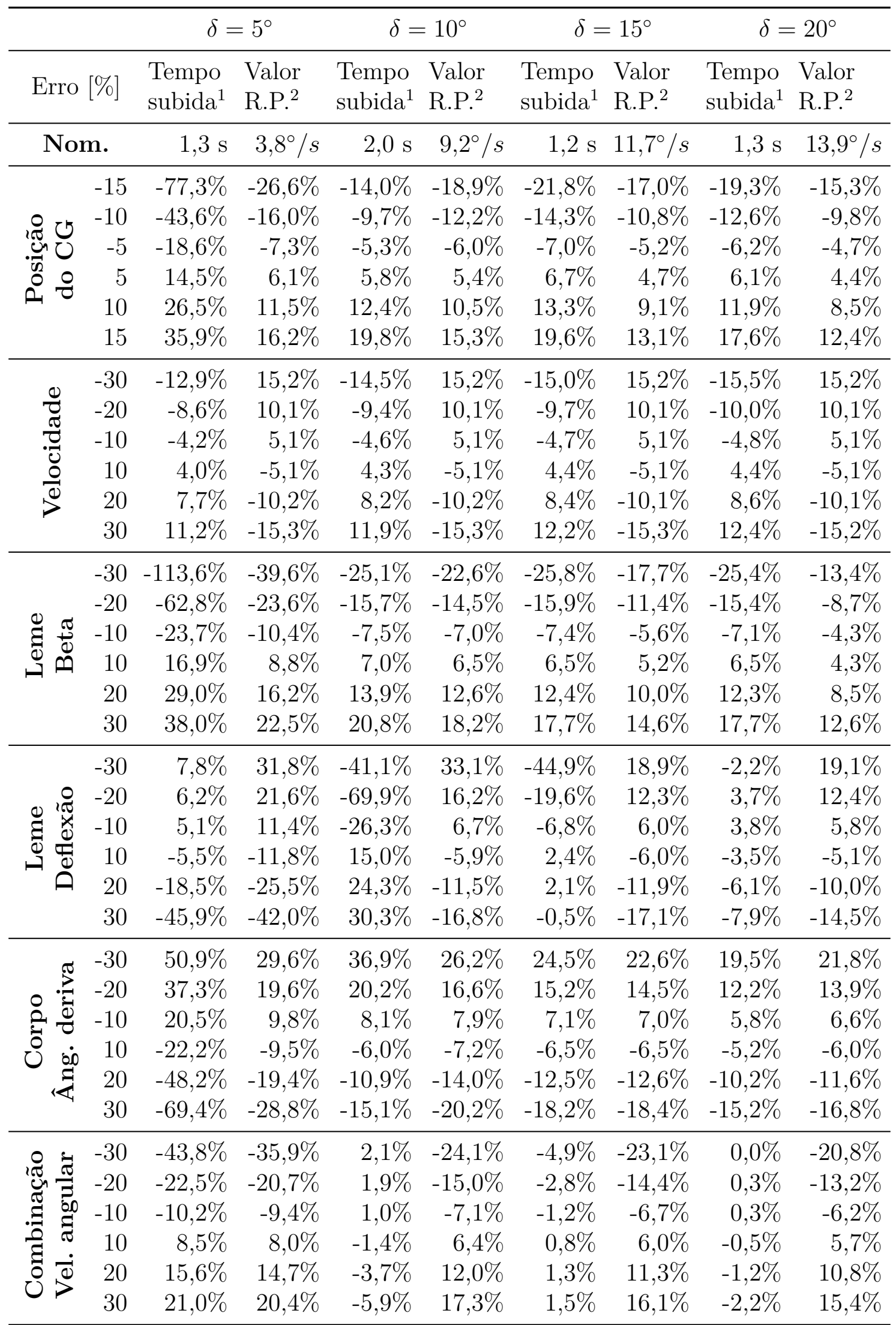

$1 \overline{\text { Definido como o período que a resposta apresenta } 90 \% \text { do valor de regime } /{ }^{2} \text { Regime Permanente }}$ 
na resposta dinâmica de giro. No entanto, no caso da variável de velocidade de deriva isto não ocorreu, pois o ganho de uma parte cancela o ganho da outra, por gerarem momentos no sentido oposto, ou seja, enquanto o corpo gera um esforço que desestabiliza o leme gera o esforço de estabilização.

Como esperado, pela análise das equações simplificadas do movimento de giro, apresentas no apêndice C, os parâmetros de massa adicional, inércia e força axial (todos os casos), somente apresentaram uma pequena modificação no regime transiente da resposta à deflexão do leme, e uma variação pouco significativa ao valor no regime permanente. Do ponto de vista da força axial, este resultado indica que uma variação na resistência do veículo impacta muito menos do que uma variação na velocidade, mesmo sendo uma variação percentualmente igual.

Os parâmetros de sensibilidade da força lateral do corpo e do leme também apresentaram uma variação baixa, mas ao considerar os dois simultaneamente (combinação) a variação foi significativa. Da mesma forma que o ângulo de deriva, o momento de rumo (eixo Z) apresentou uma variação pouco significativa para esta análise de sensibilidade.

Os parâmetros que apresentaram variações significativas na resposta dinâmica da manobra de giro foram (usando a ordem apresentada na tabela 17): massa, posição do CG, velocidade, velocidade de deriva do corpo, velocidade angular do corpo, momento de rumo do corpo, ângulo de deriva do leme, velocidade angular do leme, deflexão do leme, momento de rumo do leme, velocidade angular da combinação, e a força lateral da combinação.

Tanto pela figura 78 quanto pela tabela 20, é possível observar que uma variações linear nos parâmetros representam uma variação não linear na resposta dinâmica do AUV, e consequentemente nas características das manobras. Esta não linearidade é composta tanto por uma assimetria nas características das respostas para variações positivas e negativas, i.e., as características de manobras são diferentes para o caso positivo e negativo, quanto pela não linearidade gerada por variações sucessíveis dos parâmetros. Esta grande influência da não linearidade pode afetar significativamente o cálculo dos coeficientes de sensibilidade, pois o erro quadrático neste coeficiente, visto na equação (6.21), pode apresentar uma ordem de grandeza similar à sua própria, influenciando na estimativa da incerteza paramétrica.

Da mesma forma da análise de sensibilidade, no apêndice G são apresentados todos os cálculos dos coeficientes de sensibilidade, enquanto que na tabela 21 são apresentados estes cálculos para os mesmos coeficientes analisados na tabela 20. Por esta tabela, é verificado que na maioria dos casos, a variação do CG (centro de gravidade) apresenta o maior coeficiente de sensibilidade escalado. Contudo, os demais coeficientes desta tabela também apresentaram altos valores de sensibilidade, demonstrando que estes coeficientes influenciam bastante o movimento da manobra de giro. 


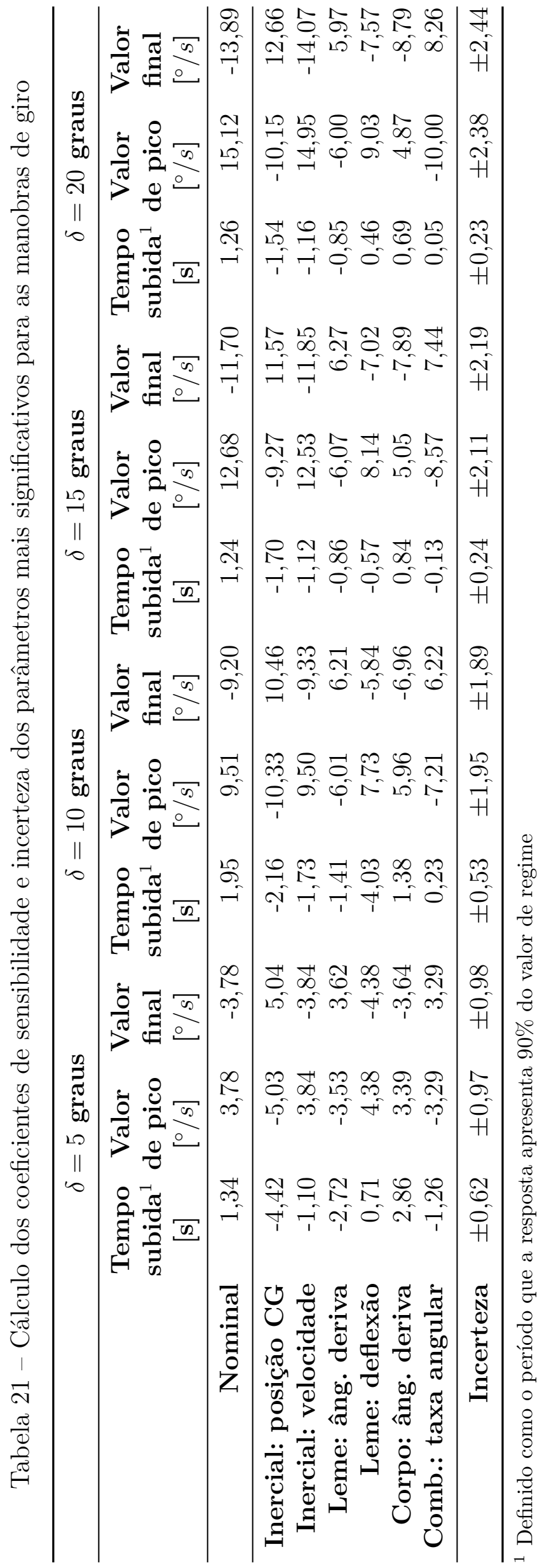


Estes coeficientes também indicam que pode ocorrer uma sobreposição dos efeitos de variações destes parâmetros, ou seja, um sistema que apresente erros em dois ou mais parâmetros podem ter o mesmo comportamento de um sistema sem erros.

Apesar da tabela 21 apresentar os valores da incerteza paramétrica, estes valores são apenas de referência, servindo para verificar as grandezas envolvidas neste tipo de incerteza, pois o cálculo correto deve envolver todos os parâmetros conforme a metodologia apresentada em 6.4.3.3. Junto aos coeficientes de sensibilidade, no apêndice G são apresentados os valores destas incertezas para cada um dos tipos de esforços considerados.

O resumo deste cálculo é apresentado na tabela 22, onde é possível realizar a comparação das diferentes incertezas paramétricas. Nesta tabela, as incertezas de cada uma das partes (corpo, leme e combinação) são divididas nas incertezas que são aplicadas as variáveis de entrada das funções hidrodinâmicas ou diretamente aos esforços, conforme apresentado na seção 6.4.3.3. Ao final desta tabela, também são apresentados os valores máximos e mínimos para as incertezas paramétricas destas características, segundo o modelo de cálculo apresentado na seção 6.4.3.3.

Com a definição das incertezas paramétricas, foi aplicada a metodologia de validação apresentada na seção 6.4.3.4, para os dois modelos numéricos considerados. Os resultados desta metodologia são apresentados na tabela 23 para três características da manobra de giro. Nesta tabela são apresentados os valores experimentais $(D)$ e numéricos $(S)$ considerados, os seus erros $(E)$, e as incertezas de validação consideradas.

Além de considerar no cálculo de validação as incertezas máximas e mínimas, apresentadas na tabela 22, também foi realizado o cálculo da incerteza de validação considerando apenas as incertezas paramétricas inerciais e de massa adicional, com a incerteza experimental. Este último caso foi adotado, pois uma eventual validação do modelo de manobra em relação a esta incerteza indicaria que as incertezas estimadas pelos métodos apresentados na seção 6.4.3.2 são muito conservadoras, e os parâmetros hidrodinâmicos do modelo de manobra foram bem determinados.

Pela tabela 23, é observado que para a deflexão de 5 graus do modelo de CFD o intervalo de confiança gerado pelas suas incertezas de validação padrão dos parâmetros inerciais e de massa adicional são suficientes para englobar o erro do modelo. No mesmo caso do modelo ASE, este tipo de incerteza apenas consegue validar o tempo de subida, sendo que as demais características são validadas quando são consideradas as demais incertezas dos parâmetro hidrodinâmicos ou um múltiplo da incerteza de validação, equivalente a $2 \sigma$ (95\%). Isso indica que o modelo hidrodinâmico CFD está bem validado para as condições lineares, enquanto o modelo ASE apresenta um erro maior.

No caso de 10 graus a situação se inverte, com o modelo ASE tendo um resultado melhor que o CFD. Neste caso, o modelo ASE é validado pela condição de incerteza 


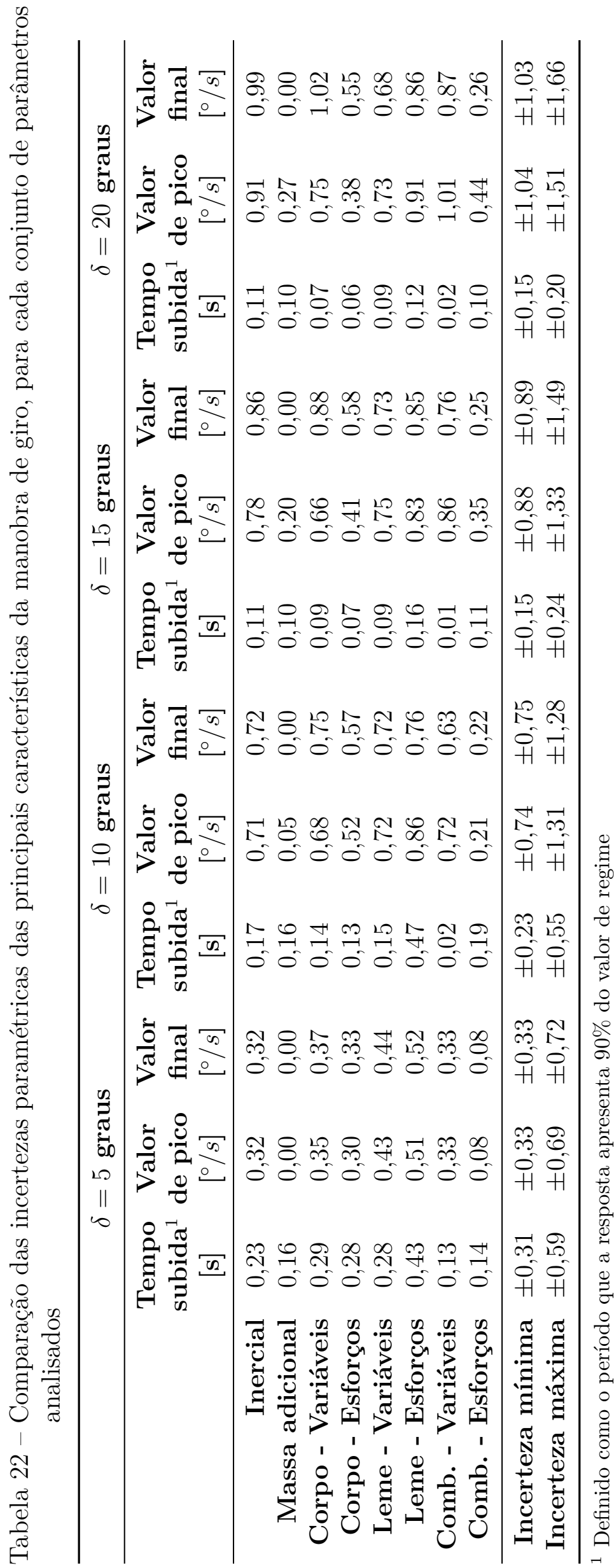




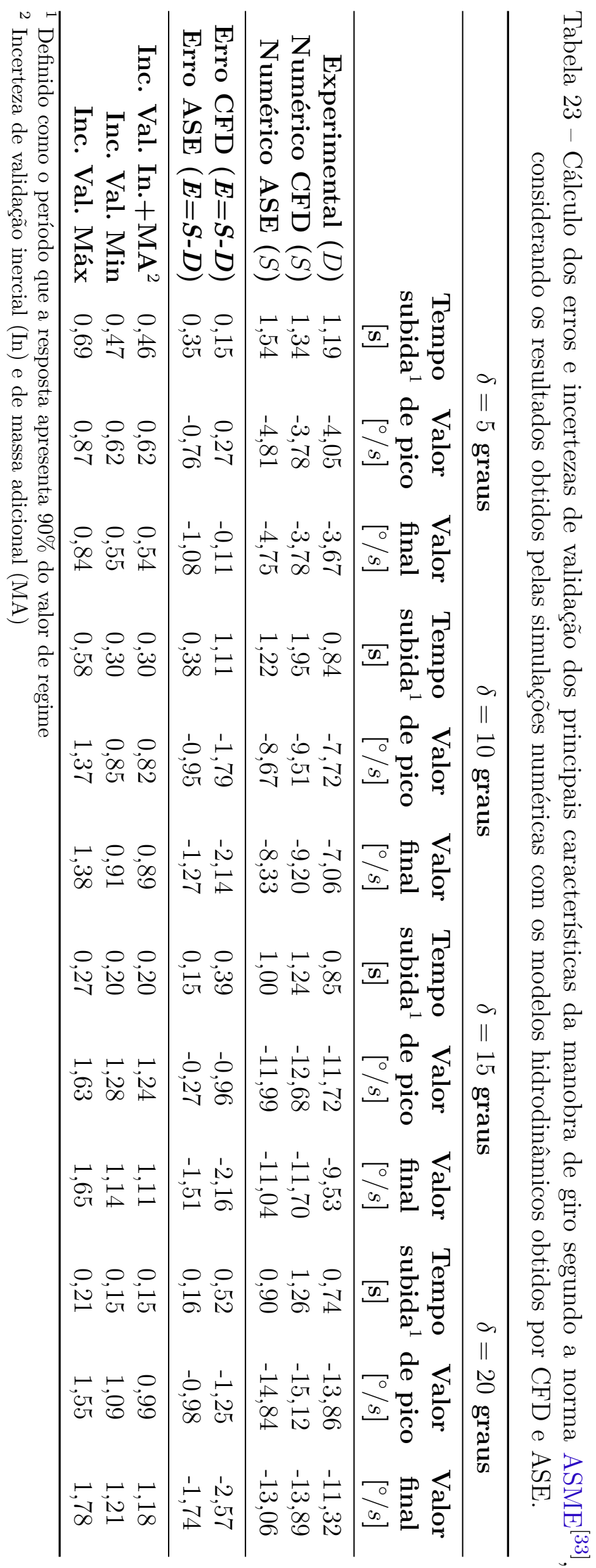


máxima, enquanto o modelo CFD apenas é validado ao considerar o intervalo de confiança de duas incertezas $(2 \sigma)$. Este resultado indica que o estol pode estar sendo melhor modelado pelo modelo ASE, pois o modelo CFD não considera o efeito da interferência entre a deflexão do leme e a taxa do movimento angular.

Nos casos de maior deflexão, ambos os modelos tiveram diferentes características de manobras validadas por diferentes combinações das incertezas paramétricas, i.e., ambos os modelos apenas conseguem validar algumas características de ambas manobras considerando a incerteza padrão $(1 \sigma)$, sendo as demais características validadas por um intervalo de confiança de duas incertezas $(2 \sigma)$. Mesmo sem apresentar uma tendencia nítida de qual modelo apresentou os melhores resultados, como os casos de menores deflexões, o modelo ASE apresentou resultados levemente superiores, do ponto de vista de número de validações, para os casos de alta deflexão.

Este resultado indica que ambos os modelos apresentaram uma excelente aderência aos resultados experimentais nas manobras de baixa deflexão, tendo a maioria das características contidas em um intervalo de confiança gerado por uma incerteza padrão $(1 \sigma)$ nos parâmetros de equação de movimento. Para o caso das maiores deflexões, apesar dos modelos apresentarem uma pior aderência, ao considerar um intervalo de confiança de duas vezes a incerteza padrão $(2 \sigma)$, todas as características de manobras puderam ser validadas, representando um bom resultado para uma condição que os esforços hidrodinâmicos apresentam características não lineares.

Esta conclusão sobre o comportamento em maiores deflexões é sustentada ao se realizar a comparação do erro percentual, razão do erro entre os modelos e a resposta experimental sobre o valor nominal, entre as diversas manobras. Ao se analisar este erro é observado que ele é menor para as maiores deflexões em relação às menores, demonstrando que os modelos apresentam uma boa representação do comportamento dinâmico do veículo para estes casos, já que eles estão percentualmente mais próximos do resultado experimental.

Também deve ser considerado que, no caso da manobra de giro, as características de "tempo de subida" e "valor de pico" não são calculados por uma média na série temporal de cada experimento, como é realizado pela característica de "valor final". Este fato dificulta a correta identificação destas características, pois os altos ruídos gerados pelos sensores e pelo ambiente prejudicam as estimações dos pontos máximos e da região que definido o tempo de subida. Desta forma pode ser considerado que estas características apresentam um erro maior, por estarem considerando os erros de forma indireta, prejudicando o seu uso durante o processo de validação. 


\subsubsection{Análise de sensibilidade e validação da manobra de zigzag}

A análise de sensibilidade da manobra de zigzag foi realizada de maneira similar à da manobra de giro; a análise completa é apresentada nos anexos $\mathrm{F}$ e $\mathrm{H}$ desta tese e apenas os resultados de maior importância são apresentados no texto principal. Também foram consideradas as quatro deflexões de leme utilizadas nos experimentos (5, 10, 15 e 20 graus), e a variação múltipla de 1, 2 e 3 dos parâmetros apresentados na tabela 17, sempre considerando os ganhos positivos e negativos.

Nesta análise, foram verificadas três características relativas ao movimento oscilatório da manobra de zigzag: o período de oscilação, e os valores máximos da taxa e do ângulo de rumo. Estes parâmetros foram selecionados por representarem características que são calculadas por médias de diversos períodos de um mesmo ensaio, aumentando a confiabilidade dos resultados experimentais, por poderem ser estimados as suas incertezas.

Repetindo o resultado da manobra de giro, os parâmetros inerciais que mais influenciaram a manobra de zigzag foram a posição do centro de gravidade (CG) e a velocidade de cruzeiro. No caso dos parâmetros relativos aos esforços hidrodinâmicos, nenhum dos parâmetros de maior sensibilidade da manobra de giro se repetiu na manobra de zigzag. Os parâmetros hidrodinâmicos que mais influenciaram o movimento de oscilação foram os ganhos nas variáveis de momento do leme, da força lateral da combinação, do momento da combinação, e a inércia (massa) adicional do movimento de guinada $(A(6,6))$.

Os gráficos da resposta dinâmica da análise de sensibilidade destes seis parâmetros são apresentados na figura 79, enquanto que os dados qualitativos são apresentados na tabela 24, contendo os valores percentuais em relação aos resultados nominais.

Esta diferença de sensibilidade entre os parâmetros que mais influenciaram as duas respostas pode ser explicada pelos tipos de esforços envolvidos em cada manobra. Na manobra de zigzag os esforços transientes, que dependem das acelerações, influenciam mais o movimento do AUV do que na manobra de giro, que por sua vez é mais influenciada pelos esforços estacionários, i.e., de regime permanente.

Apesar dos parâmetros relativos ao corpo do veículo não aparecerem entre os parâmetros de maior sensibilidade, as suas variações foram significativas em termos da característica da resposta dinâmica, e devem ser considerados na análise de sensibilidade. No caso do corpo, a variação do ganho da variável de velocidade angular foi o parâmetro que apresentou a maior influência nas características de manobra analisada.

Similar ao resultado da análise de giro, os esforços relacionados ao eixo longitudinal e a massa adicional, com exceção do termo $A(6,6)$, apresentaram sensibilidade muito menor do que os demais parâmetros analisados. Contudo, diferente do observado na manobra de giro, uma variação da resistência do veículo influenciou significativamente nas características de manobra, provavelmente devido a mudança de velocidade do veículo. Isto 

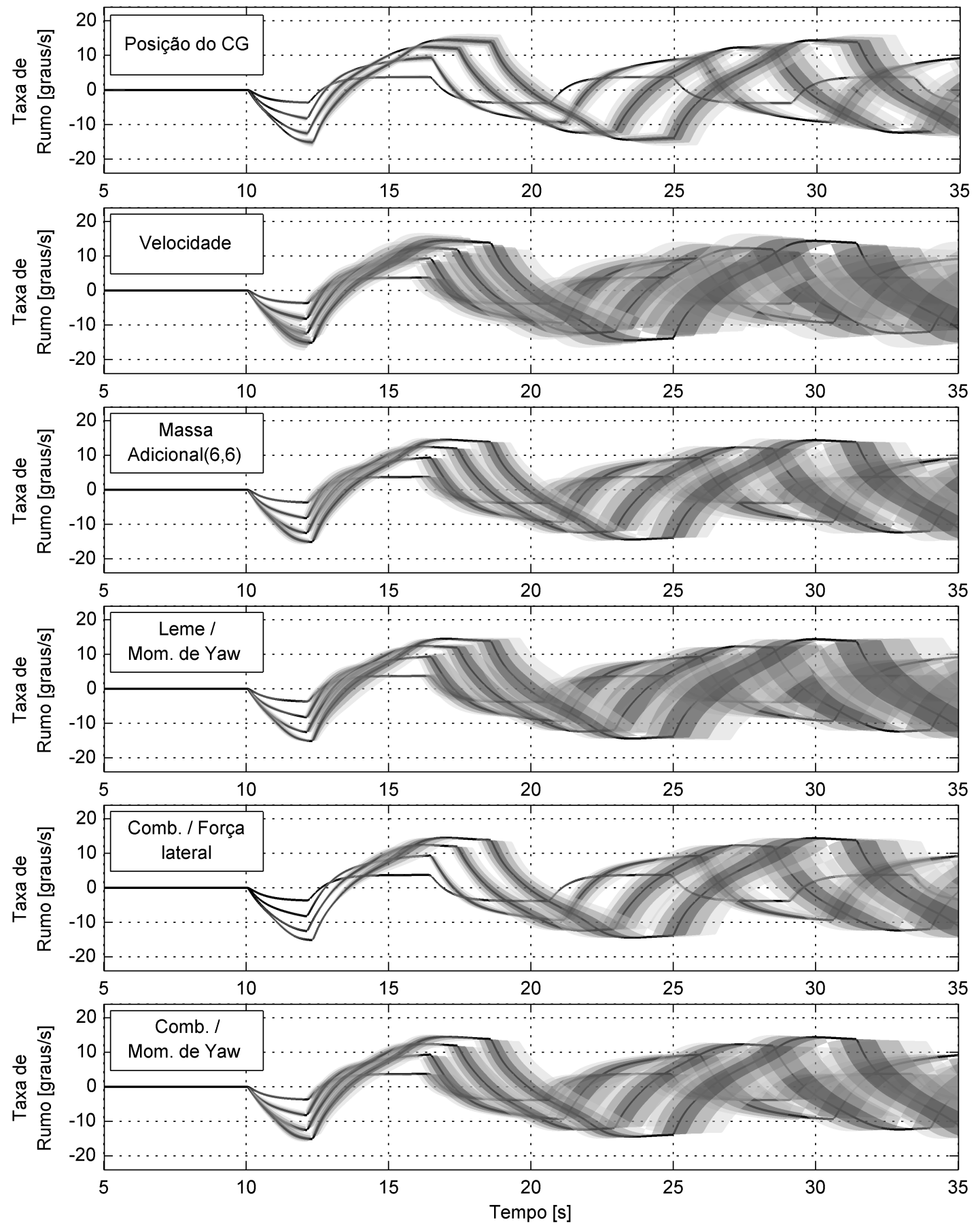

Figura 79 - Resultados da resposta dinâmica da manobra de Zigzag para a análise de sensibilidade dos parâmetros mais significativos, utilizando os modelos do simulador com os parâmetros do CFD para deflexões do leme de 5, 10, 15 e 20 graus. Os ganhos de sensibilidade utilizados são apresentados na tabela 17 multiplicados por 1, 2 e 3, que são apresentados pelas regiões cinza ao redor dos sinais do modelo nominal (linha preta) 


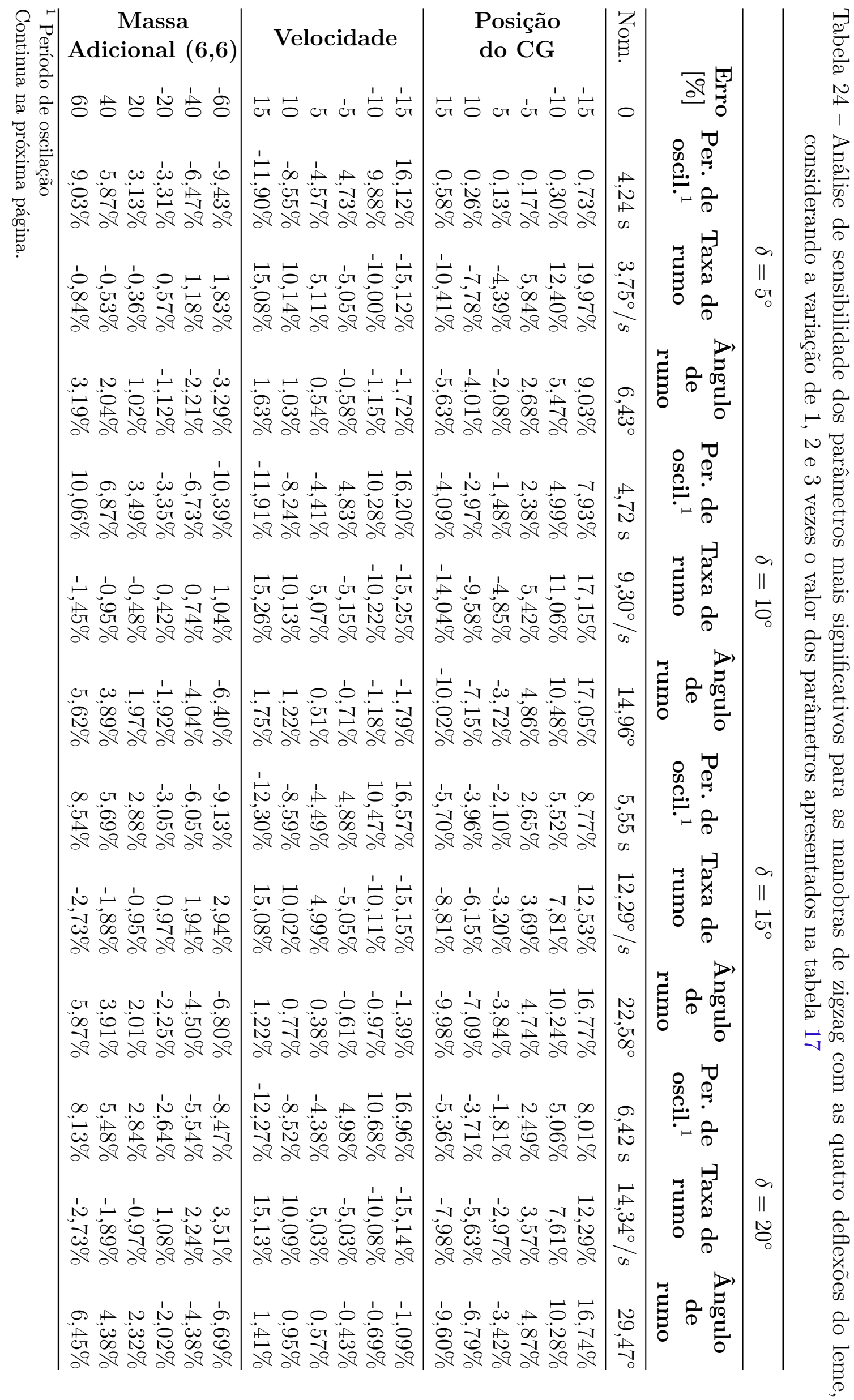




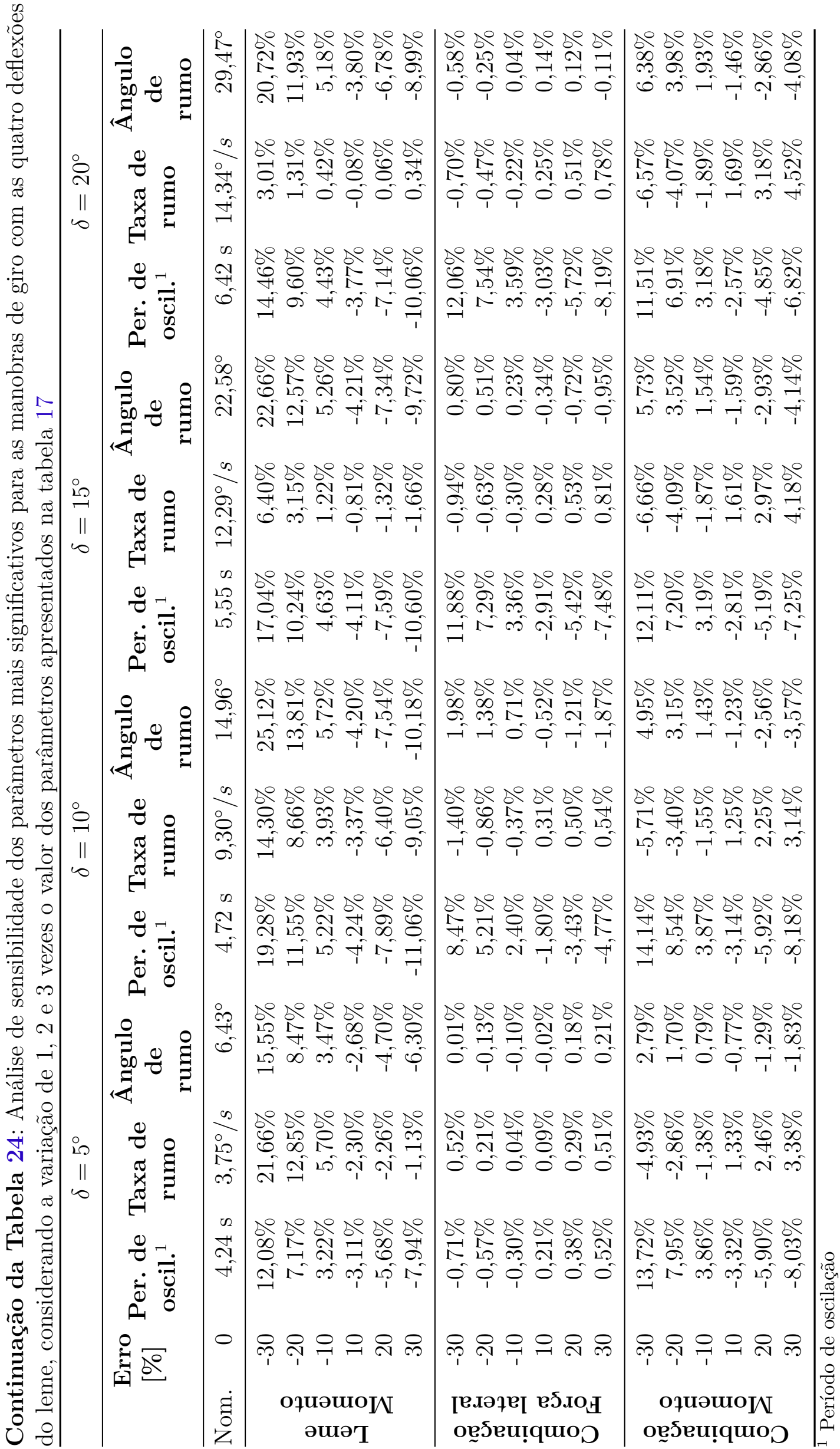


indica que a sensibilidade da força axial deve ser considerada em análises de sensibilidade mais criteriosas.

Outra semelhança à manobra de giro foi observada no comportamento não linear da sensibilidade. Este comportamento é observado tanto nas variações múltiplas $(1 \sigma, 2 \sigma$ e $3 \sigma$ ) de cada parâmetro, quanto em relação as variações positivas e negativas. Isto reforça o comportamento não linear e a assimetria das funções que definem os modelos de manobra.

Na tabela 25 são apresentados os coeficientes de sensibilidade escalonados, apresentado na seção 6.4.3.3, para os parâmetros de maior sensibilidade, e no apêndice H são apresentados estes coeficientes para todos os parâmetros. Por esta tabela, é verificado que a incerteza do CG (centro de gravidade) também apresenta o maior coeficiente de sensibilidade, para maioria das características analisadas.

No entanto, em alguns casos e para algumas características, a incerteza da velocidade do AUV representa a maior sensibilidade, demonstrando que no caso de zigzag não há um parâmetro cuja a incerteza influencie predominantemente nas manobras. Também deve ser considerado, que os demais coeficientes desta tabela também são significativos para análise de sensibilidade, demonstrando que estes coeficientes influenciam bastante o movimento de zigzag.

As incertezas da tabela 25 são apresentadas apenas por caráter ilustrativo, pois conforme a metodologia apresentada na seção 6.4.3.3, as incertezas de validação devem ser calculadas em função de uma combinatória das diferentes incertezas paramétricas.

No apêndice H são apresentados detalhadamente os cálculos de todas as incertezas paramétricas, enquanto que na tabela 26 é apresentado um resumo destas incertezas, agrupadas pelo seu tipo. Ao final desta tabela são apresentados os valores máximos e mínimos da incerteza paramétrica, utilizando a metodologia apresentada na seção 6.4.3.3.

Na tabela 27, foram utilizados os resultados dos valores máximos e mínimos da incerteza paramétrica para calcular as incertezas de validação, seguindo a metodologia da seção 6.4.3.4, e obter o intervalo de confiança para a validação dos modelos de manobra. Da mesma forma que na análise da manobra de giro, nesta tabela também são apresentadas as incertezas de validação calculadas apenas pelas incertezas paramétricas inerciais e de massa adicional, que representam uma condição em que não existam erros nos modelos hidrodinâmicos.

No caso da manobra de zigzag, o resultado de validação foi o oposto da manobra de giro para as diversas deflexões. Em outras palavras, para a deflexão de 5 graus o modelo ASE apresentou um resultado melhor, enquanto que o modelo CFD apresentou um resultado melhor para as manobras com deflexão de 10 graus. E para as demais deflexões o modelo CFD apresentou um resultado ligeiramente melhor do que o modelo ASE, contudo ambos os modelos apresentaram resultados similares. 


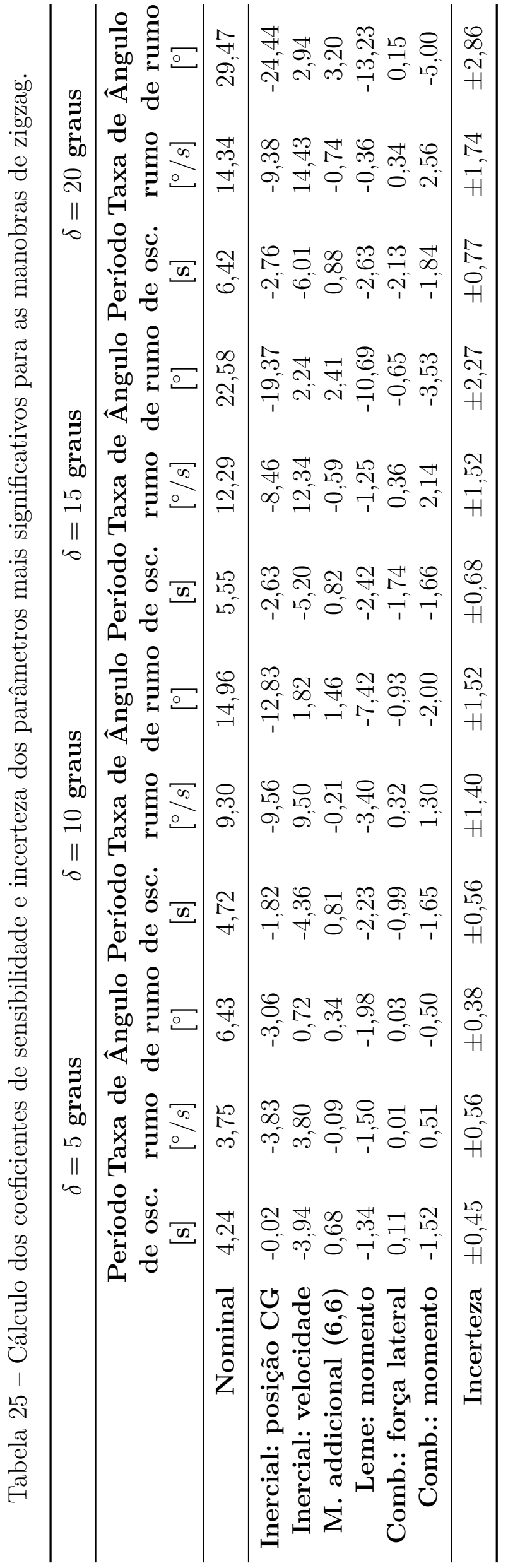




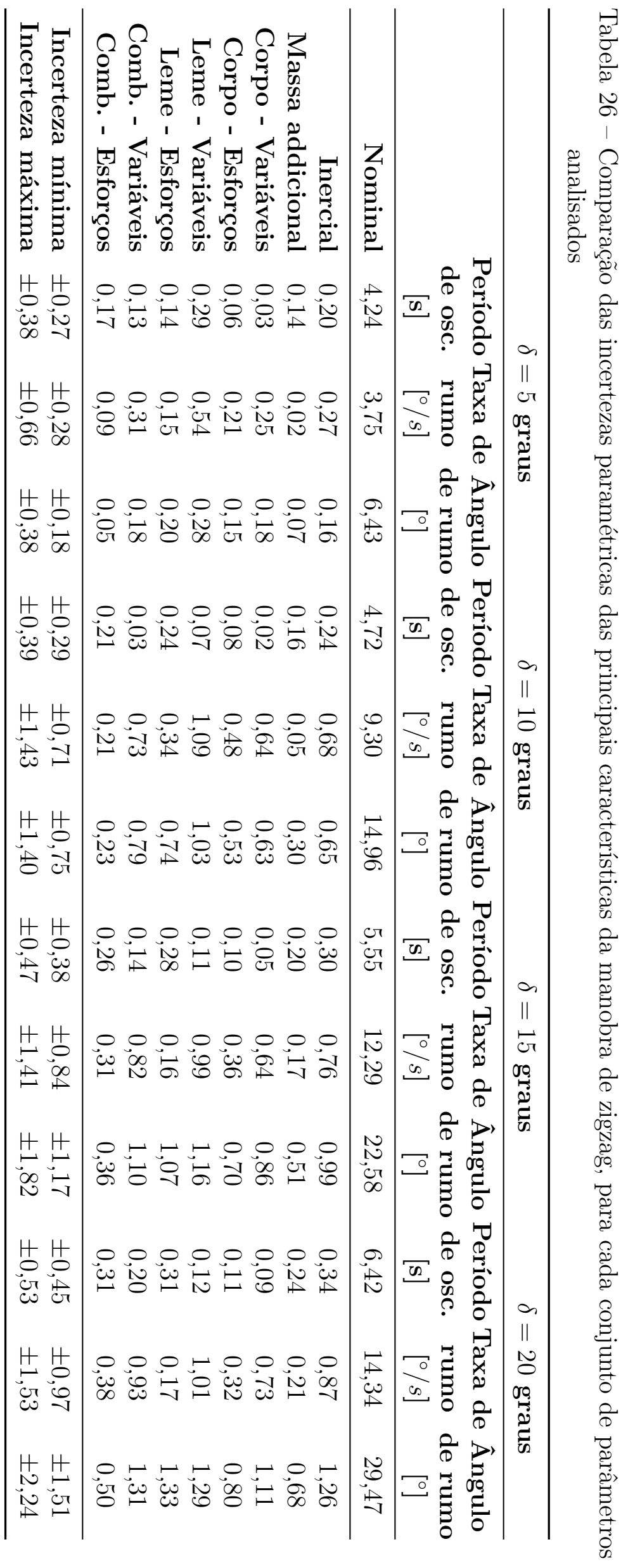




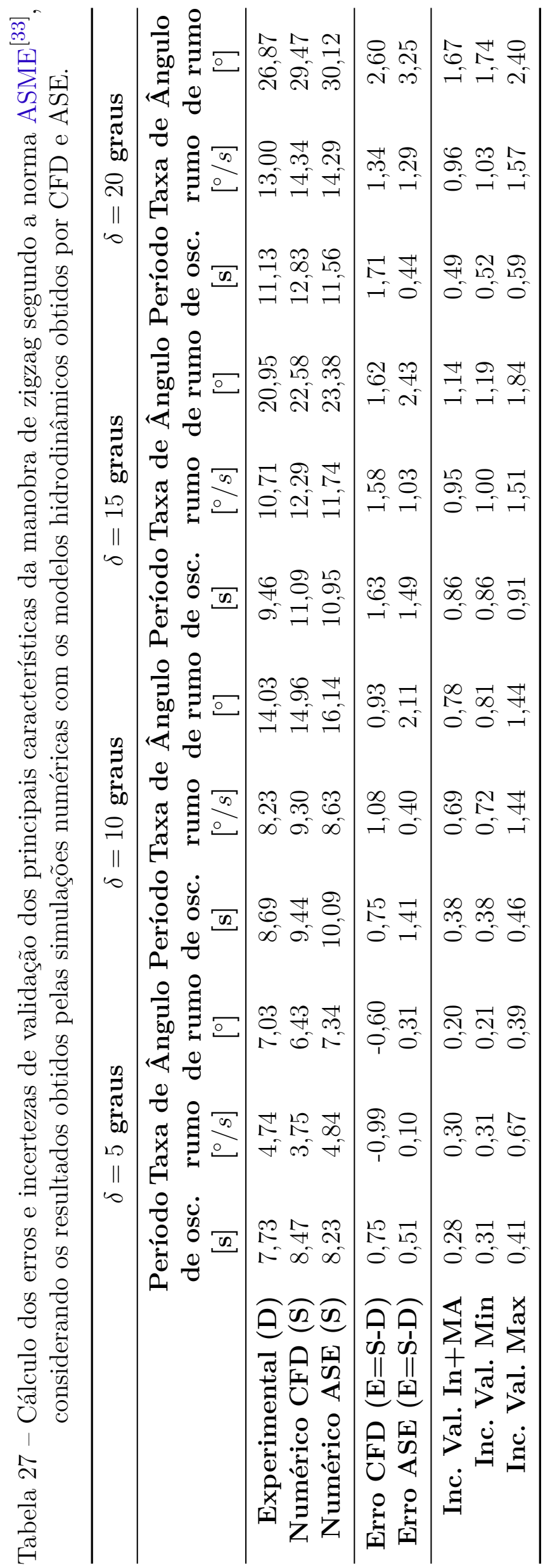


Contudo, ambos os modelos apresentaram bons resultados, no qual parte dos casos de menores deflexões foram contidos no intervalo de confiança gerado pela incerteza de validação padrão $(1 \sigma)$. E os demais casos foram validados pelo intervalo de confiança que considera duas vezes a incerteza padrão $(2 \sigma)$. Este resultado indica que os modelos de manobras também conseguem representar bem a manobra de zigzag, modelando os esfeitos transientes da dinâmica de AUVs, além dos efeitos em regime permanente da manobra de giro.

Como foi apresentado na seção 5.2, o regime transiente das manobras de zigzag se diferenciam da manobra de giro pelo veículo apresentar uma maior inclinação em relação ao escoamento (ângulo de deriva/incidência). Sendo que este efeito é mais influente para as manobras de maiores deflexões.

Este fenômeno pode explicar as diferenças observadas na validação das diferentes manobras. Pelo modelo de CFD apresentar uma melhor modelagem dos esforços hidrodinâmicos estáticos com e sem deflexão, sendo até mesmo validado para condições de leme fixo (vide seção 6.4.3.4), ele apresenta um melhor resultado nos casos que estes esforços contribuem mais para o movimento, como é o caso do movimento de zigzag.

Já no caso das manobras de giro, os esforços hidrodinâmicos devido o ângulo de deriva são relativamente menores do que os esforços gerados pela deflexão do leme e a taxa de rumo. Para este caso, o modelo ASE se destaca pelo seu equacionamento conseguir representar os fenômenos de acoplamento entre a deflexão do leme e a velocidade angular, considerando a influência combinada destas variáveis nos modelos de interferência e de estol dos lemes. Neste tipo de caso, o modelo CFD não representa bem este acoplamento, pois foi necessário realizar uma aproximação na combinação destas duas variáveis. 


\section{CONSIDERAÇÕES FINAIS}

Para melhor organizar a conclusão apresentada neste trabalho, esta seção foi dividida em quatro subseções. Primeiro, é apresentando a metodologia desenvolvida, de forma bastante sucinta. Em seguida são apresentadas conclusões gerais sobre o seu desenvolvimento da metodologia e os resultados encontrados. Depois, são apresentadas as conclusões sobre os principais processos e ferramentas utilizadas neste trabalho. E, por último, são apresentadas sugestões de trabalhos futuros, para a continuação deste projeto.

\section{METODOLOGIA DESENVOLVIDA PARA A ESTIMATIVA DO MO- DELO DE MANOBRA}

Durante a execução deste trabalho foi desenvolvida uma nova metodologia para estimar e analisar a manobrabilidade de veículos autônomos submarinos (AUVs) de casco axissimétrico e lemes em configuração cruciforme, i.e, do tipo torpedo. Esta metodologia é baseada em métodos numéricos e analíticos, utilizados para prever esforços hidrodinâmicos atuantes nestes veículos durante seus movimentos em águas calmas. O modelo de manobra teve o seu desenvolvimento dividido em duas etapas: a determinação de um procedimento para estimar os esforços hidrodinâmicos e a elaboração de uma formulação matemática que incorpore estes esforços às equações de movimento.

Cada uma destas etapas foi auxiliada através do uso de formulações analíticas, servindo de base para os modelos fluidodinâmicos e para auxiliar na interpretação destes fenômenos nas equações de movimento; de simulações numéricas do escoamento, para se estimar os esforços hidrodinâmicos dependentes de efeitos de grandes recirculações e inversões do escoamento, como o estol, que apresentam comportamentos não lineares com a incidência do escoamento, os quais não podem ser modelados analiticamente; e de resultados experimentais, para realizar a validação tanto dos esforços hidrodinâmicos quando dos resultados obtidos pelos modelos de manobras.

As informações obtidas no desenvolvimento de cada um destes procedimentos são combinadas para corrigir e melhorar os modelos gerados em cada etapa, obtendo-se, ao final, modelos que se beneficiam de diferentes tipos de abordagens.

O primeiro passo desta metodologia é determinar o envelope de operações do AUV, fazendo um levantamento das manobras que deverão ser reproduzidas pelo modelo de manobra. Em seguida, deve ser analisado se estas condições, em conjunto com as características dimensionais do veículo, podem gerar esforços hidrodinâmicos que se comportam de maneira não linear. Esta etapa pode ser realizada ao investigar as condições 
de operação de veículos geometricamente semelhantes que operam em condições similares, analisando os tipos de modelos de manobras utilizados e/ou o comportamento dos esforços hidrodinâmicos.

No segundo passo, com base nas características esperadas para os esforços hidrodinâmicos, deve ser selecionada qual a melhor abordagem para estimar os esforços hidrodinâmicos.

Para análises preliminares, podem ser adotados modelos ASE para estimar os esforços hidrodinâmicos de todo AUV, produzindo-se resultados rapidamente e com um custo bastante baixo. Contudo, neste caso, a predição da manobra parte da premissa que as condições de operação do AUV devem respeitar as restrições e suposições dos próprios modelos analíticos. Mesmo seguindo as condições estabelecidas por este modelo, as formulações analíticas podem gerar grandes erros relativos a determinação dos parâmetros semi-empíricos.

Para se realizar uma predição mais precisa dos esforços hidrodinâmicos podem ser utilizados tanto modelos puramente numéricos, baseados nas simulações de CFD, quando os modelos híbridos, compostos de formulações ASE corrigidas a partir de resultados de simulações de CFD. No caso do casco nu do AUV, o modelo híbrido utiliza as simulações de CFD para estimar a porção do casco onde a hipótese de escoamento potencial não pode ser adotada e o fator de atenuação da parcela potencial do escoamento devido a vórtices laterais gerados pelocasco, quando submetido a ângulos de incidência do escoamento, complementando o modelo estático ASE. Para o caso do leme, as simulações de CFD são utilizadas para se estimar os esforços gerados pelo leme isolado em função do ângulo de incidência. A seguir, para a combinação leme e casco, estes valores são utilizadas em conjunto com as formulações dos modelos ASEs, considerando os fatores de interferência obtidos pelos modelos ASEs não lineares.

Os modelos híbridos de esforços estáticos produzidos pela incidência do escoamento sobre casco, leme e combinação de ambos são extrapolados para o caso dinâmico, utilizando como base as formulações ASE e os parâmetros determinados pelas simulações de CFD.

No caso puramente numérico, são realizadas simulações estáticas e dinâmicas para estimar os esforços hidrodinâmicos do AUV .No caso estático, são realizadas simulações quasi-estáticas do casco isolado e da combinação casco-leme, variando o ângulo de incidência e a deflexão do leme, para se estimar os esforços hidrodinâmicos sobre o AUV. Para o AUV em movimento de rotação, os esforços hidrodinâmicos do casco isolado e da combinação casco-leme, são estimados em função do ângulo de incidência e da velocidade de rotação do veículo, através de simulações quasi-estáticas, que utilizam formulações de movimentos relativos entre o fluído e a malha para compor os dois movimentos.

É recomendado que as simulações de ambos os modelos passem por um procedimento 
de verificação e validação $(\mathrm{V} \& \mathrm{~V})$, para aumentar a confiabilidade dos resultados obtidos e estimar a incerteza destes esforços. Contudo, a escolha do procedimento que deve ser utilizado, quer seja a da ASME ${ }^{[33]}$ ou proposta por Eça, Vaz e Hoekstra ${ }^{[35]}$, depende do recurso computacional disponível, pois o uso de um destes procedimentos aumenta significativamente o tempo de execução destas simulações. Deve ser observado, que caso a convergência de discretização de malha não apresente uma convergência adequada, que ocorre, por exemplo, em condições de estol, deve ser adotado o método de Eça, Vaz e Hoekstra $^{[35]}$, por apresentar um procedimento mais robusto do que o método da ASME ${ }^{[33]}$.

Se o projeto do veículo de estudo tiver recurso suficiente para realizar ensaios de validação, como os ensaios de reboque de um modelo cativo em tanque de prova, é recomendado que estes ensaios sejam realizados, principalmente para os casos mais complexos. A utilização de um procedimento de validação é recomendada, pois mesmo em casos conhecidos os modelos ASE ou CFD podem apresentar imprecisões para modelar o efeito de algum fenômeno hidrodinâmico nos esforços gerados pelo veículo, precisando ser calibrados ou ajustados para estimar corretamente os esforços hidrodinâmicos.

Com os modelos dos esforços hidrodinâmicos definidos, deve ser seguida para a próxima etapa, onde são estabelecidas as formulações matemáticas dos modelos de manobra.

As formulações matemáticas da equações de movimento do AUV pelo modelo híbrido são definidas diretamente pelos formulações dos esforços hidrodinâmicos e pelas equações de movimento do AUV, não havendo necessidade de simplificações.

No caso do modelo CFD, os modelos dos esforços hidrodinâmicos devem ser adaptados em função das simulações de CFD realizadas, apresentando mais simplificações se forem realizadas menos simulações numéricas. Pelos esforços hidrodinâmicos estáticos e dinâmicos terem sido estimados por simulações em casos de combinação 2 a 2 das variáveis de estado (ângulo de incidência com velocidade angular, e ângulo de incidência com deflexão do leme), para reduzir o número de simulações realizadas, são utilizadas formulações derivadas a partir da organização utilizada no modelo ASE da combinação casco-leme para compor estes dois esforços, e são desprezados os efeitos dos esforços hidrodinâmicos devido ao efeito conjunto da deflexão do leme e da velocidade de rotação. Esta formulação é apresentada na equação (4.79) da seção sec:ManModel.CFD.Model. Na última etapa, o modelo de manobra deve ser validado por ensaios com manobras de giro e zigzag, verificando se as condições de operação estabelecidas no inicio desta metodologia representam as condições encontradas em condições reais. As manobras de giro foram utilizadas por terem uma maior representação dos esforços em regime permanente, i.e., quasi-estáticos, enquanto que as manobras de zigzag excitam outras frequências de forma a levar em conta também esforços em regime transiente. Com diferentes valores para a deflexão do leme, estas manobras representam uma região importante do espectro de 
movimento do veículo que pode ser analisado, validando os esforços hidrodinâmicos em condições lineares e não lineares de incidência do escoamento.

Através dos estudos conduzidos neste trabalho, recomenda-se que esta validação seja realizada através de comparações das características das respostas destas manobras, como período de oscilação ou valor em regime permanente, ao invés de uma comparação direta das respostas, pois desta forma é possível aplicar mais adequadamente um procedimento de verificação e validação, aumentando a confiabilidade de predição dos modelos de manobras e investigando melhor as incertezas envolvidas na determinação destes modelos.

Neste procedimento de validação, devem ser calculadas somente as incertezas experimentais e paramétricas, pois as incertezas numéricas, neste caso, são muito menores do que estas incertezas.

A incerteza experimental é estimada pela repetição de uma mesma manobra diversas vezes, permitindo que sejam considerados os ruídos no movimento devido ao ambiente, enquanto que a incerteza paramétrica é realizada por uma análise de sensibilidade local dos parâmetros do modelo de manobra.

A incerteza paramétrica é dividida nos parâmetros inerciais e hidrodinâmicos. A incerteza paramétrica inercial é estimada em função dos experimentos utilizados para medir os parâmetros inerciais do veículo, caso da massa, inércia e centro de massa, e de observações da condição de operação, caso da velocidade. No caso dos parâmetros hidrodinâmicos, a incerteza dos esforços estáticos são estimadas em função de medições realizadas em tanque de provas com o modelo cativo, enquanto que para os esforços dinâmicos são estimados em função das formulações dos esforços ASEs, considerando incertezas para os seus parâmetros estimados numericamente.

\section{CONCLUSÕES GERAIS SOBRE A METODOLOGIA DESENVOL- VIDA PARA O CASO DO AUV PIRAJUBA}

No intuito de se investigar os esforços hidrodinâmicos atuantes sobre um AUV em condições realistas de operação, foi adotada a simulação numérica do escoamento, devido à alta capacidade dos modelos de CFD de representar efeitos viscosos e não linearidades em esforços hidrodinâmicos que podem ocorrer nas faixas de interesse do ângulo de incidência do escoamento. Apesar de se adotar o software de CFD de volumes finitos ANSYS Fluent, bastante estabelecido no mercado, foi necessário definir diversos procedimentos para selecionar os parâmetros das simulações de CFD, como os modelos numéricos e as condições de contorno, para que fossem gerados resultados adequados. Para verificar e validar estes procedimentos, foi utilizado o procedimento de V\&V da ASME ${ }^{[33]}$, onde as estimativas destes esforços foram comparadas com as medições realizadas no tanque 
de provas, considerando tanto as incertezas numéricas quanto as incertezas experimentais.

Durante a etapa de estimativa dos esforços hidrodinâmicos, também foi realizado um estudo dos modelos analíticos e semi-empíricos (ASE), com o objetivo de reduzir o custo computacional vinculado à realização das simulações de CFD. Apesar de terem sido utilizados modelos ASE avançados da indústria naval e aeronáutica, eles não modelaram corretamente os esforços hidrodinâmicos na região de comportamento não linear, que surgem devido a efeitos hidrodinâmicos complexos, tais como o estol dos lemes e a recirculação do escoamento na lateral do corpo.

Analisando as características dos escoamentos modelados pelas simulações de CFD, foi verificado que alguns dos parâmetros dos modelos ASE não eram condizentes com as estimativas numéricas. Combinando a estimativa numérica destes parâmetros com os modelos ASE, foram gerados modelos híbridos, que apresentaram estimativas dos esforços hidrodinâmicos muito mais próximos das medições em tanque de provas, melhorando a capacidade de predição destes modelos. Deve-se observar, no entanto, que os modelos puramente numéricos apresentam desempenho pouco superior àquele produzido por modelos híbridos, particularmente na faixa dos maiores ângulos de incidência.

Em termos de custo computacional, os modelos híbridos apresentam um meio termo entre os modelos analíticos, de baixo custo, e os modelos numéricos, de alto custo. Este custo mais elevado é encontrado, pois apesar da sua estrutura ser baseada em equações matemáticas, foi necessário realizar simulações de CFD, em uma quantidade menor do que o modelo CFD, para obter uma boa estimativa dos parâmetros empíricos destas equações.

Ao final da primeira etapa, foram obtidos dois modelos confiáveis para a estimativa dos esforços hidrodinâmicos do corpo e do leme do AUV Pirajuba, sendo definido em função do ângulo de inclinação do escoamento, da velocidade angular e da deflexão do leme.

Na segunda etapa, estes modelos foram utilizados para compor os modelos de manobras investigados neste trabalho. Conforme apresentado na seção 2, também foram considerados os esforços gerados pela aceleração da gravidade, empuxo hidrostático, presença do propulsor e os esforços inerciais. Pelos esforços hidrodinâmicos, de ambos os modelos, serem obtidos em condições quasi-estáticas, uma parcela dos esforços hidrodinâmicos de massa adicional não foram considerados. Esta parcela não modelada foi denominada de esforços de "massa adicional de aceleração", sendo estimada através dos métodos das faixas.

Para que o modelo dos esforços hidrodinâmicos baseado nas simulações de CFD fosse incorporado ao modelo de manobra, foi necessário adaptá-lo para que ele pudesse estimar estes esforços para qualquer combinação das variáveis de movimento. A adaptação foi realizada ao se considerar uma função de interpolação, do tipo cúbica por partes (spline), 
para estimar os resultados numéricos entre os casos simulados. Pelas simulações de CFD deste modelo terem sido realizadas em dois casos de combinação 2 a 2 das variáveis de estado (ângulo de incidência com velocidade angular, e ângulo de incidência com deflexão do leme), as funções de interpolação tiveram que ser adaptadas para unir os casos de simulação, considerando todos os efeitos simulados. Entretanto, como não foram realizadas simulações de CFD com variações simultâneas da velocidade angular com a deflexão do leme, este modelo teve que desconsiderar o acoplamento entre estas duas variáveis, apresentando apenas o efeito acoplado destas variáveis com o ângulo de inclinação do escoamento. O procedimento de obtenção deste modelo foi apresentado na seção 4.3.

No caso do modelo de manobra baseado nos modelos híbridos (CFD-ASE) não foram necessárias realizar simplificações, pois as formulações ASE desenvolvidas consideram os efeitos acoplados das três variáveis de estado, possibilitando a estimar os esforços hidrodinâmicos em qualquer condição de operação. Esta característica do modelo de manobra híbrido apresenta uma vantagem em relação ao modelo de manobra de CFD, que se utiliza de uma simplificação para estimar certos esforços. Este modelo de manobra é apresentado na seção 4.2 .

Em termos gerais, o modelo de manobra de CFD possui a vantagem de estimar com uma melhor precisão o acoplamento entre as diferentes variáveis de estado nos esforços hidrodinâmicos, mas possui a desvantagem de não considerar o acoplamento entre a velocidade angular e a deflexão do leme. Em contrapartida, o modelo ASE híbrido, possuí a desvantagem de apresentar um erro maior para estimativa dos efeitos não lineares dos esforços hidrodinâmicos, mas apresenta a vantagem de considerar um modelo de manobra que consegue estimar os esforços hidrodinâmicos em todas as condições de operação, sem precisar realizar simplificações.

Para analisar a capacidade de predição dos modelos de manobra do AUV Pirajuba, neste trabalho, foi desenvolvido um procedimento de verificação e validação da manobrabilidade, baseado nas recomendações da ITTC $^{[45]}$ e da ASME ${ }^{[33]}$. Neste procedimento, foi proposto aplicar o critério de validação da $\mathrm{ASME}^{[33]}$ às características de manobra de giro e zigzag, como valor em regime permanente ou o período de oscilação, analisando a capacidade de previsão do modelo para manobras que possuem diferentes características dinâmicas. Neste procedimento, foi considerada a validação do modelo de manobra quando a diferença entre as características da manobra estimadas e medidas, durante os ensaios com o modelo livre, são menores que as incertezas de validação, que são compostas das incertezas numéricas, paramétricas e experimentais.

Todo o procedimento de validação foi baseado na análise dos sinais medidos e estimados da velocidade angular. Esta variável foi escolhida por apresentar uma medição simples e precisa, com o sistema de aquisição do AUV Pirajuba, em relação às demais variáveis. Apesar de esta variável apresentar um ruído maior do que o ângulo de rumo, 
que também é medido de forma relativamente fácil, ela reflete de maneira mais direta os esforços hidrodinâmicos atuantes no AUV, pois no caso do ângulo de rumo o mesmo sinal estaria filtrado pelo fator de integração.

Neste procedimento, as incertezas numéricas foram reduzidas a níveis desprezíveis, ao realizar uma investigação de quais parâmetros da integração numérica das equações do modelo de manobra apresentavam um erro significativamente menor do que as demais incertezas. As incertezas experimentais foram estimadas ao analisar estatisticamente as características das manobras ensaiadas, considerando algumas repetições de uma mesma manobra, conforme apresentado na seção 5.2. As incertezas paramétricas foram estimadas por uma análise de sensibilidade local dos parâmetros inerciais e hidrodinâmicos, em relação às características de manobra, dos modelos de manobra numéricos, conforme apresentado na seção 6.4.3.2.

Com o procedimento de validação proposto, os modelos de manobras desenvolvidos foram validados para diversas características de ambas as manobras, considerando um intervalo de confiança de $95 \%(2 \sigma)$. Contudo, algumas das características de manobras que foram utilizadas no procedimento de validação, sofreram a influência dos ruídos dos sensores e do ambiente, prejudicando parcialmente o procedimento, não indicando a validação em certas condições. Mesmo com estes problemas, foi verificado que o modelo de manobra baseado nas simulações de CFD apresentou um melhor resultado na análise de zigzag, enquanto que o modelo de manobra ASE teve uma melhor aderência aos resultados da manobra de giro.

Acredita-se que os erros do modelo de manobra de CFD estejam relacionados à simplificação do modelo de estol, em que não foram incluídos os efeitos combinados entre a velocidade angular e a deflexão do leme, que são mais significativos na manobra de giro do que na manobra de zigzag, que é mais influenciada pelo ângulo de incidência.

No caso do modelo de manobra ASE o resultado foi o oposto. Por este modelo considerar o efeito do estol do leme na presença do corpo para todas as variáveis de movimento, ele conseguiu modelar bem os esforços da dinâmica da manobra de giro, que tem grande influência da velocidade angular e da deflexão do leme. Contudo, como este modelo apresentou pequenos erros na estimativa dos esforços hidrodinâmicos em relação ao modelo de CFD, este modelo apresentou um resultado pior para as manobras de zigzag, principalmente para os casos de maior amplitude de movimento.

Mesmo apresentando alguns resultados com um erro maior do que a incerteza de validação padrão, ambos os modelos de manobra desenvolvidos, CFD e híbrido, conseguiram representar bem a dinâmica do AUV Pirajuba durante ensaios de mar, mesmo em manobras de alta deflexão. Este resultado comprovou que as metodologia proposta tem capacidade de 
determinar modelos de manobra de AUVs do tipo-torpedo ${ }^{7}$, se tornando uma alternativa viável aos modelos de manobras clássicos, que utilizam funções hidrodinâmicas com uma estrutura similar a séries de Taylor.

Acredita-se que os modelos desenvolvidos somente conseguiram alcançar tal resultado por utilizarem funções não lineares, que consideram o acoplamento das três variáveis de estado, conseguindo modelar o comportamento não linear de manobra dos AUVs. Devido a este tipo de equacionamento, pode-se considerar que os modelos desenvolvidos tem uma maior capacidade de previsão dos esforços hidrodinâmicos do que os modelos de manobras clássicos, podendo representar uma vantagem em relação a esses modelos em manobras com movimentos que impliquem em valores significativos das variáveis de movimento, em que os esforços hidrodinâmicos não podem ser representados por funções lineares.

Como comentado anteriormente, os modelos analíticos apresentam o menor custo computacional dos modelos investigados, mas também apresentam a menor capacidade de previsão dos esforços hidrodinâmicos, dependendo muito das condições que os modelos foram gerados. Os modelos puramente de CFD apresentam um alto custo computacional, que está atrelado à necessidade de realizar diversas simulações de CFD para poder estimar de maneira satisfatória os esforços hidrodinâmicos. Os modelos híbridos CFD-ASE, tem um custo computacional intermediário entre os modelos ASE e CFD, devido à necessidade de investigar as equações ASE e estimar os seus parâmetros através das simulações de CFD, apresentando um resultado pouco menos preciso que os modelos de CFD para as estimativas dos esforços hidrodinâmicos, mas apresentando uma capacidade de previsão de manobrabilidade de mesma qualidade.

Desta forma, pode-se recomendar o uso dos modelos puramente analíticos, para projetos ainda em fase conceitual, onde somente é necessário ter uma ideia da capacidade de manobrabilidade de AUVs. Durante as demais fases de projeto do AUV podem ser utilizados modelos híbridos para estimar a manobrabilidade destes veículos, tomando cuidado com as imprecisões que podem existir nos equacionamentos analíticos em certas condições, que não podem não ser verificadas com as poucas simulações de CFD. Os modelos puramente numéricos ficariam mais restritos aos casos em que se deseja estimar as características de manobras para condições de manobras com movimentos de maiores amplitudes e velocidades, ou para os casos em que os modelos ASEs não apresentam um desenvolvimento teórico a contento.

$7 \quad$ Axissimétricos com leme de popa em formato cruciforme ("+") 


\section{CONCLUSÕES ESPECÍFICAS SOBRE AS FERRAMENTAS E PRO- CEDIMENTOS UTILIZADOS}

Para a execução deste trabalho, foi necessário estudar e desenvolver diversos tipos de ferramentas e procedimentos, utilizando técnicas numéricas, analíticas e experimentais. Nesta seção, é ressaltada a importância da utilização destas ferramentas e procedimentos para o desenvolvimento desta tese.

Na seção 2, foi apresentado o modelo matemático adotado para a solução das equações de movimento de um AUV. Para o propósito desta tese, este modelo apresentou uma abordagem bastante eficiente e de fácil implementação numérica para contemplar todos os esforços hidrodinâmicos atuantes, demonstrando que este tipo de estrutura matemática é valido para estimar o movimento de um AUV típico. Os resultados apresentados na ultima seção da tese, demonstraram que a simplificação adotada no modelo hidrodinâmico de propulsão, de não modelar os efeitos transientes, não prejudicou as simulações de manobras, indicando que esta abordagem simples é útil para a análise de manobrabilidade.

Como esperado, o procedimento utilizado para determinar as condições de contorno das simulações de CFD estáticas e a própria configuração do software de CFD ANSYS Fluent, apresentado na seção 3, conseguiu identificar a maioria dos esforços hidrodinâmicos atuantes no AUV Pirajuba como um todo e em seus componentes principais, considerando diferentes condições de ângulo de deriva e de deflexão do leme. A exceção se deu para os esforços do leme na condição de pós-estol, que por ser um fenômeno hidrodinâmico de alta complexidade e majoritariamente transiente, não conseguiu ser modelado por um sistema de equações do tipo RANS. Entretanto, mesmo nesta condição, os modelos RANS utilizados conseguiram estimar os esforços hidrodinâmicos com certa margem de incerteza, podendo ser utilizados como estimativa inicial destes esforços, além de conseguir estimar corretamente a condição limite do inicio estol.

Para o caso dos esforços hidrodinâmicos dinâmicos, esforços que surgem em decorrência do movimento de rotação do veículo, a metodologia encontrada na literatura foi modificada, de forma que as simulações de CFD pudessem fornecer estimativas dos esforços hidrodinâmicos em função tanto da velocidade angular quanto do ângulo de deriva. Apesar de não ter sido possível comparar os resultados destas simulações frente a medições diretas dos esforços, pode ser considerado que estas estimativas foram validadas de forma indireta no processo de validação do modelo de manobra numérico. As informações retiradas destas simulações também auxiliaram no melhor entendimento dos fenômenos hidrodinâmicos do escoamento sobre o AUV Pirajuba, e de seu corpo.

Para aumentar a confiabilidade dos resultados extraídos das simulações numéricas, todos os casos investigados passaram por um rigoroso procedimento de verificação e validação, baseado na norma internacional da $\mathrm{ASME}^{[33]}$ e na modificação parcial deste 
procedimento proposta por Eça, Vaz e Hoekstra ${ }^{[35]}$. A vantagem da utilização do procedimento de Eça, Vaz e Hoekstra ${ }^{[35]}$ foi comprovada para o caso do leme isolado, apresentada na seção 6.2.2, onde este procedimento apresentou um resultado muito mais confiável para as incertezas numéricas nos casos em que o escoamento apresenta fenômenos com altas recirculações, como o estol do leme.

Para os esforços hidrodinâmicos estáticos, a validação foi conduzida de forma tradicional, comparando-se as estimativas destes esforços com as medições realizadas em tanque de reboque com um modelo cativo do AUV Pirajuba. No caso dos esforços dinâmicos a validação foi realizada através do modelo de manobra, realizando comparações de características de manobras estimadas e medidas em ensaios de mar, para manobras de giro e zigzag, considerando quatro diferentes deflexões, garantindo condições que se estendessem até o regime não linear de incidência, excitando desta forma diferentes modos de operação do veículo. Para reduzir o ruído do ambiente e dos sensores da análise da manobra, foi aplicado um filtro Gaussiano às médias das repetições das manobras, melhorando muito a visualização e análise dos dados experimentais. Os procedimentos de ambos os ensaios de validação são apresentados na seção 5 .

Antes de realizar as simulações de CFD de todo AUV Pirajuba, foi proposto um procedimento para determinar quais configurações do modelo numérico de CFD, do software ANSYS Fluent, gerariam a melhor modelagem do escoamento em torno do AUV. Este procedimento foi apresentado na seção 6.1.

Na primeira parte deste procedimento, simulações bidimensionais e tridimensionais de casos validados que fossem semelhantes aos casos do AUV Pirajuba, foram utilizadas para selecionar o modelo $k-\omega$ SST como o modelo de turbulência que apresentou a melhor aderência aos resultados experimentais com o melhor custo-benefício, em relação a diversos modelos testados, tendo apenas uma divergência para a força de arrasto.

$\mathrm{Na}$ segunda etapa, foi testada a ordem dos equacionamentos convectivos das equações de transporte dos modelos RANS, verificando que o modelo de primeira ordem é bastante adequado para as investigações dos esforços de manobrabilidade, que são influenciados significativamente apenas pela força normal e pelo coeficiente de momento, apresentado um menor custo que os modelos de alta ordem. Os modelos de alta ordem apresentaram uma grande melhoria para a estimativa da força axial, mantendo a boa precisão dos demais esforços obtidos pelos modelos de primeira ordem. Contudo, os modelos de alta ordem apresentaram um custo computacional de sete a vinte vezes maior, dependendo do ângulo de incidência simulado, tornado inviável o seu uso para este trabalho, já que a melhoria da estimativa do arrasto não justifica o aumento do custo computacional.

A análise dos esforços hidrodinâmicos pelo método de CFD foi complementada por análises conduzidas por métodos analíticos e semi-empíricos (ASE) originalmente propostos para a estimativa de esforços aerodinâmicos em aviões e mísseis, incluindo-se 
modificações em suas formulações com base nos resultados numéricos, ou seja, um modelo híbrido ASE-CFD. O uso destes modelos permitiu realizar uma análise mais embasada dos resultados de $\mathrm{CFD}$, possibilitando um estudo profundo sobre os efeitos de interferência hidrodinâmica corpo-leme e corpo-duto, verificando quais os efeitos desta interferência no estol experimentado pelos apêndices do veículo. Durante este estudo, também foi verificado que o modelo híbrido aumentou a capacidade de estimativa destes esforços dos modelos ASE, conseguindo prever resultados bastante próximos ao do CFD para diversos casos.

Durante as análises dos esforços hidrodinâmicos do AUV Pirajuba, foi proposta a investigação dos esforços no leme na presença do corpo, tratando-se diretamente o efeito da interferência hidrodinâmica do corpo sobre o leme. Neste estudo, foi verificado que, além do aumento de sustentação do leme gerado pelo fluxo de escoamento induzido pelo corpo (upwash), a interferência aumenta o ângulo de estol do leme, estando de acordo com o efeito proposta na teoria não linear do ângulo de ataque equivalente de Hemsch e Nielsen ${ }^{[145]}$, tanto para os casos estáticos quanto dinâmicos.

Neste estudo, também foi verificado que o estol do leme pode ser descrito por uma relação majoritariamente linear entre o ângulo de incidência e a deflexão do leme, e do ângulo de incidência e a velocidade de rotação, indicando que a região de resposta linear do leme, para os casos estáticos e dinâmicos, pode ser determinada com poucas simulações, não sendo necessária a simulação de toda uma gama de valores para estas variáveis. Ao estudar esta característica, foi verificado que o modelo de CFD e o modelo híbrido conseguiram estimar esta região de forma bastante semelhante, apresentando menos de 1 grau de incidência diferente, demonstrando que o modelo híbrido pode ser utilizado para estimar esta região com um custo muito menor do que o modelo de CFD.

Durante a realização da validação do modelo de manobra, discutida na seção anterior, foi necessário calcular a incerteza paramétrica dos modelos de manobra investigados. Além de realizar este cálculo, a análise de sensibilidade observou a relação entre variações de diversos parâmetros inerciais e hidrodinâmicos com as características de manobras, verificando quais parâmetros devem ser estimados ou medidos com maior precisão para gerar uma menor incerteza na análise validação da manobrabilidade.

\section{SUGESTÕES DE TRABALHOS FUTUROS}

Como sugestões dos trabalhos futuros, a investigação do modelo dos esforços hidrodinâmicos baseados nas ferramentas de CFD possa ser estendido, se forem consideradas adicionalmente as simulações realizadas para os casos que modelam os esforços hidrodinâmicos devido ao acoplamento da velocidade angular e da deflexão do leme. Outra opção, caso se tenha a capacidade computacional disponível, seria realizar as simulações de manobras como uma simulação de CFD transiente, de forma a modelar todos os esfor- 
ços hidrodinâmicos sem necessitar de aproximações dos modelos, como alguns trabalhos encontrados na literatura. Desta forma, seria possível verificar as suposições alegadas na discussão desta tese, sobre a capacidade de previsão dos modelos numéricos em relação aos modelos baseados nas equações ASE.

Os modelos híbridos também podem ser melhor investigados, encontrando formulações que considerem com maior precisão a estimativa dos efeitos de acoplamento das diversas variáveis de estado, além de melhor estimar os efeitos de interferência corpo-leme. Neste processo, os resultados de CFD podem ser utilizados para melhorar a estimativa de outras formulações para os fatores empíricos destas formulações, assim como propor novos fatores que considerem estes efeitos cruzados.

A análise de validação também seria beneficiada se os parâmetros dos modelos de manobras apresentassem uma menor incerteza paramétrica. Esta redução poderia surgir de ensaios mais precisos da massa e inércia do veículo submergido (considerando a parcela de água presa dentro do casco), sem precisar recorrer de métodos de estimativas numéricas pela ferramenta de CAD.

A utilização de um método mais avançado para estimar a matriz de massa adicional de aceleração, como os métodos dos painéis, ou até mesmo realizar ensaios de medição destes termos, como ensaios de balanços submersos, também resultaria numa maior precisão na determinação destes parâmetros com uma menor incerteza.

Uma redução das incertas experimentais também ajudaria no processo de validação dos modelos de manobras. Esta redução poderia vir da realização de ensaios em uma maior profundidade, para eliminar a influência dos efeitos da superfície, ou até mesmo realizar estes ensaios em grandes ambientes controlados, onde além de menores influências do ambiente poderiam ser utilizados sistemas de medições externos, obtendo melhores resultados de validação.

Por final, esta mesma metodologia poderia ser aplicada a AUVs de cascos de revoluções com geometrias diferentes da analisada neste trabalho, e.g., diferentes razões de esbelteza do casco ou diferentes geometrias de leme, para verificar a capacidade de previsão dos modelos híbridos. Despois desta verificação, também seria recomendado que a metodologia numérica fosse aplicada a outros tipos de veículos, verificando se a metodologia desenvolvida neste trabalho também é capaz de modelar outros tipos de fenômenos hidrodinâmicos. 


\section{REFERÊNCIAS}

1 COSTELLO, D. et al. The use of unmanned vehicle systems for coastal ocean surveys: Scenarios for joint underwater and air vehicle missions. In: Proceedings of the Workshop on Undersea Robotics and Intelligent Control. Lisboa, Portugal: [s.n.], 1995. Citado na página 41.

2 PASCOAL, A. The AUV MARIUS: Mission scenarios, vehicle design, construction and testing. In: Proceedings of the 2nd Workshop on Mobile Robots for Subsea Environments. Monterey Bay Aquarium, Monterey, California, USA: [s.n.], 1994. Citado na página 41.

3 PASCOAL, A. et al. MARIUS: an autonomous underwater vehicle for coastal oceanography. Robotics Automation Magazine, IEEE, v. 4, n. 4, p. 46 - 59, dez. 1997. ISSN 1070-9932. Citado na página 41.

4 WILLIAMS, S. et al. Monitoring of benthic reference sites: Using an autonomous underwater vehicle. IEEE Robotics Automation Magazine, v. 19, n. 1, p. 73-84, mar. 2012. ISSN 1070-9932. Citado na página 41.

5 ACOSTA, G. et al. Low-cost autonomous underwater vehicle for pipeline and cable inspections. In: Underwater Technology and Workshop on Scientific Use of Submarine Cables and Related Technologies, 200\%. Symposium on. [S.l.: s.n.], 2007. p. 331 -336. Citado na página 41.

6 HAMILTON, K.; EVANS, J. Subsea pilotless inspection using an autonomous underwater vehicle (spinav): concepts and results. In: Oceans 2005 - Europe. [S.l.: s.n.], 2005. v. 2, p. 775 - 781 Vol. 2. Citado na página 41.

7 KOJIMA, J. et al. Experimental results of autonomous underwater vehicle 'AQUA EXPLORER 2' for inspection of underwater cables. In: OCEANS '98 Conference Proceedings. [S.l.: s.n.], 1998. v. 1, p. 113 -117. Citado na página 41.

8 BROWN, H. C.; KIM, A.; EUSTICE, R. M. An overview of autonomous underwater vehicle research and testbed at perl. Marine Technology Society Journal, v. 43, n. 2, p. 33 - 47, 2009. Citado na página 41.

9 RAJALA, A.; EDWARDS, D. Allocating AUVs for mine map development in MCM. In: OCEANS 2006 - Asia Pacific. [S.l.: s.n.], 2006. p. 1 -8. Citado na página 41.

10 BOVIO, E.; CECCHI, D.; BARALLI, F. Autonomous underwater vehicles for scientific and naval operations. Annual Reviews in Control, v. 30, n. 2, p. 117 - 130, 2006. ISSN 1367-5788. Citado na página 41.

11 GERTLER, M.; HAGEN, G. R. Standard Equations of Motion for Submarine Simulation. Washington D.C., 1967. Citado 8 vezes nas páginas 43, 47, 48, 49, 101, 103, 104 e 131.

12 FELDMAN, J. Revised Standarrd Submarine Equations of Motion. Bethesda, Maryland, 1979. Citado 9 vezes nas páginas 43, 48, 49, 101, 103, 104, 131, 134 e 234. 
13 BOHLMANN, H. J. Berechnung Hydrodynamischer Koeffizienten von Ubooten zur Vohrhersage des Bewegungsverhaltens. Tese (DissertaÃ§̃̃ £o) — Institut fur Schifbau der Universitat Hamburg, Hamburgo, Alemanha, jan. 1990. Citado 8 vezes nas páginas 43, 48, 49, 101, 103, 104, 131 e 234.

14 PRESTERO, T. Verification of a six-degree of freedom simulation model for the REMUS autonomous underwater vehicle. Dissertação (Master Thesis) - Massachusetts Institute of Technology and Woods Hole Oceanograph Institution, 2001. Citado 9 vezes nas páginas 43, 48, 101, 103, 104, 131, 134, 234 e 295.

15 JONES, D. et al. The calculation of hydrodynamic coefficients for underwater vehicles. Edinburgh SA, Australia, 2002. Disponível em: < http://hdl.handle.net/1947/4395>. Citado 5 vezes nas páginas 43, 48, 101, 103 e 104.

16 FERREIRA, B. et al. Hydrodynamic modeling and motion limits of auv mares. In: IEEE. IECON - Industrial Electronics Conference. Porto, Portugal, 2009. p. 2241-2246. ISSN 1553-572X. Citado 5 vezes nas páginas 43, 48, 101, 103 e 104.

17 PATERSON, E. G.; WILSON, R. V.; STERN, F. General-purpose parallel unsteady RANS ship hydrodynamics code: CFD ship-iowa. IIHR report, v. 432, n. 432, p. 115, 2003. Citado 3 vezes nas páginas 44, 69 e 105.

18 GUSTAFSSON, H. et al. State of the Art CFD Analysis for Hydrodynamic Design in Submarine Development. [S.1.], 2006. Citado 3 vezes nas páginas 44, 69 e 105.

19 TYAGI, A.; SEN, D. Calculation of transverse hydrodynamic coefficients using computational fluid dynamic approach. Ocean Engineering, v. 33, n. 5-6, p. 798-809, 2006. Disponível em: <http://linkinghub.elsevier.com/retrieve/pii/S0029801805001848>. Citado 7 vezes nas páginas 44, 45, 51, 70, 71, 102 e 157.

20 BARROS, E. de et al. Investigation of normal force and moment coefficients for an AUV at nonlinear angle of attack and sideslip range. Oceanic Engineering, IEEE Journal of, v. 33, n. 4, p. 538 -549, out. 2008. ISSN 0364-9059. Citado 25 vezes nas páginas 44, 45, 50, 51, 69, 70, 71, 72, 101, 102, 103, 105, 106, 109, 112, 114, 115, 121, 157, 158, 178, 195, 208, 237 e 295.

21 JAGADEESH, P.; MURALI, K.; IDICHANDY, V. G. Experimental investigation of hydrodynamic force coefficients over AUV hull form. Ocean Engineering, v. 36, n. 1, p. 113-118, 2009. Disponível em: <http://linkinghub.elsevier.com/retrieve/pii/ S0029801808002412>. Citado 10 vezes nas páginas 44, 45, 51, 70, 71, 102, 103, 135, 138 e 157.

22 JEANS, T. L. et al. A force estimation method for viscous separated flow over slender axisymmetric bodies with tapered tails. Journal of Ship Research, v. 54, n. 1, p. 53-67, 2010. Disponível em: <http://www.ingentaconnect.com/content/sname/jsr/2010/ 00000054/00000001/art00005>. Citado 10 vezes nas páginas 44, 45, 50, 51, 69, 70, 71, 101, 102 e 157.

23 TOXOPEUS, S. L. Practical Application of Viscous-Flow Calculations for the Simulation of Manoeuvring Ships. Tese (Tese de doutorado) - Delft University of Technology, Wageningen, Holanda, maio 2011. Citado 7 vezes nas páginas 44, 47, 49, 51, 52,71 e 243. 
24 PHILliPS, A.; FURLONG, M.; TURNOCK, S. The use of computational fluid dynamics to determine the dynamic stability of an autonomous underwater vehicle. In: 10th Numerical Towing Tank Symposium (NuTTS'07). Hamburg, Germany: [s.n.], 2007. p. 6. Citado 12 vezes nas páginas 11, 44, 45, 51, 69, 70, 72, 77, 78, 102, 157 e 207.

25 PHILliPS, A.; TURNOCK, S.; FURLONG, M. Comparisons of cfd simulations and in-service data for the self propelled performance of an autonomous underwater vehicle. In: OF NAVAL RES. 27th Symp. of Naval Hydrodynamics. Seoul, Korea, 2008. p. 15. Citado 4 vezes nas páginas 44, 45, 71 e 157.

26 PHILLIPS, A. B.; TURNOCK, S. R.; FURLONG, M. Influence of turbulence closure models on the vortical flow field around a submarine body undergoing steady drift. Journal of Marine Science and Technology, v. 15, n. 3, p. 201-217, 2010. Disponível em: $<$ http://eprints.soton.ac.uk/178975/>. Citado 11 vezes nas páginas 44, 45, 46, 47, 51, 71, 102, 158, 160, 166 e 173.

27 SONG, F. X. et al. On resistance calculation for autonomous underwater vehicles. Advanced Materials Research, v. 189-193, p. 1745-1748, 2011. Citado 12 vezes nas páginas 44, 45, 46, 47, 51, 71, 102, 157, 158, 160, 172 e 173.

28 BARROS, E. A. de; DANTAS, J. L. D. Effect of a propeller duct on AUV maneuverability. Ocean Engineering, v. 42, p. 61 - 70, 2012. ISSN 0029-8018. Disponível em: <http://www.sciencedirect.com/science/article/pii/S0029801812000297>. Citado 22 vezes nas páginas 44, 45, 50, 52, 64, 70, 71, 72, 101, 102, 103, 105, 107, 123, 124, 126, 127, 128, 158, 204, 206 e 295.

29 DANTAS, J.; BARROS, E. de. Numerical analysis of control surface effects on AUV manoeuvrability. Applied Ocean Research, v. 42, p. 168 - 181, 2013. ISSN 0141-1187. Disponível em: <http://www.sciencedirect.com/science/article/pii/S014111871300045X>. Citado 8 vezes nas páginas 44, 45, 46, 47, 71, 72, 102 e 218.

30 PHILLIPS, A.; FURLONG, M.; TURNOCK, S. Virtual planar motion mechanism tests of the autonomous underwater vehicle Autosub. In: STG-Conference / Lectureday "CFD in Ship Design". Hamburg, Germany: [s.n.], 2007. p. 8. Citado 6 vezes nas páginas 44, 45, 51, 77, 102 e 166.

31 TOXOPEUS, S. et al. Collaborative CFD exercise for a submarine in a steady turn. In: OMAE2012 - 31st Int. Conf. on Ocean, Offshore and Arctic Eng. Rio de Janeiro, Brasil: ASME, 2012. Citado 14 vezes nas páginas 44, 45, 46, 47, 51, 69, 70, 71, 72, 78, 91, 102,135 e 157.

32 FUJII, K. Progress and future prospects of CFD in aerospace - wind tunnel and beyond. Progress in Aerospace Sciences, v. 41, n. 6, p. 455-470, 2005. Citado 10 vezes nas páginas 47, 52, 69, 72, 81, 82, 85, 105, 128 e 165.

33 ASME. Norma, Standard for Verification and Validation in Computational Fluid Dynamics and Heat Transfer. 2009. Citado 35 vezes nas páginas 18, 47, 50, 51, 52, 53, 70, 71, 89, 90, 91, 92, 93, 95, 96, 98, 99, 158, 162, 184, 185, 186, 187, 230, 231, 244, 246, 254, $263,267,268,270,273,345$ e 351.

34 VAZ, G.; TOXOPEUS, S.; HOLMES, S. Calculation of manoeuvring forces on submarines using two viscous-flow solvers. In: OMAE2010. ASME 
29th International Conference on Ocean, Offshore and Arctic Engineering. Shanghai, China: ASME, 2010. v. 2010, n. 49149, p. 621-633. Disponível em: <http://link.aip.org/link/abstract/ASMECP/v2010/i49149/p621/s1>. Citado 3 vezes nas páginas 47, 51 e 91.

35 EÇA, L.; VAZ, G.; HOEKSTRA, M. Code verification, solution verification and validation in RANS solvers. ASME Conference Proceedings, ASME, v. 2010, n. 49149, p. 597-605, 2010. Disponível em: < http://link.aip.org/link/abstract/ASMECP/v2010/ i49149/p597/s1>. Citado 19 vezes nas páginas 47, 51, 52, 69, 71, 89, 90, 91, 92, 93, 94, 95, 96, 167, 168, 177, 203, 267 e 274 .

36 EÇA, L.; VAZ, G.; HOEKSTRA, M. A verification and validation exercise for the flow over a backward facing step. In: PEREIRA, J. C. F.; SEQUEIRA, A. (Ed.). V European Conference on Computational Fluid Dynamics. Lisbon, Portugal: [s.n.], 2010. Citado 19 vezes nas páginas 47, 69, 71, 79, 90, 91, 92, 93, 94, 96, 97, 167, 184, 186, 187, 189, 194, 202 e 204.

37 TANG, S. et al. Estimation of the hydrodynamic coefficients of the complexshaped autonomous underwater vehicle TUNA-SAND. Journal of Marine Science and Technology, v. 14, n. 3, p. 373-386, 2009. Disponível em: <http: //www.springerlink.com/index/10.1007/s00773-009-0055-4>. Citado 12 vezes nas páginas 48, 49, 52, 69, 70, 128, 129, 135, 140, 157, 217 e 218.

38 BETtLe, M. C.; GERBER, A. G.; WATT, G. D. Unsteady analysis of the six $\{\mathrm{DOF}\}$ motion of a buoyantly rising submarine. Computers $\mathcal{E}$ Fluids, v. 38, n. 9, p. 1833 - 1849, out. 2009. ISSN 0045-7930. Disponível em: <http://www.sciencedirect.com/science/article/pii/S0045793009000577>. Citado 3 vezes nas páginas 49, 128 e 129.

39 DANTAS, J. L. D. et al. Experimental research on AUV manoeuvrability. In: COBEM 2011 - 21st International Congress of Mechanical Engineering. Natal-RN, Brasil: ABCM, 2011. Citado 17 vezes nas páginas 49, 102, 103, 135, 136, 138, 157, 158, 167, 175, 178, 180, 181, 182, 187, 203 e 295.

40 CARRICA, P. et al. Turn and zigzag maneuvers of a surface combatant using a URANS approach with dynamic overset grids. Journal of Marine Science and Technology, Springer Japan, v. 18, n. 2, p. 166-181, jun. 2013. ISSN 0948-4280. Disponível em: <http://dx.doi.org/10.1007/s00773-012-0196-8>. Citado 3 vezes nas páginas 49, 128 e 129 .

41 SAKAMOTO, N.; CARRICA, P.; STERN, F. Urans simulations of static and dynamic maneuvering for surface combatant: part 2. analysis and validation for local flow characteristics. Journal of Marine Science and Technology, Springer Japan, v. 17, n. 4, p. 446-468, dez. 2012. ISSN 0948-4280. Disponível em: <http://dx.doi.org/10.1007/s00773-012-0184-z>. Citado 3 vezes nas páginas 49, 128 e 129 .

42 LESIEUTRE, D. J.; LOVE, J. F.; DILLENIUS, M. F. E. High angle of attack missile aerodynamics including rotational rates - program M3HAX. AIAA Atmospheric Flight Mechanics Conference, jul. 1996. Citado 11 vezes nas páginas 50, 101, 106, 109, 113, 114, 115, 207, 208, 209 e 210. 
43 LESIEUTRE, D. J.; LOVE, J. F.; DILlENIUS, M. F. E. Prediction of the nonlinear aerodynamic characteristics of tandem-control and rolling-tail missiles. AIAA Atmospheric Flight Mechanics Conference, p. 12, ago. 2002. Citado 5 vezes nas páginas 50, 101, 106, 109 e 113.

44 BARROS, E. A. de; PASCOAL, A. M.; SA, E. de. Investigation of a method for predicting AUV derivatives. Ocean Engineering, v. 35, n. 16, p. 1627 - 1636, 2008. ISSN 0029-8018. Citado 9 vezes nas páginas 50, 72, 102, 105, 111, 121, 157, 158 e 295.

45 ITTC. Validation of Manoeuvring Simulation Models. [S.1.], 2011. Disponível em: $<$ http://ittc.sname.org/>. Citado 3 vezes nas páginas 51, 52 e 270.

46 WORKSHOP on Verification and Validation of Ship Manoeuvering Simulation Methods, v. 1 de SIMMAN 2008, (SIMMAN 2008, v. 1). Disponível em: < http: //www.simman2008.dk/>. Citado 2 vezes nas páginas 51 e 90.

47 STERN, F. et al. Experience from simman 2008: The first workshop on verification and validation of ship maneuvering simulation methods. Journal of Ship Research, v. 55, n. 2, p. 135-147, 2011. Citado na página 51.

48 DANTAS, J. L. D. et al. Analysis of identification methods applied to free model tests of the pirajuba auv. In: 9th IFAC Conference on Control Applications in Marine Systems. Osaka, Japão: IFAC, 2013. Citado 6 vezes nas páginas 52, 135, 139, 143, 218 e 297.

49 DANTAS, J. L. D. et al. Experimental research on underwater vehicle manoeuverability using the AUV pirajuba. In: COBEM2013 - 22nd International Congress of Mechanical Engineering. Ribeirão Preto, Brasil: ABCM, 2013. Citado 7 vezes nas páginas 52, 135, 139, 143, 233, 297 e 298.

50 SEN, D. A study on sensitivity of maneuverability performance on the hydrodynamic coefficients for submerged boddies. Journal of Ship Reasearch, v. 44, n. 3, p. 186-196, set. 2000. Citado 2 vezes nas páginas 53 e 230.

51 DANTAS, J. L. D. Software de Simulação Hardware-in-the-Loop para a Simulaçao do Sistema de Navegaçao e Controle de Veículos Autônomos Submarinos. Dissertação (Monografia de Conclusão de Curso) - Escola Politécnica da Universidade de São Paulo, 2008. Citado 3 vezes nas páginas 55, 60 e 106.

52 DANTAS, J. L. D.; BARROS, E. A. de. A real-time simulator for AUV development. In: ABCM (Ed.). Proceedings of COBEM 2009 - 20th International Congress of Mechanical Engineering. Gramado, Brasil: [s.n.], 2009. Citado 2 vezes nas páginas 55 e 101.

53 DANTAS, J. L. D.; BARROS, E. A. de; CRUZ, J. J. da. Longitudinal control of Pirajuba autonomous underwater vehicle, using techniques of robust control LQG/LTR. In: IFAC. CAMS 2010. [S.1.], 2010. p. 6. Citado 4 vezes nas páginas 55, 60, 101 e 105.

54 DANTAS, J.; BARROS, E. de; CRUZ, J. J. da. AUV control in the diving plane subject to waves. In: IFAC - INTERNATIONAL FEDERATION OF AUTOMATIC CONTROL. 9th IFAC Conference on Manoeuvring and Control of Marine Craft MCMC2012. Arenzano - GE, 2012. p. 1-6. Citado 5 vezes nas páginas 55, 60, 101, 105 e 206. 
55 LIU, S.; WANG, D.; POH, E. Non-linear output feedback tracking control for auvs in shallow wave disturbance condition. International Journal of Control, v. 81, n. 11, p. 1806-1823, 2008. Disponível em: <http://www.tandfonline.com/doi/abs/10.1080/ 00207170801898885>. Citado na página 55.

56 MOREIRA, L.; GUEDES-SOARES, C. Designs for diving and course control of an autonomous underwater vehicle in presence of waves. Oceanic Engineering, IEEE Journal of, v. 33, n. 2, p. 69 -88, april 2008. ISSN 0364-9059. Citado na página 55.

57 BARROS, E. A. de; PASCOAL, A. M.; Sá, E. de. AUV dynamics: modeling and parameter estimation using analytical, semi-empirical, and CFD methods. Proc. of CAM's 2004, 2004. Citado 3 vezes nas páginas 55, 105 e 295.

58 BARROS, E. A. de; PASCOAL, A. M.; Sá, E. de. Progress towards a method for predicting AUV maneuvers. In: MCMC2006 - 7th IFAC Conference on Manoeuvring and Control of Marine Craft. Lisbon, Portugal: [s.n.], 2006. p. 8. Citado 4 vezes nas páginas $55,105,123$ e 295.

59 MILLER, P. et al. Autonomous underwater vehicle navigation. Oceanic Engineering, IEEE Journal of, v. 35, n. 3, p. 663 -678, jul. 2010. ISSN 0364-9059. Citado na página 55.

60 DANTAS, J. L. D.; BARROS, E. A. de. ABCM symposium series in mechatronics. In: . [S.l.]: ABCM Brazilian Society of Mechanical Sciences and Engineering, 2010. v. 4, cap. A Real-Time Simulator for AUV Development, p. 449 - 508. Citado 2 vezes nas páginas 55 e 219 .

61 SNAME. Nomenclature for Treating the Motion of a Submerged Body Through a Fluid. [S.1.], 1950. Citado 8 vezes nas páginas 17, 55, 56, 68, 104, 107, 108 e 168.

62 FOnSECA, M. M. Arte Naval. 4. ed. Rio de Janeiro: Serviçoo de Documentação Geral da Marinha, 1984. Citado 3 vezes nas páginas 17, 55 e 56.

63 BROWN, R. G.; HWANG, P. Y. C. Introduction to Random Signals and Applied Kalman Filtering. Wiley, 1997. 502 p p. Disponível em: < http: //citeseerx.ist.psu.edu/viewdoc/summary?doi=10.1.1.147.3436> . Citado na página 58.

64 ISHIDERA, H. et al. Simulation and experiment of automatic controlled ROV. In: Proceedings of 5th International Offshore, Mechanical and Artic Engineering Symposium. [S.l.: s.n.], 1986. p. 260-267. Citado 2 vezes nas páginas 58 e 60.

65 BARROS, E. A. de; FREIRE, L. O.; DANTAS, J. L. D. Development of the pirajuba AUV. In: Proceedings of CAMS 2010 - Control Applications in Marine Systems. [S.l.: s.n.], 2010. Citado 3 vezes nas páginas 58, 296 e 298.

66 BARROS, E. A. de et al. New aspects in the Pirajuba AUV project. In: ABCM (Ed.). COBEM 2011 - 21st International Congress of Mechanical Engineering. Natal, RN, Brazil: [s.n.], 2011. Citado 3 vezes nas páginas 58, 296 e 298.

67 LEWANDOWSKI, E. M. The Dynamics of Marine Craft - Maneuvering and Seakeeping. World Scientific Publishing Co. Pte. Ltd., 2004. 19, 40-42 p. (Advanced Series on Ocean Engineering, v. 22). ISBN 981-02-4756-7. Disponível em: <http://ebooks.worldscinet.com/ISBN/9789812562678/9789812562678.html>. Citado 2 vezes nas páginas 60 e 157. 
68 LEWIS, E. V. Principles of Naval Architecture. Jersey City, NJ: Society of Naval Architects and Marine Engineers (U.S.), 1988. Citado 7 vezes nas páginas 11, 63, 103, $105,117,135$ e 231.

69 JACKSON, H. A. Fundamental of submarine concept design. SNAME Transactions, v. 100, p. 419-448, out. 1992. Citado 4 vezes nas páginas 64, 127, 204 e 206.

70 CAMPOS, J. Falcão de. On the Calculation of Ducted Propeller Performance in Axisymmetric Flows. Tese (Doutorado) — Delft University, 1983. Citado na página 64.

71 HOEKSTRA, M. A rans-based analysis tool for ducted propeller systems in open water condition. International Shipbuilding Progress, v. 53, n. 3, p. 205-227, jan. 2006. Disponível em: <http://iospress.metapress.com/content/73VE7EPXN8JDBK5W>. Citado na página 64.

72 WHITCOMB, L.; YOERGER, D. Comparative experiments in the dynamics and model-based control of marine thrusters. In: Proceedings of OCEANS '95. MTS/IEEE. Challenges of Our Changing Global Environment. [S.l.: s.n.], 1995. v. 2, p. 1019-1028. Citado na página 64.

73 BACHMAYER, R.; WHITCOMB, L.; GROSENBAUGH, M. A four quadrant finite dimensional thruster model. In: Proceedings of OCEANS'98 Conference. [S.l.: s.n.], 1998. v. 2, p. 660-666. Citado na página 64.

74 NEWMAN, J. N. Panel methods in marine hydrodynamics. In: 11th Australasian Fluid Mechanics Conference. Hobart, Australia: [s.n.], 1992. Citado 3 vezes nas páginas 65,66 e 69.

75 IMLAY, F. H. The Complete Expressions for Added Mass of a Rigid Body in an Ideal Fluid. [S.l.], 1961. Citado 6 vezes nas páginas 65, 66, 68, 234, 235 e 305.

76 PERRAULT, D. et al. Sensitivity of auv added mass coefficients to variations in hull and control plane geometry. Ocean Engineering, v. 30, n. 5, p. 645 - 671, 2003. ISSN 0029-8018. Disponível em: < http://www.sciencedirect.com/science/article/ B6V4F-45TTJK4-F/2/9aa8714ce0f64535ebf5f318639fc037>. Citado na página 66.

77 LIN, Z.; LIAO, S. Calculation of added mass coefficients of 3D complicated underwater bodies by FMBEM. Communications in Nonlinear Science and Numerical Simulation, v. 16, n. 1, p. 187 - 194, 2011. ISSN 1007-5704. Citado 2 vezes nas páginas 66 e 69.

78 NEWMAN, J. N. Book. Marine hydrodynamics. [S.l.]: MIT Press, Cambridge, Massachusetts, 1977. 402 p. ISBN 0262140268 0262140268. Citado 3 vezes nas páginas 66, 69 e 231.

79 NIELSEN, J. N. Missile Aerodynamics. 1st. ed. [S.l.]: AIAA - American Institute of Aeronautics \& Ast, 1988. 450 p. (Library of Flight Series). Citado 4 vezes nas páginas 66, 231, 309 e 310.

80 MILGRAM, J. Strip theory for underwater vehicles in water of finite depth. Journal of Engineering Mathematics, Springer Netherlands, v. 58, p. 31-50, 2007. ISSN 0022-0833. 10.1007/s10665-006-9101-y. Disponível em: <http: //dx.doi.org/10.1007/s10665-006-9101-y>. Citado na página 66. 
81 JAMESON, A. A perspective on computational algorithms for aerodynamic analysis and design. In: Progress in Aerospace Sciences. [S.l.: s.n.], 2001. p. 197-243. Citado 5 vezes nas páginas $69,72,81,82$ e 165 .

82 MILGRAM, J. Strip theory for underwater vehicles in water of finite depth. Journal of Engineering Mathematics, Springer Netherlands, v. 58, p. 31-50, 2007. ISSN 0022-0833. 10.1007/s10665-006-9101-y. Disponível em: <http: //dx.doi.org/10.1007/s10665-006-9101-y>. Citado na página 69.

83 FALTINSEN, O. M. Sea Loads on Ships and Offshore Structures. [S.l.]: Cambridge University Press, 1990. 328 p. (Cambridge Ocean Technology Series). ISBN: 052145870 6. Citado 6 vezes nas páginas 69, 103, 106, 155, 157 e 231.

84 FOSSEN, T. I. Marine control systems: guidance, navigation, and control of ships, rigs and underwater vehicles. 1st. ed. Trondheim, Norway: Marine Cybernetics AS, 2002. ISBN 82-92356-00-2. Disponível em: <http://books.google.com.pe/books?id= B3ZwQgAACAAJ>. Citado 8 vezes nas páginas 69, 103, 141, 144, 155, 157, 220 e 231.

85 PHILliPS, A. B.; TURNOCK, S. R.; FURLONG, M. The use of computational fluid dynamics to aid cost-effective hydrodynamic design of autonomous underwater vehicles. Proceedings of the Institution of Mechanical Engineers, Part M: Journal of Engineering for the Maritime Environment, v. 224, n. 4, p. 239-254, 2010. Disponível em: $<$ http://pim.sagepub.com/content/224/4/239.abstract>. Citado 7 vezes nas páginas 69, $70,71,72,105,128$ e 157.

86 KIMBER, N. I.; SCRIMSHAW, K. H. Hydrodynamic testing of a 3/4 scale Autosub model. In: Oceanology International 94. [S.l.: s.n.], 1994. Citado 6 vezes nas páginas 70, 102, 103, 135, 157 e 217.

87 SINGH, S. N.; SIMHA, A.; MITTAL, R. Biorobotic AUV maneuvering by pectoral fins: Inverse control design based on CFD parameterization. IEEE Journal of Oceanic Engineering, v. 29, n. 3, p. 777-785, 2004. Disponível em: $<$ http://ieeexplore.ieee.org/lpdocs/epic03/wrapper.htm?arnumber $=1353430>$. Citado na página 70.

88 LAUDER, G. V. et al. Design and performance of a fish fin-like propulsor for AUVs. Proceedings of 14th International Symposium on Unmanned Untethered Submersible Technology (UUST), p. 1-13, 2005. Citado na página 70.

89 YAMAMOTO, I. Research and development of past, present and future AUV technologies. In: TECHNOLOGY, S. for U. (Ed.). Masterclass in AUV Technology for Polar Science. [S.l.]: British Library, 2007. (469, 4), p. 99-102. Citado na página 71.

90 INOUE, T. et al. Hull form design of underwater vehicle applying CFD (Computational Fluid Dynamics). IEEE, 2010. 1-5 p. Disponível em: <http: //ieeexplore.ieee.org/xpls/abs_all.jsp?arnumber=5603875> . Citado na página 71.

91 HUSAINI, M.; SAMAD, Z.; ARSHAD, M. R. Optimum design of URRG-AUV propeller using PVL. In: 2nd Technical Seminar on Underwater System Technology: Breaking New Frontiers 2008. [S.l.: s.n.], 2008. Citado na página 71. 
92 WU, L. Applying dynamic hybrid grids method to simulate AUV docking with a tube. In: Information and Automation (ICIA), 2010 IEEE International Conference on. [S.l.: s.n.], 2010. p. 1363 -1366. Citado na página 71.

93 HUSAINI, M.; SAMAD, Z.; ARSHAD, M. R. CFD simulation of cooperative AUV motion. Indian Journal of Marine Sciences, v. 38, n. 3, p. 346-351, set. 2009. Citado na página 71.

94 ANSYS. ANSYS FLUENT 13.0 Theory Guide. [S.l.], 2012. Citado 17 vezes nas páginas 11, 73, 76, 79, 81, 83, 84, 85, 86, 88, 89, 92, 128, 159, 173, 174 e 176.

95 EÇA, L.; HOEKSTRA, M. Evaluation of numerical error estimation based on grid refinement studies with the method of the manufactured solutions. Computers Eamp; Fluids, v. 38, n. 8, p. 1580 - 1591, 2009. ISSN 0045-7930. Disponível em: $<$ http://www.sciencedirect.com/science/article/pii/S0045793009000048>. Citado 3 vezes nas páginas 79, 92 e 96.

96 POPE, S. B. Turbulent Flows. [S.l.]: Cambridge University Press, 2000. Citado 4 vezes nas páginas $81,82,88$ e 89.

97 SMAGORINSKY, J. General circulation experiments with the primitive equations. Monthly Weather Review, American Meteorological Society, v. 91, n. 3, p. 99-164, 1963. Citado na página 81.

98 SPALART, P. R.; ALLMARAS, S. R. A one-equation turbulence model for aerodynamic flows. In: AMERICAN INSTITUTE OF AERONAUTICS AND ASTRONAUTICS. Aerospace Sciences Meeting and Exhibit. Reno, NV, USA, 1992. p. 23. Citado na página 84.

99 KADER, B. A. Temperature and concentration profiles in fully turbulent boundary layers. International Journal of Heat and Mass Transfer, v. 24, n. 9, p. 1541 - 1544, 1981. ISSN 0017-9310. Disponível em: <http://www.sciencedirect.com/science/article/pii/ 0017931081902209>. Citado na página 85.

100 LAUNDER, B. E.; SPALDING, D. B. Book. Lectures in mathematical models of turbulence. [S.l.]: Academic Press Inc, London, New York, 1972. 169 p. ISBN 0124380506. Citado na página 85.

101 YAKHOT, V.; ORSZAG, S. A. Renormalization-group analysis of turbulence. Phys. Rev. Lett., American Physical Society, v. 57, n. 14, p. 1722-1724, out. 1986. Disponível em: < http://link.aps.org/doi/10.1103/PhysRevLett.57.1722>. Citado na página 85.

102 SHIH, T. H. et al. A new $k-\epsilon$ eddy viscosity model for high reynolds number turbulent flows: Model development and validation. Computers and Fluids, v. 24, n. 3, p. 227-238, 1994. Citado na página 85.

103 ORSZAG, S. et al. Renormalization group modeling and turbulence simulations. In: International Conference on Near-Wall Turbulent Flows. Tempe, Arizona: [s.n.], 1993. Citado na página 86.

104 WILCOX, D. C. Turbulence Modeling for CFD. La Cañada, CA: DCW Industries Inc., 1993. Citado 3 vezes nas páginas 86, 88 e 89 . 
105 MENTER, F. R. Two-equation eddy-viscosity turbulence models for engineering applications. AIAA Journal, American Institute of Aeronautics and Astronautics, v. 32, n. 8, p. 1598-1605, 1994. Disponível em: <http://doi.aiaa.org/10.2514/3.12149>. Citado na página 86 .

106 MENTER, F. R.; KUNTZ, M.; LANGTRY, R. Ten years of experience with the SST turbulence model. Turbulence Heat and Mass Transfer, v. 4, p. 625-632, 2003. Citado na página 86.

107 MENTER, F. R. et al. A correlation-based transition model using local variables Part I: Model formulation. Journal of Turbomachinery, ASME, v. 128, n. 3, p. 413-422, 2006. Disponível em: < http://link.aip.org/link/?JTM/128/413/1>. Citado na página 87.

108 LANGTRY, R. B. et al. A correlation-based transition model using local variables Part II: Test cases and industrial applications. Journal of Turbomachinery, ASME, v. 128, n. 3, p. 423-434, 2006. Disponível em: < http://link.aip.org/link/?JTM/128/423/1>. Citado na página 87.

109 LAUNDER, B. E.; REECE, G. J.; RODI, W. Progress in the development of a Reynolds-stress turbulence closure. Journal of Fluid Mechanics, v. 68, n. 03, p. 537-566, 1975. Disponível em: <http://dx.doi.org/10.1017/S0022112075001814>. Citado na página 88.

110 GIBSON, M. M.; LAUNDER, B. E. Ground effects on pressure fluctuations in the atmospheric boundary layer. Journal of Fluid Mechanics, v. 86, n. 03, p. 491-511, 1978. Disponível em: <http://dx.doi.org/10.1017/S0022112078001251>. Citado na página 88.

111 LAUNDER, B. E. Second-moment closure: present... and future? International Journal of Heat and Fluid Flow, v. 10, n. 4, p. 282 - 300, 1989. ISSN 0142-727X. Disponível em: <http://www.sciencedirect.com/science/article/pii/0142727X89900179>. Citado na página 88.

112 ROACHE, P. J. Verification and Validation in Computational Science and Engineering. [S.l.]: Hermosa Publishers, 1998. 8-9 p. Citado 6 vezes nas páginas 89, 90, 91, 92,93 e 97.

113 AIAA. AIAA Guide for the Verification and Validation of Computational Fluid Dynamics Simulations (G-07\%-1998). [S.1.]: American Institute of Aeronautics \& Astronautics, 1998. 19 p. ISBN 1563472856. Citado na página 90.

114 STERN, F. et al. Verification and validation of CFD simulations. [S.1.], 1999. Citado 5 vezes nas páginas 11, 90, 93, 94 e 99.

115 STERN, F. et al. Comprehensive approach to verification and validation of CFD simulations - Part 1: Methodology and procedures. Journal of Fluids Engineering, ASME, v. 123, n. 4, p. 793-802, 2001. Disponível em: <http://link.aip.org/link/?JFG/123/793/1>. Citado na página 90.

116 WILSON, R. V. et al. Comprehensive approach to verification and validation of CFD simulations - Part 2: Application for RANS simulation of a cargo/container ship. Journal of Fluids Engineering, ASME, v. 123, n. 4, p. 803-810, 2001. Disponível em: <http://link.aip.org/link/?JFG/123/803/1>. Citado na página 90. 
117 A Workshop on CFD in Ship Hydrodynamics. Citado na página 90.

118 EÇA, L. et al. Verification of RANS solvers with manufactured solutions. Engineering with Computers, Springer London, v. 23, p. 253-270, 2007. ISSN 0177-0667. 10.1007/s00366007-0067-9. Disponível em: <http://dx.doi.org/10.1007/s00366-007-0067-9>. Citado 2 vezes nas páginas 90 e 91.

119 SALAS, M. D. Some observations on grid convergence. Computers \& Fluids, v. 35, n. 7, p. 688 - 692, ago. 2006. ISSN 0045-7930. Disponível em: <http://www.sciencedirect.com/science/article/pii/S0045793006000053>. Citado na página 95.

120 DANTAS, J. L. D.; CRUZ, J. J. da; BARROS, E. A. de. Controle logitudinal do veículo autônomo submarino pirajuba, utilizando técnicas de controle robusto LQG/LTR. In: IFAC. CBA 2010. [S.1.], 2010. p. 8. Citado 3 vezes nas páginas 17, 101 e 161.

121 JORGENSEN, L. H. Prediction of static aerodynamic characteristics for slender bodies alone and with lifting surfaces to very high angles of attack. [S.l.], 1977. Citado 12 vezes nas páginas 11, 101, 103, 106, 111, 112, 113, 114, 138, 139, 180 e 238.

122 FINK, R. D. USAF Stability and Control DATCOM. Wright-Patterson afb, Ohio 45433, 1978. Citado 14 vezes nas páginas 101, 103, 105, 106, 107, 109, 111, 117, 120, 125, $127,128,231$ e 237.

123 EGESKOV, P. et al. Design, construction and hydrodynamic testing of the AUV MARIUS. In: Autonomous Underwater Vehicle Technology, 1994. AUV'94., Proceedings of the 1994 Symposium on. [S.l.: s.n.], 1994. p. 199 -207. Citado 5 vezes nas páginas 102, 103, 135, 157 e 217.

124 AZARSINA, F.; WILLIAMS, C. D. Manoeuvring simulation of the MUN Explorer AUV based on the empirical hydrodynamics of axi-symmetric bare hulls. Applied Ocean Research, v. 32, n. 4, p. 443 - 453, 2010. ISSN 0141-1187. Citado 5 vezes nas páginas 102, 103, 135, 138 e 157 .

125 BARROS, E. A. de; DANTAS, J. L. D. Metodologia analítica e semi-empírica de cálculo dos esforços hidrodinâmicos do conjunto casco-hidroplanos de AUVs. [S.l.], 2008. Citado na página 103.

126 ROSKAM, J. Airplane Design - Part VI Preliminary Calculation of Aerodynamic, Thrust and Power Characteristic. [S.l.]: Roskam Aviation and Engineering Corporation, 1985. Citado 8 vezes nas páginas 11, 103, 105, 119, 120, 127, 166 e 231.

127 JUUL, D. et al. Submersible control using the linear quadratic Gaussian with loop transfer recovery method. In: Autonomous Underwater Vehicle Technology, 1994. AUV '94., Proceedings of the 1994 Symposium on. [S.l.: s.n.], 1994. p. 417 -425. Citado na página 105.

128 MAURYA, P. et al. Control of the MAYA AUV in the vertical and horizontal planes: Theory and practical results. In: IFAC. 7th IFAC Conference MCMC2006. [S.l.], 2006. p. 7. Citado na página 105.

129 SONG, F.; AN, P. E.; FOLLECO, A. Modeling and simulation of autonomous underwater vehicles: Design and implementation. IEEE Journal of Oceanic Engineering, v. 28, n. 2, p. 283-296, abr. 2003. Citado na página 106. 
130 DEVIE, F.; LEMAIRE, J. A flexible hardware in the loop simulator for a long range autonomous underwater vehicle. OCEANS'98 Conference Proceedings, v. 3, p. 1359-1363, set. 1998. Citado na página 106.

131 SILVESTRE, C. J. F. Multi-Objective Optimization Theory with Applications to the Integrated Design of Controllers / Plants for Autonomous Vehicles. Dissertação (Tese de Doutorado) - Universidade TÃ@cnica de Lisboa, Instituto Superior TÃ@Ccnico, Departamento de Engenharia ElectrotÃ@cnica e de Computadores, 1998. Citado na página 106.

132 MUNK, M. M. The Aerodynamie Forces on Airship Hulls. [S.l.], 1924. Citado 4 vezes nas páginas 106, 109, 110 e 113.

133 ESDU, A. Normal force and pitching moment of conical boat-tails. London, U.K., 1987. Citado 4 vezes nas páginas 106, 109, 112 e 115.

134 PITTS, W. C.; NIELSEN, J. N.; KAATTARI, G. E. Lift and Center of Pressure of Wing-Body-Tail Combinations at Subsonic, Transonic, and Supersonic Speeds. [S.l.], 1957. Citado 14 vezes nas páginas 106, 109, 112, 120, 121, 122, 195, 196, 199, 200, 207, 211, 212 e 214 .

135 BURNS, K. A.; BRUNS, K. D. Development of an improved carryover interference method for missile DATCOM. AIAA Atmospheric Flight Mechanics Conference, 1996. Citado 4 vezes nas páginas 107, 120, 122 e 244.

136 MORGAn, W. B.; CASTER, E. B. Prediction of the Aerodynamic Characteristics of Annular Airfoils. [S.l.], 1965. Citado 7 vezes nas páginas 11, 107, 124, 125, 190, 194 e 203.

137 ALLEN, J. H.; PERKINS, E. W. A Study of the Effects of Viscosity on Flow Over Slender Inclined Bodies of Revolution. [S.1.], 1951. Citado 2 vezes nas páginas 110 e 111.

138 WARD, G. N. Supersonic flow past slender pointed bodies. Quar. Jour. of Mech. and Applied Math, v. 2, n. 1, p. 75-97, 1949. Citado na página 110.

139 HOPKINS, E. J. A semi-empirical method for calculating the pitching moment of bodies of revolution at low Mach numbers. Washington, 1951. Citado 4 vezes nas páginas $111,112,115$ e 237.

140 BLAIR, A. B. J. et al. Recent applications and improvements to the engineering-level aerodynamic prediction software MISL3. 40th AIAA Aerospace Sciences Meeting and Exhibit, jan. 2002. Citado na página 113.

141 ANDERSON, J. D. Fundamentals of Aerodynamics. 3. ed. [S.l.]: McGraw-Hill Science/Engineering/Math, 2001. 912 p. (aeronautical and aerospace engineering). Citado 6 vezes nas páginas 11, 116, 117, 127, 166 e 307.

142 WHICKER, L. F.; FEHLNER, L. F. Free-Stream Characteristics of A Family of Low-Aspect-Ratio, All-Movable Control Surfaces for Application to Ship Design. Washington, D.C., 1958. Citado 3 vezes nas páginas 117, 118 e 181.

143 VOEPEL, H. Tests on Wings of Small Aspect Ratio. [S.l.], 1948. Citado na página 118. 
144 ESDU, A. Pitching moment and lift force derivatives due to rate of pitch for aircraft at subsonic speeds. London, U.K., 1987. Citado 3 vezes nas páginas 118, 119 e 243.

145 HEMSCH, M. J.; NIELSEN, J. N. Equivalent angle-of-attack method for estimating nonlinear aerodynamics of missile fins. Journal of Spacecraft and Rockets, v. 20, p. 356, 1983. Disponível em: < http://adsabs.harvard.edu/abs/1983JSpRo..20..356H>. Citado 9 vezes nas páginas 120, 121, 122, 123, 195, 200, 207, 212 e 275.

146 HEMSCH, M. J.; NIELSEN, J. N. Extension of equivalent angle-of-attack method for nonlinear flowfields. Journal of Spacecraft and Rockets, v. 22, p. 304, maio 1985.

Disponível em: <http://adsabs.harvard.edu/abs/1985JSpRo..22..304H>. Citado 4 vezes nas páginas 120, 121, 122 e 200.

147 MOORE, F. G.; MCINVILLE, R. M.; HYMER, T. The 1995 Version of the NSWC Aeroprediction Code: Part I - Summary of New Theoretical Methodology. [S.l.], 1995. Citado 2 vezes nas páginas 122 e 244.

148 HWANG, Y.-L. Hydrodynamic modeling of lmrs unmanned underwater vehicle and tow tank test validation. In: Proceedings of OCEANS 2003. [S.l.: s.n.], 2003. v. 3, p. 1425-1430. Citado 3 vezes nas páginas 123, 124 e 126.

149 ALVAREZ, A. Redesigning the slocum glider for torpedo tube launching. IEEE Journal of Oceanic Engineering, v. 35, n. 4, p. 984 - 991, out. 2010. ISSN 0364-9059. Citado 2 vezes nas páginas 124 e 126.

150 MCCORMICK, B. W. Effect of a center body on a ring wing. [S.l.], 1959. Citado 2 vezes nas páginas 124 e 126.

151 FLETCHER, H. S. Experimental Investigation of Lift, Drag, and Pitching Moment of Five Annular Airfoils. Langley Aeronautical Laboratory, Langley Field, Va, 1957. Citado 6 vezes nas páginas 13, 17, 124, 189, 190 e 191.

152 BOOR, C. de. A Practical Guide to Splines. [S.1.]: Springer, 2001. (Applied Mathematical Sciences, v. 27). Citado 2 vezes nas páginas 134 e 198.

153 RODDY, R. F. Investigation of the stability and control characteristics of several configurations of the DARPA SUBOFF model (DTRC Model 5470) from captivemodel experiments. [S.1.], 1990. Citado na página 135.

154 HUANG, T. T. et al. Measurements of flows over an axisymmetric body with various appendages in a wind tunnel: the DARPA SUBOFF experimental program. In: 19th Symposium on Naval Hydrodynamics. Seoul, South Korea: [s.n.], 1992. p. 312-346. Citado na página 135.

155 MARCO, D. B.; MARTINS, A.; HEALEY, A. J. Surge motion parameter identification for the NPS Phoenix AUV. In: UNIVERSITY OF SOUTH LOUISIANA. International Advanced Robotics Program IARP 98. [S.l.], 1998. p. 197-210. Citado 2 vezes nas páginas 135 e 157.

156 RENTSCHLER, M.; HOVER, F.; CHRYSSOSTOMIDIS, C. System identification of open-loop maneuvers leads to improved AUV flight performance. IEEE Journal of Oceanic Engineering, v. 31, n. 1, p. 200 -208, jan. 2006. ISSN 0364-9059. Citado 3 vezes nas páginas 135, 157 e 218. 
157 LIANG, X. et al. Model identification for autonomous underwater vehicles based on maximum likelihood relaxation algorithm. In: Computer Modeling and Simulation, 2010. ICCMS '10. Second International Conference on. [S.l.: s.n.], 2010. v. 1, p. $128-132$. Citado 3 vezes nas páginas 135, 157 e 218.

158 HERRERO, E. R.; GONZáLEZ, F. J. V. Two-step identification of non-linear manoeuvring models of marine vessels. Ocean Engineering, v. 53, p. 72 - 82, out. 2012. ISSN 0029-8018. Disponível em: <http://www.sciencedirect.com/science/article/pii/ S0029801812002429>. Citado 3 vezes nas páginas 135, 157 e 218.

159 BHATTACHARYYA, R. Dynamics of marine vehicles. New York: John Wiley \& Sons, 1978. ISBN 9780471072065. Citado na página 136.

160 GERTLER, M.; HAGEN, G. Handling Criteria for Surface Ships. Washington D.C., 1960. Citado na página 143.

161 KEMPF, G. Measurements of the propulsive and structural characteristic of ships. In: Transactions of SNAME. [S.l.: s.n.], 1932. v. 40, p. 42 - 57. Citado na página 144.

162 NOMOTO, K. Analysis of kempfs standard manoeuvre test and proposed steering quality indices. In: 1st Symposium on Ship Manoeuvrability. Washington, D.C., USA: [s.n.], 1960. p. 275-304. Citado 2 vezes nas páginas 144 e 218.

163 BUTTERWORTH, S. On the theory of filter amplifiers. Experimental Wireless Engineer, 7, p. 536-541, 1930. Citado na página 145.

164 LINDEBERG, T. Scale-space for discrete signals. Pattern Analysis and Machine Intelligence, IEEE Transactions on, v. 12, n. 3, p. 234-254, 1990. ISSN 0162-8828. Citado na página 145 .

165 OPPENHEIM, A. V.; SCHAFER, R. W.; BUCK, J. R. Discrete-time signal processing. 2nd. ed. New-Jersey, USA: Prentice-Hall, 1999. ISBN 0-13-754920-2. Citado na página 153.

166 FRIGO, M.; JOHNSON, S. FFTW: an adaptive software architecture for the FFT. In: Proc. of the 1998 IEEE Int. Conf. on Acoustics, Speech and Signal Processing. [S.l.: s.n.], 1998. v. 3, p. 1381-1384. ISSN 1520-6149. Citado na página 153.

167 COOLEY, J. W.; TUKEY, J. W. An algorithm for the machine calculation of complex fourier series. Mathematics of Computation, American Mathematical Society, v. 19, n. 90, p. 297-301, abr. 1965. ISSN 00255718. Disponível em: <http://www.jstor.org/stable/2003354>. Citado na página 153.

168 HEWITT, G.; WATERMAN, E. Phoenix Model Measurement and Bifilar Swinging. St. John's, NL, 2005. Citado 2 vezes nas páginas 157 e 297.

169 JACOBS, E. N.; SHERMAN, A. Airfoil section characteristics as affected by variations of the Reynolds number. [S.1.], 1939, v. 586, n. 586. Disponível em: <http://hdl.handle.net/2060/19930091662>. Citado 5 vezes nas páginas 12, 161, 163, 164 e 166. 
170 HALL, R.; WOODSON, S.; CHAMBERS, J. Overview of the abrupt wing stall program. Progress in Aerospace Sciences, v. 40, n. 7, p. 417-452, 2004. Disponível em: $<$ http://linkinghub.elsevier.com/retrieve/pii/S0376042104000582>. Citado na página 165.

171 TOXOPEUS, S.; VAZ, G. Calculation of current or manoeuvring forces using a viscous-flow solver. In: OMAE2009. ASME 28th International Conference on Ocean, Offshore and Arctic Engineering. Honolulu, Hawaii: ASME, 2009. p. 717-728. Disponível em: < http://link.aip.org/link/abstract/ASMECP/v2009/i43451/p717/s1>. Citado na página 178.

172 STEVENSON, P.; FURLONG, M.; DORMER, D. AUV shapes - combining the practical and hydrodynamic considerations. In: OCEANS 200\%. [S.l.: s.n.], 2007. p. 1 -6. Citado na página 180.

173 LJUNG, L. System Identification: theory for the user. New Jersey, United States: Prentice Hall, 1999. Citado na página 218.

174 AVILA, J. P.; DONHA, D. C.; ADAMOWSKI, J. C. Experimental model identification of open-frame underwater vehicles. Ocean Engineering, v. 60, n. 0, p. 81 94, 2013. ISSN 0029-8018. Disponível em: <http://www.sciencedirect.com/science/article/ pii/S0029801812003836>. Citado na página 218.

175 JOURNéE, J. A Simple Method for Determining Manoeuvring Indices $K$ and $T$ from Zigzag Trial Data. Netherlands, 1970. Citado na página 218.

176 KIM, K. et al. Estimation of hydrodynamic coefficients of a test-bed auv-snuuv i by motion test. In: OCEANS '02 MTS/IEEE. [S.l.: s.n.], 2002. v. 1, p. 186-190 vol.1. Citado na página 218.

177 CAEtano, W. da S. Identificação de Coeficientes de Manobra de Veículos Submarinos Através de Testes com Modelos Livres. Dissertação (Tese de mestrado) Escola Politécnica da Universidade de São Paulo, 2013. Citado 6 vezes nas páginas 18, 220, 297, 298, 299 e 300.

178 KOROTKIN, A. I. Added Masses of Ship Structures. [S.l.]: Springer Netherlands, 2009. 81-102 p. (Fluid Mechanics and its Applications, v. 88). Citado 7 vezes nas páginas 234, 235, 305, 307, 308, 309 e 310.

179 BELOCERKOVVSKY, S. M. Thin lifting surface in subsonic flow of gas. Moscow, Russia, 1965. Citado 3 vezes nas páginas 234, 235 e 307.

180 POLHAMUS, E. C. A Review of Some Reynolds Number Effects Related to Bodies at High Angles of Attack. [S.l.], 1984. Citado na página 238.

181 DESA, E. et al. The small Maya AUV - initial field results. International Ocean Systems, v. 11, n. 1, p. 6-8, 2007. Citado na página 295.

182 MYRING, D. F. A theoretical study of body drag in subcritical axisymmetric flow. Aeronautical Quartely, v. 27, n. 3, p. 186-194, ago. 1976. Citado 2 vezes nas páginas 295 e 296.

183 LAMB, S. H. Hydrodynamics. 6. ed. New York: Dover Publication, 1945. 9 - 160 p. Citado na página 305. 
184 KATZ, J.; PLOTKIN, A. Low-Speed Aerodynamics. 2nd. ed. [S.l.]: Cambridge

University Press, 2001. (Cambridge Aerospace Series (Book 13)). Citado na página 307. 
Apêndices 



\section{APÊNDICE A - O VEÍCULO SUBMARINO AUTÔNOMO PIRAJUBA}

O veículo autônomo submarino (AUV) Pirajuba foi desenvolvido pelo Laboratório de Veículos Não Tripulados (LVNT) da Universidade de São Paulo (USP). Seu projeto teve início no começo de 2007, com o objetivo de desenvolver uma plataforma de validação experimental para apoiar a pesquisa de investigação de derivadas hidrodinâmicas ${ }^{[57,58,20]}$ e dos esforços hidrodinâmicos não lineares ${ }^{[44,28]}$ de veículos submarinos.

A geometria externa do casco do AUV Pirajuba foi originada do AUV Luso-Indiano Maya $^{[181]}$, que por sua vez já possuía semelhanças ao AUV americano Remus ${ }^{[14]}$. O Maya foi desenvolvido por um projeto entre o Instituto Superior Técnico de Lisboa (IST), mais especificamente o Instituto de Sistemas e Robótica (ISR), e o Instituto Nacional de Oceanografia da Índia (NOA). A cooperação do LVNT neste projeto foi dada pela

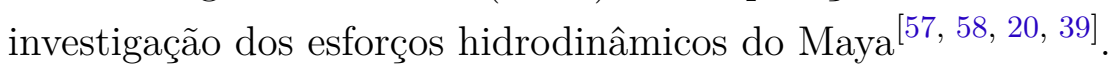

O casco do Pirajuba possui uma geometria comumente conhecida por tipo torpedo, que apresenta três partes axis-simétricas: popa (cauda), proa (nariz) e corpo central. A popa e a proa apresentam a distribuição semi-elíptica de Myring ${ }^{[182]}$, representadas pelas equações A.1 e A.2, respectivamente, enquanto o corpo central é composto de um cilindro. As características geométricas do casco deste veículo são apresentadas na tabela 28.

$$
\begin{gathered}
r(x)=\frac{1}{2} D\left[1-\left(\frac{x-L_{n}}{L_{n}}\right)^{2}\right]^{1 / n} \\
r(x)=\frac{D}{2}-\left(\frac{3 D}{2 L_{c}^{2}}-\frac{\tan (\theta)}{L_{c}}\right) x^{2}+\left(\frac{D}{L_{c}^{3}}-\frac{\tan (\theta)}{L_{c}^{2}}\right) x^{3}
\end{gathered}
$$

Este tipo de geometria é bastante empregada em AUVs comerciais e de pesquisa, por apresentar um bom aproveitamento do espaço interno para a disposição dos equipamentos, mantendo boas características hidrodinâmicas.

A principal diferença entre as geometrias do Maya e Pirajuba era encontrada na posição das superfícies de controle. Enquanto o Maya utiliza as superfícies dispostas em ' $T$ ' (duas horizontais e uma vertical apontada para baixo), o Pirajuba as utiliza em uma configuração 't' (duas verticais e duas horizontais), localizadas mais próximas a cauda do veículo. A configuração adotada no Pirajuba garante uma maior manobrabilidade, sem gerar os efeitos adversos de rolagem. Em sua nova versão, o projeto Maya adotou as superfícies de controle em configuração ',$+{ }^{,[181]}$. As superfícies de controle do AUV 
Tabela 28 - Parâmetros Geométricos do Corpo do AUV Pirajuba

\begin{tabular}{lcc}
\hline Parâmetro & Simbolo & Dimensão \\
\hline Comprimento total $(\mathrm{m})$ & $L$ & 1.742 \\
Diâmetro máximo (m) & $D$ & 0.234 \\
Diâmetro da base (m) & $D_{b}$ & 0.057 \\
Comprimento da proa/nariz $(\mathrm{m})$ & $L_{n}$ & 0.217 \\
Comprimento do corpo paralelo (m) & $L_{b}$ & 1.246 \\
Comprimento da popa/cauda (m) & $L_{c}$ & 0.279 \\
Parâmetro angular de Myring (deg)* & $\theta$ & 25 \\
Parâmetro potencial de Myring ()$^{*}$ & $n$ & 2 \\
\hline
\end{tabular}

Estes parâmetros são definidos em Myring ${ }^{[182]}$, sendo apresentadas nas equações A.1 e A.2.

Tabela 29 - Parâmetros geométricos das superfícies de controle do AUV Pirajuba.

\begin{tabular}{lr}
\hline Parâmetro & Dimensão \\
\hline Altura & $160 \mathrm{~mm}$ \\
Corda na raiz & $90 \mathrm{~mm}$ \\
Corda na ponta & $60 \mathrm{~mm}$ \\
Enflexamento & Simétrico \\
Perfil & NACA0012 \\
Posição do B.A.* & $1373 \mathrm{~mm}$ \\
\hline *Bordo de ataque, em relação ao nariz.
\end{tabular}

*Bordo de ataque, em relação ao nariz.

Pirajuba possuem a mesma geometria das utilizadas no Maya, sendo apresentadas na tabela 29.

Uma comparação entre as primeiras versões destes dois AUVs pode ser vista na figura 80 .

Atualmente o AUV Pirajuba se encontra em sua terceira versão ${ }^{[65,66]}$, tendo
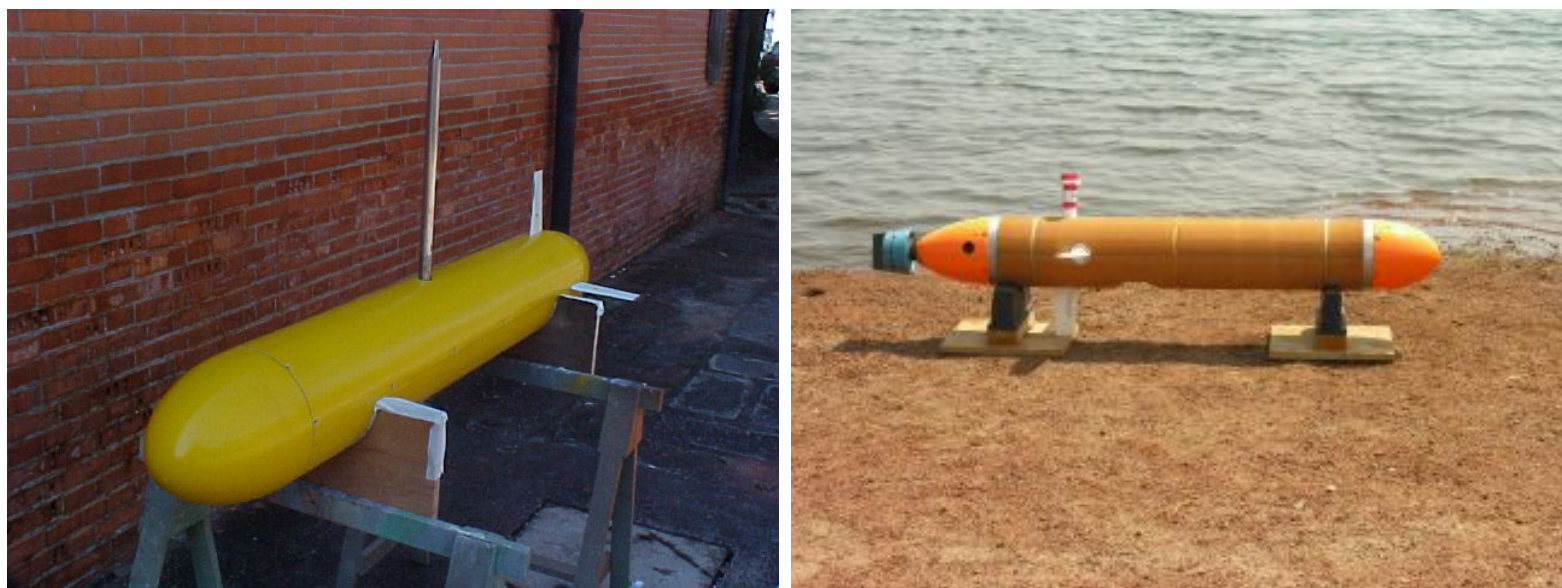

Figura 80 - Modelo cativo do AUV Pirajuba (a esquerda) e a primeira versão do Maya (a direita) 


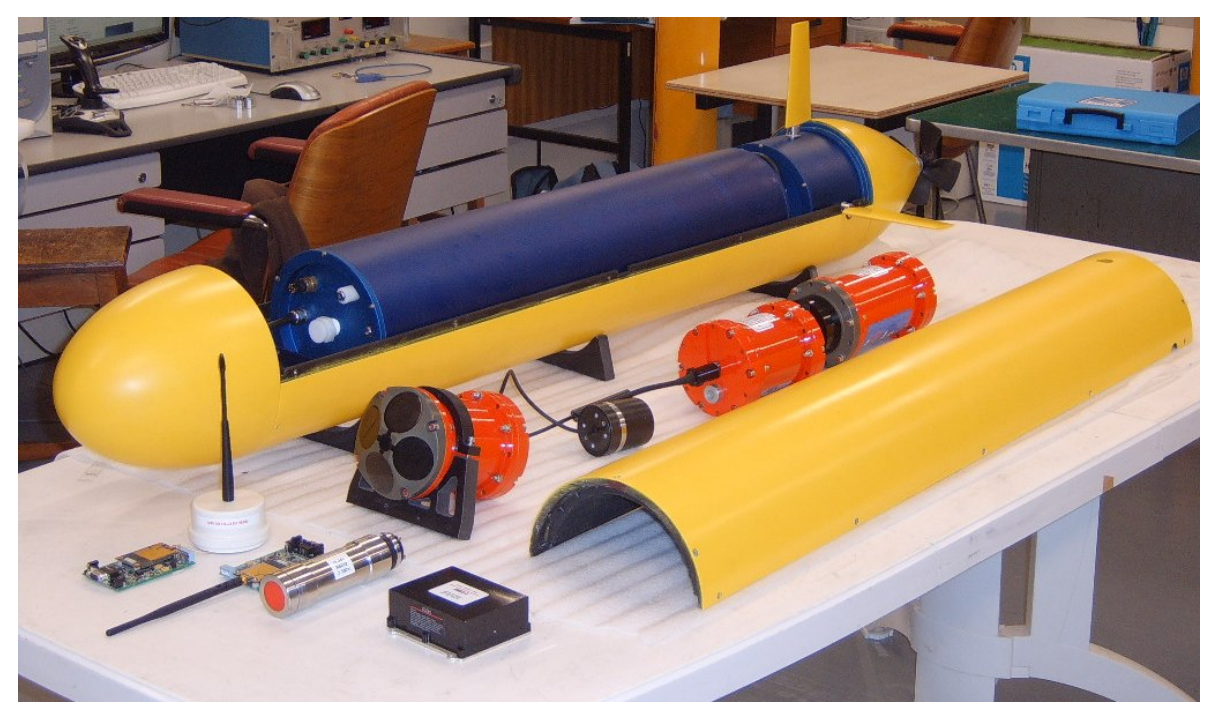

Figura 81 - Componentes do AUV Pirajuba. Dentro do veículo são apresentados os vasos de manobra e principal, no lado esquerdo, a plataforma interna do vaso principal e o DVL.

realizado diversos ensaios de mar com o propósito de identificar as suas equações de movimento ${ }^{[177,48]}$ e testar o algoritmo de navegação ${ }^{[49]}$. Em sua quarta versão, já em desenvolvimento, o veículo será capaz de realizar missões de longa duração com sensores de imageamento acústico.

O casco deste AUV é composto de uma estrutura de fibra de vidro com enchimento de espuma de PVC expandido, que serve de flutuador para deixar o veículo com flutuação neutra. A eletrônica e atuadores são acomodados em três vasos de pressão internos ao casco: o principal, o de manobra e o propulsor (ver figura 81).

O vaso principal carrega as unidades de processamento e comando embarcadas, as baterias de polímero de lítio, sistema de comunicação, eletrônicas de potência e sensores de navegação, presença de líquido e sobrecarga. O vaso de manobra é composto pelos servo-mecanismo, responsáveis por movimentar as superfícies de controle, e pela eletrônica de controle do propulsor. Um motor DC de 150W acoplado a um hélice Kaplan da série Wageningen, é utilizado como sistema de propulsão do veículo.

O sistema de navegação do AUV Pirajuba é composto de um sensor externo de pressão, utilizado para medir a profundidade, uma bússola, responsável para indicar o rumo, uma unidade de medição inercial (IMU, Inertial Measurement Unit), utilizada primariamente para se obter a orientação, e um medidor de velocidade pelo efeito Doppler (DVL, Doppler Velocity Log), que serve para medir as velocidades lineares do veículo.

As propriedades inerciais do veículo foram obtidas através de testes de balanço ${ }^{[168]}$ com o veículo totalmente montado e fora d'água, sendo os seus resultados apresentados na tabela 30. A metodologia e o aparato de montagem experimental do ensaio é apresentada 
Tabela 30 - Parâmetros inerciais do AUV Pirajuba ${ }^{[177]}$.

\begin{tabular}{lr}
\hline Parâmetro & Dimensão \\
\hline Massa & $53.8 \mathrm{~kg}$ \\
Posição do CG* & $0.88 \mathrm{~m}$ \\
Inercia em Y & $9.57 \mathrm{~kg} \cdot \mathrm{m}^{2}$ \\
Inercia em Z & $9.61 \mathrm{~kg} \cdot \mathrm{m}^{2}$ \\
\hline
\end{tabular}

* Centro de gravidade, medido a partir ao nariz.

com mais detalhes no trabalho de Caetano ${ }^{[177]}$.

Mais informação sobre o AUV Pirajuba e seus subsistemas podem ser encontrados em Barros, Freire e Dantas ${ }^{[65]}$, Barros et al. ${ }^{[66]}$ e Dantas et al. ${ }^{[49]}$. 


\section{APÊNDICE B - METODOLOGIA PARA O CÁLCULO DAS PROPRIEDADES INERCIAIS MOLHADAS DO AUV PIRAJUBA}

Veículos submarinos que apresentam casco do tipo free-fluid, que permitem a entrada de água em uma região dentro do casco, apresentam diferentes propriedades inerciais quando o veículo está fora e dentro da água. Estas diferenças aparecem devido ao adicional de inércia causado pelas massas de águas 'presas' (no sentido de movimento rápido) dentro do casco do veículo.

Portanto, neste apêndice é apresentada a metodologia utilizada para realizar o cálculo da massa de água que fica dentro do casco do AUV Pirajuba quando o veículo está submerso, e a sua influência no centro de gravidade e inércia. Neste cálculo são consideradas as medições das propriedades inerciais com o veículo seco ${ }^{[177]}$, e o uso do desenho em CAD do AUV Pirajuba.

Para simplificar, as propriedades inerciais do veículo debaixo e em cima d'água são denominadas 'molhadas' ( $m o l)$ e 'secas', respectivamente. A definição dos centros de coordenadas de gravidade seco $\left(X_{\text {seco }}\right)$ e molhado $\left(X_{\text {mol }}\right)$ são representados qualitativamente na figura 82 , junto com o centro de referência $\left(X_{r e f}\right)$, ponto onde são calculados os coeficientes hidrodinâmicos.

A massa de água interna ao veículo pode ser calculada por representações dos volumes de água no projeto de $\mathrm{CAD}$, que são definidos pela subtração booleana das diversas

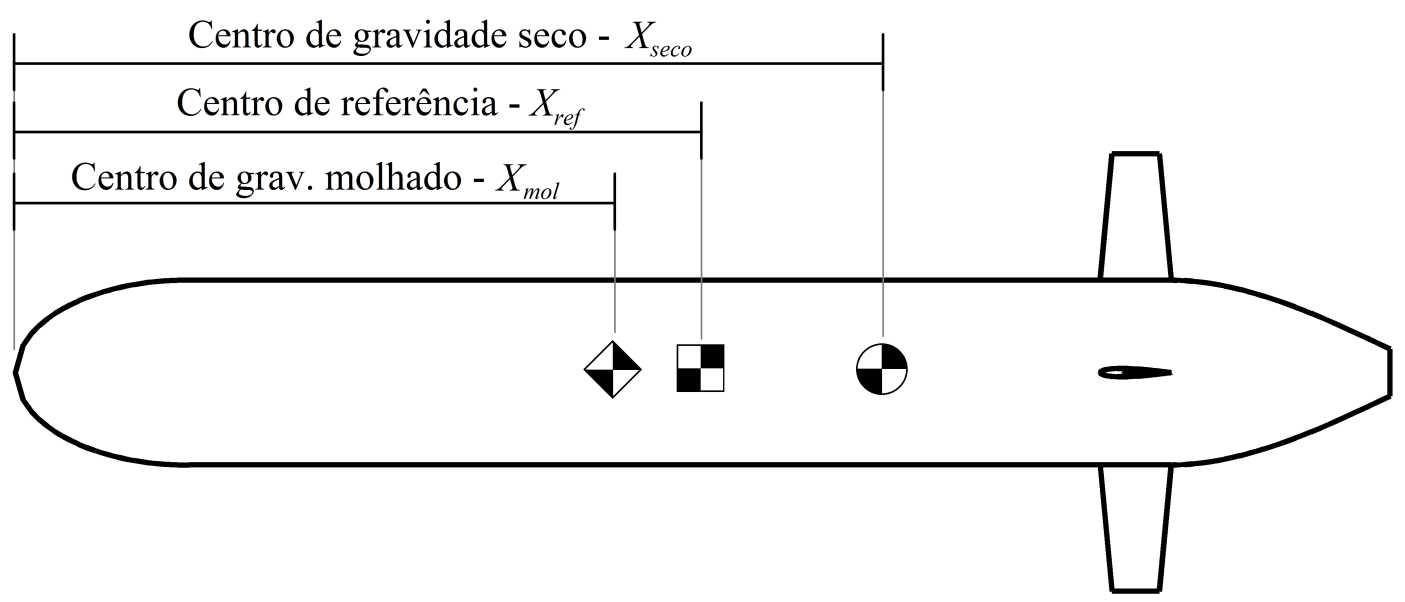

Figura 82 - Representação qualitativa dos centro de coordenadas utilizadas 


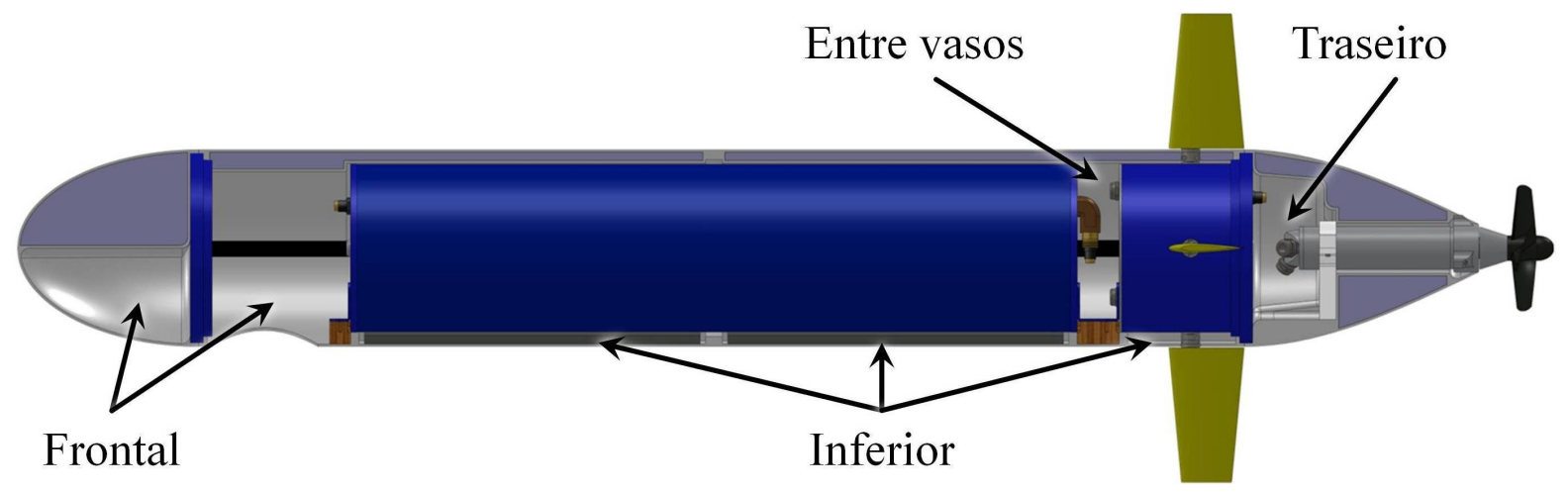

Figura 83 - Desenho em CAD do AUV Pirajuba, com a representação dos volumes de água internos ao casco mais significativos

partes do veículo com o seu volume deslocado (volume definido pela superfície externa do veículo). Entretanto, como o modelo em CAD do veículo não representa perfeitamente a geometria e inércia do veículo real ${ }^{[177]}$, devido a detalhes e peças que não puderam ser corretamente modeladas, a diferenças nas propriedades dos materiais, ou até mesmo devido a de fabricação das peças, a estimativa do volume de água estaria errado.

Para possibilitar este cálculo é assumido que as diferenças entre o modelo CAD e o veículo estão uniformemente distribuídas nas regiões que a água ocupa dentro do casco, de maneira que uma variação na densidade da água compensasse o volume das partes não modeladas. Esta variação pode ser interpretada como um fator que realiza a correção do volume $\left(\tilde{\nabla}_{\text {ăgua }}^{C A D}\right)$, e consequentemente a massa $\left(\tilde{M}_{\text {agqua }}^{C A D}\right)$, estimado pelo CAD para o valor medido experimentalmente $\left(M_{\text {ăgua }}^{\text {Exp. }}\right)$, conforme a equação abaixo.

$$
M_{\text {água }}^{E x p .}=M_{a g u a}^{C A D}=\eta_{\text {água }} \tilde{M}_{\text {água }}^{E x p .}=\eta_{\text {água }} \rho_{\text {água }} \tilde{\nabla}_{\text {água }}^{C A D}
$$

Com esta definição, o fator $\eta_{a ́ g u a ~}$ pode ser calculado pela razão entre as massas de água medidas experimentalmente e estimadas pelo CAD. Apesar desta massa não poder ser medida, ela pode ser calculada pela diferença entre a massa teórica do veículo $\left(M_{\text {Teórica }}\right)$, que é igual à massa de água deslocada pelo volume total do veículo (volume do corpo mais apêndices externos) menos a massa seca $\left(M_{\text {seca }}\right)$. A definição matemática do

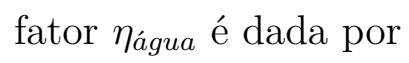

$$
\eta_{\text {água }}=\left.\left.\frac{M_{E x p .}}{M_{C A D}}\right|_{\text {água }} \frac{M_{\text {Teórica }}-M_{\text {seca }}}{M_{C A D}}\right|_{\text {água }} .
$$

Para facilitar a modelagem em CAD da massa de água interna, o volume total foi dividido em quatro regiões que concentram praticamente todo o volume de água do veículo. Estas regiões são apresentadas na figura 83.

Com esta definição a massa de água total estimada pelo CAD pode ser calculada 
pela equação

$$
M_{m o l}=M_{\text {seca }}+\sum_{i=1}^{n} M_{a ́ g u a}^{i}=M_{\text {seca }}+\eta_{\text {água }} \rho_{a ́ g u a ~} \sum_{i=1}^{n} \tilde{\nabla}_{a ́ g u a}^{i} .
$$

Nota-se que pela definição de $\eta_{a ́ g u a ~}$ (equação B.2) a massa molhada estimada pelo CAD $\left(M_{m o l}\right)$ é igual a mesma massa obtida pelos dados experimentais, pois foi assumido que a massa molhada é igual a massa teórica.

A posição do centro de gravidade molhado $\left(X_{m o l}\right)$ é calculado pela ponderação das massas de água $\left(M_{a ̂ g u a}^{i}\right)$ e seca do veículo $\left(M_{\text {seca }}\right)$, pela distância dos seus centro de massa/flutuação ( $X_{\text {água }}^{i}$ e $X_{\text {seco }}$, respectivamente), conforme a equação

$$
X_{m o l}=\frac{M_{\text {seca }} X_{\text {seco }}+\sum_{i=1}^{n} M_{a g u a}^{i} X_{a g q u a}^{i}}{M_{m o l}} .
$$

O momento de inércia molhado $\left(I_{m o l}\right)$ é calculado pela soma dos momentos de inércia do veículo seco com os dos volumes de água, calculado no centro de massa molhado. Este cálculo é realizado utilizando o pelo teorema dos eixos paralelos, ou teorema de Steiner, onde a inércia total de diversos corpos é igual a soma das inércias em seus respectivos centros de massa com os termos de transposição, que são iguais as distâncias ao quadrado dos centros de massa ao centro de massa equivalente multiplicado pelas massas individuais. Para o caso do AUV, está inércia molhada é calculada por

$$
I_{\text {mol }}=I_{\text {seca }}+M_{\text {seca }}\left(X_{\text {seco }}-X_{\text {mol }}\right)^{2}+\sum_{i=1}^{n} M_{a ́ g u a ~}^{i}\left(X_{a ́ g u a}^{i}-X_{m o l}\right)^{2} I_{a ́ g u a}^{i} .
$$





\section{APÊNDICE C - MODELO SIMPLIFICADO DAS EQUAÇÕES DINÂMICAS LATERAIS DE UM AUV}

O modelo dinâmico lateral simplificado de um AUV é obtido a partir da forma matricial das equações de movimento de seis graus de liberdade de um AUV. A equação geral deste modelo foi apresentada na seção 2.2.1 pela equação 2.16, sendo reescrita na equação

$$
\left[M_{i j}+A_{i j}\right][\dot{U}, \dot{\omega}]+F_{I}=F_{H}+F_{G}+F_{E}+F_{P} .
$$

Considerando que o movimento do veículo ocorre apenas no plano lateral, a velocidade vertical $(w)$, o ângulo de rolagem $(\phi)$ e de $\operatorname{arfagem}(\theta)$, e suas taxas $(p$ e $q$, respectivamente) podem ser consideradas nulas. Também é considerado que o veículo esteja em condição de trimagem, ou seja, a deflexão do leme $(\delta)$ e a rotação do hélice $(n)$ são mantidas constantes, para que o veículo ande em linha reta a uma velocidade de 1 $\mathrm{m} / \mathrm{s}$.

Adicionalmente, é considerado que as inércias cruzadas são desprezíveis $\left(I_{x y}=\right.$ $\left.I_{x z}=I_{y x}=0\right)$, pois são muito menores do que a inércias nos eixos principais $\left(I_{x}, I_{y}, I_{z}\right)$, e os centros de gravidade e flutuação nulos $\left(y_{g}=y_{b}=0\right)$, pois a estimativa da inércia molhada indicou um valor muito próximo do eixo do veículo.

Considerando estas simplificações a equação C.1 foi reduzida a:

$$
\begin{array}{r}
{\left[\begin{array}{ccc}
m+A_{1,1} & 0 & 0 \\
0 & m+A_{2,2} & m \cdot x_{g}+A_{2,6} \\
0 & m \cdot x_{g}+A_{6,2} & I_{z}+A_{6,6}
\end{array}\right]\left[\begin{array}{c}
\dot{u} \\
\dot{v} \\
\dot{r}
\end{array}\right]=} \\
m\left[\begin{array}{c}
v \cdot r+x_{g} \cdot r^{2} \\
-u \cdot r \\
-x_{g} \cdot u \cdot r
\end{array}\right]+\left[\begin{array}{c}
X_{H}(u, v, r, \delta, n) \\
Y_{H}(u, v, r, \delta) \\
N_{H}(u, v, r, \delta)
\end{array}\right]
\end{array}
$$

Onde, $m$ é a massa molhado do AUV, $I_{z}$ é a inércia molhada do veículo no eixo Z, $A_{a, b}$ é a massa adicional relativos as direções $a$ e $b, u$ é a velocidade longitudinal (eixo X), $v$ é a velocidade lateral (eixo Y), e $r$ é a velocidade angular de rumo (eixo Z). $X_{h}, Y_{h}$ e $N_{h}$ são funções que representam as forças hidrodinâmicas na direção X, Y, e o momento na direção Z, respectivamente.

Todos os parâmetros presentes na equação C.2 influenciam o movimento no plano lateral de um AUV, devendo ser submetidos à análise de sensibilidade. No caso particular 
da manobra de giro, é possível simplificar a equação C.2 para a condição aproximada de regime permanente, onde o veículo apresenta uma velocidade angular constante. Nesta condição os termos de aceleração são nulos, pois em regime permanente o veículo executa um movimento curvilíneo uniforme, e pode ser considerado que os esforços hidrodinâmicos podem ser linearizados no ponto de equilíbrio. Com estas simplificações a equação C.2 é resumida a:

$$
m\left[\begin{array}{c}
v \cdot r+x_{g} \cdot r^{2} \\
-u \cdot r \\
-x_{g} \cdot u \cdot r
\end{array}\right]+\left[\begin{array}{cccc}
X_{u} & X_{v} & X_{r} & X_{\delta} \\
Y_{u} & Y_{v} & Y_{r} & Y_{\delta} \\
N_{u} & N_{v} & N_{r} & N_{\delta}
\end{array}\right]\left[\begin{array}{c}
u \\
v \\
r \\
\delta
\end{array}\right]=0
$$

onde os índices subscritos nos esforços hidrodinâmicos indicam a primeira derivada em relação a estes índices. Por exemplo, $Y_{v}$ indica a derivada da força lateral em função da velocidade lateral $(v)$.

O valor da taxa de rumo no regime permanente $\left(r_{R P}\right)$ pode ser calculado ao desconsiderar a dinâmica no eixo X (primeira linha da equação C.3), que possui um pequeno acoplamento hidrodinâmico às outras dimensões. Para isolar o valor da taxa de rumo as equações resultantes foram reorganizadas em:

$$
r_{R P}=\frac{Y_{v} N_{\delta}-N_{v} Y_{\delta}}{Y_{v}\left(m \cdot x_{g} \cdot u_{R P}-N_{r}\right)-N_{v}\left(m \cdot u_{R P}-Y_{r}\right)} \delta
$$

Os parâmetros da equação C.4 representam os parâmetros que além de influenciar a resposta transiente influenciam o movimento em regime permanente. Portanto, os parâmetros da equação C.2 que não estão presentes na equação C.4 tem uma influencia mais significativa na resposta transiente. 


\section{APÊNDICE D - MODELOS PARA CÁLCULO DA MASSA ADICIONAL DE UM AUV ESBELTO DO TIPO TORPEDO}

Neste apêndice são apresentados os modelos analíticos e numéricos para o cálculo dos termos de massa adicional utilizados nesta tese.

Nas próximas seções são apresentados a formulação analítica da massa adicional de um elipsoide de revolução, o modelo utilizados para asas (lemes) finas finitas, e os coeficientes bi-dimensionais utilizados pelo método das faixas. Destes três modelos, o último foi utilizado para o cálculo da massa adicional do AUV Pirajuba (seção 2.2.4), enquanto os outros dois foram utilizados para estimar o erro/incerteza do método da faixa durante a análise de sensibilidade (seção 6.4.3.2).

\section{D.1 MODELO ANALÍTICO DE UM ELIPSOIDE DE REVOLU- ÇÃO PROLATO}

Um elipsoide/esferoide de revolução prolato é um elipsoide cuja as seções de corte perpendiculares ao maior eixo são circunferências, sendo construído geometricamente pela revolução de uma elipse. Geometricamente, em relação ao elipsoide padrão (figura 84), o elipsoide de revolução prolato possui dois semi-raios iguais, $b=c$, e menores do que o semi-raio $a$.

No caso geral de elipsoides, Lamb ${ }^{[183]}$ demonstrou que os termos de massa adicional podem ser obtidas analiticamente pela somatória de soluções particulares das equações de Laplace (método de separação de variáveis) em sistemas de coordenadas elípticos, definidas por diversas condições de contornos ${ }^{[178]}$. As soluções matemáticas destes termos são obtidas em função de três coeficientes, $A_{0}, B_{0}$ e $C_{0}$, que são calculados por integrais complexas que envolvem apenas os parâmetros geométricos do elipsoide.

Para o caso particular de um elipsoide de revolução prolato ${ }^{[75]}$, a formulação destes coeficientes são simplificadas, sendo expressas apenas em função da excentricidade

$$
e=\sqrt{a-\frac{b^{2}}{a^{2}}}
$$

da elipse contida na seção meridional do elipsoide, conforme as equações apresentadas 


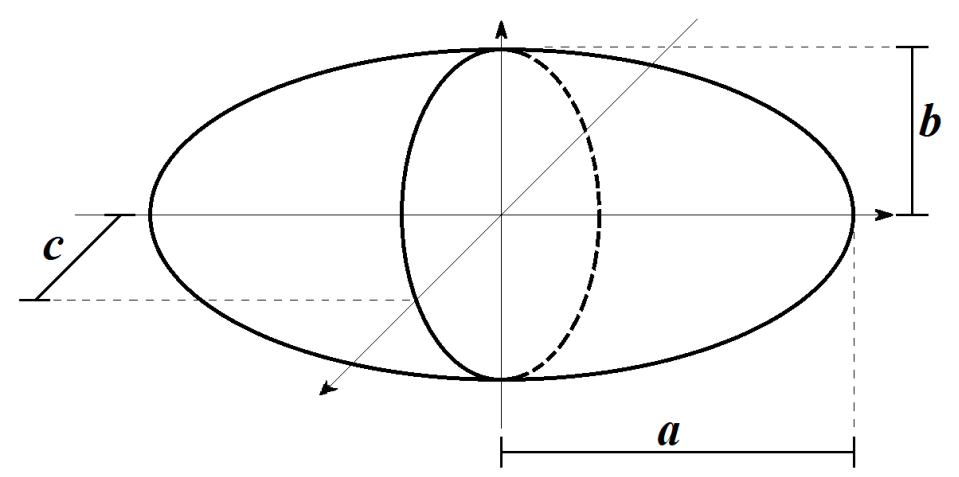

Figura 84 - Representação das características geométricas de um elipsoide

abaixo.

$$
\begin{aligned}
A_{0} & =\frac{2\left(1-e^{2}\right)}{e^{3}}\left[\frac{1}{2} \ln \frac{1+e}{1-e}-e\right] \\
B_{0}=C_{0} & =\frac{1}{e^{2}}-\frac{1-e^{2}}{2 e^{3}} \ln \frac{1+e}{1-e}
\end{aligned}
$$

Estes coeficientes podem ser utilizados para definir os coeficientes $k_{i i}$, que representam a razão dos termos de massa $\left(A_{(i, i)}\right.$ para $i=1,2$ e 3$)$ e a inércia $\left(A_{(i, i)}\right.$ para $i=4,5$ e 6 ) adicional do elipsoide adimensionalisadas pela massa e inércia, respectivamente, do volume de água contido dentro do elipsoide, conforme as equações abaixo.

$$
A_{(i, i)}=\frac{4 \pi a b^{2}}{3} k_{i i} \quad \text { para } i=1,2,3 A_{(i, i)}=\frac{4 \pi a b^{2}\left(a^{2}+b^{2}\right)}{15} k_{i i} \quad \text { para } i=4,5,6
$$

Este tipo de simplificação é utilizada para facilitar as análises e a representação dos termos de massa adicional. A relação entre os coeficientes $k_{i i}$ e os coeficientes $A_{0}$ e $B_{0}$ são definidas por

$$
\begin{aligned}
k_{11} & =\frac{A_{0}}{2 B_{0}} \\
k_{22}=k_{33} & =\frac{B_{0}}{A_{0}+B_{0}} \\
k_{44} & =0 \\
k_{55}=k_{66} & =\frac{\left(p^{2}-1\right)^{2}}{p^{2}+1} \frac{B_{0}-A_{0}}{2\left(p^{2}-1\right)+\left(A_{0}-B_{0}\right)\left(p^{2}+1\right)},
\end{aligned}
$$

sendo $p$ a razão entre os semi-raios $a$ e $b$, os subíndices 1,2 e 3 indicam a relação aos termos de massa adicional na direção que são definidas pelos semi-raios $a, b$ e $c$ (conforme figura 84), respectivamente, e os subíndices 4, 5 e 6 indicam a relação aos termos de inércia adicional definidos na mesma direção. 


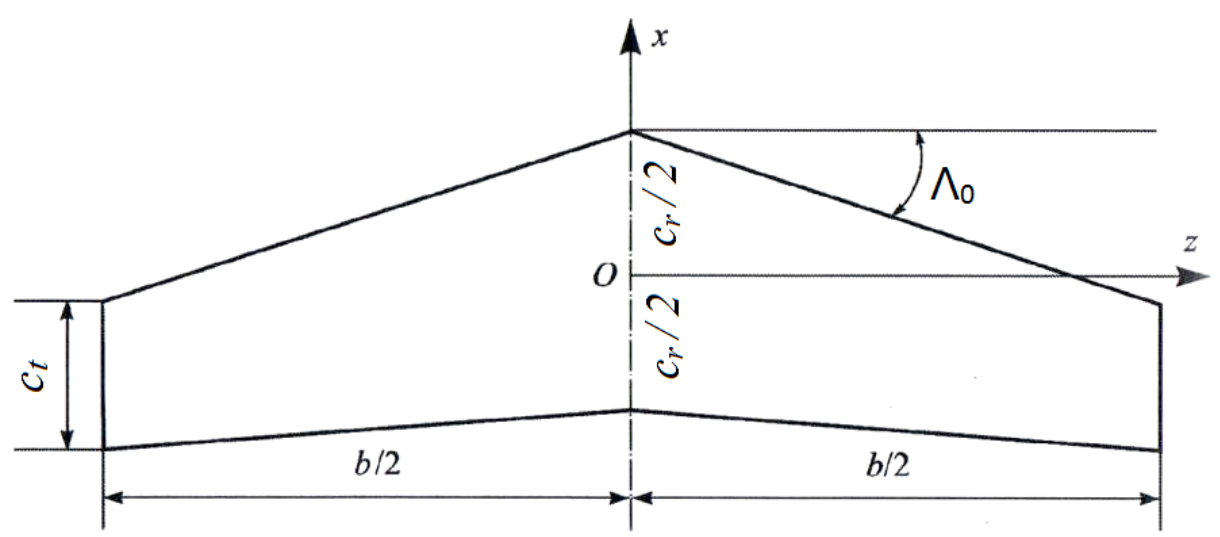

Figura 85 - Representação das características geométricas de uma asa/leme (Fonte: Ko$\operatorname{rotkin}^{[178]}$, modificada)

\section{D.2 MODELO NUMÉRICO DE UMA ASA FINA E DE ENVER- GADURA FINITA}

Diferente de um elipsoide, a massa adicional de uma asa/leme não pode ser calculada explicitamente, precisando utilizar simplificações geométricas e modelos numéricos e para realizar tal calculo ${ }^{[178]}$.

Ao considerar que a espessura da asa não tem uma influencia significativa nos termos de massa adicional não alinhados com a corda ou a envergadura, os principais termos, Belocerkovvsky ${ }^{[179]}$ realizou o cálculo dos termos de massa adicional restantes utilizando o método da superfície de vórtices ${ }^{[141,184]}$. Apesar deste método ser antiquado, ele ainda é utilizado na estimativa dos parâmetros aerodinâmicos e hidrodinâmicos de asas/lemes ${ }^{[141,184]}$.

Neste método a asa é representada por uma superfície com uma distribuição de elementos singulares do tipo vórtice ${ }^{[141,184]}$, e os termos de massa adicional são calculados pela solução do sistema linear que representa a solução da equação de Laplace para cada elemento com suas respectivas condições de contorno. A superfície da asa é definida como uma superfície aberta contida no plano de projeção da asa (superfície plana), limitada pelas dimensões impostas pelos parâmetros geométricos da asa: corda da raiz $\left(c_{r}\right)$, corda da ponta $\left(c_{t}\right)$, envergadura $(b)$, e o ângulo de enflexamento do bordo de ataque $\left(\Lambda_{0}\right)$. Estes parâmetros geométricos são apresentados na figura 85 .

Mesmo apresentando diversas simplificações, este método obteve estimativas bastante próximas a resultados experimentais ${ }^{[179,178]}$.

Belocerkovvsky ${ }^{[179]}$ utilizou este método para obter gráficos que relacionam os parâmetros geométricos das asas com os termos de massa adicional. Desta forma, o autor permitiu que massa adicional de qualquer asa fina e finita pudesse ser obtidas apenas com 

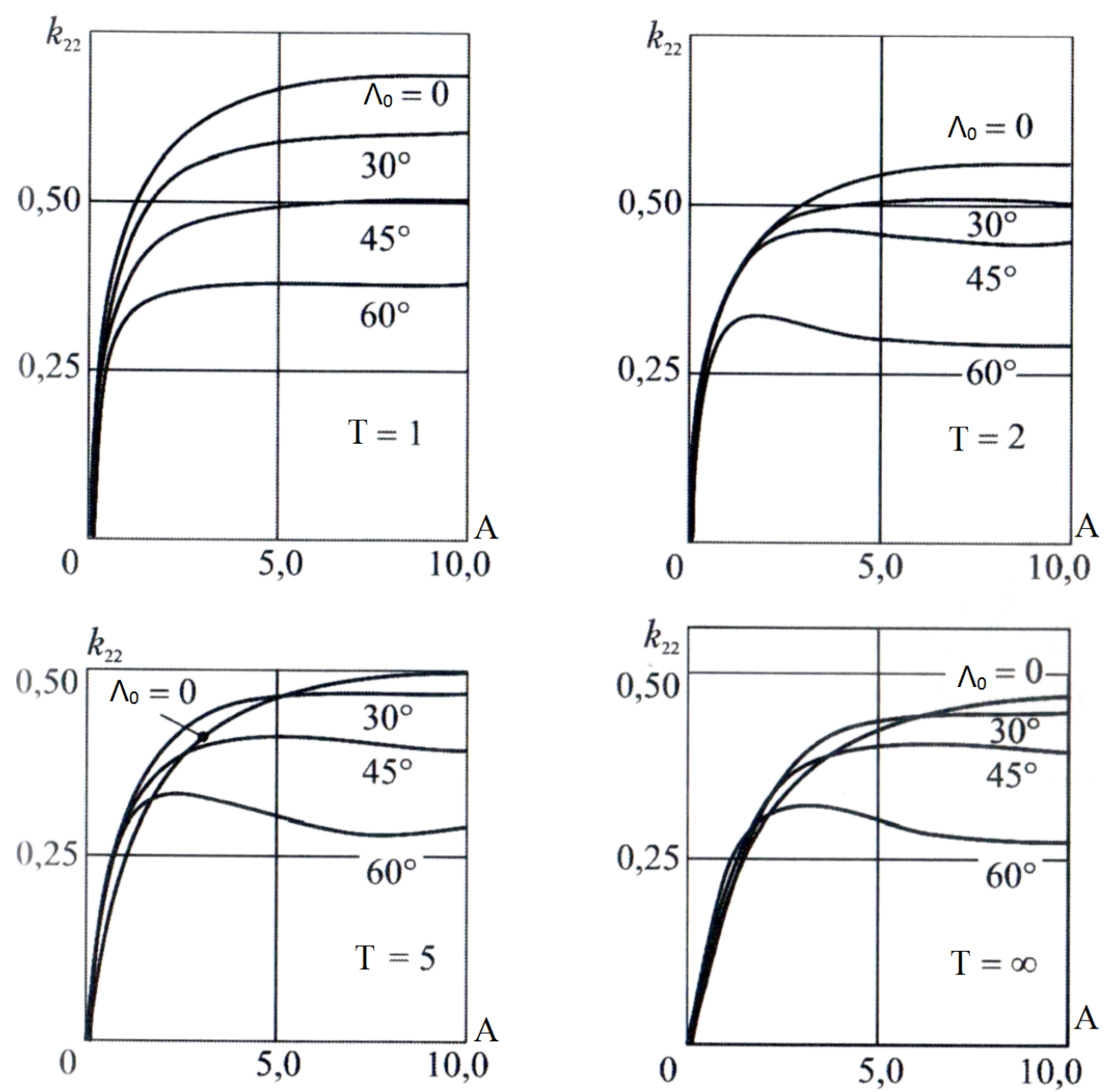

Figura 86 - Coeficiente adimensional de massa adicional de uma asa fina/leme e finita, relativo ao movimento perpendicular ao plano do leme (Fonte: Korotkin ${ }^{[178]}$, modificada)

a interpolação de tais gráficos.

Para simplificar a apresentação dos resultados, os termos de massa adicional foram apresentados nos gráficos em formato adimensional $\left(k_{i i}\right)$, similar ao caso do elipsoide, e em função da área de projeção (planform, $\left.S=b\left(c_{t}+c_{r}\right) / 2\right)$, a razão de afilamento $\left(T=c_{t} / c_{r}\right)$ e a razão de aspecto $\left(A=b^{2} / S\right)$ da asa.

Na figura 86 são apresentados os gráficos de interpolação do termo adimensional de massa adicional $k_{22}$, utilizados durante a análise de sensibilidade deste trabalho para representar a massa adicional perpendicular ao plano do leme (plano $x 0 z$ na figura 85) devido a um movimento nesta mesma direção. A transformação deste coeficiente no termo de massa adicional é dado pela equação,

$$
A(2,2)=k_{22} \rho S b
$$

onde $\rho$ é a densidade do fluído. 

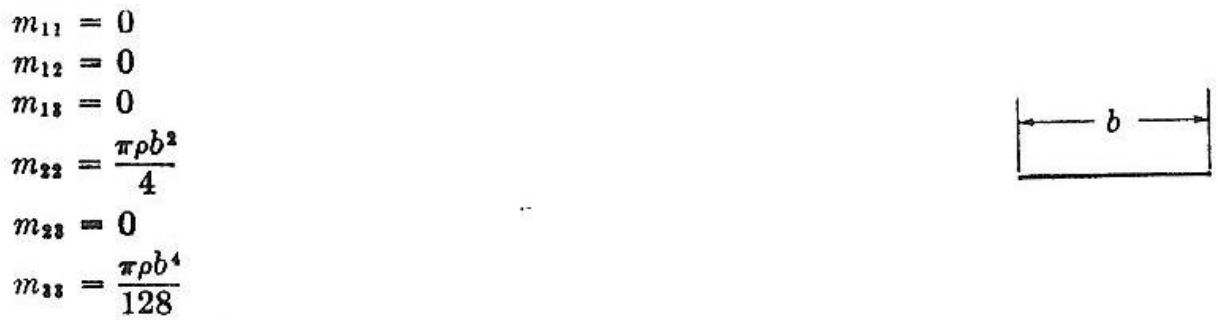

Figura 87 - Coeficientes de massa adicional bidimensional de uma placa plana, relativo ao leme do AUV (Fonte: Nielsen ${ }^{[79]}$, modificada)

$$
\begin{aligned}
& m_{11}=\pi \rho a^{2} \\
& m_{12}=0 \\
& m_{13}=0 \\
& m_{22}=\pi \rho a^{2} \\
& m_{23}=0 \\
& m_{33}=0
\end{aligned}
$$

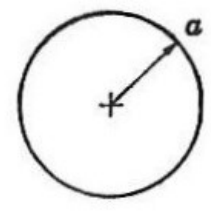

Figura 88 - Coeficientes de massa adicional bidimensional de uma seção cilíndrica, relativo ao corpo do AUV (Fonte: Nielsen ${ }^{[79]}$, modificada)

\section{D.3 FORMULAÇÃO DOS COEFICIENTES BI-DIMENSIONAIS DE CORPOS E LEMES}

Nesta seção são apresentados os coeficientes de massa adicional bidimensional $\left(m_{i j}\right)$ utilizados na seção 2.2.4, para realizar o cálculo dos termos de massa adicional do AUV Pirajuba através do método das faixas. Apesar dos coeficientes terem sidos obtidos do trabalho de Nielsen ${ }^{[79]}$, eles podem ser encontrados em referencias mais modernas, como a de ${ }^{[178]}$.

Utilizando o método das faixas, a massa adicional de um leme sozinho pode ser obtida pela integração dos coeficientes bidimensionais de uma placa plana. Estes coeficientes são apresentados na figura 87

Para o caso do corpo nu de seção cilíndrica, os coeficientes bidimensionais são os mesmos de uma seção cilíndrica. Estes coeficientes são apresentados na figura 88

No caso do corpo com os lemes (superfícies de controle), o coeficiente de massa adicional não pode ser obtido pela soma individual dos termos de massa adicional, pois desta forma não é considerado a interferência entre os corpos. Portanto, nas seções do AUV Pirajuba em que os lemes não estão presentes são utilizados os coeficientes do corpo (apresentado na figura 88), e nas seções com a presença do leme são utilizados os coeficientes apresentados na figura 90, com o coeficiente bidimensional de rotação apresentado na figura 90. 

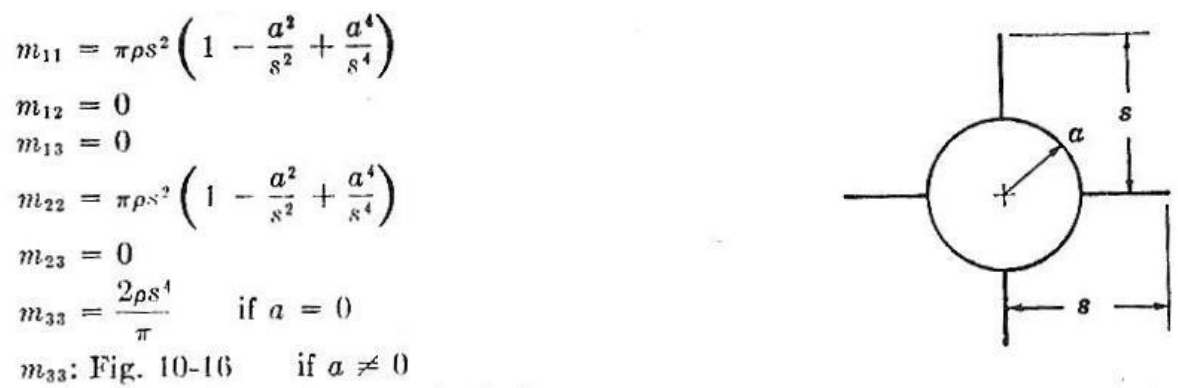

Figura 89 - Coeficientes de massa adicional bidimensional de uma seção cilíndrica com vigas/arrestas equidistantes, representando a interferência entre o corpo e o leme do AUV (Fonte: Nielsen ${ }^{[79]}$, modificada)

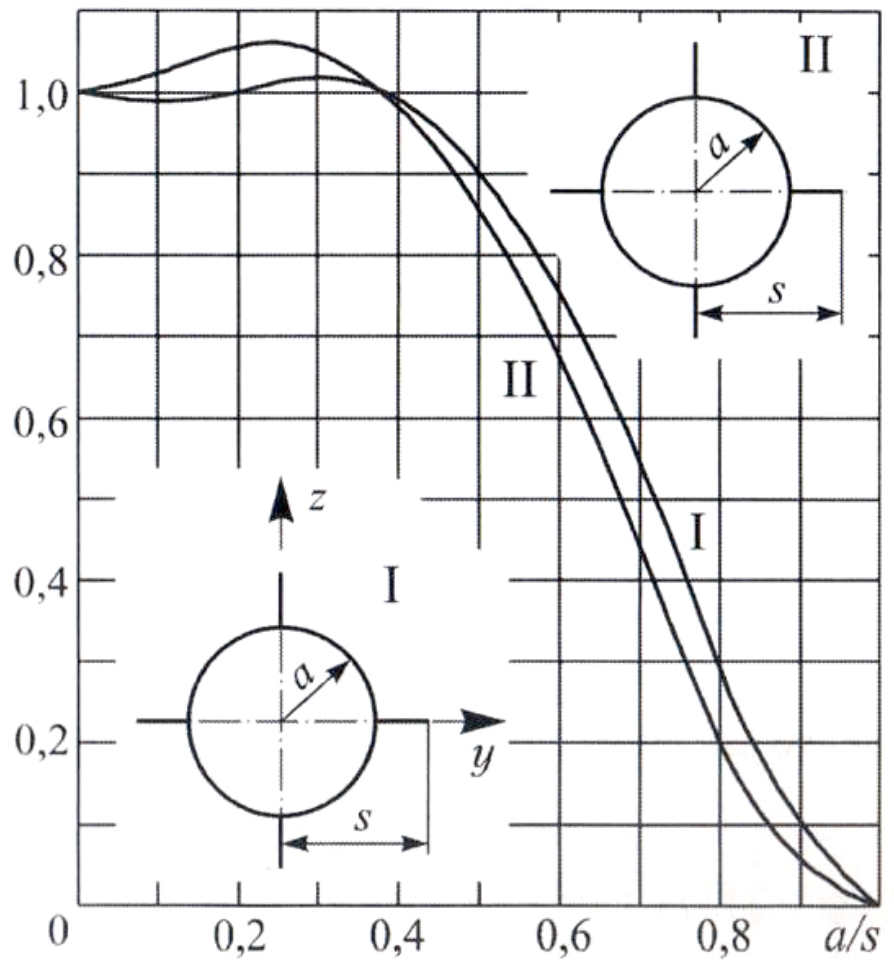

Figura 90 - Coeficientes de massa adicional bidimensional de rotação, $m_{33}$, de uma seção cilíndrica com vigas/arrestas equidistantes, representando a interferência entre o corpo e o leme do AUV (Fonte: Korotkin ${ }^{[178]}$, modificada) 


\section{APÊNDICE E - ANÁLISE DE SENSIBILIDADE DA MANOBRA DE GIRO}

Neste anexo são apresentados os resultados da análise de sensibilidade dos parâmetros do modelo dinâmico do AUV Pirajuba considerados em seu simulador de dinâmica. Esta análise é utilizada para verificar a relação da incerteza dos parâmetros do modelo com a resposta dinâmica da manobra de giro.

Os equacionamentos cinemáticos e dinâmicos seguem as formulações apresentadas no capítulo 2 desta tese, contudo para o modelo dos esforços hidrodinâmicos estáticos, dinâmicos e de controle foram utilizadas as funções de interpolação dos resultados das simulações por CFD (Computational Fluid Dynamics), apresentadas na seção 6 desta tese.

Nesta análise de sensibilidade foi considerada a variação individual de 24 parâmetros, divididos entre parâmetros inerciais e hidrodinâmicos. Para melhorar a organização e a apresentação dos resultados, os parâmetros hidrodinâmicos foram subdivididos em termos de massa adicional total, parâmetros do corpo, do leme e da combinação corpo e leme. A análise de sensibilidade de cada grupo de parâmetros é apresentada de maneira conjunta em cada uma das próximas seções, através de gráficos e tabelas que contêm informações da resposta do veículo em termos da taxa de rumo.

Os parâmetros foram variados utilizando um critério multiplicativo, considerando uma variação percentual positiva e negativa do parâmetro. Para ilustrar melhor o efeito não linear das variações dos parâmetros nas respostas de manobra, cada parâmetro teve uma variação adicional de duas e três vezes a sua variação inicial. Por exemplo, um parâmetro com um erro de 10\% também foi simulado considerando uma variação de 20 e $30 \%$.

Nos gráficos apresentados, os resultados com variação paramétrica são representados por uma região cinza ao redor da resposta nominal, que é representada por uma linha preta. As áreas ao redor dos modelos nominais têm a sua cor intensificada para as menores variações dos parâmetros, representando a maior probabilidade da resposta estar contida nesta área.

Nas tabelas são apresentados as principais características da resposta dinâmica da taxa de rumo em relação a uma resposta degrau, e.g., tempo de subida, tempo de assentamento, sobressinal, e etc. As respostas dos modelos com variação paramétrica são apresentadas em relação ao modelo nominal em termos de porcentagem. 

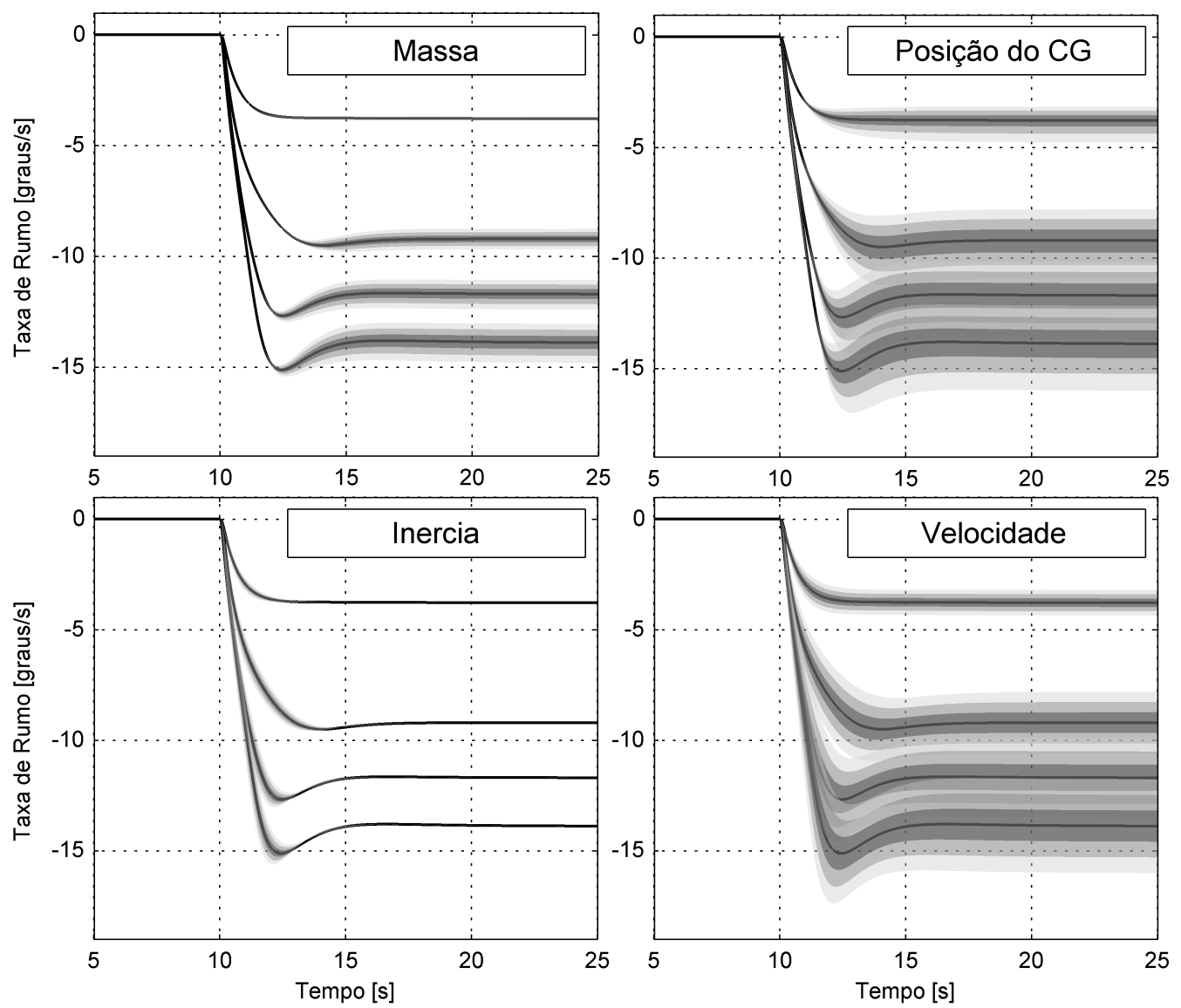

Figura 91 - Resposta da taxa de rumo para a sensibilidade dos parâmetros inerciais nas manobras de giro de $5,10,15$ e 20 graus

\section{E.1 SENSIBILIDADE DOS PARÂMETROS INERCIAIS}

Para esta análise de sensibilidade foram consideradas as incertezas de quatro parâmetros inerciais: a massa total do veículo, a sua inércia de rotação, a posição do centro de gravidade (CG) e a velocidade em que é realizada a manobra. Contudo, em todas as simulações foi considerado que o veículo estava em condição de equilíbrio, ou seja, o peso do veículo era igual a sua flutuação e o centro de flutuação (CB) coincide com o CG no plano horizontal.

A incerteza nestes parâmetros foi estimada por observações do processo de estimativa destes parâmetros (ferramentas CAD com testes em balanço), e da execução do próprio experimento no ambiente marinho, considerando a variação de lastro devido os diversos ensaios no ambiente marinho.

Com base nestas observações foi assumido um erro base para a massa de $5 \%$ (3.4 $\mathrm{kg})$, para o CG de $5 \%(40 \mathrm{~mm})$, para a inércia de $15 \%\left(2.5 \mathrm{~kg} \cdot \mathrm{m}^{2}\right)$, e de $10 \%(0.1 \mathrm{~m} / \mathrm{s})$ para a velocidade de ensaio. 


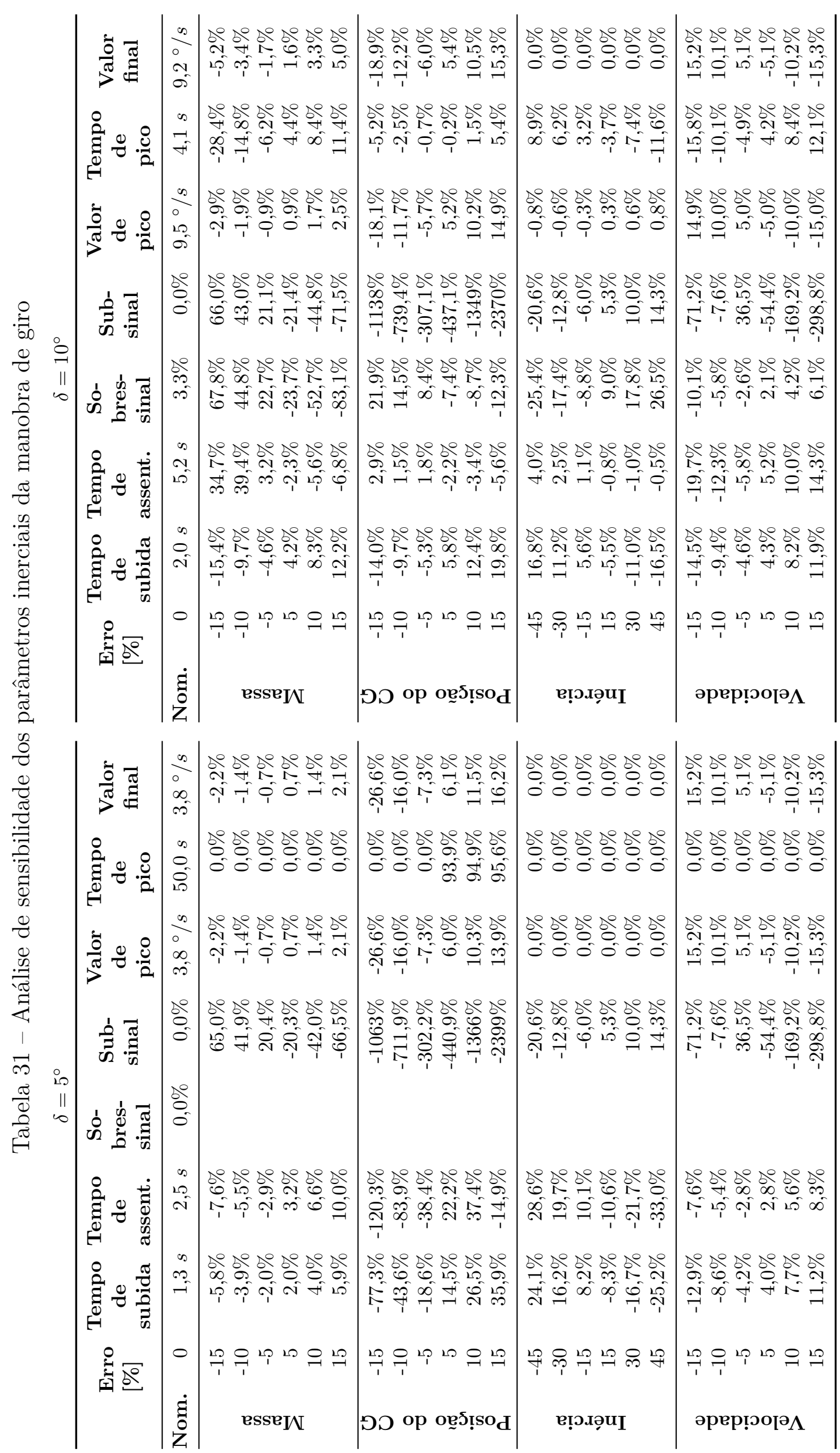




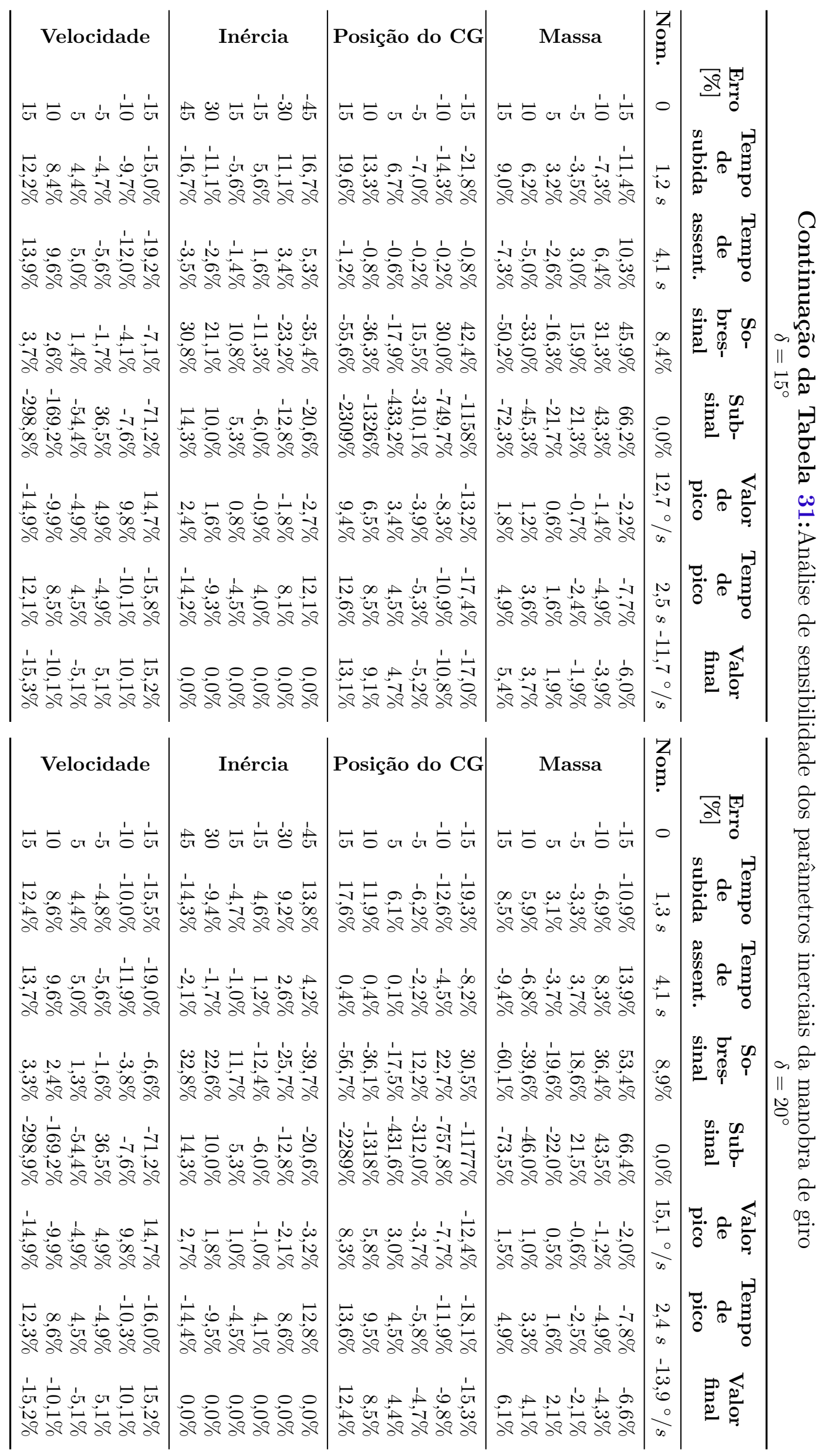




\section{E.2 SENSIBILIDADE DOS PARÂMETROS DE MASSA ADICIO- $\mathrm{NAL}$}

Os dados de massa adicional utilizados no simulador do AUV são calculados utilizando o método das faixas (apresentado na seção 2.2.4 desta tese). Apesar de este método ser bastante utilizado na indústria naval e aeronáutica para prever os parâmetros de massa adicional de corpos esbeltos, a adoção de um método puramente potencial em casos onde os efeitos viscosos são importantes e com corpos que não apresentam uma grande razão de esbelteza, pode apresentar um erro significativo na estimativa destes parâmetros.

Portanto, para os termos de massa adicional relativo à força devido a deriva $(A(2,2))$, o momento relativo a deriva $(A(2,6)$ ou $A(6,2))$, e o momento devido a rotação $(A(6,6))$, foi assumido um erro base de $20 \%$. No caso do termo de massa adicional devido ao movimento de avanço (surge, $A(1,1)$ ) foi considerado um erro base de $40 \%$, pois o cálculo deste termo é realizado utilizando o método de semelhança por elipsoides (onde o termo de massa adicional é calculado por uma elipsoide de medidas semelhantes ao corpo do AUV), que apresenta uma simplificação adicional em relação ao método das faixas.

\section{E.3 SENSIBILIDADE DOS PARÂMETROS HIDRODINÂMICOS DO CORPO}

Como as funções hidrodinâmicas dos esforços do corpo do AUV são não lineares, sendo obtidas em função do ângulo de deriva e da taxa de rotação, a análise da sensibilidade teve que ser realizada utilizando duas metodologias que abrangessem as incertezas de maneira diferente, permitindo uma melhor análise da sensibilidade. No primeiro caso é realizada a análise de sensibilidade dos parâmetros de entrada da função de esforços hidrodinâmicos, ou seja, é aplicado o ganho de sensibilidade ao ângulo de ataque e a taxa do ângulo de rumo. No segundo caso, é adotado um ganho na saída das funções dos esforços hidrodinâmicos, ou seja, na força normal, no momento de guinada (yaw) e na força axial.

\section{E.4 SENSIBILIDADE DOS PARÂMETROS HIDRODINÂMICOS DO LEME}

A análise de sensibilidade dos parâmetros hidrodinâmicos do leme foi realizada de maneira similar ao caso do corpo, mas neste caso foi adicionada a análise de sensibilidade 


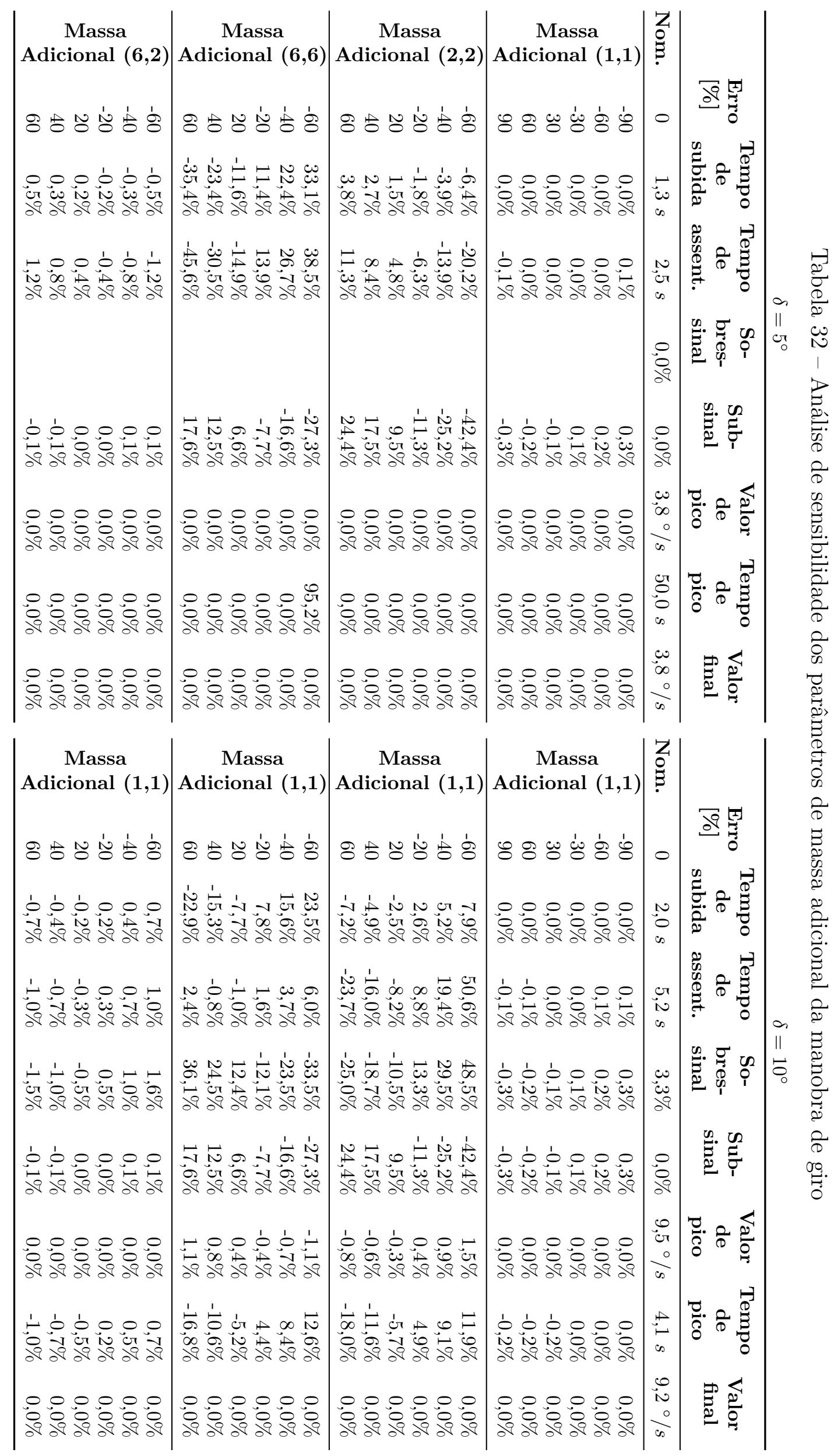




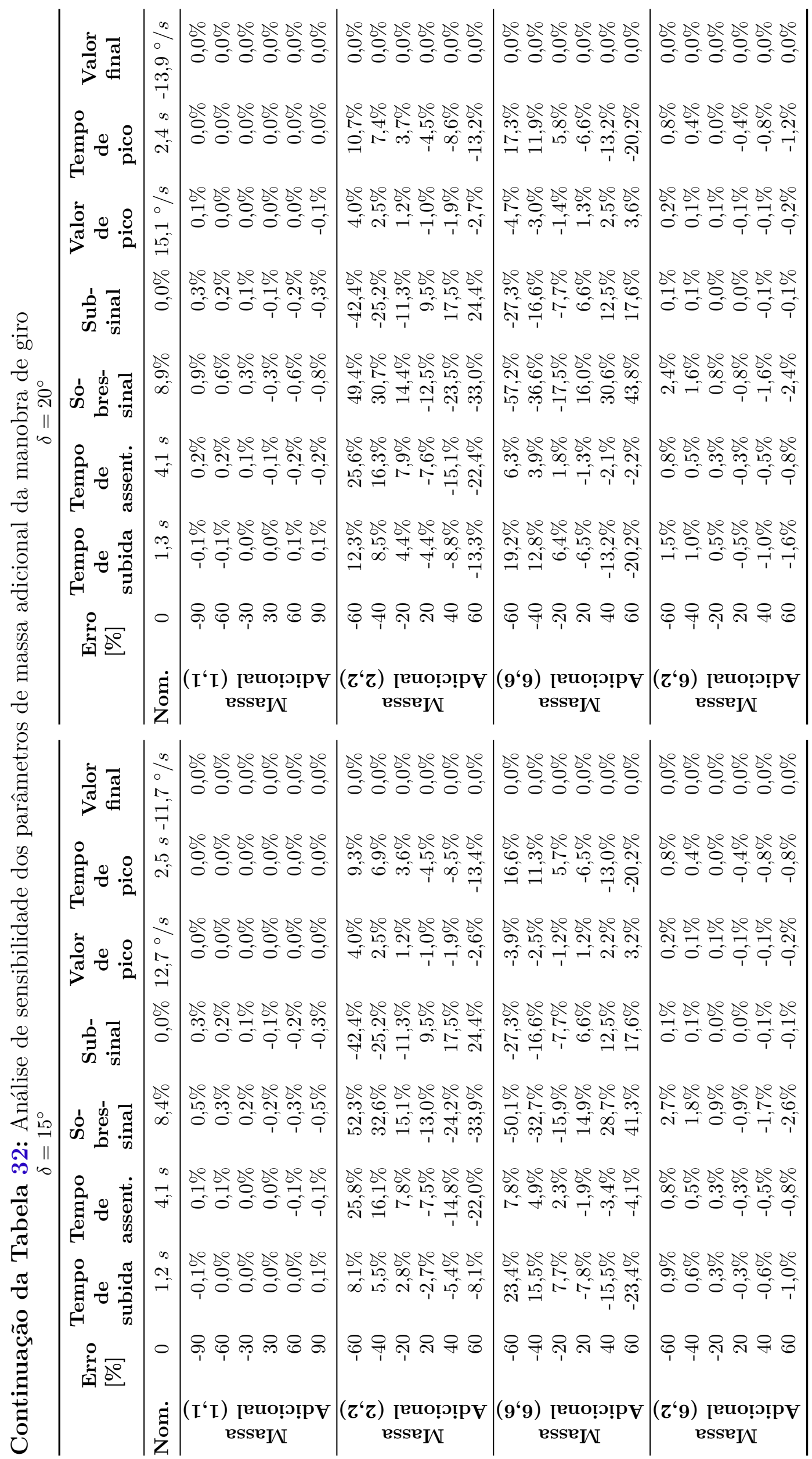




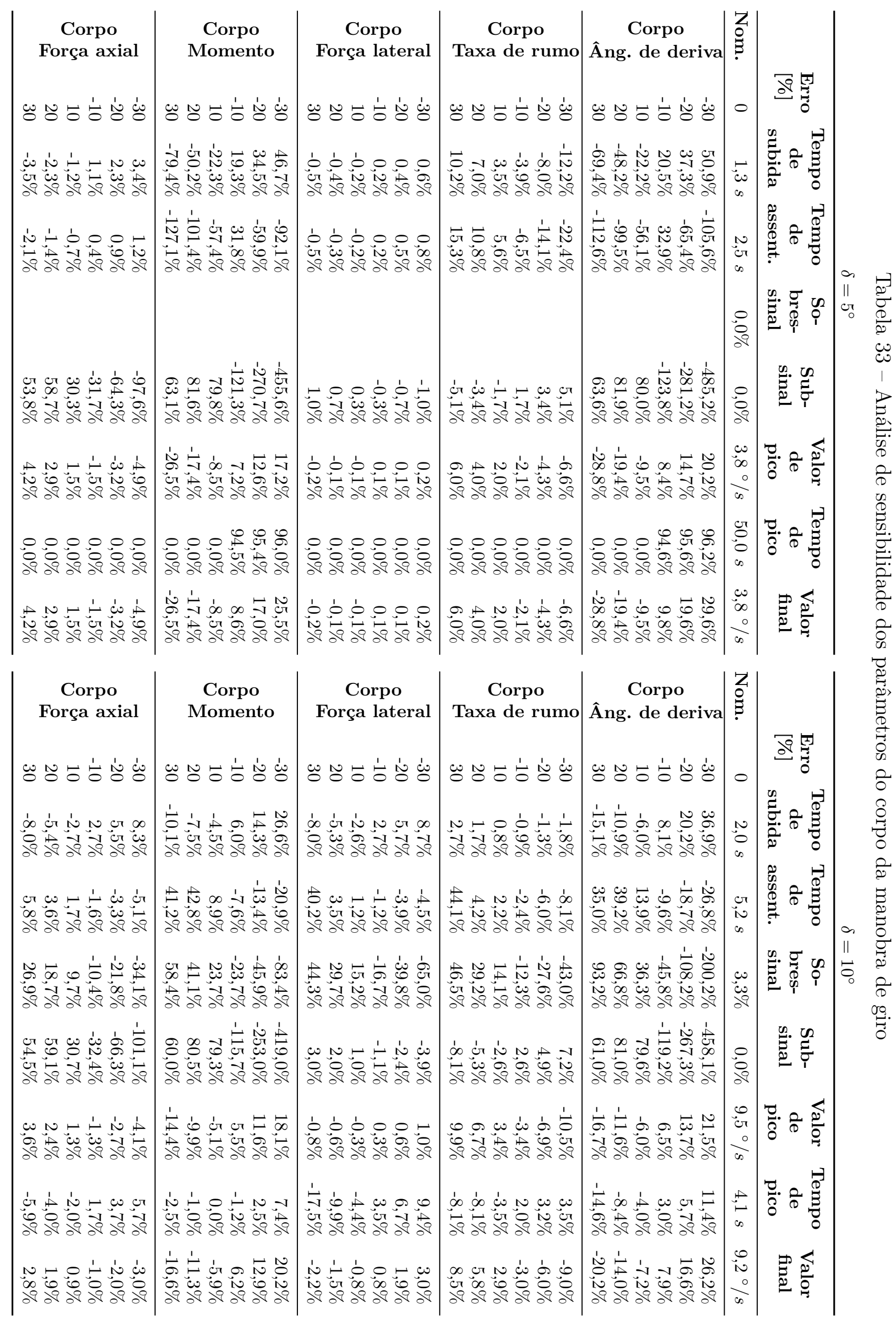




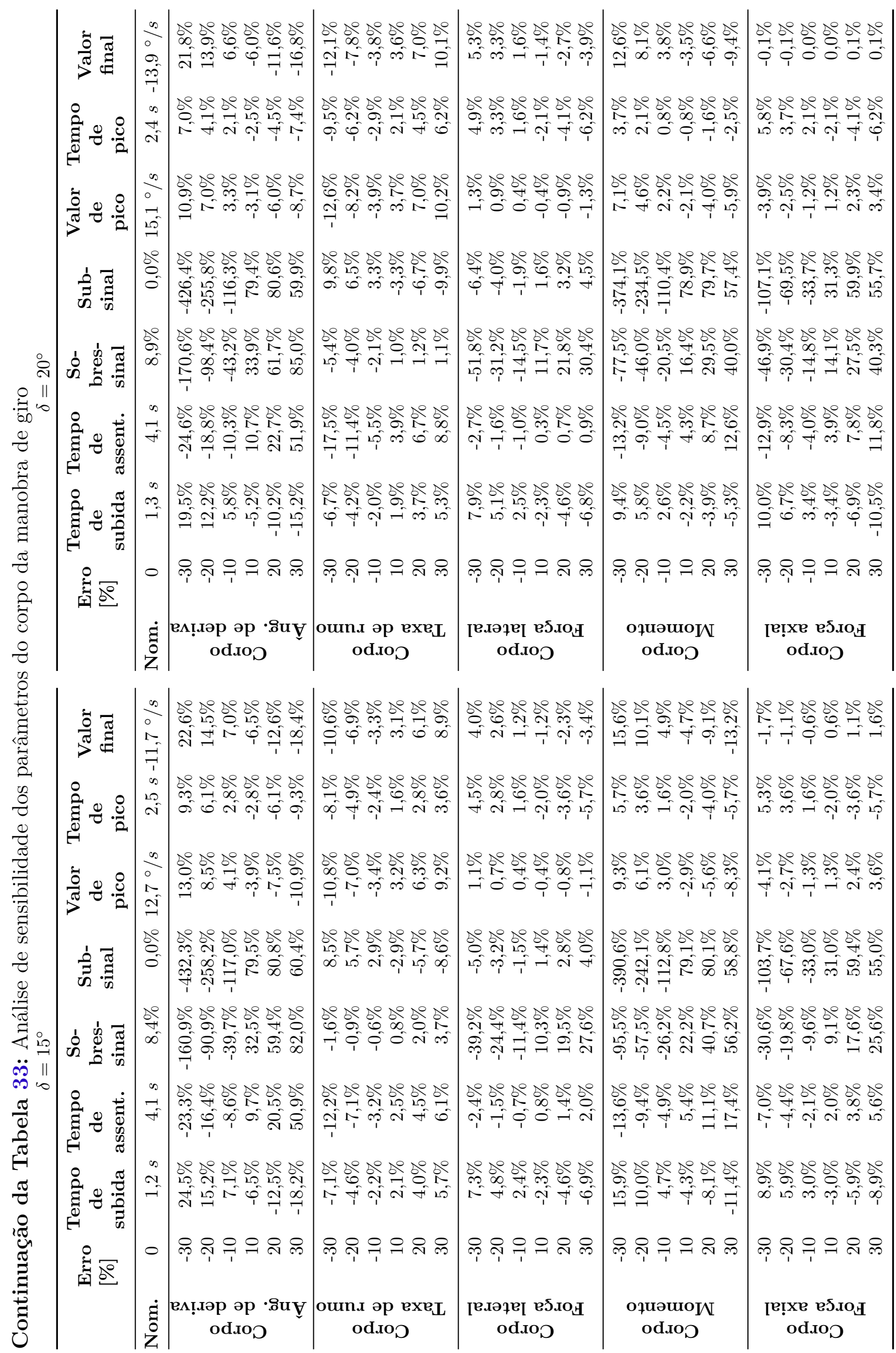



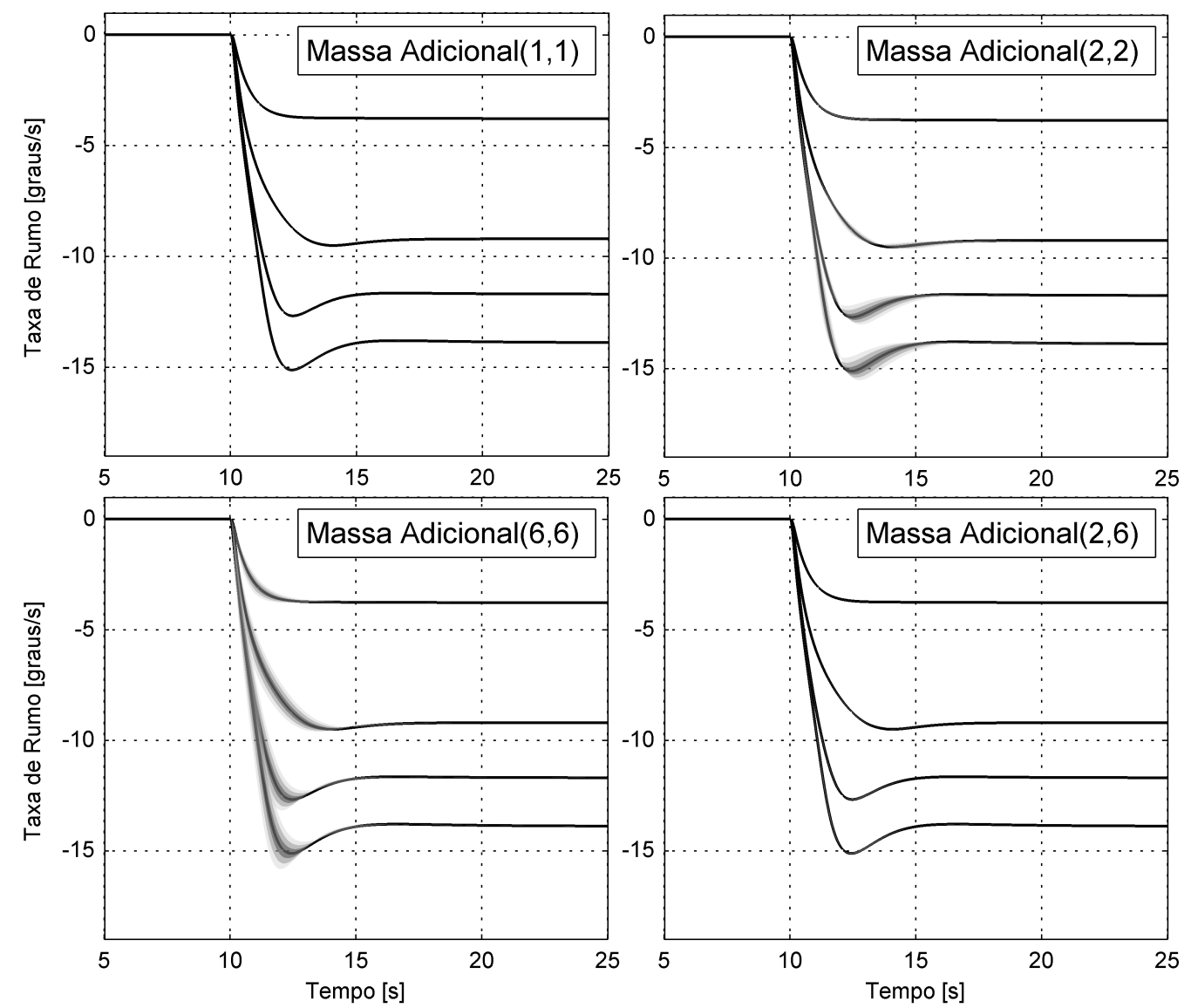

Figura 92 - Resposta da taxa de rumo para a sensibilidade dos parâmetros hidrodinâmicos de massa adicional nas manobras de giro de 5, 10, 15 e 20 graus

ao ganho na deflexão da superfície de controle, resultando em seis casos de análise da sensibilidade para a superfície de controle.

Em todos os casos foi considerado um erro base de 10\% nos ganhos.

\section{E.5 SENSIBILIDADE DOS PARÂMETROS HIDRODINÂMICOS DA COMBINAÇÃO}

A análise de sensibilidade dos parâmetros hidrodinâmicos da combinação leme-corpo foi realizada em função dos mesmos parâmetros utilizados no corpo sozinho, contudo neste caso as variações dos parâmetros do corpo e do leme são consideradas simultaneamente. Da mesma maneira que os outros casos são considerados um erro base de $10 \%$ nos ganhos. 

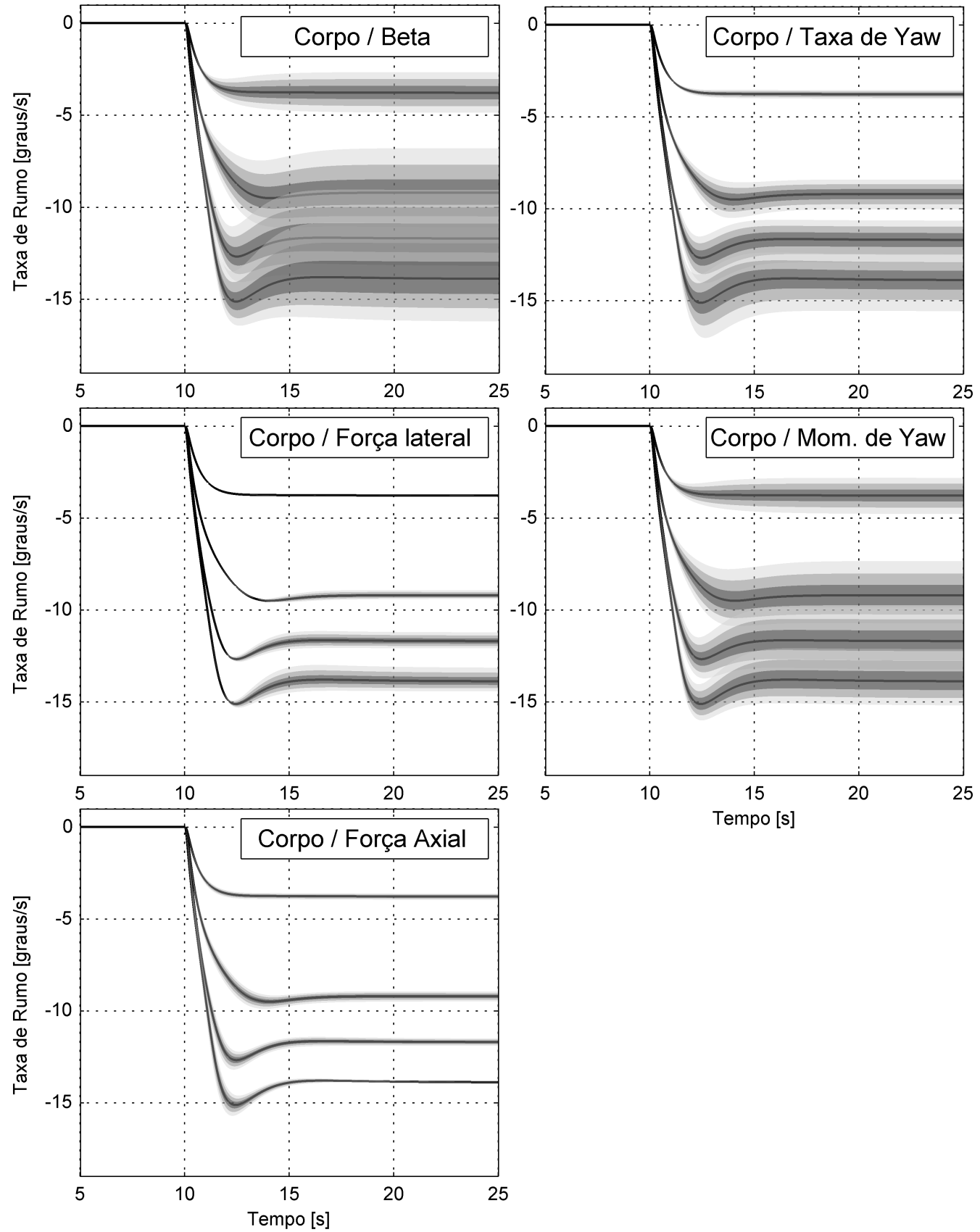

Figura 93 - Resposta da taxa de rumo para a sensibilidade dos parâmetros hidrodinâmicos do corpo do AUV nas manobras de giro de 5, 10, 15 e 20 graus 

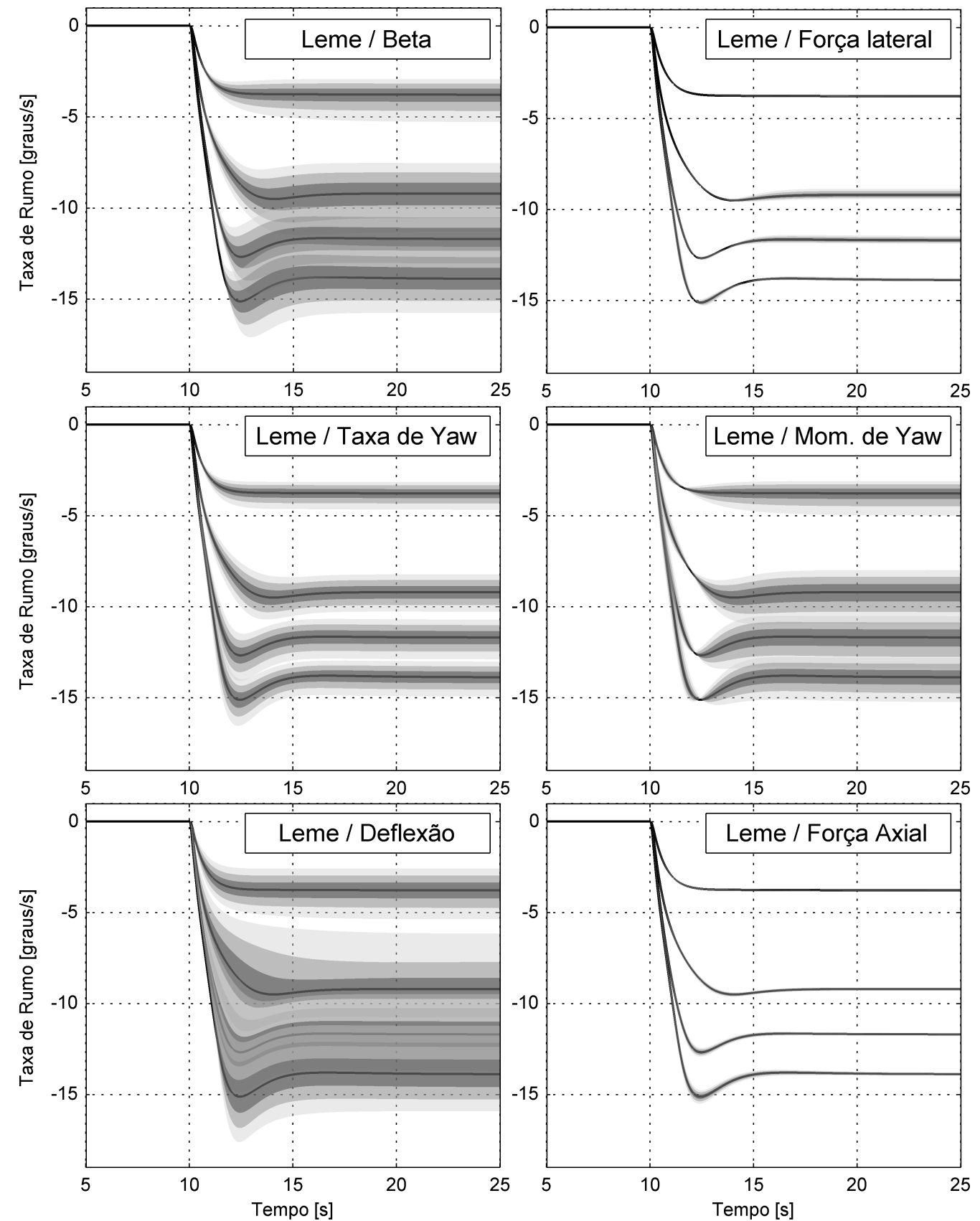

Figura 94 - Resposta da taxa de rumo para a sensibilidade dos parâmetros hidrodinâmicos do leme do AUV nas manobras de giro de 5, 10, 15 e 20 graus 


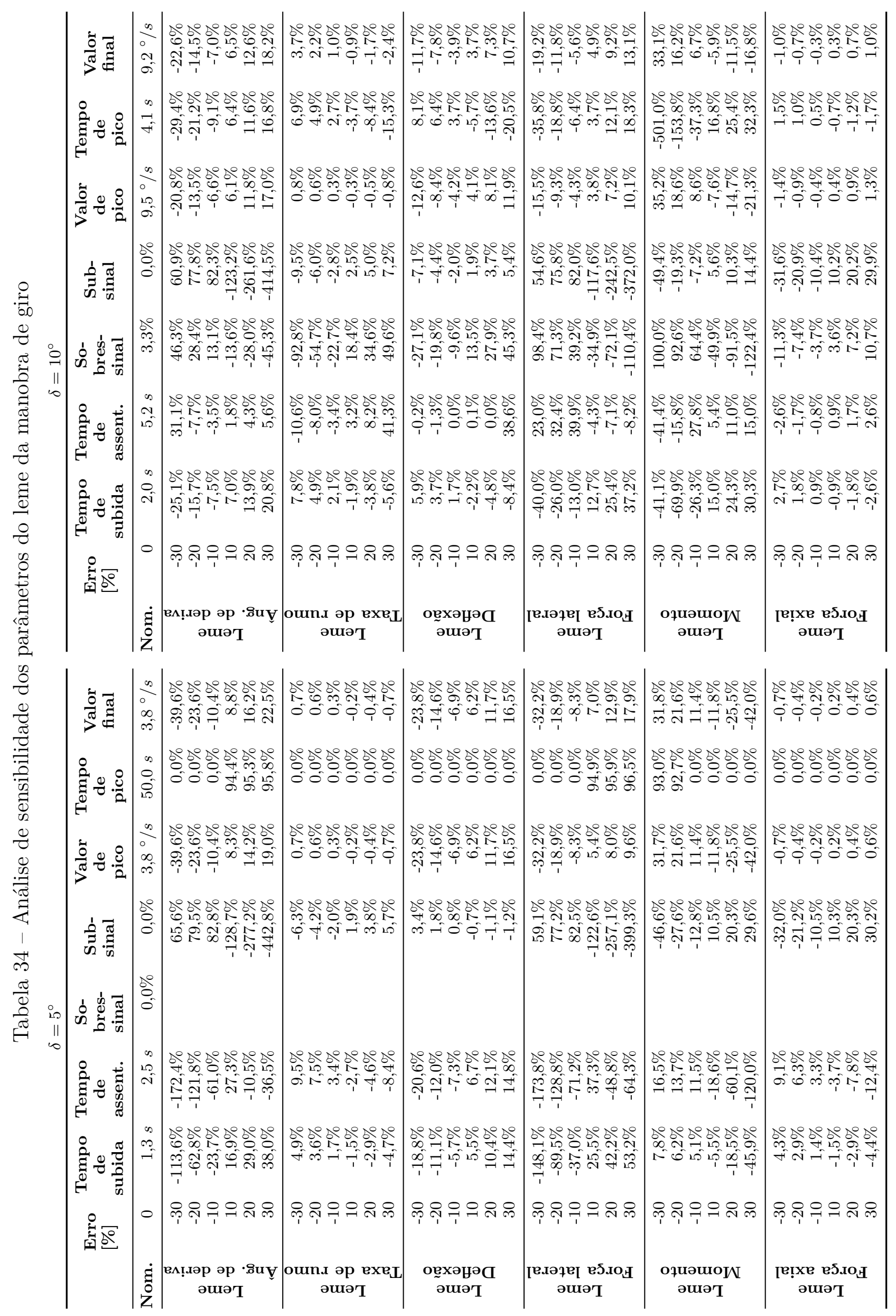




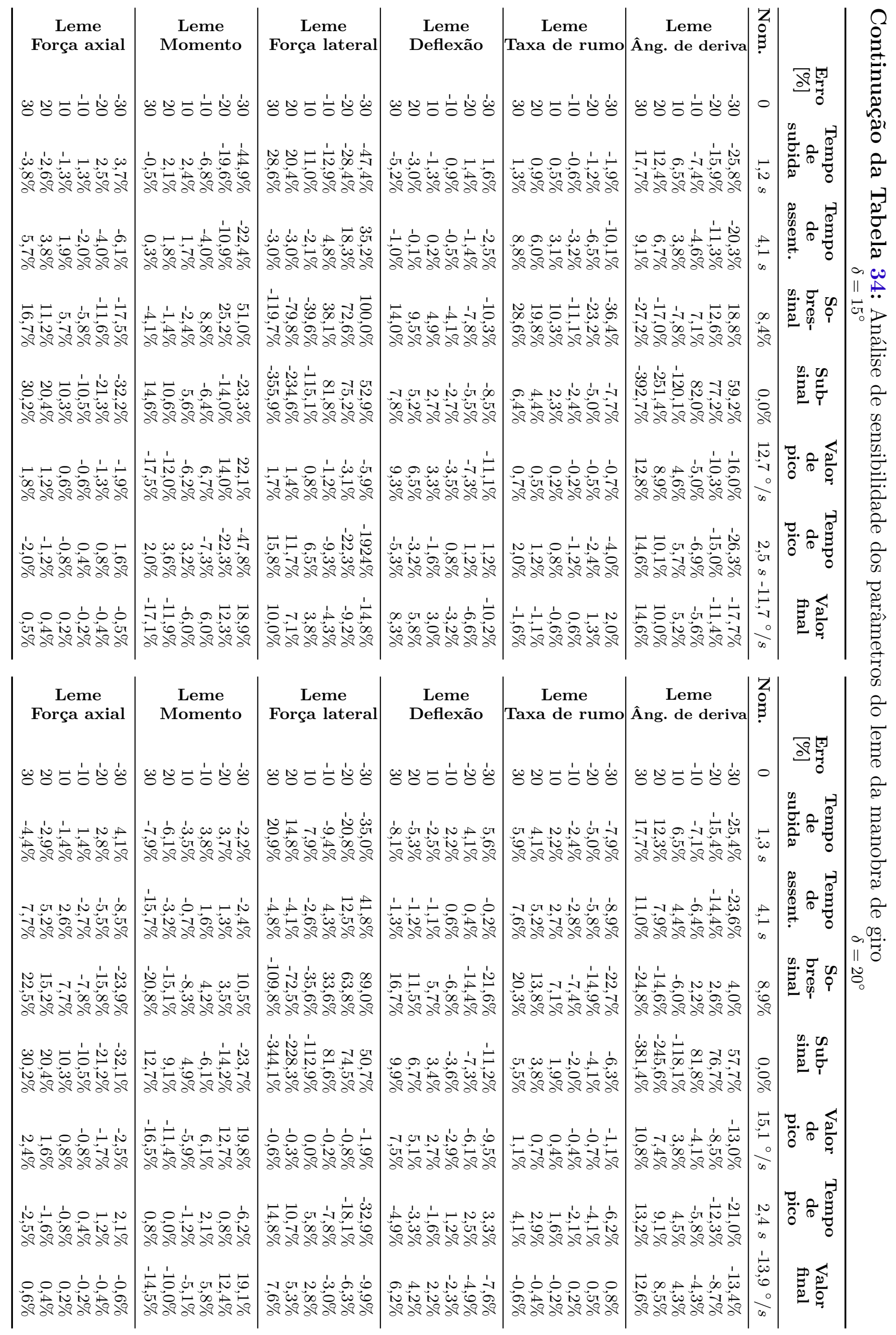



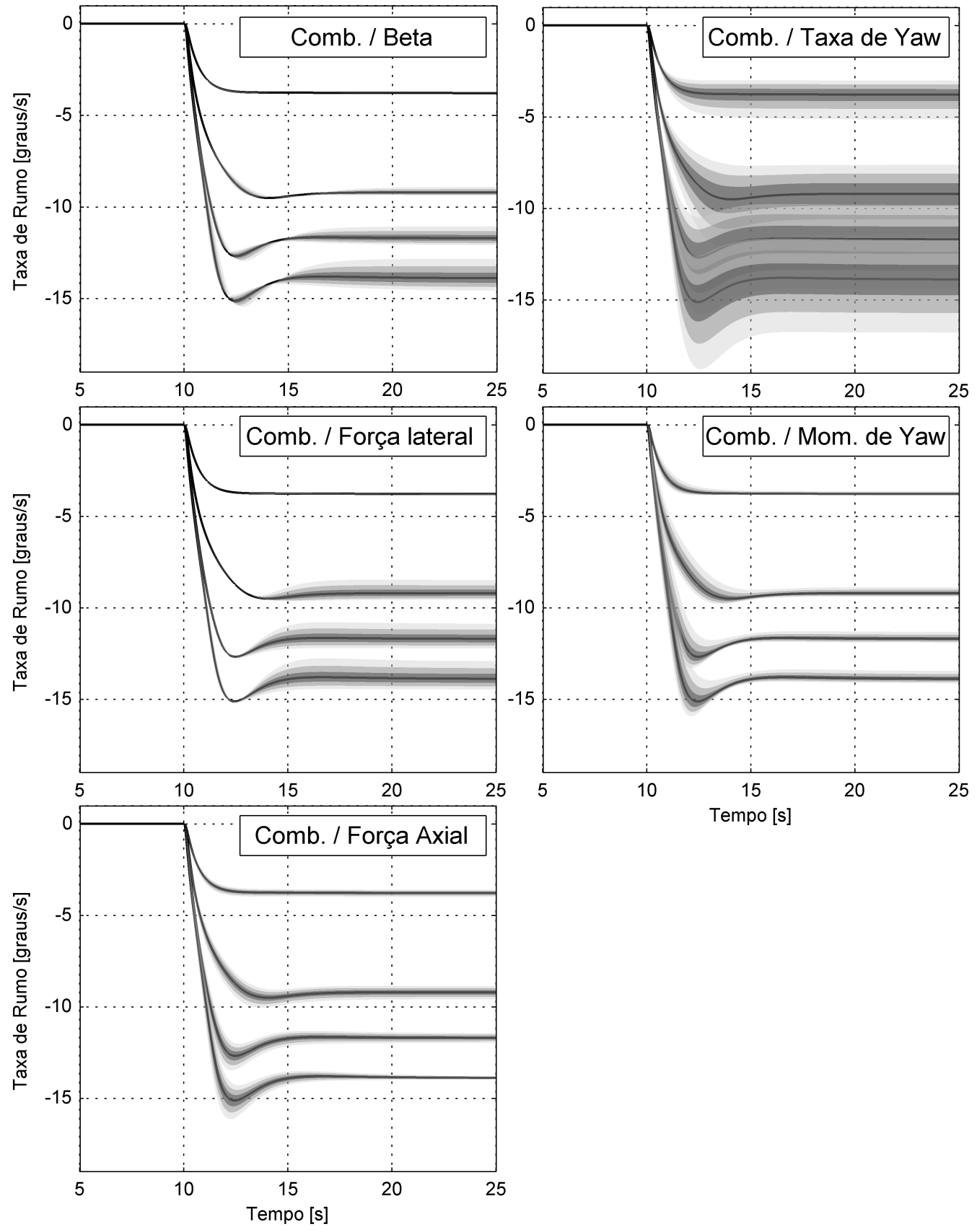

Figura 95 - Resposta da taxa de rumo para a sensibilidade dos parâmetros hidrodinâmicos do AUV (leme e corpo) nas manobras de giro de 5, 10, 15 e 20 graus 


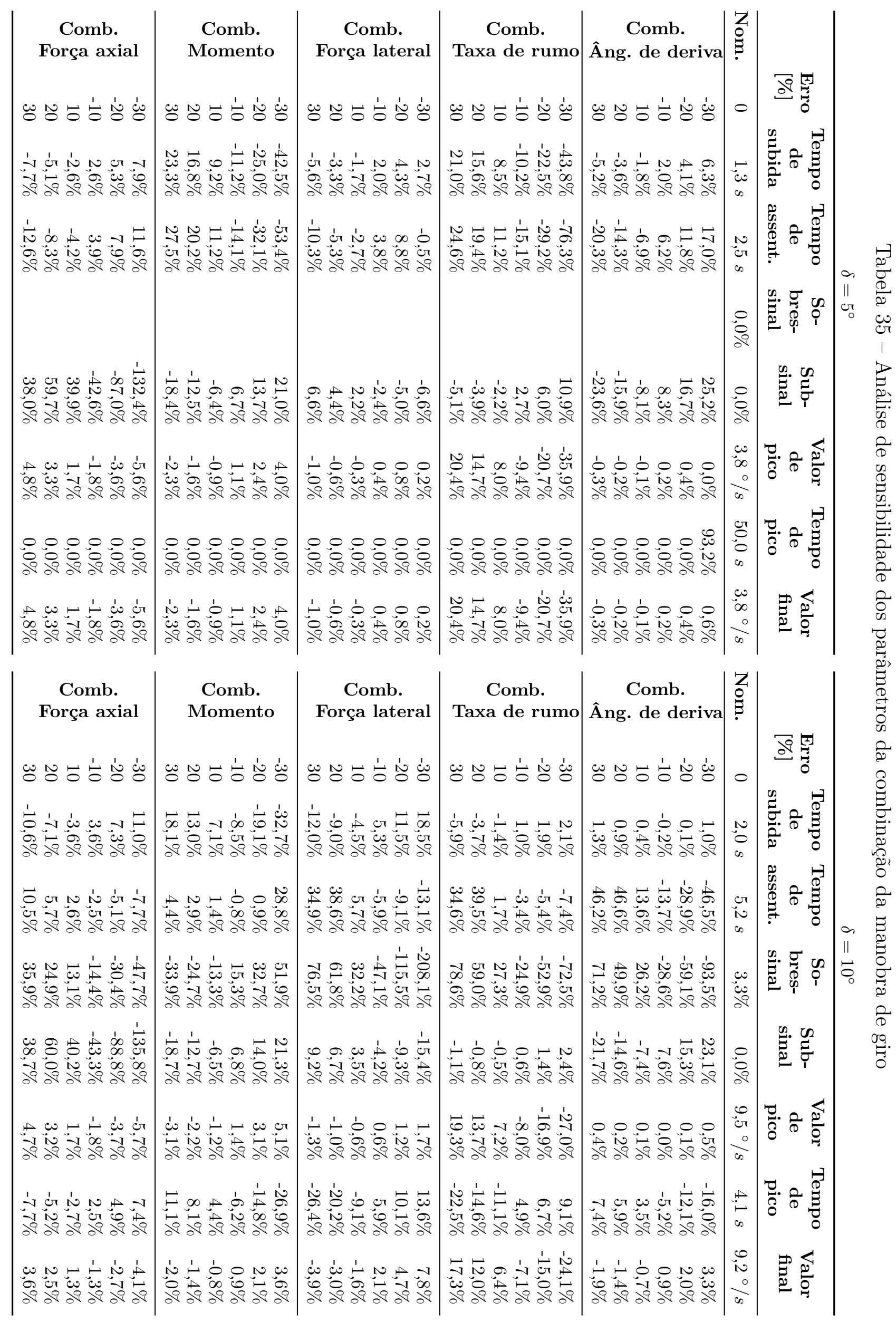




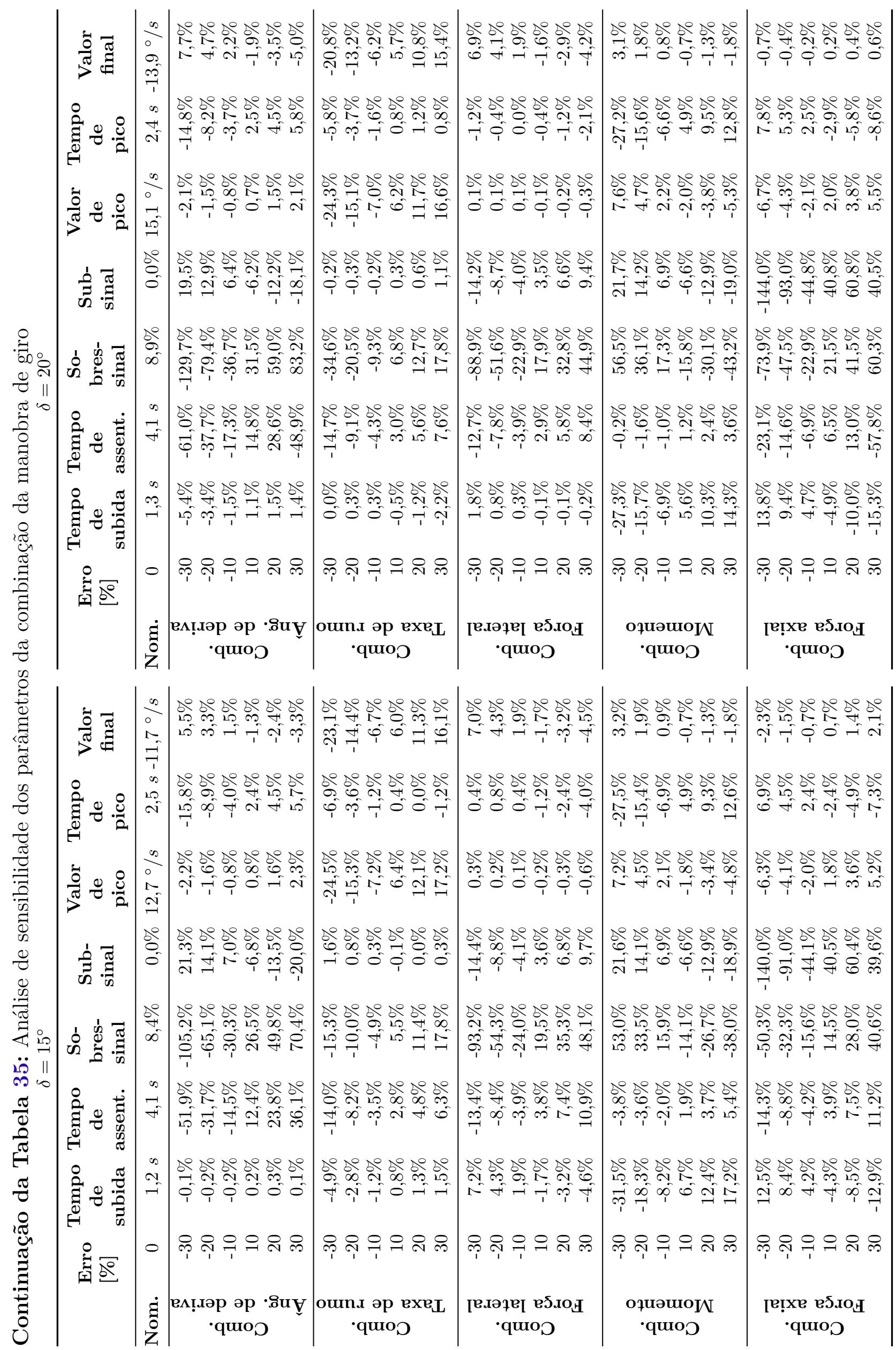





\section{APÊNDICE F - ANÁLISE DE SENSIBILIDADE DA MANOBRA DE ZIGZAG}

Neste anexo são apresentados os resultados da análise de sensibilidade dos parâmetros do modelo dinâmico do AUV Pirajuba considerados em seu simulador de dinâmica. Esta análise é utilizada para verificar a relação da incerteza dos parâmetros do modelo com a resposta dinâmica da manobra de zigzag.

Os equacionamentos cinemáticos e dinâmicos seguem as formulações apresentadas no capítulo 2 desta tese, contudo para o modelo dos esforços hidrodinâmicos estáticos, dinâmicos e de controle foram utilizadas as funções de interpolação dos resultados das simulações por CFD (Computational Fluid Dynamics), apresentadas na seção 6 desta tese.

Nesta análise de sensibilidade foi considerada a variação individual de 24 parâmetros, divididos entre parâmetros inerciais e hidrodinâmicos. Para melhorar a organização e a apresentação dos resultados, os parâmetros hidrodinâmicos foram subdivididos em termos de massa adicional total, parâmetros do corpo, do leme e da combinação corpo e leme. A análise de sensibilidade de cada grupo de parâmetros é apresentada de maneira conjunta em cada uma das próximas seções, através de gráficos e tabelas que contêm informações da resposta do veículo em termos da taxa de rumo.

Os parâmetros foram variados utilizando um critério multiplicativo, considerando uma variação percentual positiva e negativa do parâmetro. Para ilustrar melhor o efeito não linear das variações dos parâmetros nas respostas de manobra, cada parâmetro teve uma variação adicional de duas e três vezes a sua variação inicial. Por exemplo, um parâmetro com um erro de 10\% também foi simulado considerando uma variação de 20 e $30 \%$.

Nos gráficos apresentados, os resultados com variação paramétrica são representados por uma região cinza ao redor da resposta nominal, que é representada por uma linha preta. As áreas ao redor dos modelos nominais têm a sua cor intensificada para as menores variações dos parâmetros, representando a maior probabilidade da resposta estar contida nesta área.

Nas tabelas são apresentadas as principais características da resposta oscilatória do veículo, e.g., período de oscilação, amplitude de oscilação máxima do ângulo de rumo e da taxa de rumo. As respostas dos modelos com variação paramétrica são apresentadas em relação ao modelo nominal em termos de porcentagem. 

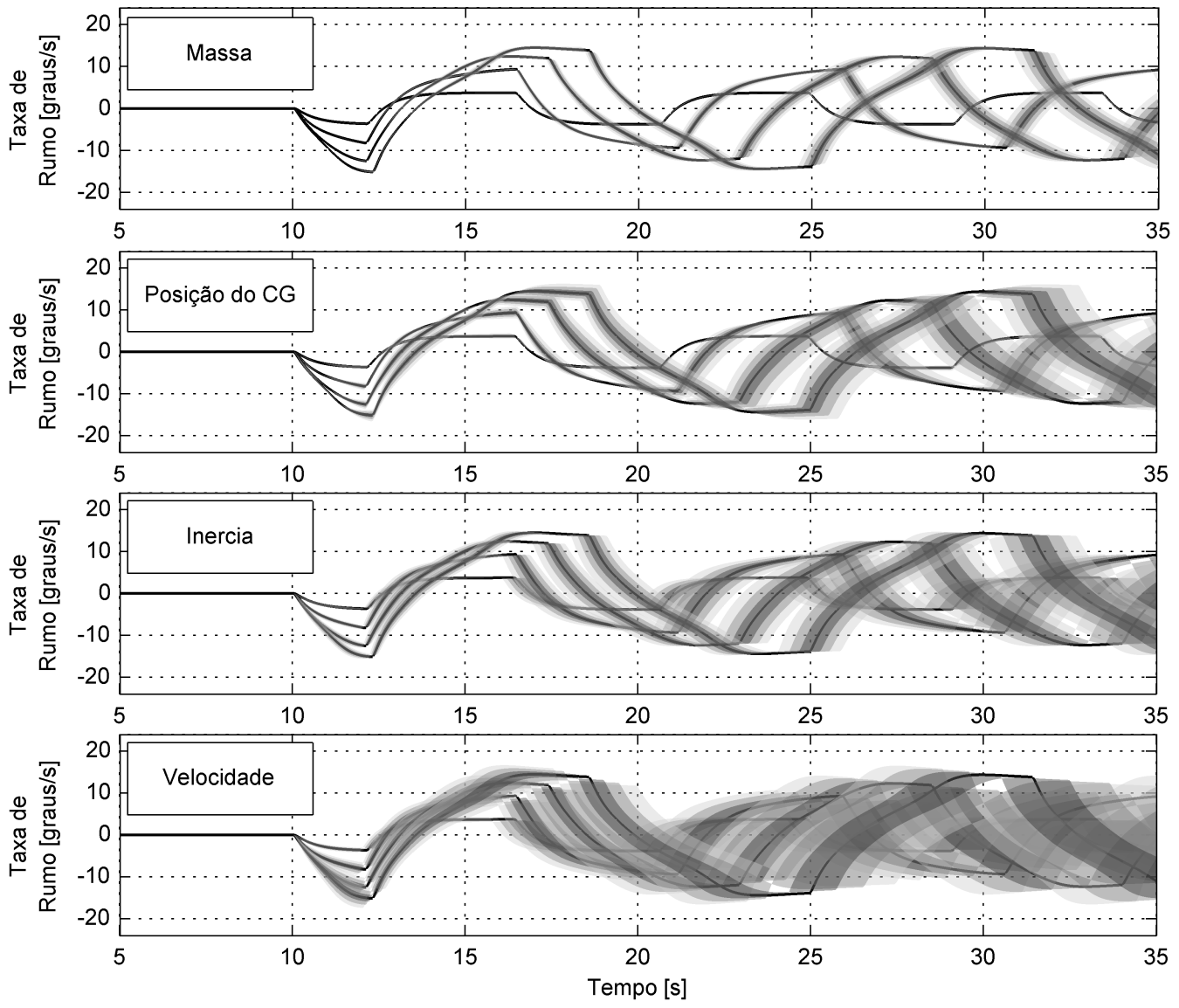

Figura 96 - Resposta da taxa de rumo para a sensibilidade dos parâmetros inerciais nas manobras de zigzag de 5, 10, 15 e 20 graus

\section{F.1 SENSIBILIDADE DOS PARÂMETROS INERCIAIS}

Para esta análise de sensibilidade foram consideradas as incertezas de quatro parâmetros inerciais: a massa total do veículo, a sua inércia de rotação, a posição do centro de gravidade (CG) e a velocidade em que é realizada a manobra. Contudo, em todas as simulações foi considerado que o veículo estava em condição de equilíbrio, ou seja, o peso do veículo era igual a sua flutuação e o centro de flutuação (CB) coincide com o CG no plano horizontal.

A incerteza nestes parâmetros foi estimada por observações do processo de estimativa destes parâmetros (ferramentas CAD com testes em balanço), e da execução do próprio experimento no ambiente marinho, considerando a variação de lastro devido os diversos ensaios no ambiente marinho.

Com base nestas observações foi assumido um erro base para a massa de $5 \%$ (3.4 $\mathrm{kg})$, para o CG de $5 \%(40 \mathrm{~mm})$, para a inércia de $15 \%\left(2.5 \mathrm{~kg} \cdot \mathrm{m}^{2}\right)$, e de $10 \%(0.1 \mathrm{~m} / \mathrm{s})$ para a velocidade de ensaio. 


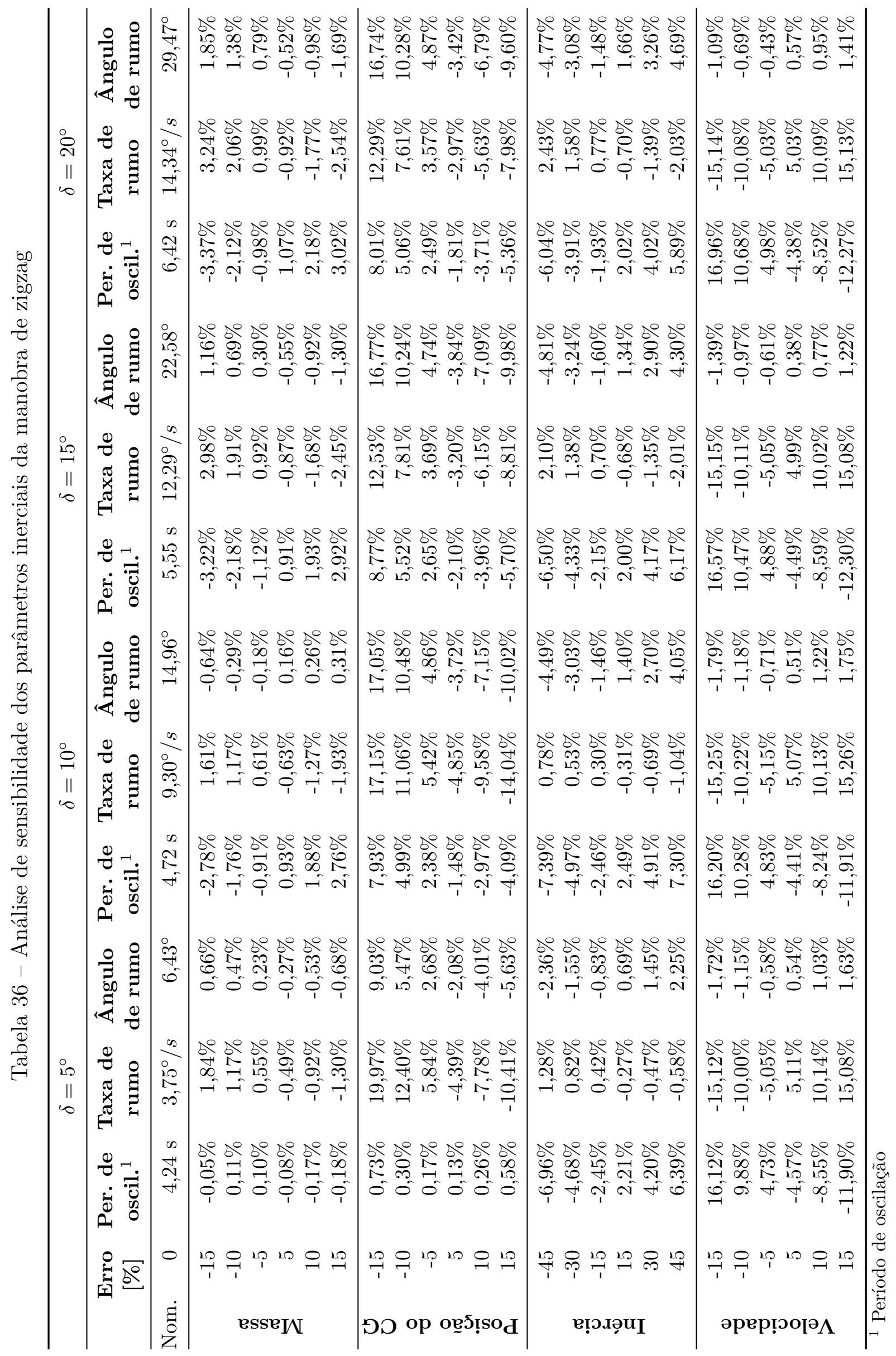



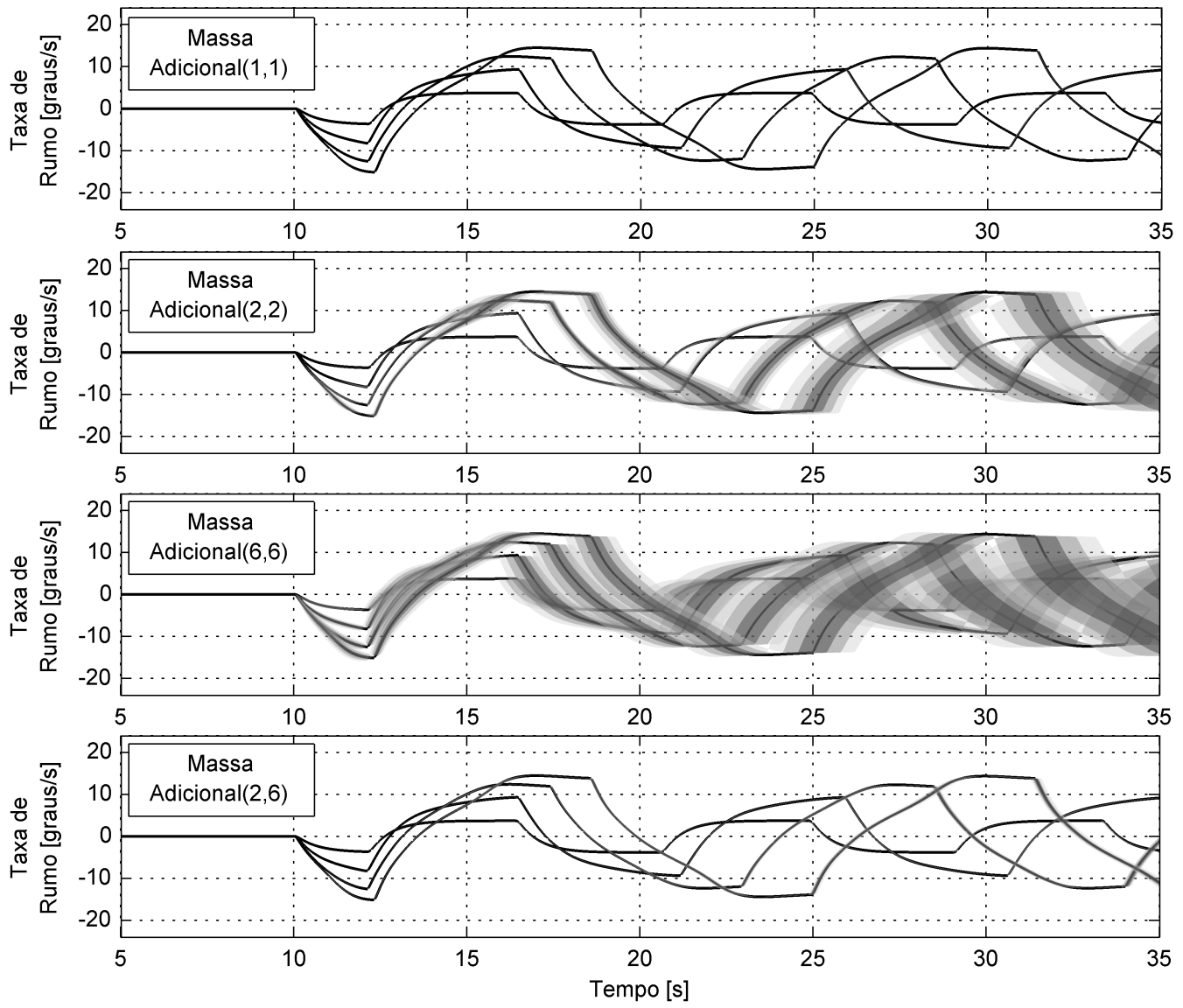

Figura 97 - Resposta da taxa de rumo para a sensibilidade dos parâmetros hidrodinâmicos de massa adicional nas manobras de zigzag de 5, 10, 15 e 20 graus

\section{F.2 SENSIBILIDADE DOS TERMOS DE MASSA ADICIONAL}

Os dados de massa adicional utilizados no simulador do AUV são calculados utilizando o método das faixas (apresentado na seção 2.2.4 desta tese). Apesar de este método ser bastante utilizado na indústria naval e aeronáutica para prever os parâmetros de massa adicional de corpos esbeltos, a adoção de um método puramente potencial em casos onde os efeitos viscosos são importantes e com corpos que não apresentam uma grande razão de esbelteza, pode apresentar um erro significativo na estimativa destes parâmetros.

Portanto, para os termos de massa adicional relativo à força devido a deriva $(A(2,2))$, o momento relativo a deriva $(A(2,6)$ ou $A(6,2))$, e o momento devido a rotação $(A(6,6))$, foi assumido um erro base de $20 \%$. No caso do termo de massa adicional devido ao movimento de avanço (surge, $A(1,1)$ ) foi considerado um erro base de $40 \%$, pois o cálculo deste termo é realizado utilizando o método de semelhança por elipsoides (onde o termo de massa adicional é calculado por uma elipsoide de medidas semelhantes ao corpo do AUV), que apresenta uma simplificação adicional em relação ao método das faixas. 


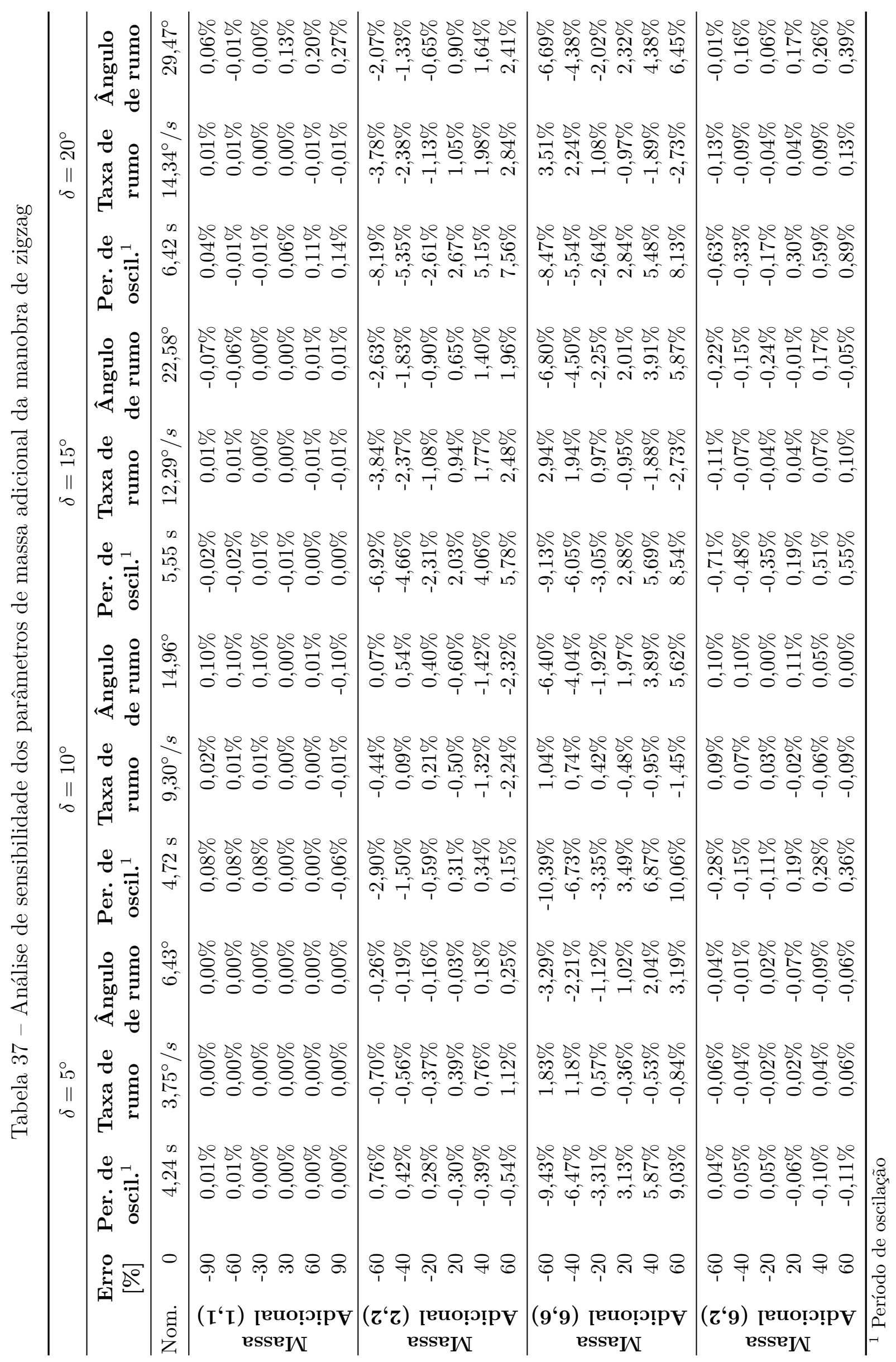



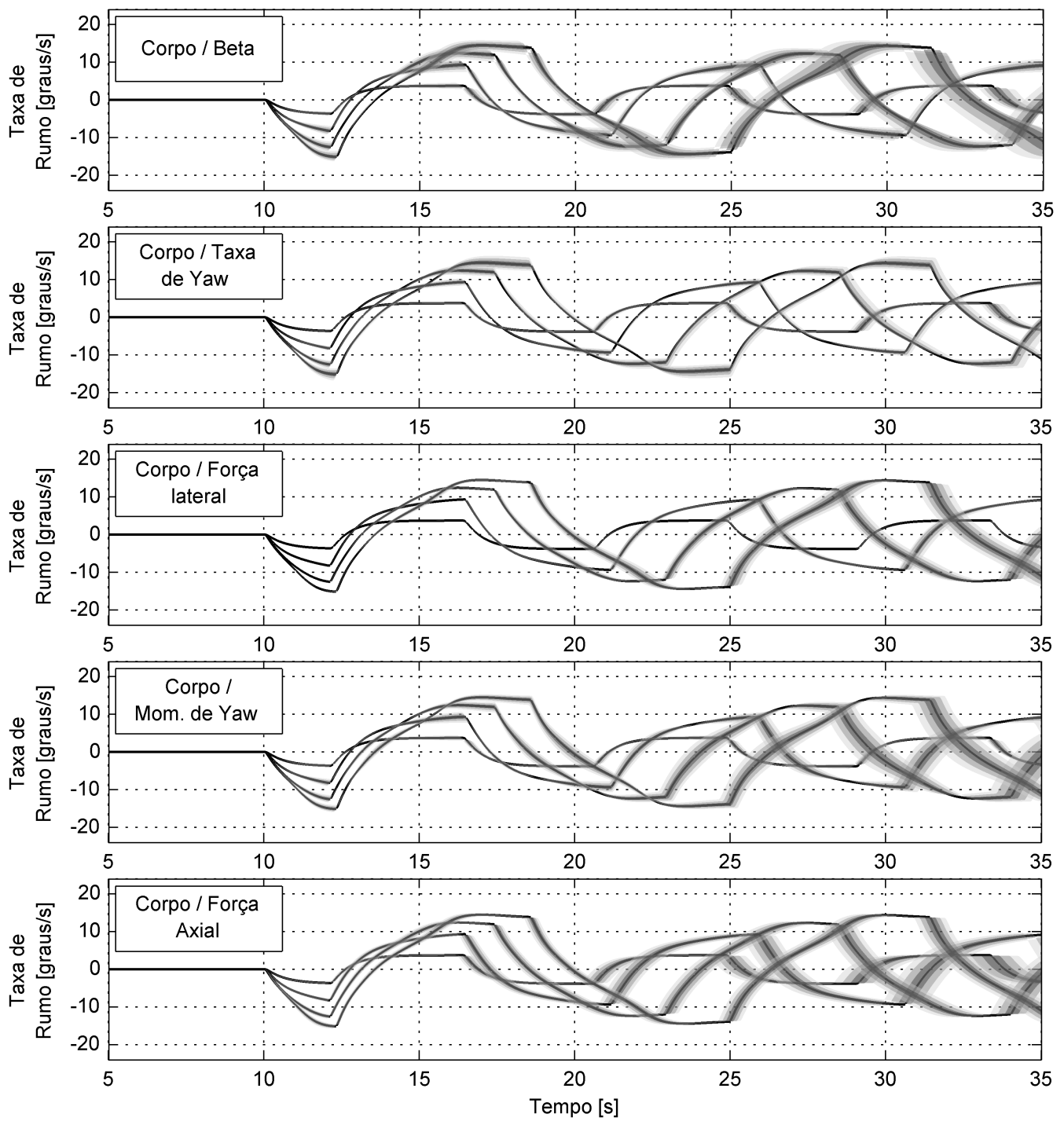

Figura 98 - Resposta da taxa de rumo para a sensibilidade dos parâmetros hidrodinâmicos do corpo do AUV nas manobras de zigzag de 5, 10, 15 e 20 graus

\section{F.3 SENSIBILIDADE DOS PARÂMETROS HIDRODINÂMICOS DO CORPO}

Como as funções hidrodinâmicas dos esforços do corpo do AUV são não lineares, sendo obtidas em função do ângulo de deriva e da taxa de rotação, a análise da sensibilidade teve que ser realizada utilizando duas metodologias que abrangessem as incertezas de maneira diferente, permitindo uma melhor análise da sensibilidade. No primeiro caso é realizada a análise de sensibilidade dos parâmetros de entrada da função de esforços hidrodinâmicos, ou seja, é aplicado o ganho de sensibilidade ao ângulo de ataque e a taxa do ângulo de rumo. No segundo caso, é adotado um ganho na saída das funções dos esforços hidrodinâmicos, ou seja, na força normal, no momento de guinada (yaw) e na força axial. 


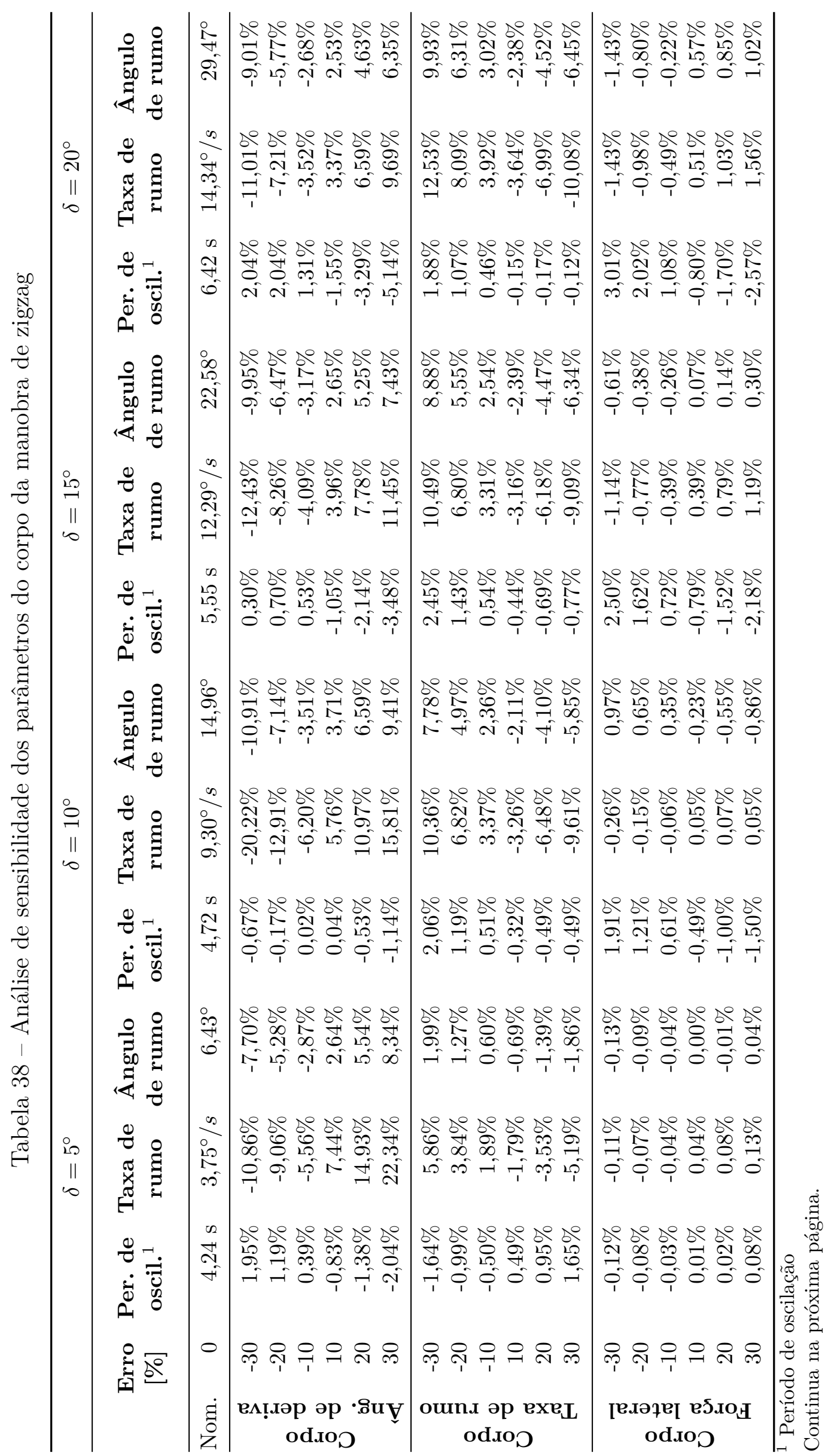




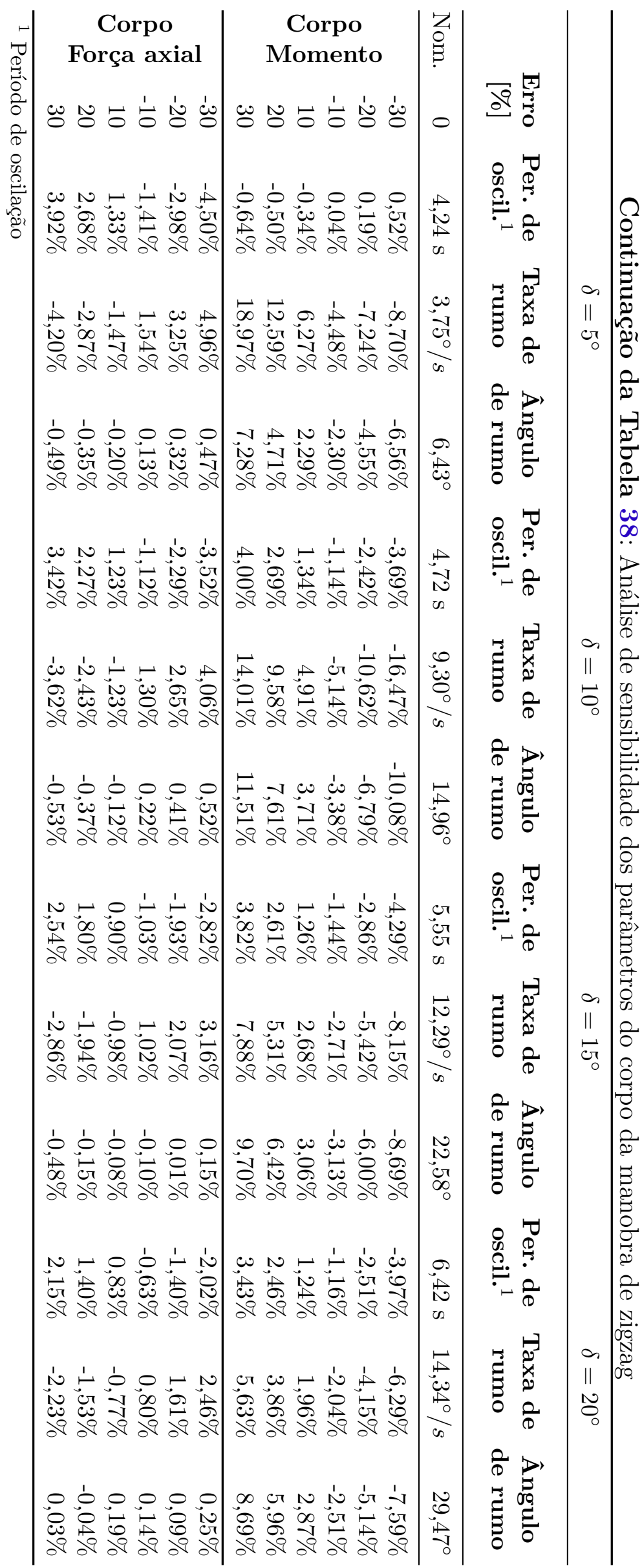




\section{F.4 SENSIBILIDADE DOS PARÂMETROS HIDRODINÂMICOS DO LEME}

A análise de sensibilidade dos parâmetros hidrodinâmicos do leme foi realizada de maneira similar ao caso do corpo, mas neste caso foi adicionada a análise de sensibilidade ao ganho na deflexão da superfície de controle, resultando em seis casos de análise da sensibilidade para a superfície de controle.

Em todos os casos foi considerado um erro base de $10 \%$ nos ganhos.

\section{F.5 SENSIBILIDADE DOS PARÂMETROS HIDRODINÂMICOS DA COMBINAÇÃO}

A análise de sensibilidade dos parâmetros hidrodinâmicos da combinação leme-corpo foi realizada em função dos mesmos parâmetros utilizados no corpo sozinho, contudo neste caso as variações dos parâmetros do corpo e do leme são consideradas simultaneamente.

Da mesma maneira que os outros casos são considerados um erro base de $10 \%$ nos ganhos. 

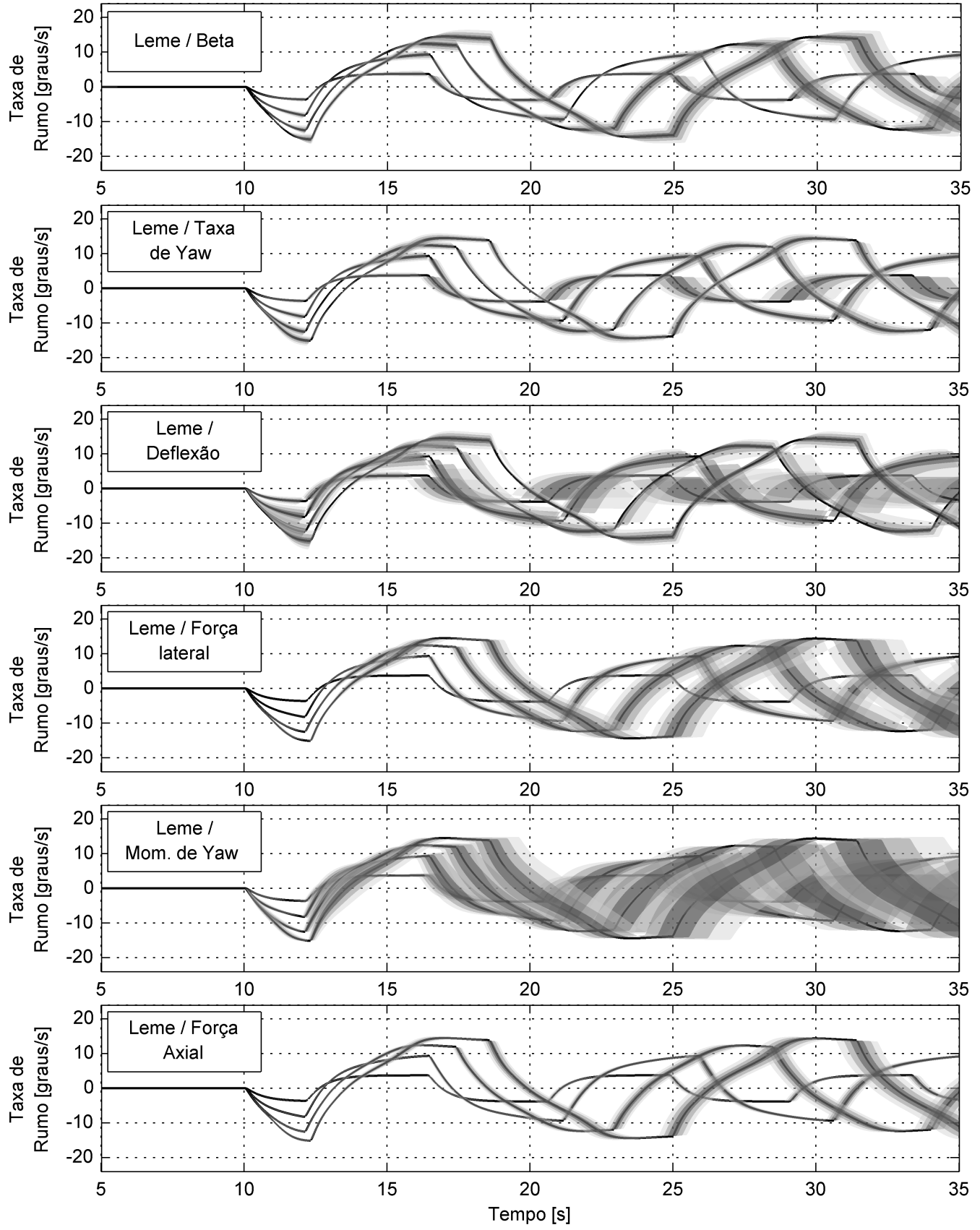

Figura 99 - Resposta da taxa de rumo para a sensibilidade dos parâmetros hidrodinâmicos do leme do AUV nas manobras de zigzag de 5, 10, 15 e 20 graus 


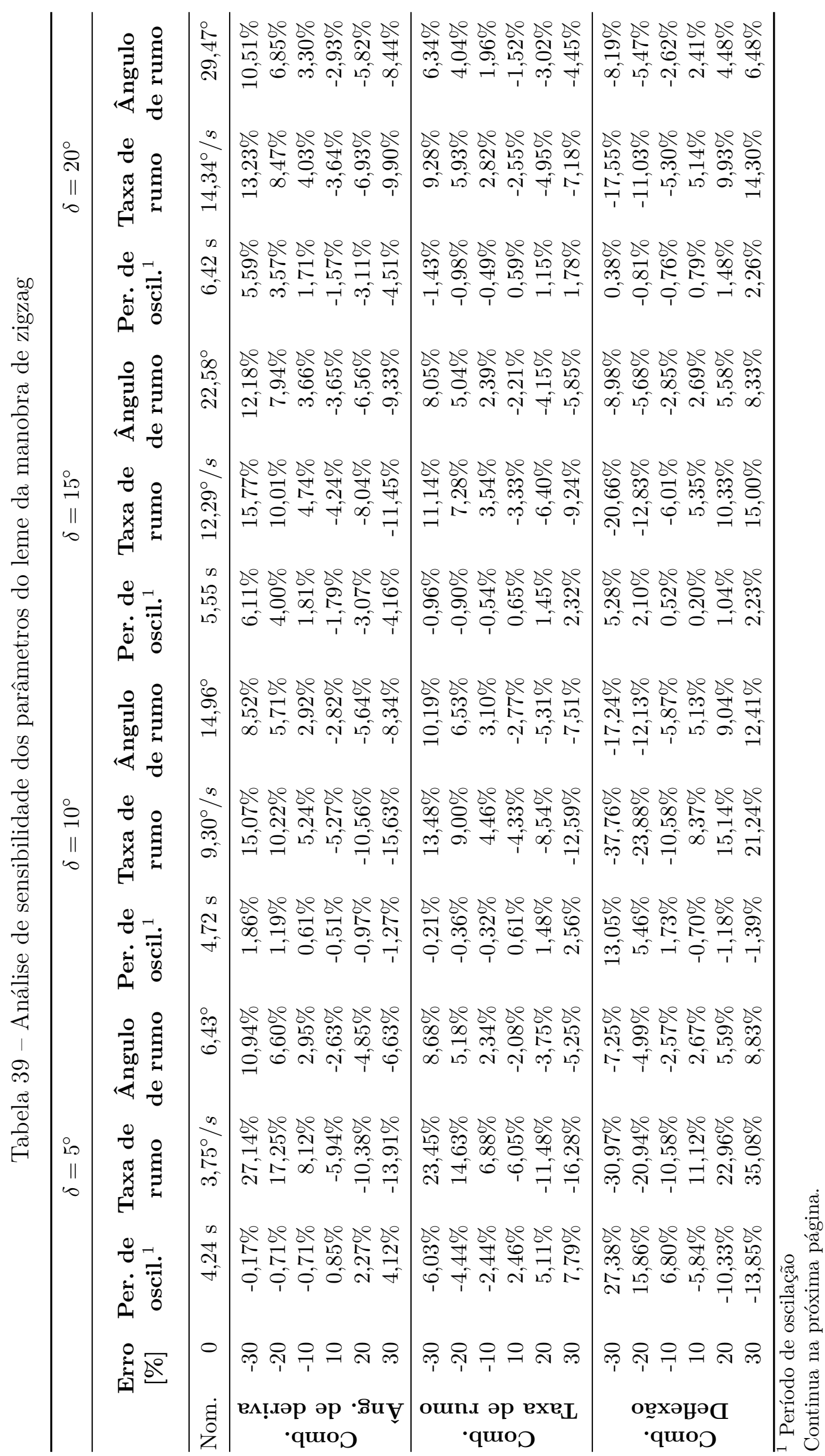




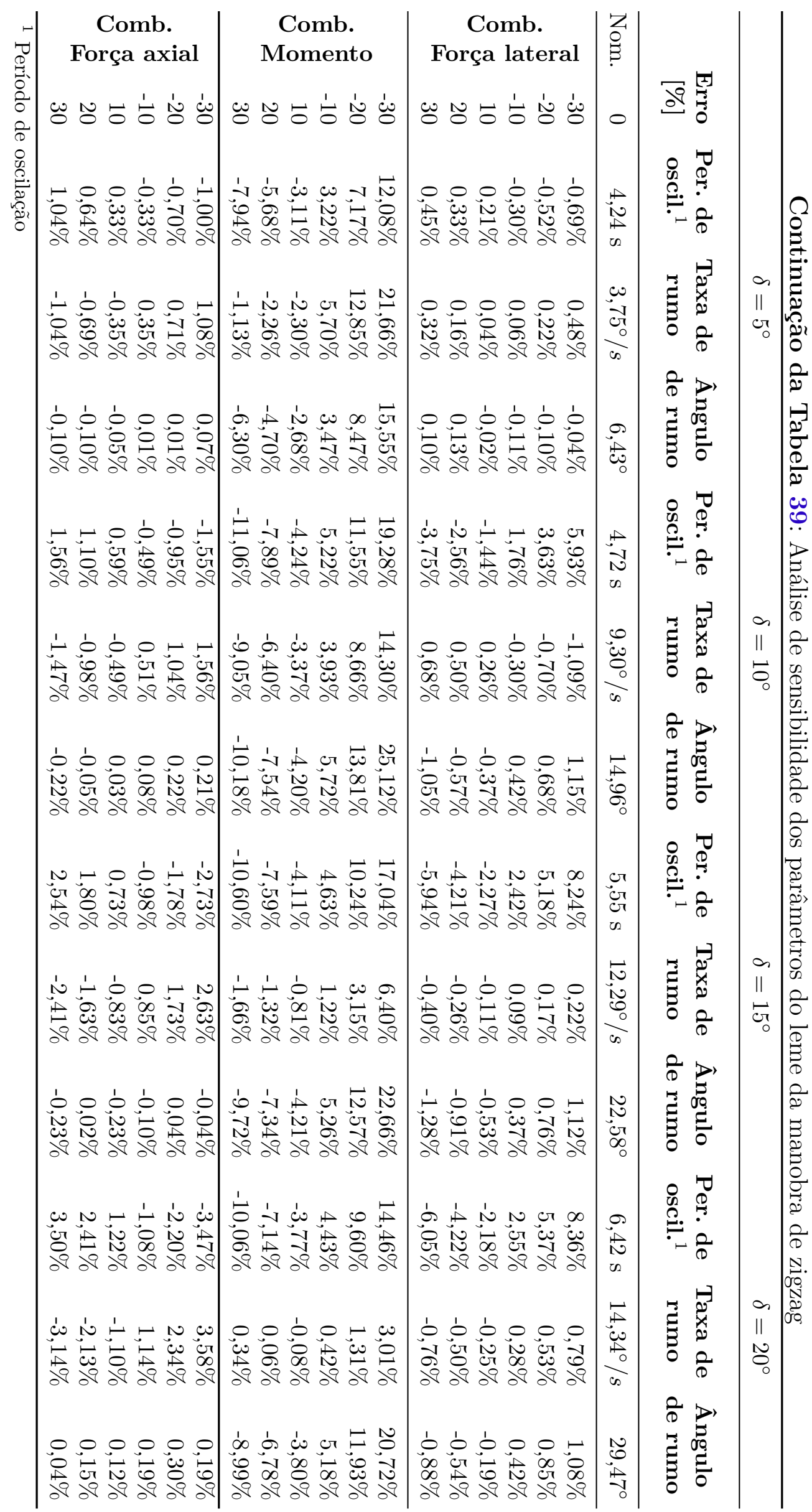




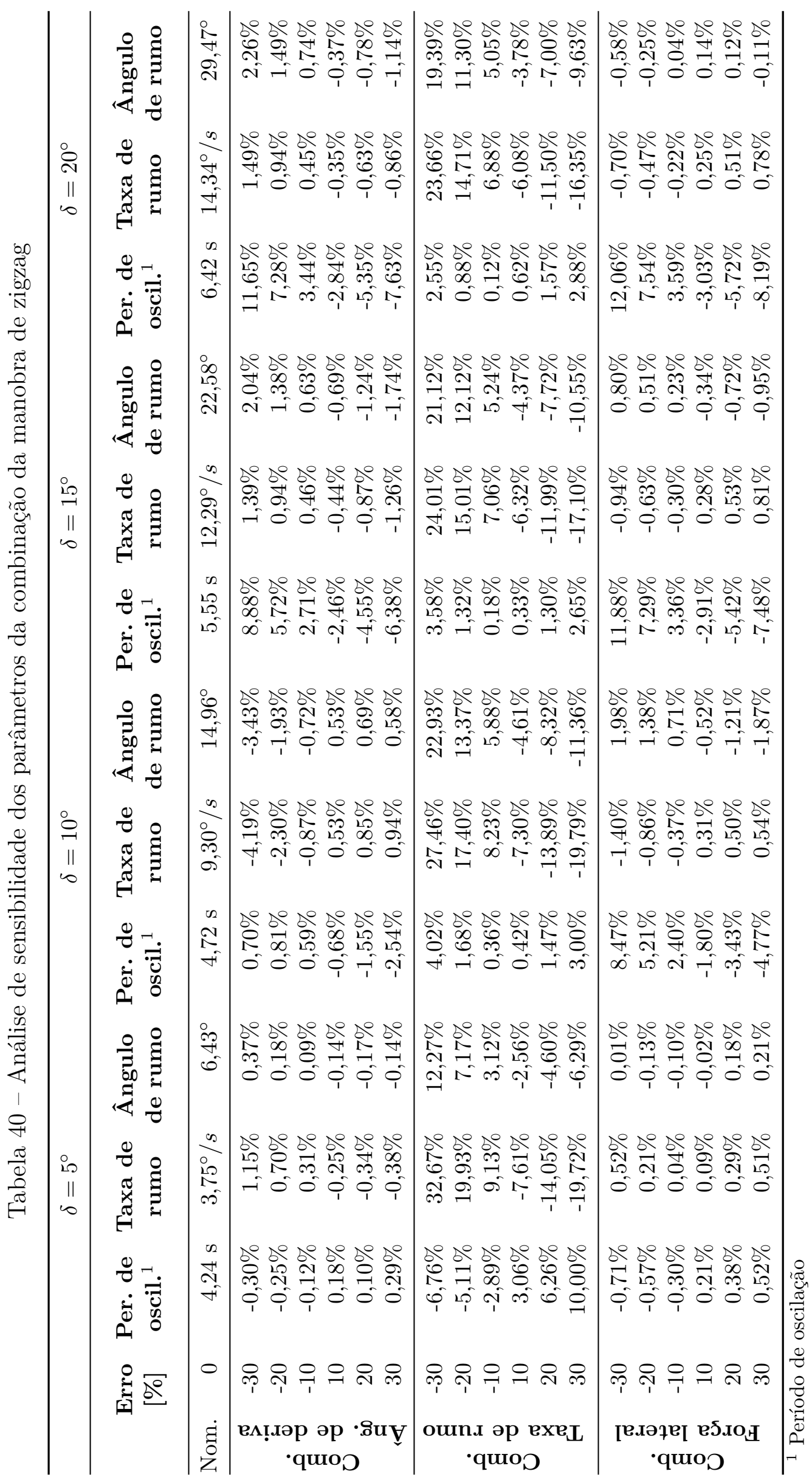




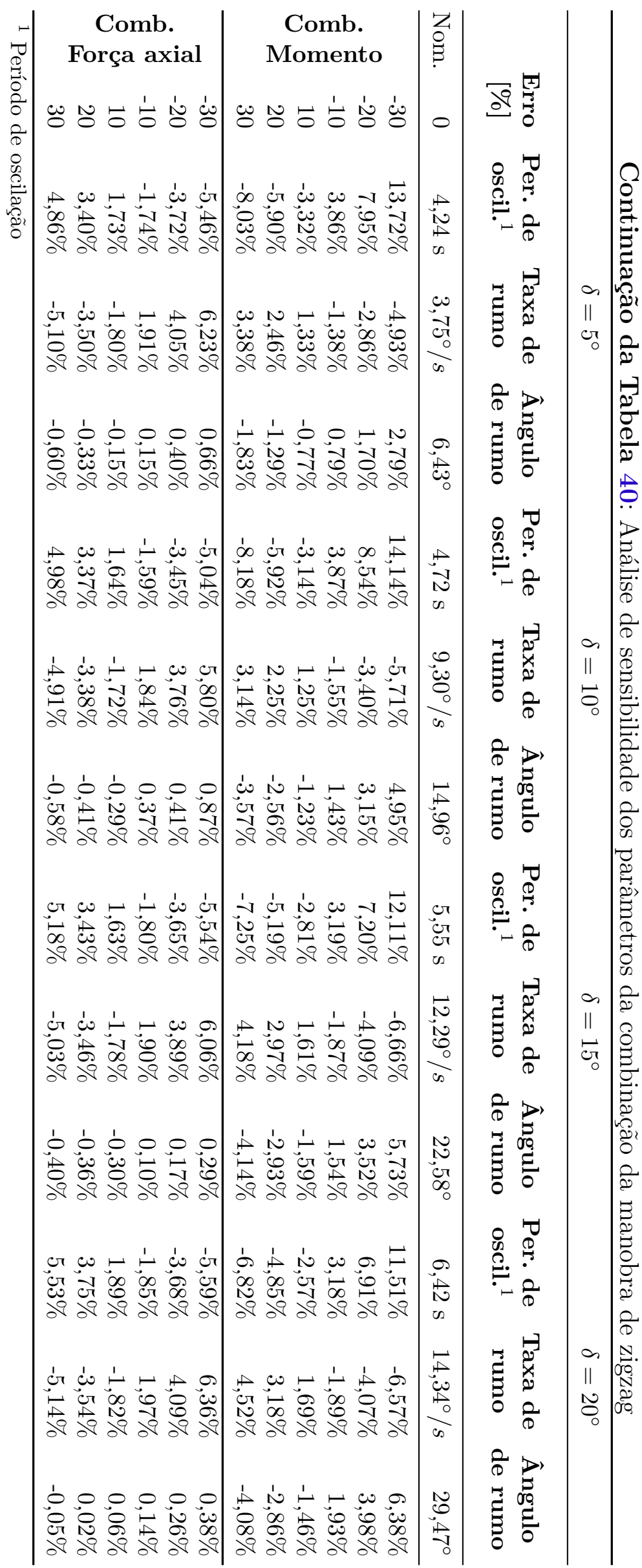



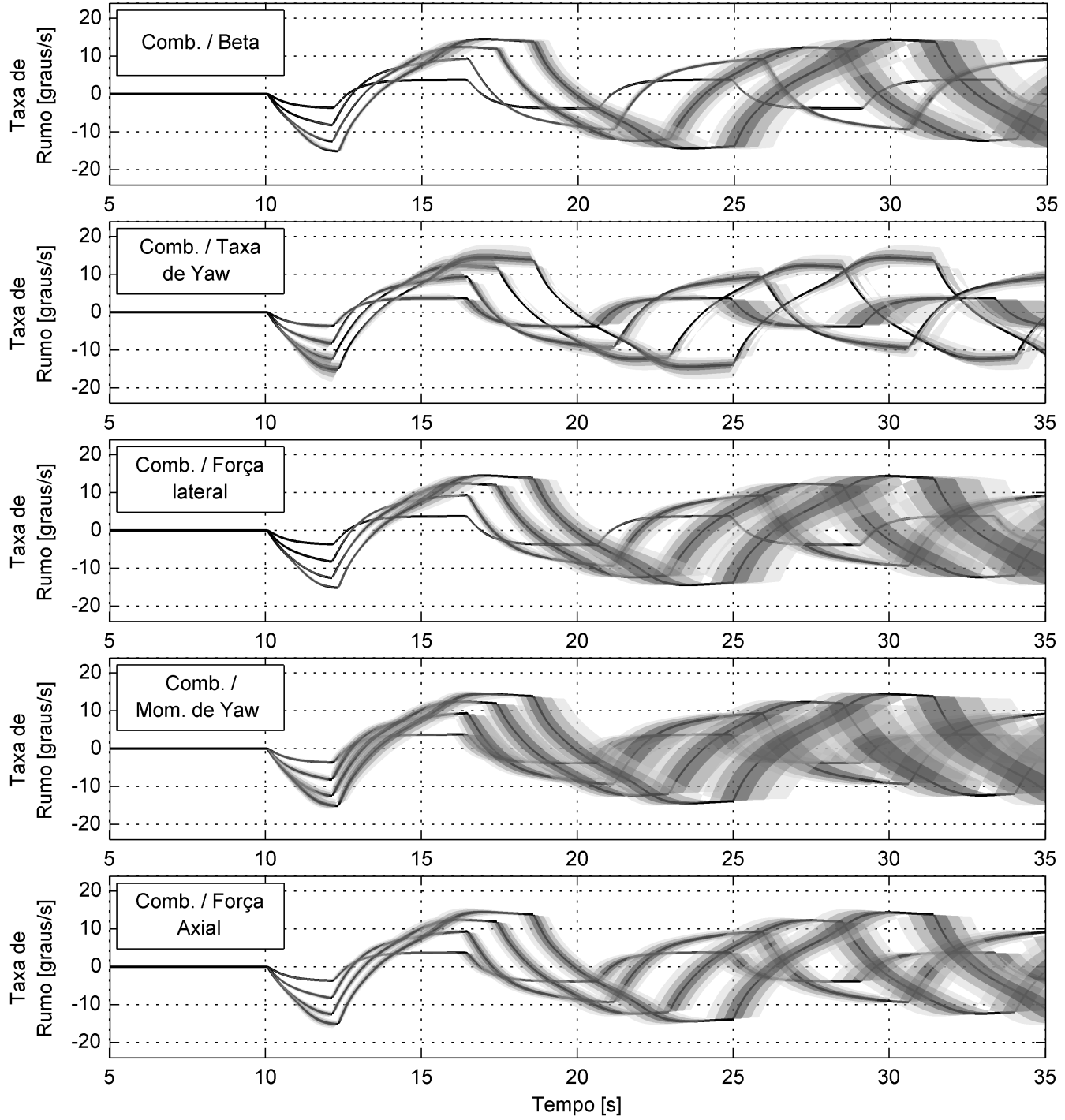

Figura 100 - Resposta da taxa de rumo para a sensibilidade dos parâmetros hidrodinâmicos do AUV (leme e corpo) nas manobras de zigzag de 5, 10, 15 e 20 graus 



\section{APÊNDICE G - CÁLCULO DOS COEFICIENTES DE SENSIBILIDADE DA MANOBRA DE GIRO}

Neste anexo são apresentados os cálculos dos coeficientes de sensibilidade e incerteza numérica dos parâmetros do modelo do AUV Pirajuba, que foram considerados no simulador de movimento. Os coeficientes de sensibilidade são utilizados para verificar a influência relativa de cada parâmetro sobre as características da manobra de giro. A incerteza numérica é calculada com base nestes coeficientes, e indica a incerteza esperada das características da manobra em função de variações dos parâmetros.

Os coeficientes de sensibilidade e a incerteza numérica são calculados pela metodologia apresentada em $\mathrm{ASME}^{[33]}$, apresentada na seção 6.4.3.3 desta tese. Estes coeficientes foram calculados utilizando os resultados de sensibilidade apresentados no apêndice E, considerando o erro nominal $(1 \sigma)$ que é apresentado na tabela 17 da seção 6.4.3.2.

Os coeficientes de sensibilidade são apresentados na forma escalada ${ }^{[33]}$, para que a comparação entre os diferentes parâmetros seja padronizada por uma mesma variação percentual de cada parâmetro. Estes coeficientes são apresentados nas tabelas de 41 a 45, sendo divididos em função dos tipos de esforços que os seus parâmetros influenciam, ou seja, inercial e hidrodinâmico de massa adicional, do corpo, do leme e da combinação corpo e leme.

Para os parâmetros inerciais e de massa adicional, a incerteza numérica é calculada considerando todos os coeficientes de sensibilidade, representando uma incerteza que contempla todos os parâmetros de uma mesma classe. Esta incerteza é apresentada nas últimas linhas das tabelas 41 e 42.

No caso dos parâmetros hidrodinâmicos do corpo, leme e combinação, apresentados nas tabelas 43, 44 e 45, respectivamente, o cálculo da incerteza deve ser dividido entre os parâmetros de ganho das variáveis de entrada das funções de esforços (ângulo de deriva, taca angular e deflexão dos lemes), e os parâmetros de ganho da saída dos esforços hidrodinâmicos (força normal, momento e força axial). Esta distinção é realizada para que no cálculo da incerteza não sejam considerados a sobreposição de fenômenos hidrodinâmicos repetidos, e se obtenha uma incerteza maior do que o realmente observado. Nestes casos, ambas as incertezas são apresentadas nas mesmas tabelas dos coeficientes de sensibilidade, mas cada uma delas é apresentada na linha abaixo dos coeficientes que a contemplam. 


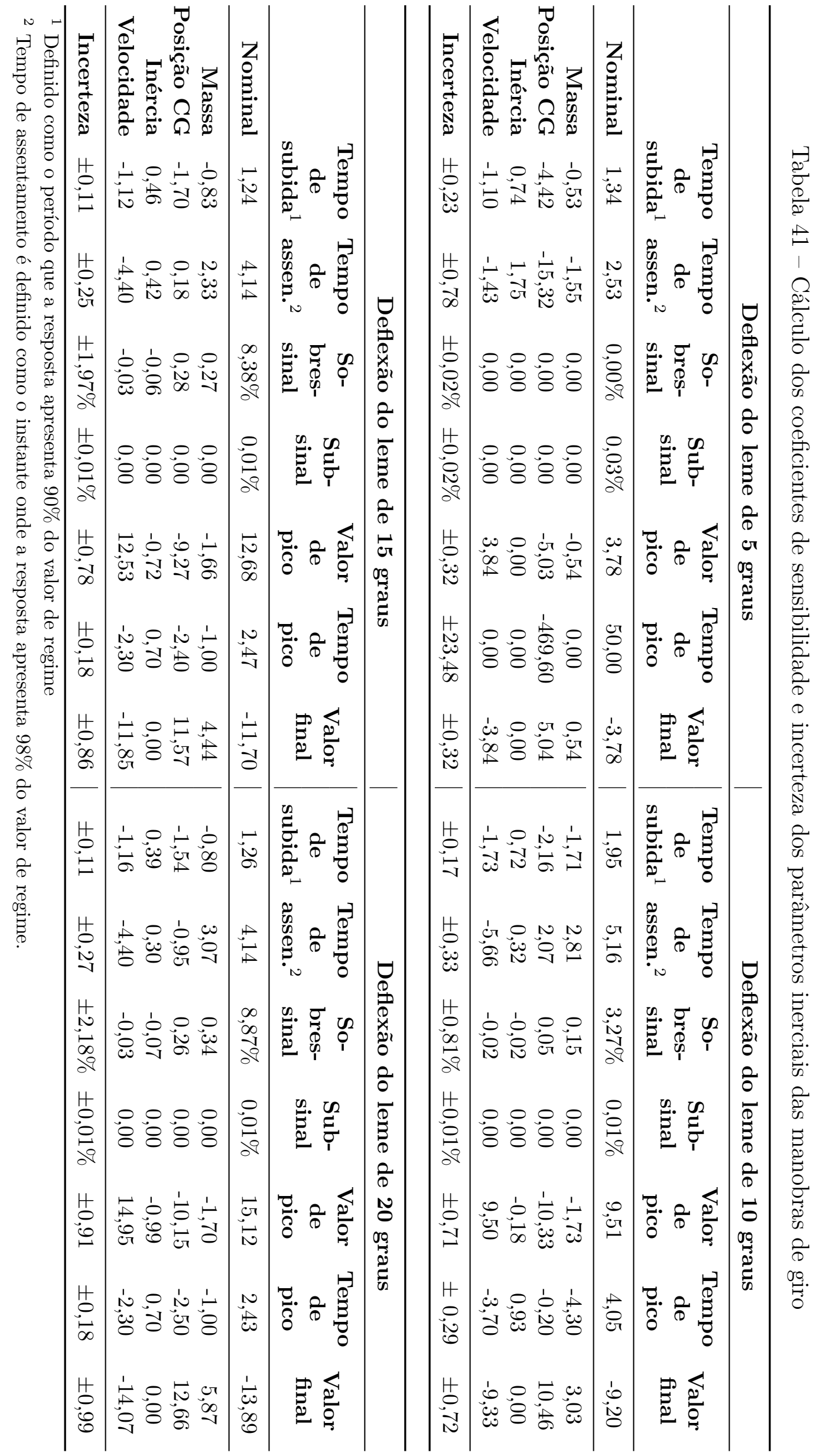




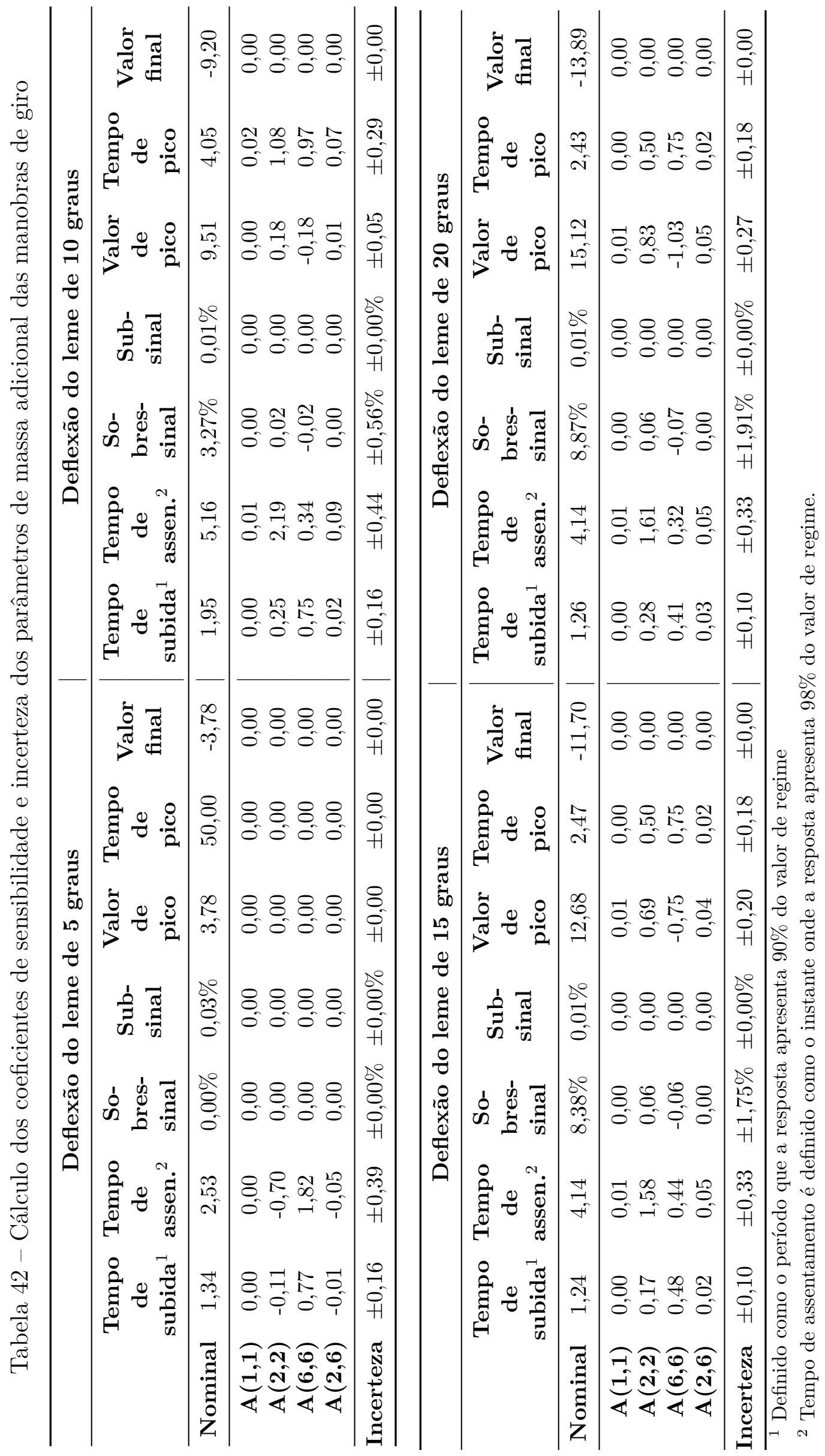




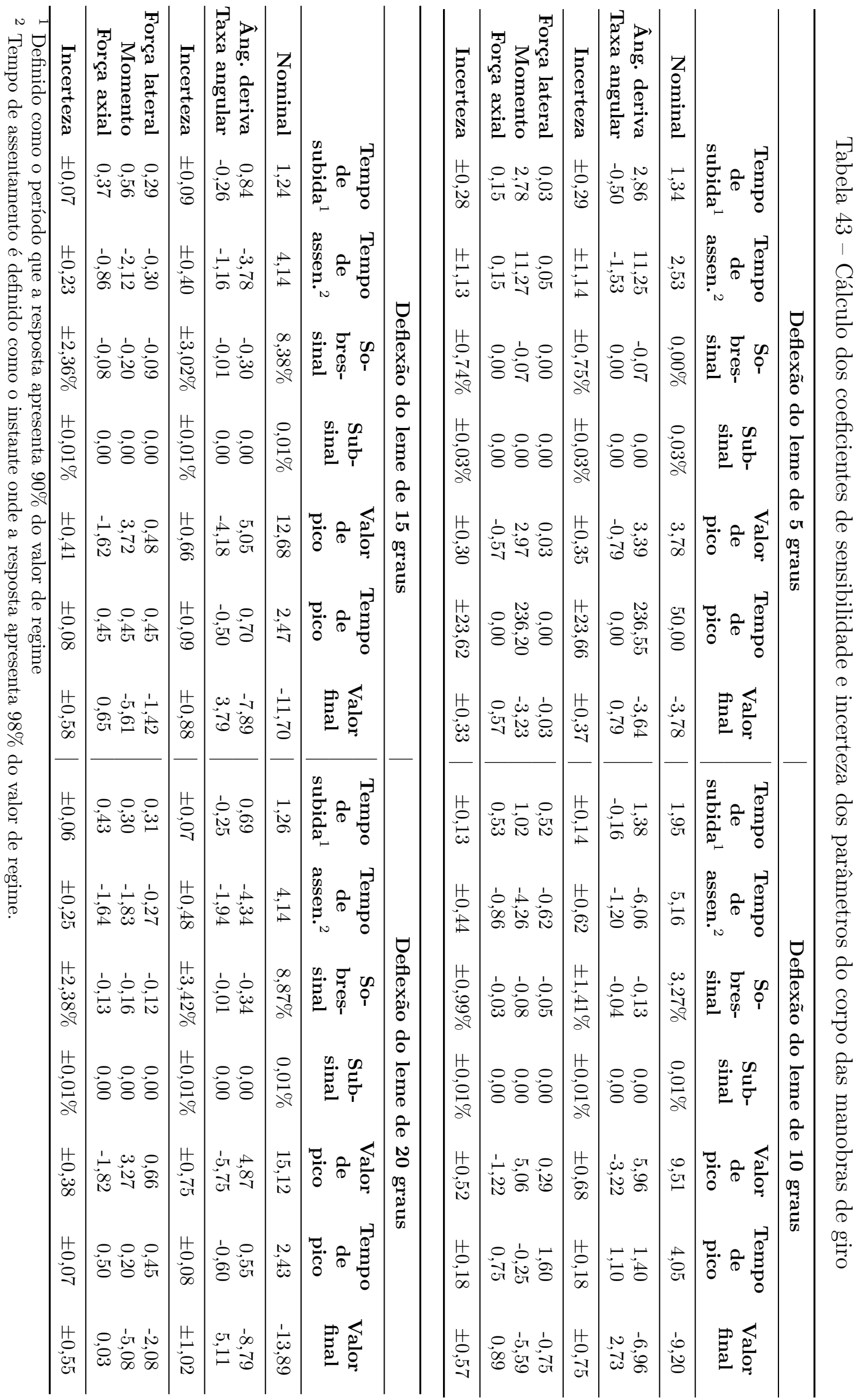




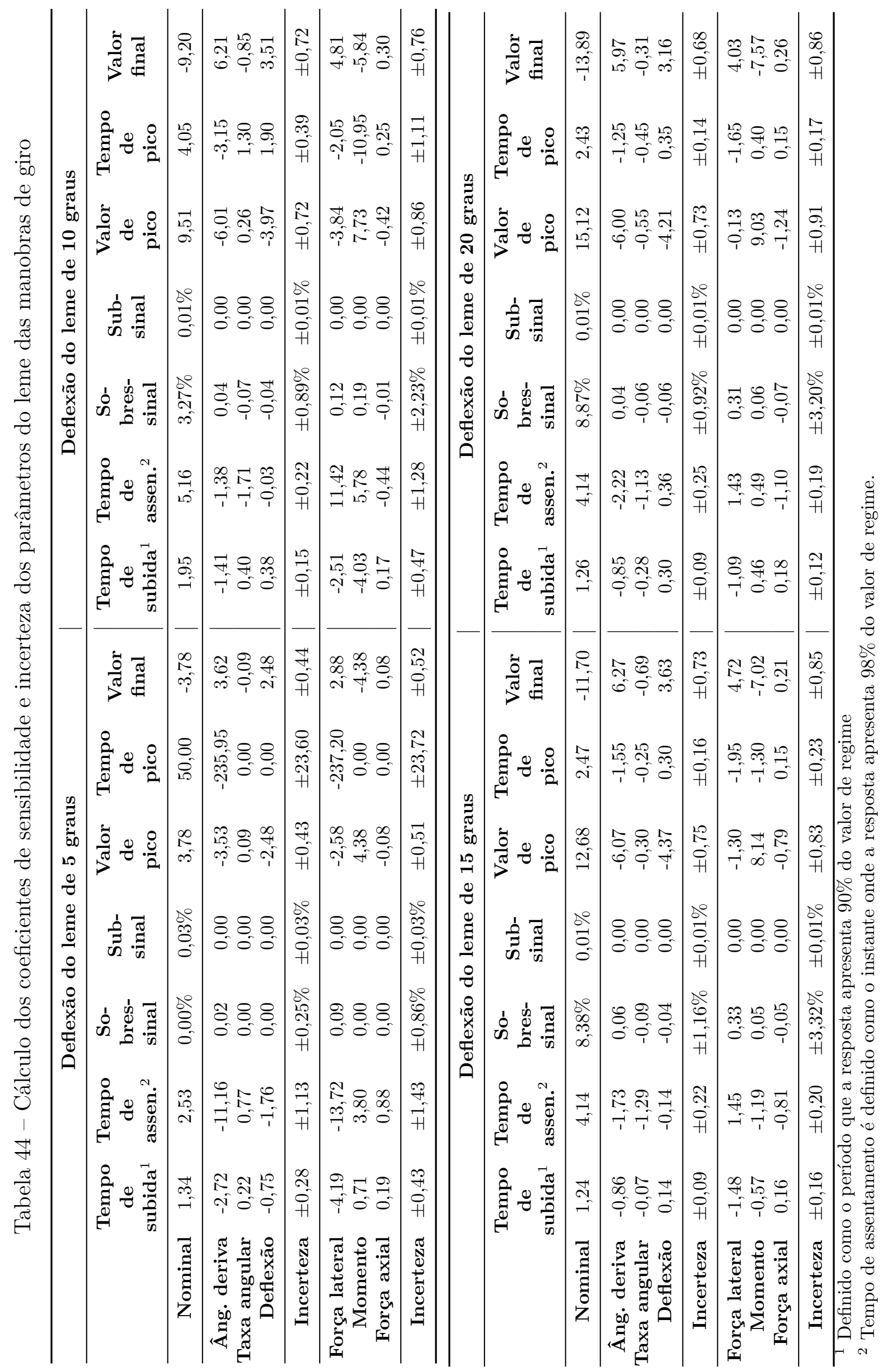




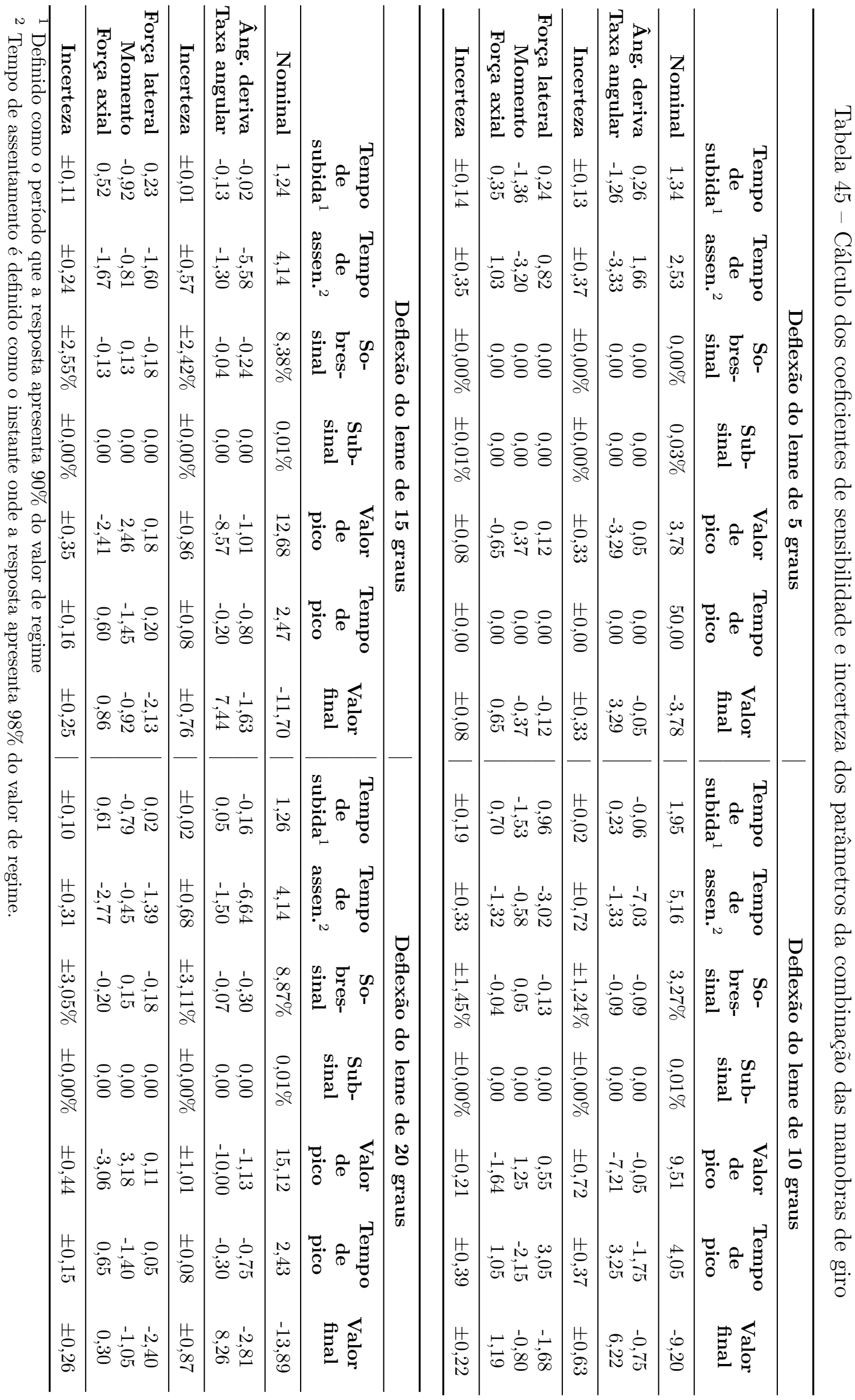




\section{APÊNDICE H - CÁLCULO DOS COEFICIENTES DE SENSIBILIDADE DA MANOBRA DE ZIGZAG}

Neste anexo são apresentados os cálculos dos coeficientes de sensibilidade e incerteza numérica dos parâmetros do modelo do AUV Pirajuba, que foram considerados no simulador de movimento. Os coeficientes de sensibilidade são utilizados para verificar a influência relativa de cada parâmetro sobre as características da manobra de zigzag. A incerteza numérica é calculada com base nestes coeficientes, e indica a incerteza esperada das características da manobra em função de variações dos parâmetros.

Os coeficientes de sensibilidade e a incerteza numérica são calculados pela metodologia apresentada em $\mathrm{ASME}^{[33]}$, apresentada na seção 6.4.3.3 desta tese. Estes coeficientes foram calculados utilizando os resultados de sensibilidade apresentados no anexo F, considerando o erro nominal $(1 \sigma)$ que é apresentado na tabela 17 da seção 6.4.3.2.

Os coeficientes de sensibilidade são apresentados na forma escalada ${ }^{[33]}$, para que a comparação entre os diferentes parâmetros seja padronizada por uma mesma variação percentual de cada parâmetro. Estes coeficientes são apresentados nas tabelas de 46 a 50, sendo divididos em função dos tipos de esforços que os seus parâmetros influenciam, ou seja, inercial e hidrodinâmico de massa adicional, do corpo, do leme e da combinação corpo e leme.

Para os parâmetros inerciais e de massa adicional, a incerteza numérica é calculada considerando todos os coeficientes de sensibilidade, representando uma incerteza que contempla todos os parâmetros de uma mesma classe. Esta incerteza é apresentada nas últimas linhas das tabelas 46 e 47.

No caso dos parâmetros hidrodinâmicos do corpo, leme e combinaçãoa, presentados nas tabelas 48, 50 e 49, respectivamente, o cálculo da incerteza deve ser dividido entre os parâmetros de ganho das variáveis de entrada das funções de esforços (ângulo de deriva, taca angular e deflexão dos lemes), e os parâmetros de ganho da saída dos esforços hidrodinâmicos (força normal, momento e força axial). Esta distinção é realizada para que no cálculo da incerteza não sejam considerados a sobreposição de fenômenos hidrodinâmicos repetidos, e se obtenha uma incerteza maior do que o realmente observado. Nestes casos, ambas as incertezas são apresentadas nas mesmas tabelas dos coeficientes de sensibilidade, mas cada uma delas é apresentada na linha abaixo dos coeficientes que a contemplam. 

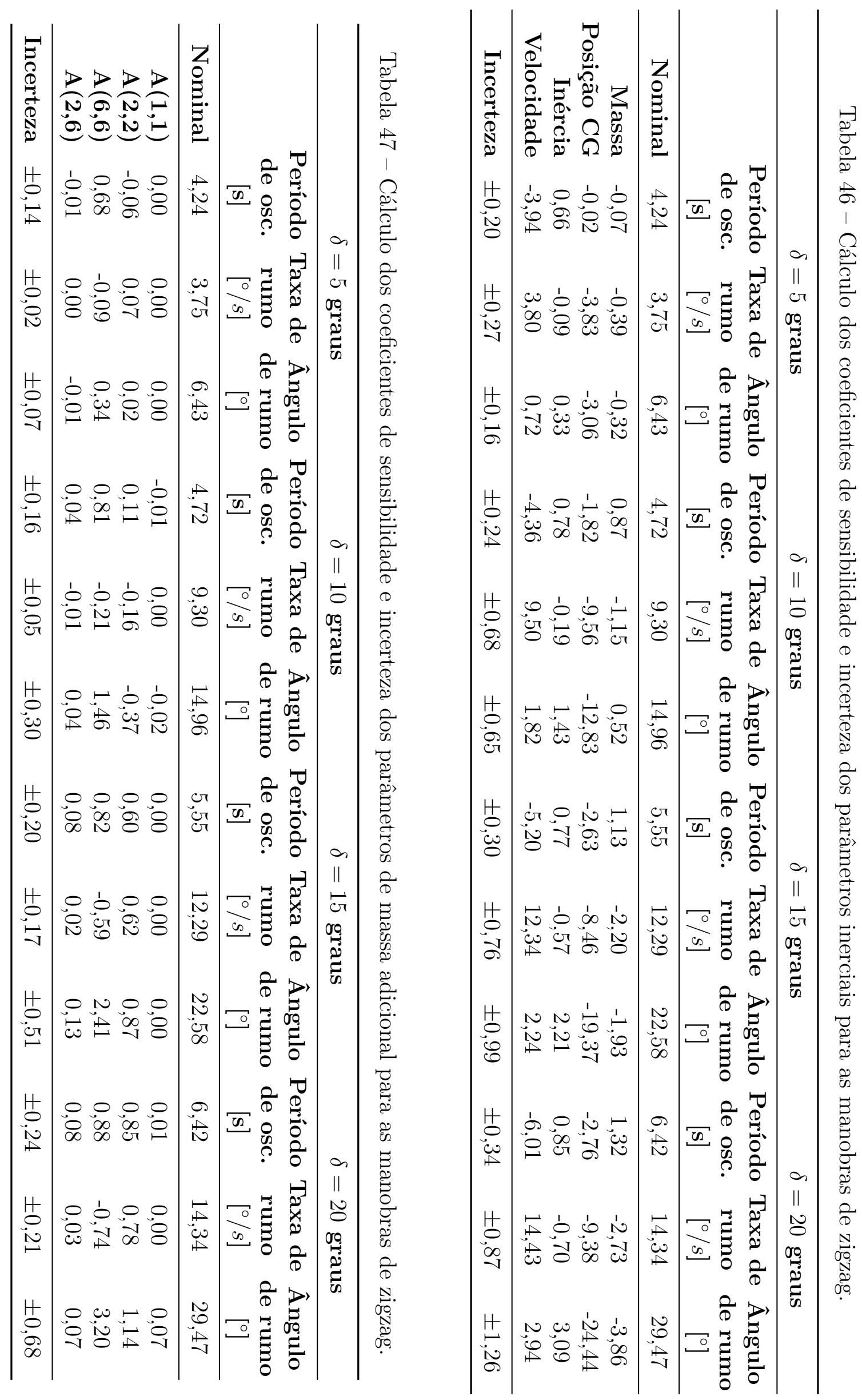


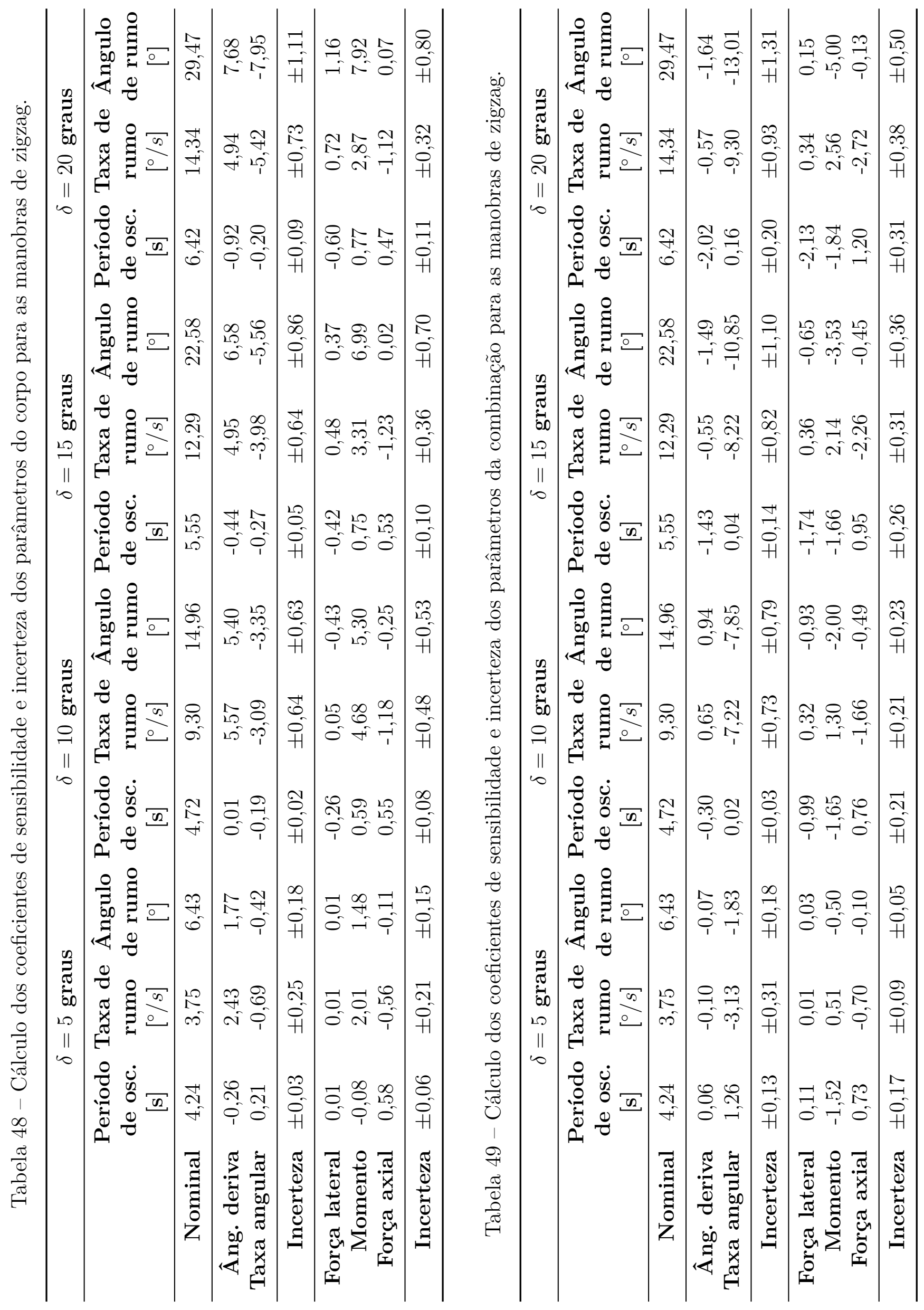




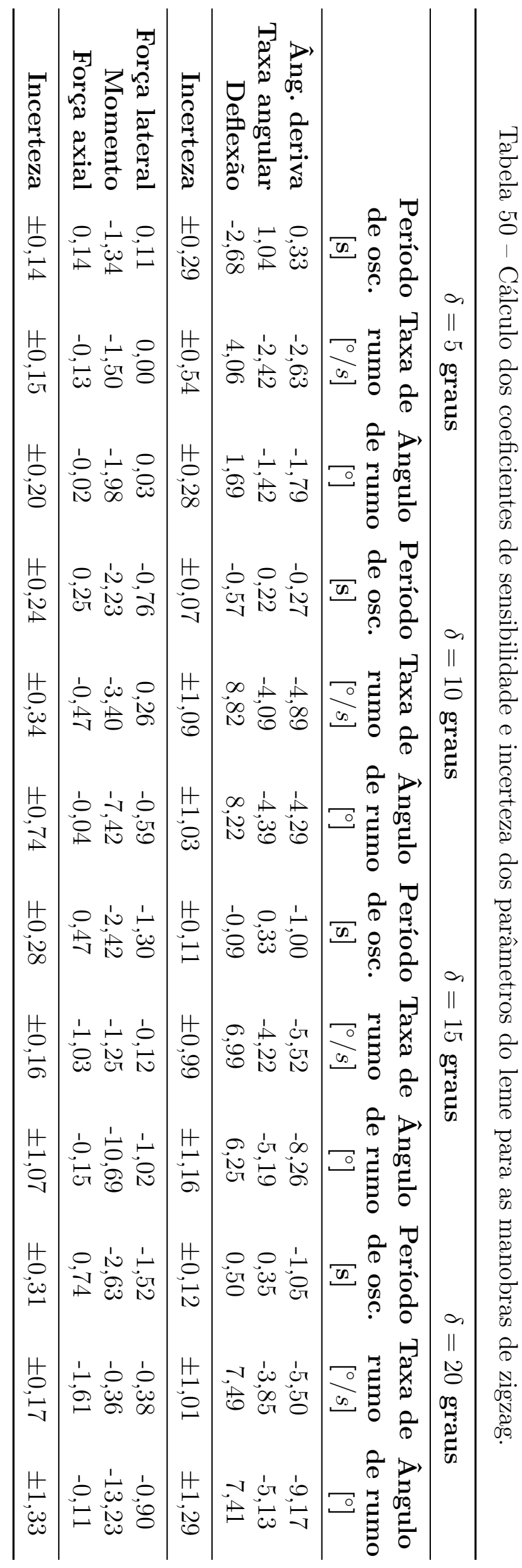

